\title{
ANÁLISE DA CONTINUIDADE EM LAJES ALVEOLARES: ESTUDO TEÓRICO E EXPERIMENTAL
}

\author{
ANDREILTON DE PAULA SANTOS
}

Tese apresentada à Escola de Engenharia de São Carlos, da Universidade de São Paulo, como parte dos requisitos para obtenção do título de Doutor em Engenharia de Estruturas.

Versão corrigida. A versão original encontra-se disponível na Escola de Engenharia de São Carlos.

Orientador: Prof. Dr. Libânio Miranda Pinheiro

Co-orientador: Prof. Dr. Roberto Chust Carvalho 
AUTORIZO A REPRODUÇĀO TOTAL OU PARCIAL DESTE TRABALHO, POR QUALQUER MEIO CONVENCIONAL OU ELETRONNICO, PARA FINS DE ESTUDO E PESQUISA, DESDE QUE CITADA A FONTE.

Santos, Andreilton de Paula

s194a Anilise da continuidade em lajes alveolares: estudo tebrico e experimental / Andreilton de Paula Santos? orientador Libinio Miranda Pinheiro; coorientador Foberto Chust Carvalho. Saso Carlos, 2014.

Tese (Doutorado) - Programa de Pbs-Graduaçlo en Engenharia de Estruturas -- Escola de Engenharia de saso Carlos da Universidade de sao Paulo, 2014.

1. continuidade. 2. laje alveolar. 3. concreto protendido. 4. concreto pre-moldado. 5. edificios. I. Titulo. 


\section{FOLHA DE JULGAMENTO}

Candidato: Engenheiro ANDREILTON DE PAULA SANITOS.

Título da tese: "Análise da continuidade em lajes alveolares: estudo teórico e experimental".

Data da defesa: 10/11/2014

Comissâo Julgadora:

Resultado:

Prof. Dr. Libänio Miranda Pinhelro (Orientador) APROVADO (Escola de Engenharia de sáo Carlos/EESC)

Prof. Titular Femando Rebouças Stucchi

[Escola Politécnica/EP-USP)

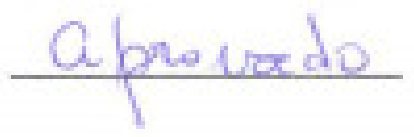

Prof. Dr. Roberto Chust Carvalho

APAO VADO

(Universidade Federal de Sōo Carlos/UFSCar)

Prof. Dr. Armando Lopes Moreno Junlor

ARROU ADO

(Universidade Estadual de Campinas/UNICAMP)

Prof. Dr. Daniel Domingues Loriggio

APRONAPO

(Universidade Federal de Santa Catarina/UFSC)

Coordenadora do Programa de Pós-Graduaçào em Engenharia Clvil [Engenharia de Estruluras):

Profa, Associoda Ana Lucia Homce de Cresce El Debs

Presidente da Comiśsão de Pós-Groduação:

Prof. Associado Paulo César Lima Seganline 

À Aline, minha esposa, com todo amor, respeito e admiração. Sem você, não teria conseguido. 



\section{AGRADECIMENTOS}

Agradeço a Deus pela sua bondade comigo, ao permitir concluir mais uma etapa na minha carreira profissional, e também por colocar em meu caminho pessoas que me ajudaram durante meu doutorado.

Ao grande amigo que fiz em São Carlos, o professor Libânio Miranda Pinheiro, pela orientação de mais um trabalho. Sempre me lembrarei do senhor, pois, em nossas reuniões, aprendi muito. $O$ senhor teve grande influência na minha formação acadêmica, profissional e pessoal.

Ao professor e amigo Roberto Chust Carvalho, por ter aceitado a co-orientação deste trabalho. Sempre vou tê-lo como referência de um grande professor e um grande engenheiro. Sentirei falta das nossas conversas descontraídas.

À minha esposa Aline Huebra Póvoa Santos por estar sempre ao meu lado. Seu apoio incondicional e sua presença em cada momento foram fundamentais para que eu nunca desistisse.

Ao amigo Tomaz Vaz, por ter me ajudado durante todos os trabalhos de laboratório. É impossível mensurar sua colaboração, meu grande amigo.

Aos amigos que auxiliaram na preparação dos modelos de laboratório: Ernesto Silva, Gabriel Eller Gusmão, Luís Augusto Bachega, Altibano Ortenzi, Matheus Lorena Gonçalves Marquesi, Fernando Madia, Gregory Pinheiro, Amaury Ignacio da Silva e Mauri Sergio Dias Guillen.

Aos amigos e chefes de laboratório, que auxiliaram na instrumentação e realização dos ensaios de caracterização e de continuidade: Bruna Catoia (NETPRE/DECiv/UFSCar), Ricardo Luiz Canato (LSE/DECiv/UFSCar) e Luiz Vicente Vareda (LE/SET/EESC/USP).

Ao professor e amigo Fernando Menezes de Almeida Filho, pelos valiosos conselhos voltados à aplicabilidade do meu trabalho, e também pelo auxílio com o material para pesquisa sobre laje alveolar.

Aos professores Marcelo de Araujo Ferreira e Mounir Khalil El Debs, pelas sugestões e contribuições no Exame de Qualificação.

Aos funcionários do Departamento de Engenharia de Estruturas, em especial a Rosi Jordão Rodrigues e Maria Nadir Minatel.

Aos amigos do SET que me deram força durante todo este período: Ellen Kellen Bellucio, Wagner Queiroz Silva, Wanderson Fernando Maia, Rodrigo Barros, Alyne Kalyane Câmara de Oliveira, Hidelbrando José Farkat Diógenes, Wellison José de Santana Gomes, Higor Sérgio Dantas de Argôlo, Marcela Filizola de Oliveira, Manuel Dênis Costa Ferreira, Enio Carlos Mesacasa Júnior, Dorival Piedade Neto, Rodrigo Ribeiro Paccola e Edson Denner Leonel. 
Aos meus pais, Maria Aparecida de Paula e Ailton dos Santos, e irmãos, Anderson de Paula Santos e Alisson Guimarães dos Santos, pelo apoio incondicional.

À ABCIC, às empresas LAJE TRELIÇADA IND. COM. LTDA., CASSOL PRÉ-FABRICADOS e TATU PRÉ-MOLDADOS, e ao amigo Rogério Durante, pela doação das lajes alveolares.

À CAPES - Coordenação de Aperfeiçoamento de Pessoal de Nível Superior - pela bolsa de doutorado concedida.

A todos vocês, muito obrigado. 
“.. AND JUSTICE FOR ALL” 



\section{RESUMO}

SANTOS, A. P. Análise da continuidade em lajes alveolares: estudo teórico e experimental. 2014. 370p. Tese (Doutorado em Engenharia de Estruturas) - Escola de Engenharia de São Carlos, Universidade de São Paulo, São Carlos, 2014.

A maioria dos edifícios de concreto pré-moldado, construídos no Brasil e no exterior, é constituída por lajes alveolares. Este trabalho considera o estudo da continuidade dessas lajes. No cálculo desses elementos, a prática comum é considerá-los como simplesmente apoiados. Para melhorar o desempenho, é possível promover a continuidade nos apoios intermediários. Isso pode ser feito colocando armadura na região tracionada da ligação, no interior da capa, ou através de barras concretadas dentro dos alvéolos. O objetivo deste trabalho é investigar o comportamento de pavimentos formados por lajes alveolares com continuidade, com armadura na capa. Para isso, foi realizado um estudo envolvendo análise teórica e experimental em três modelos. Esses modelos, em escala real, foram submetidos a um carregamento transversal, distribuído de forma linear. Os estudos teóricos consideraram uma simulação numérica com elementos de viga e a fórmula de Branson para descrever o comportamento não linear físico do material. Além disso, foram avaliadas as expressões dos principais códigos nacionais e internacionais, no que diz respeito à ruptura por cisalhamento da seção transversal e da interface laje-capa. Os resultados da análise experimental indicaram que o modelo 1 rompeu por cisalhamento da seção transversal, com o mecanismo de tração diagonal do concreto. O modelo 2 apresentou ruptura por cisalhamento da interface. No modelo 3, a ruptura foi por flexão. O comportamento dos modelos ensaiados foi governado pela fissuração da capa na região de momento negativo. A análise teórica com elementos de barra representou de forma satisfatória o comportamento dos modelos ensaiados. As únicas formulações que apresentaram resultados coerentes com os três ensaios foram: EUROCODE 2:2004, para o cálculo da resistência ao cisalhamento da interface, e FIB MODEL CODE 2010, para o cálculo da resistência ao cisalhamento da seção transversal. Conclui-se que a continuidade melhora o desempenho das lajes alveolares, uma vez que reduz os deslocamentos no meio do vão e aumenta a capacidade de carga.

Palavras-chave: continuidade; laje alveolar; concreto protendido; concreto pré-moldado; edifícios. 


\section{ABSTRACT}

SANTOS, A. P. Analysis of continuity in hollow core slabs: theoretical and experimental study. 2014. 370p. Thesis (Doctoral degree in Structural Engineering) - Engineering School of Sao Carlos, University of Sao Paulo, 2014.

Most buildings of precast concrete built in Brazil and abroad consist of hollow core slabs. This paper considers the study of the continuity of these slabs. In design of these elements the common practice is to consider them as simply supported. To improve the performance it is possible to promote the continuity in the intermediate supports. This can be done by placing reinforcement in the tensioned region of the connection, inside the topping, or by bars concreted inside the voids. The aim of this work is to investigate the behavior of hollow core floors with continuity, with reinforcement in the topping. For this, a study involving theoretical and experimental analysis was conducted in three models. The full-scale models were subjected to a transverse loading distributed linearly. The theoretical studies have considered a numerical simulation with beam elements and the Branson formula to describe the physical nonlinear behavior of the material. Furthermore, the specifications of the major Brazilian and international codes were evaluated, with respect to failure by shear of the cross section and the slab-topping interface. The results of the experimental analysis indicated that the model 1 failed by shear of the cross section with the mechanism of diagonal tension of the concrete. Model 2 presented shear failure of the interface. In model 3, the failure was by flexure. The behavior of the tested models was ruled by cracking of the topping in region of negative bending moment. Theoretical analysis with beam elements represented satisfactorily the behavior of the tested models. The only formulations that presented consistent results with the three tests were: EUROCODE 2:2004, to calculate the shear strength of the interface, and FIB MODEL CODE 2010, for calculating of the

shear strength of the cross section. It is concluded that the continuity improves the performance of the hollow core slabs, as it reduces the displacements at mid-span and increases the bearing capacity.

Keywords: continuity; hollow core slab; prestressed concrete; precast concrete; buildings. 


\section{SUMÁRIO}

1 - INTRODUÇÃO 21

1.1 - Laje alveolar 22

1.2 - Continuidade 25

1.3 - Objetivos 26

1.4 - Justificativas 27

1.5 - Método 27

1.6 - Apresentação dos capítulos 28

1.7 - Nomenclatura 30

2 - REVISÃO BIBLIOGRÁFICA 31

2.1 - Continuidade em pavimentos de lajes alveolares 33

2.1.1 - Mecanismo resistente 36

2.1.2 - Redistribuição de momento fletor devida à ductilidade na ligação 38

2.2 - Estudos feitos sobre continuidade em lajes alveolares 39

2.3 - Análise experimental de lajes alveolares 45

2.4 - Pesquisas realizadas no NETPRE/UFSCar 49

3 - CÁLCULO DA ARMADURA PASSIVA 51

3.1 - Informações iniciais sobre as lajes ensaiadas 51

3.2 - Dimensionamento na condição biapoiada 57

3.3 - Alteração no sistema estrutural 59

3.4 - Benefícios de se promover a continuidade 60

3.5 - Perdas de protensão 61

3.5.1 - Perdas de protensão na data do ensaio de continuidade EM1 63

3.5.1.1 - Perdas Iniciais - Etapa 1 64

3.5.1.2 - Perdas Diferidas - Etapa 2 65

3.5.2 - Perdas de protensão para os ensaios de caracterização do EM1 73

3.5.3 - Perdas de protensão para os demais ensaios 74

3.6 - Momento resistente $\left(M_{R}\right)$ 76

3.6.1 - Equacionamento para momento positivo 78

3.6.2 - Equacionamento para momento negativo 81

3.6.3 - Discretização em faixas 82

3.6.4 - Momento resistente $\left(M_{R}\right)$ do ensaio de continuidade EM1 83

3.6.5 - Momento resistente $\left(M_{R}\right)$ para as demais situações 84

3.7 - Determinação da armadura de continuidade 
3.7.1 - Máximo momento resistente pela armadura de protensão 86

3.7.2 - Momento $\mathrm{M}_{4}$ e a condição de apoio 88

3.7.3 - Resumo das equações 89

3.7.4 - Verificação do cisalhamento conforme a NBR 6118:2014 91

3.7.5 - Diferentes comprimentos usados no concreto protendido 95

3.7.6 - Momento de fissuração 95

3.8 - Cálculo da armadura de continuidade 96

3.8.1 - Armadura de continuidade para o EM1 97

3.8.2 - Cálculo da armadura de continuidade para os demais ensaios 104

3.8.3 - Previsão do que acontecerá nos ensaios 106

3.9 - Diagramas de iteração das lajes alveolares ensaiadas 108

3.9.1 - EM1 108

$3.9 .2-E M 2$ 110

$3.9 .3-\mathrm{EM} 3$ 113

3.9.4 - Conclusões sobre os diagramas de iteração 115

4 - ENSAIOS DE CARACTERIZAÇÃO 117

4.1 - Ensaios padronizados em lajes alveolares biapoiadas 117

4.1.1 - Ensaio de cisalhamento 118

4.1.2 - Ensaio de flexão 119

4.1.3 - Ensaio com interação de cisalhamento e flexão 121

4.2 - Avaliação das características do concreto da laje 121

4.2.1 - Cálculo de $\mathrm{f}_{\mathrm{ctm}}$ a partir de $\mathrm{M}_{\mathrm{r}}$ experimental 121

4.2.2 - Cálculo de $f_{c t d}$ a partir da resistência ao cisalhamento experimental 123

4.2.3 - Cálculo de $\mathrm{E}_{\mathrm{c}, \mathrm{ef}}$ a partir da flecha obtida no ensaio de flexão 124

4.2.4 - Evolução da resistência à compressão com o tempo 124

4.3 - Mecanismos de ruptura 125

4.4 - Mudança de rigidez nas peças de concreto sob flexão 128

4.5 - Ensaios de caracterização das lajes alveolares 130

4.5.1 - EM1 130

4.5.1.1 - Descrição dos ensaios 131

4.5.1.2 - Resultados 132

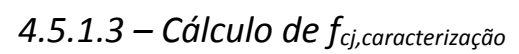
133

4.5.1.4 - Cálculo de $f_{c j, \text { continuidade }}$ 136

4.5.1.5 - Comparação com ensaios nos corpos de prova 136 4.5.1.6 - Comparação $M_{r}$ teórico e experimental 137 
4.5.2- EM2 137

4.5.2.1 - Descrição dos ensaios 138

4.5.2.2 - Resultados 139

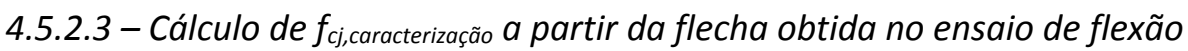
140

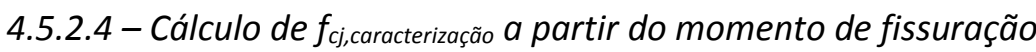
140

4.5.2.5 - Cálculo de $f_{c j, \text { continuidade }}$ 141

4.5.2.6 - Comparação com ensaios nos corpos de prova 142

4.5.2.7 - Comparação $M_{r}$ teórico e experimental 142

4.5.2.8 - Outros comentários 143

4.5.3 - EM3 143

4.5.3.1 - Descrição dos ensaios 143

4.5.3.2 - Resultados 146

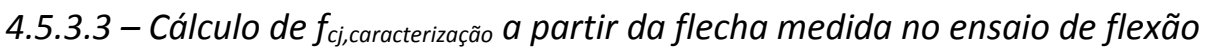
149

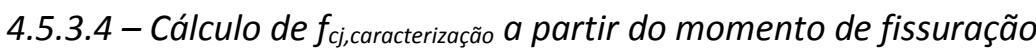
150

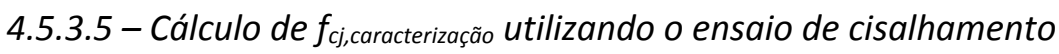
151

4.5.3.6-Cálculo de $f_{c j, \text { continuidade }}$ 151

4.5.3.7 - Comparação com resultados dos corpos de prova 151

4.5.3.8 - Comparação $M_{r}$ teórico e experimental 152

4.5.4 - Conclusões e resumo dos resultados 152

4.6 - Ensaios de caracterização da capa 153

4.6.1 - Determinação da resistência à compressão 154

4.6.2 - Determinação do módulo de elasticidade 155

4.6.3 - Resistência à tração por compressão diametral 156

4.7 - Ensaios de caracterização da armadura passiva 157

4.8 - Caracterização da armadura ativa 158

4.9 - Propriedades dos materiais após a caracterização 160

5 - ENSAIOS DE CONTINUIDADE 161

5.1 - Visão geral dos ensaios 161

5.2 - Concretagem das capas e montagem dos ensaios 165

5.3 - Instrumentação e equipamentos utilizados 171

5.4 - Mapa da instrumentação 176

5.5 - Resultados 178

5.5.1 - Modelo 1 (EM1) 179

5.5.2 - Modelo 2 (EM2) 189

5.5.3 - Modelo 3 (EM3) 199 
5.6 - Resumo dos resultados 210

6 - NLF COM ELEMENTOS DE VIGA 211

6.1 - Expressão de Branson 211

6.1.1 - Momento de fissuração 211

6.1.2 - Seção composta equivalente 212

6.1.3 - Características geométricas da seção 213

6.1.4 - Seção composta equivalente fictícia 215

6.1.5 - Expressões para seção homogeneizada nos Estádios I e II 216

6.1.6 - Modelo analítico para a análise da não linearidade física 220

6.2 - Resultados 221

6.2.1- EM1 224

$6.2 .2-\mathrm{EM} 2$ 229

6.2.3- EM3 234

6.2.4 - Comparações com capítulos anteriores 239

6.3 - Conclusão 241

7 - CISALHAMENTO NA INTERFACE 243

7.1 - Princípios gerais 243

7.1.1 - Transferência de cisalhamento na interface 243

7.1.2 - Fatores que influenciam na resistência ao cisalhamento 244

7.1.3 - Classificação quanto à rugosidade 245

7.1.4 - Cuidados durante a execução da capa 246

7.2 - Tensões de cisalhamento solicitantes 248

7.2.1 - Tensão de referência 248

7.2.2 - Tensão média 250

7.3 - Tensões de cisalhamento resistentes segundo códigos 252

7.3.1 - PRECAST/PRESTRESSED CONCRETE INSTITUTE (PCI) 252

7.3.2 - CANADIAN PRECAST/PRESTRESSED CONCRETE INSTITUTE (CPCI) 253

7.3.3 - FÉDÉRATION INTERNATIONALE DE LA PRÉCONTRAINTE (FIP) 253

7.3.4 - EUROPEAN STANDARD (EUROCODE) 255

7.3.5 - FÉDÉRATION INTERNATIONALE DU BÉTON (FIB) 256

7.3.6 - BRITISH STANDARD (BS) 256

7.3.7 - ASSOCIAÇÃO BRASILEIRA DE NORMAS TÉCNICAS (ABNT) 257

7.4 - Tensões resistentes de acordo com IBRAHIM (2008) 258

7.4.1 - Área de contato $\left(\mathrm{s}_{\mathrm{c}}\right)$ 261

7.4.2 - Umidade da interface $\left(w_{a, \text { wet }}\right)$ 261 
7.4.3 - Rugosidade da superfície $\left(\tau_{r}\right)$ 261

7.4.4 - Coeficientes de coesão (c) - EUROCODE 2:2004 263

7.4.5 - Observações quanto à formulação utilizada 263

7.5 - Resultados 264

7.5.1 - Tensões de cisalhamento solicitantes na interface 264

7.5.1.1 - Cálculo da tensão de referência 264

7.5.1.2 - Cálculo da tensão média 269

7.5.2 - Tensões de cisalhamento resistentes na interface 270

7.5.2.1 - Cálculo de acordo com PCl:2010 270

7.5.2.2 - Cálculo de acordo com o CPCl:2007 271

7.5.2.3 - Cálculo de acordo com a FIP:1982 271

7.5.2.4 - Cálculo de acordo com o EUROCODE 2:2004 272

7.5.2.5 - Cálculo de acordo com a BS 8110-1:1997 272

7.5.2.6 - Cálculo de acordo com NBR 9062:2006 273

7.5.2.7 - Cálculo de acordo com IBRAHIM (2008) 273

7.6 - Conclusão 274

8 - CISALHAMENTO NA SEÇÃO TRANSVERSAL 277

8.1 - Conceitos básicos 277

8.2 - Comportamento de vigas submetidas ao cisalhamento 281

8.2.1 - Comportamento de viga e de treliça 281

8.2.2 - A formação do leque de fissuração 282

8.2.3 - Modos de ruptura 283

8.2.4 - Mecanismo resistente em peças sem armadura de cisalhamento 285

8.2.5 - Cisalhamento na flexo-tração e na flexo-compressão 287

8.3 - Comportamento de lajes alveolares ao cisalhamento 287

8.3.1 - Ruptura por flexo-cortante 287

8.3.2 - Ruptura por tração diagonal 289

8.4 - Resistência ao cisalhamento sem armadura transversal 291

8.4.1 - Flexo-cortante - Europa 292

8.4.2 - Flexo-cortante - Brasil 293

8.4.3 - Flexo-cortante e tração diagonal - Estados Unidos 294

8.4.4 - Tração diagonal - Europa 295

8.5 - Comprimento de transferência 296

8.5.1 -NBR 6118:2014 (l $\left.\mathrm{l}_{\mathrm{bpt}}\right)$ 296

8.5.2 -NBR 14861:2011 $\left(l_{\mathrm{pt} 2}\right)$ 296 
8.5.4 - EUROCODE 2:2004 $\left(\mathrm{I}_{\mathrm{pt} 2}\right) \ldots$

8.6 - Resultados____________ 297

8.6.1 - Tensões de cisalhamento solicitantes nos ensaios de continuidade ___ 297

8.6.2 - Caracterização do concreto da laje alveolar ____ 298

8.6.3 - Comprimento de transferência ____ 300

8.6.4 - Resistência ao cisalhamento - Flexo-cortante - Europa_____ 302

8.6.5 - Resistência ao cisalhamento - Flexo-cortante - Brasil ___ 304

8.6.6 - Resistência ao cisalhamento - Flexo-cortante e tração diagonal - E.U.A. ____ 306

8.6.7 - Resistência ao cisalhamento - Tração diagonal - Europa______ 307

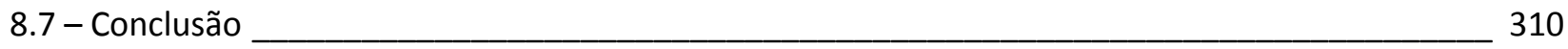

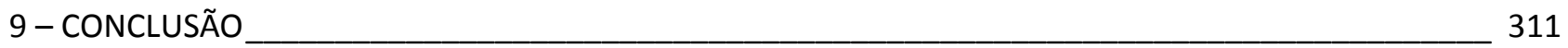

9.1 - Objetivos específicos ________________ 311

9.2 - Cálculo da armadura passiva para ensaio experimental ______ 312

9.3 - Ensaios para a caracterização de laje alveolar _____ 314

9.4 - Análise experimental utilizando continuidade _____ 314

9.5 - Análise teórica com elementos de barra _____ 315

9.6 - Resistência ao cisalhamento na interface ____ 316

9.7 - Resistência da seção transversal ao cisalhamento_____ 317

9.8 - Sugestões para trabalhos futuros_____ 320

REFERÊNCIAS BIBLIOGRÁFICAS _______________ 321

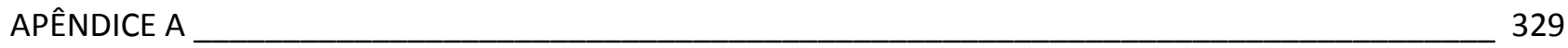

APA1 - Tabelas de discretização da laje EM1 ___ 329

APA2 - Tabelas de discretização da laje EM2 ______________ 331

APA3 - Tabelas de discretização da laje EM3 ____________ 333

APÊNDICE B ___ _ _ _ _ _ _ _ _ 335

APB1 - Caracterização do concreto das lajes alveolares_____ 335

APB2 - Ensaios de resistência à compressão ___ 336

APB3 - Determinação do módulo de elasticidade ___ 339

APB4 - Resistência à tração por compressão diametral________________ 340

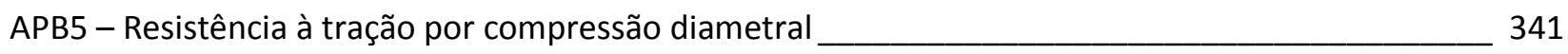

APB6 - Relatórios de ensaios da armadura ativa - EM1____ 343

APB7 - Relatórios de ensaios da armadura ativa - EM2___ 347

APB8 - Relatórios de ensaios da armadura ativa - EM3 ___ 357

APÊNDICE C ________________ 363 
APC1 - Instrumentação das armaduras passivas 363 ANEXO A 365

A1 - Cálculo de armadura longitudinal (flexão simples) 365

A2 - Cálculo do momento resistente e da armadura 367 



\section{INTRODUÇÃO}

Os edifícios de concreto pré-moldado com mais de um pavimento, comumente denominados edifícios de múltiplos pavimentos, podem ser divididos em dois subsistemas estruturais básicos: o sistema de pavimentos e o sistema de pórticos.

O sistema de pavimentos, ou simplesmente pavimentos, são constituídos por lajes e vigas, ou somente lajes. Tal sistema é responsável por coletar as ações verticais e transmiti-las aos pilares. Além disso, desempenham importante papel na estabilização da estrutura, através do efeito diafragma.

De forma simplificada, o sistema de pórticos (também conhecido como sistema em esqueleto) é formado por pilares e vigas e possui, como principal função, receber o carregamento vertical, advindo dos pavimentos, e transmiti-lo à fundação. Além disso, o sistema de pórticos é responsável por garantir a estabilidade da estrutura, mediante a atuação das ações horizontais (vento e desaprumo, por exemplo).

Normalmente, os pavimentos representam a maior parte do custo da estrutura. No entanto, os que utilizam concreto pré-moldado oferecem economia e versatilidade para qualquer tipo de edificação, principalmente porque eliminam o escoramento, diminuem o consumo de formas e aumentam muito a velocidade de execução. Segundo ELLIOT (2002) metade dos pavimentos usados em edifícios comerciais e residenciais em todo o mundo é feita de concreto pré-moldado. Essa forma oferece vantagens em termos de custo, quando comparada a tradicionais métodos de pavimentos, tais como concreto moldado no local, estruturas mistas de concreto e aço, e pisos com estruturas de madeiras.

Existem várias formas de se conceber o sistema de pavimentos utilizando concreto pré-moldado. No Brasil as formas mais utilizadas são: lajes com nervuras pré-moldadas, lajes com elementos de "pré-lajes", painéis П e painéis alveolares. Cada sistema apresenta um campo de aplicação diferenciado, variando o tipo de edificação, os vãos máximos alcançados e as alturas necessárias. A Tabela 1.1, adaptada da FIP (1994), apresenta as características dos elementos mais empregados para pavimentos de concreto pré-moldado na Europa. Embora seja confeccionada baseando-se na utilização europeia, aplica-se muito bem à realidade brasileira. 
Tabela 1.1 - Características das principais lajes empregadas no Brasil - Adaptada da FIP (1994).

\begin{tabular}{|c|c|c|c|c|c|}
\hline Tipo de elemento & $\begin{array}{l}\text { Tipo de } \\
\text { edifício }\end{array}$ & $\begin{array}{l}\text { Vão máximo } \\
(\mathbf{m})\end{array}$ & $\begin{array}{c}\text { Altura } \\
(\mathbf{c m})\end{array}$ & $\begin{array}{l}\text { Larguras } \\
\text { mais } \\
\text { comuns } \\
(\mathbf{c m})\end{array}$ & $\begin{array}{c}\text { Peso } \\
\text { por } \\
\text { unidade } \\
\text { de área } \\
\left(\mathrm{kN} / \mathrm{m}^{2}\right)\end{array}$ \\
\hline Painel alveolar protendido & $\begin{array}{c}\text { Habitacional / } \\
\text { Comercial / } \\
\text { Industrial / } \\
\text { Estacionamento }\end{array}$ & $\leq 20$ & $15-50$ & 120 & $2,0-4,8$ \\
\hline Painel $\Pi$ protendido & $\begin{array}{c}\text { Comercial / } \\
\text { Industrial / } \\
\text { Estacionamento }\end{array}$ & $\leq 30$ & $20-80$ & $120-240$ & $2,1-5,0$ \\
\hline 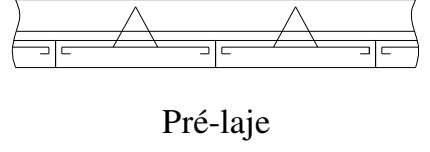 & $\begin{array}{l}\text { Habitacional / } \\
\text { Comercial }\end{array}$ & $\leq 7,2$ & $10-20$ & $60-240$ & $2,4-4,8$ \\
\hline Nervura pré-moldada & Habitacional & $\begin{array}{c}\leq 5 \text { concr. armado } \\
\leq 10 \text { treliça } \\
\quad \text { armada } \\
\leq 10 \text { concr. } \\
\text { protendido }\end{array}$ & $20-30$ & - & $1,8-2,4$ \\
\hline
\end{tabular}

\section{1 - Laje alveolar}

As lajes alveolares foram desenvolvidas nos anos 1950 nos Estados Unidos e na Europa, através do avanço nas tecnologias da produção do concreto e também da pista de protensão. Este tipo de elemento é conhecido por permitir sistemas econômicos de pavimento e também de cobertura, com alta velocidade de montagem, número pequeno de elementos e baixo peso próprio. O peso próprio de um elemento de laje alveolar pode chegar até menos que a metade do relativo a uma laje maciça de mesma altura. Exemplo disso é a laje de $20 \mathrm{~cm}$ (MELO 2007), cuja área da seção transversal possui 0,1197 m², ao invés de $0,24 \mathrm{~m}^{2}$ se fosse maciça. A Figura 1.1a mostra um exemplo de pavimento formado por laje alveolar, a Figura 1.1b apresenta elementos de laje alveolar em estoque, e a Figura 1.1c exibe uma seção transversal típica.

A superfície superior do elemento permite a composição com uma camada de concreto moldado no local, conhecida como capa. O acabamento da superfície inferior possibilita o uso de concreto aparente para o teto.

Estruturalmente as lajes alveolares oferecem a eficiência de um elemento protendido, atingindo vãos consideráveis, com elevada capacidade de carregamento e 
pequenos deslocamentos. Além disso, quando corretamente dimensionada e detalhada, auxilia na distribuição do carregamento horizontal, através do efeito de diafragma rígido.

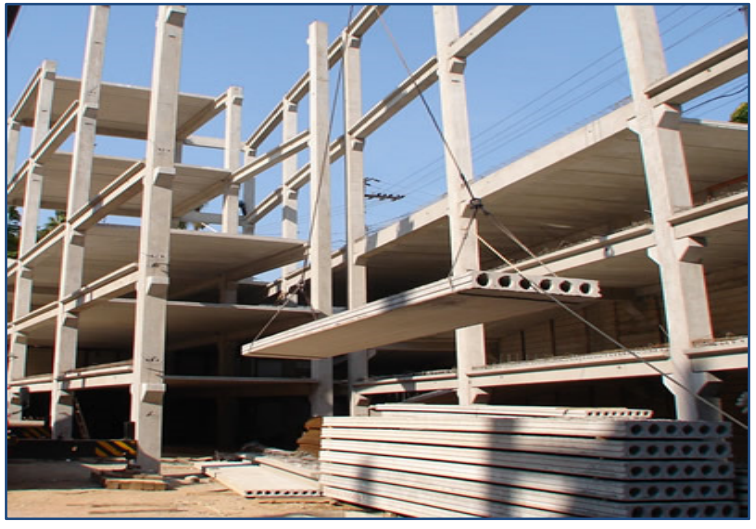

(a)

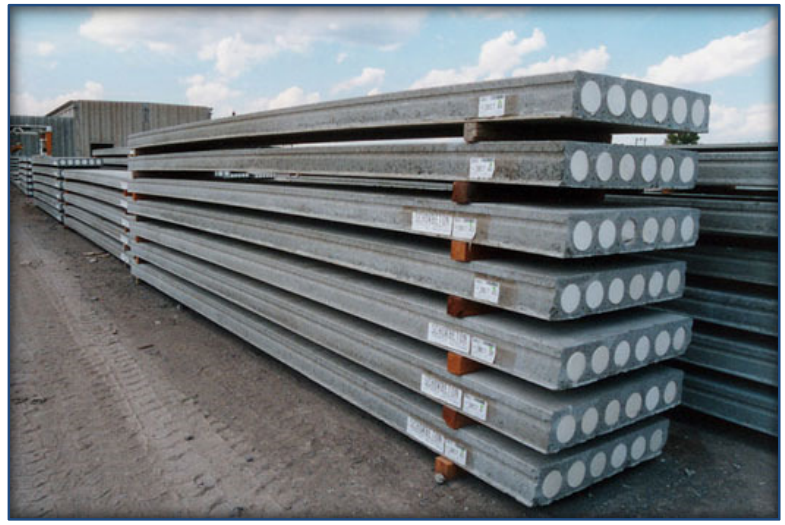

(b)

ALVÉOLO BORDA SUPERIOR CHAVE DE CISALHAMENTO

NERVURA

BORDA INFERIOR

(c)

Figura 1.1 - (a) Vista uma estrutura em esqueleto com pavimentos formados por laje alveolar;

(b) Elementos de laje alveolar em estoque; (c) Seção transversal.

(Fontes: (a) http://blogdopetcivil.com/2011/08/18/lajes-alveolares/;

(b) http://www.schokbeton.com/eng/dalles.html).

Outra importante vantagem atribuída à laje alveolar é a resistência ao fogo. De acordo com o PCl (1998), um painel alveolar pode alcançar até quatro horas de resistência, quando submetido a elevadas temperaturas. Essa resistência depende da altura do painel e também do cobrimento da armadura.

Os processos de fabricação mais utilizados na produção das lajes alveolares são: através de máquinas extrusoras (Figura 1.2a) ou moldadoras com formas deslizantes (Figura 1.2b). Nesses processos não é possível a introdução de armadura de cisalhamento. Logo, em função disso, as lajes alveolares são compostas exclusivamente de armadura ativa.

Outra possível forma de fabricação é através de concreto vibrado em formas contendo tubos de aço (Figura 1.2c), tubos de plástico preenchidos por ar (Figura 1.2d) ou isopor (Figura 1.2e). 


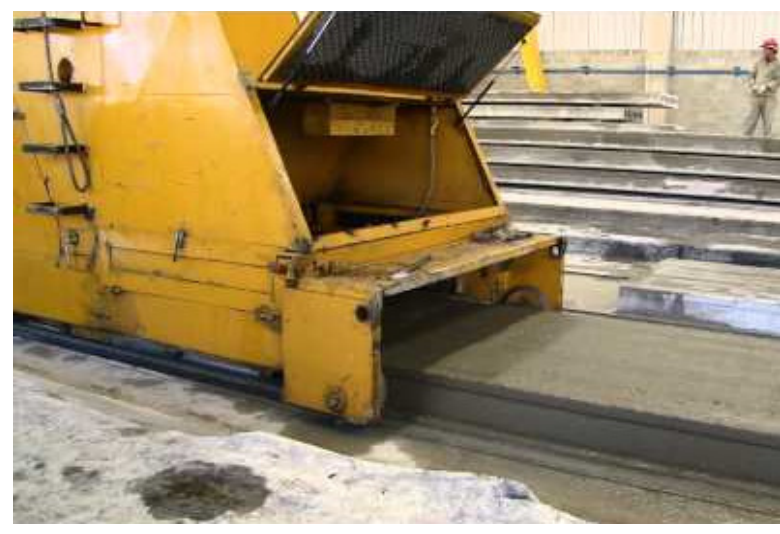

(a)

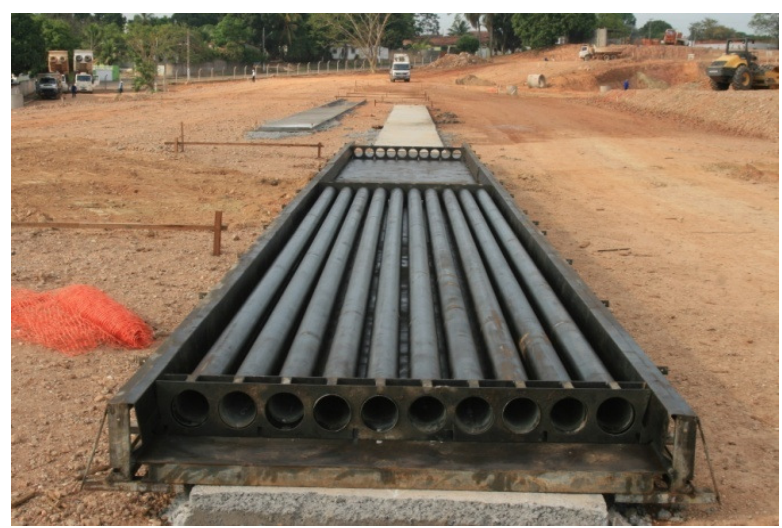

(c)

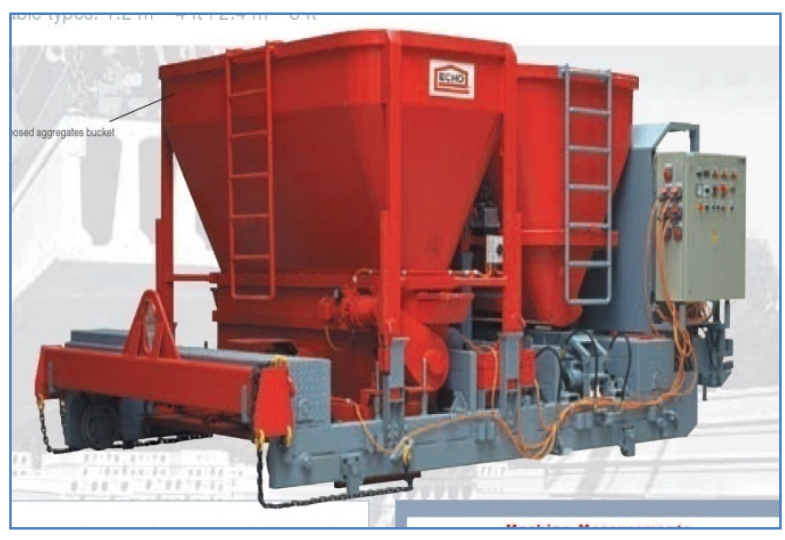

(b)

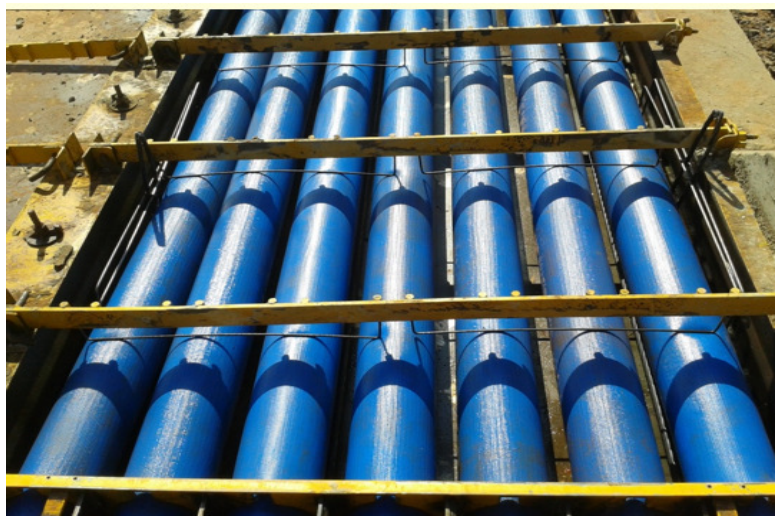

(d)

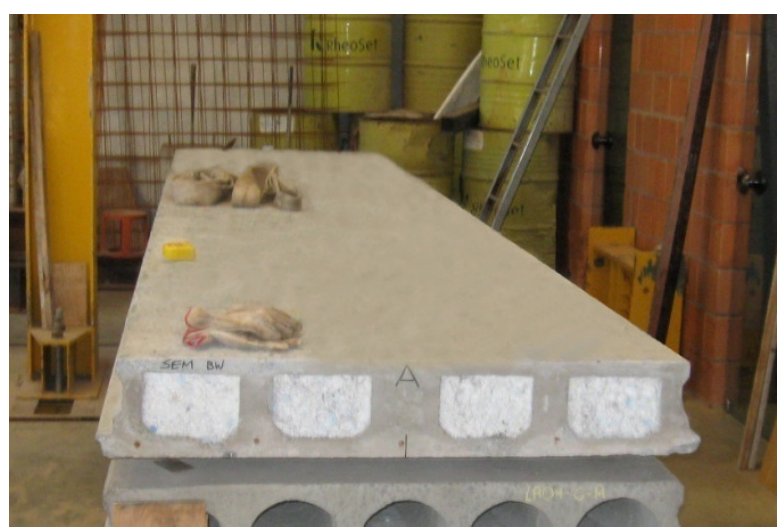

(e)

Figura 1.2 - Exemplos de equipamentos e utensílios usados nos processos de fabricação de laje alveolar: (a) Extrusora; (b) Moldadora; (c) Formas contendo tubos de aço;

(d) Formas contendo tubos de plásticos preenchidos por ar;

(e) Uso de isopor para preenchimento dos alvéolos.

(Fontes: (a) http://weiler.com.br; (b) ECHO ENGINEERING (catálogo);

(c) LAJE TRELIÇADA IND. E COM. LTDA.; (d) FÔRMA \& FÓRMA EQUIPAMENTOS LTDA; (e) NETPRE. 
Nestes processos é possível a introdução de armadura de cisalhamento. No entanto, quando se adota estes métodos de fabricação, é comum utilizar somente armadura ativa, tal como nos demais processos apresentados anteriormente.

Independente do processo de fabricação, as lajes alveolares tratadas neste trabalho são aquelas protendidas por pré-tração, e que não possuem armadura de cisalhamento.

O processo de fabricação das lajes alveolares pode ser encontrado em vários trabalhos já publicados. Para um estudo mais detalhado sobre esse assunto recomenda-se a leitura dos seguintes trabalhos: ARAUJO (2007), FERNANDES (2007), COSTA (2009) e PETRUCELLI (2009).

\section{2 - Continuidade}

Normalmente as lajes alveolares são projetadas como elementos simplesmente apoiados. Isso acontece devido ao fato de ser um elemento protendido, logo com capacidade de suportar elevadas cargas para vãos consideráveis, sofrendo pouca deformação.

Entretanto, é possível executar a ligação entre os tramos das lajes com capacidade para resistir momento fletor. A isto se dá o nome de continuidade.

Essa continuidade pode ser estabelecida colocando-se armadura na região tracionada da ligação, no interior da capa (Figura 1.3a), ou pode ser feita através de barras concretadas dentro de aberturas feitas no topo dos alvéolos (Figura 1.3b). Dessas duas formas, a continuidade é feita nas regiões de momento negativo, nos apoios intermediários.

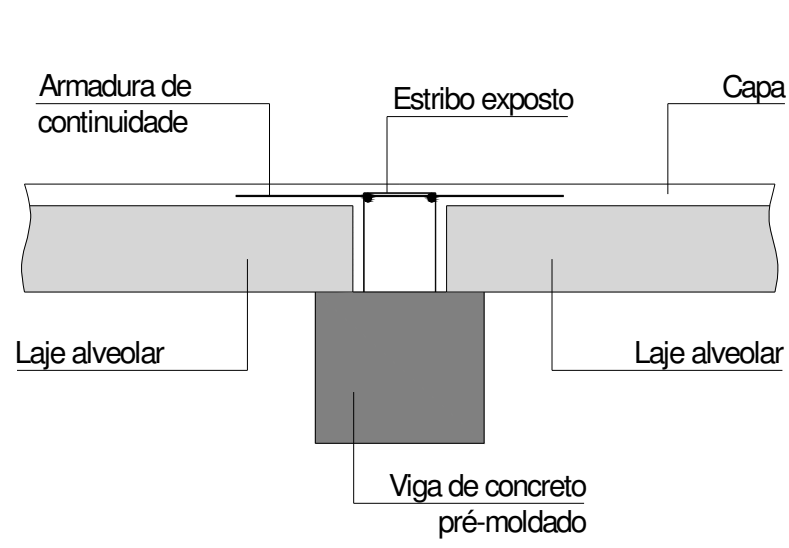

(a)

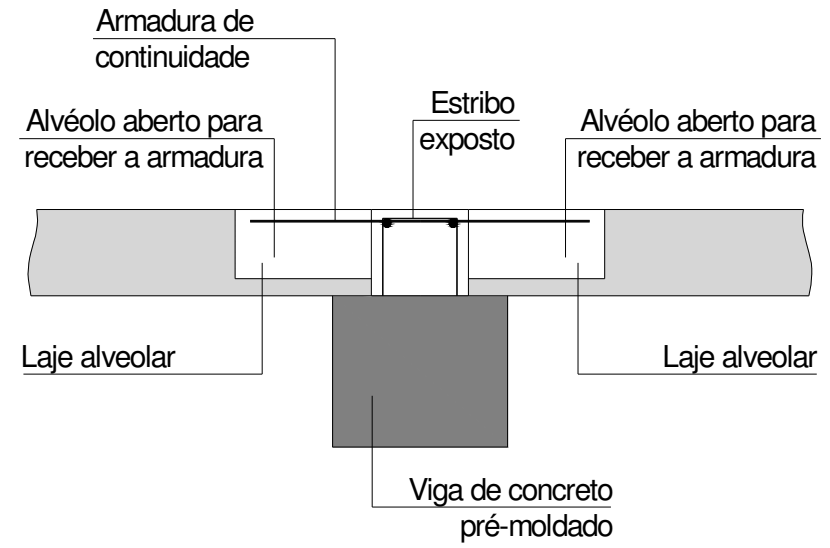

(b)

Figura 1.3 - Formas de estabelecer a continuidade nas lajes alveolares: (a) Armadura na capa; (b) Armadura em abertura feita no topo do alvéolo. 
De uma forma geral, a continuidade nos elementos de concreto pré-moldado (seja entre lajes ou entre vigas, ou ainda entre vigas e pilares) é usada principalmente para:

- Estabilizar e aumentar a rigidez do pórtico (caso das vigas);

- Reduzir a altura (vigas e lajes);

- Distribuir efeitos de segunda ordem nas vigas, e com isso reduzir os momentos fletores nos pilares;

- Promover resistência ao colapso progressivo (vigas e lajes).

Nos pavimentos formados por lajes alveolares, o objetivo principal é aumentar a capacidade portante da laje, uma vez que, com a continuidade, não só ocorre redução do momento fletor positivo, como também dos deslocamentos na região central do vão.

Nos grandes centros de pesquisa sobre concreto pré-moldado, a laje alveolar tem sido objeto de estudo dos mais variados. Entre os assuntos mais estudados estão: o comprimento de transferência no apoio (refere-se à capacidade de aderência na região do apoio), a capacidade portante à flexão e a resistência ao cisalhamento.

Os estudos sobre continuidade, embora existam, ainda são escassos quando comparados com os citados no parágrafo anterior.

\section{3 - Objetivos}

O objetivo principal deste trabalho é estudar a continuidade em pavimentos formados por lajes alveolares. Ele se concentrará na continuidade estabelecida pela colocação da armadura na capa, região tracionada da ligação (Figura 1.3a).

Como objetivos específicos, pretende-se:

- Estudar as possíveis formas de ruína e o comportamento da ligação, de forma conjunta;

- Comparar com as situações de laje simplesmente apoiada;

- Averiguar se ocorre plastificação na ligação;

- Sugerir um critério para cálculo de armadura de continuidade utilizada nas análises experimentais;

- Comparar os resultados do cálculo analítico com os obtidos nos ensaios;

- Avaliar os benefícios de se utilizar a continuidade nas edificações em que se emprega concreto pré-moldado, de acordo com a prática feita no Brasil. 


\section{4 - Justificativas}

No Brasil, grande parte das estruturas multipisos de concreto pré-moldado tem seus pavimentos construídos com laje alveolar, sendo usual o emprego da capa para solidarizar as lajes. Além disso, é comum o uso de armadura na capa na região da ligação laje-vigalaje. Entretanto, a utilização desse tipo de armadura nem sempre é levada em conta na consideração da continuidade, ou ainda, considera-se a continuidade sem saber ao certo o real aumento de eficiência.

Portanto, torna-se necessário estudar a continuidade nos pavimentos de laje alveolar em que se utilizam materiais e elementos estruturais mais compatíveis com a realidade Brasileira. Esse estudo poderá auxiliar a prática de projetos na área de concreto pré-moldado, tornando os projetos de pavimentos mais econômicos ou mesmo mais seguros.

Além disso, tal trabalho poderá levar a um avanço nos conhecimentos que se têm sobre laje alveolar, sobretudo com relação ao seu comportamento no pavimento, possibilitando inclusive melhorias na norma brasileira de lajes alveolares (ABNT NBR 14861:2011), em futuras revisões.

A execução deste trabalho possibilitou maior interação da universidade com o setor privado, através de uma parceria com a Associação Brasileira da Construção Industrializada de Concreto $(\mathrm{ABCIC})$. Essa parceria foi estabelecida entre a $\mathrm{ABCIC}$, o Núcleo de Estudo e Tecnologia em Pré-Moldados de Concreto (NETPRE) da Universidade Federal de São Carlos (UFSCar) onde os ensaios de continuidade foram realizados, e o Departamento de Engenharia de Estruturas (SET) da Escola de Engenharia de São Carlos (EESC) da Universidade de São Paulo (USP.

\section{5 - Método}

Conforme SANTOS (2004) o método aqui utilizado é o hipotético-dedutivo, que se inicia com a formulação de hipóteses, e pelo processo de inferência dedutiva, que testa a ocorrência de fenômenos abrangidos pelas hipóteses.

De acordo com FERREIRA (1998), esse método desencadeia-se a partir da percepção de uma lacuna nos conhecimentos científicos produzidos em uma determinada área até aquele momento.

Segundo SILVA e MENEZES (2005) o método hipotético-dedutivo foi proposto por Popper. Os problemas que surgem em decorrência da insuficiência de conhecimentos disponíveis devem ser testados ou falseados. Falsear significa tornar falsas as consequências deduzidas das hipóteses. 
A técnica ou o processo aplicado para que se possa chegar aos objetivos propostos para esta pesquisa é fundamentado em um estudo teórico-experimental. O trabalho é divido em quatro fases: revisão bibliográfica, estudos analíticos, análise experimental e comparação entre as formulações analíticas e os resultados experimentais.

A primeira fase da pesquisa foi composta por uma revisão da literatura, abrangendo, principalmente, os seguintes temas: teoria do concreto protendido, cálculo de laje alveolar, consideração da continuidade nos pavimentos de laje alveolar, padronização dos ensaios de lajes alveolares. Examinou-se a bibliografia existente nos estudos de continuidade em laje alveolar, não só através dos artigos publicados, mas também dos principais códigos nacionais e internacionais.

A segunda fase compreendeu os cálculos analíticos. Esses estudos incluem: cálculo da laje alveolar, com e sem continuidade, estudo da interface em elementos de concreto pré-moldado compostos, tensões cisalhantes em lajes alveolares e análise não linear, utilizando elementos de viga e a expressão de Branson.

A terceira fase da pesquisa foi composta pela análise experimental. Os ensaios foram realizados no laboratório NETPRE/UFSCar, que conta com equipamentos e experiência em estudos de lajes alveolares, além do convênio com a ABCIC. Nesta fase, foram feitos três ensaios de continuidade, avaliando o comportamento da ligação e dos mecanismos de ruína, o momento de fissuração do conjunto, a distribuição da fissuração no elemento e a ocorrência ou não da plastificação na ligação.

A quarta fase consistiu na comparação entre os resultados obtidos pelas formulações teóricas (cálculos analíticos) e os resultados encontrados nos ensaios experimentais. Com isso foi possível descrever as formas de ruínas e estabelecer quais expressões teóricas representam melhor os fenômenos estudados.

\section{6 - Apresentação dos capítulos}

Apresenta-se no capítulo 2 (REVISÃO BIBLIOGRÁFICA) os conceitos básicos acerca da continuidade em lajes alveolares, sobretudo o que dizem as principais normas internacionais. E para posicionar o trabalho em questão no contexto das pesquisas experimentais, são apresentadas as investigações científicas já realizadas sobre continuidade e um resumo dos principais estudos experimentais realizados nas lajes alveolares.

As armaduras passivas utilizadas nos ensaios experimentais foram dimensionadas de acordo com as lajes alveolares doadas pelas fábricas de concreto pré-moldado, em conjunto com a $\mathrm{ABCIC}$. Para o dimensionamento dessas armaduras o presente trabalho propõe um método baseado no máximo momento resistente positivo e na máxima força 
cortante resistente de uma laje alveolar. O capítulo 3 (CÁLCULO DA ARMADURA PASSIVA) apresenta esse dimensionamento, incluindo o cálculo das perdas de protensão. De posse de todos esses cálculos, foi possível ainda plotar os diagramas de iteração das lajes alveolares ensaiadas e também fazer uma previsão do que aconteceria nos ensaios experimentais.

O capítulo 4 (ENSAIOS DE CARACTERIZAÇÃO) mostra os resultados dos ensaios realizados para caracterização dos elementos utilizados nos ensaios de continuidade. Os ensaios de caracterização das lajes alveolares foram feitos no NETPRE/UFSCar. A caracterização do concreto da capa foi feita no Laboratório de Sistemas Estruturais (LSE) do Departamento de Engenharia Civil (DECiv) da UFSCar. E os ensaios da caracterização da armadura passiva foram realizados no Laboratório de Estruturas (LE) do Departamento de Engenharia Estruturas (SET) da EESC/USP. Além disso, são apresentados os resultados da caracterização da armadura ativa, fornecidos pelo fabricante das cordoalhas.

O capítulo 5 (ENSAIOS DE CONTINUIDADE) apresenta os ensaios e os resultados dos modelos com continuidade. São mostrados os procedimentos para a montagem dos ensaios: o posicionamento das lajes alveolares, a confecção das formas e a concretagem da capa, a instrumentação e os equipamentos utilizados.

A partir do capítulo 6 (NLF COM ELEMENTOS DE VIGA) os aspectos teóricos são discutidos. Primeiramente apresenta-se a análise não-linear física utilizando a expressão de Branson e elementos de vigas para a discretização dos modelos.

O capítulo 7 (CISALHAMENTO NA INTERFACE) discute o comportamento de elementos composto e a ruptura na interface entre a capa e a laje. São apresentadas as principais expressões normativas empregadas para o cálculo das tensões de cisalhamento na interface. Além disso, faz-se comparações entre os resultados dessas formulações e os encontrados nos ensaios de continuidade.

O capítulo 8 (CISALHAMENTO NA SEÇÃO TRANSVERSAL) aborda a ruptura por força cortante da seção transversal. São estudados os mecanismos de ruptura por flexo-cortante e por tração diagonal. Apresenta-se nesse capítulo as principais expressões normativas utilizadas no cálculo das tensões de cisalhamento na seção transversal e as comparações destas com os resultados obtidos nos ensaios de continuidade.

No capítulo 9 (CONCLUSÃO) são apresentadas as conclusões e sugestões para trabalhos futuros. Por fim, as referências bibliográficas, os apêndices e os anexos, são mostrados como apoio ao entendimento dos assuntos abordados ou apresentando informações complementares. 


\section{7 - Nomenclatura}

A fim de facilitar a descrição dos modelos ensaiados com continuidade foi adotada a seguinte nomenclatura:

- EM1, EM2 e EM3 - ensaios experimentais realizados, respectivamente, nos modelos 1,2 e 3.

Foi ensaiado um exemplar de cada modelo. 


\section{REVISÃO BIBLIOGRÁFICA}

Normalmente, um pavimento de lajes alveolares possui um elevado número de unidades, projetadas de tal forma a atender determinados vãos e carregamentos. Por outro lado, o mesmo pavimento pode formar uma única laje, em que as cargas são compartilhadas pelos elementos pré-moldados, de acordo com o comportamento estrutural de cada elemento.

A maioria dos pavimentos com laje alveolar é projetada como biapoiada. Além disso, existem pavimentos concebidos sem a utilização da capa. Isto é possível uma vez que o painel de laje alveolar possui chaves de cisalhamento que, preenchidas por argamassa fluida, formam uma única laje. Desse modo, as ações verticais e horizontais são transferidas em toda a extensão do pavimento. Entretanto, é comum realizar o cálculo e o detalhamento dos pavimentos como diafragma rígido, com base nas providências indicadas na Figura 2.1.

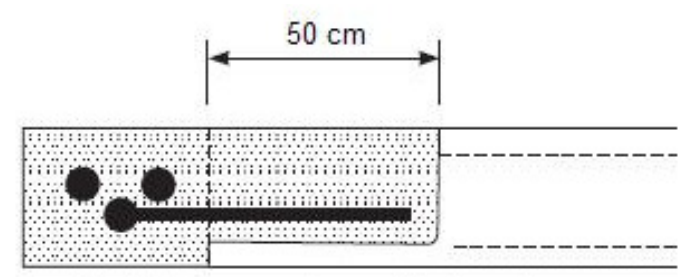

Seção transversal na região da ranhura na laje alveolar
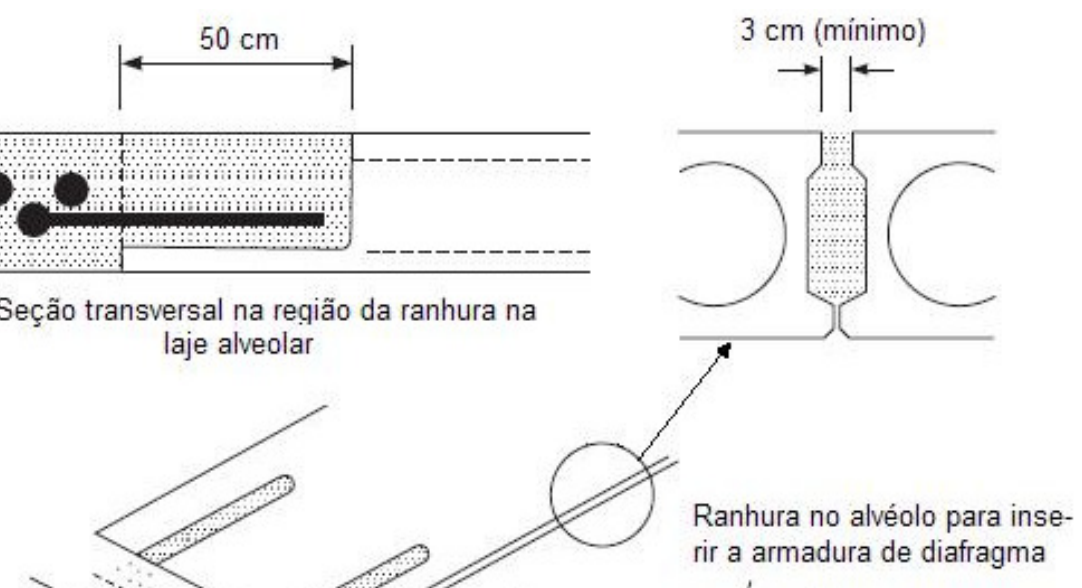
rir a armadura de diafragma

Viga de contorno ou intermediária, concretada no local, com armadura para agir como elemento do diafragma

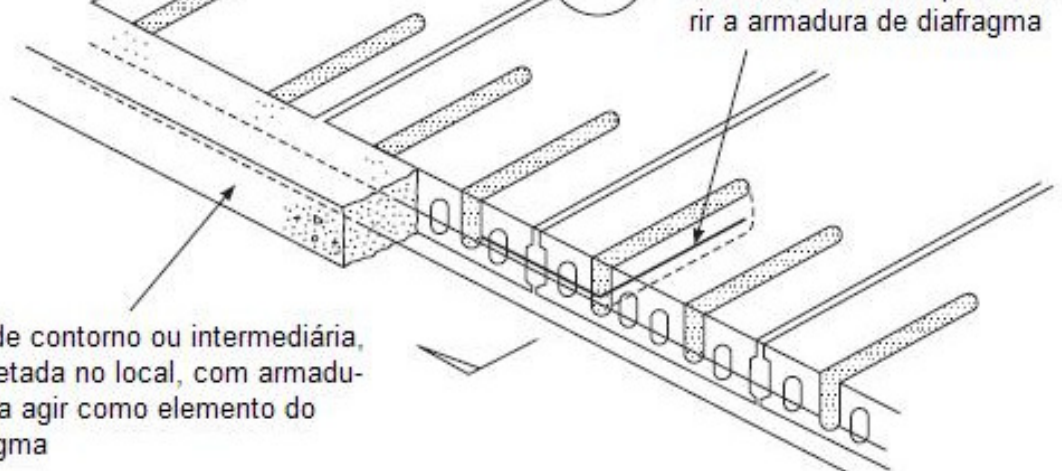

Figura 2.1 - Pavimento de laje alveolar sem capa e com função de diafragma rígido. Detalhe da chave de cisalhamento. Detalhe da seção transversal na região da ranhura no alvéolo.

(Adaptada de ELLIOT (2002)). 
No Brasil, o mais comum é utilizar capa, para distribuir as tensões no pavimento e garantir o comportamento de diafragma. Estudos devem ser feitos a fim de comprovar a influência dessa capa no comportamento da laje como diafragma rígido e de corroborar os cálculos usados no exterior, na verificação do pavimento como diafragma, considerando materiais e técnicas nacionais.

Com relação ao carregamento vertical, a situação mais usual é considerar o carregamento uniformemente distribuído nos elementos simplesmente apoiados. Cada elemento é admitido igualmente carregado, e dessa forma não é realizada a análise do pavimento como um todo.

No entanto, quando uma carga concentrada ou uma linha de carregamento atua sobre a unidade de laje alveolar, cada elemento se desloca de forma diferenciada, e com isso surgem tensões cisalhantes na interface longitudinal das unidades, e a ação passa a ser absorvida pelo conjunto de elementos. A Figura 2.2 mostra o mecanismo de distribuição nos pavimentos de lajes alveolares.

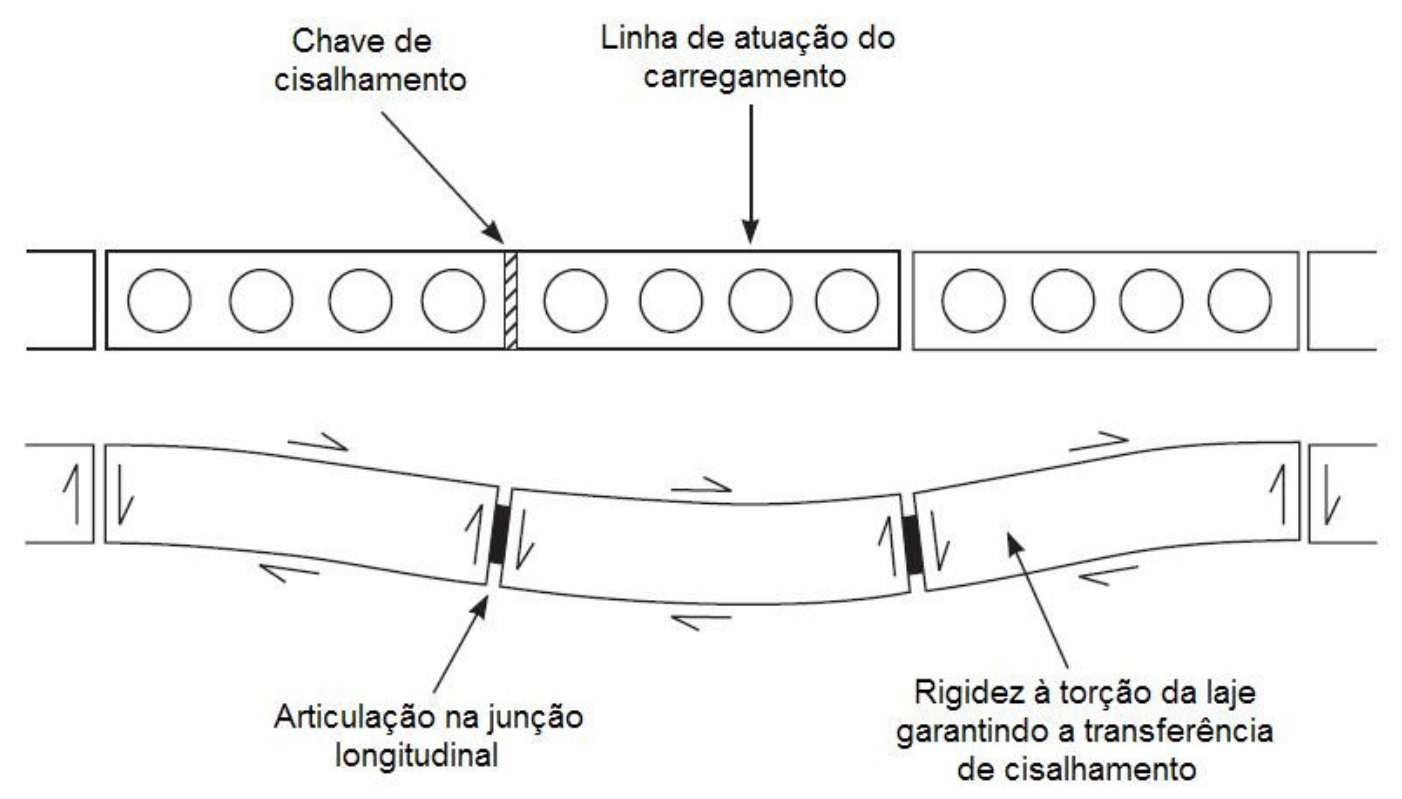

Figura 2.2-Mecanismo de distribuição lateral do carregamento vertical nas lajes alveolares. (Adaptada de ELLIOT (2002)).

Em se tratando do projeto estrutural de um elemento isolado de laje, é necessário considerar as formas de ruína relacionadas com os seguintes aspectos: condição de apoio, resistência ao cisalhamento, resistência à flexão, deformação excessiva e situações transitórias. ELLIOT (2002) apresenta um gráfico que relaciona essas formas de ruptura com o carregamento e com o vão (Figura 2.3). 


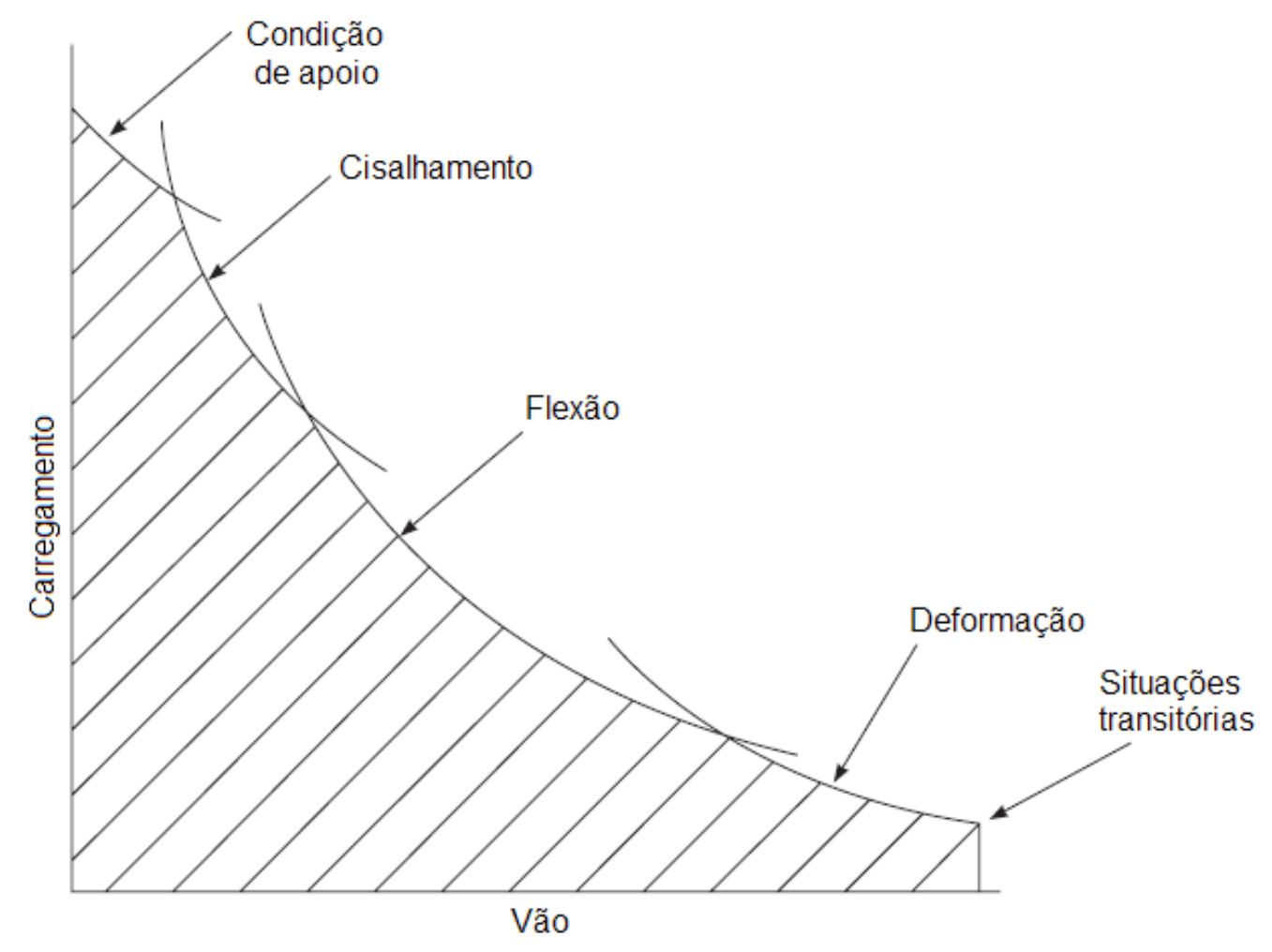

Figura 2.3 - Formas típicas de ruína relacionadas com o carregamento e o com vão. (Adaptada de ELLIOT (2002)).

\section{1 - Continuidade em pavimentos de lajes alveolares}

De acordo com a FIB (2000), no continente Europeu, os pavimentos de lajes alveolares foram projetados como simplesmente apoiados até os anos 1970. Após essa década houve um aumento no uso de pavimentos com continuidade, impulsionado principalmente por projetos que consideravam ações sísmicas, sobretudo na Itália, Espanha e Turquia. Mesmo assim a ligação sem continuidade mantém-se predominante.

Ainda segundo a FIB (2000), a continuidade é recomendada, e o fato de ser estabelecida no local da obra não deve ser considerado um problema adicional, uma vez que parte da estrutura pode ser feita com concreto moldado no local (como acontece, por exemplo, com escadas e fundações).

Quando se empregam lajes alveolares, alguns casos em que a continuidade é recomendada são listados a seguir:

- Estruturas usuais de concreto moldado no local, com pórticos ou com pilaresparede;

- Casos em que é necessário maior controle de fissuração na região dos apoios intermediários e, também, dos deslocamentos no meio do vão; 
- Situações em que há necessidade de aumentar a rigidez de uma viga, permitindo que se possa considerar uma largura colaborante.

Já o PCl (1998) apresenta uma posição, de certa forma contrária, a ponto de mencionar que "é difícil encontrar uma justificativa econômica para os projetos com continuidade". Isso se deve ao fato da alta eficiência na protensão que "combate" o momento positivo e da baixa eficácia da armadura passiva para combater o momento negativo, uma vez que pode ocorrer plastificação da ligação, na presença do momento negativo.

Segundo o $\mathrm{PCl}$ (1998), quando os apoios das lajes alveolares precisam de armadura passiva para, por exemplo, promover comportamento de diafragma ao pavimento, a quantidade de aço necessário é muito baixa e, portanto, desenvolve pouca capacidade para transferir momento fletor. Embora esse reforço possa ser considerado na verificação do estado limite de deformação excessiva, é recomendado que a laje seja projetada como biapoiada, a menos que seja conhecido o diagrama momento-curvatura para combinações de estado limite último.

Ainda segundo o PCl (1998), uma situação em que parece razoável considerar a redução de momentos positivos é quando a laje requer verificações de situações de incêndio. A região de momento negativo é bem menos afetada pelo calor, e com isso promove uma rótula plástica no apoio. Como resultado, o momento positivo no meio do vão pode ser reduzido.

Como todo processo construtivo, a continuidade possui vantagens e desvantagens, e cabe ao responsável avaliar a viabilidade da continuidade em comparação com o sistema estrutural biapoiado, levando em conta aspectos técnicos e econômicos. A ASSAP (2002) relaciona vantagens e desvantagens do uso da continuidade, indicadas na Tabela 2.1.

É necessário dizer que a tabela citada foi concebida para a realidade europeia e, em se tratando do que ocorre no Brasil, a desvantagem do alto custo da armadura adicional não ocorre, como é demonstrado no trabalho de CAMILLO (2012), além do fato de que o concreto da capa é executado independentemente da utilização da continuidade.

Em se tratando da desvantagem da verificação da protensão máxima na face inferior da laje, essa desvantagem praticamente não ocorre, como também é demonstrado no trabalho de CAMILLO (2012). 
Tabela 2.1 - Vantagens e desvantagens de se estabelecer a continuidade nos pavimentos de laje alveolar. (Adaptada da ASSAP (2002)).

\begin{tabular}{|c|c|c|}
\hline Necessidades de projeto & $\begin{array}{l}\text { Vantagens da } \\
\text { continuidade }\end{array}$ & $\begin{array}{l}\text { Desvantagens da } \\
\text { continuidade }\end{array}$ \\
\hline $\begin{array}{l}1 \text { - Controle dos } \\
\text { deslocamentos e } \\
\text { resistência ao momento } \\
\text { fletor e ao cortante. }\end{array}$ & $\begin{array}{l}\text { - Com a mesma altura da } \\
\text { laje alveolar e a mesma } \\
\text { armadura ativa, é possível } \\
\text { obter momentos } \\
\text { resistentes até } 30 \% \\
\text { maiores; } \\
\text { - A resistência ao } \\
\text { cisalhamento depende do } \\
\text { número de alvéolos } \\
\text { preenchidos. }\end{array}$ & $\begin{array}{l}\text { - Alto custo de armadura } \\
\text { adicional (até } 3 \mathrm{~kg} / \mathrm{m}^{2} \text { ) e de } \\
\text { concreto moldado no local } \\
\left.\text { (até } 20 \mathrm{l} / \mathrm{m}^{2}\right) \text {; } \\
\text { - É necessário usar } \\
\text { armadura ativa até mesmo } \\
\text { no topo das lajes e alguns } \\
\text { alvéolos podem ser } \\
\text { abertos; } \\
\text { - É necessário verificar a } \\
\text { protensão máxima nas } \\
\text { lajes na face inferior para } \\
\text { evitar compressão } \\
\text { excessiva devida ao } \\
\text { momento negativo. }\end{array}$ \\
\hline 2 - Resistência ao fogo. & $\begin{array}{l}\text { - Com a mesma altura da } \\
\text { laje alveolar e a mesma } \\
\text { armadura ativa é possível } \\
\text { aumentar cerca de } 30 \% \text {. }\end{array}$ & - Ver item 1. \\
\hline 3 - Ação sísmica. & $\begin{array}{l}\text { - Aumento no valor de "q" } \\
\text { devido ao aumento na } \\
\text { ductilidade da estrutura e } \\
\text { também na energia de } \\
\text { dissipação. }\end{array}$ & - Ver item 1. \\
\hline $\begin{array}{l}4 \text { - Consideração da fluência } \\
\text { devida às cargas de } \\
\text { longa duração. }\end{array}$ & $\begin{array}{l}\text { - Para a mesma altura da } \\
\text { laje alveolar, os } \\
\text { deslocamentos diminuem } \\
\text { de duas a cinco vezes. }\end{array}$ & - Ver item 1. \\
\hline $\begin{array}{l}5 \text { - Eliminação de fissuras } \\
\text { visíveis. }\end{array}$ & $\begin{array}{l}\text { - É atendida em todos os } \\
\text { casos, exigindo-se cuidado } \\
\text { com relação ao número, } \\
\text { diâmetro e distância entre } \\
\text { as armaduras para resistir } \\
\text { ao momento fletor. }\end{array}$ & - Ver item 1. \\
\hline $\begin{array}{l}6 \text { - Aumento da rigidez da } \\
\text { viga de apoio. }\end{array}$ & $\begin{array}{l}\text { - É obtido pela consideração } \\
\text { da largura colaborante. }\end{array}$ & - Ver item 1. \\
\hline $\begin{array}{l}7 \text { - Lajes alveolares } \\
\text { apoiadas em vigas } \\
\text { moldadas no local, com } \\
\text { mesma altura das lajes. }\end{array}$ & - Aplicação possível. & $\begin{array}{l}\text { - Ver item 1; } \\
\text { - A seção transversal da laje } \\
\text { requer uma largura da } \\
\text { nervura (cerca de } 40 \mathrm{~cm} \text { ) } \\
\text { para diminuir as tensões } \\
\text { de fendilhamento. }\end{array}$ \\
\hline
\end{tabular}




\subsection{1 - Mecanismo resistente}

O conceito básico de uma ligação com continuidade nas lajes alveolares é mostrado na Figura 2.4. A continuidade ocorre em função do surgimento de um binário com compressão na parte inferior da laje e tração na armadura superior. O binário apresentado na Figura 2.4 é específico à continuidade com armadura inserida na capa.

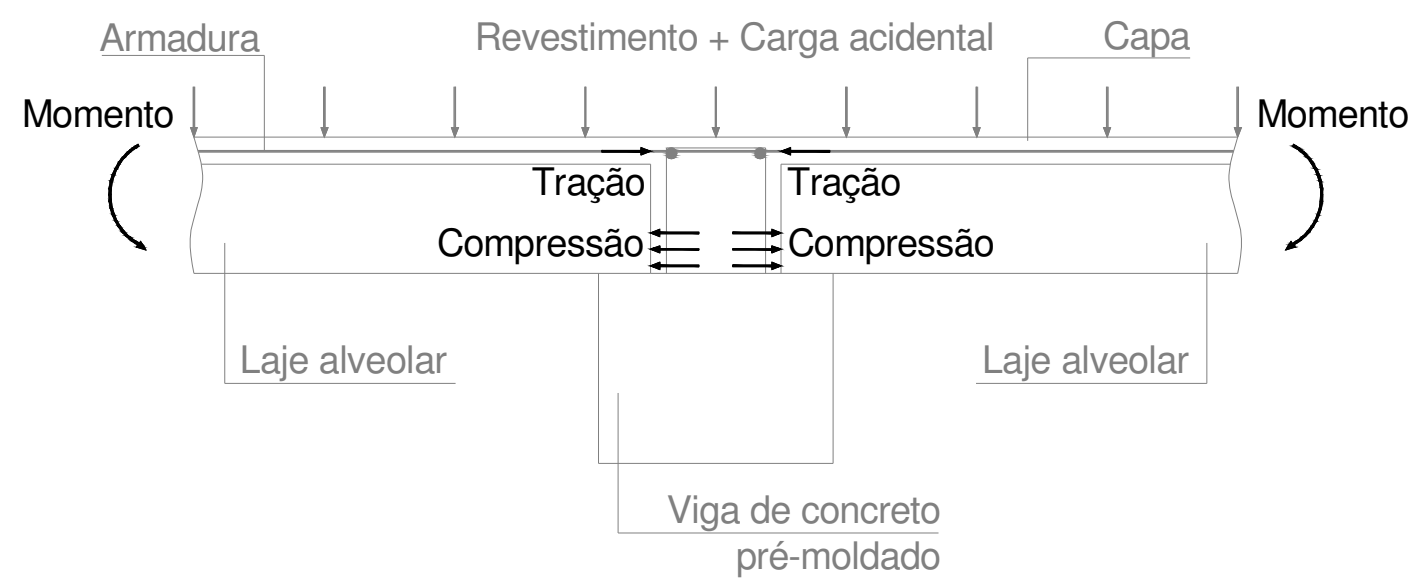

Figura 2.4 - Conceito básico de uma ligação com continuidade. (Adaptada de ELLIOT (2002)).

Conforme a ASSAP (2002), nos casos em que a continuidade é estabelecida no local, a situação das tensões internas é substancialmente melhorada, em todos os sentidos, pela presença da tensão de compressão na região inferior da ligação (como mostrada na Figura 2.4).

$\mathrm{Na}$ realidade, a possibilidade de formação de fissuras na região de momento negativo não evita o aparecimento de tensões de mecanismos de biela e tirante na extremidade da laje alveolar, como mostra a Figura 2.5, adaptada da ASSAP (2002). A presença da biela comprimida impede a união das fissuras induzidas pelos momentos fletores de sinais contrários.

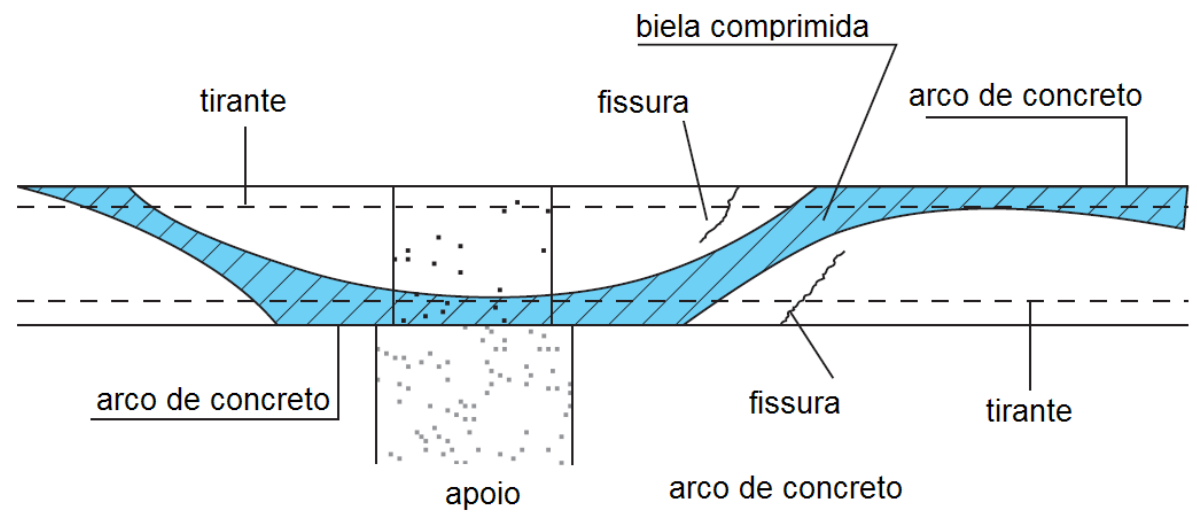

Figura 2.5 - Mecanismo de biela e tirante. (Adaptada da ASSAP (2002)). 
Ainda de acordo com a ASSAP (2002), pavimentos com lajes alveolares podem ser considerados contínuos se as seguintes condições forem atendidas:

- A altura da laje não pode ser menor que $12 \mathrm{~cm}$;

- O espaçamento entre as barras de aço colocadas para promover a continuidade não pode ser maior que $60 \mathrm{~cm}$;

- Deve ser garantida a aderência entre o concreto da laje e o concreto da capa, assim como entre o concreto da capa e a armadura de continuidade;

- A armadura de continuidade deve considerar o comprimento de ancoragem para garantir a transmissão das tensões entre o aço e o concreto.

Até o instante em que a capa passa a atuar como um componente resistente na ligação, a laje alveolar atua como um elemento biapoiado, e por isso a continuidade só absorve momentos provenientes do revestimento e da carga acidental. Por isso, no projeto considerando a continuidade, duas fases devem ser analisadas:

- A primeira corresponde à situação de laje simplesmente apoiada, em que atua o peso próprio e também o peso do concreto moldado no local, seja pela concretagem da capa ou pela concretagem das aberturas dos alvéolos. Nesta situação, a laje deve resistir ao momento positivo no meio do vão;

- A segunda fase corresponde à ligação com continuidade. Neste caso, deve-se considerar como momento positivo a soma entre o momento obtido na primeira fase e o relativo à segunda, em que atuam as cargas permanentes e as acidentais. Consequentemente, o máximo momento negativo é aquele calculado para a segunda fase, com o carregamento permanente e o acidental, nas situações mais desfavoráveis.

A Figura 2.6, adaptada de ASSAP (2002), mostra um exemplo de envoltória de momento fletor considerando as duas fases anteriormente mencionadas. Além disso, mostra também o arredondamento do momento negativo em correspondência com o comprimento da ligação.

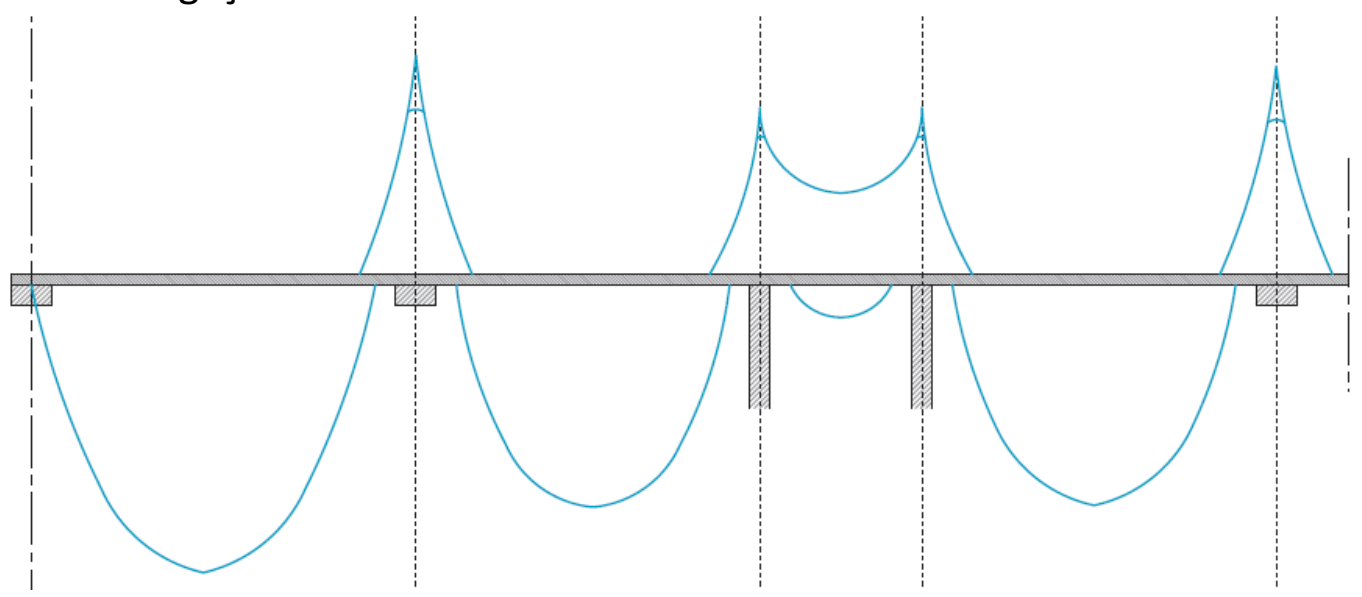

Figura 2.6 - Envoltória de momento fletor para projeto com continuidade. (Adaptada da ASSAP (2002)). 


\subsection{2 - Redistribuição de momento fletor devida à ductilidade na ligação}

Depois de calcular o máximo momento negativo no apoio e de fazer o arredondamento do diagrama conforme mencionado no item anterior, é necessário considerar a redistribuição dos momentos fletores que ocorre em função da ductilidade da ligação. Na prática há uma redução do momento negativo no apoio e um aumento do momento positivo no meio do vão.

A redistribuição de momentos deve ser feita levando em conta a soma de diferentes fatores de ductilidade na ligação, quais sejam:

- Em regime puramente linear, o concreto da ligação possui um módulo de elasticidade $\left(E_{c m}^{\prime}\right)$ menor que o módulo do concreto pré-moldado $\left(E_{c m}\right)$. $A$ redistribuição depende da relação $E^{\prime} \mathrm{cm} / \mathrm{E}_{\mathrm{cm}}$;

- Em regime plástico é necessário considerar a deformação causada por ações externas e também pela protensão. O efeito pode até mesmo ser de sinais contrários, e por isso pode ser considerado aproximadamente nulo.

Chamando de $\delta$ a relação entre o momento negativo depois da redistribuição $\left(\mathrm{M}_{\mathrm{i}}^{\prime}\right) \mathrm{e}$ o momento negativo teórico $\left(\mathrm{M}_{\mathrm{i}}\right)$, tem-se a expressão 2.1. O valor de $\delta$ também pode ser dado em função da raiz quadrada da relação entre as resistências características dos dois concretos (expressão 2.2), onde f $_{c k}$ é relativo ao concreto da ligação (moldado no local) e $\mathrm{f}_{\mathrm{ck}}$ refere-se ao concreto pré-moldado. Além disso, o valor de $\delta$ deve atender também os requisitos do Código Europeu EN 1992-1:2004.

$$
\begin{aligned}
& \delta=M_{i}^{\prime} / M_{i} \\
& \delta=\sqrt{f_{c k}^{\prime} / f_{c k}}
\end{aligned}
$$

De qualquer forma, a ASSAP (2002) recomenda utilizar valores que respeitem a condição:

$$
0,7 \leq \delta \leq 1,0
$$

Uma vez encontrado o valor $\delta$ relativo à redistribuição de esforços, é necessário calcular o número correto de barras que devem resistir o momento negativo. Além disso, deve-se detalhar corretamente o comprimento da barra, de forma a atender o necessário comprimento de ancoragem.

É importante também verificar a adição de compressão na região inferior da laje, proveniente da continuidade, com a protensão. A compressão não deve ultrapassar os limites máximos admissíveis para os elementos protendidos. 


\section{2 - Estudos feitos sobre continuidade em lajes alveolares}

Os estudos sobre continuidade em pavimentos formados por lajes alveolares são poucos quando comparados com os demais trabalhos sobre essas lajes. Além disso, as poucas pesquisas divulgadas sobre continuidade possuem menos de duas décadas. A seguir são descritos alguns estudos encontrados na literatura técnica.

TAN et al. (1996) realizaram um trabalho no qual apresentam duas tabelas para o projeto de lajes alveolares, uma para lajes com continuidade nos dois apoios e outra para continuidade em apenas um dos apoios. Essas tabelas indicam o acréscimo possível de vão para uma laje simplesmente apoiada, quando for realizada a continuidade nos apoios intermediários.

Entretanto, os autores não levaram em consideração a mudança de sistema estrutural, situação biapoiada para ligação com continuidade, que ocorre quando a capa passa a atuar como um componente resistente na ligação. Eles consideram que o sistema estrutural com continuidade é igual para todas as cargas (peso próprio, peso da capa, revestimento e carga acidental).

Outros fatores desconsiderados pelos autores na elaboração das tabelas são: o cálculo das perdas, a verificação dos estados limites de serviço e a verificação do esforço cortante. Isso sinaliza que essas tabelas devem ser utilizadas com cautela nos projetos de pavimentos com continuidade, talvez servindo melhor com propósito de prédimensionamento.

Além disso, esses autores realizaram ensaios em lajes alveolares com continuidade nos apoios (Figura 2.7) para mostrar o aparecimento do momento devido à continuidade e, também, para estudar o efeito da força cortante.

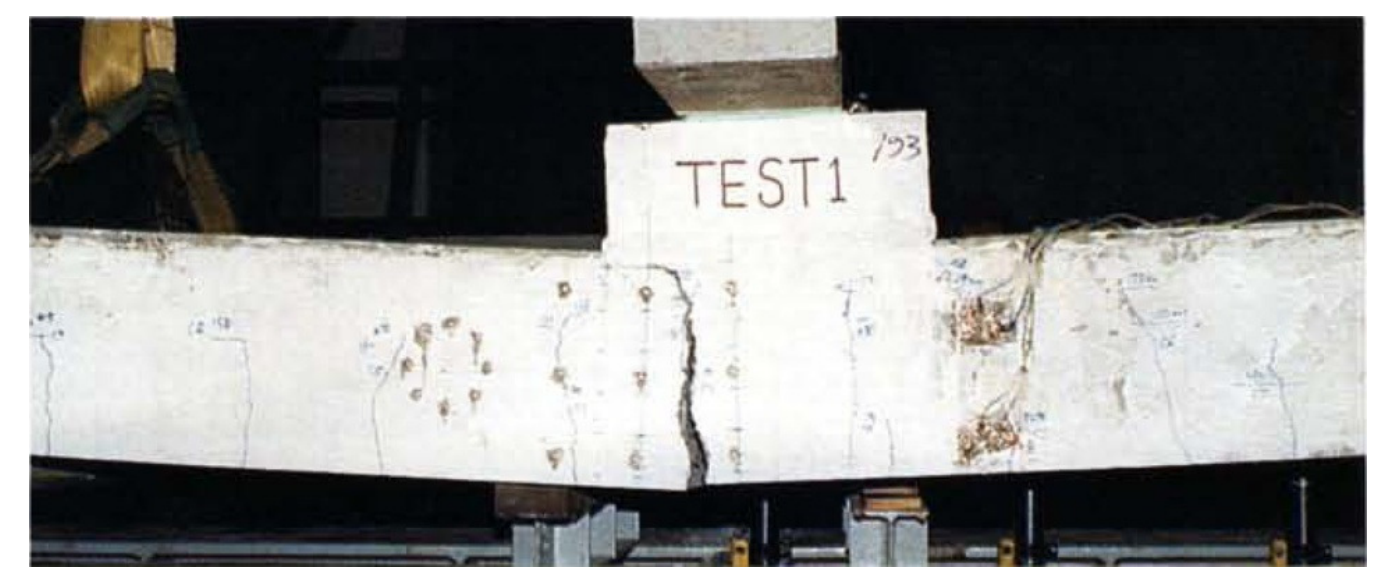

Figura 2.7 - Ensaios de lajes alveolares com continuidade realizados por TAN et al. (1996).

Os autores citados concluíram que o projeto realizado com continuidade leva ao aumento do vão vencido por um elemento de laje alveolar, quando comparado com a 
situação biapoiada. Constataram também a diminuição nos deslocamentos, e que é possível estabelecer a continuidade através da armadura inserida na capa, na região dos apoios. Sobre a resistência ao cisalhamento, eles concluíram que ela aumenta com o preenchimento dos alvéolos.

RESENDE e GASTAL (1999) realizaram uma análise numérico-experimental de lajes alveolares com continuidade sobre os apoios intermediários, sendo essa continuidade proporcionada pela adição de armadura na capa.

A análise numérica foi feita utilizando um modelo computacional, desenvolvido por GASTAL (1986), para a avaliação de vigas de pontes, sem juntas no tabuleiro, utilizando elementos finitos isoparamétricos de viga.

Nessa análise numérica foram implementadas as propriedades dependentes do tempo, permitindo assim considerar os efeitos relativos à deformação lenta, retração e relaxação. Além disso, foi considerada também a não-linearidade física do concreto.

A análise experimental foi feita na fábrica onde as lajes alveolares foram produzidas. O comprimento total dos protótipos foi de $10 \mathrm{~m}$. Cada elemento de laje alveolar tinha $5 \mathrm{~m}$ de comprimento, $12 \mathrm{~cm}$ de altura e $60 \mathrm{~cm}$ de largura. As idades médias eram da ordem de 60 dias. Esses ensaios são ilustrados pela Figura 2.8.

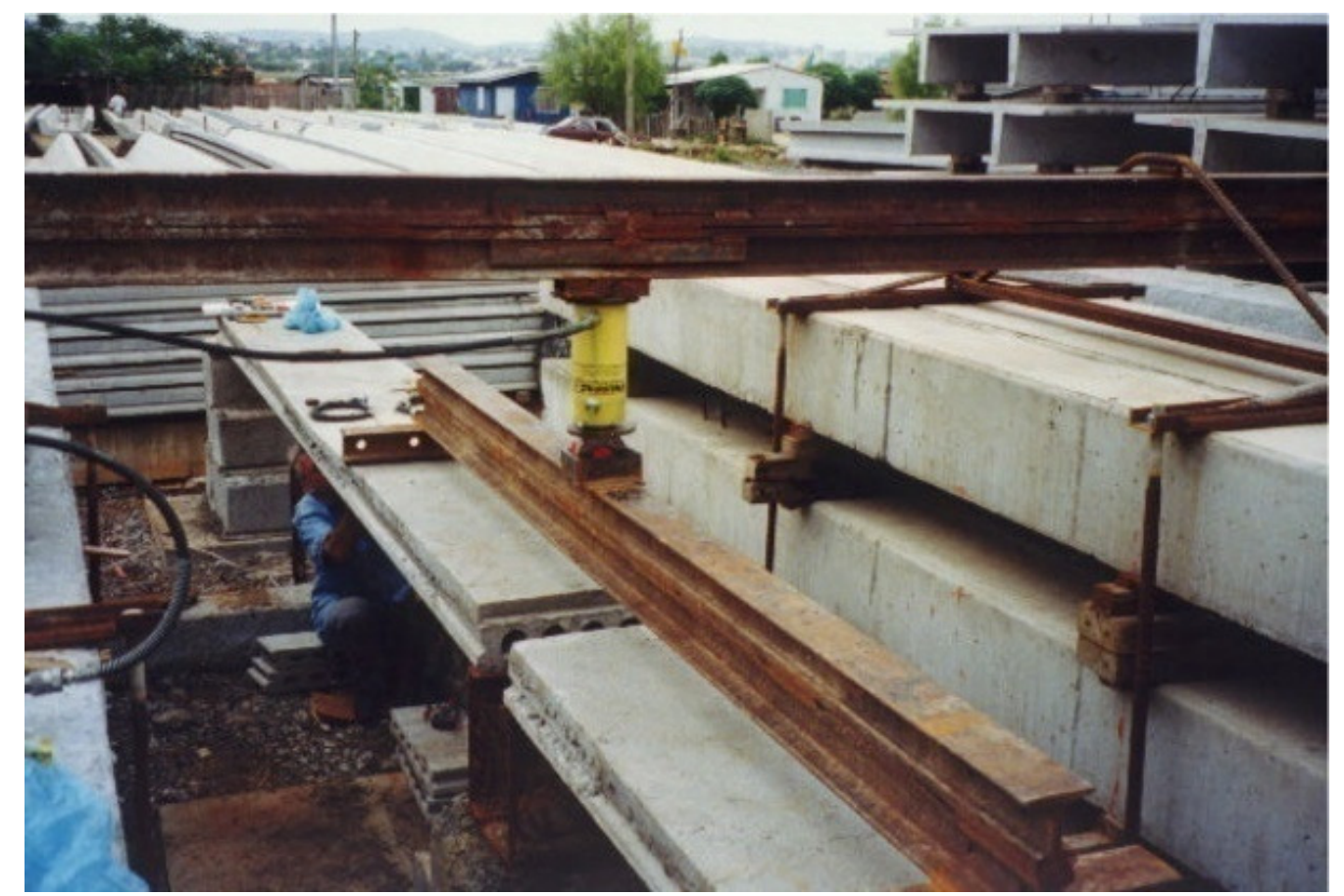

Figura 2.8 - Ensaios de lajes alveolares realizados por REZENDE e GASTAL (1999).

Foram executados três ensaios. O primeiro com dois elementos simplesmente apoiados, ou seja, sem continuidade. O segundo foi realizado considerando $40 \%$ do momento elástico, para a obtenção da armadura de continuidade. No terceiro ensaio a armadura foi obtida para $100 \%$ do momento elástico. 
Vale destacar que a aplicação da carga foi a uma distância de aproximadamente 1,50 m do apoio central, caracterizando um ensaio de interação de flexão com cisalhamento (flexo-cortante).

Os autores concluíram que o modelo numérico gerou resultados satisfatórios quando comparados com os experimentais. Entretanto alertam para o fato de serem necessários mais estudos sobre a ligação entre os concretos da capa e da laje alveolar.

Sobre os resultados experimentais, concluíram que a continuidade leva a um aumento da capacidade portante da laje e reduções nos deslocamentos verticais nos vãos.

Observando os gráficos que relacionam a força aplicada e as deformações nas barras de aço inseridas na capa, é possível concluir que a armadura não sofreu escoamento. A deformação máxima atingida não ultrapassou a deformação de escoamento teórico para barras de aço CA-50, $\varepsilon_{y d}=2,07 \%$. Com isso, é possível concluir que os modelos ensaiados atingiram a ruína por força cortante.

Utilizando o mesmo processo de análise, porém considerando a continuidade através da introdução de armaduras nos vazios longitudinais na região do apoio intermediário (Figura 2.9), BARBIERI e GASTAL (1999) chegaram a conclusões semelhantes.

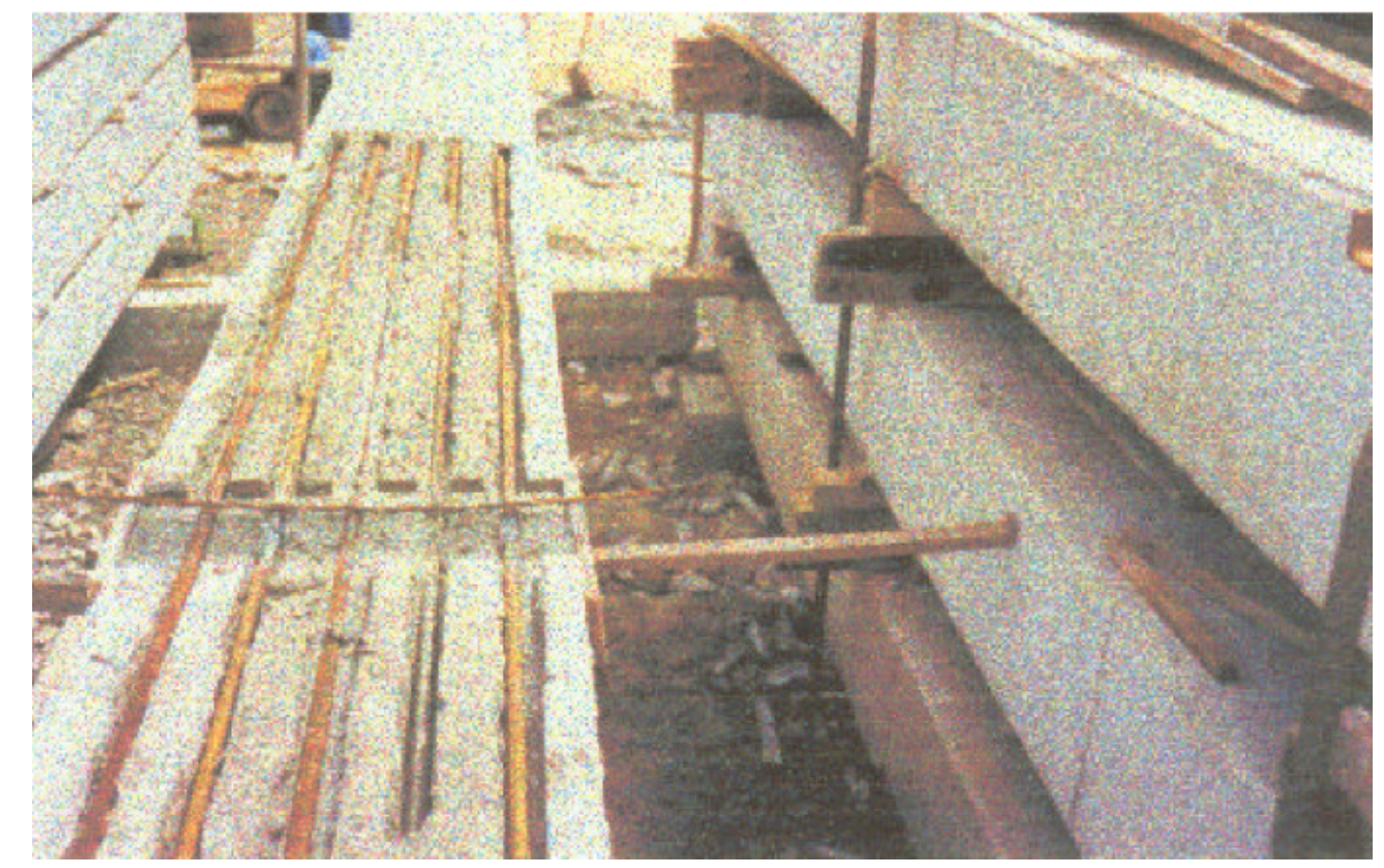

Figura 2.9 - Ensaios de lajes alveolares com continuidade por preenchimento dos alvéolos, realizados por BARBIERI e GASTAL (1999).

As lajes com continuidade por preenchimento dos alvéolos apresentaram acréscimos de rigidez quando comparadas com a situação de simplesmente apoiadas. Além disso, apresentaram diminuição dos deslocamentos e acréscimos da capacidade resistente. 
Vale ressaltar que os ensaios realizados por BARBIERI e GASTAL (1999) utilizaram lajes alveolares de $16 \mathrm{~cm}$ de altura.

MARCELLINO (2001) realizou estudo experimental de uma ligação laje-viga em que foram usadas seis partes de lajes alveolares, com dimensões $100 \mathrm{~cm}$ x $100 \mathrm{~cm}$, (Figura 2.10). As lajes, que possuíam $10 \mathrm{~cm}$ de altura, foram apoiadas em uma viga com seção transversal de $20 \mathrm{~cm} \times 40 \mathrm{~cm}$. A viga, por sua vez, foi apoiada em consolos moldados em pilares com seção transversal de $20 \mathrm{~cm}$ x $50 \mathrm{~cm}$. O vão entre eixos de apoio da viga foi de $314 \mathrm{~cm}$.

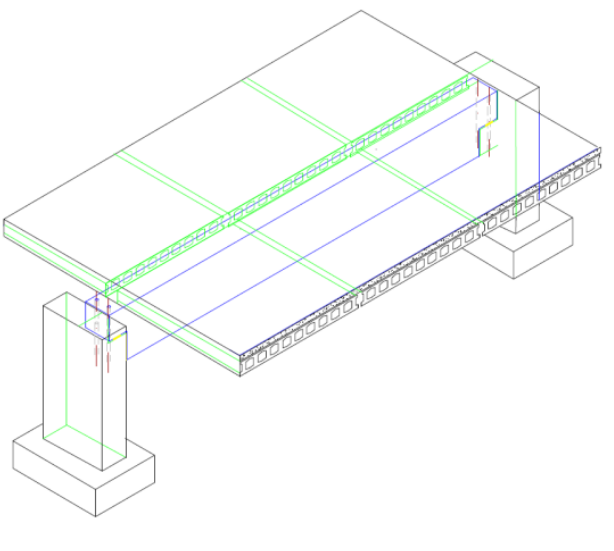

(a)

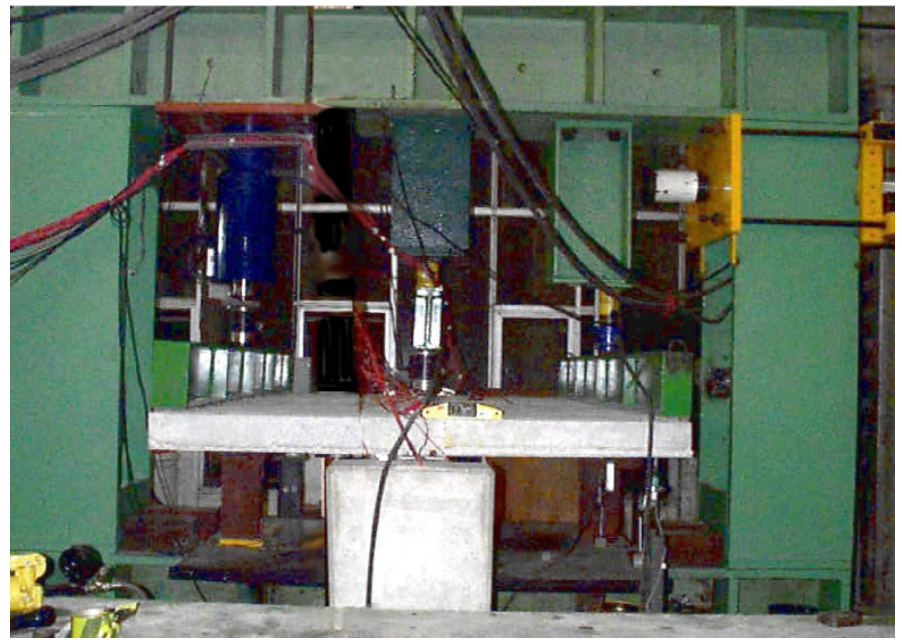

(b)

Figura 2.10 - Ensaio de ligação laje-viga realizado por MARCELLINO (2011).

(a) Plano de ensaio; (b) Foto do ensaio.

Entre os objetivos desse estudo, destaca-se a verificação da eficiência da continuidade. Conforme o autor, esta verificação foi comprovada nos três ensaios realizados, confirmando que o comportamento da parte solidarizada foi equivalente ao de uma estrutura maciça.

HOSNY et al. (2006) propuseram uma técnica para aumentar a resistência às solicitações de momento fletor negativo em lajes alveolares com balanços, como mostrado na Figura 2.11. A técnica consiste em usar tiras de fibras de carbono poliméricas (CFRP, carbon fibre reinforced polymer) coladas com adesivo à base de epoxy (Figura 2.12).

Foram feitos nove ensaios em lajes alveolares de $15 \mathrm{~cm}$ de altura, 1,20 $\mathrm{m}$ de largura e $5 \mathrm{~m}$ de comprimento. As lajes foram reunidas em três grupos e cada um deles possuía três lajes. O primeiro grupo de ensaios consistiu em lajes sem tiras de CFRP, denominadas de grupo de controle. O segundo possuía o reforço de três tiras de CFRP com $2 \mathrm{~m}$ de comprimento, posicionadas a partir da extremidade do balanço. Já no terceiro grupo, além das três tiras longitudinais, havia tiras coladas transversalmente. 


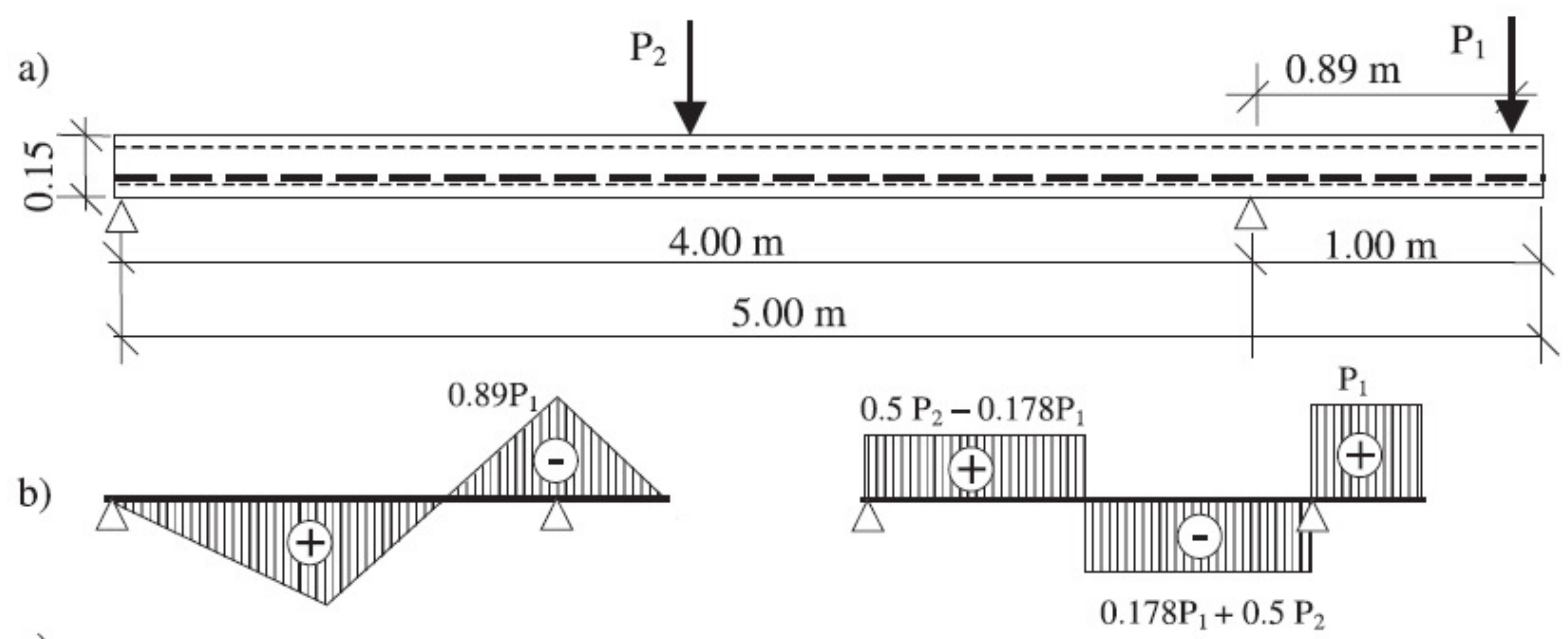

c)

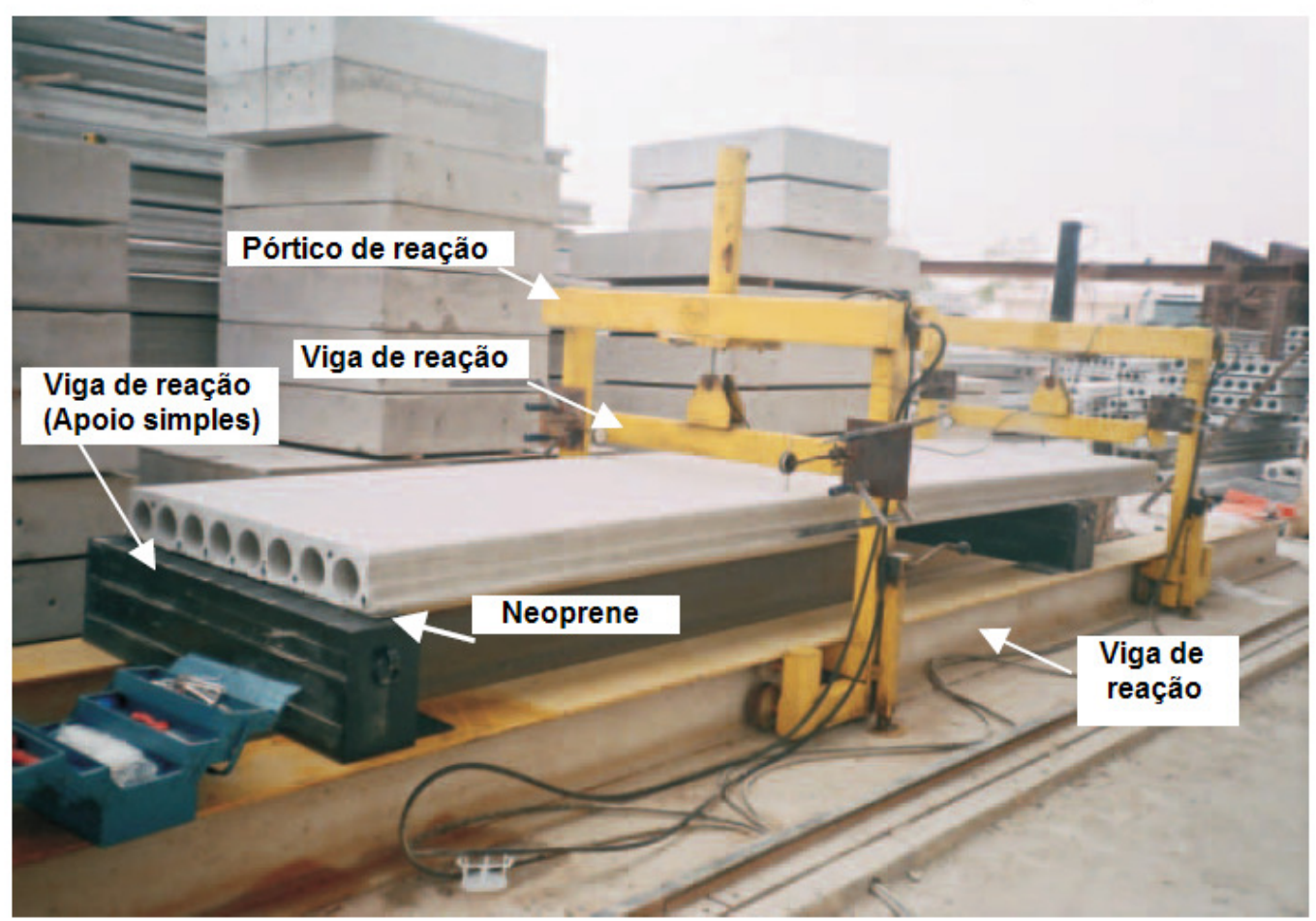

Figura 2.11 - Ensaio de laje alveolar com balanço realizado por HOSNY et al. (2006). (a) Sistema estrutural adotado; (b) Solicitações de momento fletor e força cortante; (c) Esquema estrutural do ensaio.

As lajes alveolares apresentavam elevada resistência característica à compressão, com $f_{c k}=89,5 \mathrm{MPa}$. A armadura ativa das fibras inferiores era composta por sete cordoalhas de 9,3 mm de baixa relaxação, com $1770 \mathrm{MPa}$ de resistência à tração. As fibras superiores tinham duas cordoalhas de $9,3 \mathrm{~mm}$. As tiras de CFRP possuíam $2400 \mathrm{MPa}$ de resistência à tração, enquanto que o adesivo epoxy, $32 \mathrm{MPa}$.

Através da comparação dos ensaios realizados com os três grupos, os autores concluíram que as tiras de CFRP promoveram aumento da capacidade da laje alveolar de resistir aos momentos negativos. O momento de fissuração foi acrescido de $183 \%$ a $225 \%$, enquanto que o momento negativo resistente teve um aumento de $277 \%$ a $574 \%$. 


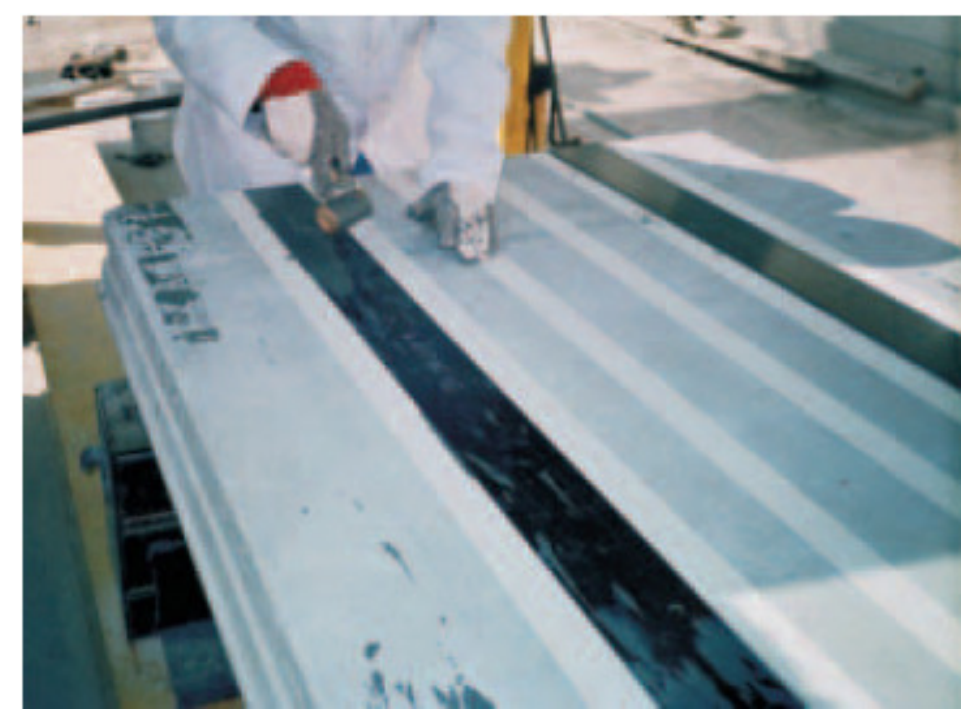

Figura 2.12 - Tiras de fibras de carbono poliméricas coladas com adesivo à base de epoxy.

De acordo com HOSNY et al. (2006), os possíveis modos de ruptura que podem ocorrer nesse tipo de ensaio são: (i) descolamento do CFRP posicionado longitudinalmente, que começa na região de máximo momento negativo e se estende até a extremidade do balanço; (ii) ruptura por flexão, seja pela ruptura à tração do CFRP ou por esmagamento do concreto; (iii) ruptura por força cortante; (iv) descolamento do CFRP posicionado transversalmente nas lajes do grupo 3.

Entretanto os modos de ruptura (ii) e (iv) não foram observados em nenhum dos ensaios, sendo precedidos pela ruptura por força cortante (iii) ou pelo descolamento das tiras de CFRP posicionadas longitudinalmente (i).

PETRUCELLI e CARVALHO (2010) estudaram a continuidade de forma analítica, considerando a plastificação do concreto nos apoios e também a perda de protensão. Para tal, apresentaram dois exemplos.

No primeiro utilizaram os mesmos dados de PETRUCELLI (2009), que abordou o dimensionamento de laje alveolar como simplesmente apoiada. Os resultados encontrados nesse exemplo mostraram que quando se considerou a continuidade houve uma redução do número de cordoalhas nas fibras inferiores, passando de dez cordoalhas de $12,7 \mathrm{~mm}$ para sete. Já nas fibras superiores o cálculo considerando a continuidade resultou na eliminação das duas cordoalhas de 9,5 mm, obtidas no cálculo da laje biapoiada.

O segundo exemplo mostra que, com um aumento da sobrecarga, houve um acréscimo do número das cordoalhas, passando a laje a necessitar de oito cordoalhas de $12,7 \mathrm{~mm}$ nas fibras inferiores e dois feixes de $3 \times 3,35 \mathrm{~mm}$ nas fibras superiores. Ainda no segundo exemplo é mostrado o cálculo da armadura passiva que garante a continuidade da ligação.

Como conclusão os citados autores recomendam que o projetista avalie as situações possíveis, considerando que, com a continuidade, ocorre uma diminuição da armadura de 
protensão. Entretanto, há um aumento do custo, devido à armadura passiva responsável pela continuidade.

\section{3 - Análise experimental de lajes alveolares}

A análise experimental de lajes alveolares tem sido feita nos grandes centros de pesquisa do mundo, com o objetivo de investigar seu comportamento, isoladamente ou em conjunto. Entre os principais assuntos investigados estão: a flexão, o cisalhamento e a condição de apoio, com grande destaque ao cisalhamento.

A Tabela 2.2 apresenta um resumo dos principais ensaios encontrados na literatura técnica, em ordem cronológica.

Tabela 2.2 - Ensaios de lajes alveolares encontrados na literatura técnica.

\begin{tabular}{|c|c|c|}
\hline $\begin{array}{c}\text { Pesquisador } \\
\text { (es) }\end{array}$ & Tipo de ensaio & Comentários \\
\hline $\begin{array}{l}\text { DAVIES et al. } \\
\text { (1990) }\end{array}$ & $\begin{array}{l}\text { Vista superior de ligação de laje-viga-laje, com } \\
\text { aberturas nos alvéolos para colocação de } \\
\text { armadura. }\end{array}$ & $\begin{array}{c}\text { Testes com lajes alveolares de } \\
20 \mathrm{~cm} \text { de altura, a fim de verificar } \\
\text { a contribuição do pavimento como } \\
\text { diafragma rígido. Mostraram que o } \\
\text { mecanismo de transferência do } \\
\text { cisalhamento horizontal depende } \\
\text { do desenvolvimento do atrito no } \\
\text { concreto moldado no local, } \\
\text { existente entre as unidades de lajes } \\
\text { alveolares. }\end{array}$ \\
\hline $\begin{array}{c}\text { UEDA e } \\
\text { STITMANNAI- } \\
\text { THUM (1991) }\end{array}$ & 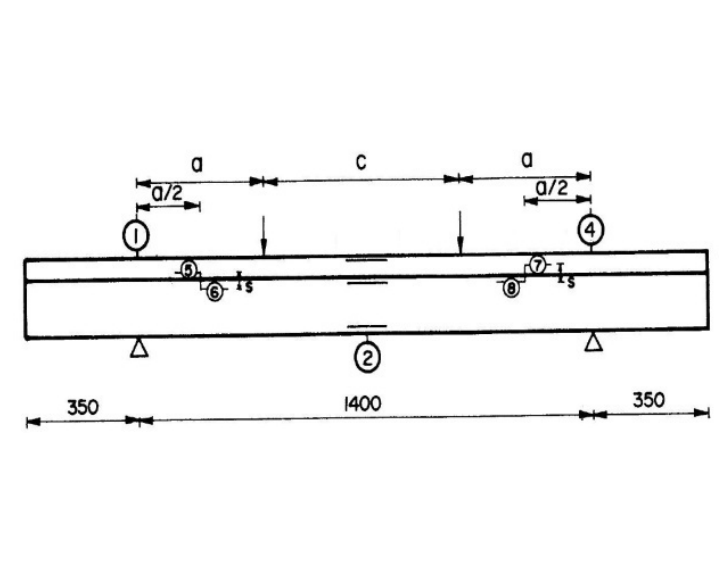 & $\begin{array}{l}\text { Ensaios em lajes alveolares para } \\
\text { investigar a resistência ao } \\
\text { cisalhamento com capa. Foram } \\
\text { testados dez elementos } \\
\text { simplesmente apoiados, com duas } \\
\text { forças concentradas, observando } \\
\text { os aspectos: força de protensão, } \\
\text { espessura da capa, razão entre } \\
\text { cortante e vão e quantidade de } \\
\text { armadura passiva. Concluiu-se que } \\
\text { a força de protensão afeta no } \\
\text { aparecimento de fissuras de } \\
\text { cisalhamento, entretanto influi } \\
\text { pouco no modo de ruína. }\end{array}$ \\
\hline
\end{tabular}




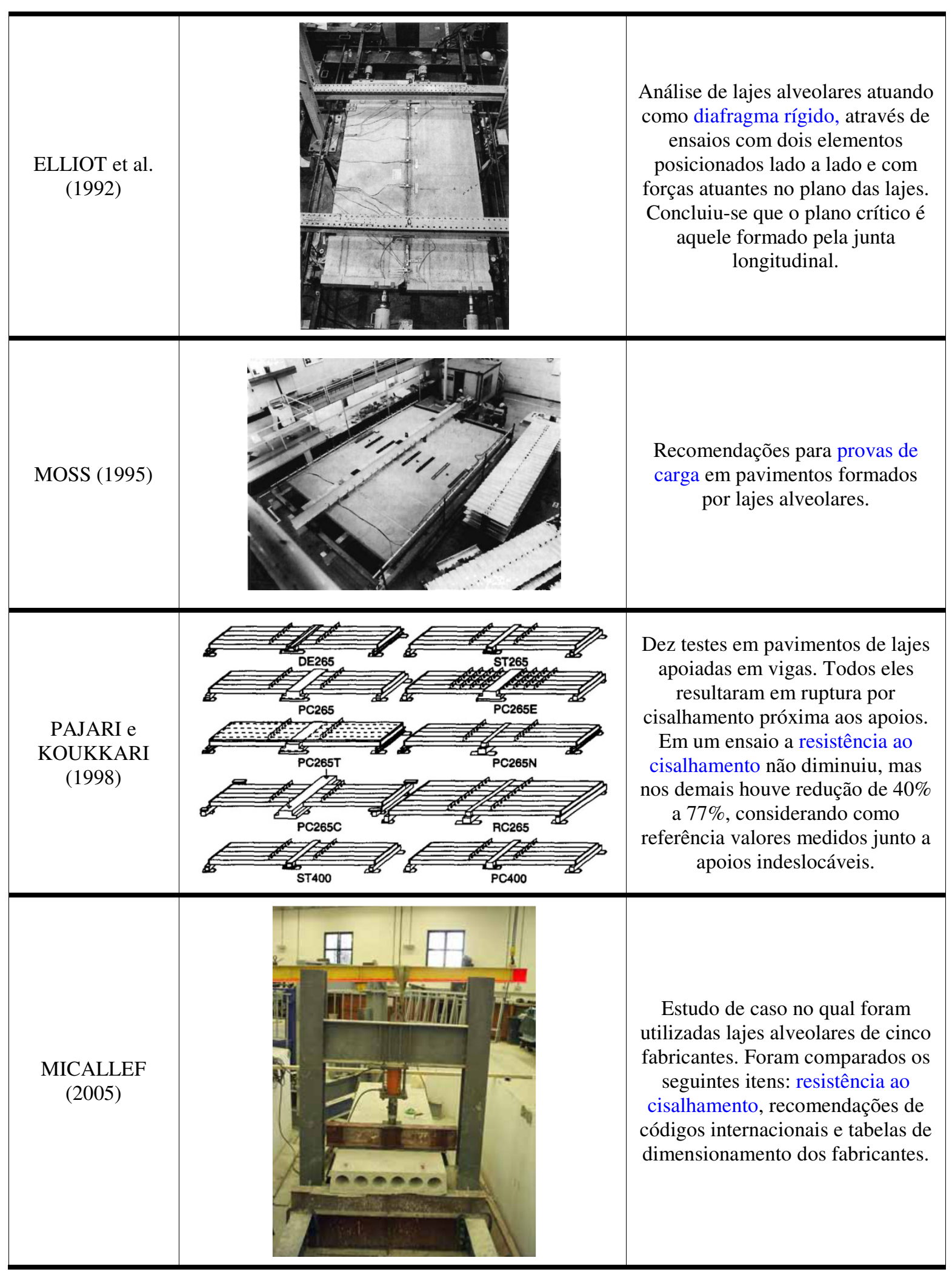




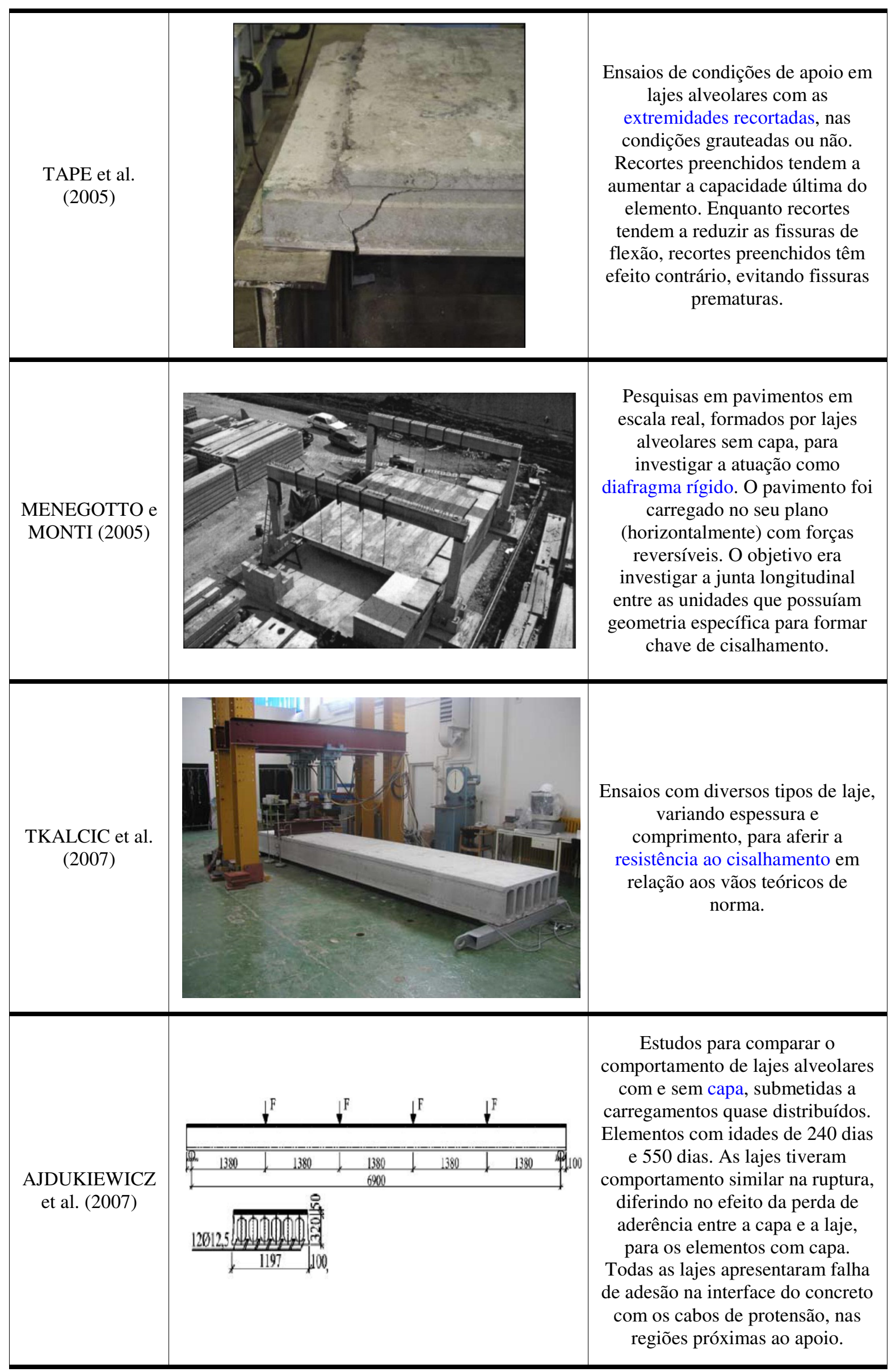




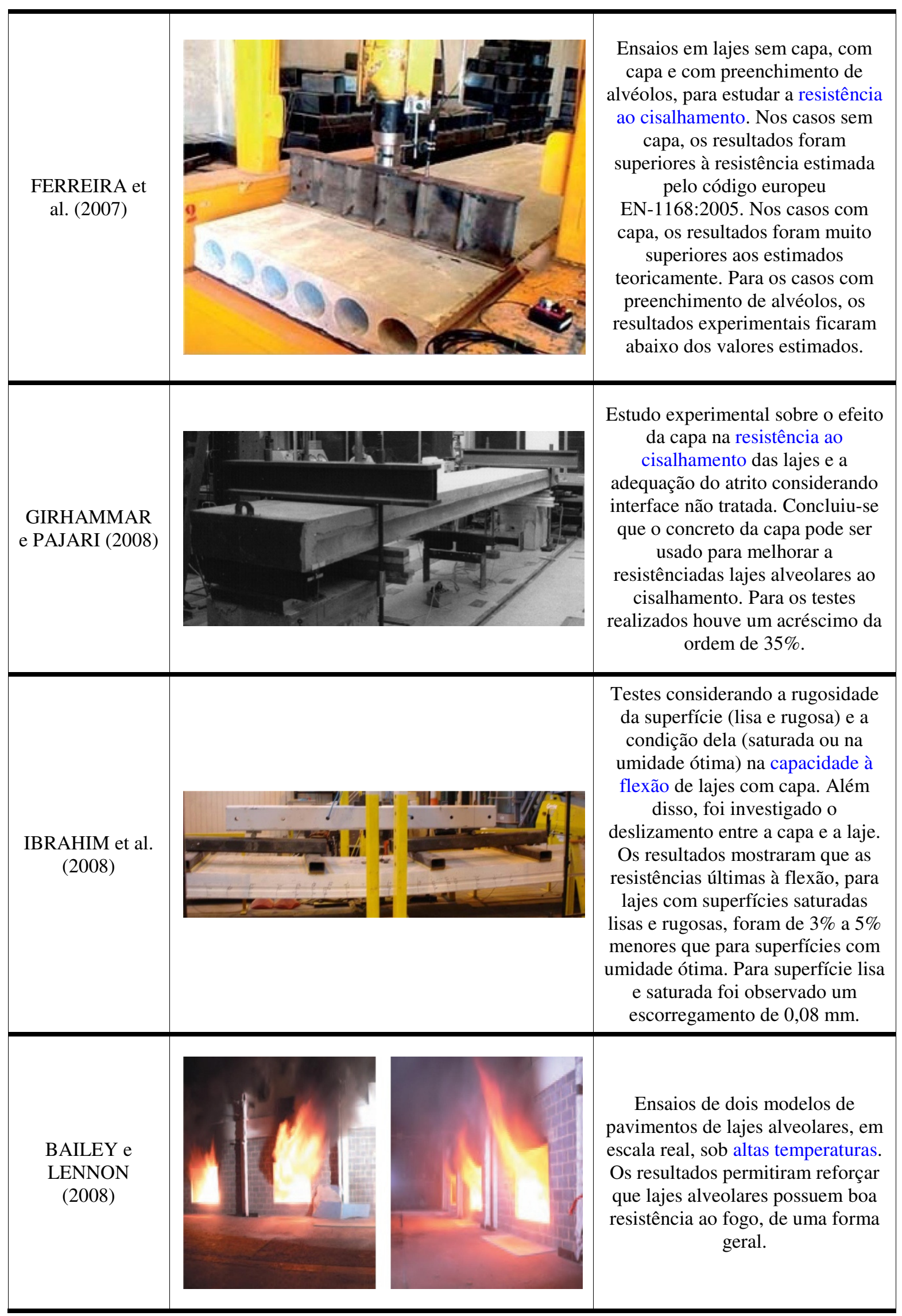




\begin{tabular}{|c|c|c|c|}
\hline $\begin{array}{c}\text { BERTAGNOLI } \\
\text { e MANCINI } \\
\text { (2009) }\end{array}$ \\
HEGGER et al. \\
(2009)
\end{tabular}

\section{4 - Pesquisas realizadas no NETPRE/UFSCar}

No Brasil, grande parte da contribuição nos estudos e aplicações das lajes alveolares vem sendo feita pelo NETPRE/UFSCar. A Tabela 2.3 apresenta de forma resumida as pesquisas realizadas em lajes alveolares, até a época em que este trabalho foi realizado. Acompanhando a tendência mundial, de certa forma ilustrada na Tabela 2.2, nota-se grande interesse nos estudos sobre a resistência ao cisalhamento.

Tabela 2.3 - Pesquisas sobre lajes alveolares realizadas no NETPRE/UFSCar.

\begin{tabular}{|c|c|c|c|}
\hline Pesquisador & & Título & Comentários \\
\hline $\begin{array}{l}\text { FERNANDES } \\
\quad(2007)\end{array}$ & $\mathrm{ME}$ & $\begin{array}{l}\text { Cisalhamento em lajes } \\
\text { alveolares pré-fabricadas de } \\
\text { concreto protendido: ensaio } \\
\text { padrão para controle de } \\
\text { qualidade }\end{array}$ & $\begin{array}{l}\text { Descreve os procedimentos do ensaio padrão } \\
\text { para avaliar a resistência ao cisalhamento de } \\
\text { lajes alveolares, seguindo recomendações da } \\
\text { FIB (2000). Mostra como esses ensaios podem } \\
\text { ser empregados no ambiente fabril, a fim de } \\
\text { garantir a qualidade do produto. }\end{array}$ \\
\hline
\end{tabular}




\begin{tabular}{|c|c|c|c|}
\hline COSTA (2009) & $\mathrm{ME}$ & $\begin{array}{c}\text { Avaliação de desempenho de } \\
\text { elementos de lajes alveolares } \\
\text { protendidas pré-fabricadas }\end{array}$ & $\begin{array}{l}\text { Teve como objetivo investigar os } \\
\text { procedimentos de ensaio para avaliação do } \\
\text { desempenho de lajes alveolares, com base em } \\
\text { referências internacionais: norma europeia } \\
\text { EN-1168:2005 e boletins técnicos da FIB. } \\
\text { Verificou-se que o procedimento de ensaio para } \\
\text { resistência ao cisalhamento é adequado para } \\
\text { avaliar lajes produzidas no Brasil. Entretanto, o } \\
\text { procedimento recomendado para ensaios de } \\
\text { flexão, com o uso de elementos de laje curtos, } \\
\text { mostrou-se inadequado, devido à grande } \\
\text { interação dos mecanismos de flexão e de } \\
\text { cisalhamento. }\end{array}$ \\
\hline $\begin{array}{l}\text { PETRUCELLI } \\
\text { (2009) }\end{array}$ & $\mathrm{ME}$ & $\begin{array}{l}\text { Considerações sobre projeto } \\
\text { e fabricação de lajes } \\
\text { alveolares protendidas }\end{array}$ & $\begin{array}{l}\text { Descreve os procedimentos para fabricação e } \\
\text { montagem dos sistemas de lajes alveolares de } \\
\text { concreto protendido. Para isso, mostra-se } \\
\text { sucintamente a teoria aplicada para o } \\
\text { desenvolvimento dos cálculos e verificações, } \\
\text { nos estados limites último e de serviço, } \\
\text { levando-se em conta o comportamento dos } \\
\text { painéis à flexão e ao cisalhamento, assim como } \\
\text { as deformações excessivas, além de tratar das } \\
\text { perdas de protensão, que mostram grande } \\
\text { importância para o resultado final. }\end{array}$ \\
\hline $\begin{array}{l}\text { CATOIA } \\
(2011) *\end{array}$ & DO & $\begin{array}{l}\text { Lajes alveolares protendidas: } \\
\text { cisalhamento em região } \\
\text { fissurada por flexão }\end{array}$ & $\begin{array}{l}\text { Realiza análise experimental em lajes } \\
\text { alveolares, tendo como objetivo a investigação } \\
\text { da resistência ao cisalhamento em regiões onde } \\
\text { ocorre fissuração devida a flexão. }\end{array}$ \\
\hline $\begin{array}{l}\text { RAYMUNDO } \\
\text { (2012) }\end{array}$ & $\mathrm{ME}$ & $\begin{array}{l}\text { Análise de pavimentos de } \\
\text { edifícios em concreto pré- } \\
\text { fabricado considerando o } \\
\text { efeito diafragma }\end{array}$ & $\begin{array}{c}\text { Estudo analítico a respeito de pavimentos } \\
\text { formados por lajes alveolares, com o objetivo } \\
\text { de determinar os esforços em pavimentos de } \\
\text { estruturas pré-fabricadas, de modo a promover } \\
\text { o seu dimensionamento para que funcione } \\
\text { corretamente, com o efeito de diafragma rígido } \\
\text { na estrutura. }\end{array}$ \\
\hline $\begin{array}{l}\text { CAMILLO } \\
\text { (2012) }\end{array}$ & $\mathrm{ME}$ & $\begin{array}{l}\text { Continuidade de painéis de } \\
\text { laje alveolar em edifícios }\end{array}$ & $\begin{array}{l}\text { Descreve os procedimentos de cálculos e } \\
\text { verificações para considerar a continuidade em } \\
\text { projetos de pavimentos formados por lajes } \\
\text { alveolares. Aborda as ações acidentais } \\
\text { alternadas e ações acidentais concentradas. }\end{array}$ \\
\hline $\begin{array}{l}\text { MARQUESI } \\
\quad(2014)\end{array}$ & $\mathrm{ME}$ & $\begin{array}{l}\text { Contribuição ao estudo dos } \\
\text { mecanismos resistentes à } \\
\text { força cortante em lajes } \\
\text { alveolares protendidas }\end{array}$ & $\begin{array}{l}\text { Analisa os dois mecanismos que descrevem a } \\
\text { resistência ao cisalhamento: flexo-cortante e } \\
\text { tração diagonal. Realiza ensaios experimentais } \\
\text { e utiliza os principais códigos normativos. }\end{array}$ \\
\hline
\end{tabular}

* Doutorado defendido no Departamento de Engenharia de Estruturas da Escola de Engenharia de São Carlos (USP), com pesquisa experimental feita no NETPRE/UFSCar.

Legenda: $\mathrm{ME}=$ dissertação de mestrado; $\mathrm{DO}=$ tese de doutorado. 


\section{CÁLCULO DA ARMADURA PASSIVA}

O dimensionamento de uma laje alveolar considerando a continuidade não difere muito da situação biapoiada. A principal mudança está na nova configuração do sistema estrutural e, portanto, nos novos diagramas de esforços solicitantes. Isto ocorre porque há uma alteração do esquema estrutural no histórico do elemento, que inicialmente funciona como simplesmente apoiado e passa a trabalhar como contínuo, após a confeç̧ão da capa com a presença da armadura de continuidade.

A armadura de continuidade pode ser dimensionada considerando a atuação integral do momento fletor negativo teórico (comumente chamado de momento elástico), ou levando em conta uma parcela desse momento.

Entretanto, dependendo do vão e dos carregamentos atuantes, a ruína pode acontecer por cisalhamento e não pelo momento negativo máximo previsto (atuante na ligação). Logo, a armadura de continuidade poderá ser condicionada pela verificação da força cortante.

Este capítulo aborda o dimensionamento do cálculo da armadura passiva dos modelos a serem ensaiados. Além disso, discute as vantagens de se promover a continuidade.

Para um estudo mais detalhado sobre o dimensionamento da laje alveolar na condição simplesmente apoiada, recomenda-se a leitura dos seguintes trabalhos: ARAUJO (2007) e PETRUCELLI (2009).

Para um estudo analítico mais aprofundado sobre os procedimentos de cálculos e verificações para considerar a continuidade em projetos de pavimentos formados por lajes alveolares, tem-se o trabalho desenvolvido por CAMILLO (2012).

Com relação aos estudos dos efeitos dependentes do tempo, sugere-se a leitura dos trabalhos de SOARES (2011) e ARAUJO (2011), por serem os mais recentes com aplicações em lajes alveolares.

\section{1 - Informações iniciais sobre as lajes ensaiadas}

A seguir serão mostradas as informações iniciais das lajes alveolares utilizadas neste trabalho. Neste capítulo, esses dados são usados para a obtenção da armadura de continuidade empregada em cada ensaio. 
As lajes alveolares foram doadas por empresas do setor de concreto pré-moldado, em conjunto com a $\mathrm{ABCIC}$.

As lajes do ensaio do modelo 1 (EM1) com seções transversais mostradas nas Figuras 3.1 e 3.2, foram doadas pela empresa LAJES TRELIÇADAS IND. E COM. LTDA., situada em Cuiabá, MT. Essas lajes foram utilizadas no estádio de futebol "Novo Verdão" (Cuiabá, MT). Elas têm 6m de comprimento.

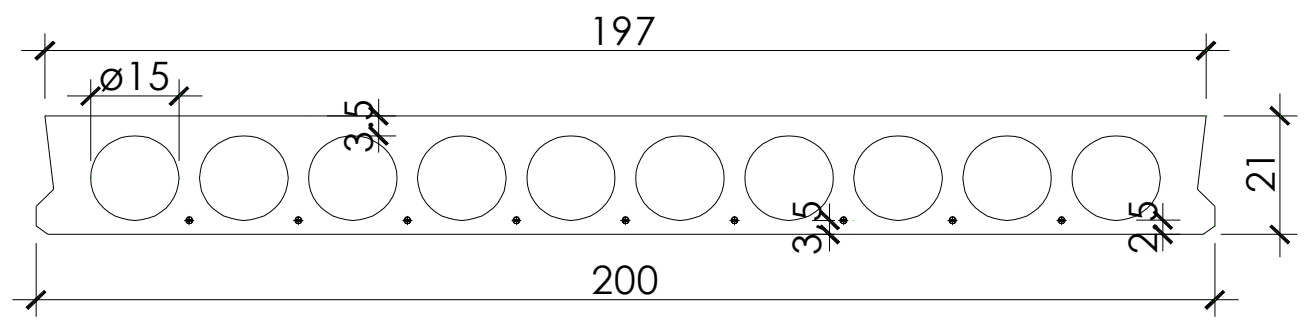

(a) Seção simples - EM1

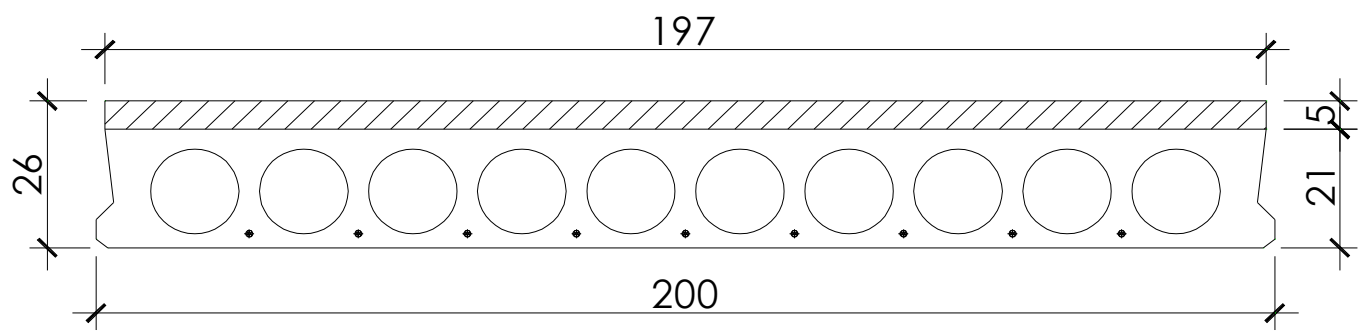

(b) Seção composta - EM1

Figura 3.1 - Seções transversais utilizadas no EM1:

(a) Laje alveolar simples; (b) Laje alveolar com capa de $5 \mathrm{~cm}$ (Desenho fornecido por LAJES TRELIÇADAS IND. E COM. LTDA.).

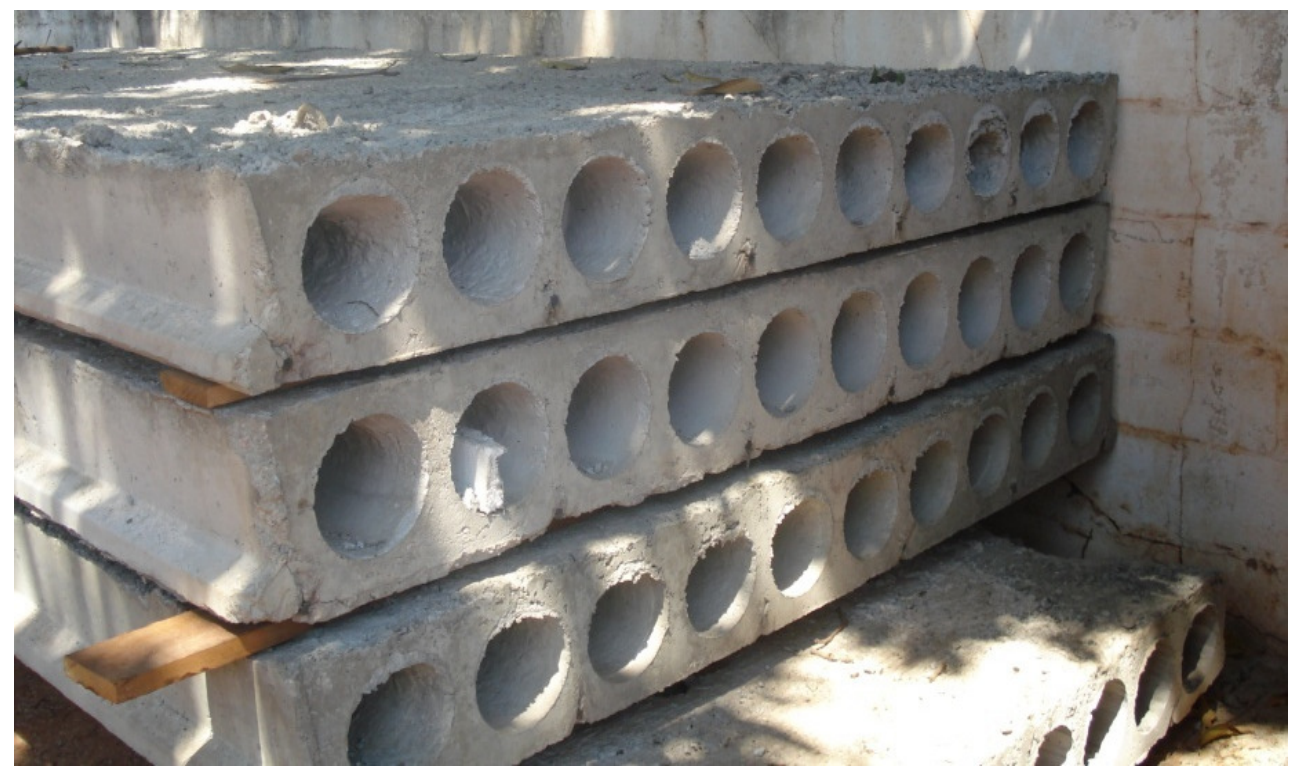

Figura 3.2 - Lajes alveolares do EM1, fornecidas por LAJES TRELIÇADAS IND. E COM. LTDA. 
Para o ensaio do modelo 2 (EM2), Figuras 3.3 e 3.4, foram utilizadas lajes alveolares da empresa CASSOL PRÉ-FABRICADOS, unidade de Monte Mor, SP. Essas lajes também têm $6 \mathrm{~m}$ de comprimento.

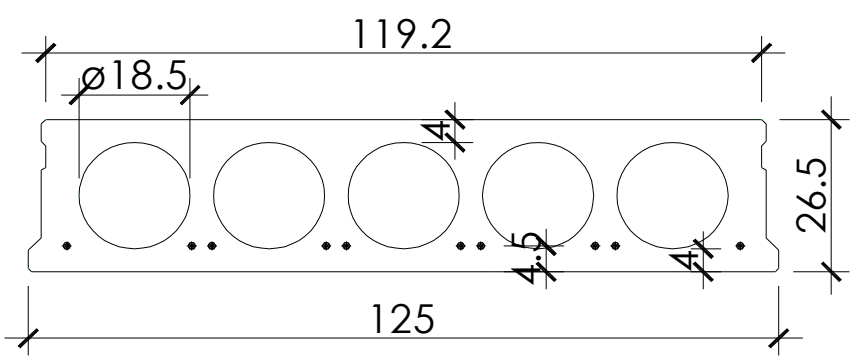

(a) Seção simples - EM2

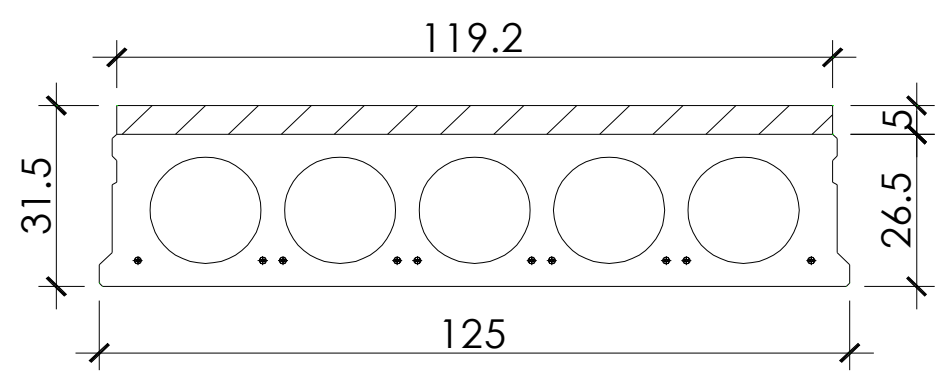

(b) Seção composta - EM2

Figura 3.3 - Seções transversais utilizadas no EM2:

(a) Laje alveolar simples; (b) Laje alveolar com capa de $5 \mathrm{~cm}$ (Desenho fornecido por CASSOL PRÉ-FABRICADOS).

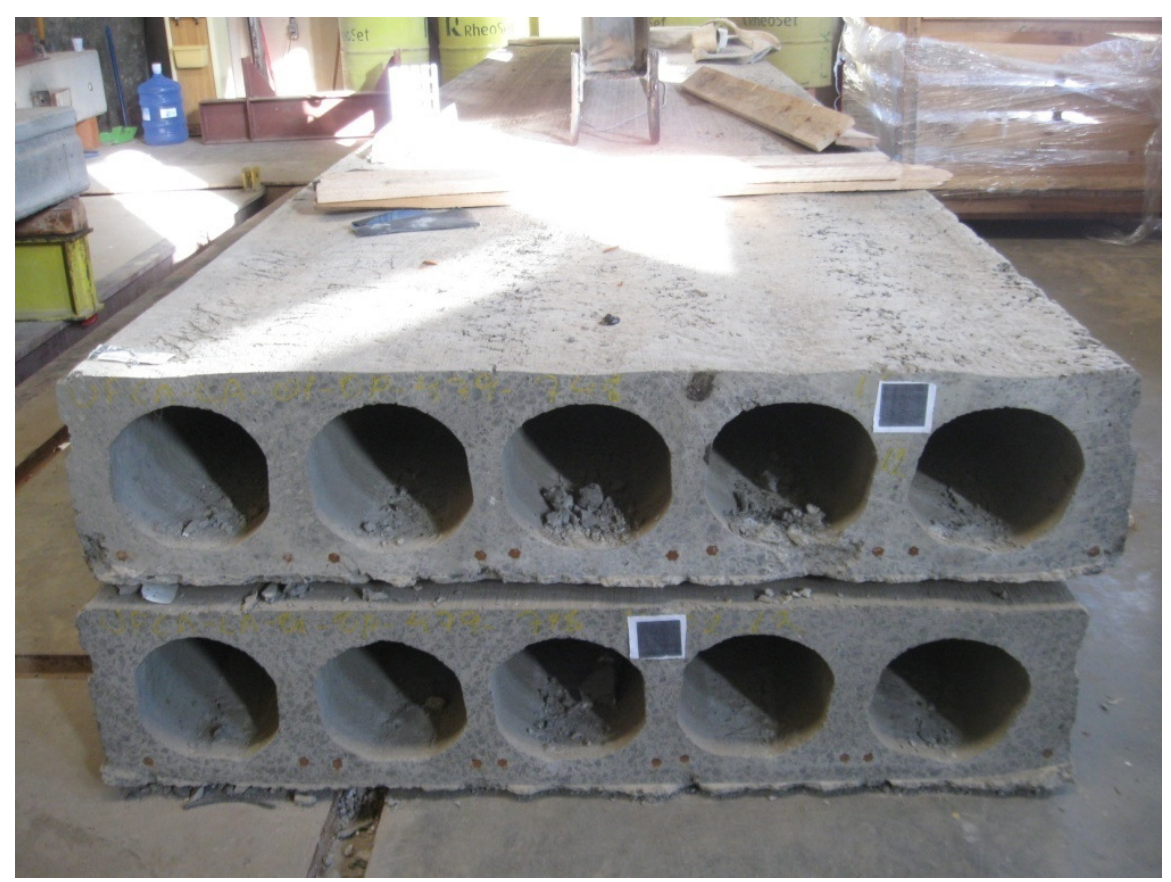

Figura 3.4 - Lajes alveolares do EM2, fornecidas pela CASSOL PRÉ-FABRICADOS. 
No EM3 (Figuras 3.5 e 3.6), foram ensaiadas lajes alveolares da empresa TATU PRÉMOLDADOS, situada em Limeira, SP. Essas lajes possuem comprimento de 5,5 m.

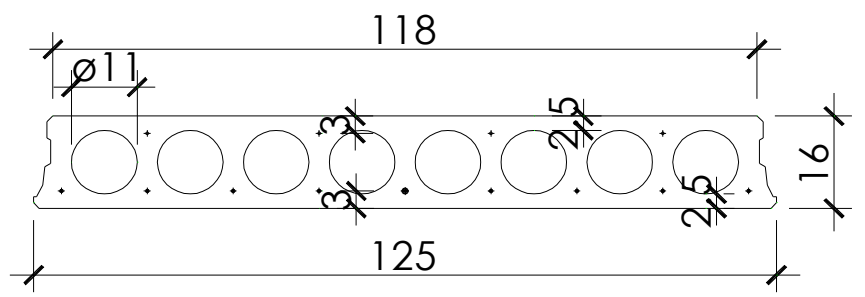

(a) Seção simples - EM3

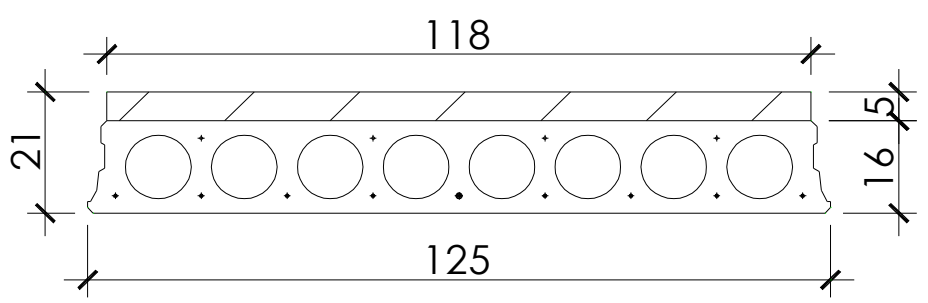

(b) Seção composta - EM3

Figura 3.5 - Seções transversais utilizadas no ensaio do modelo 3 (EM3):

(a) Laje alveolar simples; (b) Laje alveolar com capa de $5 \mathrm{~cm}$ (Desenho fornecido por TATU PRÉ-MOLDADOS).

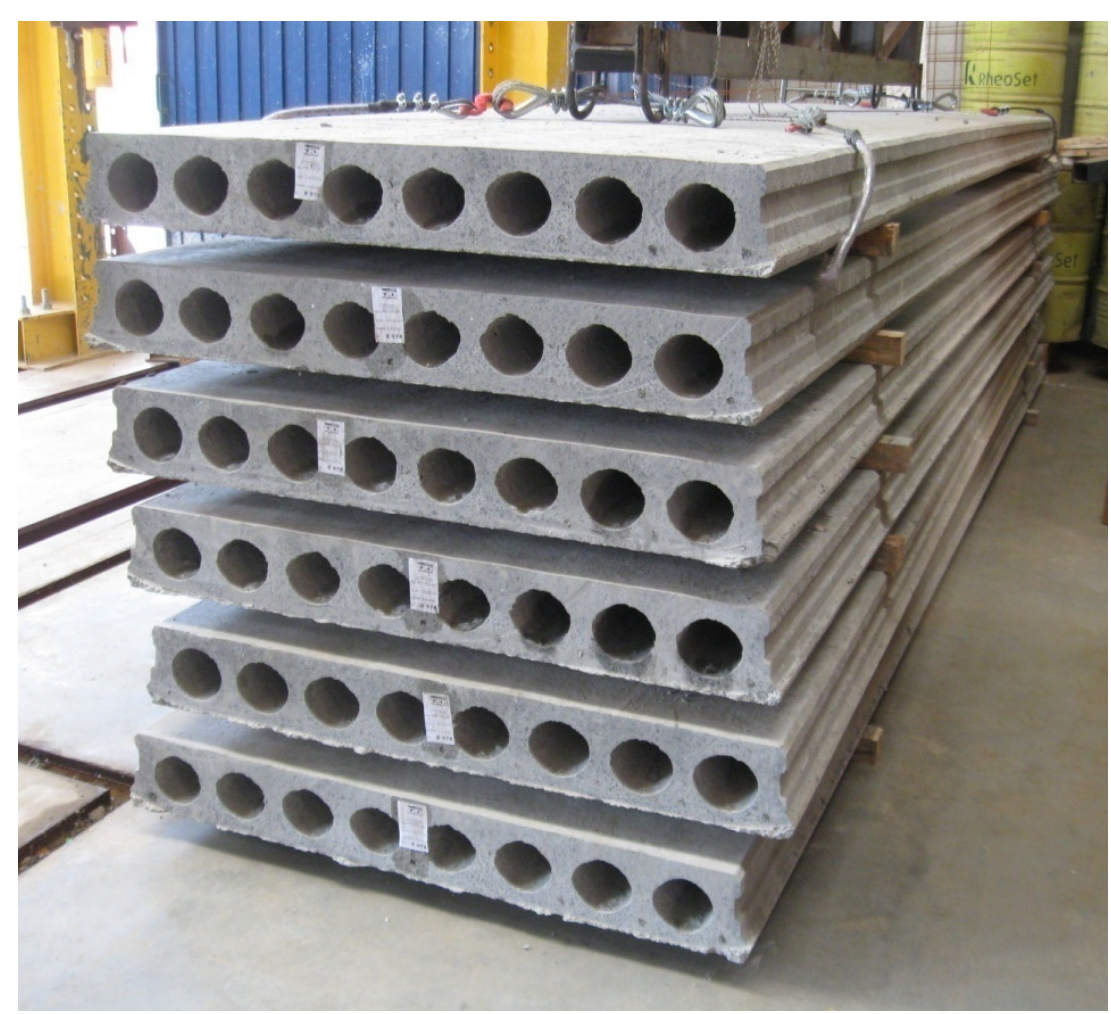

Figura 3.6 - Lajes alveolares do EM3, fornecidas por TATU PRÉ-MOLDADOS. 
As lajes do ensaio EM1 foram produzidas com concreto pré-moldado de canteiro, como mostrado na Figura 1.2, letra c. Por isso, apresentam rugosidade mais acentuada, como pode ser visto na Figura 3.2. As demais lajes (EM2 e EM3) foram produzidas nas respectivas fábricas, através de extrusora (Figura 1.2 letra a).

As Tabelas 3.1 e 3.2 apresentam respectivamente as propriedades geométricas e as propriedades do material, consideradas no cálculo da armadura de continuidade. Na Tabela 3.1, "Seção composta" significa seção com capa.

Tabela 3.1 - Propriedades geométricas.

\begin{tabular}{|c|c|c|c|c|c|c|c|}
\hline & \multicolumn{2}{|c|}{ EM1 } & \multicolumn{2}{c|}{ EM2 } & \multicolumn{2}{c|}{ EM3 } \\
\cline { 2 - 7 } Significado & Variável & $\begin{array}{c}\text { Seção } \\
\text { simples }\end{array}$ & $\begin{array}{c}\text { Seção } \\
\text { composta }\end{array}$ & $\begin{array}{c}\text { Seção } \\
\text { simples }\end{array}$ & $\begin{array}{c}\text { Seção } \\
\text { composta }\end{array}$ & $\begin{array}{c}\text { Seção } \\
\text { simples }\end{array}$ & $\begin{array}{c}\text { Seção } \\
\text { composta }\end{array}$ \\
\hline $\begin{array}{c}\text { Área da } \\
\text { armadura de } \\
\text { protensão }\end{array}$ & $\boldsymbol{A}_{\boldsymbol{p}}\left(\boldsymbol{( m}^{2}\right)$ & 8,91 & 8,91 & 9,90 & 9,90 & 2,63 & 2,63 \\
\hline $\begin{array}{c}\text { Distância da } \\
\text { armadura de } \\
\text { protensão à } \\
\text { fibra inferior }\end{array}$ & $\boldsymbol{d}^{\prime}(\boldsymbol{m})$ & 0,035 & 0,035 & 0,045 & 0,045 & 0,030 & 0,030 \\
\hline $\begin{array}{c}\text { Área da } \\
\text { seção de } \\
\text { concreto }\end{array}$ & $\boldsymbol{A}_{\boldsymbol{c}}\left(\boldsymbol{m}^{2}\right)$ & 0,2357 & 0,3342 & 0,1866 & 0,2462 & 0,1166 & 0,1752 \\
\hline $\begin{array}{c}\text { Momento de } \\
\text { inércia }\end{array}$ & $\boldsymbol{I}_{\left(\boldsymbol{m}^{4}\right)}$ & 0,0013 & 0,0024 & 0,0016 & 0,0027 & 0,0004 & 0,0008 \\
\hline $\begin{array}{c}\text { Distância da } \\
\text { fibra superior } \\
\text { ao CG da } \\
\text { seção }\end{array}$ & $\boldsymbol{y}_{\boldsymbol{s}}(\boldsymbol{m})$ & 0,1016 & 0,1143 & 0,1337 & 0,1453 & 0,0807 & 0,0952 \\
\hline $\begin{array}{c}\text { Distância da } \\
\text { fibra inferior } \\
\text { ao CG da } \\
\text { seção }\end{array}$ & $\boldsymbol{y}_{\boldsymbol{i}}(\boldsymbol{m})$ & 0,1084 & 0,1457 & 0,1313 & 0,1697 & 0,0793 & 0,1148 \\
\hline $\begin{array}{c}\text { Trabalho } \\
\text { resistente da } \\
\text { seção } \\
\text { superior }\end{array}$ & $\boldsymbol{W}_{\boldsymbol{s}}\left(\boldsymbol{m}^{\mathbf{3}}\right)$ & 0,01280 & 0,02100 & 0,01197 & 0,01860 & 0,00496 & 0,00840 \\
\hline $\begin{array}{c}\text { Trabalho } \\
\text { resistente da } \\
\text { seção } \\
\text { inferior }\end{array}$ & $\boldsymbol{W}_{\boldsymbol{i}}\left(\boldsymbol{m}^{\mathbf{3}}\right)$ & 0,01199 & 0,01647 & 0,01219 & 0,0159 & 0,00504 & 0,00700 \\
\hline $\begin{array}{c}\text { Excentricida } \\
\text { de protensão } \\
\text { (inferior) }\end{array}$ & $\boldsymbol{e}_{\boldsymbol{p}}(\boldsymbol{m})$ & 0,0734 & 0,1107 & 0,0863 & 0,1247 & 0,0493 & 0,0848 \\
\hline
\end{tabular}


Além da armadura de protensão posicionada na parte inferior, os elementos de EM3 possuem também:

- Armadura de protensão na parte superior: $A_{p, \text { sup }}=0,50 \mathrm{~cm}^{2}$;

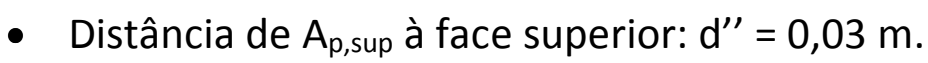

Tabela 3.2 - Propriedades dos materiais.

\begin{tabular}{|c|c|c|c|c|}
\hline Material & Variável & EM1 & EM2 & EM3 \\
\hline \multirow{2}{*}{$\begin{array}{l}\text { Concreto da } \\
\text { capa (CML) }\end{array}$} & $\mathrm{f}_{\mathrm{ck}}(\mathrm{MPa})$ & 30 & 30 & 30 \\
\hline & $\mathrm{E}_{\mathrm{ci}, \mathrm{cml}}(\mathrm{MPa})$ & 30672 & 30672 & 30672 \\
\hline \multirow{2}{*}{$\begin{array}{l}\text { Concreto da laje } \\
\text { (CPM) }\end{array}$} & $\mathrm{f}_{\mathrm{ck}}(\mathrm{MPa})$ & 40 & $40^{*}$ & 40 \\
\hline & $\mathrm{E}_{\mathrm{ci}, \mathrm{cpm}}(\mathrm{MPa})$ & 35418 & 35418 & 35418 \\
\hline \multirow{3}{*}{$\begin{array}{c}\text { Armadura } \\
\text { passiva } \\
\text { (AÇO CA-50) }\end{array}$} & $\mathrm{f}_{\mathrm{yk}}(\mathrm{MPa})$ & 500 & 500 & 500 \\
\hline & $\mathrm{E}_{\mathrm{s}}(\mathrm{MPa})$ & 210000 & 210000 & 210000 \\
\hline & $\varepsilon_{\mathrm{yd}}(\% \circ)$ & 2,07 & 2,07 & 2,07 \\
\hline \multirow{4}{*}{ Armadura ativa } & $\mathrm{f}_{\mathrm{ptk}}(\mathrm{MPa})$ & 1900 & 1900 & 1900 \\
\hline & $\mathrm{f}_{\mathrm{pyk}}(\mathrm{MPa})$ & 1710 & 1710 & 1710 \\
\hline & $\mathrm{E}_{\mathrm{p}}(\mathrm{MPa})$ & 205000 & 205000 & 205000 \\
\hline & $\varepsilon_{\mathrm{yk}}(\% \circ)$ & 8,34 & 8,34 & 8,34 \\
\hline \multirow{2}{*}{$\begin{array}{l}\text { TIPO DE AÇO } \\
\text { PROTENDIDO }\end{array}$} & $\begin{array}{l}\text { Armadura } \\
\text { superior }\end{array}$ & - & - & $\begin{array}{l}\text { CP } 150 \\
\text { RN }\end{array}$ \\
\hline & $\begin{array}{l}\text { Armadura } \\
\text { inferior }\end{array}$ & $\begin{array}{l}\text { CP } 190 \\
\text { RB }\end{array}$ & $\begin{array}{l}\text { CP } 190 \\
\text { RB }\end{array}$ & $\begin{array}{c}\text { CP } 190 \\
\text { RB }\end{array}$ \\
\hline
\end{tabular}

(*) Na realidade o $\mathrm{f}_{\mathrm{ck}}$ dos elementos de EM2 é de $30 \mathrm{MPa}$. O valor de $40 \mathrm{MPa}$ foi adotado para os cálculos neste capítulo.

Com relação à força inicial de protensão $\left(N_{p, i}\right)$, foram utilizados os dados fornecidos pelos fabricantes, apresentados na Tabela 3.3.

Tabela 3.3 - Força inicial de protensão $\left(\mathrm{N}_{p, i}\right)$.

\begin{tabular}{|c|c|c|c|c|c|c|}
\hline \multirow{2}{*}{ Variável } & \multicolumn{2}{|c|}{ EM1 } & \multicolumn{2}{c|}{ EM2 } & \multicolumn{2}{c|}{ EM3 } \\
\cline { 2 - 7 } & $\begin{array}{c}\text { Fibras } \\
\text { superiores }\end{array}$ & $\begin{array}{c}\text { Fibras } \\
\text { inferiores }\end{array}$ & $\begin{array}{c}\text { Fibras } \\
\text { superiores }\end{array}$ & $\begin{array}{c}\text { Fibras } \\
\text { inferiores }\end{array}$ & $\begin{array}{c}\text { Fibras } \\
\text { superiores }\end{array}$ & $\begin{array}{c}\text { Fibras } \\
\text { inferiores }\end{array}$ \\
\hline $\begin{array}{c}\text { Armadura } \\
\text { ativa (mm) }\end{array}$ & - & $9 \varnothing 12,7$ & - & $10 \varnothing 12,7$ & $4 \varnothing 4,0$ & $\begin{array}{c}8 \varnothing 6,4 \mathrm{e} \\
1 \varnothing 9,5\end{array}$ \\
\hline $\mathbf{N}_{\mathbf{p}, \mathbf{i}}(\mathbf{k N})$ & - & 140,6 & - & 124,5 & 13,75 & $\begin{array}{c}30,52 \mathrm{e} \\
65,10\end{array}$ \\
\hline
\end{tabular}




\section{2 - Dimensionamento na condição biapoiada}

O dimensionamento de uma laje alveolar biapoiada considera, usualmente, duas simplificações básicas. A primeira delas consiste em representar o pavimento por um elemento de laje alveolar, ou seja, considerar que o carregamento é igualmente distribuído por cada elemento.

A segunda simplificação é considerar o elemento de laje como sendo uma viga apoiada com apoios indeslocáveis na vertical. Logo, para fins de estado limite último (ELU) e tempo infinito, a armadura de protensão $\left(A_{p}\right)$ pode ser obtida considerando o momento fletor positivo representado pela soma de todos os carregamentos.

A Figura 3.7 apresenta o diagrama de momento fletor para o dimensionamento da laje alveolar na condição biapoiada, Nessa figura têm-se:

- $g_{1}$ é o carregamento de peso próprio da laje alveolar;

- $g_{2}$ corresponde ao peso próprio da capa;

- $g_{3}$ equivale às demais cargas permanentes (revestimento, por exemplo);

- q é a carga acidental.

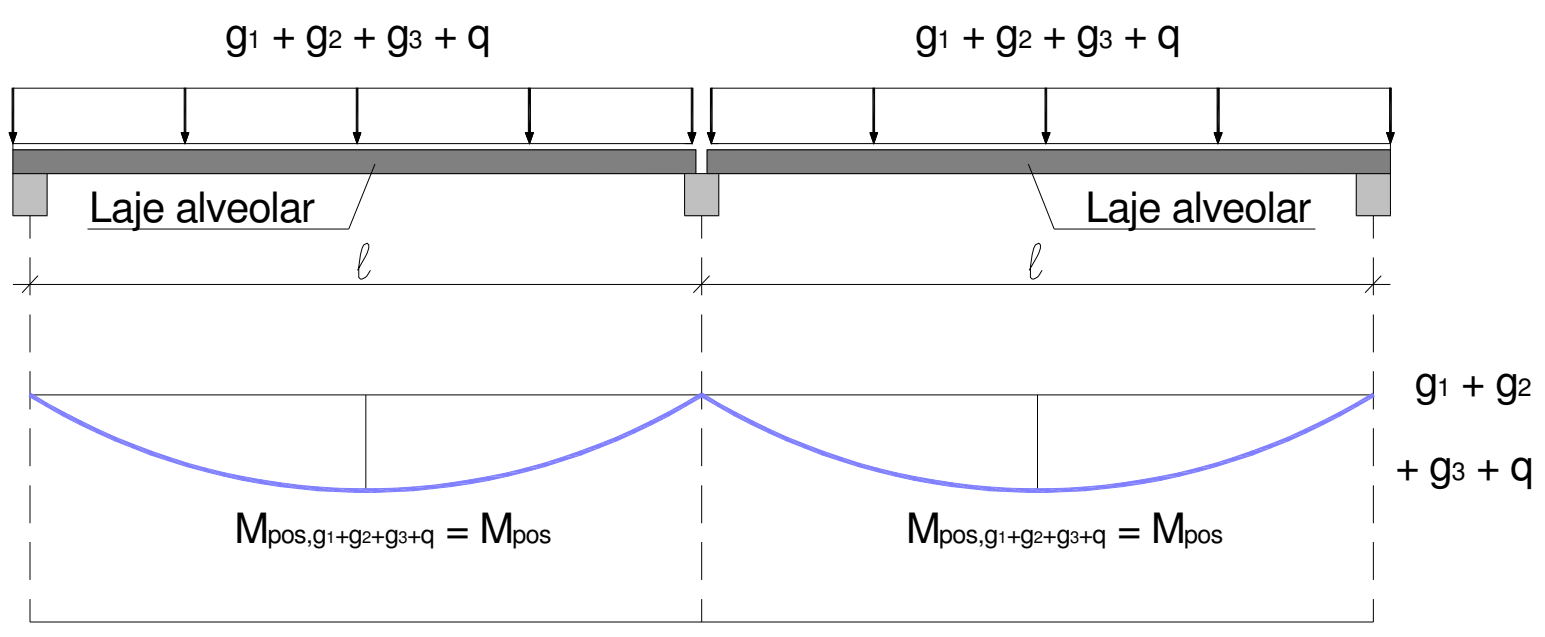

Figura 3.7 - Diagrama de momento fletor para dimensionamento na condição biapoiada.

Uma sugestão para roteiro de dimensionamento de laje alveolar simplesmente apoiada é apresentada por PETRUCELLI (2009), e reproduzida na Tabela 3.4, de forma adaptada. 
Tabela 3.4 - Sugestão para roteiro de dimensionamento de laje alveolar biapoiada. Adaptada de PETRUCELLI (2009).

\begin{tabular}{|c|c|c|}
\hline Etapa & Título & Comentários \\
\hline 1 & $\begin{array}{l}\text { Obtenção dos dados } \\
\text { iniciais. }\end{array}$ & $\begin{array}{c}\text { Propriedades geométricas e dos materiais, } \\
\text { carregamentos e etc. }\end{array}$ \\
\hline 2 & $\begin{array}{l}\text { Pré-dimensionamento de } \\
\text { A }_{p} \text { no ELU no tempo } \\
\text { infinito. }\end{array}$ & $\begin{array}{l}\text { Fase de pré-dimensionamento, em que é necessário } \\
\text { estimar as perdas totais. }\end{array}$ \\
\hline 3 & $\begin{array}{l}\text { Verificação do ELU no } \\
\text { tempo zero. }\end{array}$ & $\begin{array}{l}\text { Utilizar apenas o peso próprio, ou seja, situação em } \\
\text { vazio. É necessário calcular o comprimento de } \\
\text { transferência. A força de protensão é dada através de } A_{p} \\
\text { definida no item 2.Consideram-se os limites de } \\
\text { compressão excessiva na data da liberação da protensão } \\
\text { e na data de descompressão. Se forem atendidas as duas } \\
\text { condições (tração na borda superior e compressão } \\
\text { excessiva na borda inferior), ir para a etapa } 5\end{array}$ \\
\hline 4 & $\begin{array}{l}\text { Cálculo da armadura } \\
\text { superior. }\end{array}$ & $\begin{array}{l}\text { Ocorrendo tração nas fibras superiores, calcular a } \\
\text { armadura de protensão para a região superior. } \\
\text { Não sendo possível eliminar a tração ou a compressão } \\
\text { excessiva, adotar outro elemento com maior altura. }\end{array}$ \\
\hline 5 & $\begin{array}{l}\text { Determinação das perdas } \\
\text { de protensão. }\end{array}$ & $\begin{array}{l}\text { Cálculo das perdas iniciais e diferidas. No caso das } \\
\text { diferidas, consideram-se as etapas construtivas para a } \\
\text { determinação dos coeficientes adequados. Em geral } \\
\text { estipulam-se quatro etapas distintas de carregamentos } \\
\text { nas seções simples e composta. }\end{array}$ \\
\hline 6 & $\begin{array}{l}\text { Cálculo de } A_{p} \text { no ELU no } \\
\text { tempo infinito. }\end{array}$ & $\begin{array}{l}\text { Repete-se a etapa } 2 \text {, utilizando, no entanto, o valor final } \\
\text { das perdas calculadas na etapa } 5 .\end{array}$ \\
\hline 7 & $\begin{array}{l}\text { Verificação do ELU no } \\
\text { tempo zero. }\end{array}$ & $\begin{array}{l}\text { Repete-se a etapa 3, utilizando, no entanto, o valor final } \\
\text { das perdas calculadas na etapa } 5 .\end{array}$ \\
\hline 8 & $\begin{array}{l}\text { Cálculo da armadura } \\
\text { superior }\left(A_{p}^{\prime}\right) .\end{array}$ & $\begin{array}{c}\text { Ocorrendo tração nas fibras superiores, calcular a } \\
\text { armadura de protensão para a região superior, ou seja, } \\
\text { repete-se a etapa } 4 .\end{array}$ \\
\hline 9 & $\begin{array}{l}\text { Verificação de ELS para } \\
\text { fissuração no tempo } \\
\text { infinito. }\end{array}$ & $\begin{array}{l}\text { Deve-se considerar a combinação frequente e a quase } \\
\text { permanente para as cargas acidentais. A força de } \\
\text { protensão é obtida com o valor de } \mathrm{A}_{\mathrm{p}} \text { calculado da } \\
\text { maneira indicada na etapa 6. Os limites de tensão são } \\
\text { dados pela NBR 6118:2014, dependendo da condição de } \\
\text { agressividade ambiental. Caso as tensões não sejam } \\
\text { atendidas, deve-se aumentar a quantidade da armadura } \\
\text { superior } \mathrm{A}_{\mathrm{p}} \text { ' ou aumentar a altura da peça. }\end{array}$ \\
\hline 10 & $\begin{array}{l}\text { Verificação de ELS para } \\
\text { deformações. }\end{array}$ & $\begin{array}{c}\text { Deve-se determinar os valores das flechas para cada } \\
\text { etapa de carregamento e compará-los com os valores } \\
\text { normativos limites. }\end{array}$ \\
\hline 11 & $\begin{array}{l}\text { Verificação do } \\
\text { cisalhamento. }\end{array}$ & $\begin{array}{l}\text { Situações simples e composta. Se necessário, preencher } \\
\text { os alvéolos para diminuir as tensões. }\end{array}$ \\
\hline 12 & Detalhamento. & Detalhamento da peça para fabricação. \\
\hline
\end{tabular}




\section{3 - Alteração no sistema estrutural}

A alteração no sistema estrutural das lajes alveolares com continuidade é um fenômeno semelhante ao que ocorre nas pontes com balanços sucessivos, e, portanto, estão submetidas ao efeito de adaptação por fluência, que considera o comportamento dos materiais ao longo do tempo, principalmente para o controle das flechas. No entanto, os efeitos dependentes do tempo não foram considerados neste trabalho, uma vez que os ensaios de continuidade foram realizados em datas próximas às da moldagem da capa.

O dimensionamento de uma laje alveolar considerando a continuidade deve obedecer as duas fases descritas a seguir. Para ilustrar esse fato, tem-se a Figura 3.8.

- A primeira corresponde à situação de laje simplesmente apoiada, em que atua o peso próprio $\left(g_{1}\right)$ e também o peso do concreto moldado no local $\left(g_{2}\right)$, seja pela concretagem da capa ou pela concretagem das aberturas dos alvéolos. Nesta situação, a laje deve resistir ao momento positivo no meio do vão;

- A segunda fase corresponde à ligação com continuidade. Neste caso, deve-se considerar como momento positivo a soma entre o momento obtido na primeira fase e o relativo à segunda, em que atuam as demais cargas permanentes $\left(g_{3}\right)$ e as acidentais (q). Consequentemente, o máximo momento negativo é aquele calculado para a segunda fase, com o carregamento permanente e o acidental, nas situações mais desfavoráveis.

Capa com armadura passiva

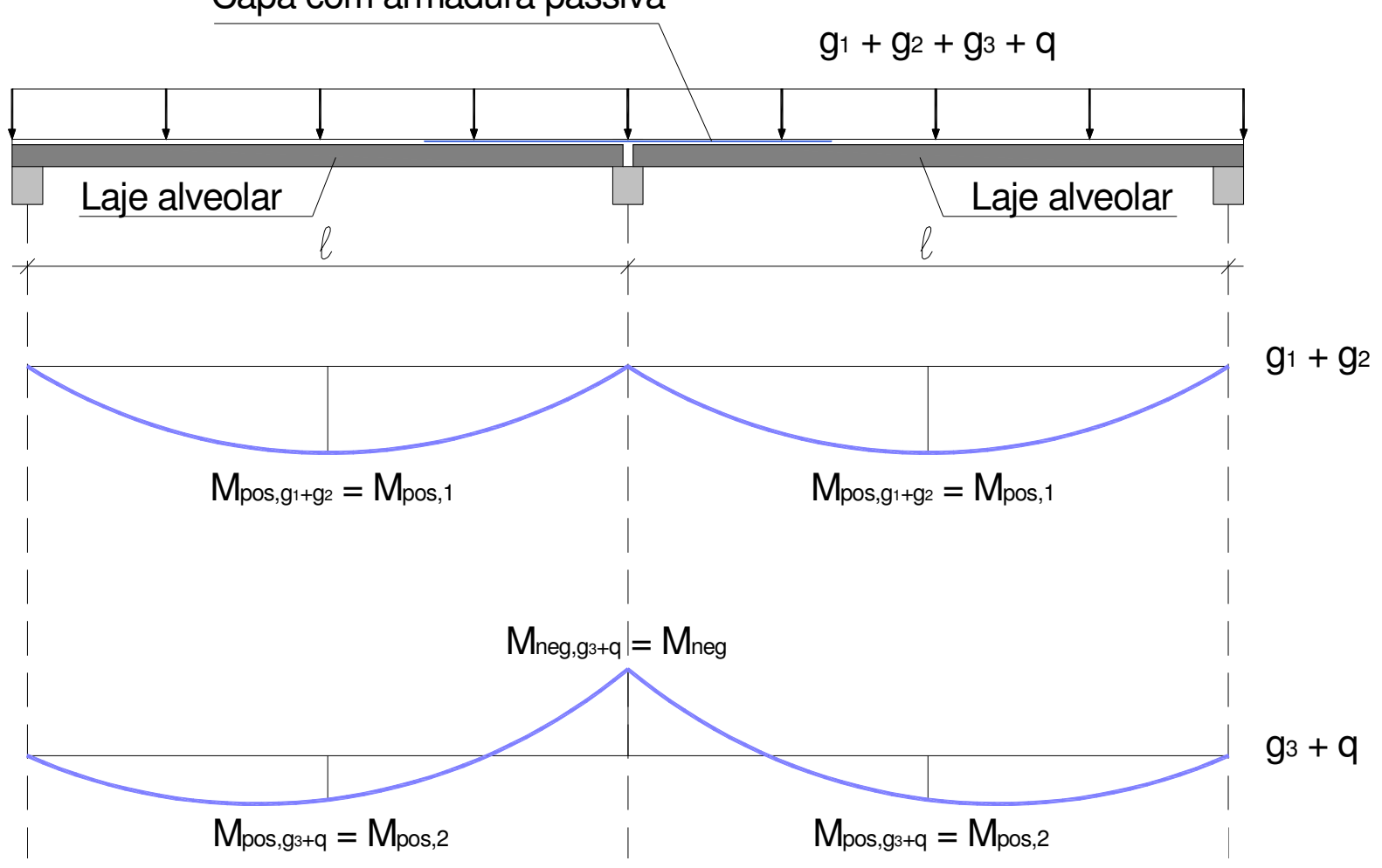

Figura 3.8 - Esquemas estruturais com os diagramas de momento fletor das duas fases para dimensionamento de uma laje alveolar com continuidade. 
Considerando o carregamento utilizado na análise experimental (ensaio de laboratório), pode ocorrer uma modificação no diagrama de momento fletor, na segunda fase.

Como pode ser visto na Tabela 2.2 do capítulo anterior, a forma mais comum de se aplicar um carregamento nos ensaios feitos em laje alveolar é através de uma viga simulando uma força concentrada. Dessa forma, o diagrama de momento fletor da segunda fase é similar ao apresentado na Figura 3.9.

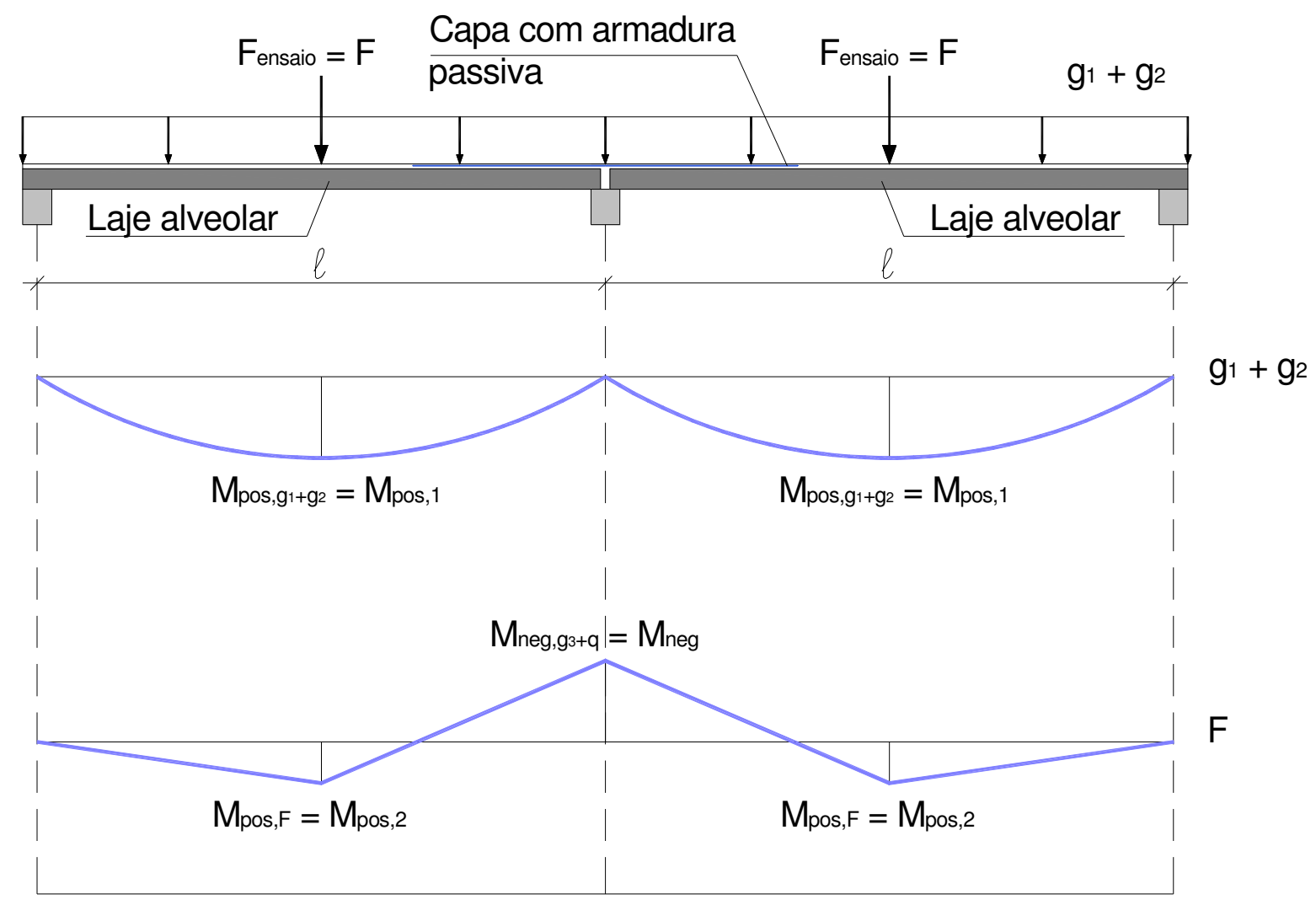

Figura 3.9 - Esquemas estruturais com os diagramas de momento fletor das duas fases para dimensionamento de uma laje alveolar com continuidade, considerando o carregamento utilizado em ensaios.

\section{4 - Benefícios de se promover a continuidade}

Consultando os trabalhos técnicos sobre continuidade já citados no Capítulo 2 (item 2.2), é possível distinguir algumas formas de se obter benefícios quando se efetua a continuidade. Para descrever essas vantagens tem-se a Tabela 3.5.

Nos projetos estruturais desses elementos, cada benefício deve ser considerado em função dos aspectos do projeto. 
Tabela 3.5 - Vantagens de se efetuar a continuidade. Comparação com a situação simplesmente apoiada.

\begin{tabular}{|c|c|c|}
\hline Vantagem & Autores & Comentários \\
\hline $\begin{array}{l}\text { Aumento da } \\
\text { capacidade } \\
\text { portante. }\end{array}$ & $\begin{array}{c}\text { RESENDE e } \\
\text { GASTAL (1999); } \\
\text { BARBIERI e } \\
\text { GASTAL (1999). }\end{array}$ & $\begin{array}{l}\text { É a primeira vantagem a ser percebida e a principal } \\
\text { vantagem comentada nos códigos internacionais. Foi } \\
\text { comprovada nos ensaios realizados pelos autores } \\
\text { citados na coluna anterior. } \\
\text { Ex.: dado um elemento de laje alveolar com as } \\
\text { propriedades geométricas e de material definidas, e } \\
\text { também para um determinado vão e quantidade de } \\
\text { armadura de protensão } \mathrm{A}_{\mathrm{p}} \text {. Esse elemento consegue } \\
\text { suportar um carregamento maior com continuidade, } \\
\text { quando comparada à situação biapoiada. }\end{array}$ \\
\hline $\begin{array}{l}\text { Aumento do } \\
\text { vão. }\end{array}$ & TAN et al. (1996). & $\begin{array}{l}\text { Ex.: dado um elemento de laje alveolar com as } \\
\text { propriedades geométricas e de material definidas, e } \\
\text { também para um determinado carregamento e } \\
\text { quantidade de armadura de protensão } \mathrm{A}_{\mathrm{p}} \text {. Esse } \\
\text { elemento consegue atender as condições normativas } \\
\text { para um vão maior com continuidade, quando } \\
\text { comparado à situação biapoiada. }\end{array}$ \\
\hline $\begin{array}{l}\text { Diminuição da } \\
\text { quantidade de } \\
\text { armadura de } \\
\text { protensão }\left(\mathrm{A}_{\mathrm{p}}\right) .\end{array}$ & $\begin{array}{c}\text { PETRUCELLI e } \\
\text { CARVALHO (2010). }\end{array}$ & $\begin{array}{l}\text { Ex.: dado um elemento de laje alveolar com as } \\
\text { propriedades geométricas e de material definidas, e } \\
\text { também para um determinado carregamento e vão. } \\
\text { Esse elemento requer uma quantidade menor de } \\
\text { armadura de protensão } \mathrm{A}_{\mathrm{p}} \text { no caso de continuidade, } \\
\text { quando comparado à situação biapoiada. }\end{array}$ \\
\hline
\end{tabular}

No entanto, levando em consideração a situação da análise experimental (ensaio de laboratório), das três vantagens citadas na Tabela 3.5, a mais plausível de ser analisada e controlada em laboratório é a primeira, na qual ensaios comparativos entre as situações biapoiada e com continuidade podem ser feitos para um mesmo elemento de laje alveolar, ou seja, com as mesmas propriedades do material, a mesma seção transversal, a mesma quantidade de armadura de protensão $\left(A_{p}\right)$ e o mesmo vão.

\section{5 - Perdas de protensão}

Antes de calcular a área de aço da armadura passiva $\left(A_{s}\right)$ a ser utilizada nos ensaios, é necessário determinar as perdas de protensão, considerando as datas de fabricação e dos ensaios.

O procedimento adotado para este trabalho foi o seguinte:

- Considerar $10 \%$ como estimativa das perdas na data do ensaio de continuidade;

- Calcular As;

- Realizar os ensaios; 
- De posse da data do ensaio de continuidade, calcular as perdas de protensão;

- Refazer os cálculos de As.

No entanto, para os exemplos deste trabalho, não houve diferença significativa no valor de $A_{s}$, com as perdas estimadas em $10 \%$ ou com as obtidas no cálculo. Portanto, seria muito extenso apresentar os cálculos de forma iterativa.

Logo, a forma adotada para apresentar os cálculos será aquela supondo que já se sabia de antemão todas as datas dos ensaios. Em outras palavras, considerando o seguinte:

- De posse da data do ensaio de continuidade, calcular as perdas de protensão;

- Calcular As.

A Tabela 3.6 apresenta as datas consideradas para o cálculo da perda de protensão. Essa tabela mostra também as datas dos ensaios de caracterização dos corpos de prova (CP's) da laje e da capa. Como já foi comentado, os ensaios experimentais realizados nas lajes alveolares, foram feitos no NETPRE/UFSCar. Entretanto, os ensaios de caracterização dos corpos de prova foram feitos no LSE/UFSCar, como será detalhado posteriormente.

Tabela 3.6 - Datas dos ensaios.

\begin{tabular}{|c|c|c|c|}
\hline Variável & EM1 & EM2 & EM3 \\
\hline Moldagem da laje na fábrica & $28 / 11 / 2011$ & $15 / 02 / 2012$ & $18 / 06 / 2012$ \\
\hline $\begin{array}{c}\text { Ensaios dos CP's da laje na } \\
\text { fábrica }\end{array}$ & $05 / 12 / 2011$ & $14 / 03 / 2012$ & $25 / 06 / 2012$ \\
\hline $\begin{array}{c}\text { Ensaios de caracterização da laje } \\
\text { no NETPRE }\end{array}$ & $20 / 01 / 2012$ & $20 / 05 / 2012$ & $27 / 07 / 2012$ \\
\hline $\begin{array}{c}\text { Moldagem da capa } \\
\text { Ensaio do modelo de } \\
\text { continuidade }\end{array}$ & $17 / 02 / 2012$ & $23 / 05 / 2012$ & $11 / 07 / 2012$ \\
\hline $\begin{array}{c}\text { Ensaios de caracterização nos } \\
\text { CP's da capa no LSE }\end{array}$ & $16 / 03 / 2012$ & $20 / 06 / 2012$ & $26 / 07 / 2012$ \\
\hline
\end{tabular}

O cálculo das perdas de protensão é baseado nos seguintes trabalhos: PETRUCELLI (2009) e CARVALHO (2012). O roteiro de cálculo é o mesmo encontrado em PETRUCELLI (2009). 


\subsection{1 - Perdas de protensão na data do ensaio de continuidade EM1}

A seguir é mostrado o cálculo das perdas de protensão para o ensaio de continuidade EM1. Para tal é necessário considerar os dados iniciais apresentados na: Figura 3.1 (medidas da seção transversal), Tabela 3.1 (propriedades geométricas), Tabela 3.2 (propriedades dos materiais), Tabela 3.3 (força inicial de protensão) e Tabela 3.6 (datas dos ensaios).

Como dados complementares, têm-se o seguinte:

- Cimento ARI;

- Umidade relativa do ar (U) igual a 70\%;

- Temperatura (T) igual a $20^{\circ}$;

Considerando as medidas da capa (Figura 3.1) e a área da seção transversal da laje ( $A_{c}$ da Tabela 3.1), os carregamentos considerados são:

- Peso próprio da laje $-\mathrm{g}_{1}=0,2357\left(\mathrm{~m}^{2}\right) * 25\left(\mathrm{kN} / \mathrm{m}^{3}\right)=5,89 \mathrm{kN} / \mathrm{m}$;

- Peso próprio da capa - $\mathrm{g}_{2}=0,05(\mathrm{~m}) * 2,00(\mathrm{~m}) * 25\left(\mathrm{kN} / \mathrm{m}^{3}\right)=2,5 \mathrm{kN} / \mathrm{m}$.

Considerando a Tabela 3.3, têm-se:

- Força inicial de protensão $-N_{p}=N_{\text {pi }} \times n^{\circ}$ de cordoalhas $=140,6 \times 9=1265,4 \mathrm{kN}$;

- Tensão inicial de protensão $-\sigma_{\mathrm{pi}}=\mathrm{N}_{\mathrm{p}} / \mathrm{A}_{\mathrm{p}}=1465,4 / 8,91=142 \mathrm{kN} / \mathrm{cm}^{2}(1420$ $\mathrm{MPa})$.

A Tabela 3.7 mostra as etapas de carregamento consideradas, o tempo decorrido da concretagem, as ações, o tipo de seção e as causas das perdas correspondentes a cada etapa.

Tabela 3.7 - Sequência considerada para determinação das perdas conforme as etapas de carregamento.

\begin{tabular}{|c|c|c|c|c|}
\hline Etapa & $\begin{array}{l}\text { Tempo decorrido da } \\
\text { concretagem }\end{array}$ & Ações & Tipo de seção & Perdas \\
\hline 1 & $\begin{array}{c}\mathrm{t}=21 \text { horas (aplicação da } \\
\text { protensão. Será } \\
\text { arredondado para } 1 \text { dia. }\end{array}$ & $\mathrm{p}+\mathrm{g}_{1}$ & Simples & $\begin{array}{c}\text { Deformação imediata } \\
\text { Deformação por ancoragem } \\
\text { Relaxação da armadura }\end{array}$ \\
\hline 2 & $\begin{array}{c}\mathrm{t}=81 \text { dias (moldagem da } \\
\text { capa) }\end{array}$ & $\mathrm{p}+\mathrm{g}_{1}+\mathrm{g}_{2}$ & Simples & $\begin{array}{l}\text { Retração do concreto } \\
\text { Fluência do concreto } \\
\text { Relaxação da armadura }\end{array}$ \\
\hline
\end{tabular}

p-força de protensão; $g_{1}$-peso próprio da laje; $g_{2}$-peso próprio da capa.

Como os cálculos das perdas de protensão serão feitos para as datas dos ensaios (ensaio de continuidade e de caracterização), não será considerado o tempo infinito, e sim o tempo t decorrido até a data do ensaio. No caso do ensaio de continuidade de EM1, t é igual a 100 dias. 


\subsubsection{1 - Perdas Iniciais - Etapa 1}

As perdas iniciais correspondem a etapa 1 da Tabela 3.7, sendo apresentadas na Tabela 3.8, na seguinte sequência: a) Deformação por ancoragem da armadura; b) Relaxação da armadura; c) Deformação imediata do concreto.

Tabela 3.8 - Cálculos das Perdas Iniciais de Protensão - Ensaio do modelo 1 (EM1).

\section{Deformação por ancoragem $\left(\Delta \sigma_{\text {anc }}\right)$}

- Comprimento da pista $(\mathrm{L})=84 \mathrm{~m}$;

- Encurtamento total do cabo $(\Delta \ell)=6 \mathrm{~mm}$;

$$
\begin{gathered}
\varepsilon \ell=\frac{\Delta \ell}{L}=\frac{0,006}{84}=0,0000714 \\
\Delta \sigma_{a n c}=E p . \varepsilon \ell=200500 \cdot 0,0000714=14,32 \mathrm{MPa}
\end{gathered}
$$

\section{Relaxação da armadura $\left(\Delta \sigma_{r}\right)$}

Obtida por:

Onde:

$$
\Delta \sigma_{r}=\psi\left(t, t_{0}\right) \cdot \sigma_{p i}
$$

$-\psi\left(t, t_{0}\right)$ é o coeficiente de relaxação da armadura: $\psi\left(t, t_{0}\right)=\psi_{1000}\left[\frac{t-t_{0}}{41,67}\right]^{0,15}$

- $\sigma_{\text {pi }}$ é a tensão da armadura de protensão no instante do seu estiramento igual a $1420 \mathrm{MPa}$.

- $\psi_{1000}$ pode ser obtido em tabela indicada por CARVALHO (2012) ou na fórmula indicada a seguir, que foi obtida por regressão linear, a partir da tabela de CARVALHO (2012).

$$
\begin{gathered}
\psi_{1000}=-7,5 \cdot R^{2}+21,45 \cdot R-8,855 \\
\psi_{1000}=-7,5 \cdot 0,7398^{2}+21,45 \cdot 0,7398-8,855 \\
\psi_{1000}=-4,10478+15,86871-8,855 \\
\psi_{1000}=2,91 \%
\end{gathered}
$$

- R é obtido pela seguinte relação:

Portanto:

$$
R=\frac{\left(\sigma_{p i}-\Delta \sigma_{a n c}\right)}{f_{p y t k}}=\frac{(1420-14,32)}{1900}=0,7398
$$

$$
\begin{gathered}
\psi\left(t, t_{0}\right)=\psi_{1000}\left[\frac{t-t_{0}}{41,67}\right]^{0,15}=2,91\left[\frac{1-0}{41,67}\right]^{0,15}=1,663 \% \\
\Delta \sigma_{r}=\psi\left(t, t_{0}\right) \cdot \sigma_{p i}=\frac{1,663}{100} 1420=23,61 \mathrm{MPa}
\end{gathered}
$$

\section{Deformação imediata do concreto $\left(\Delta \sigma_{\mathrm{p}, \mathrm{i}}\right)$}

Considerando o cabo representante e a seção do meio do vão, tem-se:

Onde:

$$
\Delta \sigma_{p, i}=\alpha_{p} \cdot \sigma_{c g, c a b o}
$$

- $\alpha$ é a relação entre os módulos de elasticidade do aço e do concreto, considerando $\mathrm{f}_{\mathrm{cj}}=20 \mathrm{MPa}$, para 1 dia: $\alpha_{p}=\frac{E_{p}}{E_{c S}}=\frac{200500}{21287}=9,42$ 
- $\sigma_{c g, c a b o}$ é a tensão no concreto no nível do baricentro da armadura de protensão, dada pela seguinte fórmula:

$$
\sigma_{c g, c a b o}=\frac{N_{p}}{A_{c}}+\frac{M_{p} \cdot e_{p}}{I}-\frac{M_{g 1} \cdot e_{p}}{I}
$$

Sendo:

- $N_{p}$ é a força total de protensão, considerando as perdas calculadas anteriormente em $\mathrm{kN} / \mathrm{m}^{2}$ :

$-N_{p}=\sigma_{i} \cdot A_{p}=(142,0-1,432-2,361) \cdot 8,91=138,207 \cdot 8,91=1231,42 \mathrm{kN}$

$-A_{c}$ é a área da seção transversal considerada igual a $0,2357 \mathrm{~m}^{2}$.

- $e_{i}$ é a excentricidade do cabo representante (distância da força de protensão $\left(\mathrm{N}_{\mathrm{p}}\right)$ ao centro de gravidade da seção transversal: $0,0734 \mathrm{~m}$

- $M_{p}$ é o momento devido à força de protensão: $M_{p}=N_{p} \cdot e_{p}=1231,42 \cdot 0,0734=90,39 \mathrm{kN} \cdot \mathrm{m}$

$-M_{g 1}$ é o momento devido à atuação do peso próprio: $M_{g 1}=\frac{g_{1} \cdot l^{2}}{8}=\frac{5,89 \cdot 6^{2}}{8}=26,51 \mathrm{kN} . \mathrm{m}$

- I é o momento de inércia igual a $0,0013 \mathrm{~m}^{4}$.

Portanto:

$$
\begin{gathered}
\sigma_{c g, c a b o}=\frac{1231,42}{0,2357}+\frac{90,39 \cdot 0,0734}{0,0013}-\frac{26,51 \cdot 0,0734}{0,0013} \\
\sigma_{c g, c a b o}=8824,48 \mathrm{kN} / \mathrm{m}^{2} \\
\sigma_{\text {cg,cabo }}=8,82 \mathrm{MPa}
\end{gathered}
$$

Por fim:

$$
\begin{aligned}
\Delta \sigma_{p, i} & =9,42.8,82 \\
\Delta \sigma_{p, i} & =83,08 M P a
\end{aligned}
$$

$$
\begin{gathered}
\text { Perdas iniciais totais } \\
\Delta \sigma_{i n i}=\Delta \sigma_{a n c} \cdot \Delta \sigma_{r} \cdot \Delta \sigma_{p, i} \\
\Delta \sigma_{i n i}=14,32.23,61.83,08 \\
\Delta \sigma_{i n i}=121,01 \mathrm{MPa}
\end{gathered}
$$

A tensão final após as perdas da etapa $1\left(\sigma_{\mathrm{pt}}\right)$, resula:

$$
\sigma_{p t, 1 \text { dia }}=1420-121,01=1298,99 \mathrm{MPa}
$$

Perdas:

$$
\begin{gathered}
\text { PERDAS INICIAIS }=\frac{\left(\sigma_{p i}-\Delta \sigma_{i n i}\right)}{\sigma_{p i}}=\frac{(1420-1298,99)}{1420}=0,0852 \\
\text { PERDAS INICIAIS }=8,52 \%
\end{gathered}
$$

\subsubsection{2 - Perdas Diferidas - Etapa 2}

As perdas ao longo do tempo (perdas diferidas) correspondem a etapa 2 (Tabela 3.7), sendo apresentadas, pelas Tabelas 3.10, 3.11, 3.12 e 3.13, na seguinte sequência: a) Perda por fluência do concreto; b) Perda por retração do concreto; c) Perda por relaxação da armadura; d) Somatório das perdas de forma Isolada e Progressiva.

Antes, é necessário distinguir duas fases na etapa 2: 
- Etapa 2, fase 1. Período logo após a aplicação da protensão, até o momento em que é realizado o ensaio experimental, sendo: tempo inicial $t_{0}=1$ dia e tempo $t=$ 100 dias;

- Etapa 2, fase 2. Período em que é feita a concretagem da capa, até o ensaio experimental, sendo: tempo inicial $t_{0}=81$ dias e tempo $t=100$ dias.

Em ambas as fases da etapa 2, a laje permanece na condição de simplesmente apoiada, sendo os apoios próximos às extremidades.

É necessário definir a área da seção e o perímetro da seção de concreto em contato com o ar. Em se tratando de uma seção transversal com alteração de simples para composta, foi adotado um critério para considerar essas modificações, baseado no trabalho de PETRUCELLI (2009).

Na fase 1 , a área $(A)$ da seção transversal considerada é a média entre as duas seções simples e composta. Portanto, $A=0,28495 \mathrm{~m}^{2}$. O perímetro da seção de concreto em contato com o ar $\left(u_{a r}\right)$ é grande, sendo composto por todo o perímetro externo da seção transversal $(4,3966 \mathrm{~m})$ mais o perímetro dos alvéolos $(4,7120 \mathrm{~m})$. Logo $u_{a r}=9,1086$ $\mathrm{m}$.

A fase 2 é aquela em que já se pode considerar a capa. Portanto, $A=0,3342 \mathrm{~m}^{2}$. Para o perímetro, como critério prático, considera-se o perímetro externo mais a metade do perímetro dos alvéolos. Logo $\mathrm{u}_{\mathrm{ar}}=6,75 \mathrm{~m}$.

Para representar de forma satisfatória a transformação da seção em contato com o ar ao longo do tempo, foi considerado para o peso próprio $\left(\mathrm{g}_{1}\right)$ a média dos valores para a área (A), como apresentado anteriormente. Entretanto, para o perímetro ( $\left.u_{a r}\right)$ foi calculada a média entre a fase atual (fase 1) e a posterior (fase 2 ).

Para a ação da capa $\left(g_{2}\right)$, foi considerada a média dos valores para a área $(A)$, como apresentado anteriormente. A mesma coisa foi feita para o perímetro $\left(u_{a r}\right)$, pois, neste caso, não existe fase posterior à da introdução da capa.

Para resumir o que foi apresentado, tem-se a Tabela 3.9, que mostra os valores de área e perímetro considerados no cálculo das perdas para cada ação.

Tabela 3.9 - Valores de área e perímetro a considerar no cálculo das perdas para cada ação.

\begin{tabular}{|c|c|c|c|}
\hline Ação & Descrição & $\begin{array}{c}\text { Área da seção } \\
\left(\mathbf{m}^{2}\right)\end{array}$ & Perímetro em contato com o ar (m) \\
\hline $\mathbf{g}_{1}$ & Peso próprio & 0,28495 & $\frac{9,1086+6,75}{2}=7,93$ \\
\hline $\mathbf{g}_{2}$ & Capa & 0,3342 & 6,75 \\
\hline
\end{tabular}


Tabela 3.10 - Perdas por fluência do concreto - Exemplo numérico 1.

\section{Fluência do concreto $\left(\Delta \sigma_{p, c}\left(t, t_{0}\right)\right)$}

A perda de protensão devida à fluência é obtida por:

$$
\Delta \sigma_{p, c}\left(t, t_{0}\right)=\alpha_{p} \cdot\left(\sigma_{c g, c a b o} \cdot \varphi\left(t, t_{0}\right)\right)
$$

Onde:

$-\alpha_{p}$ é a relação entre os módulos de elasticidade do aço e do concreto, considerando $\mathrm{f}_{\mathrm{ck}}=40 \mathrm{MPa}$, ou seja, considerando a data do ensaio (100 dias): $\alpha_{p}=\frac{E_{p}}{E_{c s}}=\frac{200500}{30105}=6,67$;

- $\sigma_{c g, c a b o}$ é a tensão no concreto no nível do baricentro da armadura de protensão, dada pela seguinte fórmula:

$$
\sigma_{c g, c a b o}=\frac{N_{p}}{A_{c}}+\frac{M_{p} \cdot e_{p}}{I}-\frac{M_{g 1} \cdot e_{p}}{I}
$$

$-\varphi\left(t, t_{0}\right)$ é o coeficiente de fluência, dado pela soma dos coeficientes de fluência rápida irreversível $\left(\varphi_{\alpha}\right)$, deformação lenta reversível $\left(\varphi_{f}\right)$ e deformação lenta reversível $\left(\varphi_{d}\right)$ :

$$
\varphi\left(t, t_{0}\right)=\varphi_{\alpha}+\varphi_{f}+\varphi_{d}
$$

A parcela entre parênteses $\left(\sigma_{c g, c a b o} \cdot \varphi\left(t, t_{0}\right)\right)$ deve ser considerada de acordo com as fases de carregamento explicadas anteriormente.

\section{Cálculo do coeficiente de fluência $-\varphi\left(t, t_{0}\right)$}

Para o cálculo do coeficiente de fluência é necessário considerar a expressão e a tabela mostradas a seguir:

$$
\varphi\left(t, t_{0}\right)=\varphi_{\alpha}+\varphi_{f \infty}\left[\beta_{f}(t)-\beta_{f}\left(t_{0}\right)\right]+\varphi_{d \infty} \beta_{d}
$$

\begin{tabular}{|c|c|c|c|c|c|c|}
\hline \multirow{2}{*}{ Fase } & \multicolumn{2}{|c|}{ Período (dias) } & \multirow{2}{*}{$\mathrm{T}_{\mathrm{i}}\left({ }^{\circ}\right)$} & \multirow{2}{*}{$\alpha$} & \multicolumn{2}{|c|}{$\begin{array}{c}\text { Idade fictícia } \\
\text { (dias) }\end{array}$} \\
\cline { 2 - 3 } \cline { 5 - 7 } & $\mathrm{t}_{0}$ & $\mathrm{t}$ & & & $\mathrm{t}_{0}$ & $\mathrm{t}_{\infty}$ \\
\hline 1 & 1 & 100 & 20 & 3 & 3 & 300 \\
\hline 2 & 81 & 100 & 20 & 3 & 243 & 300 \\
\hline
\end{tabular}

- $\mathrm{T}_{\mathrm{i}}=$ temperatura média diária do ambiente, considerada como $20^{\circ}$;

$-\alpha=$ coeficiente que considera o tipo de cimento. Para cimento ARI, $\alpha=3,0$.

- Para a idade fictícia ( $t_{0}$ ou $\left.t_{\infty}\right)$, deve-se considerar a seguinte expressão:

$$
t=\alpha \cdot \sum \frac{T_{i}+10}{30} \cdot \Delta t_{e f}
$$

- $\Delta t_{e f}$ é o período em dias, durante o qual a temperatura média diária do ambiente $\left(\mathrm{T}_{\mathrm{i}}\right)$ pode ser considerada constante.

\section{Cálculo da fluência rápida $-\varphi_{\alpha}$}

$$
\varphi_{\alpha}=0,8\left[1-\frac{f_{c}\left(t_{0}\right)}{f_{c}\left(t_{\infty}\right)}\right]
$$

$-\frac{f_{c}\left(t_{0}\right)}{f_{c}\left(t_{\infty}\right)}$ é função do aumento da resistência do concreto com o tempo, podendo ser obtido usando 
a expressão de $\beta_{1}$, que por sua vez correlaciona a resistência do concreto em função do tempo (t) com o valor da resistência característica do concreto $\left(\mathrm{f}_{\mathrm{ck}}\right)$;

$-\beta_{1}=\frac{f_{c j}}{f_{c k}} \Rightarrow f_{c j}=\beta_{1} \cdot f_{c k}$;

$-\beta_{1}=\exp \left\{s \cdot\left[1-\left(\frac{28}{t}\right)^{1 / 2}\right]\right\}$, devendo-se fazer, $\mathrm{t}=\mathrm{t}_{0}$ e $\mathrm{t}=\mathrm{t}_{\infty}$;

$-s=0,20$ para cimento ARI.

\begin{tabular}{|c|c|c|c|c|c|c|}
\hline \multirow{2}{*}{ Fase } & \multicolumn{2}{|c|}{$\begin{array}{c}\text { Idade fictícia } \\
\text { (dias) }\end{array}$} & \multirow{2}{*}{$\mathrm{s}$} & $f_{c}\left(t_{0}\right)$ & $f_{c}\left(t_{\infty}\right)$ & \multirow{2}{*}{$\varphi_{\alpha}$} \\
\cline { 2 - 4 } & $\mathrm{t}_{0}$ & $\mathrm{t}$ & & & & \\
\hline 1 & 3 & 300 & 0,20 & 0,6936 & 1,14901 & 0,317 \\
\hline 2 & 243 & 300 & 0,20 & 1,14123 & 1,14901 & 0,005 \\
\hline
\end{tabular}

Cálculo da deformação lenta reversível $-\varphi_{f \infty}\left[\beta_{f}(t)-\beta_{f}\left(t_{0}\right)\right]$

O valor de $\varphi_{f \infty}$ pode ser obtido por:

$$
\varphi_{f \infty}=\varphi_{1 c} \cdot \varphi_{2 c}
$$

- $\varphi_{1 c}=4,45-0,035 U$ é o coeficiente que depende da umidade relativa do ambiente (U) e da consistência do concreto, sendo válido para $U \leq 90 \%$ e abatimentos entre 5 e $9 \mathrm{~cm}$. Para abatimentos entre 0 e $4 \mathrm{~cm}, \varphi_{1 c}$ é $25 \%$ menor, enquanto que para abatimentos entre 10 e $15 \mathrm{~cm}$ $\varphi_{1 c}$ é $25 \%$ maior. Para a laje do ensaio 1 o concreto foi vibrado com abatimento entre 5 e $9 \mathrm{~cm}$;

$-\varphi_{2 c}=\frac{42+h_{f i c}}{20+h_{f i c}}$, é o coeficiente que depende da espessura fictícia da peça, com $\mathrm{h}_{\text {fic }}$ em centímetros;

$-h_{f i c}=\gamma \frac{2 A_{c}}{u_{a r}}$, que por sua vez depende de:

$-\gamma=1+\exp (-7,8+0,1 . U)$, coeficiente que depende da umidade relativa do ambiente (U);

$-A_{c}$ área da seção transversal da peça;

- $u_{a r}$, que corresponde à parte do perímetro externo da seção transversal da peça em contato com o ar.

\begin{tabular}{|c|c|c|c|c|c|c|}
\hline Fase & $\begin{array}{c}\mathrm{U} \\
(\%)\end{array}$ & $\gamma$ & $h_{\text {fic }}(\mathrm{cm})$ & $\varphi_{1}$ & $\varphi_{1}$ & $\varphi_{\infty}$ \\
\hline 1 & 70 & 1,449 & 10,415 & 2,00 & 1,723 & 3,447 \\
\hline 2 & 70 & 1,449 & 14,346 & 2,00 & 1,641 & 3,281 \\
\hline
\end{tabular}

$-\beta_{f}(t) e \beta_{f}\left(t_{0}\right)$ são coeficientes relativos à deformação lenta irreversível, sendo obtidos em função da idade do concreto. Esses coeficientes podem ser obtidos por gráficos, como mostra CARVALHO (2012). Entretanto, podem ser obtidos pela expressão indicada na sequência, na qual, os coeficientes $A, B, C$ e D são dados em função da altura fictícia ( $h_{\text {fic }}$ ) e pelo tempo ( $t$ ou $t_{0}$ ). Para valores de $h_{\text {fic }}$ fora do intervalo de 0,05 e 1,6 m, usam-se os extremos: 


\begin{tabular}{|c|c|}
\hline \multirow{4}{*}{$\beta_{f}(t)=\frac{t^{2}+A \cdot t+b}{t^{2}+C \cdot t+D}$} & $A=42 h_{f i c}{ }^{3}-350{h_{f i c}}^{2}+588 h_{f i c}+113$ \\
\hline & $B=768{h_{f i c}}^{3}-3060{h_{f i c}}^{2}+3234 h_{f i c}-23$ \\
\hline & $C=-200 h_{f i c}{ }^{3}+13 h_{f i c}{ }^{2}+1090 h_{f i c}+183$ \\
\hline & $D=7579 h_{f i c}{ }^{3}-31916 h_{f i c}{ }^{2}+35343 h_{f i c}+1931$ \\
\hline
\end{tabular}

\begin{tabular}{|c|c|c|c|c|c|c|c|}
\hline Fase & $\mathrm{A}$ & $\mathrm{B}$ & $\mathrm{C}$ & $\mathrm{D}$ & $\beta_{f}(t)$ & $\beta_{f}\left(t_{0}\right)$ & $\varphi_{f \infty}\left[\beta_{f}(t)-\beta_{f}\left(t_{0}\right)\right]$ \\
\hline 1 & 170 & 281 & 296 & 5274 & 0,768 & 0,141 & 2,1611 \\
\hline 2 & 190 & 380 & 339 & 6367 & 0,744 & 0,715 & 0,0970 \\
\hline
\end{tabular}

\section{Cálculo da deformação lenta irreversível $-\varphi_{d \infty^{*}} \beta_{d}$}

- $\varphi_{d \infty}$ é o valor final do coeficiente de deformação lenta reversível, que é considerado igual a 0,4;

- $\beta_{d}$, é o coeficiente relativo à deformação lenta reversível, função do tempo (t e to decorrido após o carregamento:

$$
\beta_{d}=\frac{t-t_{0}+20}{t-t_{0}+70}
$$

\begin{tabular}{|c|c|c|c|}
\hline Fase & $\varphi_{d \infty}$ & $\beta_{d}$ & $\varphi_{d \infty^{*}} \beta_{d}$ \\
\hline 1 & 0,4 & 0,86358 & 0,345 \\
\hline 2 & 0,4 & 0,60630 & 0,243 \\
\hline
\end{tabular}

\section{Valor total do coeficiente de fluência $-\varphi\left(t, t_{0}\right)$}

É a soma das parcelas calculadas anteriormente, como indicado na tabela a seguir:

\begin{tabular}{|c|c|c|c|c|}
\hline Fase & $\varphi_{\alpha}$ & $\varphi_{f \infty}\left[\beta_{f}(t)-\beta_{f}\left(t_{0}\right)\right]$ & $\varphi_{d \infty} \beta_{d}$ & $\varphi\left(t, t_{0}\right)$ \\
\hline 1 & 0,317 & 2,1611 & 0,345 & 2,824 \\
\hline 2 & 0,005 & 0,0970 & 0,243 & 0,345 \\
\hline
\end{tabular}

\section{Cálculo das perdas por fluência}

As perdas por fluência do concreto são calculadas pela expressão:

$$
\sigma_{c g, c a b o} \cdot \varphi\left(t, t_{0}\right)=\left[\frac{N_{p}}{A_{c}}+\frac{M_{p} \cdot e_{p}}{I_{s}}-\frac{M_{g 1} \cdot e_{p}}{I_{s}}\right] \cdot \varphi\left(t, t_{0}\right)-\left[\frac{M_{g 2} \cdot e_{p}}{I_{s}}\right] \cdot \varphi\left(t, t_{0}\right)
$$

Sendo:

- $N_{p}$ é a força total de protensão, considerando as perdas calculadas anteriormente em $\mathrm{kN} / \mathrm{m}^{2}$ :

$-N_{p}=\sigma_{p t, 1 d i a} \cdot A_{p}=129,899 \cdot 8,91=1157,3 k N$;

$-A_{c}$ é a área da seção transversal considerada, igual a 0,2357 m²;

$-e_{p}$ é a excentricidade do cabo representante (distância da força de protensão $\left(\mathrm{N}_{\mathrm{p}}\right)$ ao centro de 
gravidade da seção transversal, igual a 0,0734 m;

$-M_{p}$ é o momento devido à força de protensão: $M_{p}=N_{p} \cdot e_{p}=1157,4 \cdot 0,0734=84,95 \mathrm{kN}$. m;

- $M_{g 1}$ é o momento devido ao peso próprio: $M_{g 1}=\frac{g_{1} \cdot l^{2}}{8}=\frac{5,89.6^{2}}{8}=26,51 \mathrm{kN} . \mathrm{m}$;

$-M_{g 2}$ é o momento devido ao peso da capa: $M_{g 2}=\frac{g_{2} \cdot l^{2}}{8}=\frac{2,50.6^{2}}{8}=11,25 \mathrm{kN} . \mathrm{m}$;

$-I_{S}$ é o momento de inércia da seção composta, igual a 0,0013 $\mathrm{m}^{4}$.

Com esses valores, obtêm-se:

$$
\begin{gathered}
\sigma_{c g, c a b o} . \varphi\left(t, t_{0}\right)=\left[\frac{1157,3}{0,2357}+\frac{84,95 \cdot 0,0734}{0,0013}-\frac{26,51 \cdot 0,0734}{0,0013}\right] \cdot 2,824-\left[\frac{11,25 \cdot 0,0734}{0,0013}\right] \cdot 0,345 \\
\sigma_{c g, c a b o} \varphi\left(t, t_{0}\right)=22848,69 \frac{k N}{m^{2}}=22,85 \mathrm{MPa} \\
\Delta \sigma_{p, c}\left(t, t_{0}\right)=\alpha_{p} \cdot\left(\sigma_{c g, c a b o} \cdot \varphi\left(t, t_{0}\right)\right)=6,67 \cdot 22,85=152,41 \mathrm{MPa}
\end{gathered}
$$

Tabela 3.11 - Perdas por retração do concreto - Exemplo numérico 1.

\section{Retração do concreto $\left(\Delta \sigma_{p, s}\left(t, t_{0}\right)\right)$}

A perda de protensão devida à retração é obtida por:

$$
\Delta \sigma_{p, s}\left(t, t_{0}\right)=\varepsilon_{c s}\left(t, t_{0}\right) . E_{p}
$$

$-\varepsilon_{c s}\left(t, t_{0}\right)=\varepsilon_{c S \infty}\left[\beta_{s}(t)-\beta_{S}\left(t_{0}\right)\right]$ é o coeficiente da deformação específica de retração do concreto;

- $E_{p}=200500 \mathrm{MPa}$ é o módulo de elasticidade da armadura de protensão, apresentado na Tabela 3.2.

Cálculo de $\varepsilon_{c S}\left(t, t_{0}\right)$

O valor de $\varepsilon_{c S \infty}$ é obtido por:

$$
\varepsilon_{c s \infty}=\varepsilon_{1 s}+\varepsilon_{2 s}
$$

$-10^{4} \varepsilon_{1 s}=-6,16-\frac{U}{484}+\frac{U^{2}}{484}$ é o coeficiente que depende da umidade relativa do ambiente (U) e da consistência do concreto, sendo válido para $U \leq 90 \%$ e abatimentos entre 5 e $9 \mathrm{~cm}$. Para abatimentos entre 0 e $4 \mathrm{~cm}, \varepsilon_{1 s}$ é $25 \%$ menor, enquanto que para abatimentos entre 10 e $15 \mathrm{~cm}$ $\varepsilon_{1 s}$ é $25 \%$ maior. Para a laje do ensaio 1 , o concreto foi vibrado com abatimento entre 5 e $9 \mathrm{~cm}$;

$-\varepsilon_{2 s}=\frac{33+2 . h_{f i c}}{20,8+3 . h_{f i c}}$, é o coeficiente que depende da espessura fictícia da peça, com $h_{\text {fic }}$ em centímetros;

$-h_{f i c}=\gamma \frac{2 A_{c}}{u_{a r}}$, que por sua vez depende de:

$-\gamma=1+\exp (-7,8+0,1 . U)$, é o coeficiente que depende da umidade relativa do ambiente (U);

$-A_{c}$ é a área da seção transversal da peça;

$-u_{a r}$, corresponde à parte do perímetro externo da seção transversal da peça em contato com o ar. 


\begin{tabular}{|c|c|c|c|c|c|c|}
\hline \multirow{2}{*}{ Fase } & \multicolumn{2}{|c|}{ Período (dias) } & \multirow{2}{*}{$\mathrm{T}_{\mathrm{i}}\left({ }^{\circ}\right)$} & \multirow{2}{*}{$\alpha$} & \multicolumn{2}{|c|}{$\begin{array}{c}\text { Idade fictícia } \\
\text { (dias) }\end{array}$} \\
\cline { 2 - 3 } & $\mathrm{t}_{0}$ & $\mathrm{t}$ & & & $\mathrm{t}_{0}$ & $\mathrm{t}$ \\
\hline 1 & 1 & 81 & 20 & 1 & 1 & 81 \\
\hline 2 & 81 & 100 & 20 & 1 & 81 & 100 \\
\hline
\end{tabular}

- $\mathrm{T}_{\mathrm{i}}$ é a temperatura média diária do ambiente, considerada como $20^{\circ}$;

- $\alpha$ é o coeficiente que considera o tipo de cimento. Para cimento ARI, $\alpha=1,0$.

- Para a idade fictícia ( $t_{0}$ ou $t_{\infty}$ ) deve-se considerar a seguinte expressão:

$$
t=\alpha \cdot \sum \frac{T_{i}+10}{30} \cdot \Delta t_{e f}
$$

$-\Delta t_{e f}$ é o período em dias, durante o qual a temperatura média diária do ambiente $\left(\mathrm{T}_{\mathrm{i}}\right)$ pode ser considerada constante.

\begin{tabular}{|c|c|c|c|c|c|c|}
\hline Fase & $\begin{array}{c}\mathrm{U} \\
(\%)\end{array}$ & $\gamma$ & $h_{f i c}(\mathrm{~cm})$ & $\varepsilon_{1 s}$ & $\varepsilon_{2 s}$ & $\varepsilon_{c s \infty}$ \\
\hline 1 & 70 & 1,449 & 10,415 & $-0,00032$ & 1,034 & $-0,000333$ \\
\hline 2 & 70 & 1,449 & 14,346 & $-0,00032$ & 0,966 & $-0,000311$ \\
\hline
\end{tabular}

$-\beta_{s}(t)$ e $\beta_{s}\left(t_{0}\right)$ são coeficientes relativos à retração, que podem ser obtidos por gráficos, como mostra CARVALHO (2012). Entretanto, podem ser obtidos pela expressão indicada a seguir, na qual os coeficientes $A, B, C$ e D são dados em função da altura fictícia ( $h_{\text {fic }}$ ) e pelo tempo ( $t$ ou $t_{0}$ ). Para valores de $h_{\text {fic }}$ fora do intervalo entre 0,05 e 1,6 m, usam-se os extremos:

\begin{tabular}{|l|}
\hline$\beta_{s}(t)=\frac{\left(\frac{t}{100}\right)^{3}+A \cdot\left(\frac{t}{100}\right)^{2}+B \cdot\left(\frac{t}{100}\right)}{\left(\frac{t}{100}\right)^{3}+C \cdot\left(\frac{t}{100}\right)^{2}+D \cdot\left(\frac{t}{100}\right)+E}$ \\
\hline$A=40$ \\
\hline$B=116{h_{f i c}}^{3}-282{h_{f i c}}^{2}+220 h_{f i c}-4,8$ \\
\hline$C=2,5{h_{f i c}}^{3}-8,8 h_{f i c}+40,7$ \\
\hline$D=-75{h_{f i c}}^{3}+585{h_{f i c}}^{2}+496 h_{f i c}-6,8$ \\
\hline$E=-196 h_{f i c}{ }^{4}-88 h_{f i c}{ }^{3}+584 h_{f i c}{ }^{2}-39 h_{f i c}+0,8$ \\
\hline
\end{tabular}

\begin{tabular}{|c|c|c|c|c|c|c|c|c|}
\hline Fase & $\mathrm{A}$ & $\mathrm{B}$ & $\mathrm{C}$ & $\mathrm{D}$ & $\mathrm{E}$ & $\beta_{s}(t)$ & $\beta_{s}\left(t_{0}\right)$ & $\Delta \beta_{s}$ \\
\hline 1 & 40 & 15,185 & 39,786 & 51,119 & 2,950 & 0,550 & 0,051 & 0,49904 \\
\hline 2 & 40 & 21,300 & 39,445 & 76,175 & 6,881 & 0,504 & 0,463 & 0,04096 \\
\hline
\end{tabular}

\begin{tabular}{|c|c|c|c|c|}
\hline Fase & $\varepsilon_{c s \infty}$ & $\Delta \beta_{s}$ & $E_{p}(M P a)$ & $\Delta \sigma_{p, s}\left(t, t_{0}\right)$ \\
\hline 1 & $-0,000333$ & 0,49904 & 200500 & 33,353 \\
\hline 2 & $-0,000311$ & 0,04096 & 200500 & 2,558 \\
\hline
\end{tabular}

$$
\Delta \sigma_{p, s}\left(t, t_{0}\right)=35,91 M P a
$$


Tabela 3.12 - Perdas por relaxação da armadura - Exemplo numérico 1.

\section{Relaxação da armadura $\left(\Delta \sigma_{\mathrm{p}, \mathrm{r}}\right)$}

A exemplo da Etapa 1, a relaxação do aço é dada por:

$$
\Delta \sigma_{p, r}=\psi\left(t, t_{0}\right) \cdot \sigma_{p i}
$$

$-\psi\left(t, t_{0}\right)$ é o coeficiente de relaxação da armadura: $\psi\left(t, t_{0}\right)=\psi_{1000}\left[\frac{t-t_{0}}{41,67}\right]^{0,15}$

- $\sigma_{p t, 1 \text { dia }}$ é a tensão na armadura de protensão após as perdas iniciais igual a 1298,99 MPa.

- $\psi_{1000}$ pode ser obtido por tabela em CARVALHO (2012) ou na fórmula indicada a seguir, que foi obtida por regressão linear, a partir da tabela indicada por CARVALHO (2012).

$$
\begin{gathered}
\psi_{1000}=-7,5 \cdot R^{2}+21,45 \cdot R-8,855 \\
\psi_{1000}=-7,5 \cdot 0,6836+21,45 \cdot 0,6836-8,855 \\
\psi_{1000}=-3,505+14,66-8,855 \\
\psi_{1000}=2,30 \%
\end{gathered}
$$

- R é obtido pela seguinte relação:

Portanto:

$$
R=\frac{\left(\sigma_{p t, 1 d i a}\right)}{f_{p y t k}}=\frac{(1298,99)}{1900}=0,6836
$$

$$
\begin{gathered}
\psi\left(t, t_{0}\right)=\psi_{1000}\left[\frac{t-t_{0}}{41,67}\right]^{0,15}=2,30\left[\frac{100-1}{41,67}\right]^{0,15}=2,62 \% \\
\Delta \sigma_{p, r}=\psi\left(t, t_{0}\right) \cdot \sigma_{p t}=\frac{2,62}{100} 1298,99=34,03 \mathrm{MPa}
\end{gathered}
$$

Tabela 3.13 - Perdas totais aos 100 dias - Exemplo numérico 1.

\section{Perdas totais $(t=100)$}

\section{Perdas totais considerando cada uma das perdas diferidas de forma isolada}

Soma das perdas diferidas:

$$
\begin{gathered}
\Delta \sigma_{p, D I F}=\Delta \sigma_{p, c}+\Delta \sigma_{p, s}+\Delta \sigma_{p, r} \\
\Delta \sigma_{p, D I F}=152,41+35,91+34,03 \\
\Delta \sigma_{p, D I F}=222,34 \mathrm{MPa}
\end{gathered}
$$

Tensão final:

$$
\begin{gathered}
\sigma_{p t, \infty}=\sigma_{p t, 1 \text { dia }}-\Delta \sigma_{p, D I F} \\
\sigma_{p t, \infty}=1298,99-222,34 \\
\sigma_{p t, \infty}=1076,65 \mathrm{MPa}
\end{gathered}
$$

Perdas totais:

$$
\begin{gathered}
\text { PERDAS TOTAIS }=\frac{\left(\sigma_{p i}-\sigma_{p t, \infty}\right)}{\sigma_{p i}}=\frac{(1420-1076,65)}{1420}=0,2418 \\
\text { PERDAS TOTAIS }=24,18 \%
\end{gathered}
$$




\section{Perdas totais considerando a interação das perdas diferidas (perdas progressivas)}

Obtida pela seguinte expressão:

$$
\Delta \sigma_{p, \text { DIF }}=\frac{\varepsilon_{c S}\left(t, t_{0}\right) \cdot E_{p}+\alpha_{p} \cdot \sigma_{c, p o g} \cdot \varphi\left(t, t_{0}\right)+\sigma_{p t, 1 d i a} \cdot \chi\left(t, t_{0}\right)}{\chi_{p}+\chi_{c} \cdot \alpha_{p} \cdot \eta \cdot \rho_{p}}
$$

$-\varepsilon_{c s}\left(t, t_{0}\right) \cdot E_{p}=\Delta \sigma_{p, s}\left(t, t_{0}\right)=35,91 \mathrm{MPa}$, valor calculado pela Tabela 3.11;

$-\alpha_{p} \cdot \sigma_{c, p o g} \cdot \varphi\left(t, t_{0}\right)=\Delta \sigma_{p, c}\left(t, t_{0}\right)=152,41 M P a$, valor calculado pela Tabela 3.10;

- $\sigma_{p t, 1 d i a}$ é a tensão na armadura de protensão após as perdas iniciais: 1298,99 MPa (Tabela 3.8);

$-\chi\left(t, t_{0}\right)=-\ln \left[1-\psi\left(t, t_{0}\right)\right]=-\ln \left[1-\frac{2,62}{100}\right]=0,02655$, com $\psi\left(t, t_{0}\right)$ obtido na Tabela 3.12;

$-\chi_{p}=1+\chi\left(t, t_{0}\right)=1,02655$

$-\chi_{c}=1+0,5 . \varphi\left(t, t_{0}\right)=1+0,5 \cdot 2,824=2,412$; neste caso utilizou-se o valor de $\varphi\left(t, t_{0}\right)$ da fase 1;

$-\alpha_{p}=6,67$, (ver início da Tabela 3.10);

$-\eta=1+e_{i}{ }^{2} \cdot \frac{A_{c}}{I_{c}}=1+0,0734^{2} \cdot \frac{0,2357}{0,0013}=1,9768$, coeficiente calculado em função das propriedades geométricas da seção simples: área da seção transversal, momento de inércia e excentricidade de protensão da armadura inferior;

$-\rho_{p}=\frac{A_{p}}{A_{c}}=\frac{8,91}{2357}=0,00378$ (taxa de armadura ativa).

Resulta:

$$
\Delta \sigma_{p, D I F}=\frac{35,91+152,41+1298,99 \cdot 0,02655}{1,02655+2,412 \cdot 6,67 \cdot 1,9768 \cdot 0,00378}=194,29 \mathrm{MPa}
$$

Tensão final:

$$
\begin{gathered}
\sigma_{p t, \infty}=\sigma_{p t, 1 \text { dia }}-\Delta \sigma_{p, D I F} \\
\sigma_{p t, \infty}=1298,99-194,29 \\
\sigma_{p t, \infty}=1104,7 \mathrm{MPa}
\end{gathered}
$$

Perdas totais:

$$
\text { PERDAS TOTAIS }=\frac{\left(\sigma_{p i}-\sigma_{p t, \infty}\right)}{\sigma_{p i}}=\frac{(1420-1107,7)}{1420}=0,2199
$$

\subsection{2 - Perdas de protensão para os ensaios de caracterização do EM1}

Além de determinar a perda de protensão na data de ensaio, foi necessário obter as perdas na data dos ensaios de caracterização das lajes alveolares. O procedimento foi o mesmo adotado no item 3.5.1 deste trabalho.

A Tabela 3.14 mostra as etapas de carregamento consideradas, o tempo decorrido da concretagem, as ações, o tipo de seção e as causas das perdas correspondente a cada etapa. Será considerado como tempo t, o tempo decorrido até a data dos ensaios de caracterização das lajes alveolares do EM1, ou seja, 53 dias. 
Tabela 3.14 - Sequência considerada para determinação das perdas na data dos ensaios de caracterização das lajes alveolares do EM1.

\begin{tabular}{|c|c|c|c|c|}
\hline Etapa & $\begin{array}{c}\text { Tempo decorrido da } \\
\text { concretagem }\end{array}$ & Ações & Tipo de seção & Perdas \\
\hline 1 & $\begin{array}{c}\mathrm{t}=21 \text { horas (aplicação da } \\
\text { protensão. Será } \\
\text { arredondado para } 1 \text { dia. }\end{array}$ & $\mathrm{p}+\mathrm{g}_{1}$ & Simples & $\begin{array}{c}\text { Deformação imediata; } \\
\text { Deformação por ancoragem; } \\
\text { Relaxação da armadura. }\end{array}$ \\
\hline 2 & $\begin{array}{c}\text { Não houve moldagem da } \\
\text { capa }\end{array}$ & $\mathrm{p}+\mathrm{g}_{1}$ & Simples & $\begin{array}{c}\text { Retração do concreto; } \\
\text { Fluência do concreto; } \\
\text { Relaxação da armadura. }\end{array}$ \\
\hline
\end{tabular}

$\mathrm{p}$ - força de protensão; $\mathrm{g}_{1}$ - peso próprio da laje.

A Etapa 2 é composta apenas de uma única fase de carregamento, (fase 1):

- Etapa 2, fase 1. Corresponde ao período logo após a aplicação da protensão, até o momento em que é realizado o ensaio experimental, sendo o tempo inicial $t_{0}=$ 1 dia e tempo $t=53$ dias. Além disso, como não existe fase posterior, não há a necessidade de calcular o perímetro em contato com o ar ( $\left.u_{a r}\right)$, através de média. Portanto $u_{a r}=9,1086 \mathrm{~m}$ e a área $(\mathrm{A})$ da seção transversal considerada corresponde à área da seção simples $\left(0,28495 \mathrm{~m}^{2}\right)$.

Até que fossem ensaiadas para caracterização, as lajes permaneceram na condição de simplesmente apoiada, sendo os apoios próximos às extremidades.

Após realizar os cálculos, foram encontrados os seguintes resultados:

- Perdas Isoladas iguais a 23,18\%;

- Perdas Progressivas iguais a $21,41 \%$.

\subsection{3 - Perdas de protensão para os demais ensaios}

Seguindo o modelo de cálculo apresentado no item 3.5.1, foram calculadas as perdas paras os ensaios EM2 e EM3. A Tabela 3.15 mostra os resultados obtidos.

Tabela 3.15 - Perdas de protensão calculadas para os ensaios EM1, EM2 e EM3.

\begin{tabular}{|c|c|c|c|c|c|c|}
\hline \multirow{2}{*}{ Variável } & \multicolumn{2}{|c|}{ EM1 } & \multicolumn{2}{c|}{ EM2 } & \multicolumn{2}{c|}{ EM3 } \\
\cline { 2 - 7 } & $\begin{array}{c}\text { Continui- } \\
\text { dade }\end{array}$ & $\begin{array}{c}\text { Caracteri- } \\
\text { zação }\end{array}$ & $\begin{array}{c}\text { Continui- } \\
\text { dade }\end{array}$ & $\begin{array}{c}\text { Caracteri- } \\
\text { zação }\end{array}$ & $\begin{array}{c}\text { Continui- } \\
\text { dade }\end{array}$ & $\begin{array}{c}\text { Caracteri- } \\
\text { zação }\end{array}$ \\
\hline $\mathrm{g}_{1}(\mathrm{kN} / \mathrm{m})$ & 5,89 & 5,89 & 4,67 & 4,67 & 2,92 & 2,92 \\
\hline
\end{tabular}




\begin{tabular}{|c|c|c|c|c|c|c|}
\hline $\mathrm{g}_{2}(\mathrm{kN} / \mathrm{m})$ & 2,50 & - & 1,5 & - & 1,5 & - \\
\hline $\begin{array}{l}1 \text { (m) } \\
\text { (vão) }\end{array}$ & 6,00 & 6,00 & 6,00 & 6,00 & 5,50 & 5,50 \\
\hline $\begin{array}{l}\text { Etapa } 1 \\
\mathrm{t} \text { (dias) }\end{array}$ & $\begin{array}{l}\mathrm{t}=0 \\
\mathrm{t}_{0}=1\end{array}$ & $\begin{array}{l}\mathrm{t}=0 \\
\mathrm{t}_{0}=1\end{array}$ & $\begin{aligned} \mathrm{t} & =0 \\
\mathrm{t}_{0} & =1\end{aligned}$ & $\begin{aligned} t & =0 \\
t_{0} & =1\end{aligned}$ & $\begin{array}{l}\mathrm{t}=0 \\
\mathrm{t}_{0}=1\end{array}$ & $\begin{array}{l}\mathrm{t}=0 \\
\mathrm{t}_{0}=1\end{array}$ \\
\hline $\begin{array}{l}\text { Etapa } 2 \\
\text { Fase } 1 \\
\mathrm{t} \text { (dias) }\end{array}$ & $\begin{array}{c}t=1 \\
t_{0}=100\end{array}$ & $\begin{aligned} \mathrm{t} & =1 \\
\mathrm{t}_{0} & =53\end{aligned}$ & $\begin{aligned} t & =1 \\
t_{0} & =98\end{aligned}$ & $\begin{aligned} \mathrm{t} & =1 \\
\mathrm{t}_{0} & =95\end{aligned}$ & $\begin{array}{c}\mathrm{t}=1 \\
\mathrm{t}_{0}=37\end{array}$ & $\begin{array}{c}\mathrm{t}=1 \\
\mathrm{t}_{0}=39\end{array}$ \\
\hline $\begin{array}{l}\text { Etapa } 2 \\
\text { Fase } 2 \\
\mathrm{t} \text { (dias) }\end{array}$ & $\begin{aligned} \mathrm{t} & =81 \\
\mathrm{t}_{0} & =100\end{aligned}$ & - & $\begin{aligned} \mathrm{t} & =98 \\
\mathrm{t}_{0} & =112\end{aligned}$ & - & $\begin{array}{c}\mathrm{t}=23 \\
\mathrm{t}_{0}=37\end{array}$ & - \\
\hline $\begin{array}{l}\text { Armadura } \\
\text { ativa }\end{array}$ & $9 \varnothing 12,7$ & $9 \varnothing 12,7$ & $10 \varnothing 12,7$ & $10 \varnothing 12,7$ & $\begin{array}{c}8 \varnothing 6,4 \mathrm{e} \\
1 \varnothing 9,5\end{array}$ & $\begin{array}{c}8 \varnothing 6,4 \mathrm{e} \\
1 \varnothing 9,5\end{array}$ \\
\hline $\mathrm{N}_{\mathrm{pi}}(\mathrm{kN})$ & 140,6 & 140,6 & 124,5 & 124,5 & $\begin{array}{c}30,52 \mathrm{e} \\
65,10\end{array}$ & $\begin{array}{c}30,52 \mathrm{e} \\
65,10\end{array}$ \\
\hline $\operatorname{Ap}\left(\mathrm{cm}^{2}\right)$ & 8,91 & 8,91 & 9,90 & 9,90 & $\begin{array}{c}2,08+0,55= \\
2,63\end{array}$ & $\begin{array}{c}2,08+0,55= \\
2,63\end{array}$ \\
\hline $\mathrm{N}_{\mathrm{p}}(\mathrm{kN})$ & $\begin{array}{c}140,6.9= \\
1265,4\end{array}$ & $\begin{array}{c}140,6.9= \\
1265,4\end{array}$ & $\begin{array}{c}124,5.10= \\
1245,0\end{array}$ & $\begin{array}{c}124,5 \cdot 10= \\
1245,0\end{array}$ & $\begin{array}{c}30,52(8)+ \\
65,10(1)= \\
325,26\end{array}$ & $\begin{array}{c}30,52(8)+ \\
65,10(1)= \\
325,26\end{array}$ \\
\hline $\begin{array}{c}\sigma_{\mathrm{pi}} \\
\left(\mathrm{kN} / \mathrm{cm}^{2}\right)\end{array}$ & $\begin{array}{c}1265,4 / 8,91 \\
=142,0 \\
(1420 \mathrm{MPa})\end{array}$ & $\begin{array}{c}1265,4 / 8,91 \\
=142,0 \\
(1420 \mathrm{MPa})\end{array}$ & $\begin{array}{c}1245 / 9,90= \\
125,76 \\
(1257,6 \\
\mathrm{MPa})\end{array}$ & $\begin{array}{c}1245 / 9,90= \\
125,76 \\
(1257,6 \\
\text { MPa) }\end{array}$ & $\begin{array}{c}30,52 / 2,08+ \\
65,10 / 0,55= \\
133,03 \\
(1330,3 \\
\mathrm{MPa})\end{array}$ & $\begin{array}{c}30,52 / 2,08+ \\
65,10 / 0,55= \\
133,03 \\
(1330,3 \\
\mathrm{MPa})\end{array}$ \\
\hline L pista (m) & 84 & 84 & 150 & 150 & 150 & 150 \\
\hline $\begin{array}{l}\text { Perímetro } \\
\text { externo da } \\
\text { laje }(\mathrm{m})\end{array}$ & 4,3966 & 4,3966 & 3,0054 & 3,0054 & 2,7758 & 2,7758 \\
\hline $\begin{array}{l}\text { Perímetro } \\
\text { dos alvéolos } \\
(\mathrm{m})\end{array}$ & 4,712 & 4,712 & 2,906 & 2,906 & 2,7648 & 2,7648 \\
\hline $\begin{array}{l}\text { Slump } \\
(\mathrm{cm})\end{array}$ & $5-9$ & $5-9$ & $0-4$ & $0-4$ & $0-4$ & $0-4$ \\
\hline $\begin{array}{c}\Delta \sigma_{\text {anc }} \\
(\mathrm{MPa}) \\
\text { Ancoragem }\end{array}$ & 14,32 & 14,32 & 8,02 & 8,02 & 8,02 & 8,02 \\
\hline $\begin{array}{c}\Delta \sigma_{r} \\
(\mathrm{MPa}) \\
\text { Relaxação }\end{array}$ & 23,61 & 23,61 & 14,43 & 14,43 & 18,55 & 18,55 \\
\hline
\end{tabular}




\begin{tabular}{|c|c|c|c|c|c|c|}
\hline $\begin{array}{c}\Delta \sigma_{p, i} \\
(\mathrm{MPa}) \\
\text { Def. Imed. }\end{array}$ & 83,08 & 83,08 & 102,14 & 102,14 & 20,11 & 20,11 \\
\hline $\begin{array}{c}\sigma_{p t, 1 d i a} \\
(\mathrm{MPa})\end{array}$ & 1298,99 & 1298,99 & 1133,0 & 1133,0 & 1283,6 & 1283,6 \\
\hline $\begin{array}{c}\text { PERDAS } \\
\text { INICIAIS } \\
(\%)\end{array}$ & 8,52 & 8,52 & 9,91 & 9,91 & 3,51 & 3,51 \\
\hline $\begin{array}{c}\Delta \sigma_{p, c} \\
\text { (MPa) } \\
\text { Fluência }\end{array}$ & 152,41 & 143,4 & 212,75 & 219,87 & 60,65 & 68,87 \\
\hline $\begin{array}{c}\Delta \sigma_{p, s} \\
(\mathrm{MPa}) \\
\text { Retração }\end{array}$ & 35,91 & 35,72 & 37,0 & 41,93 & 27,77 & 36,73 \\
\hline $\begin{array}{c}\Delta \sigma_{p, r} \\
(\mathrm{MPa}) \\
\text { Relaxação }\end{array}$ & 34,03 & 30,9 & 16,65 & 16,24 & 27,79 & 28,02 \\
\hline $\begin{array}{c}\sigma_{p t, \infty} \\
(\mathrm{MPa}) \\
\text { Isoladas }\end{array}$ & 1076,65 & 1090,88 & 866,63 & 854,96 & 1167,40 & 1150,00 \\
\hline $\begin{array}{l}\text { PERDAS } \\
\text { TOTAIS (\%) } \\
\text { Isoladas }\end{array}$ & 24,18 & 23,18 & 31,09 & 32,02 & 12,25 & 13,55 \\
\hline $\begin{array}{c}\text { PERDAS } \\
\text { TOTAIS (\%) } \\
\text { Progressivas }\end{array}$ & 21,99 & 21,41 & 26,85 & 27,54 & 11,54 & 12,71 \\
\hline
\end{tabular}

Para todas as lajes foram considerados os seguintes dados complementares:

- Cimento ARI;

- Umidade relativa do ar (U) igual a 70\%;

- Temperatura (T) igual a $20^{\circ}$;

- Classe de agressividade ambiental (CAA) igual a II.

\section{6 - Momento resistente $\left(M_{R}\right)$}

A determinação do momento resistente segue a teoria exposta no Anexo A, item A2, que é tirada de CARVALHO (2010). De posse das lajes alveolares cedidas para ensaio (item 3.1), é necessário calcular o momento resistente $\left(M_{R}\right)$ da seção transversal, para posteriormente determinar a armadura de continuidade para o ensaio. 
Portanto, o procedimento adotado consiste em um cálculo inverso, no qual são conhecidas as seguintes variáveis: armadura ativa $\left(A_{p}\right)$, propriedades geométricas da seção transversal e propriedades dos materiais constituintes.

Para isso foram adotadas as hipóteses clássicas para o cálculo no estado limite último para solicitações normais, quais sejam:

- Hipótese de Bernoulli, na qual as seções transversais permanecem planas;

- Solidariedade entre os materiais (aço e concreto);

- Tensões de tração no concreto, normais à seção transversal, podem ser desprezadas;

- Distribuição de tensões no concreto $\left(\sigma_{c}\right)$ de acordo com o diagrama parábolaretângulo, e sua simplificação através do diagrama retangular;

- Tensões nas armaduras obtidas a partir do diagrama tensão-deformação simplificado, de acordo com a NBR 6118:2014 (Figura 3.10);

- O estado limite último é caracterizado pelas deformações específicas do concreto $\left(\varepsilon_{c}\right)$ e do aço $\left(\varepsilon_{s}\right)$ seguindo os domínios de deformação, impostos pela NBR 6118:2014.

A Figura 3.11 apresenta o equilíbrio de uma seção transversal genérica composta por laje alveolar e capa, na qual se considera que a linha neutra (LN) pode estar posicionada tanto na região dos alvéolos quanto fora deles. Nessa figura, o índice $p$ referese à armadura protendida, junto à borda inferior (armadura ativa), e o índice $\boldsymbol{s}$ corresponde à armadura passiva na capa, junto à borda superior. Além disso:

- Ap é a área da seção transversal da armadura protendida;

- As é a área da seção transversal da armadura superior;

- LN significa linha neutra;

- h é a altura da seção composta;

- $F_{c}$ é a resultante da força de compressão no concreto;

- $F_{p}$ é a resultante da força de tração na armadura protendida;

- $F_{\mathrm{s}}$ é a resultante da força de tração na armadura passiva;

- z é o braço de alavanca;

- d é a altura útil;

- d' é a distância entre a armadura considerada e a face da seção composta. 


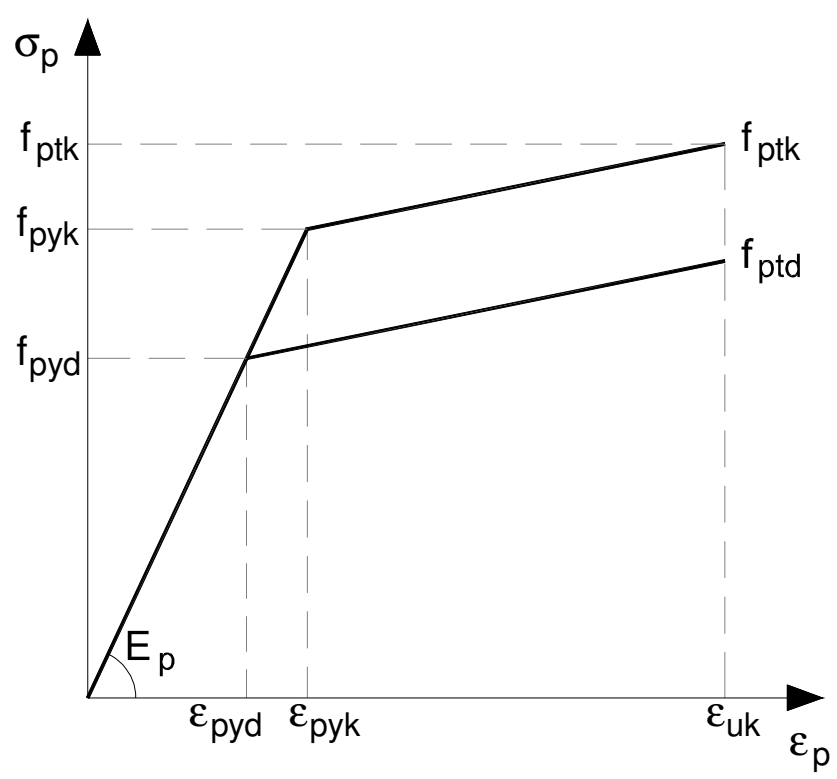

Figura 3.10 - Diagrama tensão-deformação de aços de protensão (Adaptada da figura 8.5 da NBR 6118:2014).

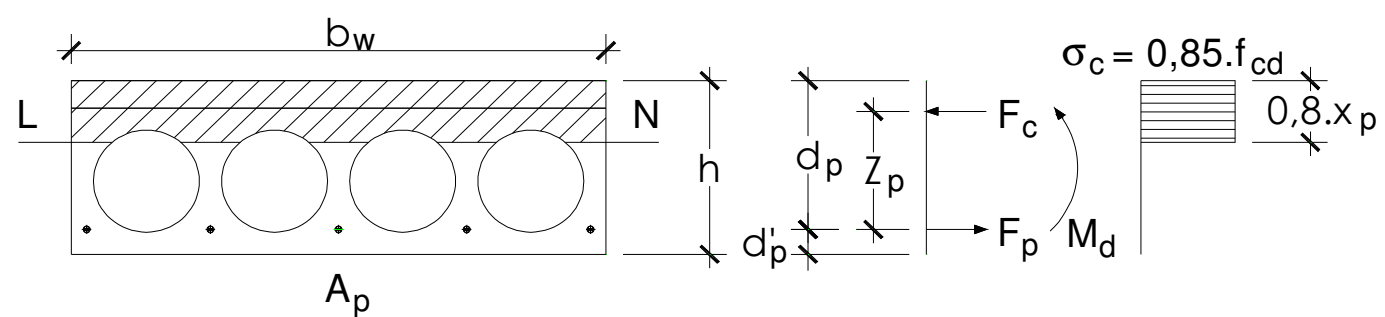

(a) - Momento Positivo

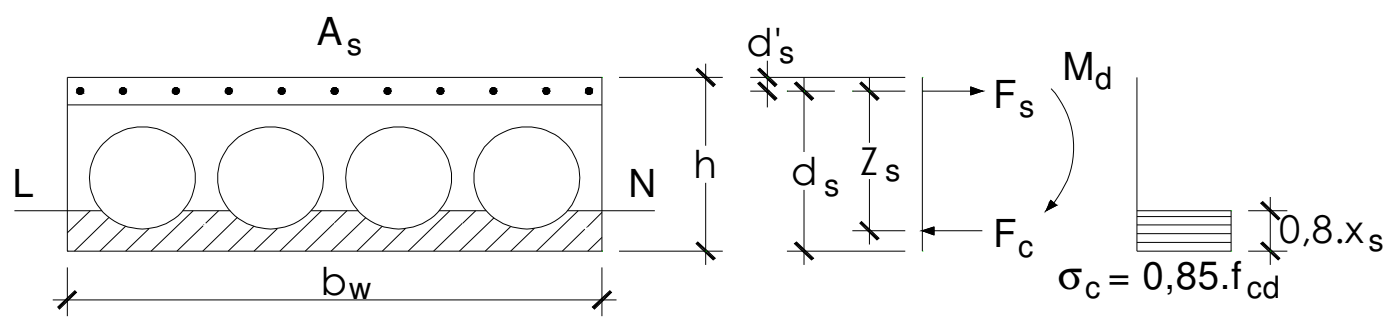

(b) - Momento Negativo

Figura 3.11 - Equilíbrio de uma seção composta:

(a) Momento positivo; (b) Momento negativo.

\subsection{1 - Equacionamento para momento positivo}

A Tabela 3.16 apresenta o equacionamento para a determinação do momento resistente positivo $\left(\mathrm{M}_{\mathrm{R}}\right)$. Para considerar o equilíbrio da seção, a laje alveolar foi discretizada em faixas com altura de $1 \mathrm{~mm}$. Dessa forma é possível saber, para cada faixa i, os seguintes valores: 
- $\quad b_{w, i}$ é a largura efetiva de cada faixa de concreto;

- $h_{i}$ é a altura de cada faixa (igual a $1 \mathrm{~mm}$ );

- $f_{c k, i}$ é a resistência característica do concreto à compressão;

- $F_{c, i}$ é a força resultante de compressão em cada faixa.

Para ilustrar a discretização em faixas, a Figura 3.12 mostra uma seção genérica discretizada, e apresenta também as seguintes variáveis:

- yi é a distância entre o centro de gravidade da faixa e a face considerada;

- $y_{c g}$ é a distância entre o centro de gravidade da região comprimida e a face considerada;

- $y_{p}$ é a altura da região comprimida;

- $x_{p}$ é a posição da linha neutra;

- $z_{p}$ é o braço de alavanca.

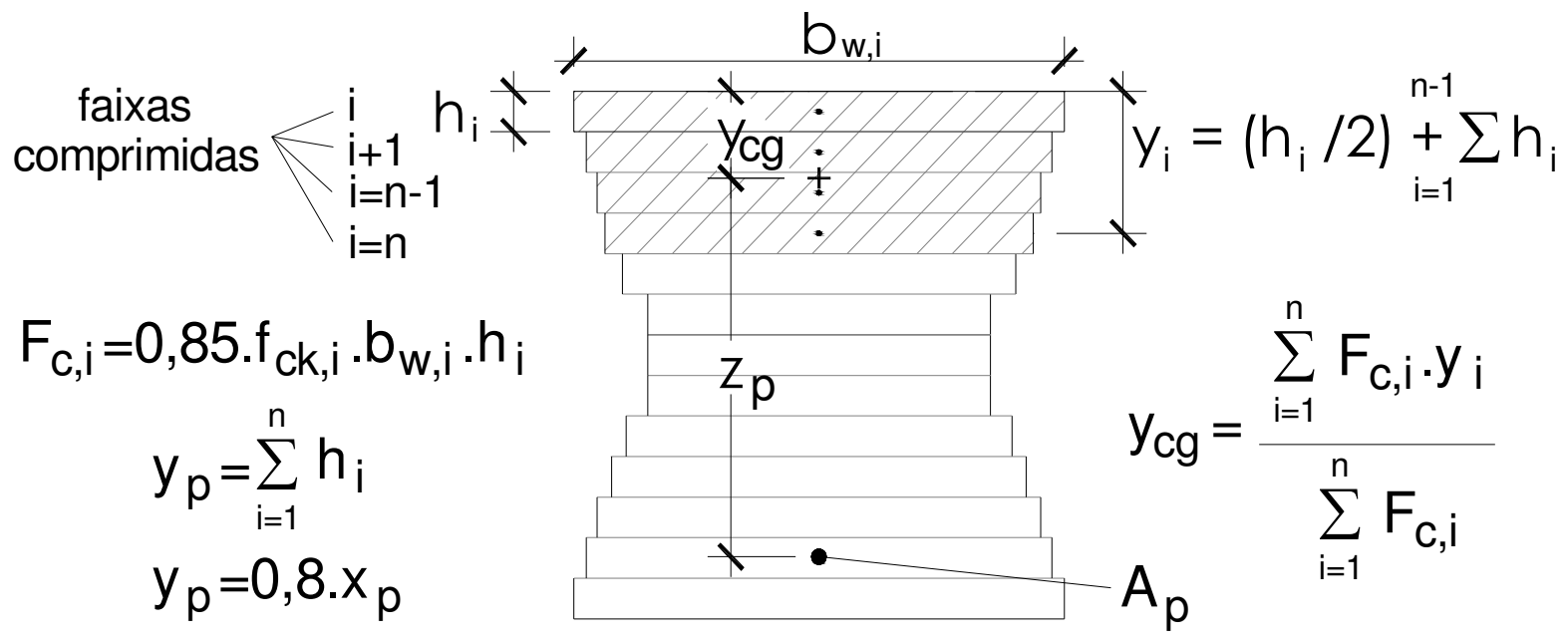

Figura 3.12 - Discretização em faixas para determinação da área comprimida de uma seção genérica.

Tabela 3.16 - Equacionamento para cálculo do momento resistente positivo (MR).

\section{Equilíbrio das forças $(\Sigma F)$}

$$
\sum F=0 \Rightarrow F_{p}=F_{c}
$$

\section{Equilíbrio dos momentos $(\Sigma M)$}

$$
\begin{array}{c|c}
\multicolumn{2}{c}{\sum M=M_{d}} \\
M_{d}=F_{c} \cdot z_{p} & M_{d}=F_{p} \cdot z_{p} \\
F_{c}=0,85 \cdot f_{c d} \cdot b_{w} \cdot 0,8 \cdot x_{p} & F_{p=} A_{p} \cdot \sigma_{p d} \\
F_{c}=0,85 \cdot f_{c k} \cdot b_{w} \cdot 0,8 \cdot x_{p} & F_{p=} A_{p} \cdot \sigma_{p k}
\end{array}
$$


Para o concreto é necessário discretizar a seção em faixas;

Cada faixa possui: largura $b_{w i}$, altura $h_{i}$, posição da linha neutra $x_{p, i}$, um braço de alavanca $z_{p, i}$ e distância $y_{i}$ do cg da faixa à face considerada.

$$
\begin{gathered}
F_{c, i}=0,85 . f_{c k, i} \cdot b_{w, i} \cdot h_{i} \\
F_{c}=\sum_{i=1}^{n} F_{c i}=\sum_{i=1}^{n} 0,85 \cdot \sigma_{c i} \cdot b_{w, i} \cdot h_{i}
\end{gathered}
$$

Onde $\sigma_{c i}$ é a tensão no nível da faixa $i$ considerada, obtida no diagrama $\sigma \times \varepsilon$ de cálculo do concreto

$\Rightarrow$ Comparar $F_{c, i}$ com $F_{p}$ até encontrar a faixa correspondente;

$\Rightarrow$ Obter o momento resistente, fazendo $M_{d}=M_{R}$;

$\Rightarrow$ Além disso, obter $x_{p, i}$ e $z_{p, i}$.

$\Rightarrow$ De posse da linha neutra, calcula-se $K X$;

$\Rightarrow$ Se $K X<K X_{2,3}$, então $\varepsilon_{s}=10 \%$ o é possível calcular $\varepsilon_{c}$;

$\Rightarrow$ Se $K X_{2,3}<K X<K X_{3,4}$, então $\varepsilon_{c}=3,5 \%$ o é possível calcular $\varepsilon_{s}$;

$\Rightarrow$ Repetem-se os cálculos com o valor de $\varepsilon_{s}$ calculado.

Após encontrar as faixas que juntas representam o equilíbrio da seção, para as quais $F_{c}=F_{p}$, é necessário calcular o centroide $\left(\mathrm{y}_{\mathrm{cg}}\right)$ da área correspondente (Figura 3.12)

$$
y_{c g}=\frac{\sum_{i=1}^{n} F_{c, i} \cdot y_{i}}{\sum_{i=1}^{n} F_{c, i}}
$$

\section{Cálculo da tensão de protensão $\left(\sigma_{\mathrm{pk}}\right)$}

A tensão na armadura ativa (valor característico, $\gamma_{s}=1,0$ ) é obtida com auxílio da Figura 3.10. Essa tensão é calculada como indicado a seguir:

Se $\varepsilon_{t}\left\{\begin{array}{l}<\varepsilon_{p y k} \Rightarrow \sigma_{p k}=E_{p} \cdot \varepsilon_{p} \\ \geq \varepsilon_{p y k} \Rightarrow \sigma_{p k}=f_{p y k}+\left(f_{p t k}-f_{p y k}\right) \frac{\varepsilon_{t}-\varepsilon_{p y k}}{\varepsilon_{u k}-\varepsilon_{p y k}}\end{array}\right.$

$-\varepsilon_{t}$ é a deformação total na armadura de protensão;

$-\varepsilon_{u k}=35,0 \%$, segundo a NBR 7483:2004;

$-\varepsilon_{p y k}=\frac{f_{p y k}}{E_{p}}$, Figura 3.10;

$-\varepsilon_{p}=\frac{\sigma_{p t, \infty}}{E_{p}}$, sendo $\sigma_{p t, \infty}$ a tensão atuante na armadura de protensão, considerando as perdas;

$-f_{p y k}=0,9 . f_{p t k}$, quando a tensão de escoamento $\left(f_{\text {pyk }}\right)$ não for fornecida;

$-f_{p t k}=1900 \mathrm{MPa}$, para o aço CP $190 \mathrm{RB}$, sendo a tensão de resistência à tração. 


\section{Cálculo da deformação total $\left(\varepsilon_{t}\right)$}

$$
\varepsilon_{t}=\varepsilon_{p}+\varepsilon_{7}+\varepsilon_{s}
$$

- $\varepsilon_{p}$ é a parcela da deformação na armadura correspondente à protensão (considerando as perdas); $-\varepsilon_{7}=\left[\frac{N_{p}}{A_{c}}+\frac{M_{p} * e_{p}}{I}\right] \cdot \frac{1}{E_{c}}$, parcela da deformação na armadura para que se tenha o estado de descompressão. $O$ primeiro termo entre colchetes representa o encurtamento da seção, enquanto que o segundo, a rotação da seção;

- $\varepsilon_{s}$ é a parcela da deformação na armadura após o estado de descompressão, que deve ser no máximo $10 \%$. Esse valor é obtido pelo equacionamento clássico de dimensionamento de seções de concreto armado no estado limite último. $O$ presente trabalho adotou as tabelas e as equações de KMD presentes em CARVALHO (2012) e reproduzidas no ANEXO A., item A1.

Indica-se a seguir o significado das variáveis envolvidas no cálculo das deformações:

- $N_{p}$ é a força total de protensão, considerando as perdas calculadas anteriormente;

- $A_{c}$ é a área da seção transversal da laje alveolar;

$-e_{p}$ é a excentricidade da armadura ativa, com relação ao centro de gravidade da seção transversal;

$-M_{p}$ é o momento devido à força de protensão;

- $M_{g 1}$ é o momento devido ao peso próprio;

- I é o momento de inércia da seção transversal;

$-E_{c}$ é o módulo de elasticidade secante do concreto.

\subsection{2 - Equacionamento para momento negativo}

O procedimento adotado para o cálculo do momento resistente negativo é o mesmo apresentado para o momento positivo (item 3.6.1). No entanto, o equilíbrio é feito com a armadura passiva (armadura de continuidade). Logo, a força resultante na armadura passiva $\left(F_{s}\right)$ deve ser determinada pela tensão na barra de aço $\left(f_{y k}\right)$ e pela correspondente deformação $\left(\varepsilon_{s}\right)$, arbitrando o valor de 10\% como mostrado na Tabela 3.16.

É necessário fazer, também, a consideração do efeito da protensão no cálculo da armadura negativa. Isto é feito com base em CARVALHO (2010).

Ao se considerar o momento $M_{d}$ atuando no apoio de um pavimento com lajes alveolares contínuas, pode-se calcular a armadura $A_{s}$, colocada na capa, de maneira usual e depois verificar se a protensão atuando concomitante não causa uma compressão excessiva. Na figura 3.13 podem ser vistas as tensões de compressão na borda inferior provocadas pelo efeito da protensão e do momento negativo $\mathrm{M}_{\mathrm{d}}$. A Figura 3.14 mostra o encurtamento devido à atuação da protensão e do momento. 


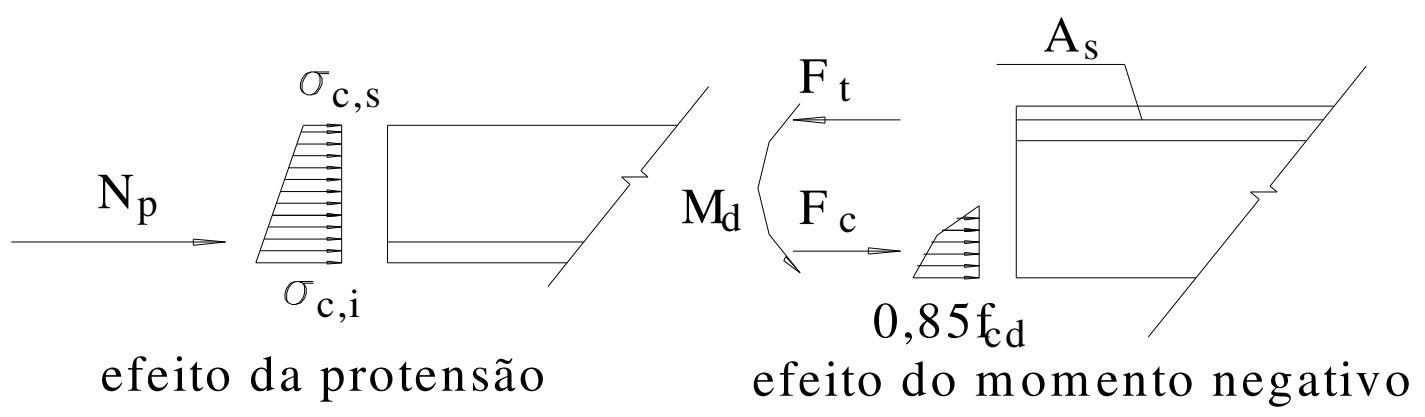

Figura 3.13 - Tensões de compressão na borda inferior considerando o efeito da protensão e do momento negativo no apoio da ligação com continuidade.

(Fonte: CARVALHO (2010)).

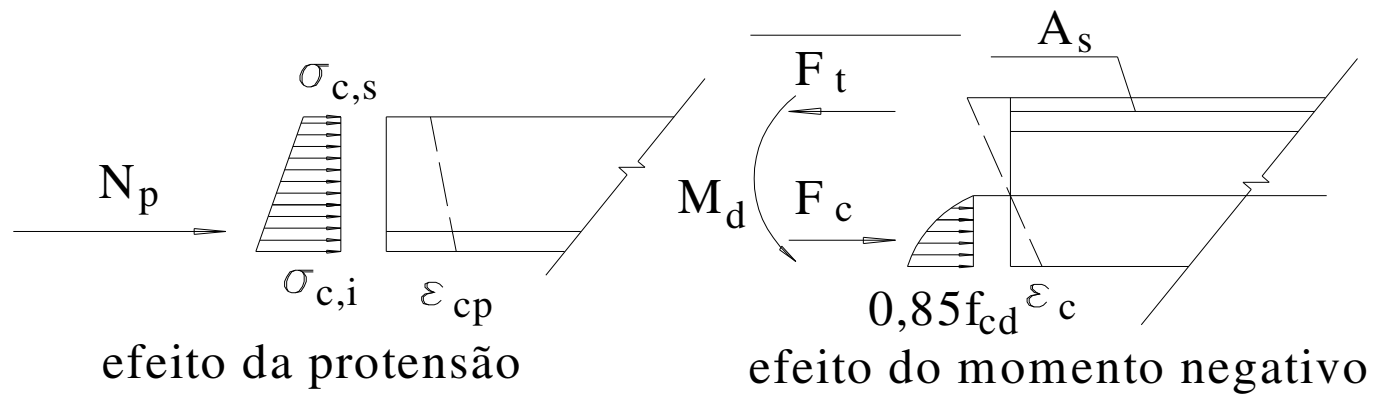

Figura 3.14 - Deformações na borda inferior considerando o efeito da protensão e do momento negativo no apoio da ligação com continuidade.

(Fonte: CARVALHO (2010)).

Ao fazer o cálculo da armadura $A_{s}$, é possível determinar o valor da deformação do concreto $\varepsilon_{\mathrm{c}}$ na borda mais comprimida e somá-lo ao valor da deformação $\varepsilon_{\mathrm{cp}}$ causada pela protensão, sendo este valor dado pela expressão 3.1.

$$
\varepsilon_{c p}=\varepsilon_{7}=\frac{1}{E_{c}}\left(\frac{N_{p}}{A}+\frac{M_{p} \cdot e_{p}}{I}\right)
$$

Desta forma, se a soma de $\varepsilon_{\mathrm{c}}$ e $\varepsilon_{\mathrm{cp}}$ for inferior a 3,5\%o, a condição está satisfeita.

\subsection{3 - Discretização em faixas}

As seções transversais apresentadas nas Figuras 3.1, 3.3 e 3.5, respectivamente dos ensaios EM1, EM2 e EM3, foram discretizadas em faixas com alturas de $1 \mathrm{~mm}$. A discretização é apresenta no APÊNDICE A, em forma de tabelas, sendo feitas para momento positivo e seção composta.

Por mostrarem apenas discretização para momento positivo, as tabelas do APÊNDICE $A$ incluem apenas as faixas correspondentes à capa, mesa superior e metade superior da altura dos alvéolos. As demais regiões (metade inferior dos alvéolos e mesa inferior) foram omitidas por estarem em região abaixo da linha neutra. 
As demais situações, momento positivo para seção simples e momento negativo para seção composta, seguem o mesmo procedimento de discretização.

\subsection{4 - Momento resistente $\left(M_{R}\right)$ do ensaio de continuidade EM1}

A seguir (Tabela 3.17) será mostrado o cálculo do momento resistente $\left(M_{R}\right)$ para o ensaio de continuidade EM1. É necessário considerar os dados iniciais apresentados em: Figura 3.1 (medidas da seção transversal), Tabela 3.1 (propriedades geométricas), Tabela 3.2 (propriedades dos materiais), Tabela 3.3 (força inicial de protensão) e Tabela 3.15 (resultados das perdas de protensão).

Tabela 3.17 - Cálculo do momento resistente positivo (MR) - Ensaio do modelo 1 (EM1).

\begin{tabular}{|c|}
\hline Cálculo da deformação total $\left(\varepsilon_{t}\right)$ \\
\hline $\begin{array}{c}\varepsilon_{t}=\varepsilon_{p}+\varepsilon_{7}+\varepsilon_{s} \\
\varepsilon_{p}=\frac{\sigma_{p t, \infty}}{E_{p}}=\frac{1076,65}{200500}=0,00537=5,37 \% 0 \\
-N_{p}=\sigma_{p t, \infty} \cdot A_{p}=107,665.8,91=959,29 \mathrm{kN} \\
-M_{p}=N_{p} \cdot e_{p}=959,29.0,0734=70,41 \mathrm{kN} \cdot \mathrm{m} \\
-E_{c s}=0,85 \cdot E_{c i}=0,85.35418=30105 \mathrm{MPa}=30105000 \mathrm{kN} \cdot \mathrm{m}^{2} \\
\varepsilon_{7}=\left[\frac{N_{p}}{A_{c}}+\frac{M_{p} \cdot e_{p}}{I}\right] \cdot \frac{1}{E_{c s}}=\left[\frac{959,29}{0,2357}+\frac{70,41 \cdot 0,0734}{0,0013}\right] \cdot \frac{1}{30105000}=0,000267=0,27 \% \\
\varepsilon_{t}=\varepsilon_{p}+\varepsilon_{7}+\varepsilon_{s}=5,37+0,27+10,00=15,64 \% 0\end{array}$ \\
\hline Cálculo da tensão de protensão $\left(\sigma_{\mathrm{pk}}\right)$ \\
\hline $\begin{array}{l}\text { Aço CP } 190 \mathrm{RB}: \\
-f_{p t k}=1900 \mathrm{MPa} \\
-f_{p y k}=0,9.1900=1710 \mathrm{MPa} \\
-\varepsilon_{p y k}=\frac{f_{p y k}}{E_{p}}=\frac{1710}{200500}=0,008529=8,53 \% \\
\text { Como: } \varepsilon_{t}>\varepsilon_{p y k} \\
\qquad \sigma_{p k}=f_{p y k}+\left(f_{p t k}-f_{p y k}\right) \frac{\varepsilon_{t}-\varepsilon_{p y k}}{\varepsilon_{u k}-\varepsilon_{p y k}} \\
\qquad \sigma_{p k}=171,0+(190,0-171,0) \frac{15,64-8,53}{35,00-8,53}=176,10 \mathrm{kN} / \mathrm{cm}^{2}\end{array}$ \\
\hline
\end{tabular}




\section{Força atuante na armadura no equilíbrio $\left(F_{p}\right)$}

$$
F_{p=} A_{p} \cdot \sigma_{p k}=8,91 \cdot 176,10=1569,05 k N
$$

\section{Força atuante no concreto no equilíbrio $\left(F_{c}\right)$}

Consultando o Apêndice A, Tabela APA1.1, tem-se:

$$
\begin{gathered}
F_{c . t o t, i=1566,72 \mathrm{kN}} \\
\boldsymbol{M}_{\boldsymbol{R}=} \mathbf{3 2 7}, \mathbf{4 4} \boldsymbol{k N} \cdot \boldsymbol{m} \\
z_{p=0}, 209 \mathrm{~m} \\
y_{p=0} 032 \mathrm{~m} \\
x_{p=0,040 \mathrm{~m}}
\end{gathered}
$$

Os resultados correspondem à Faixa 32, ou seja, $32 \mathrm{~mm}$ da face superior da seção composta. Logo a a posição da linha neutra encontra-se na região da capa.

\section{Verificação de $\left(\varepsilon_{\mathrm{s}}\right)$}

Conforme o Anexo A:

$$
K X=\frac{x_{p}}{d}=\frac{0,040}{0,225}=0,177
$$

Onde:

$-d=\left(h_{\text {laje }}+h_{\text {capa }}\right)-d^{\prime}=(0,21+0,05)-0,035=0,225 m$

$$
K X_{2,3}=\frac{3,5}{3,5+10,0}=0,2593
$$

Como $\mathrm{KX}<\mathrm{KX}_{2,3} \rightarrow \varepsilon_{s}=10,00 \%$

Ver tabela de KMD de CARVALHO (2012), no ANEXO A.

Portanto, resulta DOMÍNIO 2. Não é necessário realizar outra iteração.

Logo:

$$
K X=\frac{\varepsilon_{c}}{\varepsilon_{c}+\varepsilon_{s}} \Rightarrow \varepsilon_{c}=\frac{K X \cdot \varepsilon_{s}}{(1-K X)}=\frac{0,177 \cdot 10,0}{(1-0,177)}=2,1622 \% 0
$$

Esse valor de $\varepsilon_{\mathrm{c}}$ confere com o da tabela de $\mathrm{KMD}$, anteriormente citada.

\subsection{5 - Momento resistente $\left(M_{R}\right)$ para as demais situações}

Seguindo o modelo de cálculo apresentado no item 3.6.4, foi calculado o $M_{R}$ para os demais ensaios (EM2 e EM3). A Tabela 3.18 apresenta os resultados obtidos. 
Tabela 3.18 - Cálculo do momento resistente positivo $\left(M_{R}\right)$ para os ensaios EM1, EM2 e EM3.

\begin{tabular}{|c|c|c|c|c|c|c|}
\hline \multirow{2}{*}{ Variável } & \multicolumn{2}{|c|}{ EM1 } & \multicolumn{2}{|c|}{ EM2 } & \multicolumn{2}{|c|}{ EM3 } \\
\hline & $\begin{array}{l}\text { Continui- } \\
\text { dade }\end{array}$ & $\begin{array}{l}\text { Caracteri- } \\
\text { zação }\end{array}$ & $\begin{array}{l}\text { Continui- } \\
\text { dade }\end{array}$ & $\begin{array}{l}\text { Caracteri- } \\
\text { zação }\end{array}$ & $\begin{array}{l}\text { Continui- } \\
\text { dade }\end{array}$ & $\begin{array}{c}\text { Caracteri- } \\
\text { zação }\end{array}$ \\
\hline$\sigma_{p t, \infty}(\mathrm{MPa})$ & 1076,65 & 1090,88 & 866,63 & 854,96 & 1167,40 & 1150,00 \\
\hline$e_{p}(\mathrm{~m})$ & 0,0734 & 0,0734 & 0,0863 & 0,0863 & 0,0493 & 0,0493 \\
\hline$A_{p}\left(\mathrm{~cm}^{2}\right)$ & 8,91 & 8,91 & 9,90 & 9,90 & $\begin{array}{c}2,08+0,55= \\
2,63\end{array}$ & $\begin{array}{c}2,08+0,55= \\
2,63\end{array}$ \\
\hline$E_{p}(\mathrm{MPa})$ & 200500 & 200500 & 200500 & 200500 & 200500 & 200500 \\
\hline $\begin{array}{c}E_{c s, \text { laje }} \\
\text { (MPa) }\end{array}$ & 30105 & 30105 & 30105 & 30105 & 30105 & 30105 \\
\hline$\varepsilon_{p}(\% \circ)$ & 5,37 & 5,44 & 4,19 & 4,11 & 5,82 & 5,74 \\
\hline$N_{p}(\mathrm{kN})$ & 959,29 & 971,94 & 857,95 & 846,37 & 285,42 & 281,19 \\
\hline$M_{p}(\mathrm{kN} . \mathrm{m})$ & 70,41 & 71,34 & 74,04 & 73,04 & 14,07 & 13,86 \\
\hline$\varepsilon_{7}(\% \circ)$ & 0,27 & 0,27 & 0,285 & 0,282 & 0,14 & 0,14 \\
\hline$\varepsilon_{S}(\% \circ)$ & 10,00 & 10,00 & 10,00 & 10,00 & 10,00 & 10,00 \\
\hline$\varepsilon_{t}(\% \circ)$ & 15,64 & 15,71 & 14,61 & 14,55 & 15,96 & 15,87 \\
\hline$f_{p t k}(\mathrm{MPa})$ & 1900 & 1900 & 1900 & 1900 & 1900 & 1900 \\
\hline$f_{p y k}(\mathrm{MPa})$ & 1710 & 1710 & 1710 & 1710 & 1710 & 1710 \\
\hline$\varepsilon_{y k}(\% \circ)$ & 8,53 & 8,53 & 8,53 & 8,53 & 8,53 & 8,53 \\
\hline $\begin{array}{c}\sigma_{p k} \\
\left(\mathrm{kN} / \mathrm{cm}^{2}\right)\end{array}$ & 176,10 & 176,15 & 175,36 & 175,32 & 176,33 & 176,27 \\
\hline$F_{p}(\mathrm{kN})$ & 1569,05 & 1569,55 & 1736,10 & 1735,65 & 463,76 & 463,59 \\
\hline$F_{c, t o t, i}(\mathrm{kN})$ & 1566,72 & 1538,41 & 1747,26 & 1745,38 & 461,04 & 486,20 \\
\hline$M_{R}(\mathbf{k N} . \mathbf{m})$ & 327,44 & 251,54 & 445,55 & 346,72 & 79,30 & 60,28 \\
\hline$z_{p}(\mathrm{~m})$ & 0,2090 & 0,1635 & 0,2550 & 0,1987 & 0,1720 & 0,1240 \\
\hline$y_{p}(\mathrm{~m})$ & 0,0320 & 0,0230 & 0,0300 & 0,0427 & 0,0160 & 0,0120 \\
\hline$x_{p}(\mathrm{~m})$ & 0,0400 & 0,0287 & 0,0375 & 0,0534 & 0,0200 & 0,0150 \\
\hline
\end{tabular}




\begin{tabular}{|c|c|c|c|c|c|c|}
\hline Região & Capa & $\begin{array}{c}\text { Mesa } \\
\text { superior }\end{array}$ & Capa & Alvéolo & Capa & $\begin{array}{c}\text { Mesa } \\
\text { superior }\end{array}$ \\
\hline$K X$ & 0,177 & 0,164 & 0,139 & 0,243 & 0,111 & 0,115 \\
\hline$d(\mathrm{~m})$ & 0,225 & 0,175 & 0,270 & 0,220 & 0,180 & 0,130 \\
\hline$\varepsilon_{c}(\% \circ)$ & 2,1622 & 1,9617 & 1,6129 & 3,2029 & 1,2500 & 1,3043 \\
\hline DOMÍNIO & 2 & 2 & 2 & 2 & 2 & 2 \\
\hline Iterações & 1 & 1 & 1 & 1 & 1 & 1 \\
\hline
\end{tabular}

\section{7 - Determinação da armadura de continuidade}

O dimensionamento de uma laje alveolar levando em conta a continuidade segue as mesmas etapas descritas na Tabela 3.4, acrescentando um item que consiste no cálculo da armadura de continuidade $\left(A_{s}\right)$. Além do mais, deve-se considerar a alteração de esforços discutida no item 3.3 e ilustrada pelas Figuras 3.8 e 3.9.

Como citado anteriormente, essa armadura pode ser obtida considerando a atuação integral do momento fletor negativo teórico, que é comumente chamado de momento elástico e está representado por $M_{\text {neg }}$ nas Figuras 3.8 e 3.9. Além disso, $A_{s}$ pode ser calculada levando em conta uma parcela desse momento.

Entretanto, o momento fletor negativo teórico depende do valor do carregamento aplicado. Considerando que esta é uma variável na análise experimental, fica a dúvida de como estabelecer qual é a quantidade de armadura $\left(A_{s}\right)$ correspondente a $100 \%$ de continuidade, para as análises em ensaios.

Para resolver essa questão é preciso estabelecer um critério e através deste obter o que seria a armadura $A_{s}$, referente a $100 \%$ de continuidade.

\subsection{1 - Máximo momento resistente pela armadura de protensão}

Um possível critério é o de considerar o máximo momento resistente pela armadura de protensão $\left(A_{p}\right)$ da laje alveolar a ser ensaiada. O momento resistente foi obtido no item 3.6.

As Figuras 3.15 e 3.16 reproduzem as Figuras 3.8 e 3.9 com modificações no carregamento atuante, sendo atualizadas para as situações de ensaio experimental: biapoiadas e com continuidade, respectivamente. 


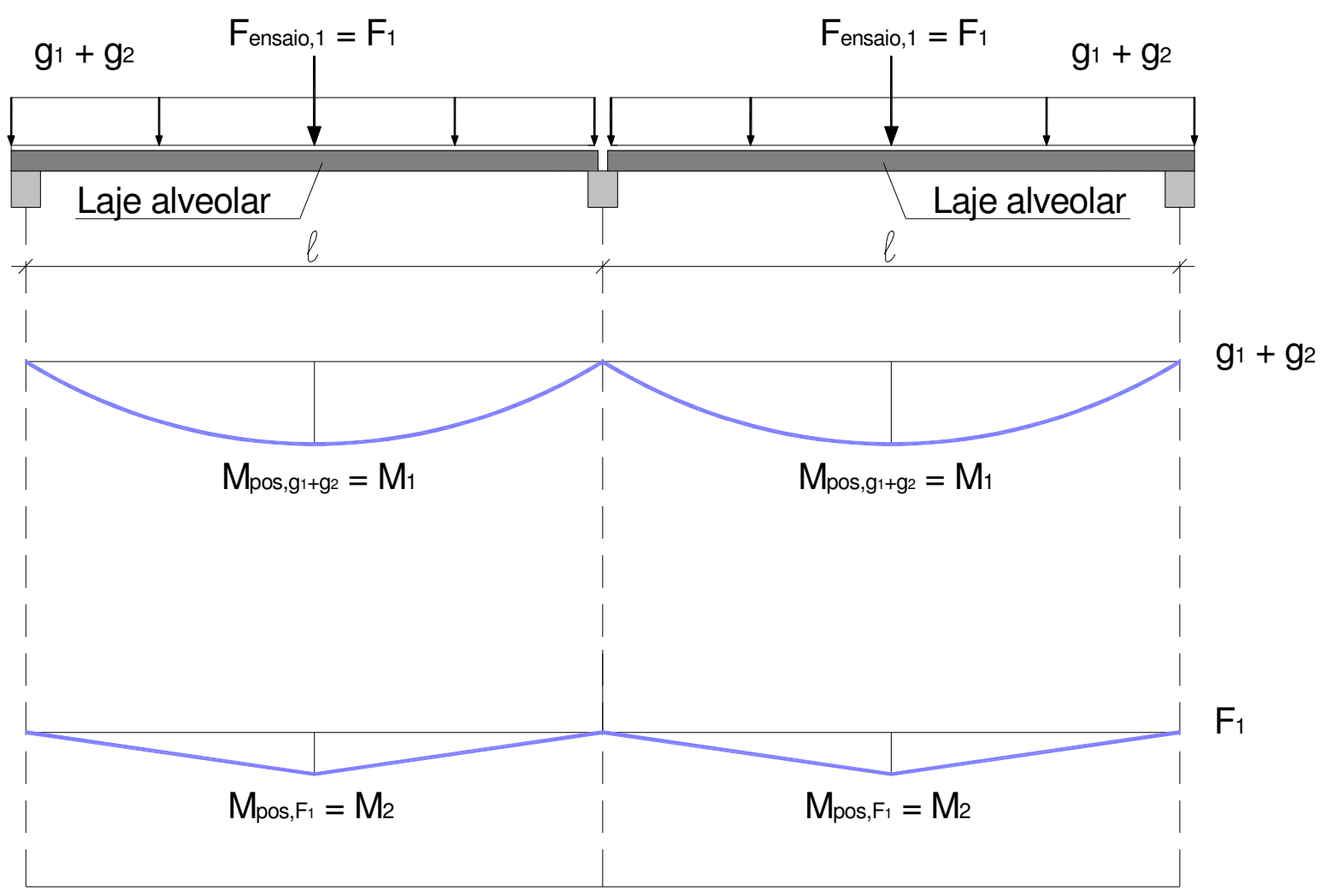

Figura 3.15 - Diagramas de momento fletor para ensaio de laje alveolar biapoiada.

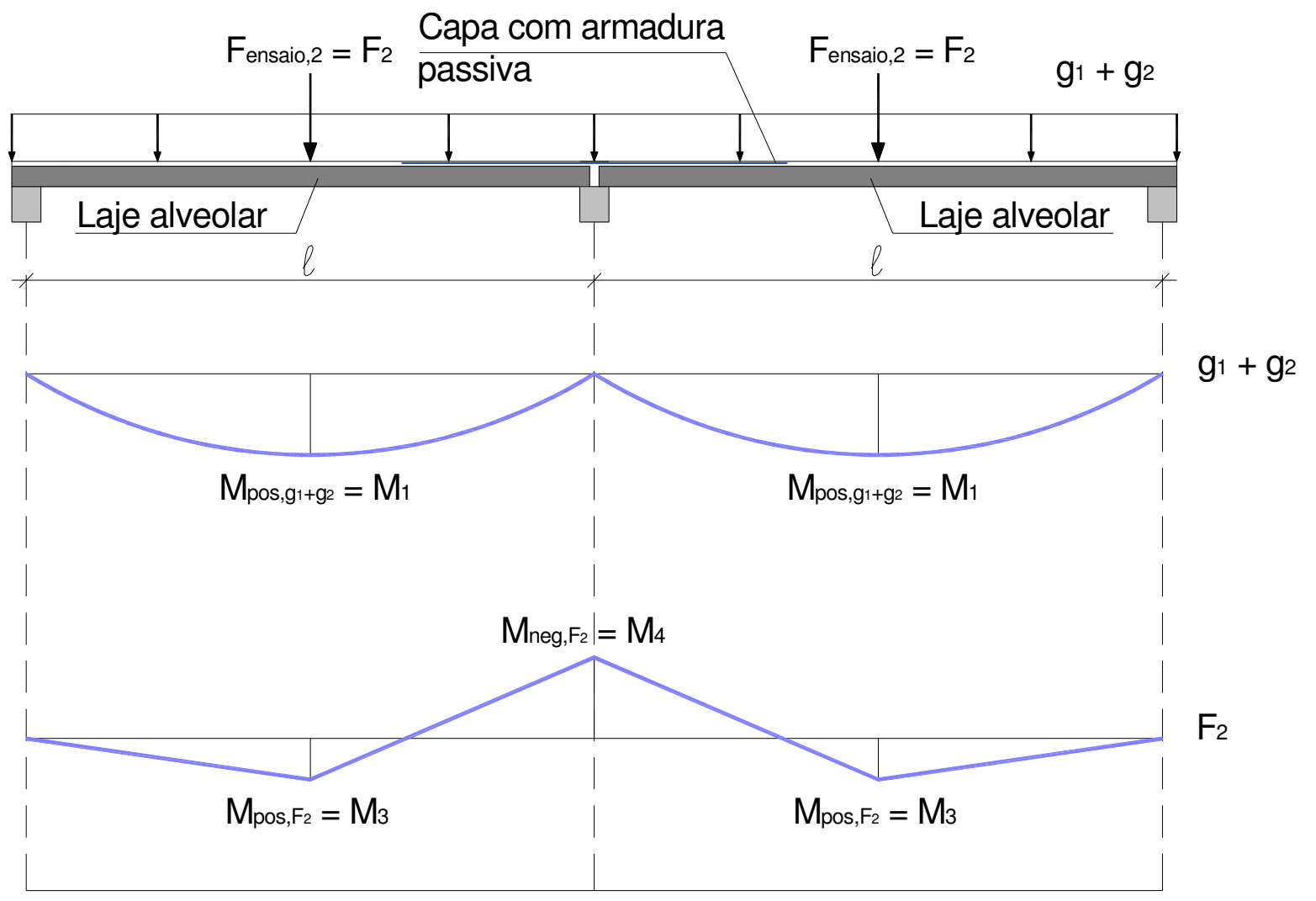

Figura 3.16 - Diagramas de momento para ensaio de laje alveolar com continuidade. 
Portanto, considerando um elemento de laje alveolar para condições definidas de propriedades da seção geométrica e de material, armadura de protensão $\left(A_{p}\right)$ e vão $(\ell)$, o máximo momento positivo resistente pela armadura $A_{p}$, na condição biapoiada ( $M_{\text {pos,tot,1) }}$, é dado pela soma dos momentos positivos correspondentes às cargas $g_{1}+g_{2}+F_{1}$, como indicado na expressão 3.2 .

$$
\mathrm{M}_{\text {pos,tot }, 1}=\mathrm{M}_{1}+\mathrm{M}_{2}
$$

Dessa forma, o momento positivo total para o ensaio com continuidade $\left(M_{\text {pos,tot, } 2)}\right)$ é dado pela expressão 3.3.

$$
M_{\text {pos,tot }, 2}=M_{1}+M_{3}
$$

De posse do valor de $A_{p}$, é possível calcular $M_{\text {pos,tot,1, }}$ como foi mostrado no item 3.6. Igualando $M_{\text {pos,tot,1 }}$ com $M_{\text {pos,tot,2 }}$ obtém-se o valor de $M_{3}$, que corresponde ao momento positivo devido à força $F_{2}$ aplicada no meio do vão, para ensaio com continuidade.

Uma vez conhecido $M_{3}$, é possível calcular o valor da carga $F_{2}$, e através de $F_{2}$, obter o momento $\mathrm{M}_{4}$. Por fim, utilizando $\mathrm{M}_{4}$, calcula-se a armadura passiva $A_{s}$, referente a $100 \%$ de continuidade.

Após isso é possível estabelecer a razão entre $F_{1}$ e $F_{2}$. Se $F_{2}$ for maior que $F_{1}$, comprova-se o aumento da capacidade portante.

\subsection{2 - Momento $\mathrm{M}_{4}$ e a condição de apoio}

Como o apoio intermediário é composto por uma ligação em concreto pré-moldado, é necessário considerar a influência do apoio na ligação. Para isso será adotada uma simplificação em que o centro de giro ocorre na seção onde se inicia o apoio da laje, como mostra a Figura 3.17. Logo, para calcular o valor de $A_{s}$, é necessário utilizar o momento fletor negativo $\left(\mathrm{M}_{4}\right)$ na seção em que ocorre a rotação. Na Figura 3.17 tem-se:

- $F_{2}$ é a carga de ruptura aplicada no meio do vão, para o ensaio com continuidade;

- $\theta$ é a rotação no apoio, considerada na seção onde a laje começa a se apoiar na viga;

- $M_{4,1}$ é o momento negativo no centro do apoio;

- $M_{4,2}$ é o momento negativo na seção onde ocorre a rotação $\theta$;

- $\mathrm{M}_{3}$ é o momento positivo devido à carga $F_{2}$;

- a é a distância entre as extremidades das lajes alveolares;

- b é o comprimento de apoio da laje alveolar;

- c é a distância entre o ponto de momento nulo e a seção onde ocorre a rotação; 
- $\mathrm{h}_{\mathrm{c}}$ é a altura da capa;

- hı é a altura da laje alveolar;

- $l_{1}$ é a distância entre o engaste e o ponto de momento nulo;

- $\ell_{2}$ é a distância entre o ponto de aplicação da carga $F_{2}$ e o de momento nulo;

- $\ell / 2$ é a metade do vão.

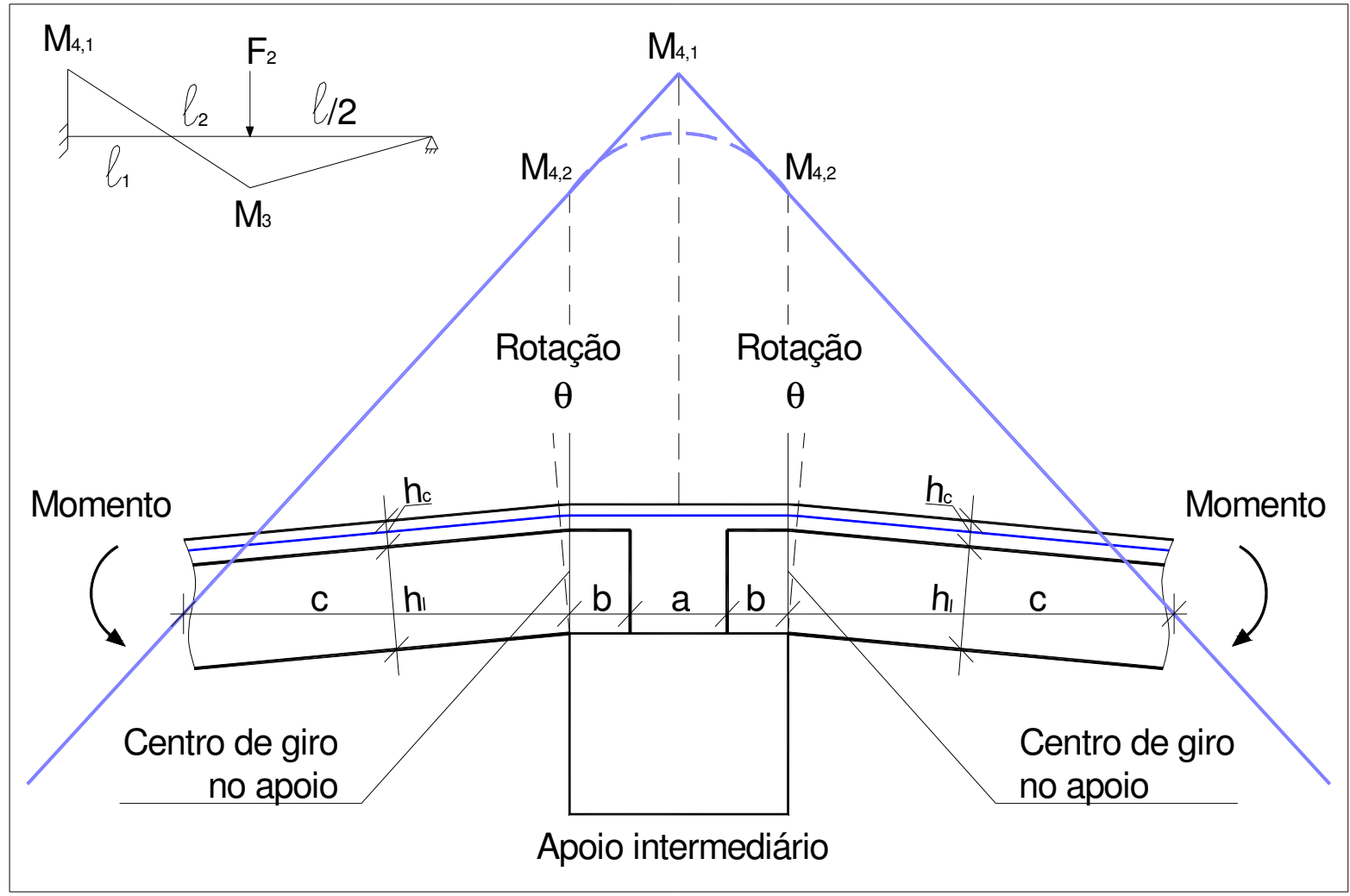

Figura 3.17 - Diagrama de momento fletor no apoio intermediário com continuidade.

Considerando a Figura 3.17 é fácil demonstrar as relações estabelecidas nas expressões 3.4 e 3.5. Além disso, como regra prática, é adotada para o comprimento de apoio (b) metade da altura da laje, considerando seção composta, expressão 3.6.

$$
\begin{aligned}
& M_{4,2}=M_{4,1}\left(\frac{l_{1}-\left(b+\left(\frac{a}{2}\right)\right)}{l_{1}}\right) \\
& l_{1}=0,273 . l \\
& b=\frac{h_{c}+h_{l}}{2}
\end{aligned}
$$

\subsection{3 - Resumo das equações}

As Tabelas 3.19 e 3.20 mostram o resumo das equações utilizadas na metodologia sugerida nos itens 3.7.1 e 3.7.2. A Tabela 3.19 se refere ao ensaio com a laje simplesmente apoiada, enquanto que a Tabela 3.20, ao ensaio com continuidade. Além das variáveis já definidas, essas tabelas apresentam também: 
- $\sigma_{p k}$ é a tensão atuante nas cordoalhas no equilíbrio da seção, considerando estado limite último (ELU). Ver item 3.6 e Tabela 3.16;

- z é o braço de alavanca relativo ao equilibro de uma seção com flexão simples. Ver Figuras 3.11 e 3.12;

- $f_{y k}$ é o valor característico da tensão de escoamento da armadura passiva.

Tabela 3.19 - Equações para dimensionamento de $A_{s}$, referentes à laje biapoiada.

\begin{tabular}{|c|c|c|}
\hline Variável & Equação & Comentários \\
\hline $\mathrm{M}_{\text {pos,tot, } 1}$ & $M_{\text {pos }, \text { tot }, 1}=M_{R}$ & Ver item 3.6. \\
\hline $\mathrm{M}_{1}$ & $M_{1}=\frac{\left(g_{1}+g_{2}\right) \cdot l^{2}}{8}$ & Ver Figura 3.15. \\
\hline $\mathrm{M}_{2}$ & $M_{2}=M_{\text {pos,tot }, 1}-M_{1}$ & Ver Figura 3.15. \\
\hline $\mathrm{F}_{1}$ & $M_{2}=\frac{F_{1} \cdot l}{4} \Rightarrow F_{1}=\frac{4 \cdot M_{2}}{l}$ & Ver Figura 3.15. \\
\hline
\end{tabular}

Tabela 3.20 - Equações para dimensionamento de $A_{s}$, referentes à laje com continuidade.

\begin{tabular}{|c|c|c|}
\hline Variável & Equação & Comentários \\
\hline $\mathrm{M}_{\text {pos,tot, }}$ & $M_{\text {pos }, \text { tot }, 2}=M_{\text {pos }, \text { tot }, 1}=M_{R}$ & Ver Equações 3.2 e 3.3. \\
\hline $\mathrm{M}_{3}$ & $M_{3}=M_{\text {pos,tot }, 2}-M_{1}$ & Ver Figura 3.16. \\
\hline $\mathrm{F}_{2}$ & $M_{3}=\frac{5 \cdot F_{2} \cdot l}{32} \Rightarrow F_{2}=\frac{32 \cdot M_{3}}{5 . l}$ & Ver Figura 3.16. \\
\hline $\mathrm{M}_{4,1}$ & $M_{4,1}=\frac{3 \cdot F_{2} \cdot l}{16}$ & Ver Figuras 3.16 e 3.17. \\
\hline $\mathrm{M}_{4,2}$ & $\left.\left(\frac{l_{1}}{\left(V_{1}-\left(b+\left(\frac{a}{2}\right)\right)\right.}\right)\right)$ & Ver Equações 3.4, 3.5 e \\
& $M_{4,2}=M_{4,1}\left(\frac{M_{4,2}}{z \cdot f_{y k}}\right.$ & Ver Figura 3.17. \\
\hline $\mathrm{A}_{\mathrm{s}}$ & $A_{s}$ & Ver Figura 3.17. \\
\hline
\end{tabular}




\subsection{4 - Verificação do cisalhamento conforme a NBR 6118:2014}

O critério sugerido para estabelecer $100 \%$ da armadura de continuidade, através do máximo momento resistente pela armadura de protensão, deve ser complementado pela verificação da tensão de cisalhamento.

Realizando um ensaio de continuidade (Figura 3.16) é possível que a laje alveolar atinja a ruína por cisalhamento antes que a armadura longitudinal alcance a ruptura ou mesmo entre em escoamento. Em outras palavras, a força de ruptura atingida no ensaio de continuidade pode ser menor do que a prevista para ruptura por flexão $\left(F_{2}\right)$.

Para a verificação da tensão de cisalhamento foi escolhida a formulação da NBR 6118:2014, que é baseada nas antigas versões europeias, à exemplo do manual da FIB (2000), a qual influenciou na formulação adotada pela NBR 14861:2011. Entretanto, os resultados são semelhantes principalmente quando não há preenchimento de alvéolos, caso deste trabalho.

Esta verificação de cisalhamento será feita com a formulação da NBR 6118:2014, para fins de cálculos preliminares. 0 capítulo 8 deste trabalho tratará da verificação da força cortante considerando também outras formulações.

Conforme a NBR 6118:2014, uma laje pode prescindir de armadura transversal para resistir aos esforços de tração oriundos da força cortante, quando:

$$
V_{S d} \leq V_{R d 1}=\left[\tau_{R d} \cdot k\left(1,2+40 \cdot \rho_{1}\right)+0,15 \sigma_{c p}\right] \cdot b_{w} \cdot d
$$

- V $V_{s d}$ é a força cortante solicitante de cálculo;

- V $V_{\mathrm{Rd} 1}$ é a força cortante resistente de cálculo;

- $\tau_{R d}$ é a tensão cisalhante resistente de cálculo $-\tau_{R d}=0,25 f_{c t d} ;$

- $f_{c t d}$ é a resistência à tração $-f_{c t d}=f_{c t k, \text { inf }} / \gamma_{c}$;

- $k=|1,6-d| \geq 1$, com $d$ em metros;

- $\rho_{1}=A_{s 1} /\left(b_{w} \cdot d\right) \leq 0,02$;

- $\sigma_{\mathrm{cp}}$ é a tensão de compressão no concreto devida à força de protensão, $\sigma_{\mathrm{cp}}=$ $N_{s d} / A_{c} ;$

- d é a altura útil da seção;

- $b_{w}$ é a largura da laje, descontados os vazios correspondentes aos alvéolos;

- $\mathrm{N}_{\mathrm{sd}}$ é a força longitudinal devida à protensão;

- $A_{s 1}$ é a área de armadura da seção correspondente.

FIB (2000) apresenta uma formulação parecida com expressão 3.7. No entanto, apresenta quatro expressões, para considerar as variações de laje alveolar com e sem capa ou com e sem o preenchimento de alvéolo.

Tomando como base a expressão da norma brasileira, as expressões da FIB (2000) podem ser apresentadas da seguinte forma:

- Laje alveolar sem capa e sem preenchimento de alvéolo - A equação NBR 6118:2014 é igual à da FIB (2000); 


$$
\mathrm{V}_{\mathrm{Rd} 1}=\left[\tau_{\mathrm{Rd}} \cdot \mathrm{k}\left(1,2+40 \cdot \rho_{1}\right)+0,15 \sigma_{\mathrm{cp}}\right] \cdot \mathrm{b}_{\mathrm{w}} \cdot \mathrm{d}
$$

- Laje alveolar com capa e sem preenchimento de alvéolo - A equação da NBR 6118:2014 é igual à da FIB (2000). Entretanto, utiliza-se a altura útil ( $d_{\text {comp }}$ ) da seção composta;

$$
\mathrm{V}_{\mathrm{Rd} 1}=\left[\tau_{\mathrm{Rd}} \cdot \mathrm{k}_{\mathrm{comp}}\left(1,2+40 \cdot \rho_{1}\right)+0,15 \sigma_{\mathrm{cp}}\right] \cdot \mathrm{b}_{\mathrm{w}} \cdot \mathrm{d}_{\mathrm{comp}}
$$

- Laje alveolar sem capa e com preenchimento de alvéolo - A equação da FIB (2000) é ajustada no valor de $b_{w}$. Somente a primeira parcela entre colchetes,

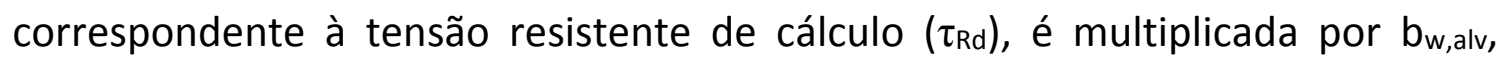
relativo ao preenchimento de alvéolo;

$$
\mathrm{V}_{\mathrm{Rd} 1}=\left[\tau_{\mathrm{Rd}} \cdot \mathrm{k} \cdot \mathrm{b}_{\mathrm{w}, \text { alv }}\left(1,2+40 \cdot \rho_{1, \mathrm{alv}}\right)+0,15 \sigma_{\mathrm{cp}} \cdot \mathrm{b}_{\mathrm{w}}\right] \cdot \mathrm{d}
$$

- Laje alveolar com capa e com preenchimento de alvéolo - A equação da FIB (2000) é ajustada tanto para altura útil $\left(d_{\text {comp }}\right)$ da seção composta quanto para $\mathrm{b}_{\mathrm{w}, \mathrm{alv}}$, relativo ao preenchimento de alvéolo;

$$
\mathrm{V}_{\mathrm{Rd} 1}=\left[\tau_{\mathrm{Rd}} \cdot \mathrm{k}_{\mathrm{comp}} \cdot \mathrm{b}_{\mathrm{w}, \mathrm{alv}}\left(1,2+40 \cdot \rho_{1, \mathrm{alv}}\right)+0,15 \sigma_{\mathrm{cp}} \cdot \mathrm{b}_{\mathrm{w}}\right] \cdot \mathrm{d}_{\mathrm{comp}}
$$

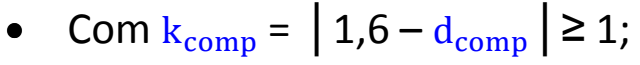

- $E b_{w, a l v}=b_{w}+n \cdot b_{c} \cdot\left(E_{c} / E_{p}\right)$;

- $\mathrm{n}$ é o número de alvéolos preenchidos;

- $b_{c}$ é a largura da capa de concreto;

- $E_{c} / E_{p}$ é a relação entre os módulos de elasticidade da capa e da laje alveolar.

Portanto as expressões da FIB (2000) para laje sem o preenchimento de alvéolo são similares às da NBR 6118:2014, desde que corrigidas com a altura útil da seção composta.

Além do exposto, o manual FIB (2000) prescreve que $V_{\mathrm{Rd} 1}$ deve ser limitado a um valor de $\mathrm{V}_{\mathrm{Rd} 2}$ como mostra a expressão 3.12.

$$
\mathrm{V}_{\mathrm{Rd} 1} \leq \mathrm{V}_{\mathrm{Rd} 2}=0,5 \cdot v \cdot \mathrm{f}_{\mathrm{cd}} \cdot \mathrm{b}_{\mathrm{w}} \cdot 0,9 \cdot \mathrm{d}
$$

- $\quad v=0,7-\left(f_{c k} / 200\right) \geq 0,5$;

- $\mathrm{f}_{\mathrm{cd}}=\mathrm{f}_{\mathrm{ck}} / \gamma_{\mathrm{c}}$;

- $b_{w}$ e d modificados para $b_{w, a l v}$ e $d_{\text {comp }}$ nos casos de preenchimento de alvéolo e seção composta.

Com base na Figura 3.18, a expressão 3.13 mostra o valor de $V_{S d}$ em função da força de ensaio com continuidade, que leva à ruptura por força cortante $\left(F_{2,0}\right)$.

$$
\mathrm{V}_{\mathrm{sd}}=\frac{\left(g_{1}+g_{2}\right) \cdot V}{2}+\frac{11}{16} \cdot \mathrm{F}_{2, \mathrm{Q}}
$$

Supondo que $V_{R d 1}$ (expressão 3.7) seja menor que $V_{R d 2}$ (expressão 3.12), igualando as expressões 3.7 e 3.13 , tem-se:

$$
\frac{\left(g_{1}+g_{2}\right) \cdot V}{2}+\frac{11}{16} \cdot \mathrm{F}_{2, \mathrm{Q}}=\left[\tau_{\mathrm{Rd}} \cdot \mathrm{k}\left(1,2+40 \cdot \rho_{1}\right)+0,15 \sigma_{\mathrm{cp}}\right] \cdot \mathrm{b}_{\mathrm{w}} \cdot \mathrm{d}
$$




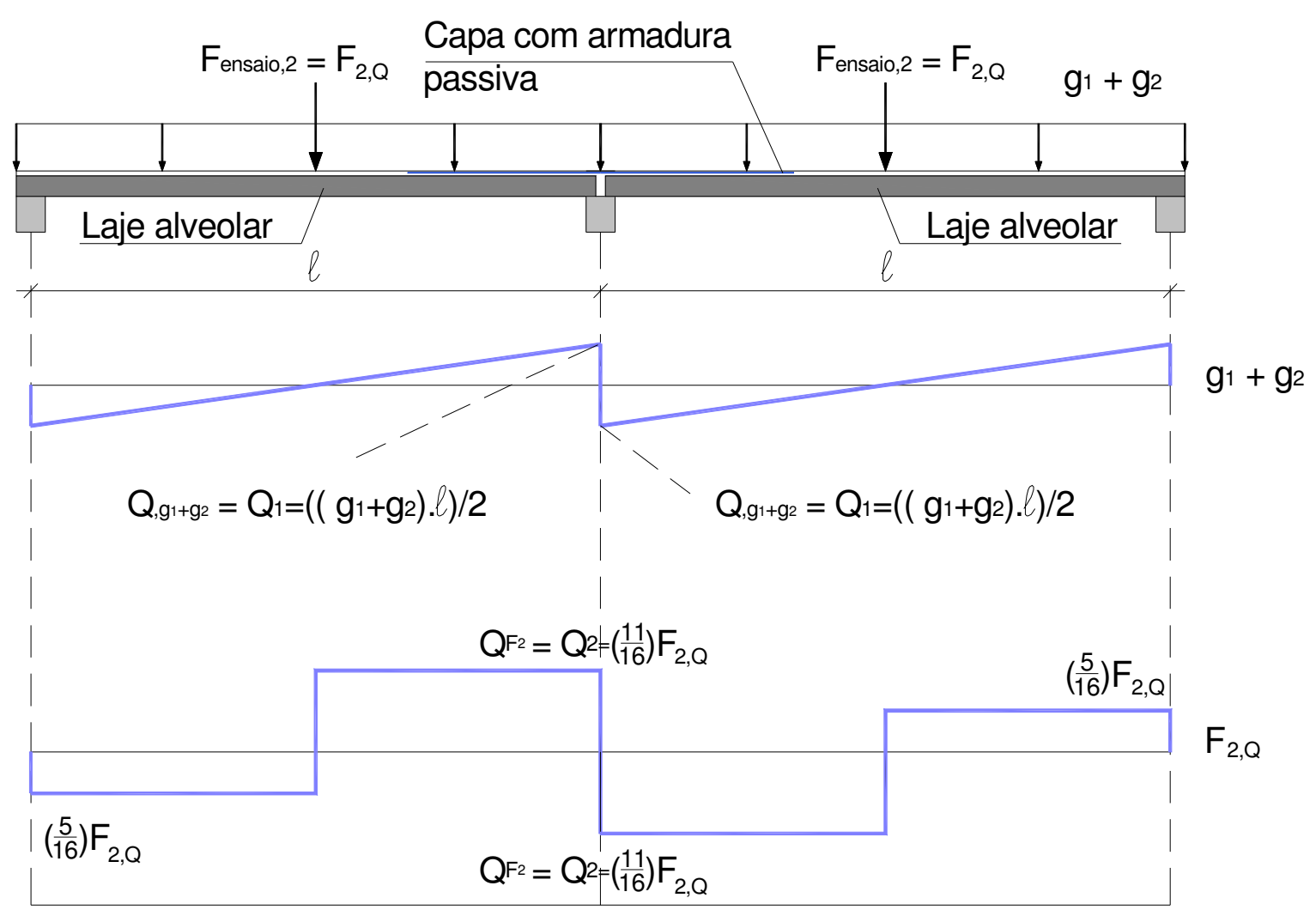

Figura 3.18 - Diagramas de força cortante para ensaio de laje alveolar com continuidade.

Portanto, a força que se deseja saber $\left(F_{2,0}\right)$ é função da taxa de armadura $\rho_{1}$, ou seja, da armadura passiva $A_{s}$.

Logo, para efetuar a verificação da força cortante, considera-se, na expressão 3.14, o valor de $A_{s}$ obtido em função das Tabelas 3.19 e 3.20, e com isso calcula-se $F_{2, a}$.

Se $F_{2}$ for menor que $F_{2,0}$ a laje não irá romper por força cortante. Caso contrário, a armadura de continuidade deverá ser calculada novamente, limitada pela força $F_{2, Q}$. Isto pode ser feito substituindo na Tabela $3.20 \mathrm{~F}_{2}$ por $\mathrm{F}_{2, \mathrm{Q}}$, calculando novamente $\mathrm{M}_{4,1}$ e $\mathrm{M}_{4,2}$, e por fim $A_{s}$.

Para resumir o equacionamento da verificação da força cortante tem-se a Tabela 3.21 .

Tabela 3.21 - Equações para dimensionamento de $A_{s}$ referente à laje com continuidade Verificação da força cortante.

\begin{tabular}{|c|c|c|}
\hline Variável & Equação & $\begin{array}{c}\text { Comen- } \\
\text { tários }\end{array}$ \\
\hline \multirow{2}{*}{$\mathrm{A}_{\mathrm{s}}$} & \multirow{2}{*}{$A_{s}=\frac{M_{4,2}}{z \cdot f_{y k}}$} & Ver \\
& & Tabela \\
& & 3.20. \\
\hline
\end{tabular}




\begin{tabular}{|c|c|c|}
\hline $\mathrm{F}_{2, \mathrm{Q}}$ & $\frac{\left(g_{1}+g_{2}\right) \cdot l}{2}+\frac{11}{16} \cdot \mathrm{F}_{2, \mathrm{Q}}=\left[\tau_{\mathrm{Rd}} \cdot \mathrm{k}\left(1,2+40 \cdot \rho_{1}\right)+0,15 \sigma_{\mathrm{cp}}\right] \cdot \mathrm{b}_{\mathrm{w}} \cdot \mathrm{d}$ & $\begin{array}{c}\text { Ver } \\
\text { Figura } \\
3.16 .\end{array}$ \\
\hline $\begin{array}{c}\mathrm{Se} \\
\mathrm{F}_{2} \geq \mathrm{F}_{2, \mathrm{Q}}\end{array}$ & $\begin{array}{c}\text { OK. A é igual ao valor obtido na Tabela 3.20. A laje não irá romper } \\
\text { por força cortante. }\end{array}$ & $\begin{array}{c}\text { Ver } \\
\text { Tabela } \\
3.20 .\end{array}$ \\
\hline $\mathrm{Se}$ & Calcula-se novamente $\mathrm{M}_{4,1}, \mathrm{M}_{4,2}$ e $\mathrm{A}_{\mathrm{s}}$, substituindo-se $\mathrm{F}_{2}$ por $\mathrm{F}_{2, \mathrm{Q}} \cdot \mathrm{na}$ & $\begin{array}{c}\text { Ver } \\
\text { Tabela 3.20. } \\
\mathrm{F}_{2}<\mathrm{F}_{2, \mathrm{Q}}\end{array}$ \\
$\begin{array}{c}\text { Tabela } \\
3.20 .\end{array}$ \\
\hline
\end{tabular}

A Figura 3.19 apresenta um fluxograma com a sequencia de cálculos para obtenção de $A_{s}$ considerando o critério sugerido.

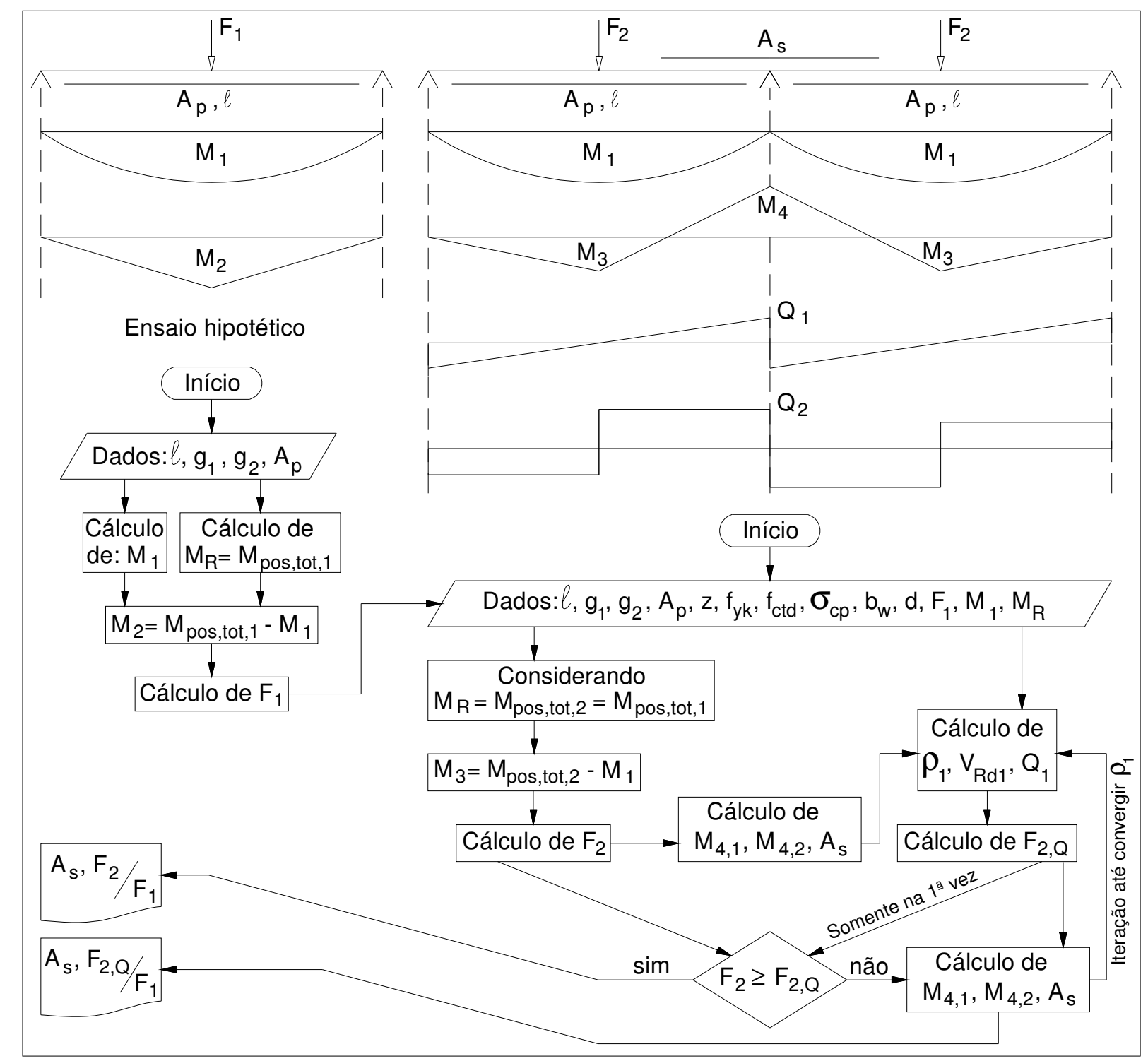

Figura 3.19 - Fluxograma com os cálculos de $A_{s}$ através do método do máximo momento resistente pela laje alveolar. 


\subsection{5 - Diferentes comprimentos usados no concreto protendido}

No concreto protendido com pré-tração, não existem dispositivos de ancoragem ou de distribuição de tensão como ocorre no caso da pós-tração. A transferência de ação ocorre por aderência aço-concreto. Além disso, existem quatro situações distintas, com relação aos comprimentos que devem utilizados. A seguir são apresentados esses comprimentos com definições extraídas de CARVALHO (2012) e fórmulas, da NBR 6118:2014, para as cordoalhas:

- Comprimento de ancoragem básico ( $\left.l_{\mathrm{bp}}\right)$. Menor comprimento necessário para que no estado limite último a ruptura ocorra na armadura. Considera-se a armadura com o maior esforço possível, e o concreto em torno dela, com a menor resistência e com fissuras;

$$
\mathrm{l}_{\mathrm{bp}}=\frac{7 \cdot \phi}{436} \frac{\mathrm{f}_{\mathrm{pyd}}}{\mathrm{f}_{\mathrm{bpd}}}
$$

- Comprimento de transferência $\left(l_{\mathrm{bpt}}\right)$. Comprimento necessário, em geral em serviço, para que o esforço de protensão se transfira por aderência, da armadura para o concreto;

$$
\mathrm{l}_{\mathrm{bpt}}=0,5 \cdot \mathrm{l}_{\mathrm{bp}} \frac{\sigma_{\mathrm{pi}}}{\mathrm{f}_{\mathrm{pyd}}}
$$

- Comprimento de ancoragem necessário (l $\left.\mathrm{l}_{\mathrm{bpd}}\right)$. Utilizado para fazer o detalhamento de uma peça, considerando as tensões atuantes e os comprimentos definidos anteriormente;

$$
\mathrm{l}_{\mathrm{bpd}}=\mathrm{l}_{\mathrm{bpt}}+\mathrm{l}_{\mathrm{bp}} \frac{\mathrm{f}_{\mathrm{pyd}}-\sigma_{\mathrm{p} \infty}}{\mathrm{f}_{\mathrm{pyd}}}
$$

- Distância de regularização $\left(l_{p}\right)$. Distância da extremidade da peça à seção em que se considera todo o esforço de protensão;

$$
l_{p}=\sqrt{h^{2}+\left(0,6 . l_{b p t}\right)^{2}} \geq l_{b p t}
$$

- h é a altura do elemento estrutural;

- $f_{\text {pyd }}$ é o valor característico da resistência ao escoamento da armadura ativa;

- $\mathrm{f}_{\mathrm{bpd}}$ é a resistência de aderência de cálculo da armadura ativa;

- $\sigma_{\mathrm{pi}}$ é a tensão na armadura ativa, logo após a aplicação da protensão;

- $\sigma_{\mathrm{pt}, \infty}$ é a tensão na armadura ativa, após todas as perdas ao longo do tempo.

\subsection{6 - Momento de fissuração}

O momento de fissuração $\mathrm{Mr}_{\mathrm{r}}$ deve ser calculado para duas situações distintas, uma levando em conta a fissuração da capa e outra a fissuração da laje. 
Por se tratar de uma seção de concreto armado, o momento de fissuração da capa pode ser calculado através da expressão 3.19, indicada na NBR 6118:2014.

$$
\mathrm{M}_{\mathrm{r}}=\frac{\alpha \cdot \mathrm{f}_{\mathrm{ct}} \cdot \mathrm{I}_{\mathrm{C}}}{\mathrm{y}_{\mathrm{t}}}
$$

- $\alpha=\left\{\begin{array}{l}1,2 \text { para seções } \mathrm{T} \text { ou duplo } \mathrm{T} \\ 1,5 \text { para seções retangulares }\end{array}\right.$

- $\alpha$ é o fator que correlaciona aproximadamente a resistência à tração na flexão com a resistência à tração direta;

- $\mathrm{f}_{\mathrm{ct}}=\mathrm{f}_{\mathrm{ctk}, \mathrm{inf}}=0,7 \cdot \mathrm{f}_{\mathrm{ct}, \mathrm{m}}=0,7 \cdot 0,3 \cdot \mathrm{f}_{\mathrm{ck}}^{2 / 3}, \operatorname{com~}_{\mathrm{ck}}$ em MPa;

- $\mathrm{f}_{\mathrm{ct}}=\mathrm{f}_{\mathrm{ctk}, \text { inf }}$, para formação de fissura;

- $\mathrm{f}_{\mathrm{ct}}=\mathrm{f}_{\mathrm{ct}, \mathrm{m}}$, para deformação excessiva;

- $\mathrm{I}_{\mathrm{c}}$ é o momento de inércia no Estádio I (da seção bruta ou homogeneizada);

- $y_{t}$ é a distância do centro de gravidade da seção à fibra mais tracionada.

Para a seção de laje alveolar, CARVALHO (2012) apresenta a expressão 3.20 para o cálculo do momento de fissuração. Além da parcela contida na expressão 3.19, a fórmula abaixo leva em consideração à parcela do efeito da protensão $\left(N_{p} / A\right)$ e da sua excentricidade $\left(\mathrm{N}_{\mathrm{p}}\right.$.e.y)/ $\mathrm{I}_{\mathrm{c}}$

$$
\mathrm{M}_{\mathrm{r}}=\frac{\alpha \cdot \mathrm{f}_{\mathrm{ct}} \cdot \mathrm{I}_{\mathrm{c}}}{\mathrm{y}_{\mathrm{t}}}+\frac{\mathrm{N}_{\mathrm{p}} \cdot \mathrm{I}_{\mathrm{c}}}{\mathrm{A} \cdot \mathrm{y}_{\mathrm{t}}}+N_{p} \cdot e
$$

- $\mathrm{N}_{\mathrm{p}}$ é a força normal de protensão;

- A é a área da seção transversal de concreto, em geral da seção bruta;

- e equivale à distância do centro de gravidade da seção à fibra mais tracionada.

\section{8 - Cálculo da armadura de continuidade}

A seguir será mostrado o cálculo da armadura de continuidade para o EM1, considerando: as informações iniciais apresentadas no item 3.1, as perdas de protensão (item 3.5), os momentos resistentes (item 3.6), a formulação apresentada anteriormente (item 3.7) e a análise estrutural considerando comportamento elástico linear.

O critério escolhido para estabelecer o valor de $100 \%$ da armadura de continuidade é do máximo momento resistente pela armadura de protensão, considerando a verificação da força cortante.

A Figura 3.20 apresenta a geometria utilizada nas análises experimentais realizadas neste trabalho (EM1, EM2, EM3). Observa-se que a carga aplicada não está situada no meio do vão, diferentemente do que é indicado nas Figuras 3.15, 3.16 e 3.18.

A análise linear foi feita com o programa FTOOL, como mostra a Figura 3.21. Com esse programa foi possível obter relações para valores dos esforços solicitantes em função do carregamento. Esses valores são mostrados na Tabela 3.22. 


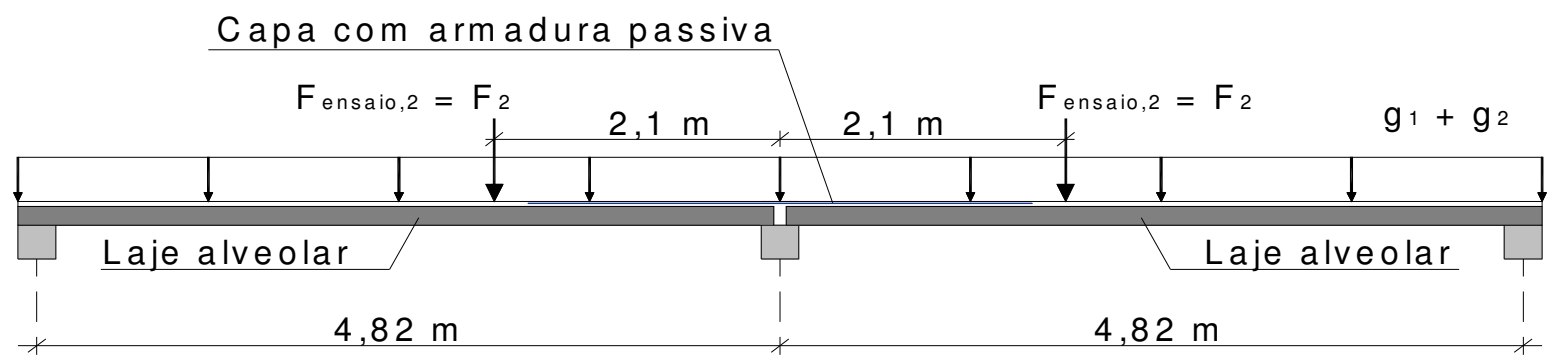

Figura 3.20 - Geometria do ensaio EM1.
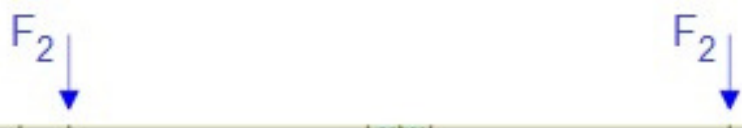

Figura 3.21 - Geometria do ensaio EM1 lançada no programa FTOOL.

Tabela 3.22 - Relações entre os esforços solicitantes e o carregamento aplicado.

\begin{tabular}{|c|c|c|}
\hline $\mathbf{M}_{4,1}$ & $\mathrm{~K} 1 \cdot \mathrm{F}_{2} \cdot \mathrm{V}$ & $\mathrm{K} 1=0,192324$ \\
\hline $\mathbf{M}_{3}$ & $\mathrm{~K} 2 \cdot \mathrm{F}_{2} \cdot \mathrm{V}$ & $\mathrm{K} 2=0,137344$ \\
\hline $\mathbf{Q}$ & $\mathrm{K} 3 \cdot \mathrm{F}_{2}$ & $\mathrm{~K} 3=0,7565$ \\
\hline
\end{tabular}

Vale ressaltar que o cálculo da armadura de continuidade apresentado neste trabalho não tem foco na situação de projeto estrutural, e sim em análises hipotéticas de ensaio, visando estudar principalmente a força de ruptura e uma forma de se calcular a que represente $100 \%$ de armadura de continuidade.

Nos casos práticos de projetos estruturais, devem-se levar em consideração as verificações dos estados limites de serviço (ELS), os valores e a forma dos carregamentos atuantes.

É importante destacar também que este trabalho utiliza carregamento concentrado nos ensaios, e que se houver mudança na forma de aplicar o carregamento, os cálculos deverão levar em conta essa modificação. Mesmo assim, acredita-se que a laje tenha comportamento semelhante ao caso com carga concentrada no meio do vão, em se tratando do estudo da continuidade.

\subsection{1 - Armadura de continuidade para o EM1}

A Tabela 3.23 apresenta os cálculos para obtenção do valor de $F_{2}$ considerando o máximo momento positivo resistente pela armadura de protensão, em um ensaio 
(hipotético) considerando laje simplesmente apoiada. De posse de $F_{2}$, obtém-se a armadura de continuidade para a flexão, como indicado na Tabela 3.24.

Em seguida, apresentam-se os cálculos para a verificação da força cortante (Tabela 3.25). Para tal, é necessário considerar o valor de $b_{w}=0,44 \mathrm{~m}$.

Tabela 3.23 - Cálculos para obter a força de ruptura $\left(F_{2}\right)$ para o ensaio de continuidade - EM1.

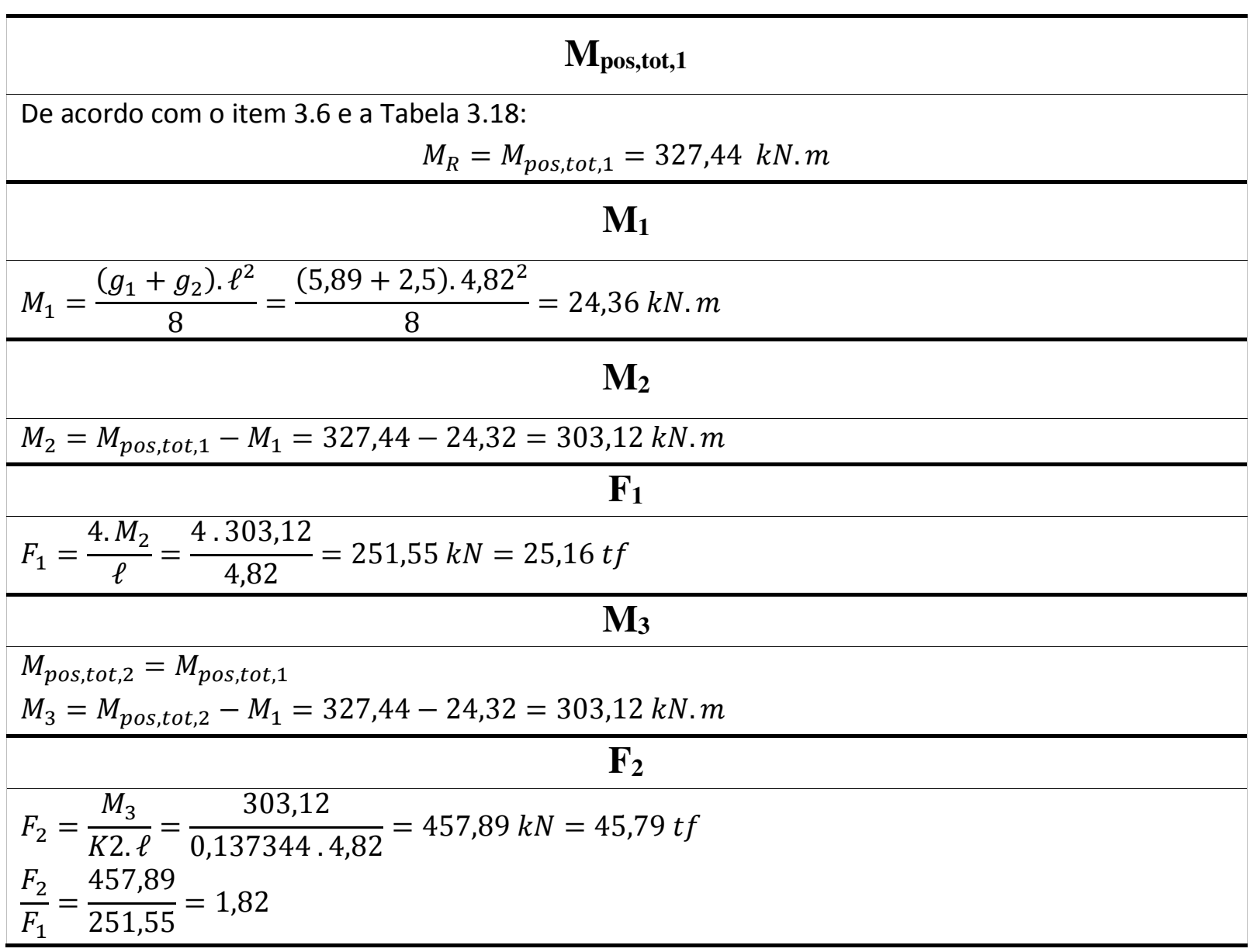

Tabela 3.24 - Cálculo da armadura de continuidade $\left(A_{s}\right)$ para flexão - EM1.

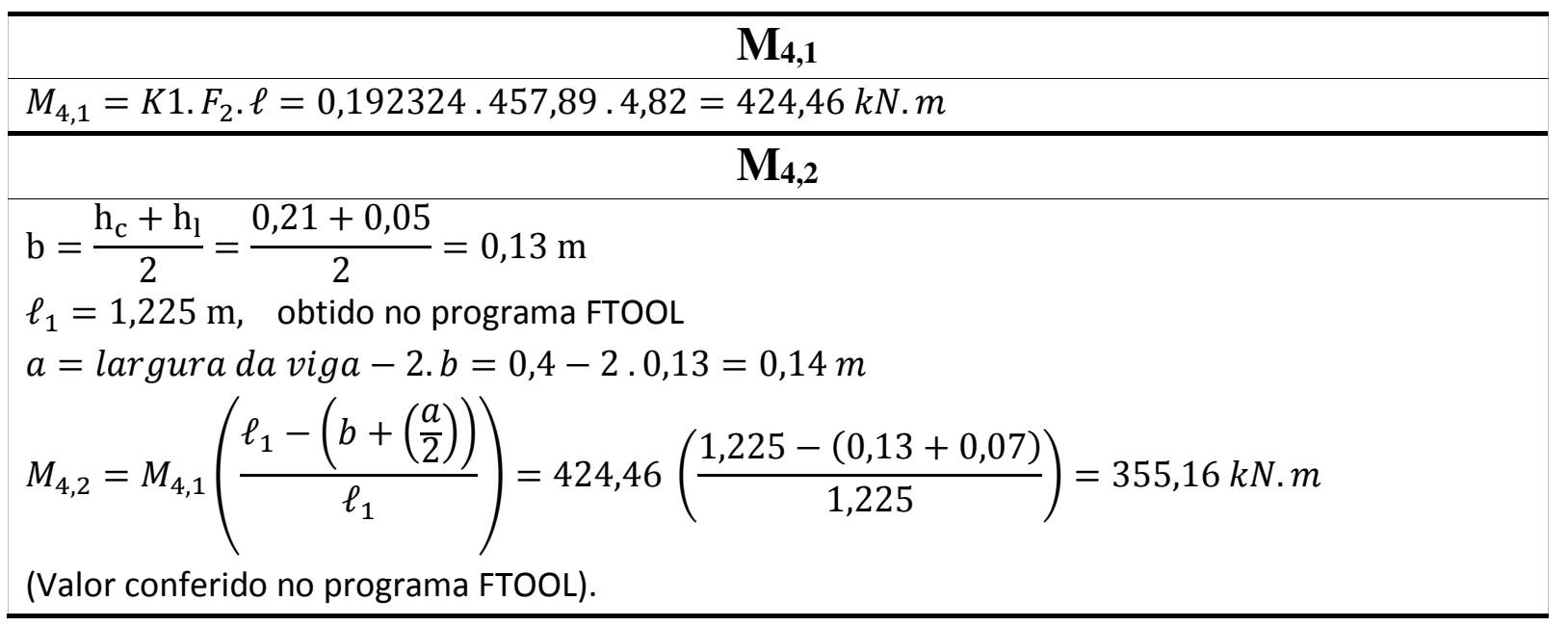




\section{$\mathbf{Z}_{\mathbf{s}}$}

O cálculo do braço de alavanca é feito com base no item 3.6.2, equacionamento para momento resistente negativo que segue o mesmo padrão que o cálculo do momento resistente positivo.

$$
\begin{gathered}
M_{4,2}=F_{c} \cdot z \\
F_{c, i}=0,85 \cdot f_{c k, i} \cdot b_{w, i} \cdot h_{i} \\
M_{R}=M_{4,2}=\left(0,85 \cdot f_{c k, i} \cdot b_{w, i} \cdot h_{i}\right) \cdot z=355,16 \mathrm{kN} \cdot \mathrm{m}
\end{gathered}
$$

De acordo com a Tabela APA1.2, do a Apêndice A, essa situação corresponde à Faixa 25 (de baixo para cima), ou seja, $25 \mathrm{~mm}$ da face inferior da seção composta. Logo a linha neutra encontra-se na mesa inferior (bem próximo ao alvéolo), com os seguintes resultados.

$$
\begin{gathered}
F_{c . t o t, i}=1690,23 \mathrm{kN} \\
\boldsymbol{M}_{\boldsymbol{R}}=\mathbf{3 5 9 , 1 1} \boldsymbol{k N} . \boldsymbol{m} \\
z_{s}=0,212 \mathrm{~m} \\
y_{s}=0,025 \mathrm{~m} \\
x_{s}=0,031 \mathrm{~m}
\end{gathered}
$$

\begin{tabular}{|c|}
\hline$V_{\text {Rd2 }}$ \\
\hline $\begin{array}{l}d=h_{t o t}-d^{\prime}=0,26-0,035=0,225 m \text { (armadura negativa) } \\
v=0,7-\frac{f_{c k}}{200}=0,7-\frac{40}{200}=0,5 \geq 0,5 \\
V_{\mathrm{Rd} 2}=0,5 \cdot v \cdot \mathrm{f}_{\mathrm{ck}} \cdot \mathrm{b}_{\mathrm{w}} \cdot 0,9 \cdot \mathrm{d}=0,5 \cdot 0,5 \cdot 40000 \cdot 0,44 \cdot 0,9 \cdot 0,225=891,0 \mathrm{kN}\end{array}$ \\
\hline$V_{\text {Rd1 }}$ \\
\hline $\begin{array}{l}\tau_{R d}=0,25 \cdot f_{c t d} \text { ou } 0,25 \cdot f_{c t k}=0,25 \cdot f_{c t k, \text { inf }}=0,25 \cdot 2456\left(\frac{k N}{m^{2}}\right)=614,00 \mathrm{kN} / \mathrm{m}^{2} \\
k=|1,6-d|=1,6-0,225=1,375 \\
\rho_{1}=\frac{A_{s}}{b_{w} \cdot d}=\frac{33,51}{44 \cdot 23,0}=0,0331 \leq 0,02 \Rightarrow \rho_{1}=0,02 \\
N_{s k, p t, \infty}=\sigma_{p t, \infty} A_{p}=107,665 \cdot 8,91=959,30 \mathrm{kN} \\
\sigma_{c p}=\frac{N_{s k, p t, \infty}}{A_{c}}=\frac{959,30}{0,2357}=4070,00 \mathrm{kN} / \mathrm{m}^{2} \text { (considerando seção simples) } \\
\mathrm{V}_{\mathrm{Rd} 1}=\left[\tau_{\mathrm{Rd}} \cdot \mathrm{k}\left(1,2+40 \cdot \rho_{1}\right)+0,15 \cdot \sigma_{\mathrm{cp}}\right] \cdot \mathrm{b}_{\mathrm{w}} \cdot \mathrm{d} \\
\mathrm{V}_{\mathrm{Rd} 1}=[614 \cdot 1,375(1,2+40 \cdot 0,02)+0,15 \cdot 4070,00] \cdot 0,44 \cdot 0,225 \\
\mathrm{~V}_{\mathrm{Rd} 1}=[1688,5+610,50] \cdot 0,44 \cdot 0,225=227,60 \mathrm{kN} \\
\mathrm{V}_{\mathrm{Rd} 1} \leq \mathrm{V}_{\mathrm{Rd} 2}\end{array}$ \\
\hline$F_{2, Q}$ \\
\hline
\end{tabular}

Lembra-se que o índice s equivale ao equilíbrio da seção composta, considerando tração na armadura passiva.

$$
A_{s}=\frac{M_{4,2}}{z_{s} \cdot f_{y k}}=\frac{355,16}{0,212.500000}=0,003351 \mathrm{~m}^{2}=33,51 \mathrm{~cm}^{2}
$$

Tabela 3.25 - Verificação da força cortante e obtenção da força $F_{2, Q}$ - EM1. 


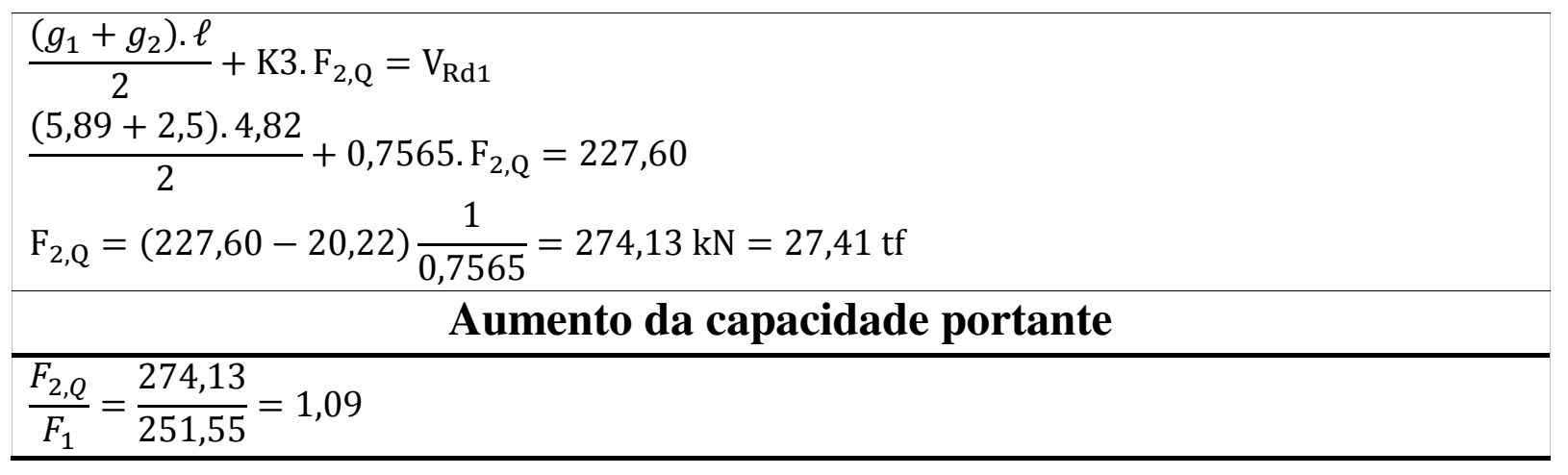

Verifica-se que o valor de $V_{\mathrm{Rd} 2}$ é maior que $\mathrm{V}_{\mathrm{Rd1}}$. Além disso, é necessário citar que foi utilizado o valor de $f_{c k}$ ao invés de $f_{c d}$, uma vez que se trata de análise experimental. $O$ mesmo vale para o valor de $f_{c t d}$, que foi substituído por $f_{c t k, \text { inf. }}$

Uma vez que o valor de $F_{2, Q}$ é menor que $F_{2}$, deve-se repetir os cálculos da Tabela 3.25, utilizando $F_{2, Q}$ ao invés de $F_{2}$, é o que é feito na Tabela 3.26.

Vale destacar que o aumento da capacidade portante para a laje (considerando a carga concentrada próxima ao meio do vão) foi de 1,09 (Tabela 3.25), e não 1,82 (Tabela 3.23).

Tabela 3.26 - Cálculo da armadura de continuidade $\left(A_{s}\right)$ para flexão, limitado pela verificação de cisalhamento - EM1.

\begin{tabular}{l}
\hline \multicolumn{1}{c}{$\mathbf{M}_{4,1}$} \\
\hline$M_{4,1}=K 1 \cdot F_{2} \cdot \ell=0,192324.274,13 \cdot 4,82=254,12 \mathrm{kN} . \mathrm{m}$ \\
\hline $\mathbf{M}_{4,2}$ \\
$\mathrm{~b}=\frac{\mathrm{h}_{\mathrm{c}}+\mathrm{h}_{1}}{2}=\frac{0,21+0,05}{2}=0,13 \mathrm{~m}$ \\
$\ell_{1}=1,225 \mathrm{~m}, \quad$ obtido no programa FTOOL \\
$a=$ largura da viga $-2 \cdot b=0,4-2 \cdot 0,13=0,14 \mathrm{~m}$ \\
$\mathrm{M}_{4,2}=\mathrm{M}_{4,1}\left(\frac{\ell_{1}-\left(\mathrm{b}+\left(\frac{\mathrm{a}}{2}\right)\right)}{\ell_{1}}\right)=254,12\left(\frac{1,225-(0,13+0,07)}{1,225}\right)=212,63 \mathrm{kN} . \mathrm{m}$ \\
(Valor conferido no programa FTOOL)
\end{tabular}

\section{$\mathbf{Z}_{\mathbf{S}}$}

O cálculo do braço de alavanca é feito com base no item 3.6.2, equacionamento para momento resistente negativo, que segue o mesmo padrão que o cálculo do momento resistente positivo.

$$
\begin{gathered}
M_{4,2}=F_{c} \cdot z \\
F_{c, i}=0,85 \cdot f_{c k, i} \cdot b_{w, i} \cdot h_{i} \\
M_{R}=M_{4,2}=\left(0,85 \cdot f_{c k, i} \cdot b_{w, i} \cdot h_{i}\right) \cdot z=212,63 \mathrm{kN} \cdot \mathrm{m}
\end{gathered}
$$

De acordo com a Tabela APA1.2, do a Apêndice A, essa situação corresponde à Faixa 15 (de baixo para cima), portanto $15 \mathrm{~mm}$ ou $1,5 \mathrm{~cm}$ da face inferior da seção composta. Logo a linha neutra 
encontra-se na mesa inferior (distante do alvéolo), com os seguintes resultados.

$$
\begin{gathered}
F_{c . t o t, i}=1010,23 \mathrm{kN} \\
\boldsymbol{M}_{\boldsymbol{R}}=\mathbf{2 1 9 , 7 1} \boldsymbol{k N} \cdot \boldsymbol{m} \\
z_{s}=0,217 \mathrm{~m} \\
y_{s}=0,015 \mathrm{~m} \\
x_{s}=0,019 \mathrm{~m}
\end{gathered}
$$

Lembrando que o índice s equivale ao equilíbrio da seção composta, considerando tração na armadura passiva.

\begin{tabular}{l}
\hline \multicolumn{1}{c}{$\mathbf{A}_{\mathbf{s}} \mathbf{e} \boldsymbol{\rho}_{\mathbf{1}}$} \\
\hline$A_{s}=\frac{M_{4,2}}{Z \cdot f_{y k}}=\frac{212,63}{0,217.500000}=0,001956 \mathrm{~m}^{2}=19,56 \mathrm{~cm}^{2}$ \\
$\rho_{1}=\frac{A_{s}}{b_{w} \cdot d}=\frac{19,56}{44.23} \cong 0,02 \Rightarrow \rho_{1}=0,02$ \\
Portanto, o cálculo iterativo para a taxa de armadura, além de ter funcionado, ficou limitado ao \\
valor de 0,02.
\end{tabular}

\section{Verificação de compressão da borda inferior}

Tensão de compressão em função da atuação do momento fletor negativo.

$K M D=\frac{M_{d}}{b_{w, i} \cdot d^{2} \cdot f_{c d}}=\frac{M_{4,2}}{b_{w} \cdot d^{2} \cdot f_{c k}}=\frac{212,63}{1,981 \cdot 0,23^{2} \cdot \frac{40000}{1,0}}=0,0507$

$K X=\frac{x}{d}=\frac{0,019}{0,23}=0,0826$

$K X_{2,3}=\frac{3,5}{3,5+10,0}=0,2593$

Como $\mathrm{KX}<\mathrm{KX}_{2,3} \rightarrow \varepsilon_{s}=10,00 \%$

Ver tabela de KMD de CARVALHO (2012) no ANEXO A.

Portanto: DOMÍNIO 2.

Logo:

$$
K X=\frac{\varepsilon_{c}}{\varepsilon_{c}+\varepsilon_{s}} \Rightarrow \varepsilon_{c}=\frac{K X * \varepsilon_{s}}{(1-K X)}=\frac{0,0826 * 10,0}{(1-0,0826)}=0,90 \%
$$

Valor de $\varepsilon_{\mathrm{c}}$ confere com a da tabela de KMD, anteriormente citada.

Tensão de compressão em função da protensão.

$$
\varepsilon_{c p}=\varepsilon_{7}=\frac{1}{E_{c}}\left(\frac{N_{p}}{A_{c}}+\frac{M_{p} \cdot e_{p}}{I}\right)
$$

Sendo:

- $N_{p}$ é a força total de protensão, considerando as perdas calculadas anteriormente;

- $A_{c}$ é a área da seção transversal da laje alveolar;

- $e_{p}$ é a excentricidade da armadura ativa, com relação ao centro de gravidade da seção transversal;

$-M_{p}$ é o momento devido à força de protensão; 
$-I$ é o momento de inércia da seção transversal;
$-E_{c}$ é o módulo de elasticidade secante do concreto.
$-N_{p}=\sigma_{p t, \infty} * A_{p}=107,665 * 8,91=959,29 \mathrm{kN}$
$-M_{p}=N_{p} * e_{p}=959,29 * 0,0734=70,41 \mathrm{kN} \cdot \mathrm{m}$
$-E_{c s}=0,85 * E_{c i}=0,85 * 35418=30105 \mathrm{MPa}=30105000 \mathrm{kN} \cdot \mathrm{m}^{2}$
$\varepsilon_{7}=\left[\frac{N_{p}}{A_{c}}+\frac{M_{p} * e_{p}}{I}\right] \cdot \frac{1}{E_{c s}}=\left[\frac{959,29}{0,2357}+\frac{70,41 * 0,0734}{0,0013}\right] \cdot \frac{1}{30105000}=0,000267=0,27 \%$

Tensão total de compressão.

$\varepsilon_{t}=\varepsilon_{c p}+\varepsilon_{c}=0,90+0,27=1,17 \%$

Como $\varepsilon_{\mathrm{t}}<3,5 \%$, está feita a condição quanto à compressão excessiva na borda inferior do concreto.

Logo, a armadura considerada é $A_{s}=19,56 \mathrm{~cm}^{2}$, limitada pela verificação da tensão de cisalhamento. Portanto, serão utilizadas $17 \varnothing 12,5 \mathrm{~mm}$, totalizando $A_{s}=20,86 \mathrm{~cm}^{2}$.

O momento de fissuração $\left(M_{r}\right)$ deve ser calculado como o exposto no item 3.7.6. Devem ser calculados os momentos de fissuração da capa e da laje alveolar. Esses cálculos são apresentados na Tabela 3.27 e foram feitos considerando que o efeito da protensão atua somente na seção simples.

Tabela 3.27 - Cálculo do momento de fissuração - EM1.

\begin{tabular}{|c|c|c|}
\hline Seção & Equação & Comentários \\
\hline \multirow[b]{2}{*}{ Capa } & $\begin{array}{c}M_{r}=\frac{\alpha \cdot f_{c t} \cdot I_{C}}{y_{t}} \\
M_{r}=\frac{1,5 \cdot 2027 \cdot 0,0024}{0,1143} \\
M_{r}=63,84 \mathrm{kN} \cdot \mathrm{m}\end{array}$ & $\begin{array}{l}\text { Formação de } \\
\text { fissura. }\end{array}$ \\
\hline & $\begin{array}{c}M_{r}=\frac{\alpha \cdot f_{c t} \cdot I_{C}}{y_{t}} \\
M_{r}=\frac{1,5 \cdot 2896 \cdot 0,0024}{0,1143} \\
M_{r}=91,21 \mathrm{kN} \cdot \mathrm{m}\end{array}$ & $\begin{array}{c}\text { Deformação } \\
\text { excessiva. }\end{array}$ \\
\hline \multirow[t]{2}{*}{ Laje } & $\begin{array}{c}M_{r}=\frac{\alpha \cdot f_{c t} \cdot I_{c}}{y_{t}}+\frac{N_{s k, p t, \infty} I_{c}}{A \cdot y_{t}}+N_{s k, p t, \infty} e \\
M_{r}=\frac{1,5 \cdot 2456 \cdot 0,0024}{0,1457}+\frac{959,30 \cdot 0,0013}{0,2357 \cdot 0,1084}+959,30 \cdot 0,0734 \\
M_{r}=60,68+48,81+70,41 \\
M_{r}=179,90 \mathrm{kN} \cdot \mathrm{m}\end{array}$ & $\begin{array}{l}\text { Formação de } \\
\text { fissura. }\end{array}$ \\
\hline & $\begin{array}{c}M_{r}=\frac{\alpha \cdot f_{c t} \cdot I_{c}}{y_{t}}+\frac{N_{s k, p t, \infty} I_{c}}{A \cdot y_{t}}+N_{s k, p t, \infty} e \\
M_{r}=\frac{1,5 \cdot 3509 \cdot 0,0024}{0,1457}+\frac{959,30 \cdot 0,0013}{0,2357 \cdot 0,1084}+959,30.0,0734 \\
M_{r}=86,70+48,81+70,41 \\
M_{r}=205,92\end{array}$ & $\begin{array}{c}\text { Deformação } \\
\text { excessiva. }\end{array}$ \\
\hline
\end{tabular}


De posse do momento de fissuração, é possível determinar qual é o valor da carga $\mathrm{F}_{2}$ correspondente. Para isso, tem-se a Tabela 3.28.

Para calcular o valor do carregamento $F_{2}$ correspondente ao momento de fissuração $\left(\mathrm{M}_{\mathrm{r}}\right)$ na capa é necessário igualar este momento ao momento negativo para o qual provavelmente ocorrerá a fissuração, ou seja, na seção de centro de giro do apoio, conforme a Figura 3.15. Logo: $M_{r}=M_{4,2}$.

Com relação à fissuração na laje alveolar, o valor de $\mathrm{Mr}_{\mathrm{r}}$ deve ser igualado ao

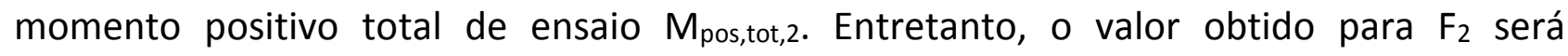
calculado de forma simplificada, uma vez que, quando há fissuração na capa, o comportamento do modelo passa a ser regido pela não linearidade física, ou seja, ocorre diminuição do momento negativo e, consequentemente, aumento do momento positivo. Portanto, o valor real de $F_{2}$, para este caso, deverá ser menor do que o calculado.

Tabela 3.28 - Valores de $F_{2}$ correspondentes a Mr - EM1.

\begin{tabular}{|c|c|c|}
\hline Seção & Equação & Comentários \\
\hline \multirow[b]{2}{*}{ Capa } & $\begin{array}{c}M_{r}=M_{4,2} \Rightarrow M_{4,1}=M_{4,2} \cdot \frac{1,225}{1,025}=63,84 \cdot \frac{1,225}{1,025} \\
M_{4,1}=76,30 \mathrm{kN} \cdot \mathrm{m} \\
M_{4,1}=K 1 \cdot F_{2} \cdot l=0,192324 . F_{2} \cdot 4,82 \\
76,30=0,192324 . F_{2} \cdot 4,82 \\
F_{2}=82,31 \mathrm{kN}=8,23 \mathrm{tf}\end{array}$ & $\begin{array}{c}\text { Formação de } \\
\text { fissuração. } \\
\text { Momento negativo } \\
\text { na ligação. }\end{array}$ \\
\hline & $\begin{array}{c}M_{r}=M_{4,2} \Rightarrow M_{4,1}=M_{4,2} \cdot \frac{1,225}{1,025}=91,21 \cdot \frac{1,225}{1,025} \\
M_{4,1}=109,01 \mathrm{kN} \cdot \mathrm{m} \\
M_{4,1}=K 1 \cdot F_{2} \cdot l=0,192324 \cdot F_{2} \cdot 4,82 \\
109,01=0,192324 . F_{2} \cdot 4,82 \\
F_{2}=117,59 \mathrm{kN}=11,76 \mathrm{tf}\end{array}$ & $\begin{array}{c}\text { Deformação } \\
\text { excessiva. } \\
\text { Momento negativo } \\
\text { na ligação. }\end{array}$ \\
\hline \multirow[t]{2}{*}{ Laje } & $\begin{array}{c}M_{r}=M_{\text {pos }, t o t, 2}=M_{1}+M_{3} \\
179,90=K 2 \cdot F_{2} \cdot l+\frac{\left(g_{1}+g_{2}\right) \cdot l^{2}}{8} \\
179,90=0,137344 \cdot F_{2} \cdot 4,82+\frac{(5,89+2,5) \cdot 4,82^{2}}{8} \\
179,90=0,137344 \cdot F_{2} \cdot 4,82+24,36 \\
F_{2}=234,96 \mathrm{kN}=23,50 \mathrm{tf}\end{array}$ & $\begin{array}{l}\text { Formação de } \\
\text { fissuração. } \\
\text { Momento positivo } \\
\text { no meio da laje. }\end{array}$ \\
\hline & $\begin{array}{c}M_{r}=M_{\text {pos }, t o t, 2}=M_{1}+M_{3} \\
205,92=K 2 \cdot F_{2} \cdot l+\frac{\left(g_{1}+g_{2}\right) \cdot l^{2}}{8} \\
205,92=0,137344 \cdot F_{2} \cdot 4,82+\frac{(5,89+2,5) \cdot 4,82^{2}}{8} \\
205,92=0,137344 \cdot F_{2} \cdot 4,82+24,36 \\
F_{2}=274,26 \mathrm{kN}=27,43 \mathrm{tf}\end{array}$ & $\begin{array}{c}\text { Deformação } \\
\text { excessiva. } \\
\text { Momento positivo } \\
\text { no meio da laje. }\end{array}$ \\
\hline
\end{tabular}




\subsection{2 - Cálculo da armadura de continuidade para os demais ensaios}

Seguindo o modelo de cálculo apresentado no item 3.8.1, foram calculadas as armaduras de continuidade $\left(A_{s}\right)$ paras os ensaios EM2 e EM3. A Tabela 3.29 mostra os resultados alcançados, reapresentando os resultados do ensaio EM1.

Tabela 3.29 - Armadura de continuidade calculadas para os ensaios EM1, EM2 e EM3.

\begin{tabular}{|c|c|c|c|}
\hline Variável & EM1 & EM2 & EM3 \\
\hline $\mathrm{g}_{1}(\mathrm{kN} / \mathrm{m})$ & 5,89 & 4,67 & 2,92 \\
\hline $\mathrm{g}_{2}(\mathrm{kN} / \mathrm{m})$ & 2,50 & 1,5 & 1,5 \\
\hline $\begin{array}{l}1(\mathrm{~m}) \\
\text { (vão) }\end{array}$ & 4,82 & 4,82 & 4,82 \\
\hline $\begin{array}{c}\sigma_{p t, \infty}(\mathrm{MPa}) \\
\text { Isoladas }\end{array}$ & 1076,65 & 866,63 & 1167,40 \\
\hline Armadura ativa & $9 \varnothing 12,7$ & $10 \varnothing 12,7$ & $\begin{array}{c}8 \varnothing 6,4 \mathrm{e} \\
1 \varnothing 9,5\end{array}$ \\
\hline $\begin{array}{c}M_{R} \text { (kN.m) } \\
\text { (Positivo) }\end{array}$ & 327,44 & 445,55 & 79,30 \\
\hline$M_{1}(\mathrm{kN} . \mathrm{m})$ & 24,36 & 18,06 & 12,84 \\
\hline$M_{2}(\mathrm{kN} . \mathrm{m})$ & 303,12 & 427,49 & 66,46 \\
\hline$F_{1}(\mathrm{kN})$ & $251,55(25,16 \mathrm{tf})$ & $\begin{array}{c}354,76 \\
(35,48 \mathrm{tf}) \\
\end{array}$ & $\begin{array}{c}55,15 \\
(5,52 \mathrm{tf}) \\
\end{array}$ \\
\hline$M_{3}(\mathrm{kN} . \mathrm{m})$ & 303,12 & 427,49 & 66,46 \\
\hline$F_{2}(\mathrm{kN})$ & $\begin{array}{c}457,89 \\
(45,79 \text { tf) }\end{array}$ & $\begin{array}{c}645,76 \\
(64,58 \mathrm{tf}) \\
\end{array}$ & $\begin{array}{c}100,39 \\
(10,04 \mathrm{tf})\end{array}$ \\
\hline$F_{2} / F_{1}$ & 1,82 & 1,82 & 1,82 \\
\hline$M_{4,1}(\mathrm{kN} . \mathrm{m})$ & 424,46 & 598,62 & 93,06 \\
\hline$a(\mathrm{~m})$ & 0,14 & 0,085 & 0,19 \\
\hline$b(\mathrm{~m})$ & 0,13 & 0,1575 & 0,105 \\
\hline$l_{1}(\mathrm{~m})$ & 1,225 & 1,225 & 1,225 \\
\hline$M_{4,2}(\mathrm{kN} . \mathrm{m})$ & 355,16 & 500,87 & 77,87 \\
\hline $\begin{array}{c}M_{R}(\text { kN.m) } \\
\text { (Negativo) }\end{array}$ & 359,11 & 500,33 & 80,72 \\
\hline$z_{S}(\mathrm{~m})$ & 0,212 & 0,246 & 0,1745 \\
\hline
\end{tabular}




\begin{tabular}{|c|c|c|c|}
\hline FAIXA & $\begin{array}{c}25 \\
\text { (de baixo para cima) }\end{array}$ & $\begin{array}{c}50 \\
\text { (de baixo para cima) }\end{array}$ & $\begin{array}{c}15 \\
\text { (de baixo para cima) }\end{array}$ \\
\hline REGIÃO & Mesa inferior & Alvéolo & Mesa inferior \\
\hline$f_{y k}\left(\mathrm{kN} / \mathrm{m}^{2}\right)$ & 500000 & 500000 & 500000 \\
\hline$A_{S}\left(\mathrm{~cm}^{2}\right)$ & 33,51 & 40,72 & 8,92 \\
\hline$d(\mathrm{~m})$ & 0,225 & 0,285 & 0,180 \\
\hline$b_{w}(\mathrm{~m})$ & 0,440 & 0,285 & 0,308 \\
\hline$v$ & 0,50 & 0,50 & 0,50 \\
\hline$V_{R d 2}(\mathrm{kN})$ & 891,00 & 859,61 & 498,96 \\
\hline$\tau_{R d}\left(\mathrm{kN} / \mathrm{m}^{2}\right)$ & 614,00 & 614,00 & 614,00 \\
\hline$k$ & 1,375 & 1,315 & 1,420 \\
\hline$\rho_{1}$ & 0,0331 & 0,05049 & 0,01609 \\
\hline$N_{s k, p t, \infty}(\mathrm{kN})$ & 959,30 & 857,93 & $356,53(*)$ \\
\hline$\sigma_{c p}\left(\mathrm{kN} / \mathrm{m}^{2}\right)$ & 4070,00 & 3484,7 & 3057,72 \\
\hline$V_{R d 1}(\mathrm{kN})$ & 227,60 & 172,33 & 114,54 \\
\hline$F_{2, Q}(\mathrm{kN})$ & $\begin{array}{c}274,13 \\
(27,41 \mathrm{tf})\end{array}$ & $\begin{array}{c}207,98 \\
(20,80 \mathrm{tf})\end{array}$ & $\begin{array}{c}137,33 \\
(13,73 \mathrm{tf})\end{array}$ \\
\hline$F_{2} / F_{1}$ & 1,09 & 0,59 & 2,49 \\
\hline Menor valor & $F_{2, Q}$ & $F_{2, Q}$ & $F_{2}$ (flexão) \\
\hline$M_{4,1}(\mathrm{kN} . \mathrm{m})$ & 254,12 & 192,80 & idem \\
\hline$M_{4,2}(\mathrm{kN} . \mathrm{m})$ & 212,63 & 161,32 & idem \\
\hline $\begin{array}{c}M_{R}(\mathbf{k N} . m) \\
\text { (Negativo) }\end{array}$ & 219,71 & 156,20 & idem \\
\hline$z_{S}(\mathrm{~m})$ & 0,217 & 0,263 & idem \\
\hline FAIXA & $\begin{array}{c}15 \\
\text { (de baixo para cima) }\end{array}$ & $\begin{array}{c}14 \\
\text { (de baixo para cima) }\end{array}$ & idem \\
\hline REGIÃO & Mesa inferior & Mesa inferior & idem \\
\hline$f_{y k}\left(\mathrm{kN} / \mathrm{m}^{2}\right)$ & 500000 & 500000 & $595000(* *)$ \\
\hline$A_{S}\left(\mathbf{c m}^{2}\right)$ & 19,56 & 12,26 & 6,50 (***) \\
\hline
\end{tabular}




\begin{tabular}{|c|c|c|c|}
\hline$\rho_{1}$ & 0,02 & 0,01509 & 0,01127 \\
\hline$N^{\circ}$ DE BARRAS & $17 ø 12,5$ mm & $\begin{array}{c}11 \emptyset 12,5 \mathrm{~mm} \\
(* * * *)\end{array}$ & $5 \emptyset 12,5 \mathrm{~mm}(* * *)$ \\
\hline$\varepsilon_{c p}+\varepsilon_{c}(\% \circ)$ & 1,17 & 0,96 & 0,88 \\
\hline Dimensionamento & $\begin{array}{l}\text { Limitado pelo } \\
\text { cisalhamento }\end{array}$ & $\begin{array}{l}\text { Limitado pelo } \\
\text { cisalhamento }\end{array}$ & $\begin{array}{l}\text { Limitado pela } \\
\text { flexão }\end{array}$ \\
\hline $\begin{array}{l}M_{r, \text { capa }}(\mathrm{kN} . \mathrm{m}) \\
\text { Formação de Fissuras }\end{array}$ & 63,84 & 56,50 & 25,55 \\
\hline $\begin{array}{c}M_{r, \text { capa }}(\mathrm{kN} . \mathrm{m}), \\
\text { Deformação Excessiva }\end{array}$ & 91,21 & 80,72 & 36,50 \\
\hline $\begin{array}{l}M_{r, l a j e}(\mathrm{kN} . \mathrm{m}) \\
\text { Formação de Fissuras }\end{array}$ & 179,90 & 194,12 & 58,67 \\
\hline $\begin{array}{c}M_{r, l a j e}(\mathrm{kN} . \mathrm{m}) \\
\text { Deformação Excessiva }\end{array}$ & 205,92 & 223,28 & 69,68 \\
\hline $\begin{array}{c}F_{2, c a p a}(\mathrm{kN}) \\
\text { Formação de Fissuras }\end{array}$ & $\begin{array}{c}82,31 \\
(8,23 \mathrm{tf})\end{array}$ & $\begin{array}{c}72,84 \\
(7,28 \mathrm{tf})\end{array}$ & $\begin{array}{c}32,94 \\
(3,29 \mathrm{tf})\end{array}$ \\
\hline $\begin{array}{c}F_{2, \text { capa }}(\mathrm{kN}), \\
\text { Deformação Excessiva }\end{array}$ & $\begin{array}{c}117,59 \\
(11,76 \mathrm{tf})\end{array}$ & $\begin{array}{c}104,07 \\
(10,41 \mathrm{tf})\end{array}$ & $\begin{array}{c}47,05 \\
(4,71 \mathrm{tf})\end{array}$ \\
\hline $\begin{array}{c}F_{2, \text { laje }}(\mathrm{kN}), \\
\text { Formação de Fissuras. }\end{array}$ & $\begin{array}{c}234,96 \\
(23,50 \mathrm{tf})\end{array}$ & $\begin{array}{c}256,44 \\
(25,64 \mathrm{tf})\end{array}$ & $\begin{array}{c}69,23 \\
(6,92 \mathrm{tf})\end{array}$ \\
\hline $\begin{array}{c}F_{2, \text { laje }}(\mathrm{kN}) \\
\text { Deformação Excessiva }\end{array}$ & $\begin{array}{c}274,26 \\
(27,43 \mathrm{tf})\end{array}$ & $\begin{array}{c}300,48 \\
(30,05 \mathrm{tf})\end{array}$ & $\begin{array}{c}85,86 \\
(8,59 \mathrm{tf})\end{array}$ \\
\hline
\end{tabular}

$(*)$ Considerou-se:

Perdas da armadura inferior como calculado no item 3.5 e Tabela 3.15;

Perdas da armadura superior, adotando $10 \%$.

$N_{s k, p t, \infty}=49,5+307,03=356,53 \mathrm{kN}$

$\left(^{* *}\right) \mathrm{Na}$ época do ensaio do modelo 3 (EM3), já se conhecia os resultados da caracterização das barras da armadura passiva. Portanto, optou-se por adotar para o cálculo da armadura de continuidade $\left(A_{s}\right)$ o valor da tensão de escoamento $f_{y k}=$ igual à $595 \mathrm{MPa}$. Com isso obteve-se $A_{s}=7,50 \mathrm{~cm}^{2}$.

${ }^{(* * *)}$ Por questão de simetria, preferiu-se utilizar $5 \varnothing 12,5 \mathrm{~mm}$, totalizando $A_{s}=6,25 \mathrm{~cm}^{2}$.

$(* * *)$ Por questão de simetria, preferiu-se utilizar $11 \varnothing 12,5 \mathrm{~mm}$, totalizando $A_{s}=13,75 \mathrm{~cm}^{2}$.

\subsection{3 - Previsão do que acontecerá nos ensaios}

A Tabela 3.30 apresenta um resumo da Tabela 3.29, enfatizando os possíveis valores de carregamento $\left(F_{2}\right)$ e de momentos fletores que poderão ocorrer nos ensaios. Todos os cálculos foram feitos considerando a linearidade física do material. Não foi considerada a fissuração do modelo. Isso será feito posteriormente no capítulo 6 . 
Tabela 3.30 - Previsão de carregamentos para os ensaios EM1, EM2 e EM3.

\begin{tabular}{|c|c|c|c|c|}
\hline Variável & Comentários & EM1 & EM2 & EM3 \\
\hline $\begin{array}{c}F_{2, \text { capa }}(\mathrm{kN}), \\
\text { Formação de Fissuras }\end{array}$ & \multirow{2}{*}{$\begin{array}{c}\text { Fissuração da } \\
\text { capa. Atuação } \\
\text { do momento } \\
\text { negativo }\end{array}$} & $\begin{array}{c}117,59 \\
(11,76 \mathrm{tf})\end{array}$ & $\begin{array}{c}72,84 \\
(7,28 \mathrm{tf})\end{array}$ & $\begin{array}{c}32,94 \\
(3,29 \mathrm{tf})\end{array}$ \\
\hline $\begin{array}{c}M_{r, \text { capa }}(\mathrm{kN} . \mathrm{m}), \\
\text { Formação de Fissuras }\end{array}$ & & 63,84 & 56,50 & 25,55 \\
\hline $\begin{array}{c}F_{2, l a j e}(\mathrm{kN}), \\
\text { Formação de Fissuras }\end{array}$ & \multirow{2}{*}{$\begin{array}{c}\text { Fissuração da } \\
\text { laje. Atuação } \\
\text { do momento } \\
\text { positivo. }\end{array}$} & $\begin{array}{c}234,96 \\
(23,50 \mathrm{tf})\end{array}$ & $\begin{array}{c}256,44 \\
(25,64 \mathrm{tf})\end{array}$ & $\begin{array}{c}69,23 \\
(6,92 \mathrm{tf})\end{array}$ \\
\hline $\begin{array}{l}M_{r, l a j e}(\mathrm{kN} . \mathrm{m}), \\
\text { Formação de Fissuras }\end{array}$ & & 179,90 & 194,12 & 58,67 \\
\hline$F_{2, Q}(\mathrm{kN})$ & \multirow{7}{*}{$\begin{array}{l}\text { Ruptura no } \\
\text { ensaio de } \\
\text { continuidade }\end{array}$} & $\begin{array}{c}274,13 \\
(27,41 \mathrm{tf})\end{array}$ & $\begin{array}{c}207,98 \\
(20,80 \mathrm{tf})\end{array}$ & - \\
\hline$F_{2}(\mathrm{kN})$ & & - & - & $\begin{array}{c}100,39 \\
(10,04 \mathrm{tf})\end{array}$ \\
\hline Ensaio & & $\begin{array}{l}\text { Limitado } \\
\text { pelo } \\
\text { cisalhamento }\end{array}$ & $\begin{array}{c}\text { Limitado } \\
\text { pelo } \\
\text { cisalhamento }\end{array}$ & $\begin{array}{c}\text { Limitado } \\
\text { pela } \\
\text { flexão }\end{array}$ \\
\hline$M_{1}(\mathrm{kN} . \mathrm{m})$ & & 24,36 & 18,06 & 12,84 \\
\hline$M_{3}(\mathrm{kN} . \mathrm{m})$ & & 303,12 & 427,49 & 66,46 \\
\hline$M_{4,1}(\mathrm{kN} . \mathrm{m})$ & & 254,12 & 192,80 & 93,06 \\
\hline$M_{4,2}(\mathrm{kN} . \mathrm{m})$ & & 212,63 & 161,32 & 77,87 \\
\hline$M_{1}(\mathrm{kN} . \mathrm{m})$ & \multirow{3}{*}{$\begin{array}{c}\text { Ruptura no } \\
\text { ensaio } \\
\text { biapoiado, para } \\
\text { o mesmo vão. } \\
\text { Valor } \\
\text { hipotético para } \\
\text { comparação. }\end{array}$} & 24,36 & 18,06 & 12,84 \\
\hline$M_{2}(\mathrm{kN} . \mathrm{m})$ & & 303,12 & 427,49 & 66,46 \\
\hline$F_{1}(\mathrm{kN})$ & & $\begin{array}{c}251,55 \\
(25,16 \mathrm{tf})\end{array}$ & $\begin{array}{c}354,76 \\
(35,48 \mathrm{tf})\end{array}$ & $\begin{array}{c}55,15 \\
(5,52 \mathrm{tf})\end{array}$ \\
\hline$F_{2} / F_{1}$ & $\begin{array}{c}\text { Aumento real } \\
\text { da capacidade } \\
\text { portante. }\end{array}$ & $\begin{array}{c}1,09 \\
\text { cisalhamento }\end{array}$ & $\begin{array}{c}0,66 \\
\text { cisalhamento }\end{array}$ & $\begin{array}{c}1,82 \\
\text { flexão }\end{array}$ \\
\hline
\end{tabular}




\section{9 - Diagramas de iteração das lajes alveolares ensaiadas}

Determinados os valores das armaduras para os ensaios de continuidade, e, além disso, obtida a forma como se dará a ruptura do ensaio (cisalhamento ou flexão), é possível, através do equacionamento do item 3.7, obter resultados de esforços solicitantes para ensaios hipotéticos com diversos vãos.

\subsection{1 - EM1}

A Tabela 3.31 apresenta os resultados dos ensaios hipotéticos para o EM1, enquanto que a Tabela 3.32 indica o resumo das forças de ruptura. A Figura 3.22 mostra os resultados em forma de gráfico, para o mesmo ensaio.

Tabela 3.31 - Resultados de ensaios hipotéticos para a laje alveolar do EM1.

\begin{tabular}{|c|c|c|c|c|c|c|}
\hline $\boldsymbol{l}(\mathbf{m})$ & $\mathbf{3 , 7 5}$ & $\mathbf{5 , 0 0}$ & $\mathbf{6 , 2 5}$ & $\mathbf{7 , 5 0}$ & $\mathbf{8 , 7 5}$ & $\mathbf{1 0 , 0 0}$ \\
\hline $\mathrm{M}_{1}(\mathrm{kN} . \mathrm{m})$ & 14,75 & 26,22 & 40,97 & 58,99 & 80,29 & 104,88 \\
\hline $\mathrm{M}_{2}(\mathrm{kN} . \mathrm{m})$ & 312,69 & 301,22 & 286,47 & 268,45 & 247,15 & 222,57 \\
\hline $\mathrm{F}_{1}(\mathrm{kN})$ & 333,54 & 240,98 & 183,34 & 143,17 & 112,98 & 89,03 \\
\hline $\mathrm{M}_{3}(\mathrm{kN} . \mathrm{m})$ & 312,69 & 301,22 & 286,47 & 268,45 & 247,15 & 222,57 \\
\hline $\mathrm{F}_{2}(\mathrm{kN})$ & 533,66 & 385,56 & 293,35 & 229,08 & 180,77 & 142,44 \\
\hline $\mathrm{F}_{2} / \mathrm{F}_{1}$ & 1,60 & 1,60 & 1,60 & 1,60 & 1,60 & 1,60 \\
\hline $\mathrm{M}_{4,1}(\mathrm{kN} . \mathrm{m})$ & 375,23 & 361,47 & 343,77 & 322,14 & 296,57 & 267,08 \\
\hline$l_{l}(\mathrm{~m})$ & 1,024 & 1,365 & 1,706 & 2,048 & 2,389 & 2,730 \\
\hline $\mathrm{M}_{4,2}(\mathrm{kN} . \mathrm{m})$ & 301,93 & 308,50 & 303,47 & 290,67 & 271,74 & 247,51 \\
\hline $\begin{array}{c}\text { Região de } \\
\text { compressão }\end{array}$ & $\begin{array}{c}\text { Mesfa } \\
\text { inferior }\end{array}$ & $\begin{array}{c}\text { Mesa } \\
\text { inferior }\end{array}$ & $\begin{array}{c}\text { Mesa } \\
\text { inferior }\end{array}$ & $\begin{array}{c}\text { Mesa } \\
\text { inferior }\end{array}$ & $\begin{array}{c}\text { Mesa } \\
\text { inferior }\end{array}$ & $\begin{array}{c}\text { Mesa } \\
\text { Anferior }\end{array}$ \\
\hline $\mathrm{A}_{\mathrm{s}}\left(\mathrm{cm}{ }^{2}\right)$ & 28,16 & 28,77 & 28,30 & 27,04 & 25,22 & 22,87 \\
\hline$\rho_{1}($ calculado) & 0,02537 & 0,02576 & 0,02511 & 0,02375 & 0,02182 & 0,01939 \\
\hline$\rho_{1}($ adotado) & $0,01433 *$ & 0,02 & 0,02 & 0,02 & 0,02 & 0,02 \\
\hline $\mathrm{V}_{\mathrm{Rd} 1}(\mathrm{kN})$ & 208,64 & 227,60 & 227,60 & 227,60 & 227,60 & 227,60 \\
\hline $\mathrm{F}_{2, \mathrm{Q}}(\mathrm{kN})$ & 280,60 & 300,55 & 292,92 & 285,29 & 277,67 & 270,04 \\
\hline
\end{tabular}




\begin{tabular}{|c|c|c|c|c|c|c|}
\hline $\mathrm{F}_{2, \mathrm{Q}} / \mathrm{F}_{1}$ & 0,84 & 1,25 & 1,59 & 1,99 & 2,46 & 3,03 \\
\hline $\mathrm{F}_{2}$ (adotado) & 280,60 & 300,55 & 292,93 & 229,08 & 180,08 & 142,44 \\
\hline $\mathrm{F}_{2} / \mathrm{F}_{1}(\mathrm{real})$ & 0,84 & 1,25 & 1,59 & 1,60 & 1,60 & 1,60 \\
\hline $\mathrm{M}_{4,1}(\mathrm{kN} . \mathrm{m})$ & 197,30 & 281,76 & 343,27 & 322,14 & 296,57 & 267,08 \\
\hline $\mathrm{M}_{4,2}(\mathrm{kN} . \mathrm{m})$ & 158,75 & 240,48 & 303,03 & 290,67 & 271,74 & 247,51 \\
\hline $\mathrm{A}_{\mathrm{s}}\left(\mathrm{cm}^{2}\right)$ & 14,50 & 22,17 & 28,26 & 27,04 & 25,22 & 22,81 \\
\hline$\rho_{1}(\mathrm{calculado})$ & $0,01433 *$ & 0,02190 & 0,02792 & 0,02672 & 0,02492 & 0,02254 \\
\hline $\mathrm{A}_{\mathrm{p}}\left(\mathrm{cm}{ }^{2}\right)$ & 8,91 & 8,91 & 8,91 & 8,91 & 8,91 & 8,91 \\
\hline$\rho_{1}(\mathrm{calculado})$ & 0,008804 & 0,008804 & 0,008804 & 0,008804 & 0,008804 & 0,008804 \\
\hline $\mathrm{V}_{\mathrm{Rd} 1 \mathrm{~F} 1 \mathrm{Q}}(\mathrm{kN})$ & 190,17 & 190,17 & 190,17 & 190,17 & 190,17 & 190,17 \\
\hline $\mathrm{F}_{1, \mathrm{Q}}(\mathrm{kN})$ & 348,878 & 338,39 & 327,42 & 317,42 & 306,93 & 296,44 \\
\hline
\end{tabular}

* Obtido por iteração até o valor final $\rho_{1}$ (calculado2) ser igual ao adotado $\rho_{1}$ (adotado).

Tabela 3.32 - Forças de ruptura para a laje alveolar do EM1.

\begin{tabular}{|c|c|c|c|c|c|c|}
\hline $\boldsymbol{l}(\mathbf{m})$ & $\mathbf{F}_{\mathbf{1}}(\mathbf{k N})$ & $\mathbf{F}_{\mathbf{1}, \mathbf{Q}}(\mathbf{k N})$ & $\mathbf{F}_{\mathbf{2}}(\mathbf{k N})$ & $\mathbf{F}_{2, \mathbf{Q}}(\mathbf{k N})$ & $\mathbf{F}_{2, \mathbf{E}}(\mathbf{k N})$ & $\mathbf{F}_{\mathbf{2}} / \mathbf{F}_{\mathbf{1}}$ \\
\hline 3,75 & 333,54 & 348,88 & 533,66 & 280,60 & 280,60 & 0,84 \\
\hline 5,00 & 240,98 & 338,39 & 385,56 & 300,55 & 300,55 & 1,25 \\
\hline 6,25 & 183,34 & 327,90 & 293,35 & 292,92 & 292,92 & 1,59 \\
\hline 7,50 & 143,17 & 317,42 & 229,08 & 285,29 & 229,08 & 1,60 \\
\hline 8,75 & 112,98 & 306,93 & 180,77 & 277,67 & 180,77 & 1,60 \\
\hline 10,00 & 89,03 & 296,44 & 142,44 & 270,04 & 142,44 & 1,60 \\
\hline
\end{tabular}

$F_{1}$ é a força aplicada no meio do vão, em ensaio de laje simplesmente apoiada em que a ruptura ocorre por flexão;

$\mathrm{F}_{1, \mathrm{Q}}$ é a força aplicada no meio do vão, em ensaio de laje simplesmente apoiada em que a ruptura ocorre (hipoteticamente) por cisalhamento;

$F_{2}$ é a força aplicada no meio do vão, em ensaio de continuidade em que a ruptura ocorre por flexão;

$F_{2, Q}$ é a força aplicada no meio do vão, em ensaio de continuidade em que a ruptura ocorre por cisalhamento; $F_{2, E}$ é a envoltória da força $F_{2}$, considerando a ruptura ora por flexão, ora por cisalhamento;

$V_{\mathrm{Rd} 1, F 1 \mathrm{O}}$ é a força cortante resistente relativa à força aplicada no meio do vão, em ensaio de laje simplesmente apoiada em que a ruptura ocorre (hipoteticamente) por cisalhamento. 


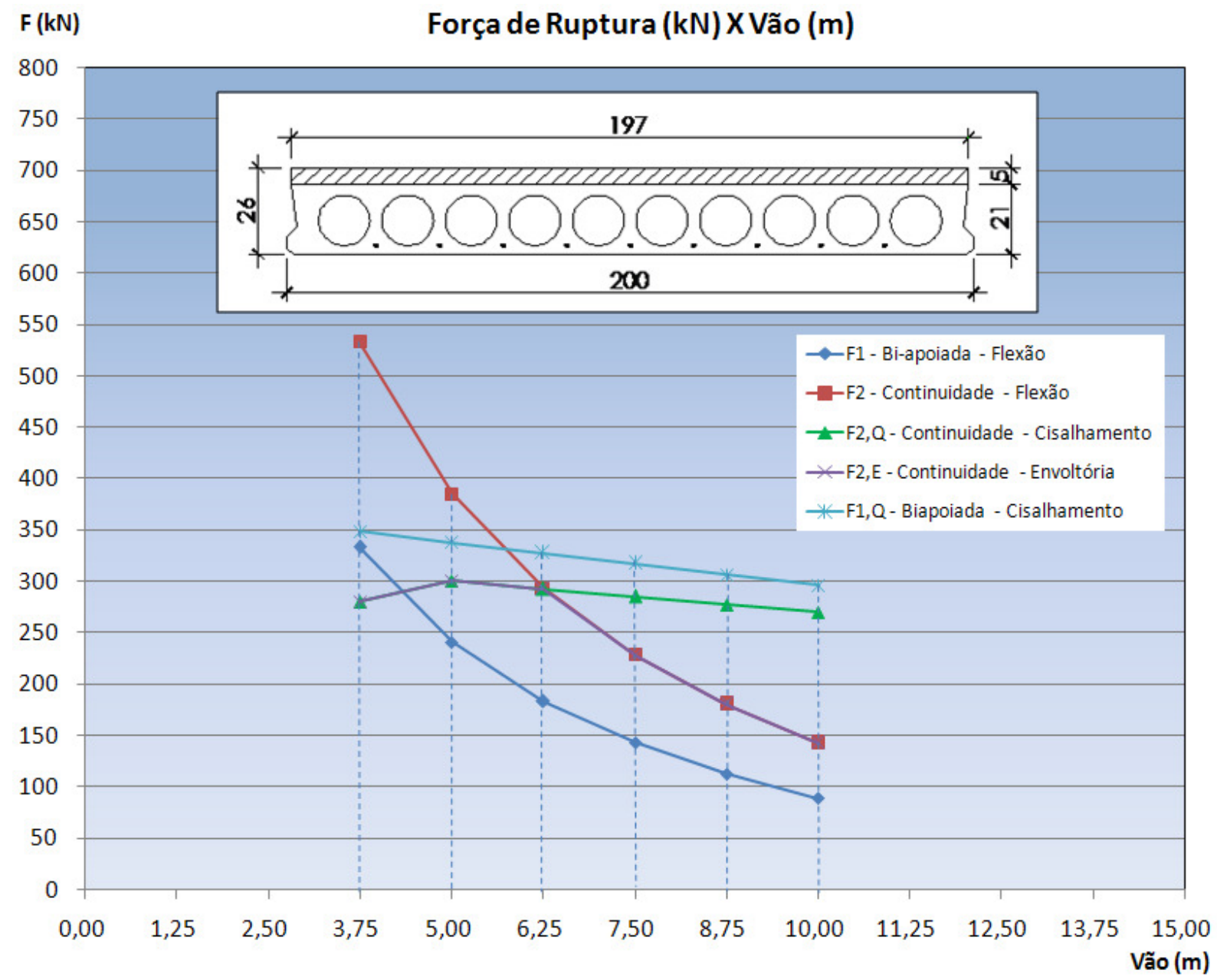

Figura 3.22 - Diagramas de iteração da laje alveolar utilizada no EM1.

\subsection{2- EM2}

A Tabela 3.33 apresenta os resultados dos ensaios hipotéticos para a laje alveolar utilizado no EM2, enquanto que a Tabela 3.34 indica o resumo das forças de ruptura. A Figura 3.23 mostra os resultados em forma de gráfico, para o mesmo ensaio.

Tabela 3.33 - Resultados de ensaios hipotéticos para a laje alveolar do EM2.

\begin{tabular}{|c|c|c|c|c|c|c|}
\hline $\boldsymbol{l}(\mathbf{m})$ & $\mathbf{3 , 7 5}$ & $\mathbf{5 , 0 0}$ & $\mathbf{6 , 2 5}$ & $\mathbf{7 , 5 0}$ & $\mathbf{8 , 7 5}$ & $\mathbf{1 0 , 0 0}$ \\
\hline $\mathrm{M}_{1}(\mathrm{kN} . \mathrm{m})$ & 10,95 & 19,47 & 30,42 & 43,80 & 59,62 & 77,88 \\
\hline $\mathrm{M}_{2}$ (kN.m) & 434,60 & 426,08 & 415,13 & 401,75 & 385,93 & 367,68 \\
\hline $\mathrm{F}_{1}(\mathrm{kN})$ & 463,57 & 340,87 & 265,68 & 214,26 & 176,42 & 147,07 \\
\hline $\mathrm{M}_{3}(\mathrm{kN} . \mathrm{m})$ & 434,60 & 426,08 & 415,13 & 401,75 & 385,93 & 367,68 \\
\hline $\mathrm{F}_{2}(\mathrm{kN})$ & 741,72 & 545,38 & 425,09 & 342,82 & 282,28 & 235,31 \\
\hline
\end{tabular}




\begin{tabular}{|c|c|c|c|c|c|c|}
\hline $\mathrm{F}_{2} / \mathrm{F}_{1}$ & 1,60 & 1,60 & 1,60 & 1,60 & 1,60 & 1,60 \\
\hline $\mathrm{M}_{4,1}(\mathrm{kN} . \mathrm{m})$ & 521,52 & 511,30 & 498,16 & 482,09 & 463,11 & 441,21 \\
\hline$l_{l}(\mathrm{~m})$ & 1,024 & 1,365 & 1,706 & 2,048 & 2,389 & 2,730 \\
\hline $\mathrm{M}_{4,2}(\mathrm{kN} \cdot \mathrm{m})$ & 419,63 & 436,38 & 439,76 & 435,00 & 424,34 & 408,89 \\
\hline $\begin{array}{l}\text { Região de } \\
\text { compressão }\end{array}$ & $\begin{array}{l}\text { Mesa } \\
\text { inferior }\end{array}$ & $\begin{array}{l}\text { Mesa } \\
\text { inferior }\end{array}$ & $\begin{array}{l}\text { Mesa } \\
\text { inferior }\end{array}$ & $\begin{array}{l}\text { Mesa } \\
\text { inferior }\end{array}$ & $\begin{array}{l}\text { Mesa } \\
\text { inferior }\end{array}$ & $\begin{array}{l}\text { Mesa } \\
\text { inferior }\end{array}$ \\
\hline $\mathrm{A}_{\mathrm{s}}\left(\mathrm{cm}^{2}\right)$ & 33,50 & 34,98 & 35,32 & 34,87 & 33,95 & 32,59 \\
\hline$\rho_{1}($ calculado $)$ & 0,041248 & 0,043066 & 0,043487 & 0,04293 & 0,041794 & 0,040128 \\
\hline$\rho_{1}$ (adotado) & $0,0104^{*}$ & $0,0167^{*}$ & 0,02 & 0,02 & 0,02 & 0,02 \\
\hline $\mathrm{V}_{\mathrm{Rd} 1}(\mathrm{kN})$ & 174,17 & 163,67 & 172,33 & 172,33 & 172,33 & 172,33 \\
\hline $\mathrm{F}_{2, \mathrm{Q}}(\mathrm{kN})$ & 197,04 & 215,41 & 222,34 & 216,68 & 211,01 & 205,35 \\
\hline $\mathrm{F}_{2, \mathrm{Q}} / \mathrm{F}_{1}$ & 0,43 & 0,63 & 0,84 & 1,01 & 1,20 & 1,40 \\
\hline $\mathrm{F}_{2}$ (adotado) & 197,04 & 215,41 & 222,34 & 216,68 & 211,01 & 205,35 \\
\hline $\mathrm{F}_{2} / \mathrm{F}_{1}(\mathrm{real})$ & 0,43 & 0,63 & 0,84 & 1,01 & 1,20 & 1,40 \\
\hline $\mathrm{M}_{4,1}(\mathrm{kN} . \mathrm{m})$ & 138,54 & 201,95 & 260,55 & 304,70 & 346,19 & 385,03 \\
\hline $\mathrm{M}_{4,2}(\mathrm{kN} . \mathrm{m})$ & 111,48 & 172,36 & 230,01 & 274,94 & 317,21 & 356,82 \\
\hline $\mathrm{A}_{\mathrm{s}}\left(\mathrm{cm}^{2}\right)$ & 8,41 & 13,16 & 17,73 & 21,35 & 24,83 & 28,15 \\
\hline$\rho_{1}$ (calculado2) & $0,0104^{*}$ & $0,0167^{*}$ & 0,02182 & 0,02629 & 0,03057 & 0,03466 \\
\hline $\mathrm{A}_{\mathrm{p}}\left(\mathrm{cm}^{2}\right)$ & 9,90 & 9,90 & 9,90 & 9,90 & 9,90 & 9,90 \\
\hline$\rho_{1}($ calculado $)$ & 0,012188 & 0,012188 & 0,012188 & 0,012188 & 0,012188 & 0,012188 \\
\hline $\mathrm{V}_{\mathrm{Rd1}, \mathrm{F} 1 \mathrm{Q}}(\mathrm{kN})$ & 151,84 & 151,84 & 151,84 & 151,84 & 151,84 & 151,84 \\
\hline $\mathrm{F}_{1, \mathrm{Q}}(\mathrm{kN})$ & 280,31 & 272,51 & 264,73 & 256,94 & 249,15 & 241,37 \\
\hline
\end{tabular}

* Obtido por iteração até o valor final $\rho_{1}$ (calculado2) ser igual ao $\rho_{1}$ (adotado).

Tabela 3.34 - Forças de ruptura para a laje alveolar do EM2.

\begin{tabular}{|c|c|c|c|c|c|c|}
\hline $\boldsymbol{l}(\mathbf{m})$ & $\mathbf{F}_{\mathbf{1}}(\mathbf{k N})$ & $\mathbf{F}_{\mathbf{1}, \mathbf{Q}}(\mathbf{k N})$ & $\mathbf{F}_{\mathbf{2}}(\mathbf{k N})$ & $\mathbf{F}_{2, \mathbf{Q}}(\mathbf{k N})$ & $\mathbf{F}_{2, \mathbf{E}}(\mathbf{k N})$ & $\mathbf{F}_{\mathbf{2}} / \mathbf{F}_{\mathbf{1}}$ \\
\hline 3,75 & 463,57 & 280,30 & 741,72 & 197,04 & 197,04 & 0,43 \\
\hline 5,00 & 340,87 & 272,52 & 545,38 & 215,41 & 215,41 & 0,63 \\
\hline
\end{tabular}




\begin{tabular}{|c|c|c|c|c|c|c|}
\hline 6,25 & 265,68 & 264,73 & 425,09 & 222,34 & 222,34 & 0,84 \\
\hline 7,50 & 214,26 & 256,94 & 342,82 & 216,68 & 216,68 & 1,01 \\
\hline 8,75 & 176,42 & 249,15 & 282,28 & 211,01 & 211,01 & 1,20 \\
\hline 10,00 & 147,07 & 241,37 & 235,31 & 205,35 & 205,35 & 1,40 \\
\hline
\end{tabular}

$F_{1}$ é a força aplicada no meio do vão, em ensaio de laje simplesmente apoiada em que a ruptura ocorre por flexão;

$\mathrm{F}_{1, \mathrm{Q}}$ é a força aplicada no meio do vão, em ensaio de laje simplesmente apoiada em que a ruptura ocorre (hipoteticamente) por cisalhamento;

$\mathrm{F}_{2}$ é a força aplicada no meio do vão, em ensaio de continuidade em que a ruptura ocorre por flexão;

$\mathrm{F}_{2, \mathrm{Q}}$ é a força aplicada no meio do vão, em ensaio de continuidade em que a ruptura ocorre por cisalhamento;

$F_{2, E}$ é a envoltória da força $F_{2}$, considerando a ruptura ora por flexão, ora por cisalhamento;

$V_{R d 1, F 1 Q}$ é a força cortante resistente relativa à força aplicada no meio do vão, em ensaio de laje simplesmente apoiada em que a ruptura ocorre (hipoteticamente) por cisalhamento.

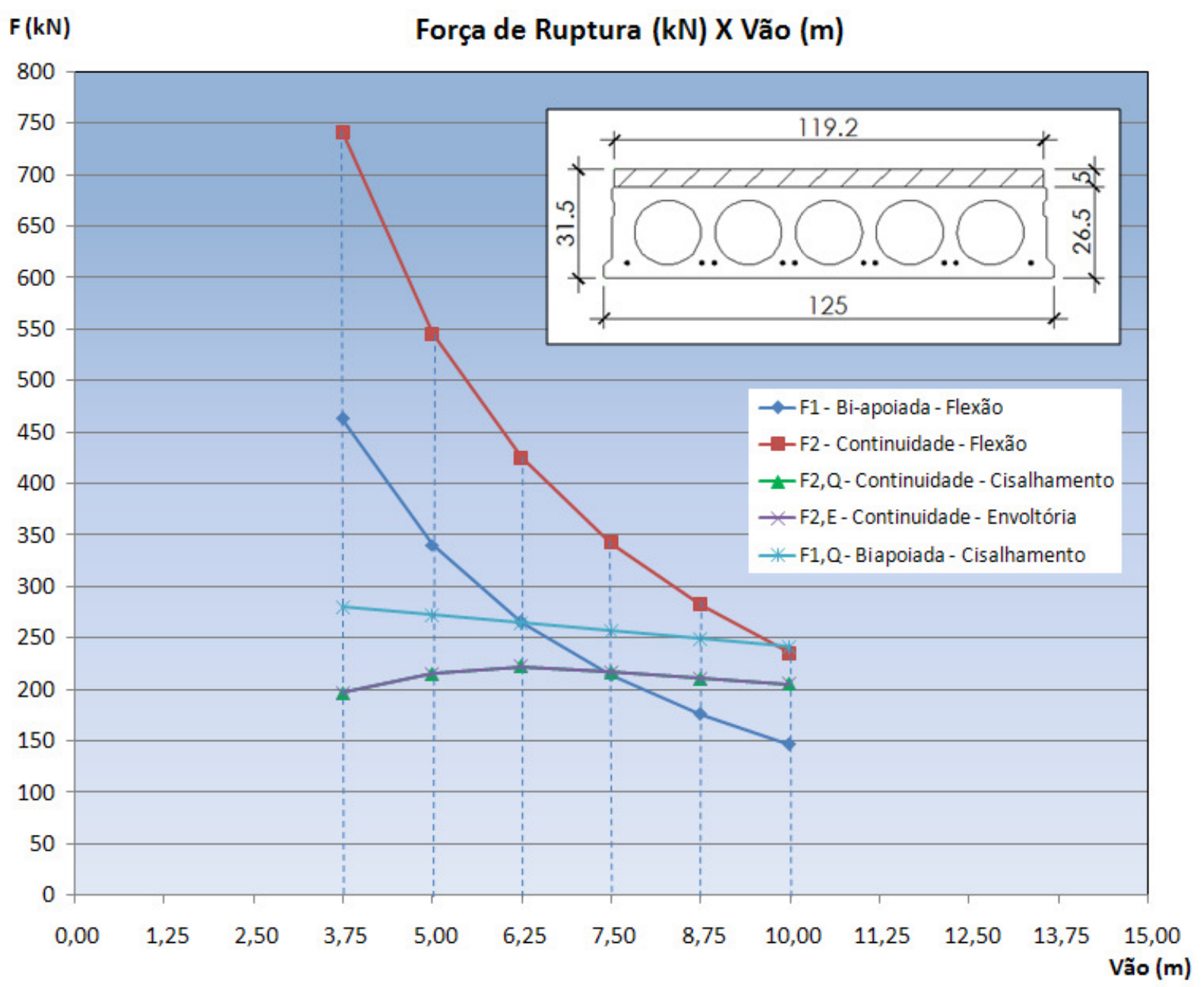

Figura 3.23 - Diagramas de iteração da laje alveolar utilizado no EM2. 


\subsection{3 - EM3}

A Tabela 3.35 apresenta os resultados dos ensaios hipotéticos para a laje alveolar utilizado no EM3, enquanto que a Tabela 3.36 indica o resumo das forças de ruptura. A Figura 3.24 mostra os resultados em forma de gráfico, para o mesmo ensaio.

Tabela 3.35 - Resultados de ensaios hipotéticos para a laje alveolar do EM3.

\begin{tabular}{|c|c|c|c|c|c|c|}
\hline$l(\mathbf{m})$ & 3,75 & 5,00 & 6,25 & 7,50 & 8,75 & 10,00 \\
\hline $\mathrm{M}_{1}(\mathrm{kN} . \mathrm{m})$ & 7,77 & 13,81 & 21,58 & 31,08 & 42,30 & 55,25 \\
\hline $\mathrm{M}_{2}(\mathrm{kN} . \mathrm{m})$ & 71,53 & 65,49 & 57,72 & 48,22 & 37,00 & 24,05 \\
\hline $\mathrm{F}_{1}(\mathrm{kN})$ & 76,30 & 52,39 & 36,94 & 25,72 & 16,91 & 9,62 \\
\hline $\mathrm{M}_{3}(\mathrm{kN} . \mathrm{m})$ & 71,53 & 65,49 & 57,72 & 48,22 & 37,00 & 24,05 \\
\hline $\mathrm{F}_{2}(\mathrm{kN})$ & 122,08 & 83,82 & 59,10 & 41,15 & 27,06 & 15,39 \\
\hline $\mathrm{F}_{2} / \mathrm{F}_{1}$ & 1,60 & 1,60 & 1,60 & 1,60 & 1,60 & 1,60 \\
\hline $\mathrm{M}_{4,1}(\mathrm{kN} . \mathrm{m})$ & 85,84 & 78,59 & 69,26 & 57,87 & 44,40 & 28,86 \\
\hline$l_{l}(\mathrm{~m})$ & 1,024 & 1,365 & 1,706 & 2,048 & 2,389 & 2,730 \\
\hline $\mathrm{M}_{4,2}(\mathrm{kN} . \mathrm{m})$ & 69,07 & 67,07 & 61,14 & 52,21 & 40,68 & 26,75 \\
\hline $\begin{array}{l}\text { Região de } \\
\text { compressão }\end{array}$ & $\begin{array}{l}\text { Mesa } \\
\text { inferior }\end{array}$ & $\begin{array}{c}\text { Mesa } \\
\text { inferior }\end{array}$ & $\begin{array}{c}\text { Mesa } \\
\text { inferior }\end{array}$ & $\begin{array}{c}\text { Mesa } \\
\text { inferior }\end{array}$ & $\begin{array}{c}\text { Mesa } \\
\text { inferior }\end{array}$ & $\begin{array}{c}\text { Mesa } \\
\text { inferior }\end{array}$ \\
\hline $\mathrm{A}_{\mathrm{s}}\left(\mathrm{cm}^{2}\right)$ & 7,87 & 7,64 & 6,96 & 5,92 & 4,60 & 3,01 \\
\hline$\rho_{1}$ (calculado) & 0,014197 & 0,013787 & 0,012561 & 0,010672 & 0,008291 & 0,005421 \\
\hline$\rho_{1}$ (adotado) & 0,014197 & 0,013787 & 0,012561 & 0,010672 & 0,008291 & 0,005421 \\
\hline $\mathrm{V}_{\mathrm{Rd} 1}(\mathrm{kN})$ & 110,88 & 110,09 & 107,72 & 104,07 & 99,46 & 93,91 \\
\hline $\mathrm{F}_{2, \mathrm{Q}}(\mathrm{kN})$ & 149,23 & 144,06 & 136,59 & 127,26 & 116,55 & 104,46 \\
\hline $\mathrm{F}_{2, \mathrm{Q}} / \mathrm{F}_{1}$ & 1,96 & 2,75 & 3,70 & 4,95 & 6,89 & 10,86 \\
\hline $\mathrm{F}_{2}$ (adotado) & 122,08 & 83,82 & 59,10 & 41,15 & 27,06 & 15,39 \\
\hline $\mathrm{F}_{2} / \mathrm{F}_{1}(\mathrm{real})$ & 1,60 & 1,60 & 1,60 & 1,60 & 1,60 & 1,60 \\
\hline $\mathrm{M}_{4,1}(\mathrm{kN} \cdot \mathrm{m})$ & 85,84 & 78,59 & 69,26 & 57,87 & 44,40 & 28,86 \\
\hline $\mathrm{M}_{4,2}(\mathrm{kN} \cdot \mathrm{m})$ & 69,07 & 67,07 & 61,14 & 52,21 & 40,68 & 26,75 \\
\hline $\mathrm{A}_{\mathrm{s}}\left(\mathrm{cm}^{2}\right)$ & 14,50 & 22,17 & 28,26 & 27,04 & 25,22 & 22,81 \\
\hline
\end{tabular}




\begin{tabular}{|c|c|c|c|c|c|c|}
\hline$\rho_{1}($ calculado2) & $-*$ & $-*$ & $-*$ & $-*$ & $-*$ & $-*$ \\
\hline $\mathrm{A}_{\mathrm{p}}\left(\mathrm{cm}^{2}\right)$ & 2,63 & 2,63 & 2,63 & 2,63 & 2,63 & 2,63 \\
\hline$\rho_{1}($ calculado) & 0,004744 & 0,004744 & 0,004744 & 0,004744 & 0,004744 & 0,004744 \\
\hline $\mathrm{V}_{\mathrm{Rd} 1, \mathrm{~F} 1 \mathrm{Q}}(\mathrm{kN})$ & 92,60 & 92,60 & 92,60 & 92,60 & 92,60 & 92,60 \\
\hline $\mathrm{F}_{1, \mathrm{Q}}(\mathrm{kN})$ & 168,63 & 163,11 & 157,58 & 152,06 & 146,53 & 141,01 \\
\hline
\end{tabular}

* Não houve necessidade de calcular $\rho_{1}$ (calculado2), pelo fato do dimensionamento ser governado pela flexão.

Tabela 3.36 - Forças de ruptura para a laje alveolar do EM3.

\begin{tabular}{|c|c|c|c|c|c|c|}
\hline $\boldsymbol{l}(\mathbf{m})$ & $\mathbf{F}_{\mathbf{1}}(\mathbf{k N})$ & $\mathbf{F}_{\mathbf{1}, \mathbf{Q}}(\mathbf{k N})$ & $\mathbf{F}_{\mathbf{2}}(\mathbf{k N})$ & $\mathbf{F}_{2, \mathbf{Q}}(\mathbf{k N})$ & $\mathbf{F}_{2, \mathbf{E}}(\mathbf{k N})$ & $\mathbf{F}_{2} / \mathbf{F}_{\mathbf{1}}$ \\
\hline 3,75 & 76,30 & 168,63 & 122,08 & 149,23 & 122,08 & 1,60 \\
\hline 5,00 & 52,39 & 163,11 & 83,82 & 144,06 & 83,82 & 1,60 \\
\hline 6,25 & 36,94 & 157,58 & 59,10 & 136,59 & 59,10 & 1,60 \\
\hline 7,50 & 25,72 & 152,06 & 41,15 & 127,26 & 41,15 & 1,60 \\
\hline 8,75 & 16,91 & 146,53 & 27,26 & 116,55 & 27,26 & 1,60 \\
\hline 10,00 & 9,62 & 141,01 & 15,39 & 104,46 & 15,39 & 1,60 \\
\hline
\end{tabular}

$F_{1}$ é a força aplicada no meio do vão, em ensaio de laje simplesmente apoiada em que a ruptura ocorre por flexão;

$\mathrm{F}_{1, \mathrm{Q}}$ é a força aplicada no meio do vão, em ensaio de laje simplesmente apoiada em que a ruptura ocorre (hipoteticamente) por cisalhamento;

$\mathrm{F}_{2}$ é a força aplicada no meio do vão, em ensaio de continuidade em que a ruptura ocorre por flexão;

$\mathrm{F}_{2, \mathrm{Q}}$ é a força aplicada no meio do vão, em ensaio de continuidade em que a ruptura ocorre por cisalhamento; $F_{2, E}$ é a envoltória da força $F_{2}$, considerando a ruptura ora por flexão, ora por cisalhamento;

$V_{\mathrm{Rd} 1, F 1 Q}$ é a força cortante resistente relativa à força aplicada no meio do vão, em ensaio de laje simplesmente apoiada em que a ruptura ocorre (hipoteticamente) por cisalhamento. 


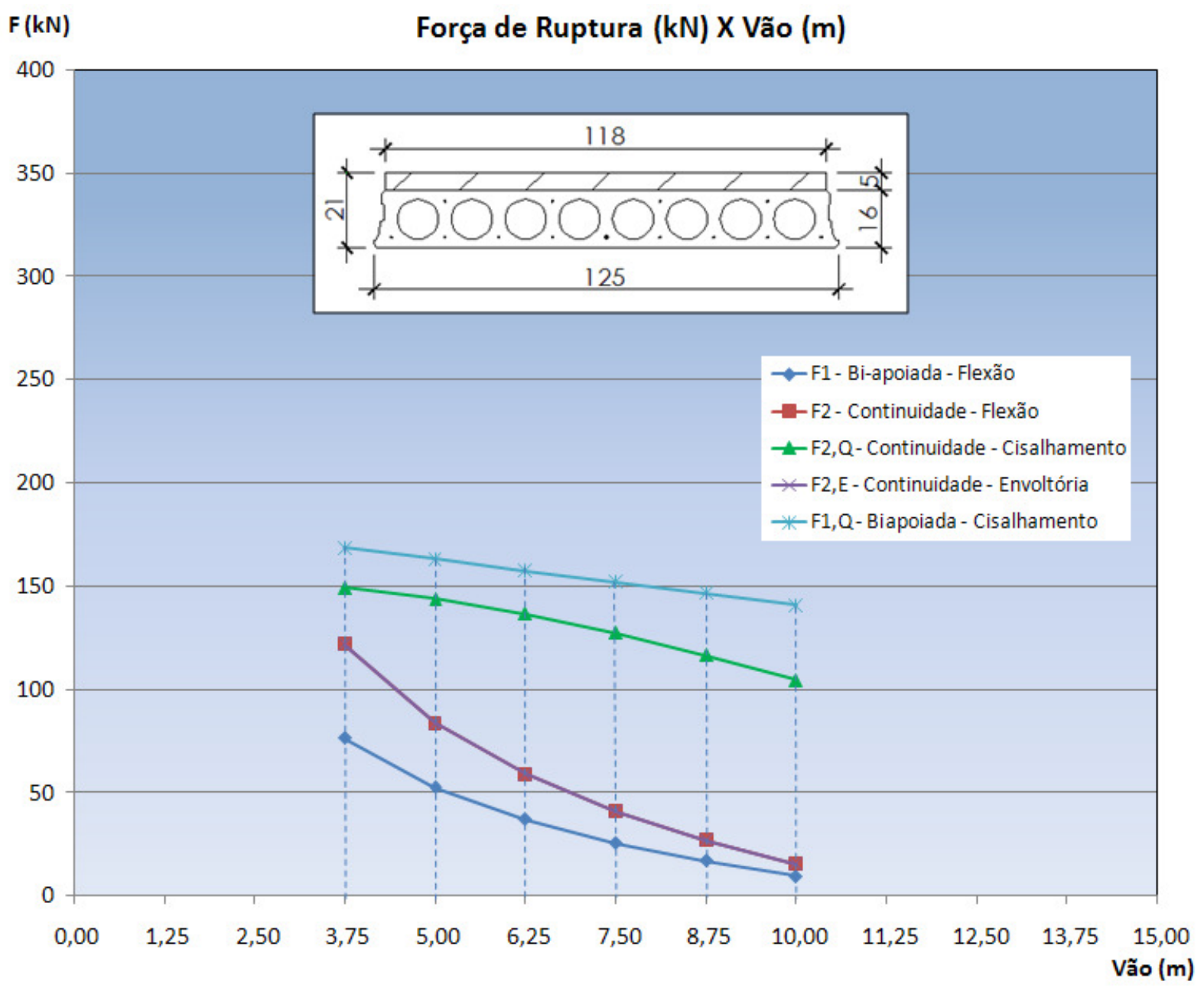

Figura 3.24 - Diagramas de iteração da laje alveolar utilizado no EM3.

\subsection{4 - Conclusões sobre os diagramas de iteração}

Através dos resultados e dos diagramas apresentados no item 3.9 para as lajes ensaiadas, é possível tirar algumas conclusões sobre o comportamento em ensaios (hipotéticos) biapoiados e de continuidade.

\section{Ruptura no ensaio de continuidade:}

- EM1. Será governada pelo cisalhamento para os vãos: 3,75 m, 5,00 m e 6,25 m. Será governada pela flexão se os vãos forem: 7,50 m, 8,75 m ou 10 m;

- EM2. Em todos os vãos a ruptura se dará por cisalhamento;

- EM3. Em todos os casos a ruptura se dará por flexão.

Aumento real da capacidade portante. Considera-se aumento (ou diminuição) da capacidade portante a relação entre a força de ruptura do ensaio de continuidade, seja por flexão $\left(F_{2}\right)$ ou por cisalhamento $\left(F_{2,0}\right)$, e a força de ruptura em um ensaio de flexão na condição biapoiada $\left(F_{1}\right)$, admitindo-se os mesmos parâmetros para os dois ensaios: 
- EM1. Governado pela envoltória, ou seja, ora pelo cisalhamento, ora pela flexão. Nesse caso há diminuição da capacidade portante para o vão de 3,75 m;

- EM2. Governado pelo cisalhamento, sendo diminuição da capacidade portante para os vãos entre 3,75 e 6,25 m;

- EM3. Governado pela flexão. Nesse caso o valor é constante para todos os vãos e equivale a um aumento de $60 \%$.

Aumento (hipotético) da capacidade portante, considerando somente a flexão. Comparação entre as forças de ruptura por flexão para os ensaios de continuidade $\left(F_{2}\right)$ e biapoiados $\left(F_{1}\right)$ :

- EM1. Aumento de 60\%;

- EM2. Aumento de 60\%;

- EM3. Aumento de $60 \%$.

Diminuição (hipotética) da capacidade portante, considerando somente o cisalhamento. Comparação entre as forças de ruptura por cisalhamento para os ensaios de continuidade $\left(F_{2,0}\right)$ e biapoiados $\left(F_{1,0}\right)$ :

- EM1, EM2 e EM3. Diminuição da capacidade portante dependendo da taxa de armadura adotada no cálculo.

Este fato já era esperado, uma vez que, na situação biapoiada a força cortante equivale à metade da força $F_{1, Q}$, enquanto que na condição com continuidade o apoio considerado "absorve mais carga", sendo esta relação de (11/16) F2,a. Para os casos em a continuidade ocorre nos dois apoios, a curva de $F_{1, Q}$ é igual à de $F_{2, Q}$. Isto ocorre porque, neste caso, mesmo com continuidade, a força cortante equivale à metade da força aplicada. 


\section{ENSAIOS DE CARACTERIZAÇÃO}

Além de servir para verificar a capacidade portante da laje alveolar e certificar o produto, os ensaios com elementos simplesmente apoiados também são utilizados para determinar, de forma indireta, a resistência à compressão e o módulo de elasticidade da laje.

Descrevem-se neste capítulo os procedimentos para a realização de tais ensaios e também os demais ensaios de caracterização dos materiais: concreto moldado no local para a capa, armadura passiva e armadura ativa.

Todos os ensaios para caracterização das lajes alveolares foram realizados no laboratório do NETPRE/DECiv/UFSCar. Com relação ao modelo EM1 (Figuras 3.1 e 3.2), os resultados foram retirados de um trabalho de extensão realizado pelo NETPRE/UFSCar, entre Dezembro de 2011 e Janeiro de 2012.

Para o modelo EM2 (Figuras 3.3 e 3.4), os resultados foram obtidos em ensaios realizados por MARQUESI (2014), realizados no mês de Maio de 2012.

Já para o modelo EM3 (Figuras 3.5 e 3.6), os ensaios de caracterização das lajes foram realizados pelo autor deste trabalho e, assim como os demais, serão mostrados a seguir.

\section{1 - Ensaios padronizados em lajes alveolares biapoiadas}

Os ensaios em lajes simplesmente apoiadas devem ser realizados de acordo com normas específicas. Com base no trabalho de COSTA (2009), são descritos os seguintes ensaios:

- Ensaio de cisalhamento;

- Ensaio de flexão;

- Ensaio com interação de cisalhamento e flexão.

COSTA (2009) descreve também procedimentos e medidas que devem ser tomados antes dos ensaios. São eles:

- Medidas preliminares. Efetuar medidas da geometria da seção transversal do elemento a ser ensaiado, tais como afundamento junto à face externa da cordoalha, dimensões dos alvéolos e etc. Além disso, anotar também alguma eventual imperfeição existente na peça, através de uma inspeção visual; 
- Registro dos ensaios. Identificação da laje alveolar e marcação da instrumentação utilizada;

- Velocidade de aplicação do carregamento. De acordo com a FIP (1992) o carregamento deverá ser aplicado a uma taxa de $50 \mathrm{kN}$ por minuto. Já a EN 1168:2005 recomenda aplicação de 10\% da carga última por minuto;

- Condições de apoio. O apoio não poderá ter nenhuma obstrução ao deslocamento horizontal, para não introduzir esforços adicionais no elemento ensaiado.

\subsection{1 - Ensaio de cisalhamento}

Para avaliar a resistência das lajes ao cisalhamento, pode-se utilizar o ensaio padrão presente no manual da FIP (1992) e na norma europeia EN 1168:2005.

A peça a ser ensaiada deve ser um elemento de largura real, com vão de $4 \mathrm{~m}$ ou $15 \mathrm{~h}$ ( $\mathrm{h}$ = altura da laje), prevalecendo o maior. A Figura 4.1 mostra um desenho esquemático do ensaio de cisalhamento. A Figura 4.2, uma foto de um ensaio realizado.
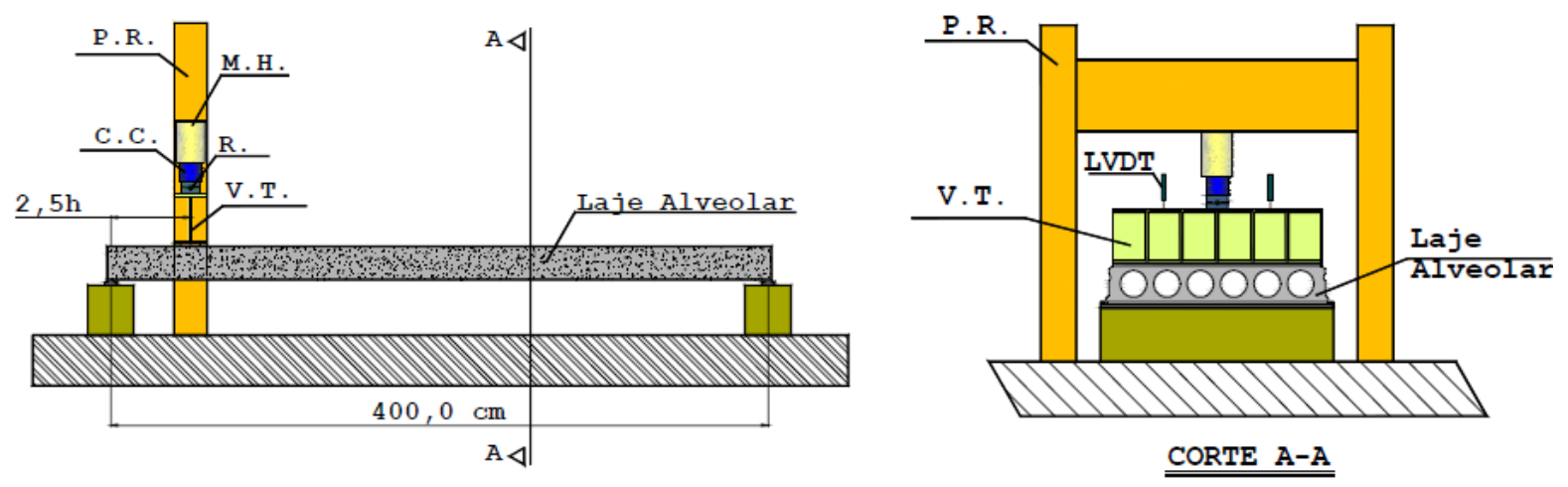

$$
\begin{array}{ll}
\text { P.R. = pórtico de reação; } & \text { M.H. = macaco hidráulico; } \\
\text { C.C. = célula de carga; } & \text { R. = rótula; } \\
\text { V.T. = viga de transferência } & \text { L.V.D.T. = transdutor }
\end{array}
$$

Figura 4.1 - Desenho esquemático do ensaio de cisalhamento. Vista lateral e corte. (Adaptado de COSTA (2009)).

A transferência de força para a laje deve ser realizada através de uma viga rígida, aconselhando-se a utilização de uma viga metálica. A viga rígida tem o propósito de garantir uma distribuição uniforme do carregamento, ao longo de toda a largura do elemento ensaiado. Essa viga deve possuir altura de no mínimo $15 \mathrm{~cm}$, sendo indicada a altura de $25 \mathrm{~cm}$ para ensaios com utilização de macaco hidráulico.

O apoio mais próximo do ponto de aplicação da força deve ser móvel, de tal forma que nenhuma força axial seja gerada pela rotação do elemento no apoio. 


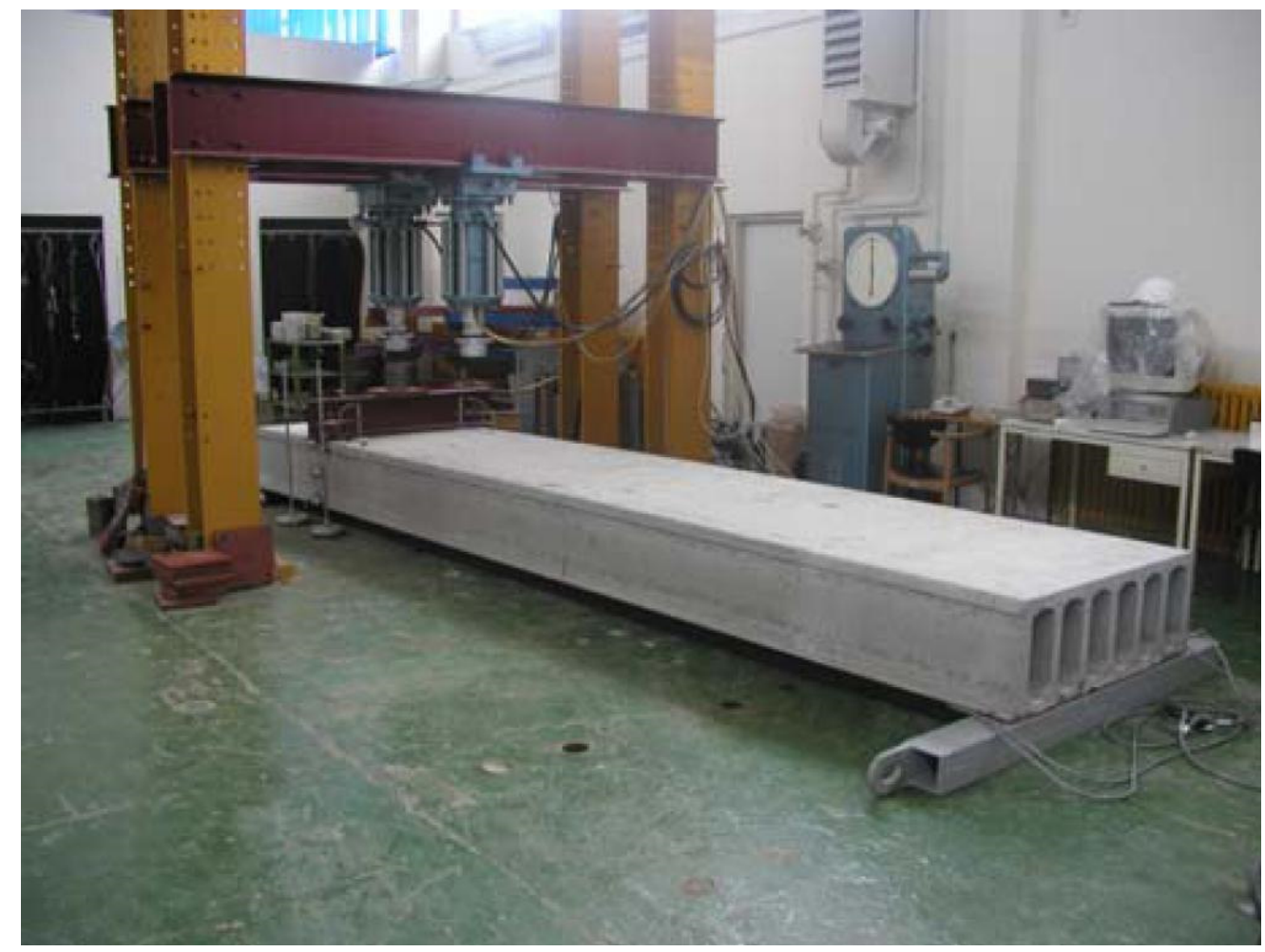

Figura 4.2 - Foto do ensaio de cisalhamento. (Fonte: TKALCIC (2007)).

Deve-se utilizar, entre a laje e a viga metálica, um material para distribuição das forças e também para compensar as irregularidades da superfície da laje e alguma eventual curvatura do elemento. Para esse material pode ser utilizado um dos seguintes exemplos: madeira compensada com $1 \mathrm{~cm}$ de altura, neoprene, faixa de argamassa ou gesso.

\subsection{2 - Ensaio de flexão}

O ensaio de flexão pode ser feito conforme o manual da FIP (1992). Segundo esse documento, é possível utilizar a parte remanescente da peça utilizada no ensaio de cisalhamento, desde que seja descartada do ensaio de flexão a região já ensaiada ao cisalhamento. Nesse caso, deve-se levar em consideração o vão utilizado para o ensaio de flexão, pois pode haver influência significativa da força cortante nos resultados, caso a parte remanescente for curta, como comenta FERNANDES (2007).

A força concentrada é aplicada no meio do vão, como mostra o desenho esquemático da Figura 4.3 e a foto do ensaio, Figura 4.4. 


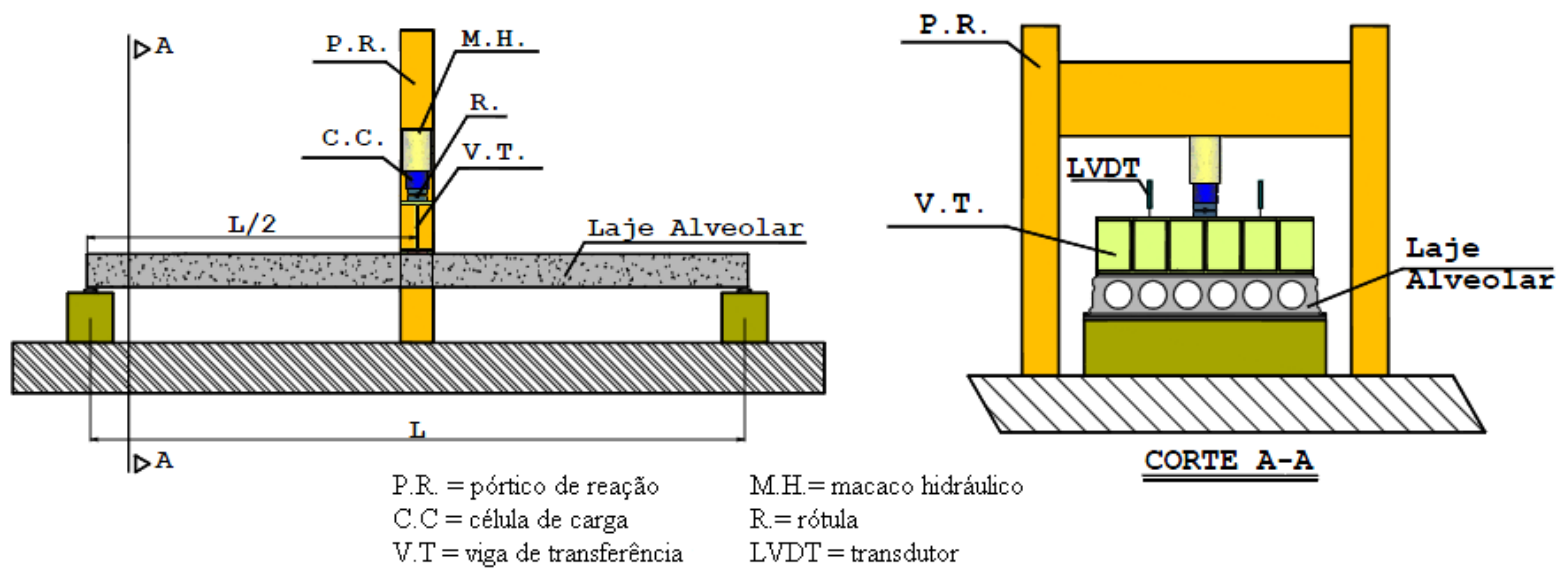

Figura 4.3 - Desenho esquemático do ensaio de flexão. Vista lateral e corte. (Adaptado de COSTA (2009)).

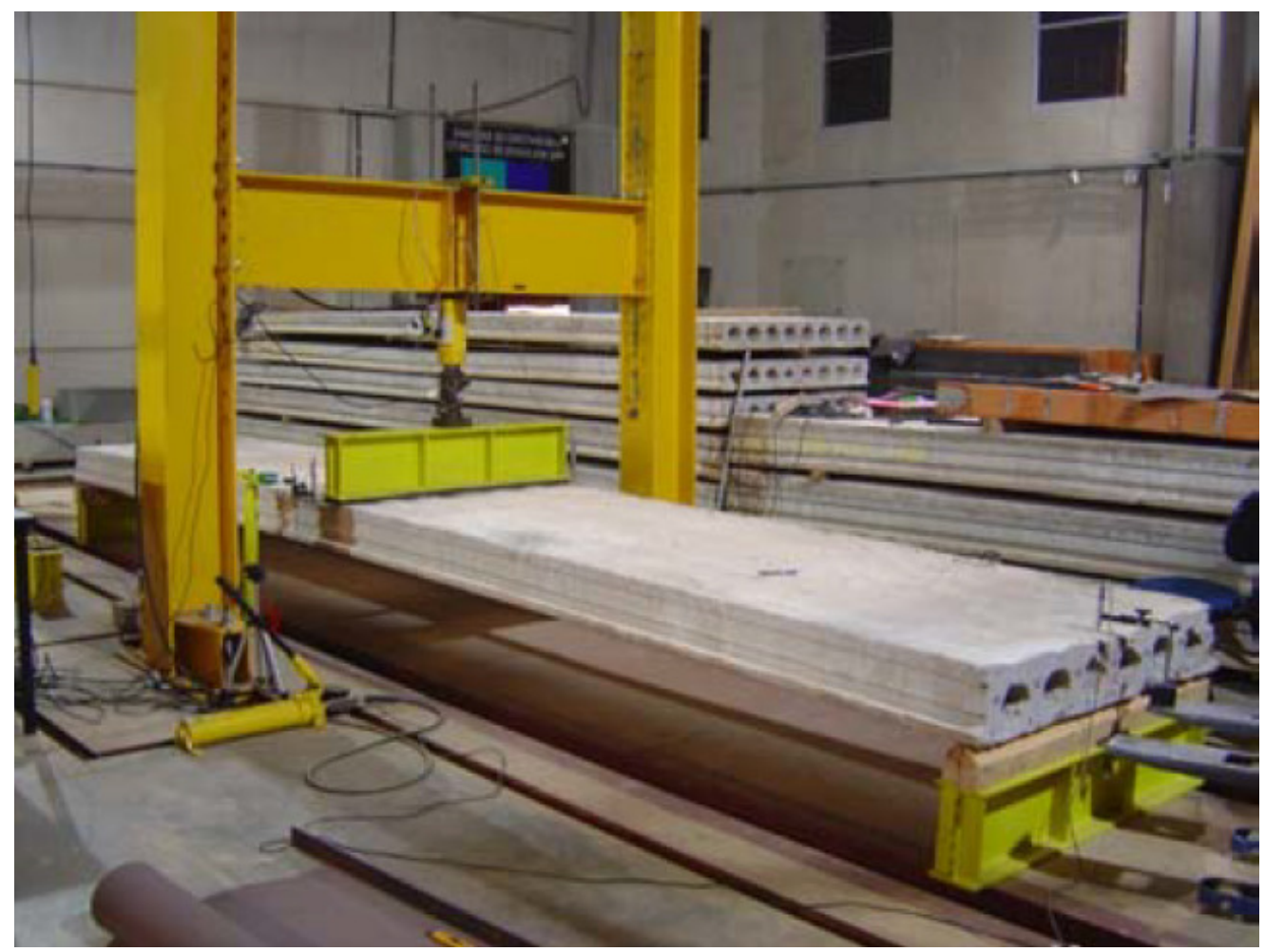

Figura 4.4 - Foto de um ensaio de flexão em laje alveolar.

(Fonte: COSTA (2009)).

Durante o ensaio, a intensidade do carregamento é aumentada até que ocorram fissuras por flexão. A partir desse ponto, a laje é descarregada e carregada novamente. Quando o momento de descompressão for atingido, as fissuras abrirão novamente. Por meio do momento de fissuração e do momento de descompressão, é possível obter a resistência à tração do concreto na flexão $\left(f_{c t, f}\right)$ e a tensão de protensão no aço $\left(\sigma_{p}\right)$. 


\subsection{3 - Ensaio com interação de cisalhamento e flexão}

A fim de estudar a interação de cisalhamento e flexão, é possível realizar um ensaio no qual o carregamento deve ficar disposto a uma distância específica do apoio. Conforme o documento da FIP (1982), essa distância deve ser de $1 \mathrm{~m}$ para uma laje de $3 \mathrm{~m}$ de comprimento. Entretanto, conforme recomendações indicadas em COSTA (2009), esse valor pode ser também de $5 \mathrm{~h}$ ( $\mathrm{h}=$ altura da laje alveolar). A Figura 4.5 ilustra esse tipo de ensaio.

É preciso considerar também os comentários de MARQUESI (2014), indicando que a distância de aplicação da força no ensaio é função de se atingir a tensão de tração do concreto na região próxima ao apoio. Assim, além da geometria, a intensidade da protensão também é um fator importante nos ensaios de interação do cisalhamento com a flexão.

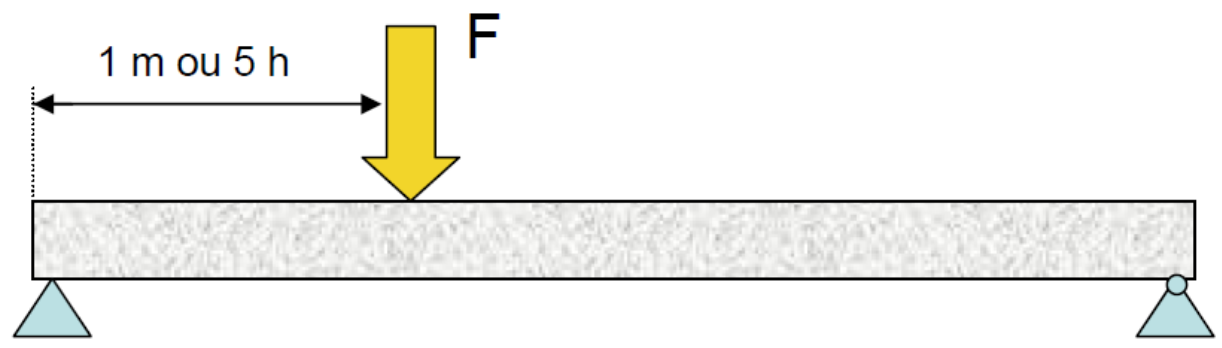

Figura 4.5 - Ensaio de interação de cisalhamento e flexão. (Fonte: FIP (1982)).

\section{2 - Avaliação das características do concreto da laje}

A partir dos resultados obtidos nos ensaios de cisalhamento e flexão (descritos anteriormente), é possível obter valores de resistência à tração e do módulo de elasticidade da peça. Esses procedimentos são descritos a seguir.

\subsection{1 - Cálculo de $\mathrm{f}_{\mathrm{ctm}}$ a partir de $\mathrm{M}_{\mathrm{r}}$ experimental}

Através de um ensaio de flexão, como o apresentado no item 4.1.2, pode-se calcular a resistência do concreto à tração. Isso pode ser feito através da expressão do momento de fissuração para peças em concreto protendido, apresentada no capítulo 3 (expressão 3.19):

$$
M_{r}=\frac{\alpha \cdot f_{c t} \cdot I_{c}}{y_{t}}+\frac{N_{p} \cdot I_{c}}{A \cdot y_{t}}+N_{p} \cdot e
$$


Isolando o valor da resistência à tração e utilizando o valor do momento de fissuração relativo à força aplicada no ensaio correspondente à primeira fissura, tem-se a expressão 4.1.

$$
f_{c t m}=\left[\frac{N_{p}}{A}+\frac{N_{p} \cdot e \cdot y_{t}}{I_{c}}-\frac{M_{r, e x p} \cdot y_{t}}{I_{c}}\right] / \alpha
$$

- $\mathrm{f}_{\mathrm{ct}}=\mathrm{f}_{\mathrm{ctk} \text {,inf }}$ para formação de fissura;

- $\mathrm{f}_{\mathrm{ct}}=\mathrm{f}_{\mathrm{ctm}}$ para deformação excessiva;

- $\mathrm{N}_{\mathrm{p}}$ = força normal de protensão na data do ensaio;

- A = área da seção transversal de concreto, em geral da seção bruta;

- e = excentricidade da força de protensão;

- $\mathrm{y}_{\mathrm{t}}=$ distância do centro de gravidade da seção à fibra mais tracionada;

- $\mathrm{I}_{\mathrm{c}}=$ momento de inércia no Estádio I (da seção bruta ou homogeneizada);

- $\mathrm{M}_{\mathrm{r}, \exp }=$ momento de fissuração relativo à força aplicada no ensaio de flexão da laje alveolar sem capa;

- $\alpha=$ fator que relaciona a resistência à tração na flexão com a resistência à tração direta;

- $\alpha=\left\{\begin{array}{l}1,2 \text { para seções T ou duplo T; } \\ 1,5 \text { para seções retangulares. }\end{array}\right.$

O valor da força aplicada no ensaio que representa a primeira fissura corresponde à mudança de inclinação nos diagramas dos ensaios (Força versus Deslocamento). Essa mudança pode ocorrer em um ponto ou em um trecho do diagrama.

Considerando a nomenclatura do capítulo 3 (especialmente a apresentada na Figura 3.13), a expressão 4.2 mostra como é feito o cálculo do momento de fissuração relativo ao ensaio.

$$
M_{r, \exp }=M_{1}+M_{2}=\frac{g_{1} \cdot l^{2}}{8}+\frac{F_{1} \cdot l}{4}
$$

- $\mathrm{g}_{1}=$ peso próprio da laje alveolar;

- $l=$ vão utilizado no ensaio;

- $\mathrm{F}_{1}=$ força aplicada no ensaio de flexão.

Foi considerado $f_{c t}=f_{c t m}$, que corresponde à deformação excessiva na formulação do momento de fissuração. $O$ resultado para $f_{c t m}$ obtido por este procedimento é o mais representativo, em função da menor variabilidade dos resultados para a formação do mecanismo de fissuração de flexão. 


\subsection{2 - Cálculo de $f_{c t d}$ a partir da resistência ao cisalhamento experimental}

Considerando o ensaio de cisalhamento descrito no item 4.1.1 e, além disso, a força concentrada a uma distância de $2,5 \mathrm{~h}$ do apoio ( $\mathrm{h}=$ altura da laje), é possível obter o valor da resistência à tração a partir da expressão que calcula o valor da força cortante resistente da seção (expressão 3.6).

$$
\mathrm{V}_{\mathrm{Rd} 1}=\left[\tau_{\mathrm{Rd}} \cdot \mathrm{k}\left(1,2+40 \cdot \rho_{1}\right)+0,15 \sigma_{\mathrm{cp}}\right] \cdot \mathrm{b}_{\mathrm{w}} \cdot \mathrm{d}
$$

Isolando-se a resistência do concreto à tração e utilizando o valor da força cortante resistente correspondente à força de ruptura obtida no ensaio de cisalhamento, chega-se à expressão 4.3.

$$
f_{c t m}=\left[\frac{V_{R d 1, e x p}-0,15 \cdot \sigma_{c p} \cdot b_{w} \cdot d}{0,25 \cdot k\left(1,2+40 \cdot \rho_{1}\right) \cdot b_{w} \cdot d}\right] / 0,70
$$

$\mathrm{Na}$ expressão 4.3 , considera-se que $f_{\text {ctd }}=f_{\text {ctk }}$ por se tratar de ensaio experimental. Em outras palavras, $f_{c t d}=f_{c t k, \text { inf }} / \gamma_{c}$, com $\gamma_{c}$ igual a 1,0. Logo, $f_{c t d}=0,7 f_{c t m}$.

A expressão 4.4 mostra o valor da força cortante resistente correspondente ao ensaio.

$$
V_{R d 1, \exp }=F_{1, Q} \cdot\left(\frac{l-2,5 \cdot h}{l}\right)+\frac{g_{1} \cdot l}{2}
$$

- $\quad \mathrm{V}_{\mathrm{Rd} 1}=$ força cortante resistente de cálculo;

- $\tau_{\mathrm{Rd}}=$ tensão cisalhante resistente de cálculo $-\tau_{\mathrm{Rd}}=0,25 . \mathrm{f}_{\mathrm{ctd}}$;

- $\mathrm{f}_{\mathrm{ctd}}=$ resistência à tração $-\mathrm{f}_{\mathrm{ctd}}=\mathrm{f}_{\mathrm{ctk} \text {,inf }} / \gamma_{\mathrm{c}}$;

- $k=|1,6-d| \geq 1$ (d em metros);

- $\rho_{1}=A_{s 1} /\left(b_{w} \cdot d\right) \leq 0,02$;

- $\sigma_{\mathrm{cp}}=$ tensão de compressão no concreto devida à força de protensão $\sigma_{c p}=N_{s d} / A_{c} ;$

- $\quad d$ = altura útil da seção;

- $b_{w}=$ largura da laje descontados os vazios correspondentes aos alvéolos;

- $\mathrm{N}_{\mathrm{sd}}=$ força longitudinal devida à protensão;

- $\mathrm{A}_{\mathrm{s} 1}=$ área de armadura da seção correspondente;

- $l$ = vão utilizado no ensaio;

- $\mathrm{g}_{1}=$ peso próprio da laje alveolar;

- $F_{1, Q}=$ força concentrada aplicada no ensaio de cisalhamento.

COSTA (2009) alerta que o valor obtido pela expressão 4.3 deve ser considerado como uma estimativa para controle do desempenho da peça ao cisalhamento, uma vez que pode haver uma interação ou combinação dos mecanismos de fissuração nos ensaios de cisalhamento, podendo gerar uma interpretação errônea nos resultados. 


\subsection{3 - Cálculo de $E_{c, \text { ef }}$ a partir da flecha obtida no ensaio de flexão}

Por meio do ensaio de flexão (item 4.1.2), também é possível determinar o valor do módulo de elasticidade do concreto. Isso pode ser feito através da leitura do deslocamento da laje alveolar $\left(\delta_{\text {exp }}\right)$. O módulo de elasticidade efetivo $\left(E_{c, e f}\right)$ da peça pode ser calculado pela seguinte expressão:

$$
E_{c, e f}=\frac{F_{1}}{\delta_{\text {exp }}} \cdot\left(\frac{l^{3}}{48 . I_{c}}\right)
$$

\subsection{4 - Evolução da resistência à compressão com o tempo}

Como existe uma defasagem das datas dos ensaios de caracterização das lajes com as dos ensaios de continuidade, será necessário estimar a resistência à compressão do concreto da laje alveolar através dos ensaios de caracterização. Isto é feito através das expressões 4.6 e 4.7. Além disso, é necessário utilizar a expressão 4.8, que calcula o valor da resistência à compressão na idade $\mathrm{j}\left(\mathrm{f}_{\mathrm{cj}}\right)$ de acordo com um valor de resistência médio $\left(f_{c m}\right)$ e um desvio padrão $(S)$.

$$
\begin{aligned}
& f_{c j, \text { continuidade }}=f_{c j, \text { caracterização }} \cdot \beta_{1} \\
& \beta_{1}=\exp \left\{s \cdot\left[1-\left(t_{\text {caracterização }} / t_{\text {continuidade }}\right)^{1 / 2}\right]\right\} \\
& f_{c j}=f_{c m}-(1,645 . S)
\end{aligned}
$$

- $f_{c j, c o n t i n u i d a d e}=$ resistência à compressão do concreto na data do ensaio de continuidade;

- $f_{c j, \text { caracterização }}=$ resistência à compressão do concreto na data do ensaio de caracterização;

- $\beta_{1}=$ coeficiente que relaciona a resistência à compressão do concreto de acordo com a idade;

- $s=0,20$ para cimento ARI;

- $t_{\text {caracterização }}=$ idade do concreto na data do ensaio de caracterização;

- $t_{\text {continuidade }}=$ idade do concreto na data do ensaio de continuidade;

- $f_{c m}=$ resistência média do concreto à compressão;

- $S=$ desvio padrão. 


\section{3 - Mecanismos de ruptura}

Os modos de ruptura descrevem as diferentes formas de como pode ocorrer a ruptura física da peça estrutural (FUSCO, 2008). Nos ensaios de laje alveolar é necessário identificar quais são esses mecanismos, para auxiliar na interpretação dos resultados.

Os trabalhos de PAJARI (1989), GIRHAMMAR (1992) e RETTNE e EDEKLING (2006) reúnem os mecanismos de ruptura em dois principais grupos: ruptura por flexão e ruptura por cisalhamento. RETTNE e EDEKLING (2006) ilustram que as fissuras podem ocorrer também pela interação de esforços de flexão com cisalhamento (Figura 4.6).

Nessa figura, as fissuras de cisalhamento (letra a) ocorrem quando as tensões de cisalhamento são elevadas e as tensões de flexão, baixas. As fissuras de flexão (letra c) ocorrem na situação inversa. Já as fissuras de cisalhamento e flexão (letra b) ocorrem quando ambas as tensões estão em nível intermediário.

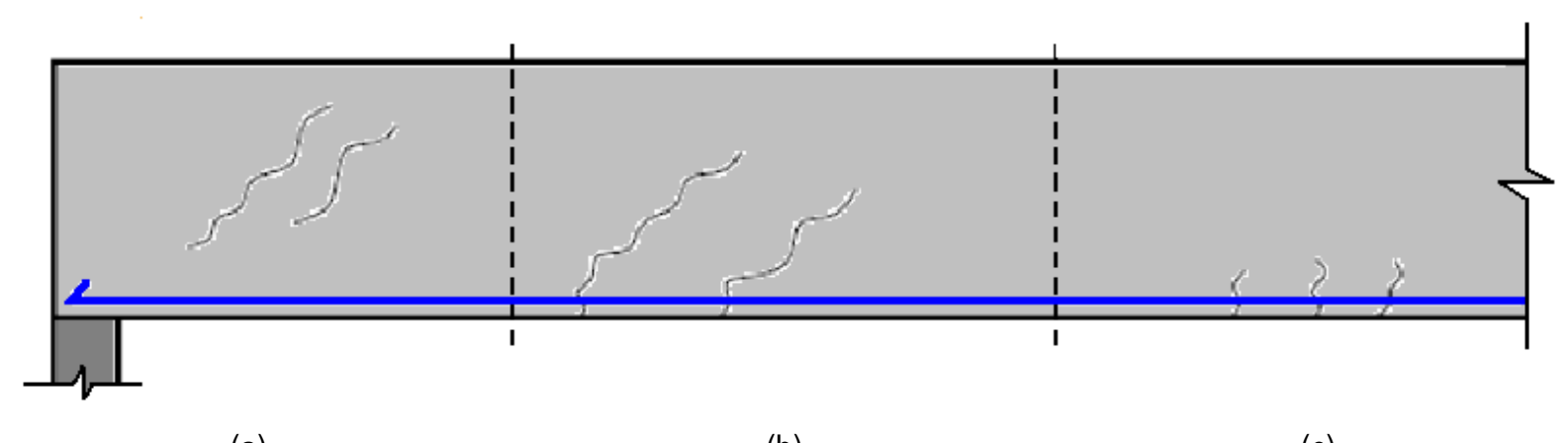

(a)

(b)

(c)

Figura 4.6 - Tipos de fissuras em elementos de concreto protendido. (a) Fissuras devidas ao cisalhamento; (b) Fissuras de cisalhamento e flexão; (c) Fissuras de flexão.

(Adaptado de RETTNE e EDEKLING (2006)).

Uma vez que as técnicas mais empregadas para fabricação de lajes alveolares (Figura 1.2, letras a e b) não permitem a utilização de armadura de cisalhamento, as rupturas por cisalhamento são caracterizadas por pequenas flechas e também pela falta de ductilidade. Isto faz com que a ruptura por cisalhamento ocorra, possivelmente, sem aviso. Logo é desejável que as resistências últimas sejam governadas pela flexão.

Conforme PAJARI (1989) e RETTNE e EDEKLING (2006), os mecanismos de ruptura na flexão estão associados aos seguintes mecanismos:

- Deformação excessiva da laje.

- Ruptura por tração nas fibras superiores da laje. Ocorre quando a resistência do concreto à tração é ultrapassada em função da flexão que acontece após a liberação da protensão na fábrica. Portanto não é uma situação de ensaio. No entanto essa situação deve ser verificada em situações de projeto;

- Ruptura do concreto à compressão devida à solicitação por flexão; 
- Ruptura das cordoalhas por tração em função da flexão;

- Fissuração por tração nas fibras inferiores. Ocorre quando os momentos fletores positivos ultrapassam o momento de fissuração (Figura 4.7);

\section{CATOIA (2011) observa que,}

... Em ensaios de flexão com aplicação de força concentrada, dependendo do comprimento da laje, fissuras de flexão podem se propagar na forma de uma fissura diagonal, caso o cisalhamento na seção seja significante. Nesse caso, haverá uma iteração dos mecanismos de flexão e cisalhamento. Se essa região estiver longe do apoio, deve-se ter uma condição de ancoragem ainda razoável e a maior probabilidade é que essa fissura diagonal avance em direção à face superior da laje, devendo ocorrer ruptura por compressão do concreto. Por outro lado, para o caso de uma laje de pequeno comprimento, seria mais provável que se desenvolvesse uma fissura de fendilhamento, a partir do encontro da fissura de flexão com a fissura diagonal.

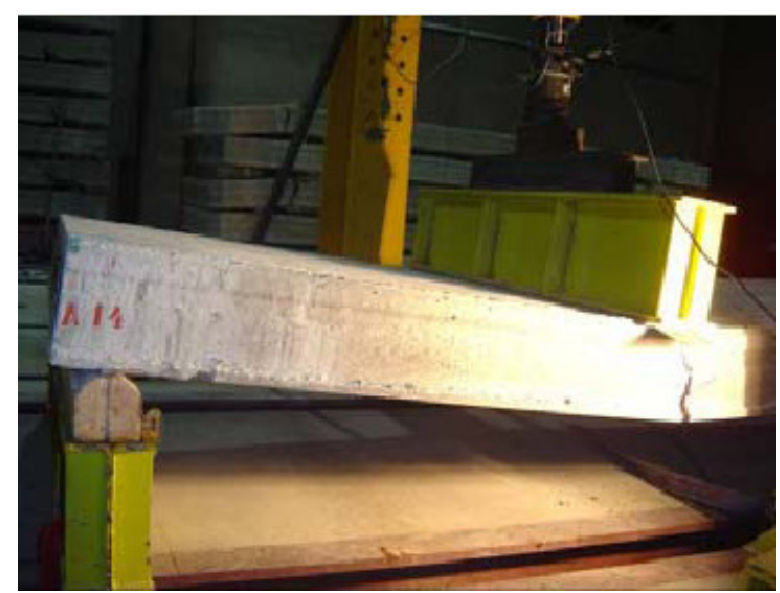

(a)

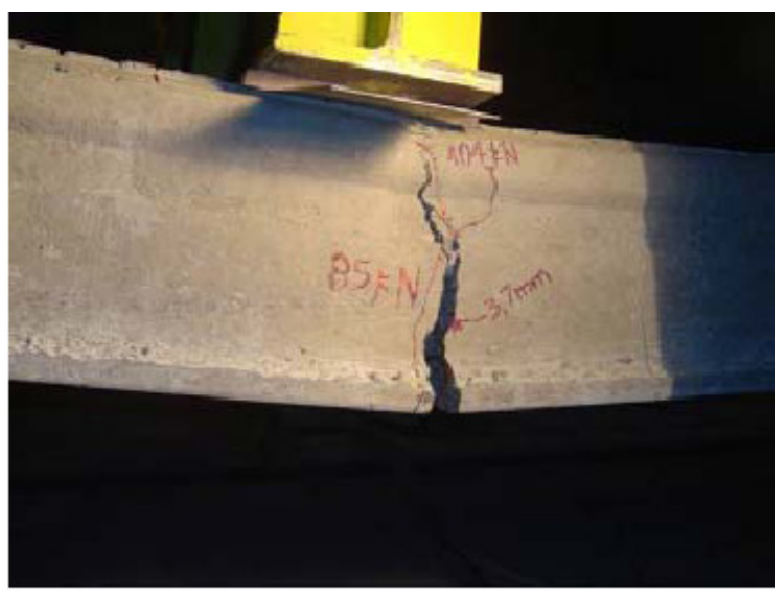

(b)

Figura 4.7 - Fissura por tração nas fibras inferiores. (a) Aplicação de carregamento concentrado em ensaio de flexão; (b) Vista lateral ampliada. (Fonte: COSTA (2009)).

A Figura 4.8 mostra um exemplo que caracteriza a interação de fissuras de flexão com fissuras de cisalhamento.

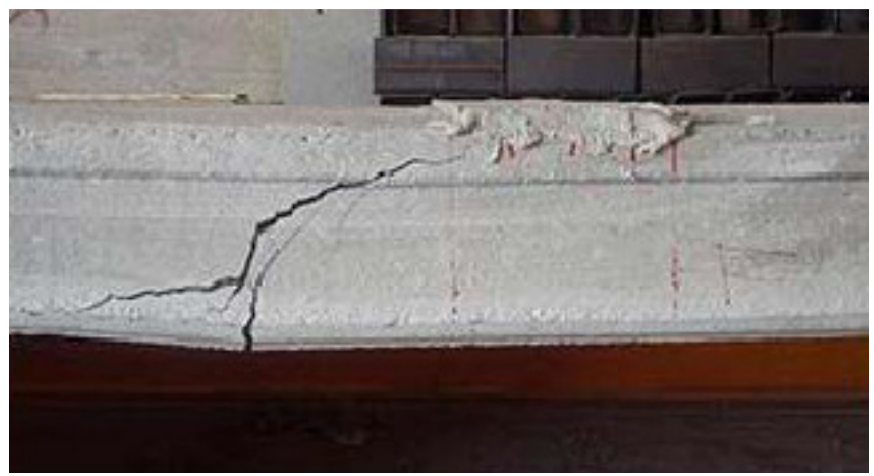

Figura 4.8 - Fissuras caracterizando interação de flexão com cisalhamento. (Fonte: COSTA (2009)). 
Basicamente, os mecanismos de ruptura por cisalhamento podem ser classificados em:

- Ruptura da nervura por tração gerada pelo cisalhamento;

- Ocorre em função da tração diagonal do concreto na região da nervura, nos casos em que há cisalhamento sem a presença de fissuras de flexão;

- Para peças submetidas a cisalhamento com a presença de fissuras de flexão, a distribuição das tensões tangenciais ao longo da seção apresenta um aumento nas fibras inferiores da laje, na região da cordoalha, aparecendo uma interação das fissuras de flexão com as fissuras diagonais de cisalhamento;

- Fissuração do concreto devida à interação de cisalhamento e flexão (Figura 4.9). Conforme KONG e EVANS (2001), essa fissuração ocorre quando o carregamento linear está aplicado a uma distância do apoio de acordo com a relação: $6>\left(a_{v} / d\right)$ $>2,5$, na qual $a_{v}$ é a distância entre o carregamento e o apoio; e d é a altura útil do elemento;

- Ruptura da nervura por compressão devida ao cisalhamento. Acontece quando a tensão principal de compressão na nervura alcança a resistência do concreto à compressão. Mas, segundo YANG (1994), é praticamente impossível ocorrer este tipo de ruptura nas lajes alveolares protendidas sem armadura de cisalhamento, uma vez que a ruptura da nervura por tração ocorre antes;

- Ruptura por escorregamento devido ao cisalhamento ao longo de uma fissura inclinada. Ocorre quando há falha na transferência de cisalhamento, podendo ser ocasionada pela falta de atrito ou falha no intertravamento na microestrutura do concreto, ou ainda falha no efeito pino da armadura ativa;

- Falha na ancoragem dos cabos:

○ Em regiões fissuradas por flexão;

- Em regiões onde há interação entre fissuras inclinadas de cisalhamento e fissuras de flexão.

Além dos mecanismos de rupturas por flexão ou por cisalhamento, existem ainda os mecanismos de ruptura em lajes alveolares com capa, que, de acordo com GIRHAMMAR e PAJARI (2008), podem acontecer de três diferentes maneiras, ilustradas na Figura 4.10: ruptura por cisalhamento na interface da capa de concreto com a laje alveolar (letra a); ruptura da nervura por tração em função da força cortante (letra b); ruptura da armadura ativa por flexão (letra c). 


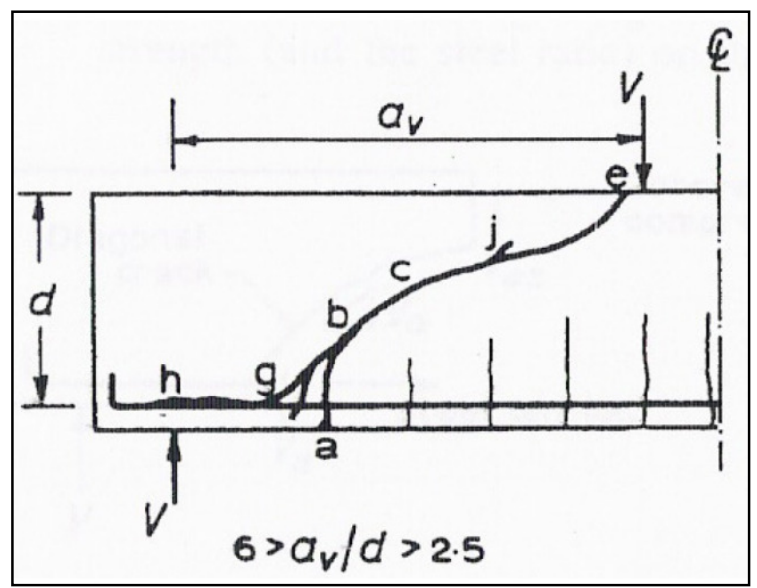

(a)

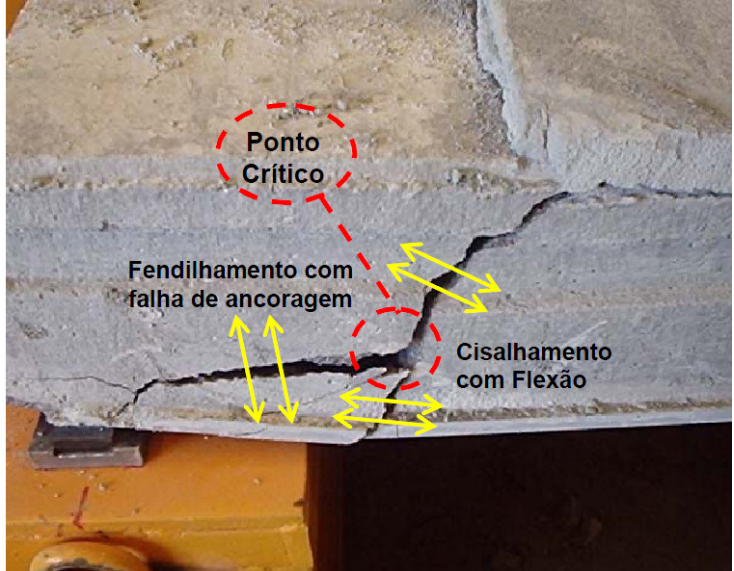

(b)

Figura 4.9 - Fissuras de cisalhamento e flexão. (a) Adaptado de KONG e EVANS (2001);

(b) Fonte: COSTA (2009).

(a)

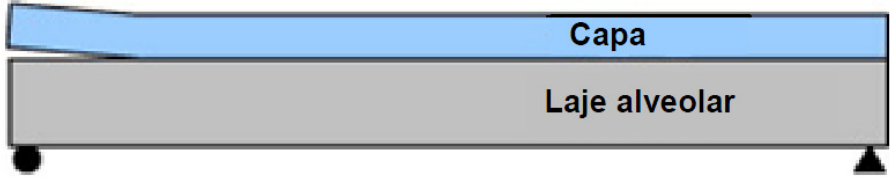

(b)

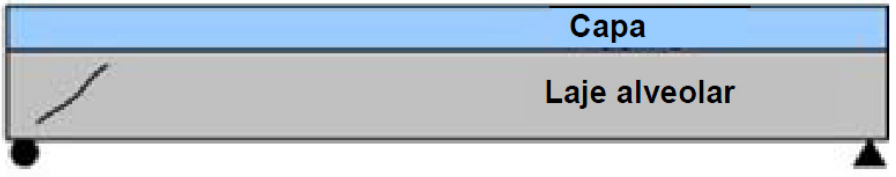

(c)

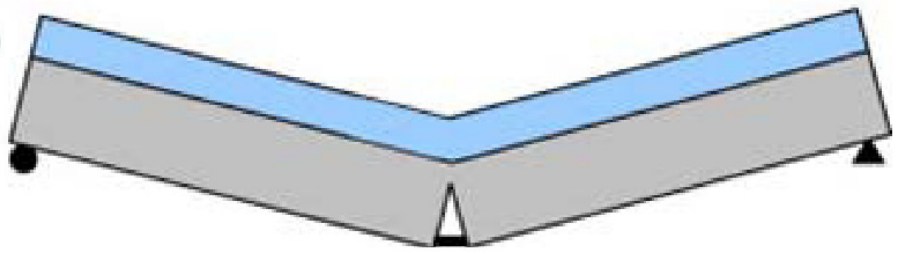

Figura 4.10 - Mecanismos de ruptura de laje alveolar com capa. (a) Falha por cisalhamento na interface; (b) Ruptura da nervura por tração devida ao cisalhamento; (c) Ruptura da armadura ativa.

(Adaptado de GIRHAMMAR e PAJARI (2008)).

\section{4 - Mudança de rigidez nas peças de concreto sob flexão}

MARCELLINO (2001) discorre sobre a mudança de rigidez nas peças de concreto quando submetidas à flexão. Sob efeito de uma força crescente em elementos de concreto armado submetidos à flexão, é possível distinguir quatro fases distintas nas deformações dos elementos estruturais, como mostra a Figura 4.11. 


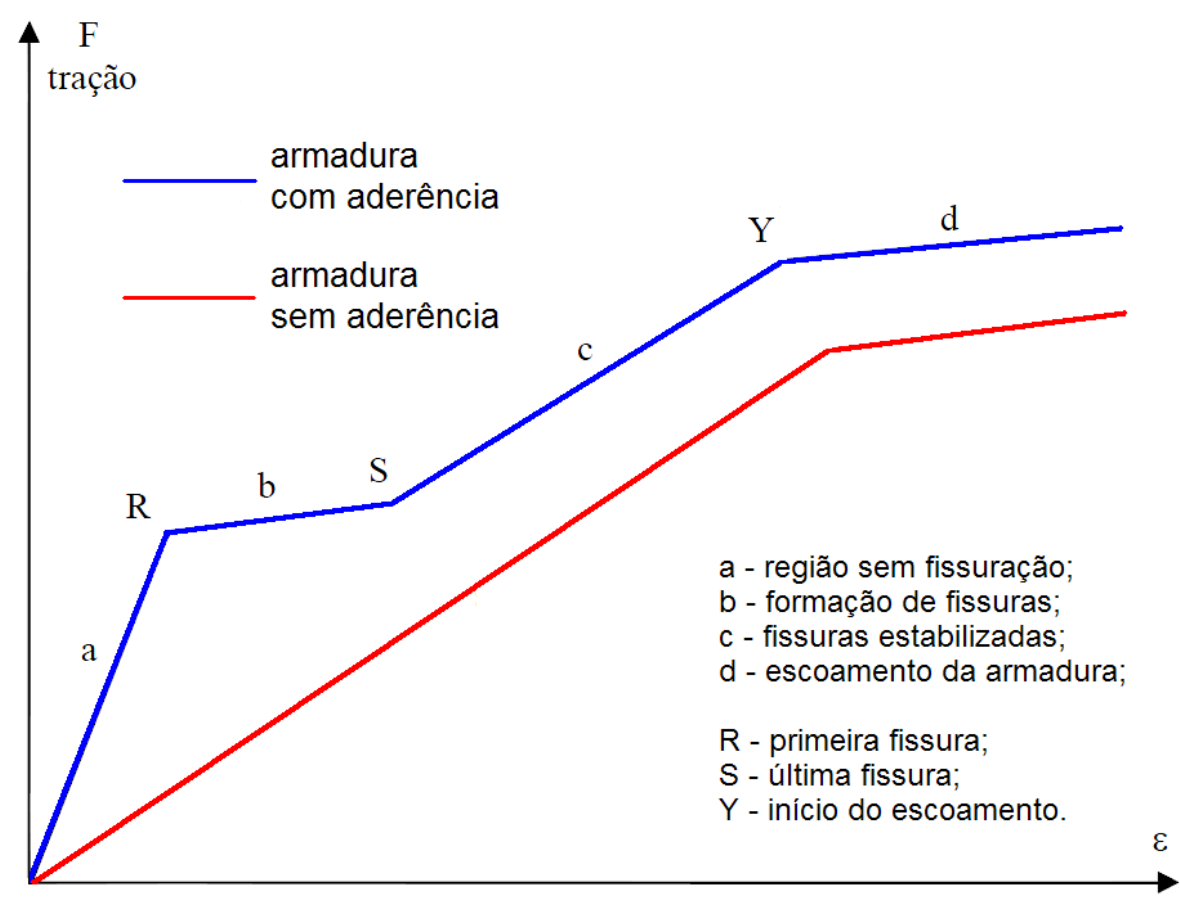

Figura 4.11 - Fases da evolução das deformações. (Adaptado de MARCELLINO (2001)).

Para a curva com armadura aderente ao concreto, o primeiro trecho da curva (trecho a) corresponde ao estádio I, ou seja, região sem fissuras. Nessa fase a parte tracionada da seção pode contar com a resistência do concreto à tração. Portanto a colaboração do aço se restringe ao valor dessa resistência do concreto. Além disso, a seção homogeneizada representa perfeitamente o comportamento linear do elemento.

Aumentando a solicitação, ocorre a primeira fissura (ponto R) quando a tensão de tração atuante for maior que a resistente, em outras palavras, quando o momento de fissuração $\left(M_{r}\right)$ é alcançado. Neste caso a seção passa do estádio I para o II.

Uma vez no estádio II, na seção fissurada, ocorre transferência das tensões de tração resistida pelo concreto para a armadura, e a seção passa então para a segunda fase (trecho b da curva: armadura com aderência). Neste caso novas fissuras aparecerão com o aumento da força aplicada. Sob certas condições, tal como a aderência entre o aço e o concreto, pode-se definir a distância, ou o espaçamento, entre as fissuras.

A aderência entre o aço e o concreto faz com que uma parte da tensão de tração existente no aço seja transmitida ao concreto vizinho, que até este momento não está fissurado. Esse efeito é chamado de contribuição do concreto entre as fissuras para o aumento da rigidez da seção (tension stiffening effect).

Com o aparecimento de novas fissuras, fica restrita a capacidade de transferência de tensões da armadura para o concreto. Logo, o espaçamento entre as fissuras ficará restrito por um valor mínimo, estabilizando este efeito (ponto $\mathrm{S}$ ).

Isto caracteriza a terceira fase da curva (trecho c), em que novas fissuras não podem surgir e, desse modo, somente as existentes sofrem aumento de abertura em função do 
carregamento crescente Essa fase também é conhecida como fissuração estabilizada e termina com início do escoamento do aço (ponto $\mathrm{Y}$ ).

$\mathrm{Na}$ fase seguinte (trecho d), o fenômeno do alongamento ocorre justamente onde o aço não tem aderência, ocorrendo também abertura de fissuras, mas de modo distinto da fase anterior. Nesse ponto a tensão de tração na armadura é igual à tensão de escoamento do aço.

\section{5 - Ensaios de caracterização das lajes alveolares}

Este tópico apresenta os resultados dos ensaios de caracterização realizados nas lajes alveolares. Tais ensaios foram feitos em elementos do mesmo lote dos utilizados nos ensaios de continuidade. Para facilitar a leitura, optou-se por reproduzir a Tabela 3.6, que apresenta as datas das principais etapas da análise experimental deste trabalho. Os resultados dos ensaios nos corpos de prova correspondentes ao concreto das lajes são mostrados no APÊNDICE B.

Tabela 3.6 - Datas dos ensaios.

\begin{tabular}{|c|c|c|c|}
\hline Variáveis & EM1 & EM2 & EM3 \\
\hline Moldagem da laje na fábrica & $28 / 11 / 2011$ & $15 / 02 / 2012$ & $18 / 06 / 2012$ \\
\hline $\begin{array}{c}\text { Ensaios dos CP's da laje na } \\
\text { fábrica }\end{array}$ & $05 / 12 / 2011$ & $14 / 03 / 2012$ & $25 / 06 / 2012$ \\
\hline $\begin{array}{c}\text { Ensaios de caracterização da laje } \\
\text { no NETPRE }\end{array}$ & $20 / 01 / 2012$ & $20 / 05 / 2012$ & $27 / 07 / 2012$ \\
\hline $\begin{array}{c}\text { Moldagem da capa } \\
\text { Ensaio do modelo de } \\
\text { continuidade }\end{array}$ & $17 / 02 / 2012$ & $23 / 05 / 2012$ & $11 / 07 / 2012$ \\
\hline $\begin{array}{c}\text { Ensaios de caracterização nos } \\
\text { CP's da capa no LSE }\end{array}$ & $16 / 03 / 2012$ & $20 / 06 / 2012$ & $26 / 07 / 2012$ \\
\hline
\end{tabular}

\subsection{1 - EM1}

As lajes correspondentes ao modelo EM1 foram ensaiadas no dia 20/01/2012 no NETPRE/UFSCar. De acordo com a Tabela 3.6 (capítulo 3), essas lajes foram ensaiadas com 53 dias para caracterização e estavam com 100 dias no ensaio de continuidade. 


\subsubsection{1 - Descrição dos ensaios}

Foram ensaiadas três unidades à flexão e três ao cisalhamento. As Figuras 4.12 e 4.13 mostram desenhos esquemáticos dos ensaios de flexão e de cisalhamento, enquanto que as Figuras 4.14 e 4.15 mostram fotos desses ensaios. No ensaio de cisalhamento, a força foi aplicada a uma distância de 2,5h do apoio (sendo h a altura da laje).

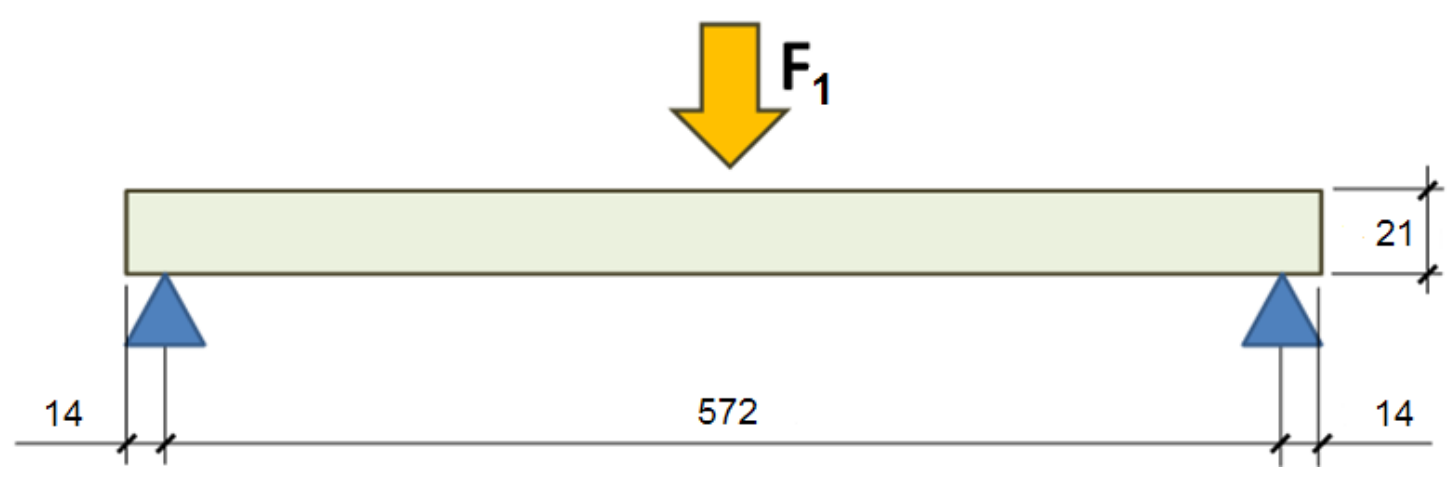

Figura 4.12 - Desenho esquemático do ensaio de flexão utilizado para caracterização da laje alveolar do EM1. Medidas em cm. (Fonte: NETPRE/UFSCar).

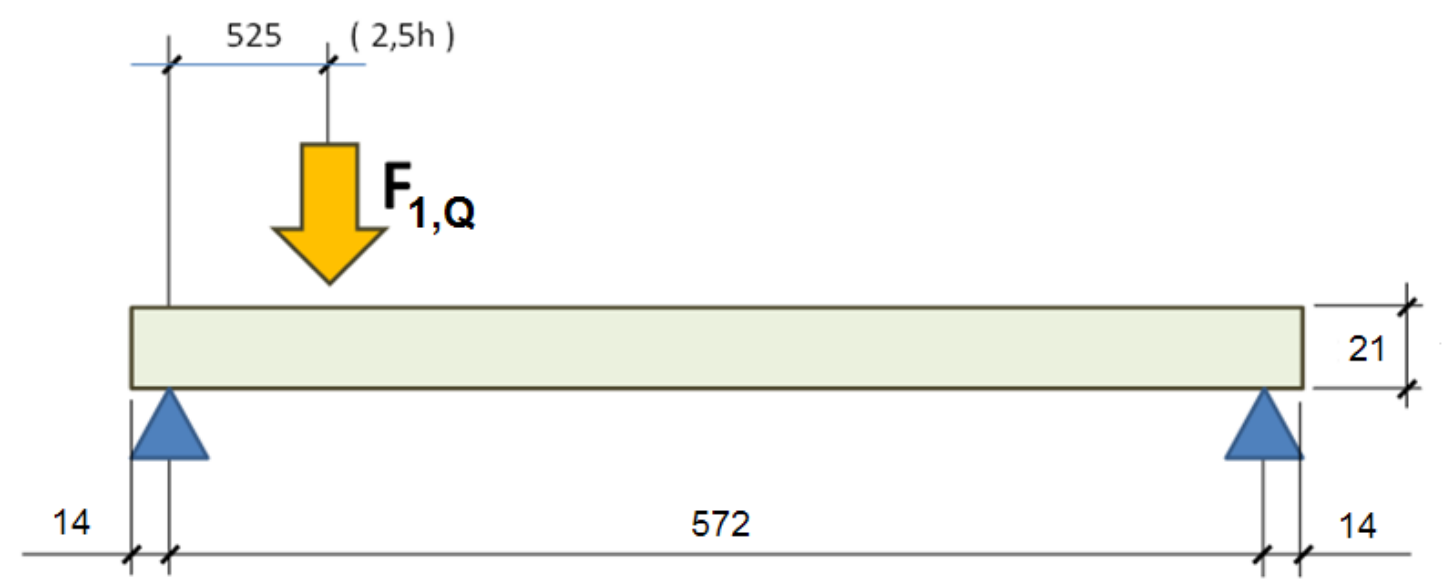

Figura 4.13 - Desenho esquemático do ensaio de cisalhamento utilizado para caracterização da laje alveolar do EM1. Medidas em cm. (Fonte: NETPRE/UFSCar). 


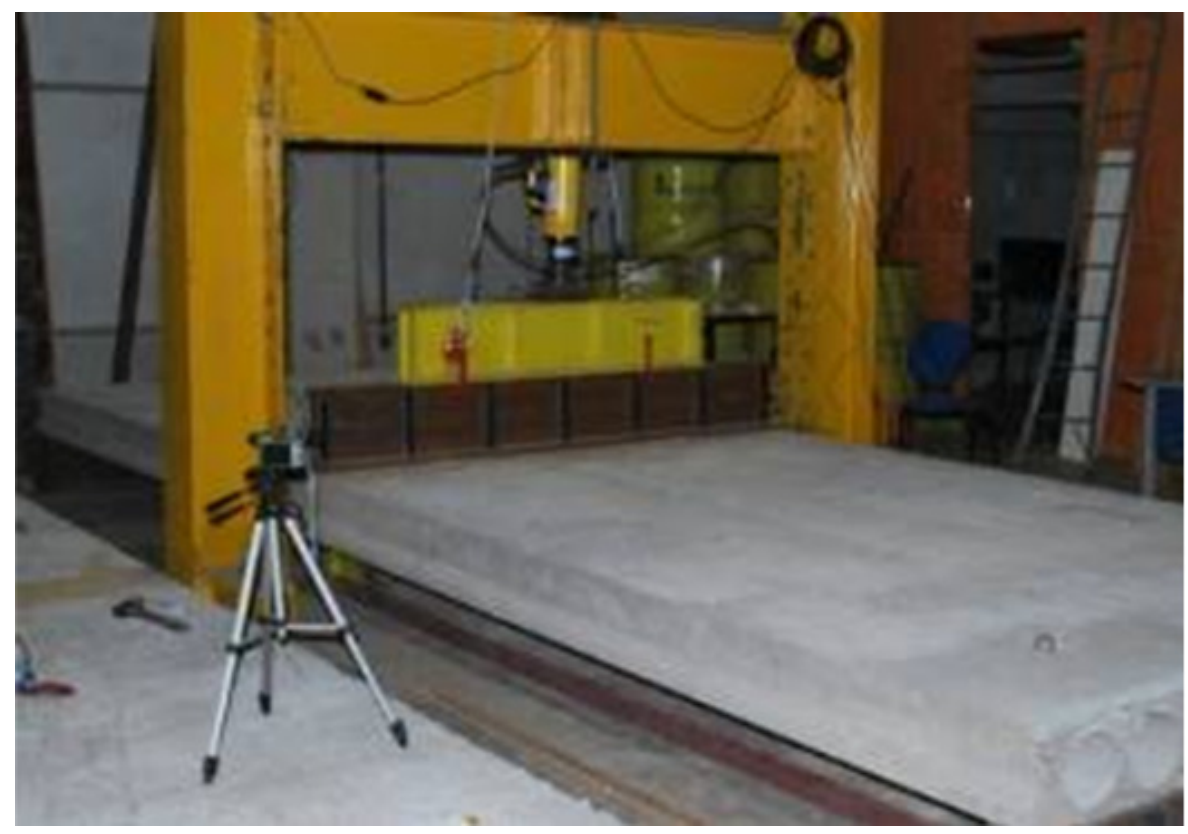

Figura 4.14 - Foto do ensaio de flexão utilizado para caracterização da laje alveolar do EM1. (Fonte: NETPRE/UFSCar).

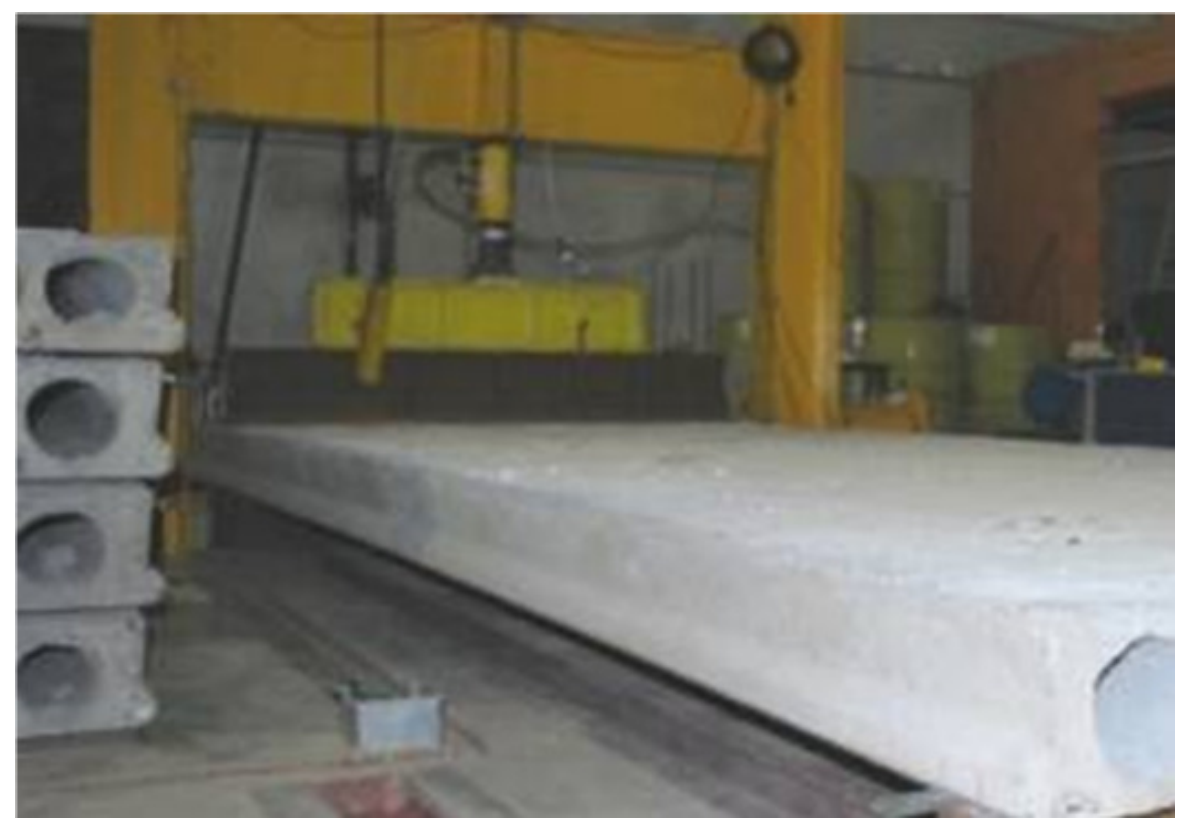

Figura 4.15 - Foto do ensaio de cisalhamento utilizado para caracterização da laje alveolar do EM1. (Fonte: NETPRE/UFSCar).

\subsubsection{2 - Resultados}

A Tabela 4.1 apresenta os resultados obtidos nos ensaios de flexão, enquanto que a Tabela 4.2 mostra os resultados experimentais relativos aos ensaios de cisalhamento. Nas Tabelas 4.1 e 4.2, $F_{1, r}$ e $F_{1, u}$ representam, respectivamente, os valores dos carregamentos nos instantes de fissuração e de ruína da peça. Vale lembrar que o valor da força aplicada 
no ensaio que representa a primeira fissura corresponde à mudança de inclinação nos diagramas dos ensaios (Força $x$ Deslocamento). Essa mudança pode ser representada por um ponto ou por um patamar.

Tabela 4.1 - Resultados dos ensaios de flexão. (Fonte: NETPRE/UFSCar).

\begin{tabular}{|c|c|c|}
\hline \multicolumn{3}{|c|}{ ENSAIOS DE FLEXÃO } \\
\hline LAJES & $\mathbf{F}_{\mathbf{1 , r} \mathbf{r}}(\mathbf{k N})$ & $\mathbf{F}_{\mathbf{1 , u}} \mathbf{( k N )}$ \\
\hline EM1-L1 & 123,0 & 183,6 \\
\hline EM2-L2 & 117,5 & 204,5 \\
\hline EM3-L3 & 125,0 & 185,8 \\
\hline MÉDIA & $\mathbf{1 2 1 , 8}$ & $\mathbf{1 9 1 , 3}$ \\
\hline
\end{tabular}

Tabela 4.2 - Resultados dos ensaios de cisalhamento. (Fonte: NETPRE/UFSCar).

\begin{tabular}{|c|c|c|}
\hline \multicolumn{3}{|c|}{ ENSAIOS DE CISALHAMENTO } \\
\hline LAJES & $\mathbf{F}_{\mathbf{1 , r}} \mathbf{( k N )}$ & $\mathbf{F}_{\mathbf{1 , u}} \mathbf{( k N )}$ \\
\hline EM1-L4 & 117,5 & 174,5 \\
\hline EM1-L5 & 92,5 & 100,6 \\
\hline EM1-L6 & 127,0 & 180,8 \\
\hline MÉDIA & $\mathbf{1 1 2 , 3}$ & $\mathbf{1 5 2 , 0}$ \\
\hline
\end{tabular}

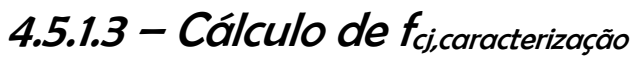

De posse dos resultados obtidos nos ensaios de cisalhamento e de flexão, foram calculados os valores de resistência média do concreto à tração $\left(f_{c t m}\right)$ e também de seu respectivo valor característico da resistência à compressão na data do ensaio $\left(f_{c j}\right.$,caracterização). Como não foram registrados os valores de deslocamentos, não foi possível calcular o valor do módulo de elasticidade das lajes alveolares (por esse processo).

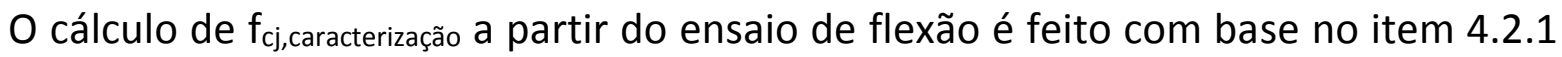
(deste capítulo) e apresentado na Tabela 4.3, para a laje EM1-L1.

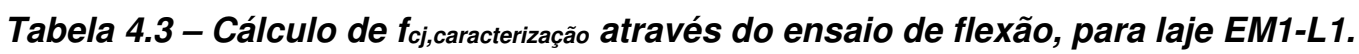

\begin{tabular}{c}
$\mathbf{M}_{\mathbf{r}, \exp }$ \\
\hline$M_{r, \exp }=M_{1}+M_{2}=\frac{g_{1} \cdot l^{2}}{8}+\frac{F_{1, r} \cdot l}{4}$ \\
$M_{r, \exp }=\frac{5,89.5,72^{2}}{8}+\frac{123,0.5,72}{4}=24,09+175,89=199,98 \mathrm{kN} . \mathrm{m}$ \\
\hline
\end{tabular}




$$
\begin{gathered}
\mathbf{f}_{\text {cj,caracterização }} \\
f_{c t m}=\left[\frac{N_{s k, p t, \infty}}{A}+\frac{N_{s k, p t, \infty} \cdot e \cdot y_{t}}{I_{c}}-\frac{M_{r, \text { exp }} \cdot y_{t}}{I_{c}}\right] / \alpha \\
f_{c t m}=\left[\frac{971,97}{0,2357}+\frac{971,97 \cdot 0,0734 \cdot 0,1084}{0,0013}-\frac{199,98 \cdot 0,1084}{0,0013}\right] / 1,5 \\
f_{c t m}=\frac{[4123,76+5948,88-16675,26]}{1,5}=-4401,75 \frac{k N}{m^{2}}=-4,40 M P a \\
f_{c t m}=0,3 \cdot f_{c k}^{2 / 3} \Rightarrow f_{c k}=\sqrt[2]{\left(\frac{f_{c t m}}{0,3}\right)^{3}}=\sqrt[2]{\left(\frac{4,40}{0,3}\right)^{3}}=56,17 M P a \\
\Rightarrow f_{c j, \text { caracterização }}=56,17 M P a
\end{gathered}
$$

O cálculo de $f_{c j}$,caracterização utilizando o ensaio de cisalhamento é feito com base no item 4.2.2 (deste capítulo) e apresentado na Tabela 4.4, para a laje EM1-L4.

Tabela 4.4 - Cálculo de $f_{c t m}$ através do ensaio de cisalhamento.

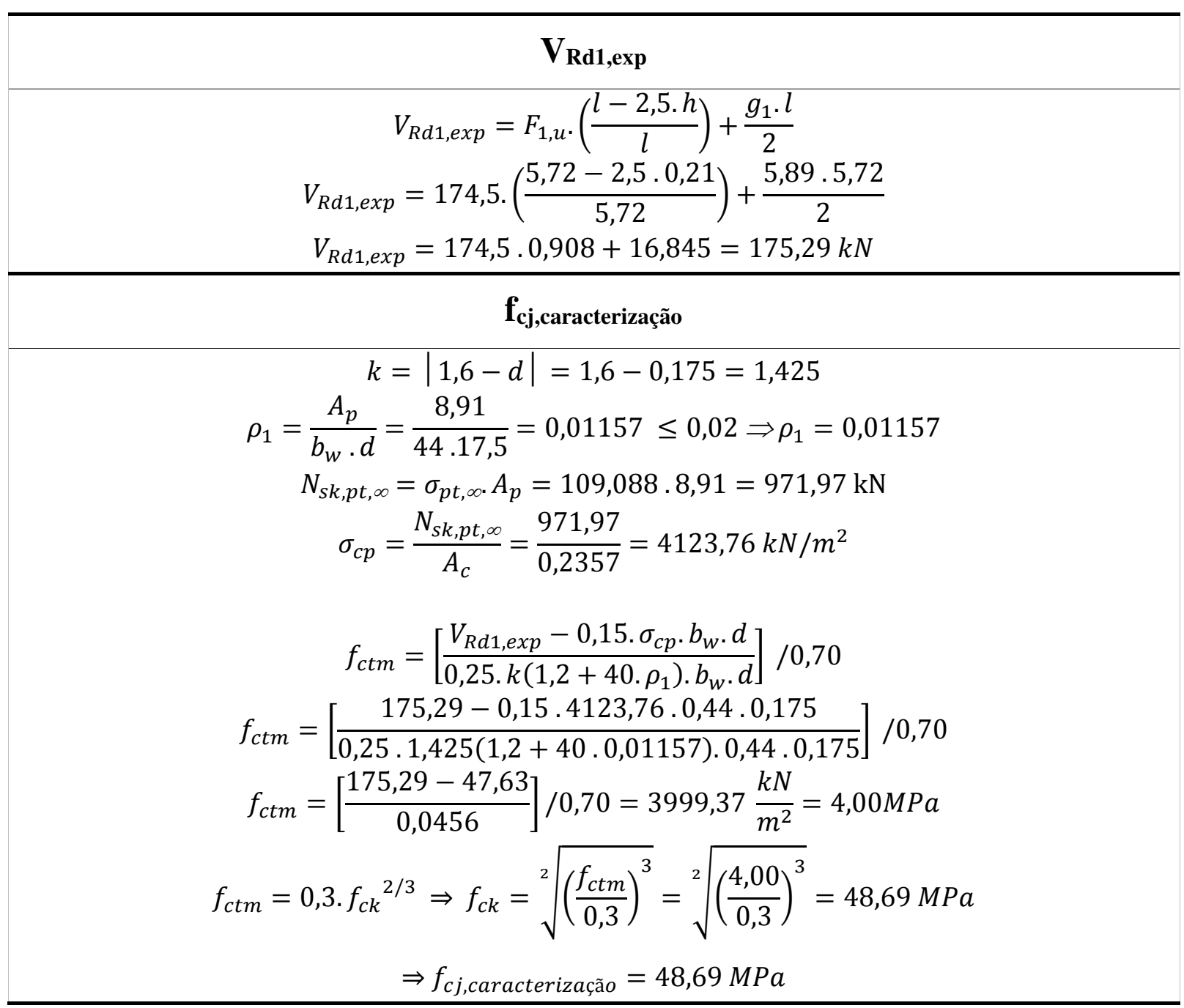


A Tabela 4.5 apresenta os resultados de $f_{c t m}$ para todas as lajes e também para os

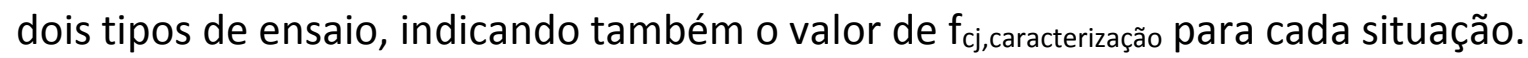

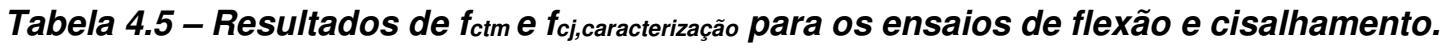

\begin{tabular}{|c|c|c|c|c|}
\hline \multicolumn{5}{|c|}{ DADOS INICIAIS } \\
\hline $\mathrm{g}_{1}(\mathrm{kN} / \mathrm{m})$ & 5,89 & & $A_{p}\left(\mathrm{~cm}^{2}\right)$ & 8,91 \\
\hline $1(\mathrm{~m})$ & 5,72 & & $2,5 . \mathrm{h}(\mathrm{m})$ & 0,525 \\
\hline $\mathrm{h}(\mathrm{m})$ & 0,21 & & $\mathrm{~d}(\mathrm{~m})$ & 0,175 \\
\hline$N_{s k, p t, \infty}(\mathrm{kN})$ & 971,94 & & $\mathrm{k}$ & 1,425 \\
\hline$e_{p}(\mathrm{~m})$ & 0,0734 & & $b_{w}(\mathrm{~m})$ & 0,44 \\
\hline$y_{t}(\mathrm{~m})$ & 0,1084 & & $\rho_{1}(\mathrm{~m})$ & 0,01157 \\
\hline$A_{C}\left(\mathrm{~m}^{2}\right)$ & 0,2357 & & $\sigma_{c p}(\mathrm{~m})$ & 4123,76 \\
\hline$I_{C}\left(\mathrm{~m}^{4}\right)$ & 0,0013 & & - & - \\
\hline$\alpha$ & 1,5 & & - & - \\
\hline \multicolumn{5}{|c|}{ ENSAIO DE FLEXÃO } \\
\hline Varíavel & EM1-L1 & EM1-L2 & EM1-L3 & EM1- (MÉDIO) \\
\hline$M_{r, \exp }(\mathrm{kN} . \mathrm{m})$ & 199,98 & 192,11 & 202,83 & 198,31 \\
\hline$f_{c t m}(\mathrm{MPa})$ & 4,40 & 3,96 & 4,56 & 4,31 \\
\hline$f_{c j, c a r a c t e r i z a c ̧ a ̃ o}(\mathrm{MPa})$ & 56,17 & 48,04 & 59,27 & 54,50 \\
\hline \multicolumn{5}{|c|}{ ENSAIO DE CISALHAMENTO } \\
\hline Varíavel & EM1-L4 & EM1-L5 & EM1-L6 & $\begin{array}{c}\text { EM1- } \\
\text { (MÉDIO)* }\end{array}$ \\
\hline$V_{R d 1, \exp }(\mathrm{kN})$ & 175,33 & 108,21 & 181,05 & - \\
\hline$f_{c t m}(\mathrm{MPa})$ & 4,00 & 1,90 & 4,18 & 3,36 ou 4,09 \\
\hline$f_{c j, \text { caracterização }}(\mathrm{MPa})$ & 48,67 & 15,91 & 51,98 & 38,85 ou 50,33 \\
\hline
\end{tabular}

${ }^{*}$ ) Considerando a média entre as três lajes e também descartando a laje EM1-L5.

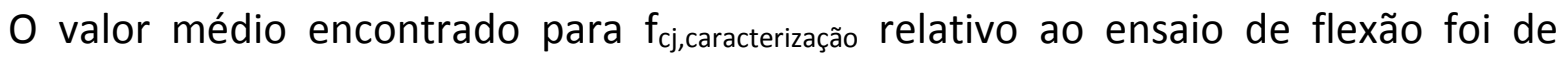
54,50 MPa. Para o ensaio de cisalhamento, o resultado foi de 38,85 MPa. Entretanto, descartando a laje EM1-L5, tem-se um valor de 50,33 MPa, sendo este último um valor mais coerente, uma vez que o valor da resistência característica de projeto à compressão $\left(f_{c k}\right)$ para essa laje é de $40 \mathrm{MPa}$.

Com relação à utilização do valor da tensão na armadura ativa após as perdas, $\left(\sigma_{\mathrm{pt}, \infty}=1090,88 \mathrm{MPa} ; \mathrm{N}_{\mathrm{sk}, \mathrm{pt}, \infty}=971,94 \mathrm{kN}\right.$; Perdas Isoladas = 23,18\%), é possível refazer as contas apresentadas na Tabela 4.5 utilizando o valor de 21,41\% para as perdas totais, considerando o cálculo como Perdas Progressivas. Isso resulta em $\sigma_{\mathrm{pt}, \infty}=1115,98 \mathrm{MPa}$ e

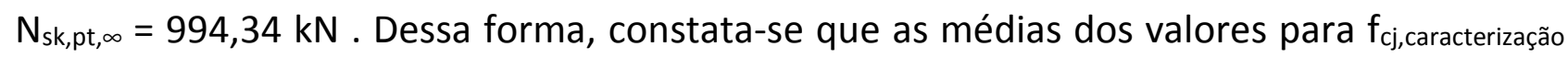
dos ensaios de flexão e de cisalhamento e se aproximam, como mostrado na Tabela 4.6. 


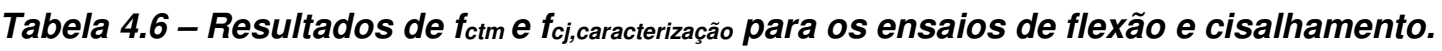

\begin{tabular}{|c|c|c|c|c|}
\hline \multicolumn{5}{|c|}{ ENSAIO DE FLEX̃̃O } \\
\hline Variável & EM1-L1 & EM1-L2 & EM1-L3 & EM1- (MÉDIO) \\
\hline$M_{r, \exp }(\mathrm{kN.m})$ & 199,98 & 192,11 & 202,83 & 198,31 \\
\hline$f_{c t m}(\mathrm{MPa})$ & 4,24 & 3,81 & 4,41 & 4,15 \\
\hline$f_{c j, \text { caracterização }}(\mathrm{MPa})$ & 53,27 & 45,26 & 56,29 & $\mathbf{5 1 , 6 0}$ \\
\hline \multicolumn{5}{|c|}{ ENSAIO DE CISALHAMENTO } \\
\hline Variável & EM1-L4 & EM1-L5 & EM1-L6 & $\begin{array}{c}\text { EM1- } \\
\text { (MÉDIO)* }\end{array}$ \\
\hline$V_{\text {Rd1,exp }}(\mathrm{kN})$ & 175,33 & 108,21 & 181,05 & - \\
\hline$f_{\text {ctm }}(\mathrm{MPa})$ & 3,97 & 1,86 & 4,14 & 3,32 ou 4,05 \\
\hline$f_{c j, \text { caracterização }}(\mathrm{MPa})$ & 48,05 & 15,48 & 51,34 & 38,29 ou 49,70 \\
\hline
\end{tabular}

$\left({ }^{*}\right)$ Considerando a média entre as três lajes e também descartando a laje EM1-L5.

\subsubsection{4 - Cálculo de $f_{c j \text { continuidade }}$}

Considerando os resultados mostrados na Tabela 4.6 para $f_{c j}$,caracterização $(51,60 \mathrm{MPa} e$ 49,70 MPa) e fazendo o cálculo de um valor médio, é possível estabelecer que, na data do

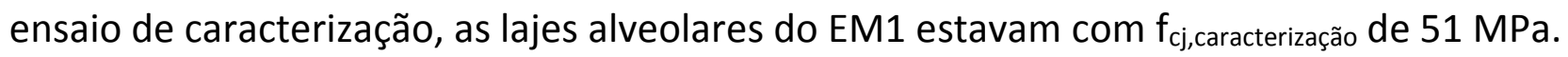

Utilizando as expressões 4.6 e 4.7, conclui-se que o valor da resistência do concreto à compressão na data do ensaio de continuidade ( $f_{c j}$,continuidade $)$ é de $54 \mathrm{MPa}$ (Tabela 4.7).

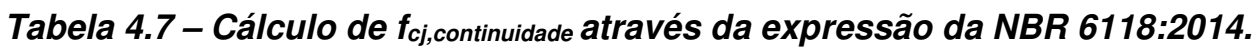

\begin{tabular}{|c|c|}
\hline \multicolumn{2}{|c|}{$\mathbf{f}_{\text {cj,continuidade }}$} \\
\hline \multicolumn{2}{|c|}{$\begin{array}{l}\beta_{1}=\exp \left\{s \cdot\left[1-\left(t_{\text {caracterização }} / t_{\text {continuidade }}\right)^{1 / 2}\right]\right\} \\
\beta_{1}=\exp \left\{0,20 \cdot\left[1-(53 / 100)^{1 / 2}\right]\right\} \\
\beta_{1}=1,0559\end{array}$} \\
\hline $\begin{aligned} f_{c j, \text { continuidade }} & =f_{c j, \text { caracterização }} \cdot \beta_{1} \\
f_{c j, \text { continuidade }} & =51 \cdot 1,0559 \\
f_{c j, \text { continuidade }} & =\mathbf{5 4} \mathrm{MPa}\end{aligned}$ & $\begin{array}{l}f_{c t m, \text { continuidade }}=f_{\text {ctm,caracterização }} \cdot \beta_{1} \\
f_{c t m, \text { continuidade }}=\frac{4,15+4,05}{2} \cdot(1,0559) \\
f_{c t m, \text { continuidade }}=4,32 \mathrm{MPa}\end{array}$ \\
\hline
\end{tabular}

\subsubsection{5 - Comparação com ensaios nos corpos de prova}

$O$ valor de $\mathrm{f}_{\mathrm{cj} \text {, continuidade }}=54 \mathrm{MPa}$ confere com os dados de ensaios de corpos de prova, ensaiados aos 7 dias, fornecidos pelo fabricante (APÊNDICE B, Tabela APB1.1).

Utilizando as expressões 4.6 e 4.7 e o valor médio de $f_{c j}$,caracterização (51 MPa), e, além disso, retroagindo de 100 dias (data da caracterização) para 7 dias (data dos ensaios dos 
corpos de prova), estima-se que o valor da resistência à compressão relativos aos corpos

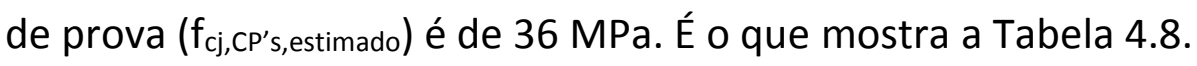

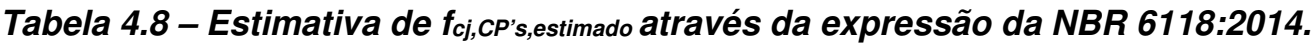

\begin{tabular}{c}
$\mathbf{f}_{\text {cj,CP's.estimado }}$ \\
\hline$\beta_{1}=\exp \left\{s \cdot\left[1-\left(t_{\text {caracterizaçãoo }} / t_{C P \prime s}\right)^{1 / 2}\right]\right\}$ \\
$\beta_{1}=\exp \left\{0,20 \cdot\left[1-(53 / 7)^{1 / 2}\right]\right\}$ \\
$\beta_{1}=0,7045$ \\
$f_{c j, C P^{\prime} \text { s,estimado }}=f_{c j, \text { caracterização }} \cdot \beta_{1}$ \\
$f_{c j, C P^{\prime}{ }^{\prime} \text {,estimado }}=51 \cdot 0,7045$ \\
$f_{c j, C P^{\prime} \text { s,estimado }}=36 \mathrm{MPa}$ \\
\hline
\end{tabular}

Valor próximo (34 MPa) é encontrado para $f_{\mathrm{cj}, \mathrm{CP} \text { 's }}$ quando se empregam os dados fornecidos pelo fabricante: $\mathrm{f}_{\mathrm{cm}}=37,4 \mathrm{MPa}$ e desvio padrão $\mathrm{S}=2,0 \mathrm{MPa}$, para os corpos de prova (APÊNDICE B). De acordo com a expressão 4.8, tem-se a Tabela 4.9.

Tabela 4.9 - Cálculo de $f_{c j, c P ' s}$ através da expressão da NBR 6118:2014.

$$
\begin{gathered}
\mathbf{f}_{\mathbf{c j}, \mathbf{C P} \text { 's }} \\
f_{c j, C P^{\prime \prime} s}=f_{c m}-(1,65 . S) \\
f_{c j, C P^{\prime \prime} s}=37,4-(1,65.2) \\
f_{c j, C P^{\prime \prime} s}=\mathbf{3 4} \mathrm{MPa}
\end{gathered}
$$

\subsubsection{6 - Comparação $M_{r}$ teórico e experimental}

Na Tabela 3.29 do capítulo 3, os valores teóricos para $M_{r}$ são: de 179,9 kN.m para Formação de Fissuras e de 205,92 kN.m para Deformação excessiva. Já a Tabela 4.6 apresenta os valores de $M_{r}$ encontrados nos ensaios de flexão. O valor médio é de 198,31 kN.m. Esses valores indicam que há coerência entre os valores teóricos e os experimentais.

\subsection{2- EM2}

No dia 20/05/2012, foi realizado um ensaio de flexão na laje alveolar do modelo EM2. Na data desse ensaio, a laje ensaiada estava com 95 dias, e na data do ensaio de continuidade, 112 dias. 


\subsubsection{1 - Descrição dos ensaios}

O ensaio foi feito com aplicação da carga concentrada em duas linhas, formando um ensaio de quatro pontos. A instrumentação utilizada permitia, além da leitura da força aplicada, leitura de deslocamentos, rotações no apoio e deformações no concreto.

Na Figura 4.16, apresenta-se um desenho esquemático do ensaio, e na Figura 4.17, uma foto panorâmica.

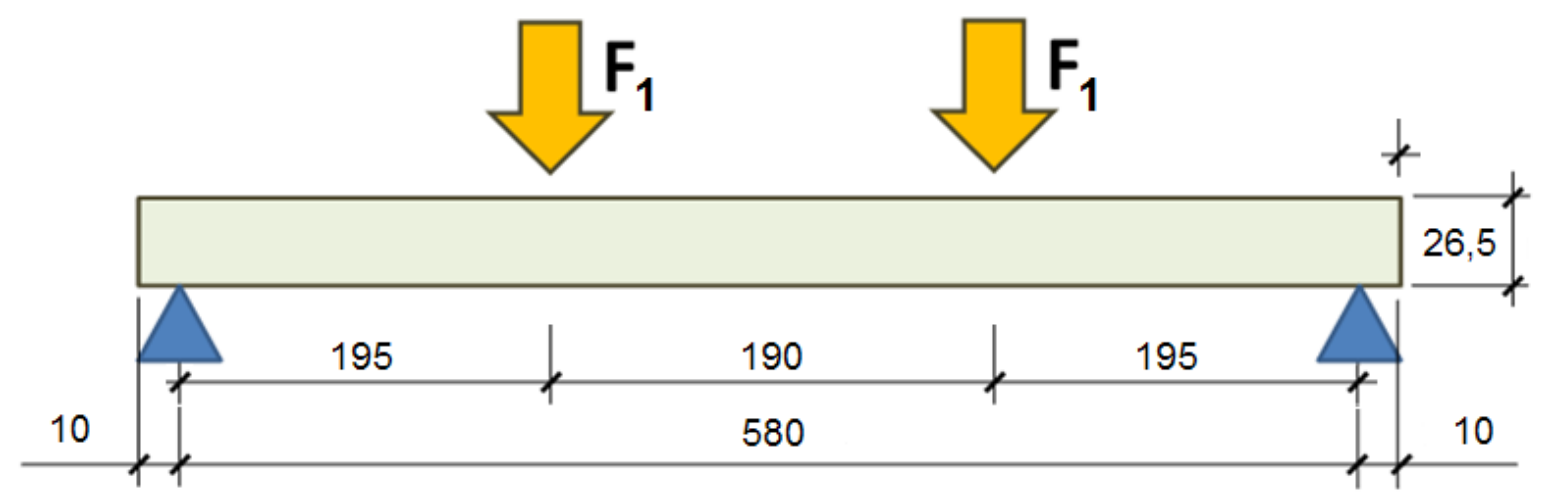

Figura 4.16 - Desenho esquemático do ensaio de flexão utilizado para caracterização da laje alveolar do EM2. Medidas em cm. (Dados: MARQUESI (2014)).

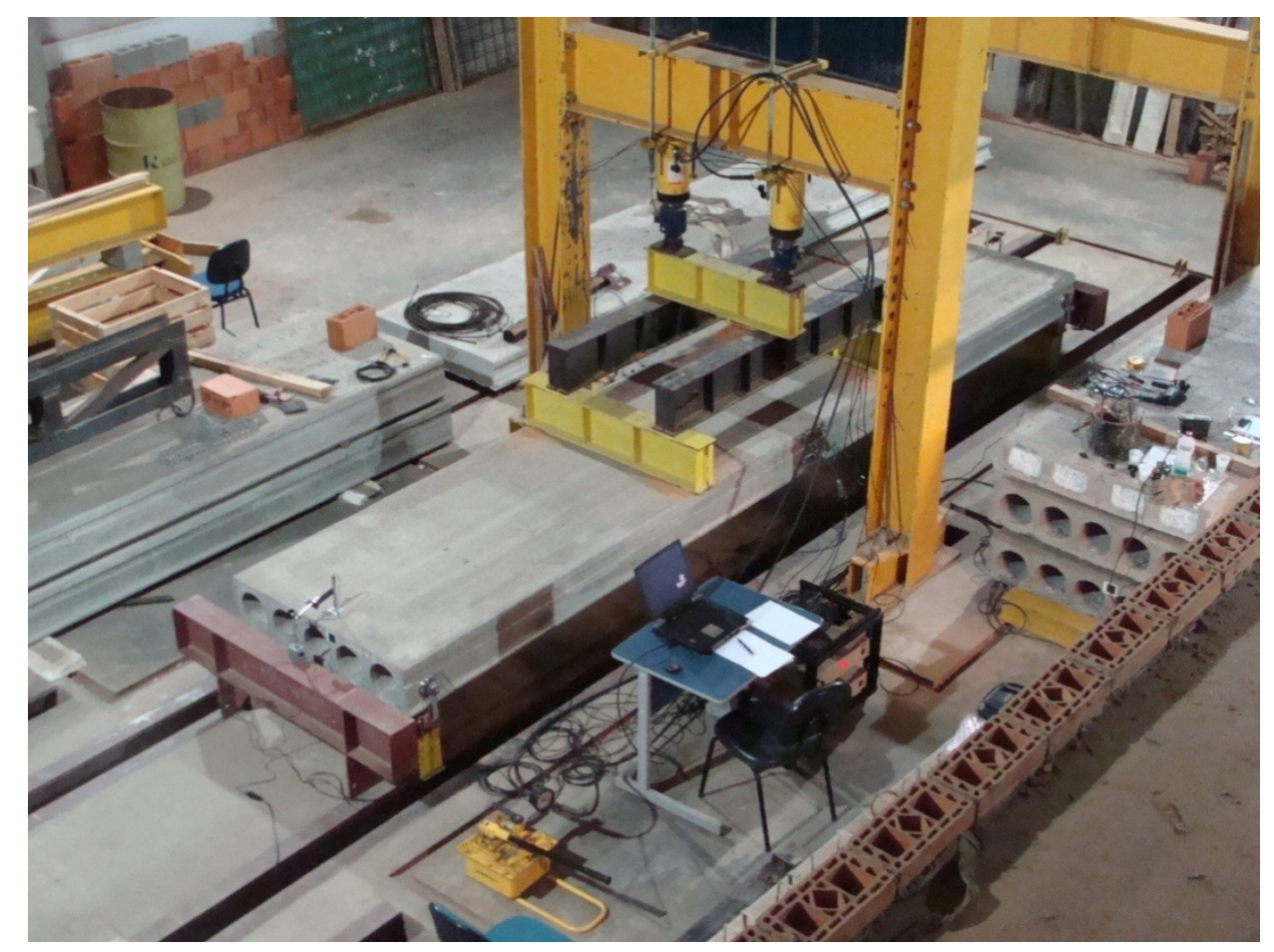

Figura 4.17 - Foto do ensaio de flexão utilizado para caracterização da laje alveolar do EM2. (Fonte: MARQUESI (2014)). 
A Figura 4.18 apresenta um gráfico força versus deslocamento, sendo que $F_{1}$ corresponde à força média dos dois atuadores (mostrados na Figura 4.17), enquanto que $\delta$, ao deslocamento do LVDT posicionado no meio da laje na face inferior.

O gráfico da Figura 4.18 mostra, também, a linha de tendência traçada a partir do trecho inicial do diagrama de F1 x $\delta$. O trecho inicial foi estabelecido a partir da força correspondente ao início da fissuração, ou seja $F_{1, r}=90,5$ kN. Foi considerado como o ponto inicial $10 \%$ de $F_{1, r}$, e como ponto final, $30 \%$ de $F_{1, r}$.

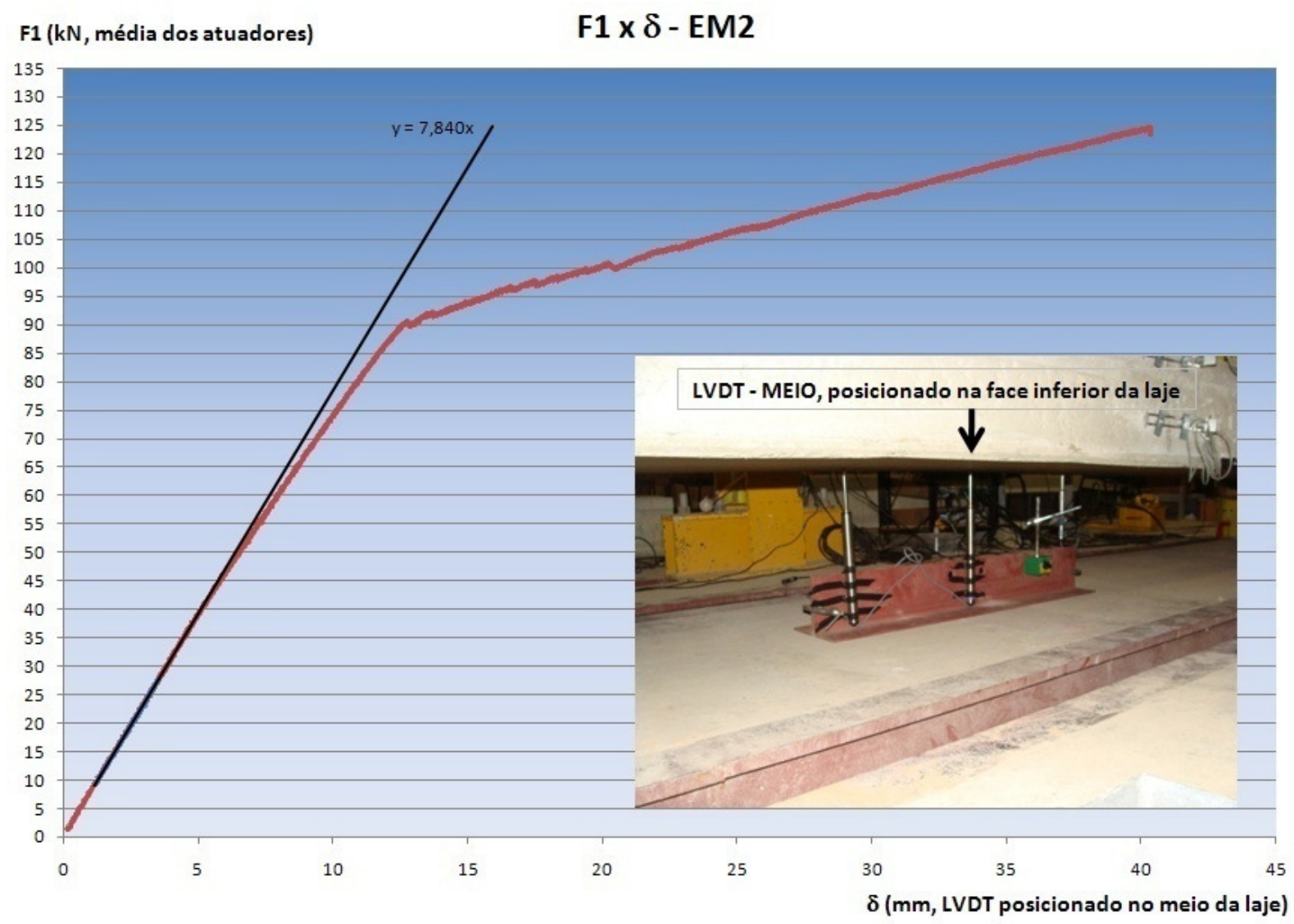

Figura 4.18 - Gráfico F1 x $\delta$ do ensaio de caracterização da laje EM2. F1 corresponde à média dos valores indicados pelos dois atuadores, e $\delta$, ao do LVDT posicionado no meio da laje.

(Dados: MARQUESI (2014)).

\subsubsection{2 - Resultados}

A Tabela 4.10 apresenta resultados de força e deslocamento de três pontos pertencentes ao trecho inicial da curva da Figura 4.18. 
Tabela 4.10 - Resultados experimentais do trecho inicial considerado no gráfico F1 x $\delta$ do EM2. (Fonte: MARQUESI (2014)).

\begin{tabular}{|c|c|c|}
\hline Pontos da curva & $\mathbf{F}_{\mathbf{1}}(\mathbf{k N})$ & $\boldsymbol{\delta}(\mathbf{m m})$ \\
\hline $\mathrm{F}_{1, \mathrm{r}}$ & 90,5 & 13,22 \\
\hline $10 \%$ de $\mathrm{F}_{1, \mathrm{r}}$ & 9,05 & 1,16 \\
\hline $20 \%$ de $\mathrm{F}_{1, \mathrm{r}}$ & 18,10 & 2,30 \\
\hline $30 \%$ de $\mathrm{F}_{1, \mathrm{r}}$ & 27,15 & 3,51 \\
\hline
\end{tabular}

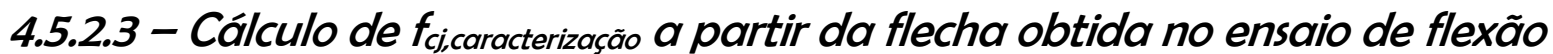

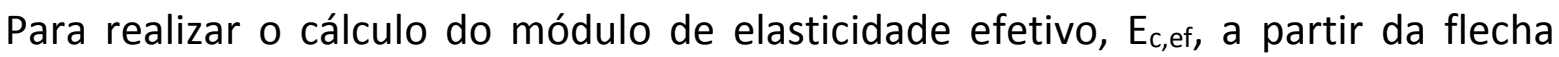
obtida no ensaio de flexão, item 4.2.3 e expressão 4.5 , é necessário considerar que o ensaio foi feito com duas linhas de aplicação de força, caracterizando um ensaio de quatro pontos. Logo, é necessário utilizar a expressão 4.9, que introduz a variável $\boldsymbol{a}$, distância entre a aplicação da força e o apoio, considerando ensaio simétrico. Na Figura 4.16, $a$ é igual a $1,95 \mathrm{~m}$.

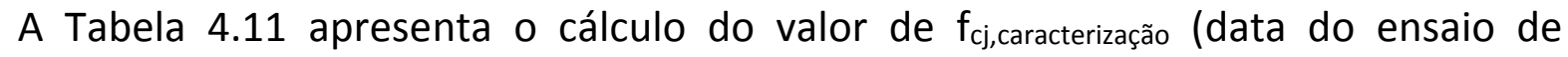
caracterização) para a laje EM2, através dos deslocamentos medidos no ensaio de flexão.

$$
E_{c, e f}=\frac{F_{1} \cdot a}{24 \cdot \delta_{\text {exp }} \cdot I_{c}} \cdot\left(3 \cdot l^{2}-4 \cdot a^{2}\right)
$$

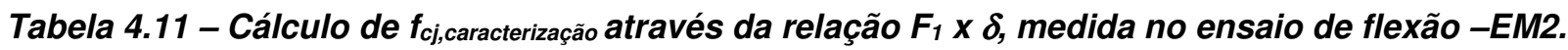

\begin{tabular}{|c|c|c|c|c|}
\hline $\begin{array}{c}\text { Pontos da } \\
\text { curva }\end{array}$ & $F_{1}(k N)$ & $\delta(\mathrm{mm})$ & $\begin{array}{c}\mathbf{E}_{\mathbf{c i}} \\
(\mathrm{MPa})\end{array}$ & $\begin{array}{c}\mathbf{f}_{\text {cj,caracterização }} \\
\text { (MPa) }\end{array}$ \\
\hline $10 \%$ de $F_{1, \mathrm{r}}$ & 9,05 & 1,16 & 34510 & 38,0 \\
\hline $20 \%$ de $\mathrm{F}_{1, \mathrm{r}}$ & 18,10 & 2,30 & 34288 & 37,5 \\
\hline $30 \%$ de $F_{1, r}$ & 27,15 & 3,51 & 34118 & 37,1 \\
\hline \multicolumn{3}{|c|}{ Média } & 34305 & 37,5 \\
\hline
\end{tabular}

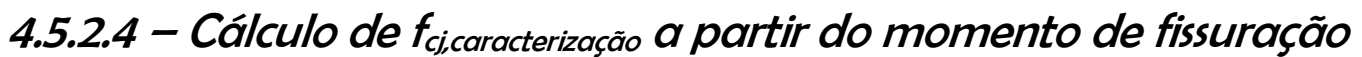

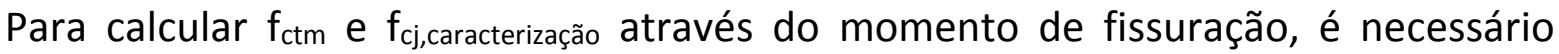
adaptar a expressão 4.2 do item 4.2.1 para o ensaio de quatro pontos. Para isso, tem-se a expressão 4.10, na qual $\boldsymbol{a}$ corresponde à distância entre a posição de aplicação da força e o apoio, considerando ensaio simétrico. Na Figura 4.16, a é igual a 1,95 m.

$$
M_{r, \exp }=M_{1}+M_{2}=\frac{g_{1} \cdot l^{2}}{8}+F_{1} \cdot a
$$

A Tabela 4.12 apresenta o cálculo do valor de $f_{c j}$,caracterização para a laje EM2, através do momento de fissuração. 


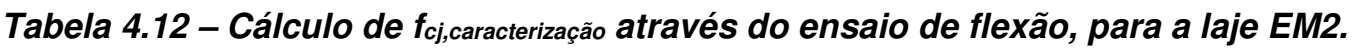

\begin{tabular}{|c|}
\hline $\mathbf{M}_{\mathbf{r}, \exp }$ \\
\hline $\begin{array}{c}M_{r, \exp }=M_{1}+M_{2}=\frac{g_{1} \cdot l^{2}}{8}+F_{1, r} \cdot a \\
F_{i, r}=90,5+0,94=91,44 \mathrm{kN} \text {, média dos atuadores }+ \text { peso dos equipamentos }(0,94 \mathrm{kN}) . \\
M_{r, \exp }=\frac{4,67 \cdot 5,80^{2}}{8}+91,44.1,95=19,64+178,31=197,95 \mathrm{kN} . \mathrm{m}\end{array}$ \\
\hline $\mathbf{f}_{\mathrm{ctm}}$ \\
\hline $\begin{array}{c}f_{c t m}=\left[\frac{N_{s k, p t, \infty}}{A}+\frac{N_{s k, p t, \infty} \cdot e \cdot y_{t}}{I_{c}}-\frac{M_{r, \text { exp }} \cdot y_{t}}{I_{c}}\right] / \alpha \\
f_{c t m}=\left[\frac{902,14}{0,1866}+\frac{902,14 \cdot 0,0863 \cdot 0,1313}{0,0016}-\frac{197,95 \cdot 0,1313}{0,0016}\right] / 1,5 \\
f_{c t m}=\frac{[4834,62+6388,95-16244,27]}{1,5}=-3346,88 \frac{\mathrm{kN}}{\mathrm{m}^{2}}=-3,35 \mathrm{MPa} \\
f_{c t m}=0,3 \cdot f_{c k}{ }^{2 / 3} \Rightarrow f_{c k}=\sqrt[2]{\left(\frac{f_{c t m}}{0,3}\right)^{3}}=\sqrt[2]{\left(\frac{3,35}{0,3}\right)^{3}}=37,3 \mathrm{MPa} \\
\Rightarrow f_{c j, \text { caracterização }}=\mathbf{3 7}, \mathbf{3 M P a}\end{array}$ \\
\hline
\end{tabular}

\subsubsection{5 - Cálculo de $f_{c j \text { continuidade }}$}

Considerando os resultados mostrados nas Tabela 4.11 e 4.12 para $\mathrm{f}_{\mathrm{cj} \text {,caracterização }}$ (37,5 MPa e 37,3 MPa) e fazendo o cálculo de um valor médio, é possível estabelecer que, na data do ensaio de caracterização, as lajes alveolares do EM1 estavam com $\mathrm{f}_{\mathrm{cj} \text {,caracterização }}$ de 37,4 MPa.

Utilizando as expressões 4.6 e 4.7, conclui-se que o valor da resistência do concreto à compressão na data do ensaio de continuidade $\left(f_{c j}\right.$,continuidade $)$ é de $38 \mathrm{MPa}$ (Tabela 4.13)

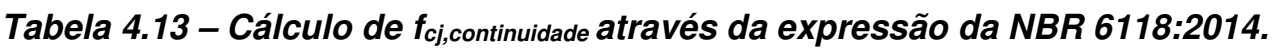

\begin{tabular}{|c|c|}
\hline \multicolumn{2}{|c|}{$\mathbf{f}_{\text {cj,continuidade }}$} \\
\hline \multicolumn{2}{|c|}{$\begin{array}{l}\beta_{1}=\exp \left\{s \cdot\left[1-\left(t_{\text {caracterização }} / t_{\text {continuidade }}\right)^{1 / 2}\right]\right\} \\
\beta_{1}=\exp \left\{0,20 \cdot\left[1-(95 / 112)^{1 / 2}\right]\right\} \\
\beta_{1}=1,0159\end{array}$} \\
\hline $\begin{aligned} f_{c j, \text { continuidade }} & =f_{c j, \text { caracterização }} \cdot \beta_{1} \\
f_{c j, \text { continuidade }} & =37,4.1,0159 \\
f_{c j, \text { continuidade }} & =\mathbf{3 8} \mathrm{MPa}\end{aligned}$ & $\begin{array}{l}f_{\text {ctm,continuidade }}=f_{\text {ctm,caracterização }} \cdot \beta_{1} \\
f_{\text {ctm,continuidade }}=3,35.1,0159 \\
f_{\text {ctm,continuidade }}=3,40 \mathrm{MPa}\end{array}$ \\
\hline
\end{tabular}




\subsubsection{6 - Comparação com ensaios nos corpos de prova}

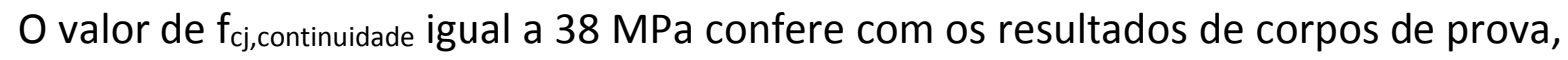
ensaiados aos 28 dias, fornecidos pelo fabricante (APÊNDICE B, Tabela APB1.2).

Utilizando as expressões 4.6 e 4.7 e o valor médio de $f_{c j \text {,caracterização }}(37,4 \mathrm{MPa})$, e, além disso, retroagindo de 95 dias (data da caracterização) para 28 dias (data dos ensaios dos corpos de prova), estima-se que o valor da resistência à compressão encontrado nos corpos de prova $\left(\mathrm{f}_{\mathrm{cj}, \mathrm{CP} \text { 's,estimado }}\right)$ é de 31,6 MPa, como mostra a Tabela 4.14.

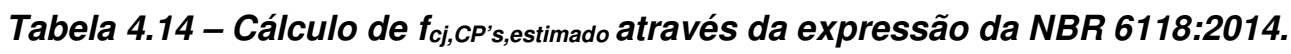

\begin{tabular}{c}
\hline $\mathbf{f}_{\mathbf{c j}, \mathbf{C P} \text { 's,estimado }}$ \\
\hline$\beta_{1}=\exp \left\{s \cdot\left[1-\left(t_{\text {caracterização }} / t_{C P \prime s}\right)^{1 / 2}\right]\right\}$ \\
$\beta_{1}=\exp \left\{0,20 \cdot\left[1-(95 / 28)^{1 / 2}\right]\right\}$ \\
$\beta_{1}=0,845$ \\
$f_{c j, C P^{\prime} \text { 's,estimado }}=f_{\text {cj,caracterização }} \cdot \beta_{1}$ \\
$f_{c j, C P^{\prime} \text { 's,estimado }}=37,38 \cdot 0,845$ \\
$f_{c j, C P^{\prime} \text { s,estimado }}=\mathbf{3 1 , 6} \mathrm{MPa}$ \\
\hline
\end{tabular}

O valor de 32,9 MPa é encontrado para $f_{c k}\left(f_{c j, 28}\right)$ quando se empregam os dados fornecidos pelo fabricante: $f_{c m}=41,65 \mathrm{MPa}$ e desvio padrão $S=5,3 \mathrm{MPa}$ (Tabela 4.15).

Tabela 4.15 - Cálculo de $f_{c j, C P ’ s}$ através da expressão da NBR 6118:2014.

\begin{tabular}{c}
\hline $\mathbf{f}_{\mathbf{c j}, \mathbf{C P} \text { 's }}$ \\
\hline$f_{c j, C P^{\prime \prime} s}=f_{c m}-(1,65 . S)$ \\
$f_{c j, C P^{\prime \prime} s}=41,65-(1,65.5,3)$ \\
$f_{c j, C P^{\prime \prime} s}=\mathbf{3 2}, \mathbf{9} M P a$ \\
\hline
\end{tabular}

\subsubsection{7 - Comparação $M_{r}$ teórico e experimental}

Na Tabela 3.29 do capítulo 3, os valores teóricos para Mr são: 194,1 kN.m para Formação de Fissuras e de 223,3 kN.m para Deformação excessiva. Já a Tabela 4.12 apresenta $M_{r}=197,95$ kN.m, obtido no ensaio de flexão. Esses resultados indicam que há coerência entre os valores teóricos e os experimentais, sendo que o valor de $\mathrm{Mr}_{r}$ experimental se aproxima muito do valor de $\mathrm{M}_{\mathrm{r}}$ teórico para Formação de Fissuras. 


\subsubsection{8 - Outros comentários}

Para concluir a caracterização da laje alveolar utilizada no EM2, é necessário fazer mais dois comentários. O primeiro é quanto à utilização das perdas. Igualmente ao que aconteceu na caracterização da laje do EM1, as perdas progressivas apresentaram resultados satisfatórios, enquanto que as perdas isoladas elevaram em aproximadamente

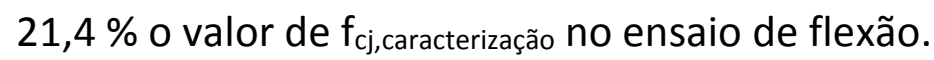

O segundo ponto a comentar é quanto à utilização do ensaio de cisalhamento. Nesse caso, esses valores não foram utilizados por apresentarem resultados sem coerência quando se utiliza a expressão 3.6 para o cálculo de $V_{R d 1}$. Os valores encontrados para

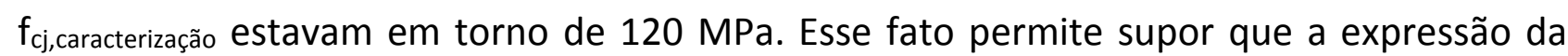
NBR 6118:2014, utilizada no cálculo de $V_{R d 1}$, não retratou satisfatoriamente os resultados de cisalhamento desse ensaio.

\subsection{3 - EM3}

Os ensaios de caracterização referentes às lajes do modelo EM3 foram feitos pelo autor desse trabalho, entre os dias 27 de Julho e 01 de Agosto de 2012, no NETPRE/UFSCar. Para facilitar os cálculos das perdas de protensão e também a apresentação dessas informações, adotou-se como data de referência o dia 27 de Julho de 2012 (ver Tabela 3.6). Logo, o tempo considerado para os ensaios de caracterização é de 39 dias. Na data do ensaio de continuidade, as lajes estavam com 37 dias de idade.

\subsubsection{1 - Descrição dos ensaios}

Foram realizados cinco ensaios, como mostra a Tabela 4.16. Para se obter a distância entre a face da laje alveolar e o centro do apoio foi utilizado um critério prático. Esse critério é de $\mathrm{h} / 2$. No caso da laje com seção composta, o critério foi utilizado considerando a altura total do elemento ensaiado. As Figuras 4.19 e 4.20 apresentam, respectivamente, um desenho esquemático e uma foto panorâmica do ensaio EM3-L1.

Tabela 4.16 - Ensaios de caracterização para as lajes alveolares do EM3.

\begin{tabular}{|c|c|c|}
\hline LAJES & Tipo de ensaio & Seção \\
\hline EM3-L1 & Flexão & Composta \\
\hline EM3-L2 & Flexão & Simples \\
\hline EM3-L3 & Flexão & Simples \\
\hline EM3-L4-A & Cisalhamento & Simples \\
\hline EM3-L4-B & Cisalhamento & Simples \\
\hline
\end{tabular}




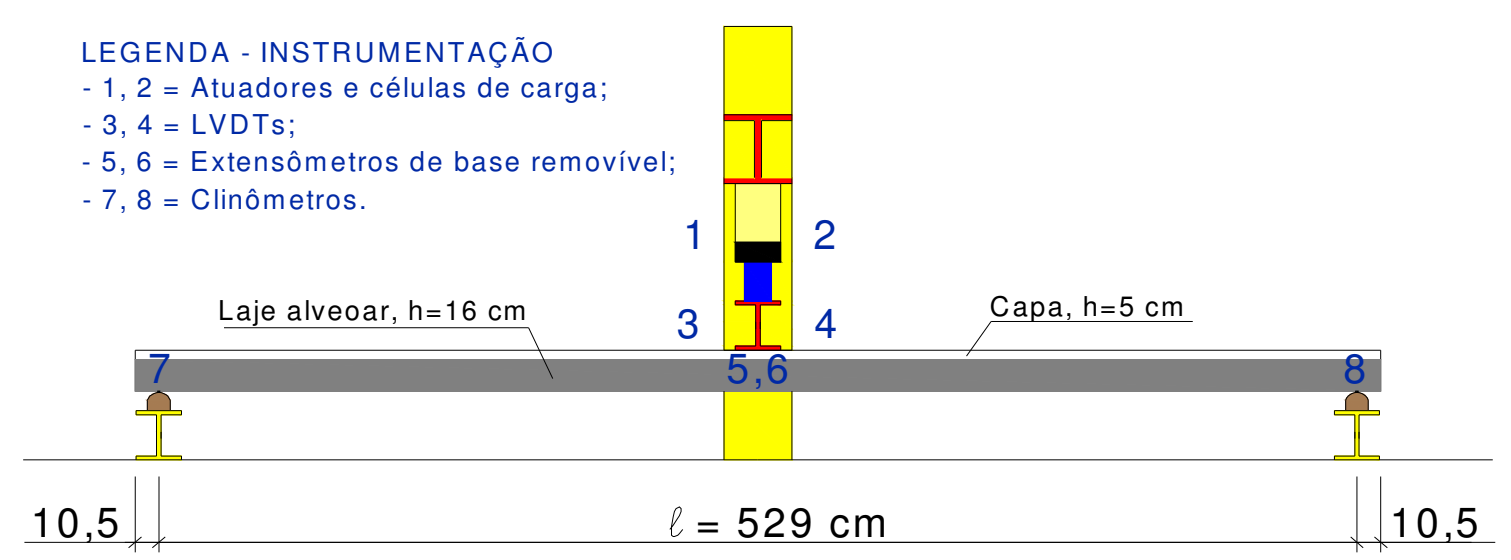

Figura 4.19 - Desenho esquemático do ensaio de flexão da laje EM3-L1.

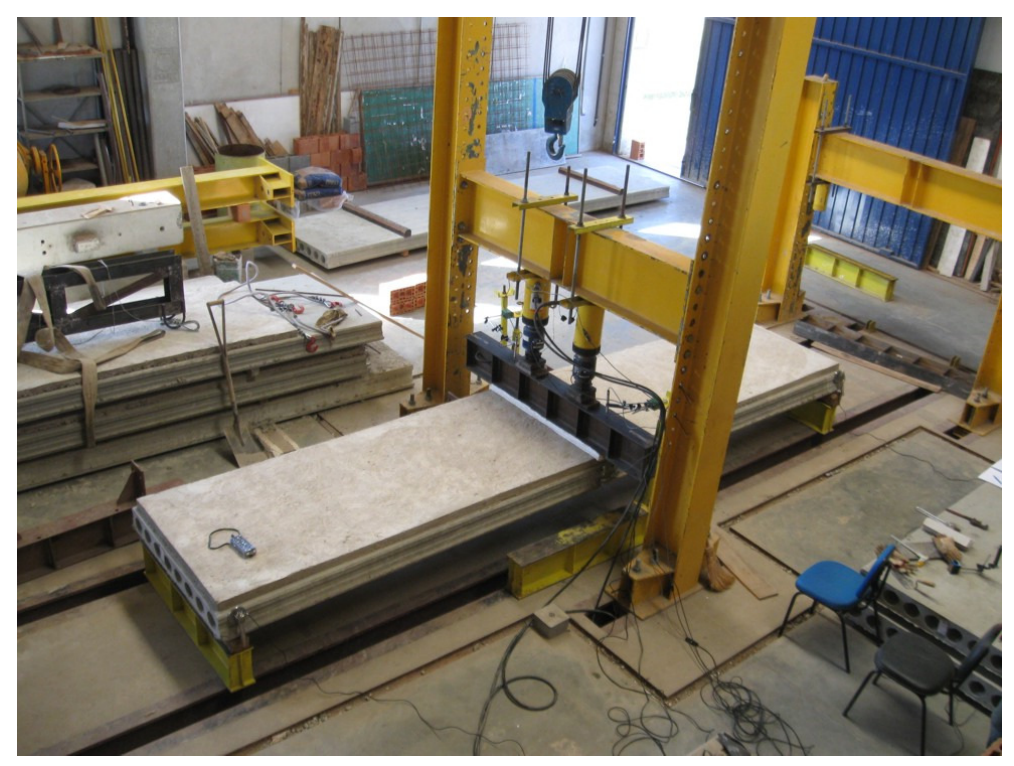

Figura 4.20 - Foto do ensaio de flexão da laje EM3-L1.

A Figura 4.21 mostra fotos dos ensaios de flexão de lajes sem capa (EM3-L2 e EM3L3). O desenho esquemático do ensaio é o mesmo apresentado na Figura 4.19, porém com as lajes sem a capa. A distância entre a extremidade da laje e o centro do apoio era de $8 \mathrm{~cm}$, sendo altura da laje de $16 \mathrm{~cm}$. Por consequência, o vão era de 5,34 m.

Os ensaios de cisalhamento foram feitos em uma única laje, ambos considerando 2,5 h como a medida entre o centro do apoio e o centro da linha de aplicação da carga. Primeiro, o ensaio foi feito em um lado (laje EM3-L4-A), com a laje intacta. Depois a laje foi girada para que o ensaio pudesse ser refeito (EM3-L4-B). Portanto, no segundo ensaio, a laje estava com o lado oposto rompida por cisalhamento.

As Figuras 4.22 e 4.23 apresentam o desenho esquemático e uma foto com visão panorâmica do ensaio EM3-L4-A, enquanto que as Figuras 4.24 e 4.25 são relativas ao ensaio EM3-L4-B. 


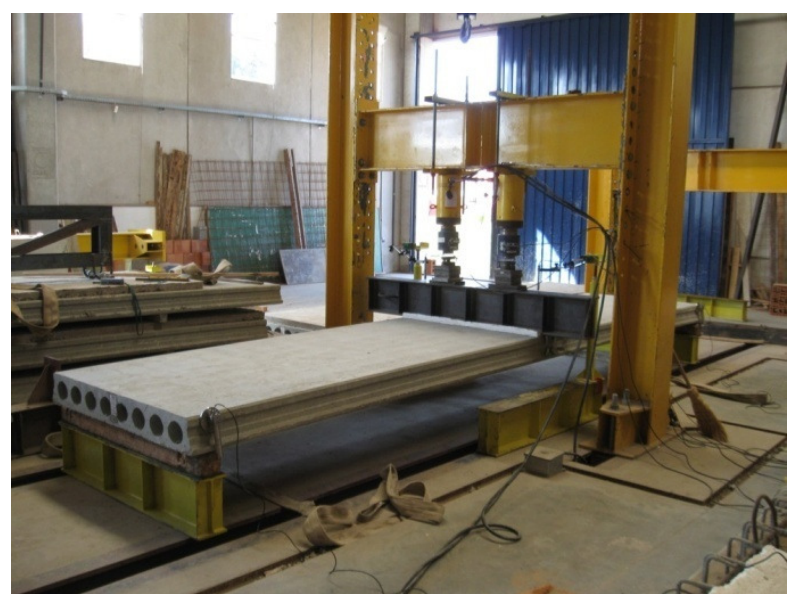

(a)

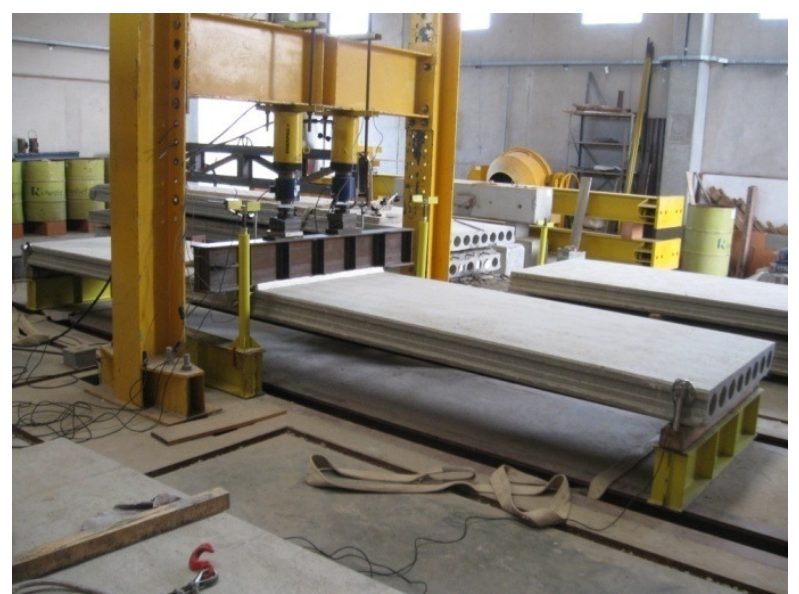

(b)

Figura 4.21 - Fotos dos ensaios de caracterização de lajes sem capa.

(a) EM3-L2; (b) EM3-L3.

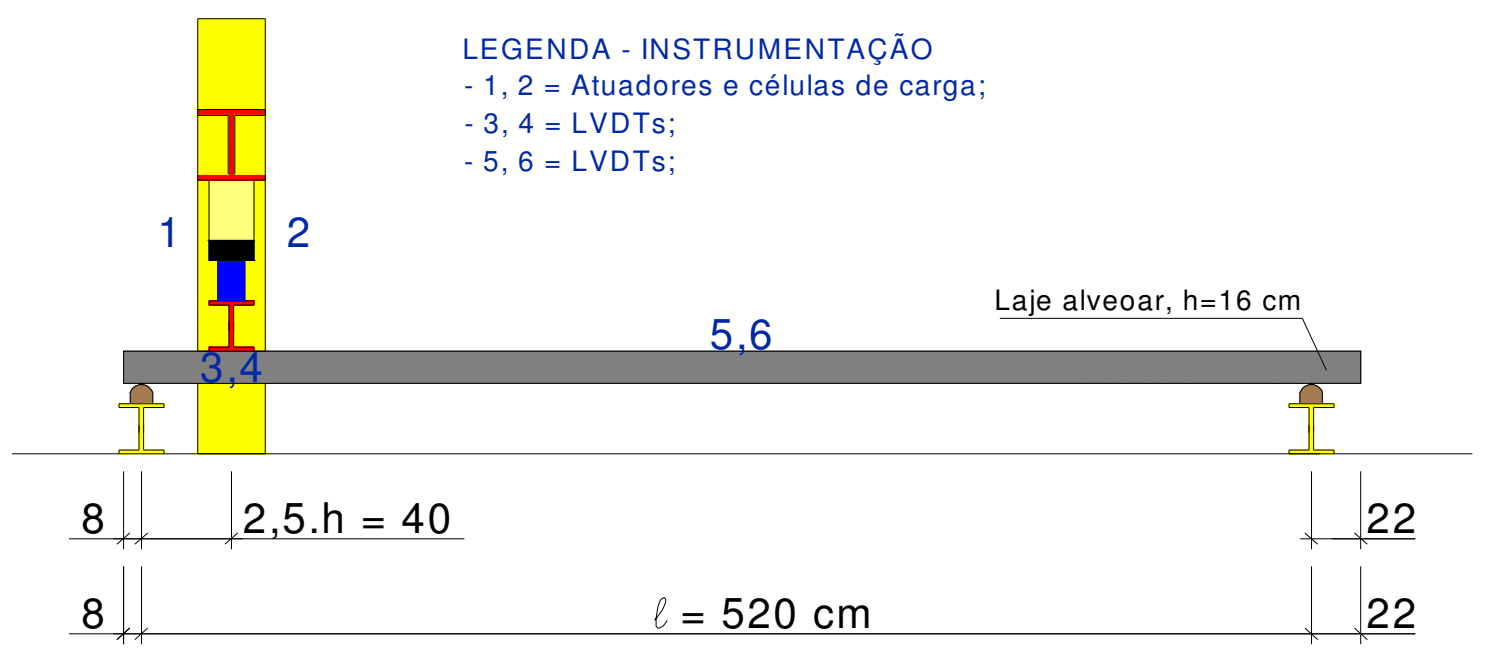

Figura 4.22 - Desenho esquemático do ensaio de cisalhamento da laje EM3-L4-A.

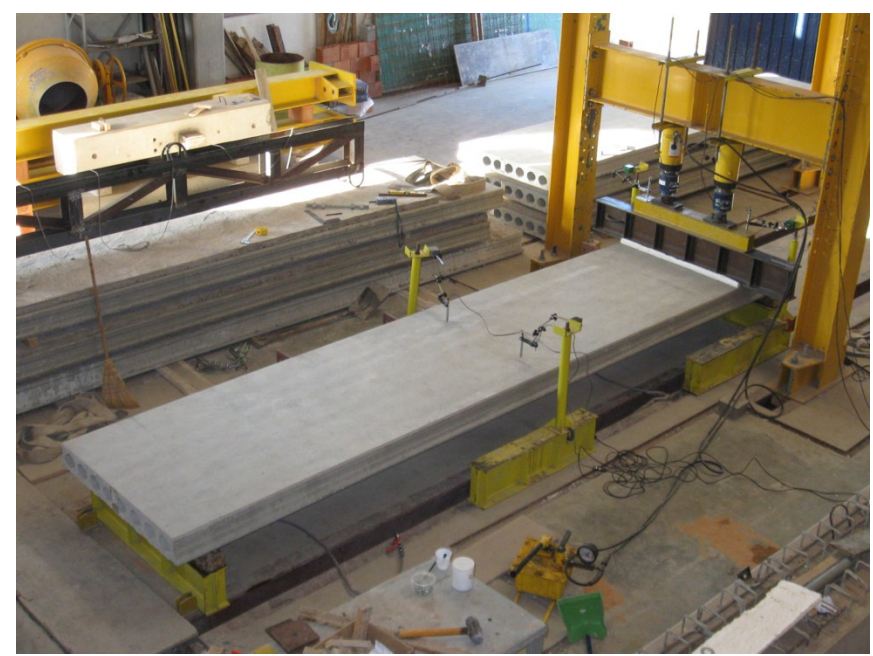

Figura 4.23 - Foto do ensaio de cisalhamento da laje EM3-L4-A. 


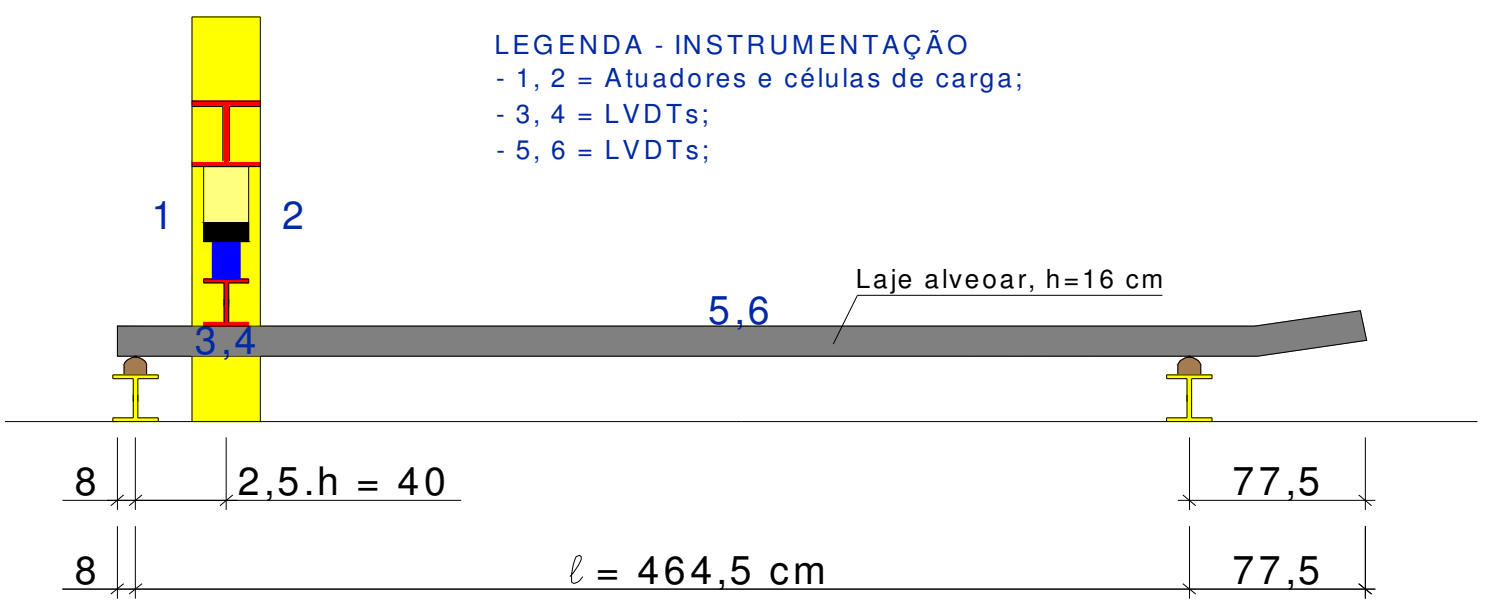

Figura 4.24 - Desenho esquemático do ensaio de cisalhamento da laje EM3-L4-B.

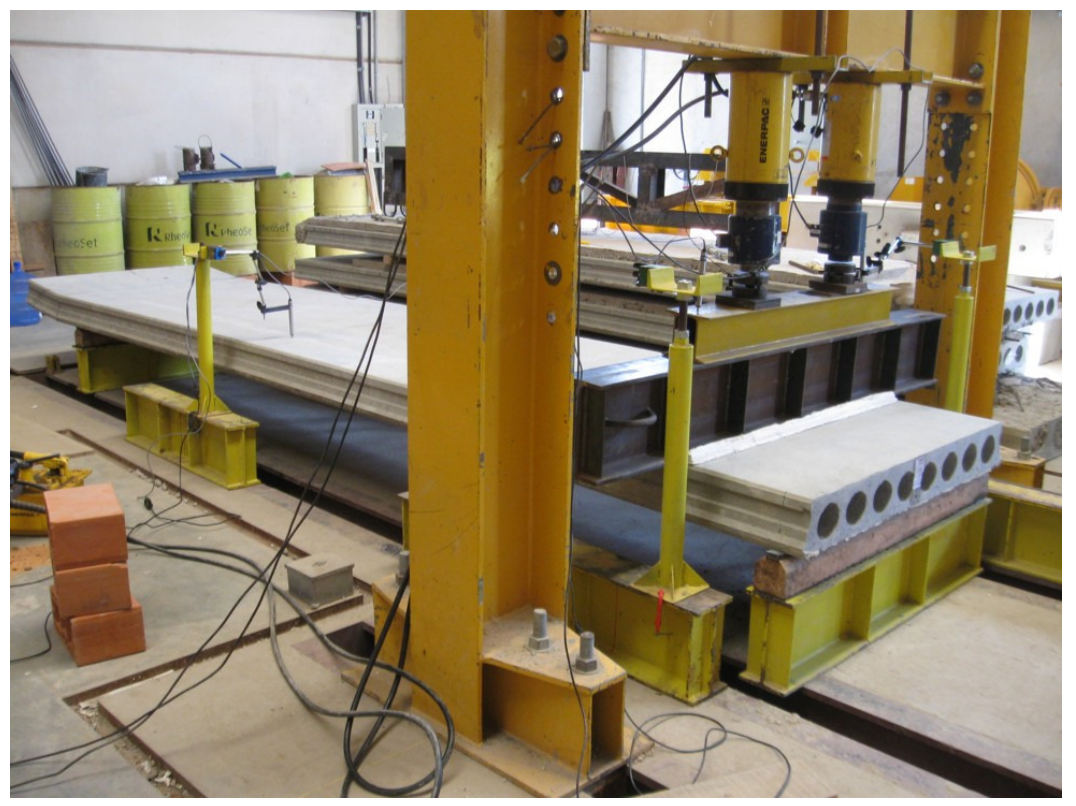

Figura 4.25 - Foto do ensaio de cisalhamento da laje EM3-L4-B.

\subsubsection{2 - Resultados}

A seguir são apresentados os gráficos força versus deslocamento dos cinco ensaios realizados para o modelo EM3. Lembra-se que a nomenclatura adotada para força aplicada no ensaio de flexão é $F_{1}$, e no ensaio de cisalhamento é $F_{1, Q}$. Neste tópico, serão mostrados apenas os resultados de deslocamentos no meio do vão, ou seja, nos pontos de instrumentação 3 e 4 para flexão, mostrados na Figura 4.19, e os pontos 5 e 6, indicados nas Figuras 4.22 e 4.24 .

A Figura 4.26 apresenta o gráfico que correlaciona a força $F_{1}$, aplicada no meio do modelo, o deslocamento $\delta$, também no meio do modelo, para a laje EM3-L1 (modelo com capa). 


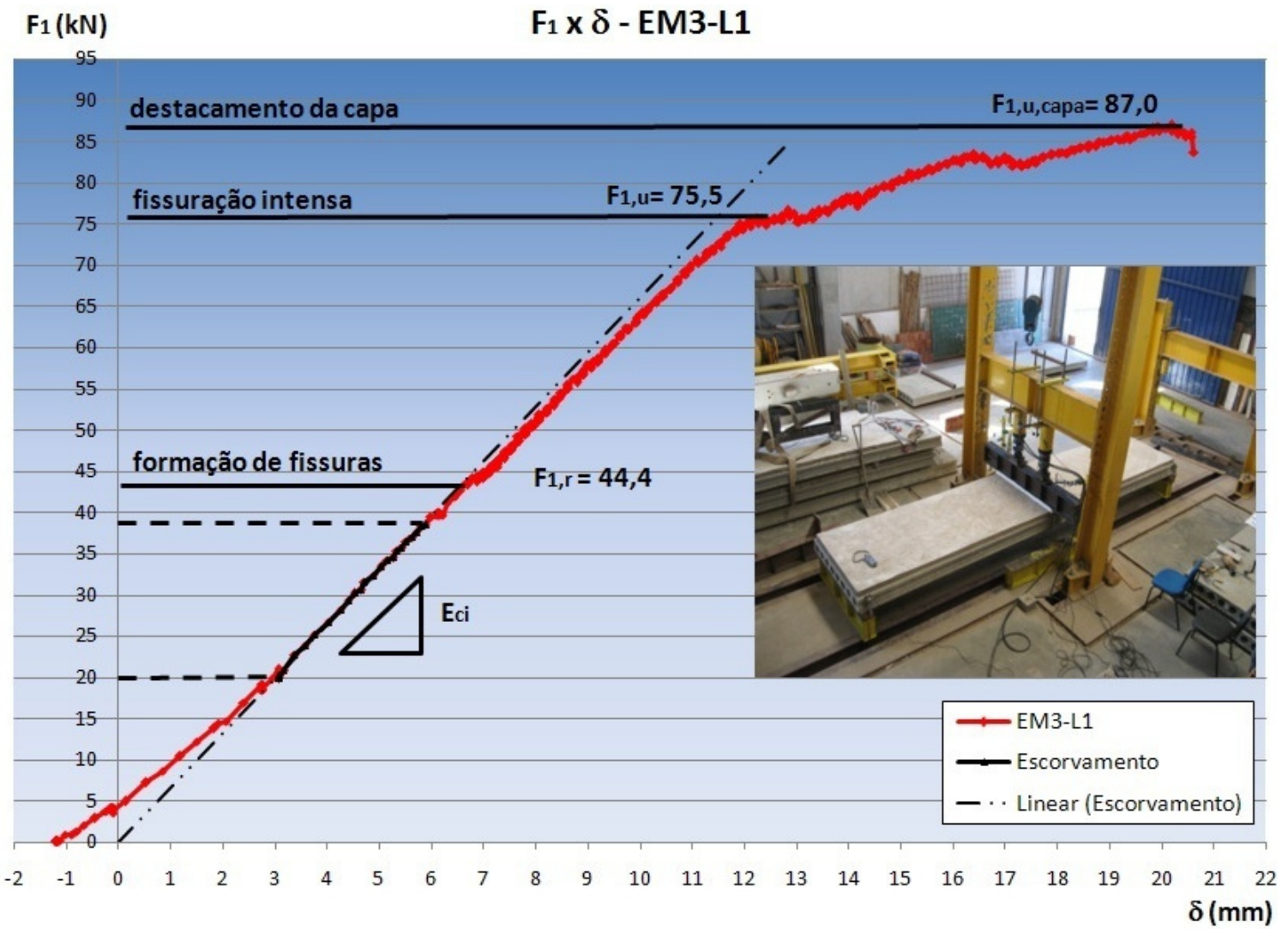

Figura 4.26 - Gráfico $F_{1}$ x $\delta$ do ensaio de flexão da laje EM3-L1 (com capa).

As Figuras 4.27 e 4.28 mostram o diagrama $F_{1} \times \delta$, para os ensaios EM3-L2 e EM3-L3, respectivamente.

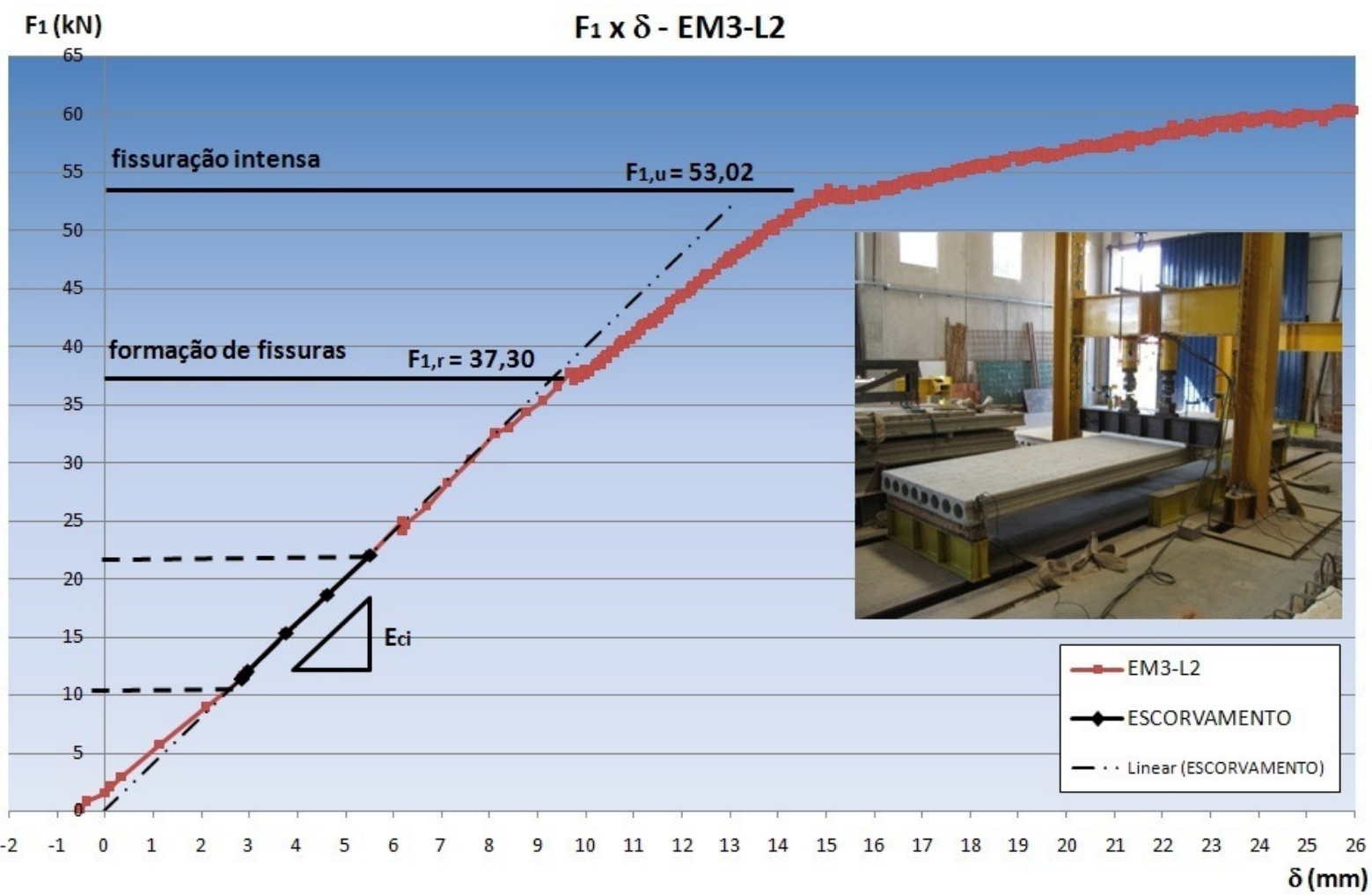

Figura 4.27 - Gráfico $F_{1}$ x $\delta$ do ensaio de flexão da laje EM3-L2 (sem capa). 


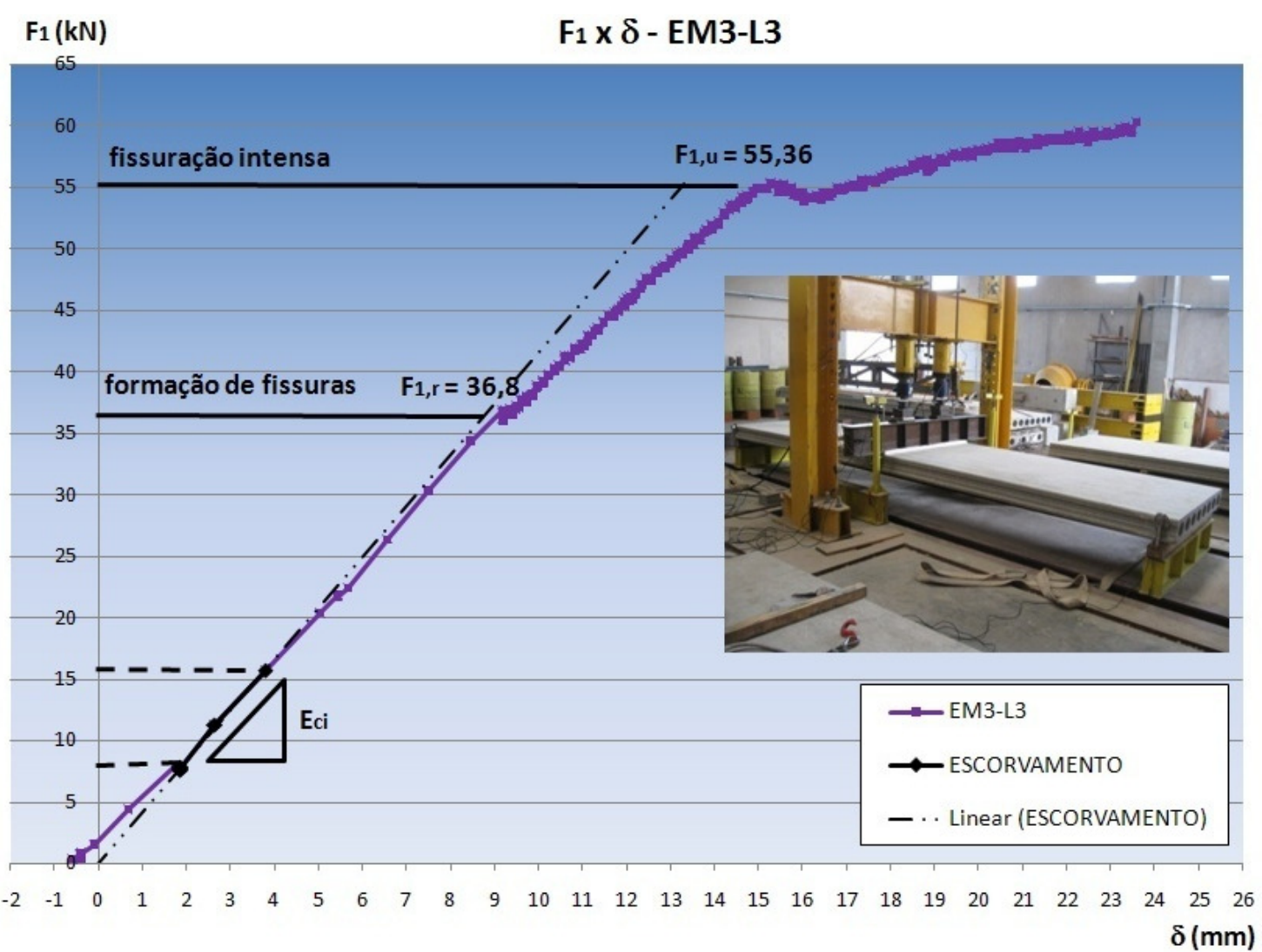

Figura 4.28 - Gráfico $F_{1}$ x $\delta$ do ensaio de flexão da laje EM3-L3 (sem capa).

A Figura 4.29 mostra o gráfico que relaciona $F_{1, Q}$ aplicada à $2,5 \mathrm{~h}$ do apoio (Figura 4.22) e $\delta$ lido no meio do modelo, para a laje EM3-L4-A e EM3-L4-B.

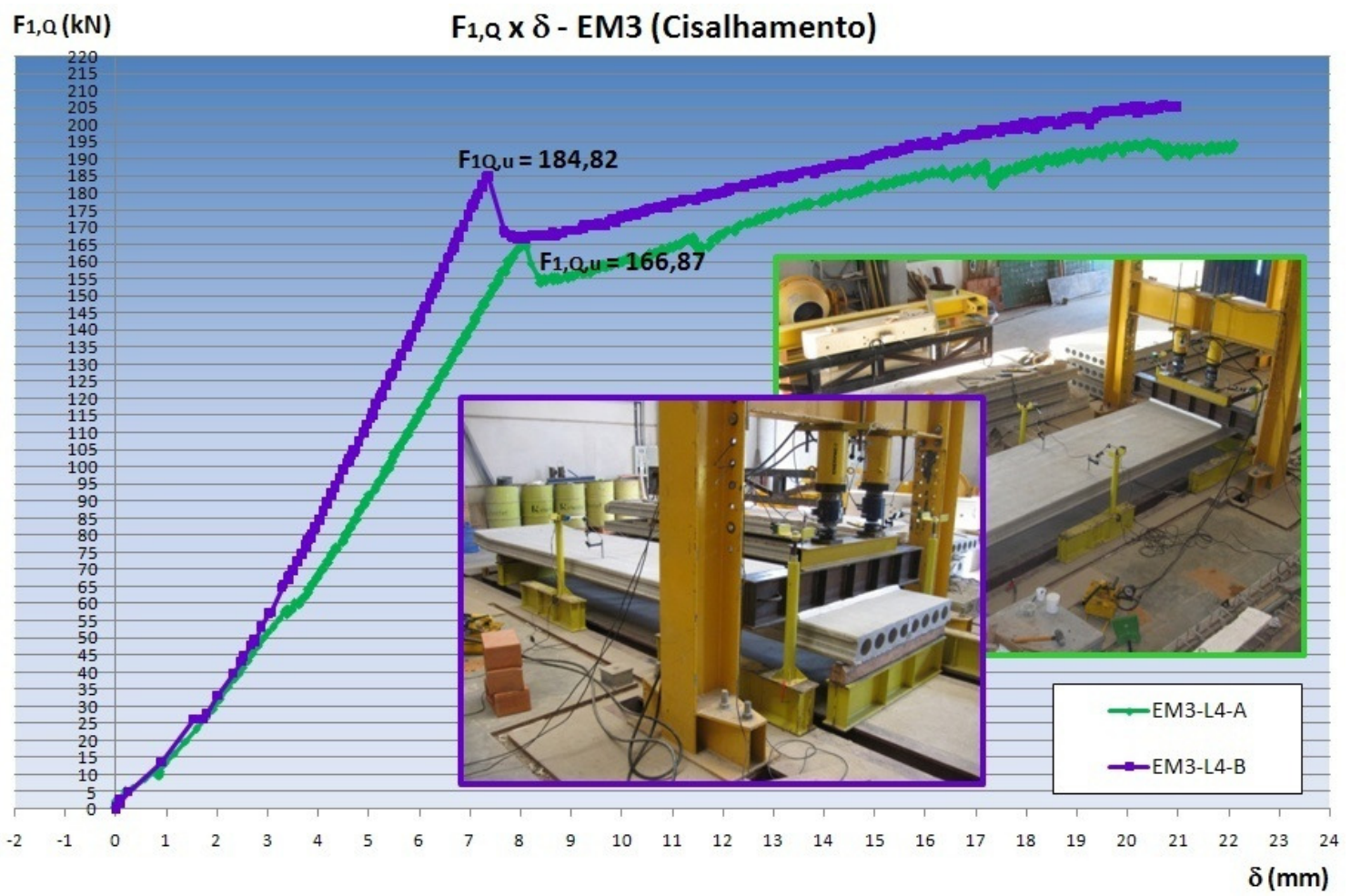

Figura 4.29 - Gráfico $F_{1} X \delta$ do ensaio de cisalhamento (EM3-L4-A e EM3-L4-B). 
Pela forma como foram feitos os ensaios do modelo EM3, é possível obter o valor

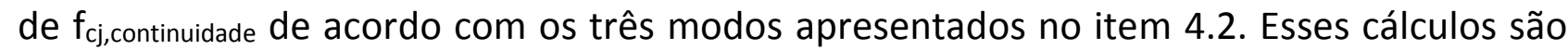
mostrados a seguir.

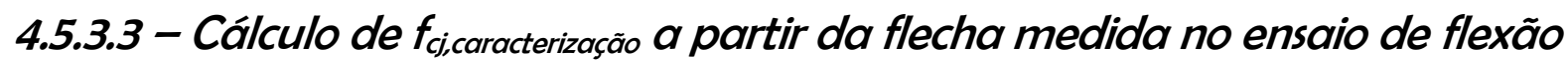

Primeiramente, $f_{c j}$,caracterização será avaliado, de forma indireta, com base no módulo de elasticidade efetivo do concreto da laje alveolar $\left(E_{c, e f}\right)$, obtido a partir da flecha obtida no ensaio de flexão (ver item 4.2.3).

Após correção dos gráficos, em função da acomodação do modelo carregado, definiu-se o trecho correspondente ao valor do módulo de elasticidade tangente inicial $\left(E_{c i}\right)$. Tal trecho é destacado nas Figuras 4.26, 4.27 e 4.28. A Tabela 4.17 apresenta pares de força e deslocamento em três pontos das figuras anteriormente citadas. Ela mostra também os pares correspondentes aos pontos de fissuração e de ruptura, relativos aos ensaios.

Tabela 4.17 - Valores de $F_{1} \times \delta$ para os trechos iniciais dos ensaios de flexão.

\begin{tabular}{|c|c|c|c|}
\hline LAJES & \multicolumn{2}{|c|}{$F_{1}(k N)$} & $\delta(\mathbf{m m})$ \\
\hline \multirow{6}{*}{$\begin{array}{c}\text { EM3-L1 } \\
\text { (laje com capa) }\end{array}$} & $\mathrm{F}_{1, \mathrm{u}, \mathrm{capa}}$ & 87,0 & 20,19 \\
\hline & $\mathrm{F}_{1, \mathrm{u}}$ & 75,5 & 12,73 \\
\hline & $\mathrm{F}_{1, \mathrm{r}}$ & 44,4 & 6,87 \\
\hline & $51,0 \% \mathrm{~F}_{1, \mathrm{u}}$ & 38,5 & 5,89 \\
\hline & $40,0 \% F_{1, u}$ & 30,2 & 4,53 \\
\hline & $27,7 \% \mathrm{~F}_{1, \mathrm{u}}$ & 20,9 & 3,06 \\
\hline \multirow{5}{*}{$\begin{array}{c}\text { EM3-L2 } \\
\text { (laje sem capa) }\end{array}$} & $\mathrm{F}_{1, \mathrm{u}}$ & 53,0 & 14,84 \\
\hline & $\mathrm{F}_{1, \mathrm{r}}$ & 37,3 & 10,09 \\
\hline & $41,5 \% F_{1, u}$ & 22,0 & 5,52 \\
\hline & $28,9 \% F_{1, u}$ & 15,3 & 3,78 \\
\hline & $22,6 \% \mathrm{~F}_{1, \mathrm{u}}$ & 11,3 & 2,86 \\
\hline \multirow{5}{*}{$\begin{array}{c}\text { EM3-L3 } \\
\text { (laje sem capa) }\end{array}$} & $\mathrm{F}_{1, \mathrm{u}}$ & 55,4 & 15,27 \\
\hline & $\mathrm{F}_{1, \mathrm{r}}$ & 36,8 & 9,18 \\
\hline & $28,3 \% F_{1, u}$ & 15,7 & 3,80 \\
\hline & $20,2 \% F_{1, u}$ & 11,2 & 2,64 \\
\hline & $14,1 \% F_{1, u}$ & 7,8 & 1,74 \\
\hline
\end{tabular}

Utilizando os pares $F_{1} \times \delta$ da Tabela 4.17, nos trechos correspondentes ao módulo

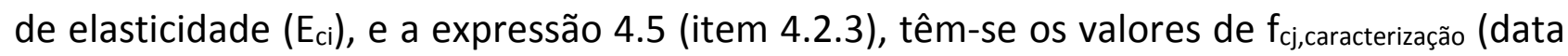
do ensaio de caracterização) para a laje EM3, apresentados na Tabela 4.18. Essa tabela não considera os dados da laje EM3-L1, uma vez que este é composto por capa estrutural. 
Tabela 4.18 - Valores de $F_{1}$ x $\delta$ para as etapas iniciais dos ensaios de flexão.

\begin{tabular}{|c|c|c|c|c|c|}
\hline LAJES & \multicolumn{2}{|c|}{$\mathbf{F}_{1}(\mathbf{k N})$} & $\delta(\mathbf{m m})$ & $\begin{array}{c}\mathbf{E}_{c i} \\
(\mathbf{M P a})\end{array}$ & $\begin{array}{c}\mathbf{f}_{\text {cj,caracterização }} \\
\text { (MPa) }\end{array}$ \\
\hline \multirow{4}{*}{$\begin{array}{c}\text { EM3-L2 } \\
\text { (laje sem capa) }\end{array}$} & $41,5 \% \mathrm{~F}_{1, \mathrm{u}}$ & 22,0 & 5,52 & 31462 & 32 \\
\hline & $28,9 \% \mathrm{~F}_{1, \mathrm{u}}$ & 15,3 & 3,78 & 32059 & 33 \\
\hline & $22,6 \% \mathrm{~F}_{1, \mathrm{u}}$ & 11,3 & 2,86 & 31666 & 33 \\
\hline & \multicolumn{4}{|r|}{ Média } & 33 \\
\hline \multirow{4}{*}{$\begin{array}{c}\text { EM3-L3 } \\
\text { (laje sem capa) }\end{array}$} & $28,3 \% \mathrm{~F}_{1, \mathrm{u}}$ & 15,7 & 3,80 & 35461 & 40 \\
\hline & $20,2 \% \mathrm{~F}_{1, \mathrm{u}}$ & 11,2 & 2,64 & 33706 & 36 \\
\hline & $14,1 \% \mathrm{~F}_{1, \mathrm{u}}$ & 7,8 & 1,74 & 32663 & 34 \\
\hline & \multicolumn{4}{|r|}{ Média } & 37 \\
\hline \multicolumn{5}{|c|}{ Média entre EM3-L2 e EM3-L3 * } & 35 \\
\hline
\end{tabular}

(*) Descartando os resultados da EM3-L1, pois trata-se de um ensaio com capa.

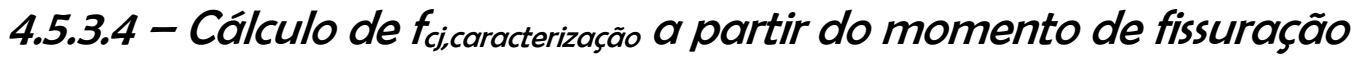

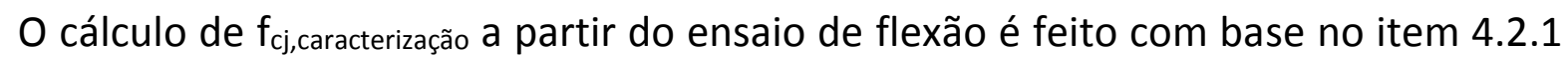
(deste capítulo), e é apresentado na Tabela 4.19, para as lajes EM3-L2 e EM3-L3.

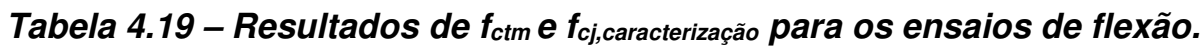

\begin{tabular}{|c|c|c|c|c|}
\hline \multicolumn{5}{|c|}{ DADOS INICIAIS } \\
\hline $1(\mathrm{~m})$ & 5,34 & \multicolumn{2}{|c|}{$\mathrm{g}_{1}(\mathrm{kN} / \mathrm{m})$} & 1,50 \\
\hline $\mathrm{h}(\mathrm{m})$ & 0,16 & \multicolumn{2}{|c|}{$\begin{array}{l}\text { Peso próprio da viga de ensaio } \\
\qquad(\mathrm{kN})\end{array}$} & 0,94 \\
\hline$N_{s k, p t, \infty, i n f}(\mathrm{kN})$ & 305,40 & \multicolumn{2}{|c|}{$N_{s k, p t, \infty, s u p}(\mathrm{kN})$} & 12,37 \\
\hline$e_{p, i n f}(\mathrm{~m})$ & 0,0493 & \multicolumn{2}{|c|}{$e_{p, \text { sup }}(\mathrm{m})$} & 0,0507 \\
\hline$y_{t, \text { inf }}(\mathrm{m})$ & 0,0793 & \multicolumn{2}{|c|}{$y_{t, \text { sup }}(\mathrm{m})$} & 0,0807 \\
\hline$A_{c}\left(\mathrm{~m}^{2}\right)$ & 0,1166 & - & - & - \\
\hline$I_{C}\left(\mathrm{~m}^{4}\right)$ & 0,0004 & \multicolumn{2}{|c|}{$\alpha$} & 1,5 \\
\hline \multicolumn{5}{|c|}{ ENSAIO DE FLEXÃO } \\
\hline Variável & EM3-L1* & EM3-L2 & EM3-L3 & $\begin{array}{c}\text { EM3- } \\
\text { (MÉDIO) }\end{array}$ \\
\hline$M_{r, \exp }(\mathrm{kN} . \mathrm{m})$ & - & 61,46 & 60,79 & 61,12 \\
\hline$f_{c t m}(\mathrm{MPa})$ & - & 4,39 & 4,30 & 4,34 \\
\hline cj,caracterização (MPa) & - & 56 & 54 & 55 \\
\hline
\end{tabular}

(*) Descartando os resultados da EM3-L1, pois trata-se de um ensaio com capa. 


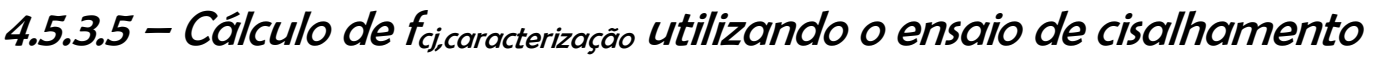

Assim como ocorreu com o modelo EM2, o ensaio de cisalhamento não foi satisfatório. Portanto, não foi utilizado.

A Figura 4.29 mostra os valores da força de ruptura $\left(F_{1, Q}\right)$ relativos aos ensaios de cisalhamento: $F_{1, Q}=166,87$ kN (EM3-L4-A) e $F_{1, Q}=184,82$ kN (EM3-L4-B). Quando esses valores são usados no cálculo de $f_{c j}$,caracterização pela expressão de $V_{R d 1}$ (ver item 4.2.2), obtêm-se resultados para $f_{c j}$,caracterização incoerentes: 174,3 MPa para EM3-L4-A e 200,1 MPa para EM3-L4-B.

Esse fato permite supor que a expressão da NBR 6118:2014, utilizada no cálculo de

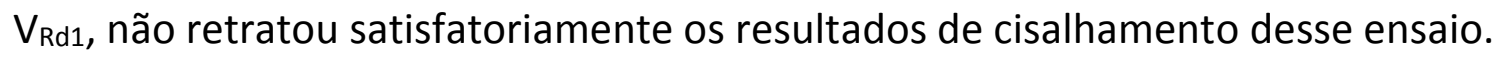

\subsubsection{6 - Cálculo de $f_{c j \text { continuidade }}$}

De acordo com a Tabela 3.6, as lajes do modelo EM3 foram ensaiadas com 39 dias após a fabricação. Além disso, o $\mathrm{f}_{\mathrm{ck}}$ dessa laje é de $40 \mathrm{MPa}$. Com base nesses dados, preferiu-se ignorar o resultado de $f_{c j \text {,caracterização }}=35 \mathrm{MPa}$, obtido a partir da flecha medida

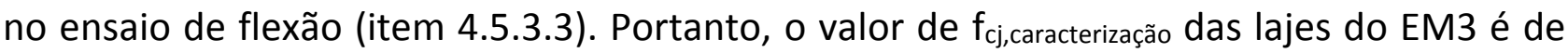
$55 \mathrm{MPa}$, obtido a partir do momento de fissuração (item 4.5.3.4).

Utilizando as expressões 4.6 e 4.7, conclui-se que o valor da resistência do concreto à compressão na data do ensaio de continuidade ( $f_{c j}$,continuidade $)$ é de $55 \mathrm{MPa}$ (Tabela 4.20).

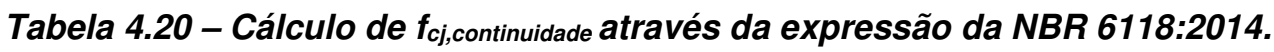

\begin{tabular}{|c|c|}
\hline \multicolumn{2}{|c|}{$\mathbf{f}_{\text {cj,continuidade }}$} \\
\hline \multicolumn{2}{|c|}{$\begin{array}{c}\beta_{1}=\exp \left\{s \cdot\left[1-\left(t_{\text {caracterização }} / t_{\text {continuidade }}\right)^{1 / 2}\right]\right\} \\
\beta_{1}=\exp \left\{0,20 \cdot\left[1-(39 / 37)^{1 / 2}\right]\right\} \\
\beta_{1}=0,9947\end{array}$} \\
\hline $\begin{aligned} f_{c j, \text { continuidade }} & =f_{c j, \text { caracterização }} \cdot \beta_{1} \\
f_{c j, \text { continuidade }} & =55 \cdot 0,9947 \\
f_{c j, \text { continuidade }} & =\mathbf{5 5} \mathrm{MPa}\end{aligned}$ & $\begin{aligned} f_{c t m, \text { continuidade }} & =f_{c t m, \text { caracterização }} \cdot \beta_{1} \\
f_{c t m, \text { continuidade }} & =4,34 \cdot 0,9947 \\
f_{c t m, \text { continuidade }} & =4,32 \mathrm{MPa}\end{aligned}$ \\
\hline
\end{tabular}

\subsubsection{7 - Comparação com resultados dos corpos de prova}

O valor de $\mathrm{f}_{\mathrm{cj} \text {,continuidade }}=55 \mathrm{MPa}$ fica coerente com os resultados de corpos de prova, ensaiados aos 7 dias, fornecidos pelo fabricante $\left(f_{c m}=41,6 \mathrm{MPa}\right.$ e desvio padrão $S=2,0$ MPa). 


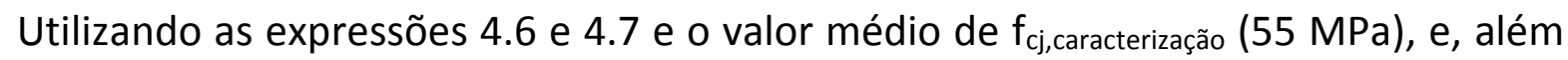
disso, retroagindo de 39 dias (data da caracterização) para 7 dias (data dos ensaios dos corpos de prova), estima-se que o valor da resistência à compressão encontrado nos

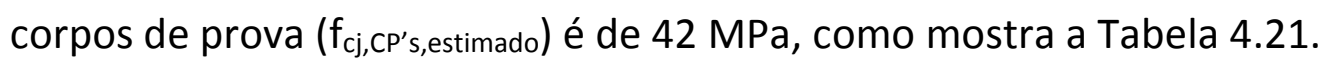

O valor de $38,3 \mathrm{MPa}$ é encontrado para $\mathrm{f}_{\mathrm{cj}, \mathrm{CP} \text { 's }}$ quando se empregam os dados fornecidos pelo fabricante: $f_{c m}=41,6 \mathrm{MPa}$ e desvio padrão $S=2,0 \mathrm{MPa}$ (Tabela 4.22).

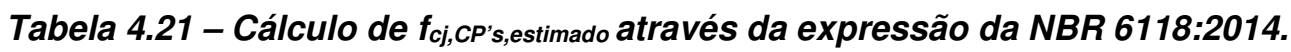

\begin{tabular}{c}
$\mathbf{f}_{\mathbf{c j}, \mathbf{C P} \text { 's,estimado }}$ \\
\hline$\beta_{1}=\exp \left\{s \cdot\left[1-\left(t_{\text {caracterização }} / t_{C P \prime s}\right)^{1 / 2}\right]\right\}$ \\
$\beta_{1}=\exp \left\{0,20 \cdot\left[1-(39 / 7)^{1 / 2}\right]\right\}$ \\
$\beta_{1}=0,7618$ \\
$f_{c j, C P^{\prime}{ }^{\prime}, \text { estimado }}=f_{c j, \text { caracterização }} \cdot \beta_{1}$ \\
$f_{c j, C P{ }^{\prime} \text { s,estimado }}=55 \cdot 0,7618$ \\
$f_{c j, C P ' \text { s,estimado }}=\mathbf{4 2 M P a}$ \\
\hline
\end{tabular}

Tabela 4.22 - Cálculo de $f_{c j, C P ’ s}$ através da expressão da NBR 6118:2014.

$$
\begin{gathered}
\mathbf{f}_{\mathbf{c j}, \mathbf{C P}{ }^{\prime} \mathbf{s}} \\
f_{c j, C P^{\prime \prime} s}=f_{c m}-(1,65 . S) \\
f_{c j, C P^{\prime \prime} s}=41,6-(1,65.2,0) \\
f_{c j, C P^{\prime \prime} s}=\mathbf{3 8}, \mathbf{3} \mathrm{MPa}
\end{gathered}
$$

\subsubsection{8 - Comparação $M_{r}$ teórico e experimental}

Na Tabela 3.29 do capítulo 3, os valores teóricos para $M_{r}$ são de 58,67 kN.m para Formação de Fissuras e de 69,68 kN.m para Deformação Excessiva. Já a Tabela 4.19 apresenta $M_{r}=61,12 \mathrm{kN} . \mathrm{m}$, obtido no ensaio de flexão. Esses valores indicam que há coerência entre os valores teóricos e os experimentais, sendo que o valor de $\mathrm{Mr}_{\mathrm{r}}$ experimental se aproxima muito do valor de $\mathrm{M}_{\mathrm{r}}$ teórico, para Formação de Fissuras.

\subsection{4 - Conclusões e resumo dos resultados}

Após os cálculos apresentados para a resistência à compressão do concreto na data do ensaio de continuidade $\left(f_{c j}\right.$,continuidade), apresenta-se neste item um resumo com dos resultados (Tabela 4.23 ). 
Tabela 4.23 - Resumos dos resultados dos ensaios de caracterização das lajes

\begin{tabular}{|c|c|c|c|}
\hline Variável & EM1 & EM2 & EM3 \\
\hline$f_{c k}(\mathrm{MPa})$ & 40 & 30 & 40 \\
\hline $\begin{array}{l}\text { Idade da laje na data dos ensaios de } \\
\text { caracterização (dias) }\end{array}$ & 53 & 95 & 39 \\
\hline$f_{c j, c a r a c t e r i z a c ̧ a ̃ o}(\mathrm{MPa})$ & 51 & 37,4 & 55,0 \\
\hline $\begin{array}{l}\text { Idade da laje na data dos ensaios de } \\
\text { continuidade (dias) }\end{array}$ & 100 & 112 & 37 \\
\hline$f_{c j, \text { continuidade }}(\mathrm{MPa})$ & 54 & 38 & 55 \\
\hline $\mathrm{E}_{\mathrm{ce}}(\mathrm{MPa})$ & - & 34305 & - \\
\hline \multicolumn{4}{|c|}{ MÉTODOS UTILIZADOS (ITEM 4.2) } \\
\hline Momento de fissuração (ensaio de flexão) & SIM & SIM & SIM \\
\hline $\begin{array}{l}\text { Módulo de elasticidade obtido pela leitura dos } \\
\text { deslocamentos (ensaio de flexão) }\end{array}$ & $\begin{array}{l}\text { NÃO existe a } \\
\text { possibilidade }\end{array}$ & SIM & IGNORADO \\
\hline Cisalhamento & SIM & IGNORADO & IGNORADO \\
\hline
\end{tabular}

Os cálculos apresentados no item 4.5 permitem concluir as seguintes informações para as lajes ensaiadas:

- A utilização das Perdas Progressivas gerou resultados mais próximos, entre os métodos de momento de fissuração e cisalhamento;

- A fórmula para estimar o $V_{R d 1}$ da NBR 6118:2014 (expressão 3.6) não foi satisfatória para representar os ensaios dos modelos EM2 e EM3;

- O método do módulo de elasticidade não foi satisfatório para o modelo EM3. Já para o modelo EM2, os resultados ficaram próximos aos do método do momento de fissuração;

- O método do momento de fissuração foi o único utilizado nos três modelos e apresentou, para todos, resultados coerentes com os estimados no capítulo 3.

\section{6 - Ensaios de caracterização da capa}

Os ensaios de caracterização do concreto da capa foram feitos no Laboratório de Sistemas Estruturais do Departamento de Engenharia Civil da Universidade Federal de São Carlos (LSE/DECiv/UFSCar). Foram utilizados corpos de prova cilíndricos, com diâmetro de $100 \mathrm{~mm}$ e altura de $200 \mathrm{~mm}$.

Novamente, optou-se por reproduzir a Tabela 3.6, que mostra as datas das principais etapas: de concretagem do concreto, dos ensaios de caracterização e dos ensaios de continuidade. 
Os resultados dos ensaios dos corpos de prova correspondentes ao concreto das capas são mostrados no APÊNDICE B.

Tabela 3.6 - Datas dos ensaios.

\begin{tabular}{|c|c|c|c|}
\hline Variáveis & EM1 & EM2 & EM3 \\
\hline Moldagem da laje na fábrica & $28 / 11 / 2011$ & $15 / 02 / 2012$ & $18 / 06 / 2012$ \\
\hline $\begin{array}{c}\text { Ensaios dos CP's da laje na } \\
\text { fábrica }\end{array}$ & $05 / 12 / 2011$ & $14 / 03 / 2012$ & $25 / 06 / 2012$ \\
\hline $\begin{array}{c}\text { Ensaios de caracterização da laje } \\
\text { no NETPRE }\end{array}$ & $20 / 01 / 2012$ & $20 / 05 / 2012$ & $27 / 07 / 2012$ \\
\hline $\begin{array}{c}\text { Moldagem da capa } \\
\text { Ensaio do modelo de } \\
\text { continuidade }\end{array}$ & $17 / 02 / 2012$ & $23 / 05 / 2012$ & $11 / 07 / 2012$ \\
\hline $\begin{array}{c}\text { Ensaios de caracterização dos } \\
\text { CP's da capa no LSE }\end{array}$ & $16 / 03 / 2012$ & $20 / 06 / 2012$ & $26 / 07 / 2012$ \\
\hline
\end{tabular}

\subsection{1 - Determinação da resistência à compressão}

Os resultados dos ensaios dos corpos de prova para a determinação da resistência à compressão, realizados de acordo com a NBR 5739:2007, são apresentados nas Tabelas APB2.1, APB2.2 e APB2.3 do APÊNDICE B.

Foram moldados três corpos de prova para cada ensaio de resistência à compressão (Figura 4.30a), sendo ensaiados até a ruptura em prensa servo-hidráulica, com velocidade de carregamento de 0,3 MPa/s (Figura 4.30b). Todos os corpos de prova foram submetidos à cura por imersão.

A Tabela APB2.1 (APÊNDICE B) apresenta os resultados dos corpos de prova correspondentes à capa do modelo EM1. Esse concreto foi moldado no dia 17/02/2012. De acordo com a Tabela 3.6, estava com 19 dias na data do ensaio de continuidade e com 28 dias na data dos ensaios dos corpos de prova.

Já Tabela APB2.2 (APÊNDICE B) apresenta os resultados dos corpos de prova correspondentes à capa do modelo EM2. Esse concreto foi moldado no dia 23/05/2012 e, de acordo com a Tabela 3.6, estava com 14 dias na data do ensaio de continuidade e com 28 dias na data dos ensaios dos corpos de prova.

Por fim, a Tabela APB2.3 (APÊNDICE B) apresenta os resultados dos corpos de prova correspondentes à capa do modelo EM3. Esse concreto foi moldado no dia 11/07/2012 e, de acordo com a Tabela 3.6, estava com 14 dias na data do ensaio de continuidade e com 15 dias na data dos ensaios nos corpos de prova. 


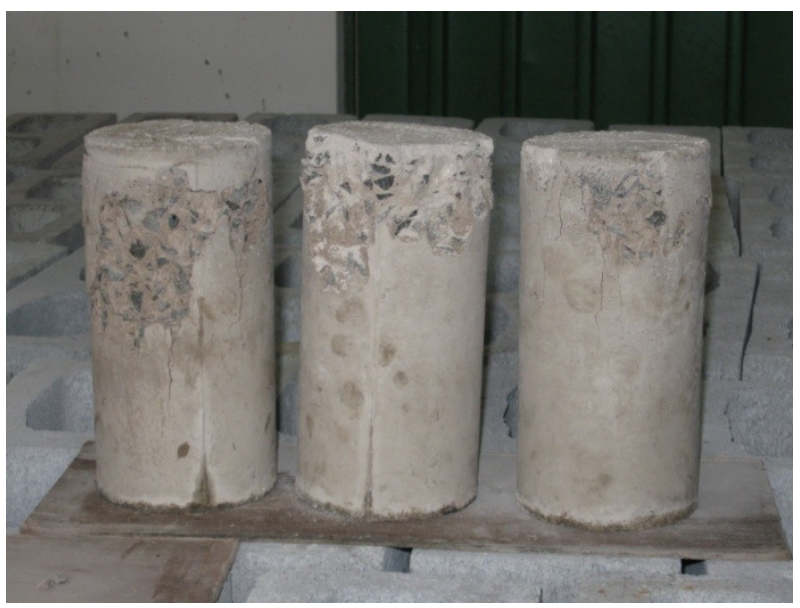

(a)

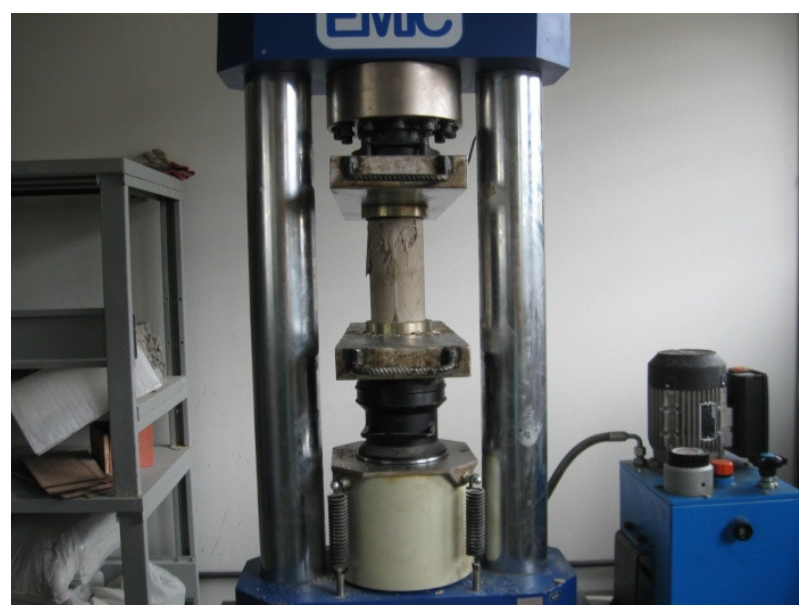

(b)

Figura 4.30 - Ensaios de resistência à compressão do concreto da capa. (a) Três corpos de prova ensaiados para cada modelo; (b) Prensa servo-hidráulica utilizada (LSE/UFSCar).

De posse desses resultados, é possível obter os valores de $f_{c j, c o n t i n u i d a d e ~}$ (Tabela 4.24). Isso foi feito considerando as expressões e as variáveis contidas nas expressões 4.6, 4.7 e 4.8, com desvio padrão de $4 \mathrm{MPa}$ e cimento CP III 40 RS.

Tabela 4.24 - Resistência à compressão do concreto da capa do modelo EM1 na data do ensaio de continuidade.

\begin{tabular}{|c|c|c|c|}
\hline Variável & EM1 & EM2 & EM3 \\
\hline $\begin{array}{c}\text { Idade do concreto na data na data dos } \\
\text { ensaios dos CP's (dias) }\end{array}$ & 28 & 28 & 15 \\
\hline$f_{c m}(\mathrm{MPa})$ & 36,8 & 70,4 & 51,1 \\
\hline Desvio Padrão (S) & 4 & 4 & 4 \\
\hline$f_{c k}(\mathrm{MPa})$ & 30 & 64 & 48 \\
\hline $\begin{array}{c}\text { Idade do concreto na data dos ensaios de } \\
\text { continuidade (dias) }\end{array}$ & 19 & 14 & 14 \\
\hline$\beta_{1}$ & 0,9219 & 0,8544 & 0,9868 \\
\hline$f_{c j, \text { continuidade }}(\mathrm{MPa})$ & $\mathbf{2 8}$ & $\mathbf{5 5}$ & $\mathbf{4 4}$ \\
\hline
\end{tabular}

\subsection{2 - Determinação do módulo de elasticidade}

Os ensaios para determinação do módulo de elasticidade foram feitos apenas para os corpos de prova da capa do modelo 3, e de acordo com a NBR 8522:2008. Os resultados são mostrados na Tabela APB3.1, APÊNDICE B.

Três corpos de prova foram moldados para esse ensaio (Figura 4.31a). A velocidade de carregamento foi de 0,3 MPa/s, e o comprimento da haste para a medição da deformação, de 150 mm (Figura 4.31b). 


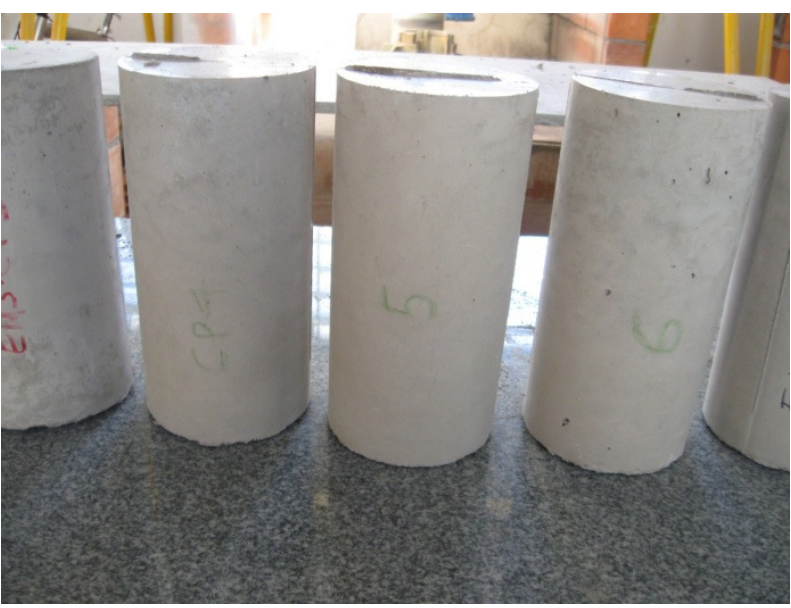

(a)

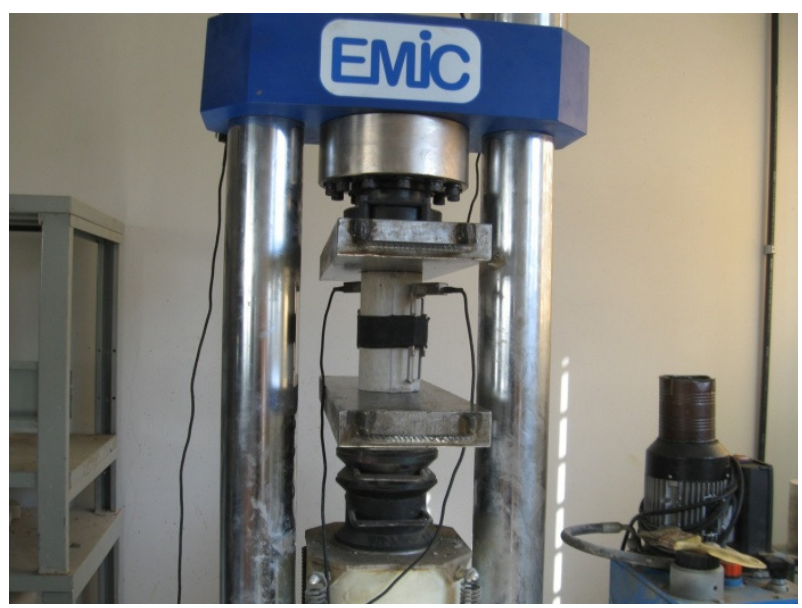

(b)

Figura 4.31 - Ensaios para determinação do módulo de elasticidade do concreto da capa - EM3. (a) Três corpos de prova ensaiados; (b) Prensa servo-hidráulica utilizada (LSE/UFSCar).

De acordo com os resultados, para esse ensaio, o valor médio do módulo de deformação tangente inicial $\left(E_{c i}\right)$ foi de $42610 \mathrm{MPa}$.

\subsection{3 - Resistência à tração por compressão diametral}

O ensaio que determina a resistência à tração por compressão diametral foi realizado apenas para os corpos de prova EM3. Esses ensaios foram feitos conforme a NBR 7222:2011, e os resultados são apresentados na Tabela APB4.1, APÊNDICE B.

Para esse ensaio, três corpos de prova foram moldados (Figura 4.32a). Os ensaios foram feitos com velocidade de carregamento de 0,05 $\mathrm{MPa} / \mathrm{s}$, e a largura da tira de madeira, utilizada no ensaio, era de $1,5 \mathrm{~cm}$ (Figura 4.32b).

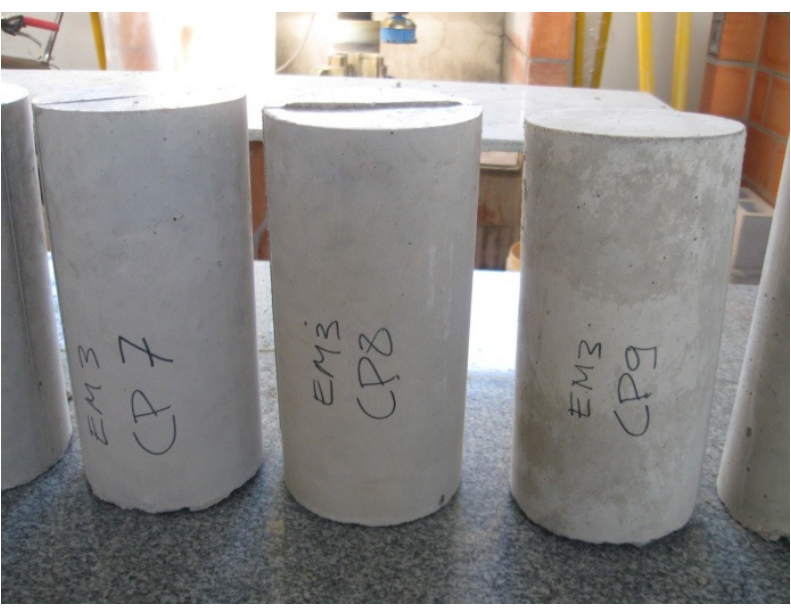

(a)

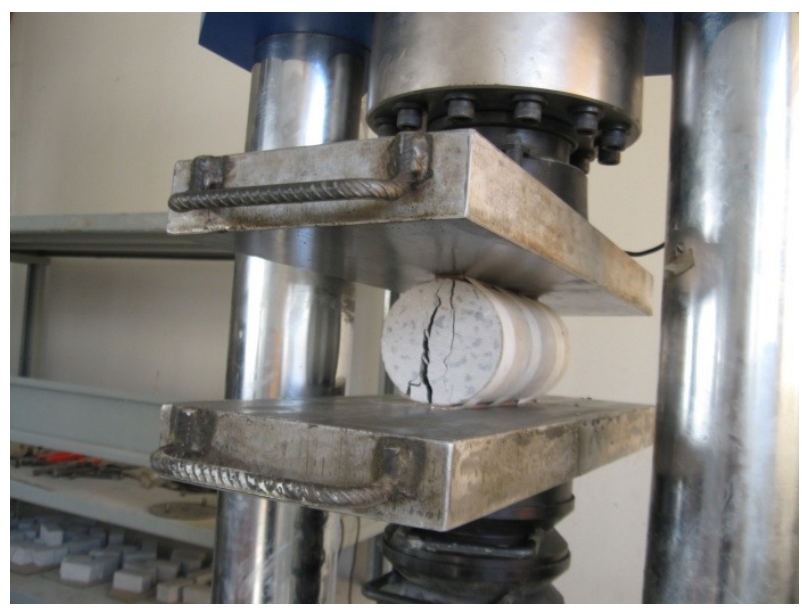

(b)

Figura 4.32 - Determinação da resistência à tração do concreto da capa por compressão diametral EM3. (a) Três corpos de prova ensaiados; (b) Prensa servo-hidráulica utilizada (LSE/UFSCar). 
De acordo com os resultados, para esse ensaio, o valor médio da resistência do concreto à tração $\left(f_{c t m}\right)$ é de 4,5 MPa. Entretanto, conforme a NBR 6118:2014, a resistência à tração direta $\left(f_{c t}\right)$ é igual à $90 \%$ da tração medida no ensaio de compressão diametral. Logo, o valor da resistência do concreto à tração direta $\left(f_{c t}\right)$ é de 4,0 MPa.

\section{7 - Ensaios de caracterização da armadura passiva}

Os ensaios de caracterização da armadura passiva (fornecida pela GERDAU) foram realizados no Laboratório de Estruturas do Departamento de Engenharia de Estruturas da Escola de Engenharia de São Carlos (LE/SET/EESC), no dia 21 de Maio de 2012. Os corpos de prova, com comprimento de aproximadamente $1 \mathrm{~m}$, foram obtidos a partir do lote de barras adquiridas para os ensaios de continuidade.

Foram ensaiados três corpos de prova à tração direta, de acordo com a NBR 6892:2013. Antes de realizar os ensaios determinou-se a medida e o peso de cada corpo de prova. Foram utilizados dois extensômetros de base removível, com haste de comprimento igual a $100 \mathrm{~mm}$, sendo registrados os deslocamentos do pistão e do corpo de prova. O ensaio foi feito com controle de deslocamentos, sendo utilizada velocidade de $0,05 \mathrm{~mm} / \mathrm{s}$ até o escoamento da barra e de $0,5 \mathrm{~mm} / \mathrm{s}$ após o escoamento, até a ruptura.

Para encontrar os valores da resistência característica de escoamento $\left(f_{y k}\right)$, foi necessário traçar os diagramas tensão versus deformação, de cada corpo de prova, e uma reta paralela ao trecho inicial da curva. Em seguida, foi traçada uma nova reta paralela, relativa à a deformação característica de escoamento $\left(\varepsilon_{y k}\right)$ igual a $2,07 \%$. 0 ponto de interseção entre esta reta e a curva $\sigma$ versus $\varepsilon$ define o valor de $f_{y k}$. Os diagramas tensãodeformação das barras são apresentados no APÊNDICE B, Figuras APB5.1, APB5.2 e APB5.3.

A Tabela 4.25 mostra os resultados de módulo de elasticidade tangente inicial $\left(E_{s}\right)$, resistência de escoamento $\left(f_{\mathrm{yk}}\right)$ e resistência última $\left(f_{\mathrm{uk}}\right)$, relativa à ruptura das barras da armadura passiva. Sendo:

- $F_{\mathrm{u}}=$ força de ruptura do corpo de prova;

- $\sigma_{\mathrm{a}}=$ tensão correspondente a $10 \%$ da força de ruptura;

- $\sigma_{b}=$ tensão correspondente a $30 \%$ da força de ruptura;

- $\varepsilon_{a}=$ deformação correspondente a $10 \%$ da força de ruptura;

- $\varepsilon_{\mathrm{a}}=$ deformação correspondente a $30 \%$ da força de ruptura;

- $\mathrm{E}_{\mathrm{s}}$ = módulo de elasticidade do aço;

- $\mathrm{f}_{\mathrm{uk}}=$ resistência característica de ruptura;

- $\mathrm{f}_{\mathrm{yk}}=$ resistência característica de escoamento. 
Tabela 4.25 - Resultados dos ensaios de tração na armadura passiva.

\begin{tabular}{|c|c|c|c|}
\hline Variável & CP1 & CP2 & CP3 \\
\hline Peso $(\mathrm{N})$ & 9,154 & 9,442 & 9,433 \\
\hline Comprimento $(\mathrm{m})$ & 0,999 & 1,002 & 1,001 \\
\hline Peso / Comprimento $(\mathrm{N} / \mathrm{m})$ & 9,2 & 9,4 & 9,4 \\
\hline Peso específico $\left(\mathrm{kN} / \mathrm{m}^{3}\right)$ & 785 & 785 & 785 \\
\hline Área $\left(\mathrm{cm}^{2}\right)$ & 1,167 & 1,200 & 1,200 \\
\hline $\mathrm{F}_{\mathrm{u}}(\mathrm{kN})$ & 104,43 & 102,52 & 102,92 \\
\hline$\sigma_{\mathrm{a}}\left(\mathrm{kN} / \mathrm{cm}^{2}\right)$ & 9,73 & 8,66 & 8,66 \\
\hline$\sigma_{\mathrm{b}}\left(\mathrm{kN} / \mathrm{cm}^{2}\right)$ & 26,79 & 25,78 & 26,47 \\
\hline$\varepsilon_{\mathrm{a}}\left(\mathrm{mm} / \mathrm{mm}^{2}\right)$ & 0,00049 & 0,00048 & 0,00050 \\
\hline$\varepsilon_{\mathrm{a}}\left(\mathrm{mm} / \mathrm{mm}^{2}\right)$ & 0,00132 & 0,00134 & 0,00141 \\
\hline $\mathrm{E}_{\mathrm{s}}(\mathrm{MPa})$ & 205554 & 199116 & 195703 \\
\hline $\mathrm{E}_{\mathrm{s}}(\mathrm{MPa})(\mathrm{médio})$ & \multicolumn{3}{|l|}{} \\
\hline $\mathrm{f}_{\mathrm{uk}}(\mathrm{MPa})$ & $\mathbf{2 0 0 1 2 5}$ & 857 \\
\hline $\mathrm{f}_{\mathrm{uk}}(\mathrm{MPa})(\mathrm{médio})$ & 895 & 854 & $\mathbf{8 6 9}$ \\
\hline $\mathrm{f}_{\mathrm{yk}}(\mathrm{MPa})$ & 590 & 595 & 600 \\
\hline $\mathrm{f}_{\mathrm{yk}}(\mathrm{MPa})(\mathrm{médio})$ & $\mathbf{5 9 5}$ \\
\hline
\end{tabular}

\section{8 - Caracterização da armadura ativa}

Os resultados de caracterização da armadura ativa foram fornecidos pelo fabricante das cordoalhas (ArcelorMittal) às empresas fornecedoras das lajes alveolares usadas neste trabalho.

Todos os relatórios fornecidos estão presentes no APÊNDICE B, itens APB6 (EM1), APB7 (EM2) e APB8 (EM3), em formato de figuras. De acordo com as figuras apresentadas nesses itens, existem informações sobre alguns diâmetros dos aços de protensão. A Tabela 4.26 mostra quais são esses diâmetros e os relaciona com as figuras do APÊNDICE B. A ordem dessa tabela segue a sequência de aparecimento no APÊNCIDE B.

O relatório técnico apresentado pela empresa do modelo EM3 contém informações sobre a cordoalha de diâmetro igual a 9,6 mm (cordoalha com 3 fios de diâmetro igual a $4,5 \mathrm{~mm}$ ), que não foi utilizada na respectiva laje. Curiosamente, o diâmetro usado, uma cordoalha de 9,5 mm com 7 fios, consta do relatório fornecido pela empresa do modelo EM2, e, portanto, será utilizado. 
Tabela 4.26 - Diâmetros incluídos nos relatórios técnicos sobre os aços de protensão.

\begin{tabular}{|c|c|c|c|c|}
\hline Diâmetro (mm) & Produto & Figuras & Tipo & Modelo \\
\hline 12,7 & CP 190 RB 7 & $\begin{array}{c}\text { APB6.1 } \\
\text { APB6.2 } \\
\text { APB6.3 } \\
\text { APB6.4 } \\
\text { APB7.6 } \\
\text { APB7.7 } \\
\text { APB7.8 } \\
\text { APB7.9 } \\
\text { APB7.10 }\end{array}$ & $\begin{array}{c}\text { CORDOALHA } \\
7 \varnothing\end{array}$ & $\begin{array}{c}\text { EM1 } \\
\mathrm{e} \\
\text { EM2 }\end{array}$ \\
\hline 9,5 & CP 190 RB 7 & $\begin{array}{l}\text { APB7.1 } \\
\text { APB7.2 } \\
\text { APB7.3 } \\
\text { APB7.4 } \\
\text { APB7.5 }\end{array}$ & $\begin{array}{c}\text { CORDOALHA } \\
7 \varnothing\end{array}$ & EM3 \\
\hline 4,0 & $\mathrm{CP} 150 \mathrm{RN}$ & $\begin{array}{l}\text { APB8.1 } \\
\text { APB8.2 }\end{array}$ & FIO & EM3 \\
\hline 6,5 & $\begin{array}{c}\text { CP } 190 \mathrm{RB} \\
3 \times 3,0\end{array}$ & $\begin{array}{l}\text { APB8.3 } \\
\text { APB8.4 }\end{array}$ & $\begin{array}{c}\text { CORDOALHA } \\
3 \varnothing\end{array}$ & EM3 \\
\hline 9,6 & $\begin{array}{c}\text { CP } 190 \mathrm{RB} \\
3 \times 4,5\end{array}$ & $\begin{array}{l}\text { APB8.5 } \\
\text { APB8.6 }\end{array}$ & $\begin{array}{c}\text { CORDOALHA } \\
3 \varnothing\end{array}$ & Nenhum \\
\hline
\end{tabular}

A seguir, a Tabela 4.27 apresenta os resultados do aço de protensão com base nas informações dos relatórios técnicos fornecidos pelos fabricantes das lajes alveolares. Uma vez que o fornecedor da armadura ativa é o mesmo para todas as lajes utilizadas neste trabalho, os itens da Tabela 4.27 representam os valores médios de cada cordoalha ou fio, independentemente do relatório ou dos fabricantes das lajes.

Tabela 4.27 - Resultados dos ensaios nos aços de protensão.

\begin{tabular}{|c|c|c|c|c|}
\hline Variável & $\mathbf{1 2 , 7}$ & $\mathbf{9 , 5}$ & $\mathbf{6 , 5}$ & $\mathbf{4 , 0}$ \\
\hline $\mathrm{E}_{\mathrm{p}}(\mathrm{MPa})$ & 200387 & 204750 & 201000 & 196231 \\
\hline $\mathrm{f}_{\mathrm{ptk}}(\mathrm{MPa})$ & 1987 & 2008 & 1963 & 1780 \\
\hline $\mathrm{f}_{\mathrm{pyk}}(\mathrm{MPa})$ & 1824 & 1843 & 1817 & 1480 \\
\hline$\varepsilon_{\mathrm{yk}}(\%)$ & 9,10 & 9,04 & 9,04 & 7,50 \\
\hline
\end{tabular}

- $\mathrm{E}_{\mathrm{p}}=$ módulo de elasticidade do aço (armadura ativa);

- $\mathrm{f}_{\mathrm{ptk}}=$ resistência de ruptura da armadura ativa;

- $\mathrm{f}_{\mathrm{pyk}}=$ resistência característica de escoamento da armadura ativa;

- $\varepsilon_{\mathrm{yk}}=$ deformação característica de escoamento; 


\section{9 - Propriedades dos materiais após a caracterização}

Após a caracterização dos materiais, apresenta-se na Tabela 4.28 um resumo com as principais propriedades dos materiais empregados nos ensaios de continuidade. Essa tabela é semelhante à apresenta no capítulo 3 (Tabela 3.2) e será utilizada no decorrer deste trabalho, em todas as formulações teóricas para simulação dos modelos ensaiados.

Quando for necessário determinar outros valores, serão utilizadas expressões consagradas na literatura, que dependam diretamente das variáveis apresentadas na Tabela 4.28. Um exemplo disso é o valor do módulo de elasticidade tangente inicial $\left(E_{\mathrm{ci}}\right)$, que de acordo com a NBR 6118:2014, está diretamente relacionado com a resistência à compressão.

Tabela 4.28 - Propriedades dos materiais após os ensaios de caracterização.

\begin{tabular}{|c|c|c|c|c|c|}
\hline Material & $\begin{array}{c}\text { Variáveis / } \\
\text { Modelos }\end{array}$ & \multicolumn{2}{|c|}{ EM1 } & EM2 & EM3 \\
\hline \multirow{2}{*}{$\begin{array}{l}\text { Concreto da } \\
\text { capa (CML) }\end{array}$} & $\mathrm{f}_{\mathrm{cj}, \text { continuidade }}(\mathrm{MPa})$ & \multicolumn{2}{|l|}{28} & 55 & 44 \\
\hline & $\mathrm{E}_{\mathrm{ci}, \mathrm{cml}}(\mathrm{MPa})$ & \multicolumn{2}{|l|}{-} & - & 42610 \\
\hline \multirow{2}{*}{$\begin{array}{l}\text { Concreto da } \\
\text { laje (CPM) }\end{array}$} & $\mathrm{f}_{\mathrm{cj}, \text { continuidade }}(\mathrm{MPa})$ & \multicolumn{2}{|l|}{54} & 38 & 55 \\
\hline & $\mathrm{E}_{\mathrm{ci}, \mathrm{cpm}}(\mathrm{MPa})$ & - & \multicolumn{2}{|c|}{34305} & - \\
\hline \multirow{3}{*}{$\begin{array}{c}\text { Armadura } \\
\text { passiva } \\
\text { (AÇO } \\
\text { CA-50) }\end{array}$} & $\mathrm{f}_{\mathrm{yk}}(\mathrm{MPa})$ & \multicolumn{4}{|c|}{595} \\
\hline & $\mathrm{E}_{\mathrm{s}}(\mathrm{MPa})$ & \multicolumn{4}{|c|}{200125} \\
\hline & $\varepsilon_{\text {yd }}(\%$ o & \multicolumn{4}{|c|}{-} \\
\hline Material & $\begin{array}{c}\text { Variáveis / } \\
\text { Bitola (mm) }\end{array}$ & 12,7 & 9,5 & 6,5 & 4,0 \\
\hline \multirow{6}{*}{$\begin{array}{l}\text { Armadura } \\
\text { ativa }\end{array}$} & $\mathrm{f}_{\mathrm{ptk}}(\mathrm{MPa})$ & 1987 & 2008 & 1963 & 1780 \\
\hline & $\mathrm{f}_{\mathrm{pyk}}(\mathrm{MPa})$ & 1824 & 1843 & 1817 & 1480 \\
\hline & $\mathrm{E}_{\mathrm{p}}(\mathrm{MPa})$ & 200387 & 204750 & 201000 & 196231 \\
\hline & $\varepsilon_{\mathrm{yk}}(\% \circ)$ & 9,10 & 9,04 & 9,04 & 7,50 \\
\hline & Tipo & $\begin{array}{l}\text { Cordoalhas } \\
\quad(7 \varnothing)\end{array}$ & $\begin{array}{l}\text { Cordoalhas } \\
\quad(7 \varnothing)\end{array}$ & $\begin{array}{c}\text { Cordoalhas } \\
(3 \varnothing \text { de } 3,3 \\
\text { mm })\end{array}$ & Fios \\
\hline & Aço & CP $190 \mathrm{RB}$ & CP $190 \mathrm{RB}$ & CP 190 RB & $\begin{array}{l}\text { CP } 150 \\
\text { RN }\end{array}$ \\
\hline
\end{tabular}




\section{ENSAIOS DE CONTINUIDADE}

Os ensaios dos modelos com continuidade foram realizados no laboratório NETPRE/DECiv/UFSCar nas seguintes datas: 07/03/2012, modelo 1; 06/06/2012, modelo 2 e 25/07/2012, modelo 3.

Apresenta-se neste capítulo a descrição dos três ensaios, tendo em vista os seguintes aspectos: montagem, instrumentação e resultados.

\section{1 - Visão geral dos ensaios}

A Figura 5.1 mostra esquemas dos ensaios de continuidade.

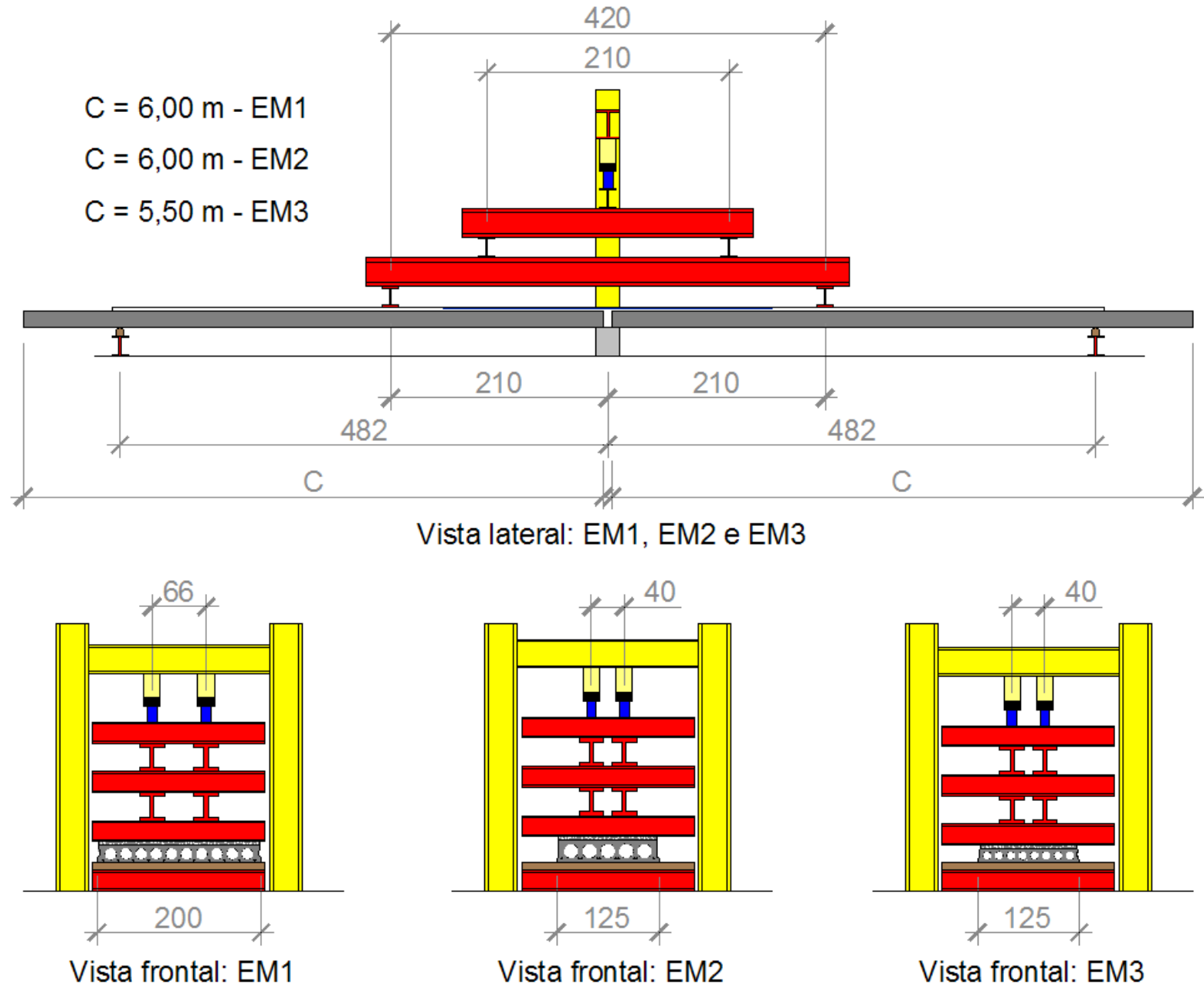

Figura 5.1 - Esquemas dos ensaios de continuidade: vistas lateral e frontais. 
Na Figura 5.1 apresenta-se uma vista lateral, que representa os três modelos ensaiados (EM1, EM2 e EM3) e três vistas frontais, uma para cada modelo. O destaque são as principais medidas utilizadas. Na sequência, as Figuras 5.2, 5.3 e 5.4 mostram uma visão geral, respectivamente dos modelos 1,2 e 3 .

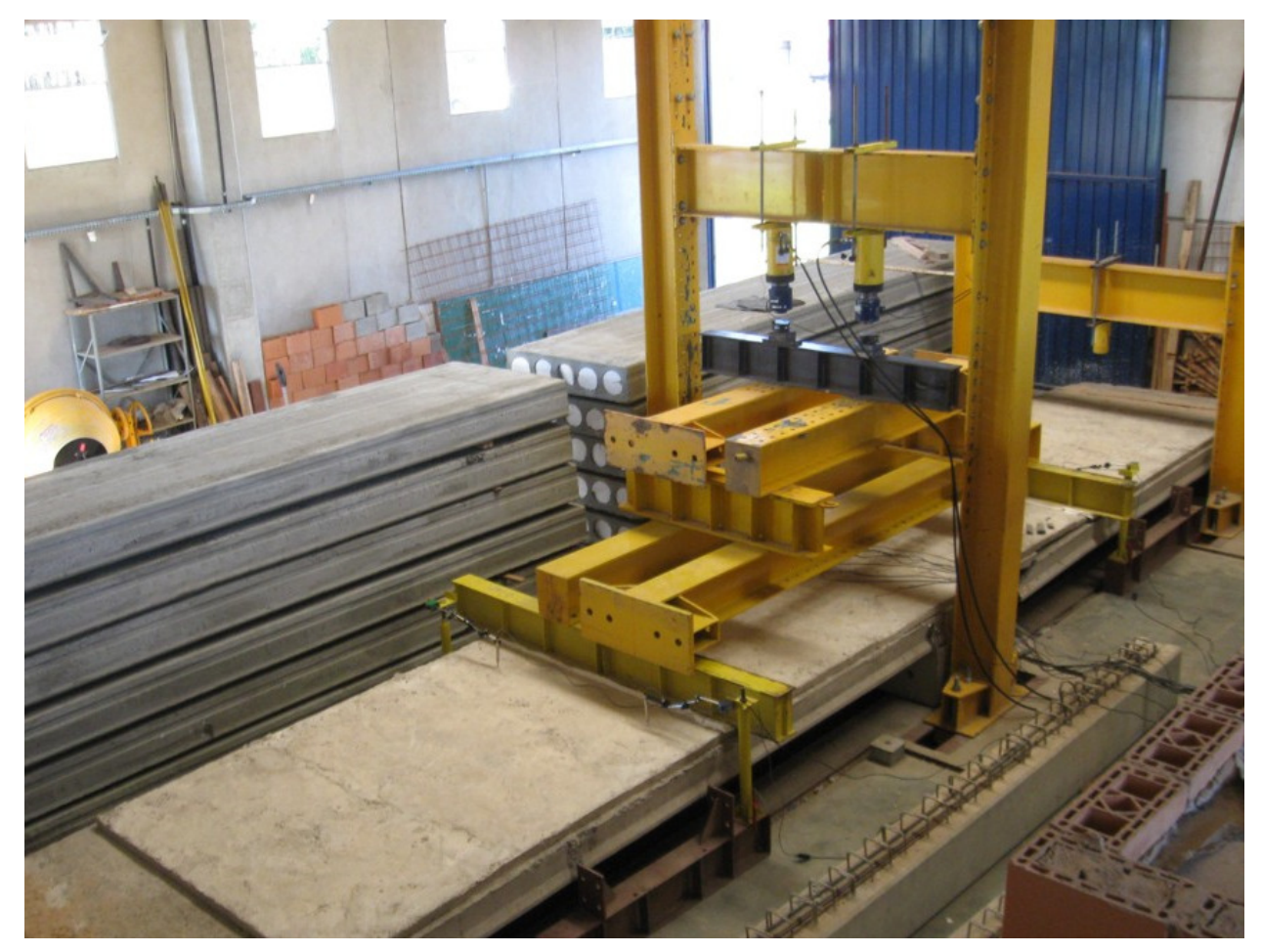

Figura 5.2 - Visão geral do modelo 1 (EM1).

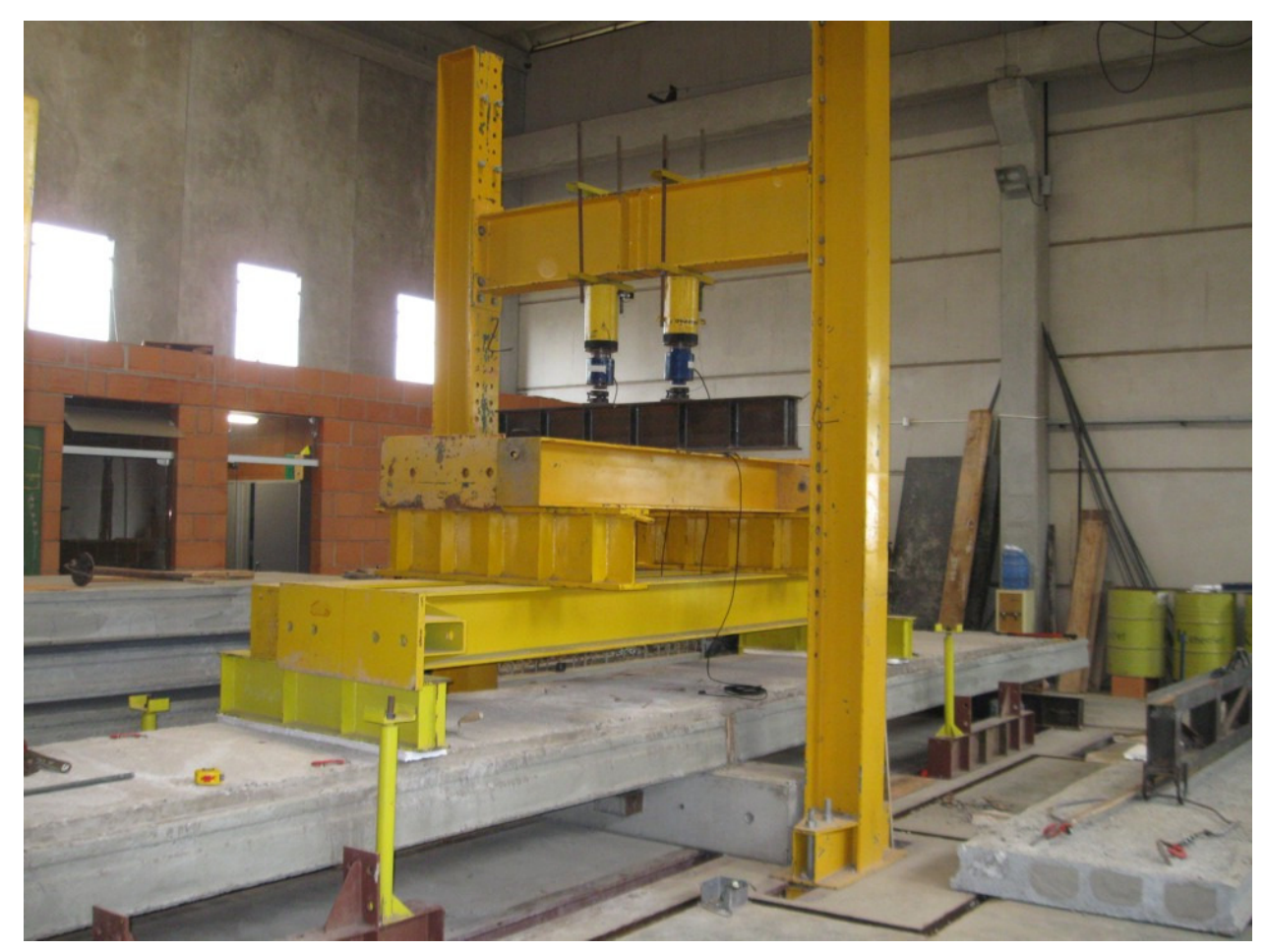

Figura 5.3 - Visão geral do modelo 2 (EM2). 


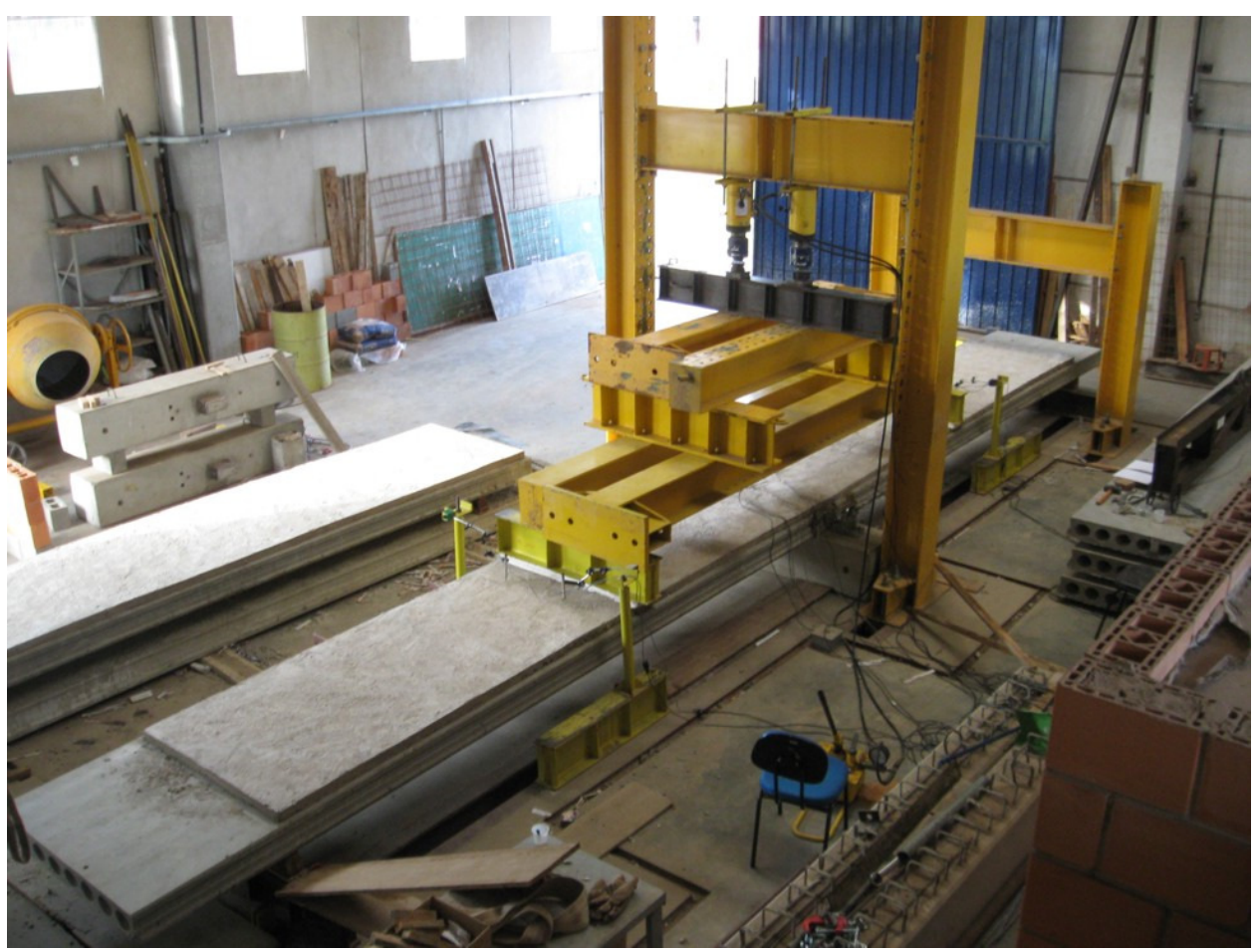

Figura 5.4 - Visão geral do modelo 3 (EM3).

A Figura 5.5 apresenta quatro aspectos gerais desses ensaios. O primeiro deles é o conjunto para aplicação da força. Foi utilizado um pórtico de reação e vigas de transmissão, ambos metálicos. Foram usados também dois atuadores hidráulicos com capacidade de $500 \mathrm{kN}$ cada, duas células de carga e duas rótulas (Figura 5.5a). Além disso, os ensaios foram feitos sobre uma laje de reação com comprimento de $10 \mathrm{~m}$.

Cada modelo era composto basicamente por duas lajes alveolares protendidas com pré-tração, capa estrutural de concreto e armadura passiva. No apoio intermediário (Figura 5.5b), foi utilizada uma viga de concreto armado, e nos apoios extremos do modelo (Figura 5.5c), foram usadas vigas metálicas. Todos os apoios possuíam rigidez suficiente para caracterizar os ensaios como sendo sobre apoios rígidos, ou seja, os apoios não sofreram deformações e deslocamentos verticais.

Os apoios das extremidades eram compostos por: vigas metálicas apoiadas na laje de reação; duas chapas metálicas bem finas contendo graxa, apoiadas sobre a viga metálica; madeira para manter o nível do apoio intermediário, apoiada sobre as chapas; e uma tira de neoprene com $1 \mathrm{~cm}$ de espessura, apoiada sobre a madeira. Portanto, os apoios da extremidade permitiam rotação e deslocamento horizontal do modelo.

O tamanho da laje de reação era de $10 \mathrm{~m}$, portanto, o vão máximo que poderia ser utilizado era de 4,82 $\mathrm{m}$. Isso fez com que parte da laje ficasse em balanço na região dos apoios extremos, sendo: $1,11 \mathrm{~m}$ para o modelo $1,1,13 \mathrm{~m}$ para o modelo 2 e 0,59 m para o modelo 3 . A capa estrutural foi concretada com $5 \mathrm{~cm}$ de espessura até a região dos apoios 
da extremidade, nos três modelos. Em outras palavras, a parte da laje que ficou em balanço não continha capa (Figura 5.5d).

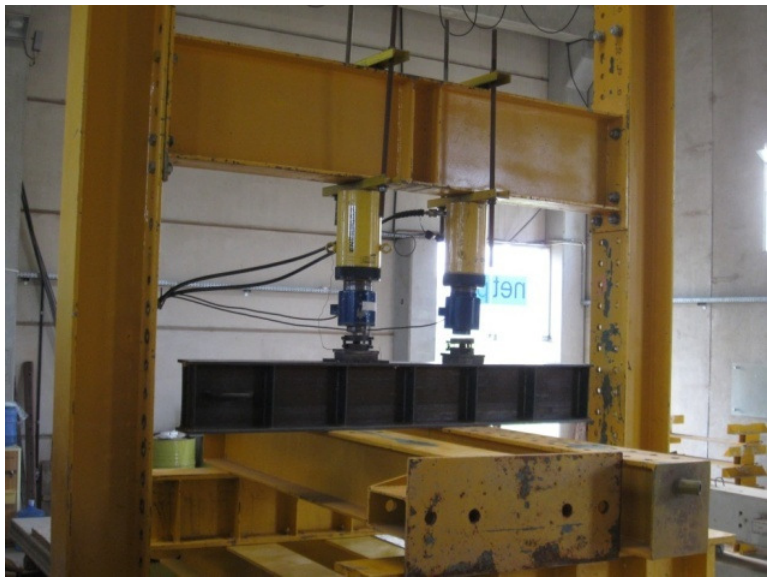

(a)

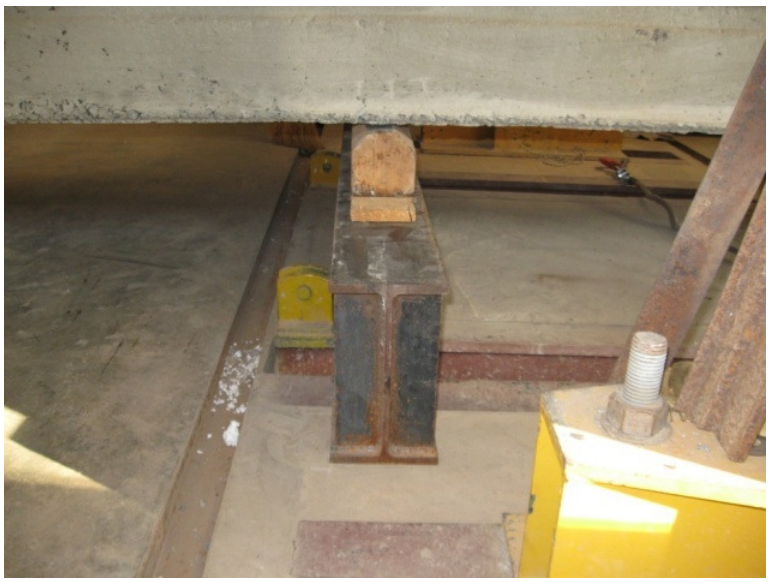

(c)

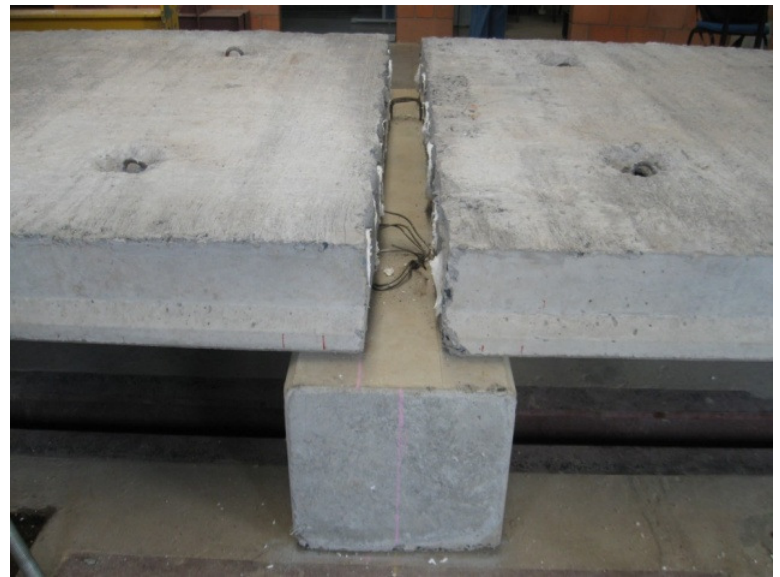

(b)

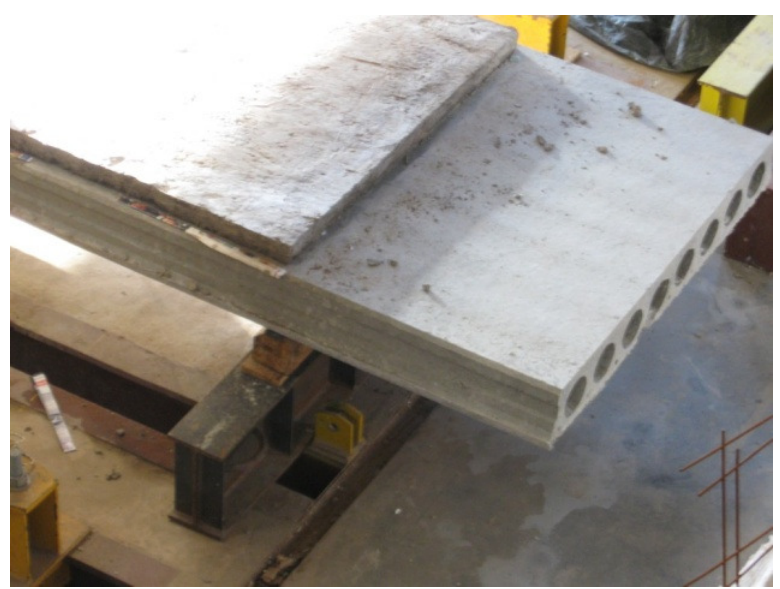

(d)

Figura 5.5 - Aspectos gerais do ensaio de continuidade: (a) Pórtico de reação, vigas de transmissão, atuadores hidráulicos, células de carga e rótulas; (b) Apoio intermediário com viga de concreto armado; (c) Apoio da extremidade; (d) Parte da laje em balanço.

Também por limitação geométrica, a força no ensaio $\left(F_{2}\right)$ não pôde ser aplicada exatamente no meio do vão. A distância entre a força aplicada e o eixo do apoio intermediário foi de $2,10 \mathrm{~m}$.

As medidas preliminares foram feitas conforme COSTA (2009). Foram feitas leituras das medidas da seção geométrica, principalmente das nervuras, bem como o aprofundamento das cordoalhas e fios. 


\section{2 - Concretagem das capas e montagem dos ensaios}

Antes da montagem das lajes, os alvéolos foram vedados com isopor, na região do apoio intermediário, para evitar a entrada de concreto durante a concretagem da capa (Figura 5.6a). Após isso, procedeu-se a colocação das lajes sobre os apoios (Figura 5.6b).

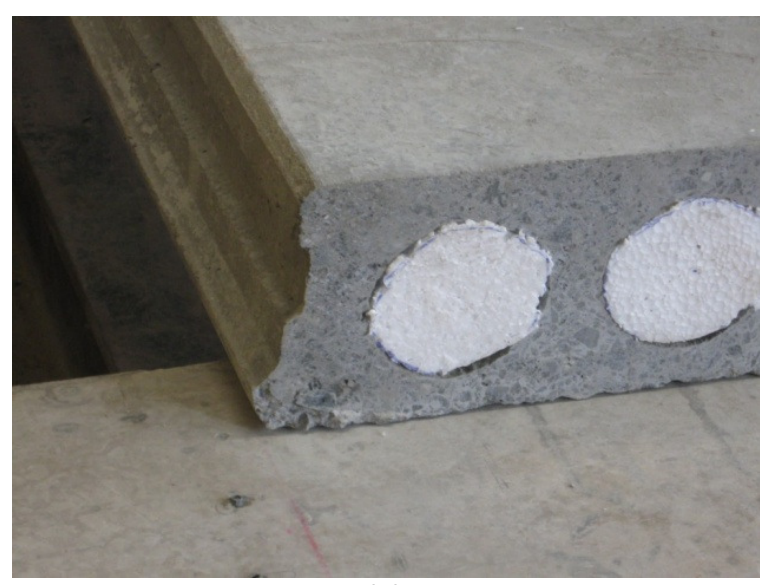

(a)

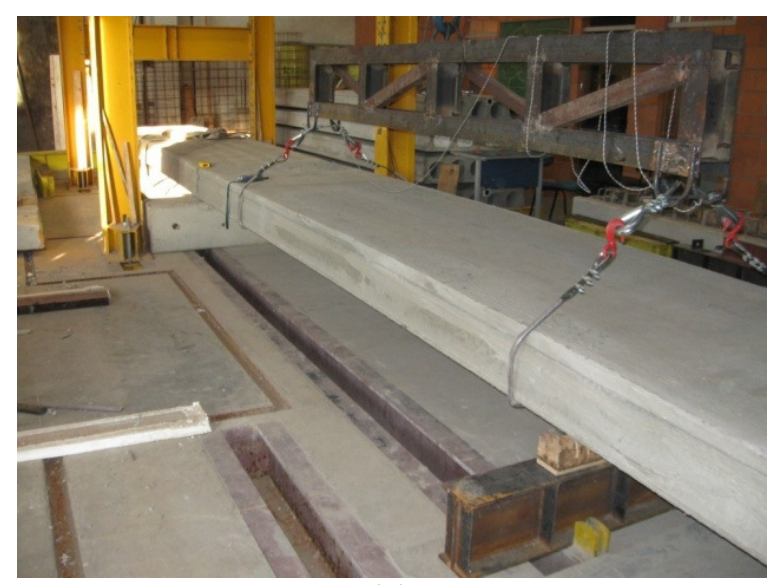

(b)

Figura 5.6 - Aspectos gerais de montagem: (a) Alvéolos vedados por isopor na região do apoio interno; (b) Montagem das lajes nos apoios.

Como mencionado no capítulo 3, as lajes do modelo 1 (EM1) foram feitas utilizando concreto pré-moldado de canteiro, logo apresentavam rugosidade mais acentuada na superfície superior. As demais lajes (EM2 e EM3) foram produzidas nas fábricas através de extrusora.

Foi possível observar que as lajes do modelo 1 apresentaram formatos aleatórios para a rugosidade da superfície superior (Figura 5.7a).

As lajes do modelo 2 apresentaram uma direção preferencial para a rugosidade, paralela à maior dimensão da laje, ou seja, a rugosidade era longitudinal em relação à laje (Figura 5.7b).

As lajes do modelo 3 apresentaram pouca rugosidade, sendo que à distância elas podiam ser caracterizadas como lisas. Além disso, a superfície superior apresentava uma película de cimento (Figura 5.7c).

Com as lajes posicionadas, foi feita a limpeza de suas faces superiores, utilizando vassoura. Em seguida iniciou-se a confecção de uma forma de madeira com $5 \mathrm{~cm}$ de espessura (Figura 5.8a).

Posteriormente à montagem das formas, as superfícies das lajes foram novamente limpas utilizando vassoura. Especificamente no caso das lajes alveolares do modelo 3, foi necessário remover a película de cimento que havia sobre sua superfície. Para tal foi utilizado um pano úmido, sendo necessário aplicá-lo três vezes (Figura 5.8b). 


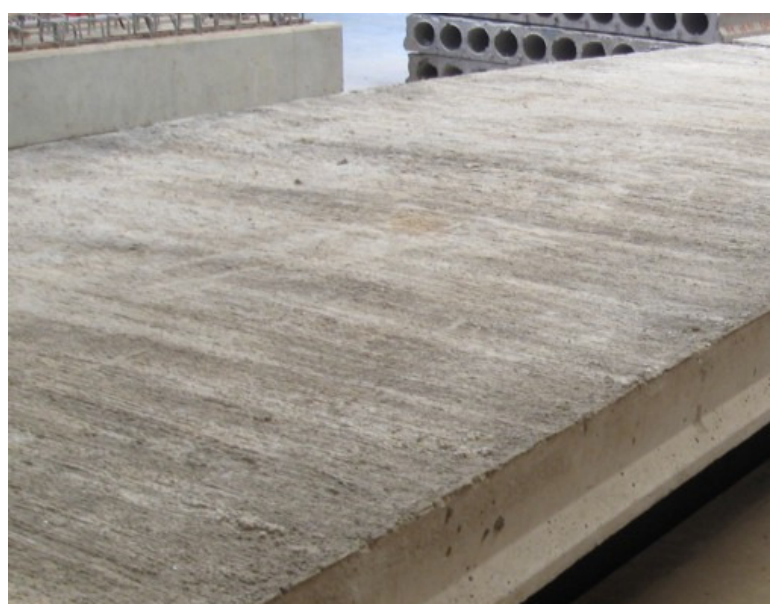

(a)

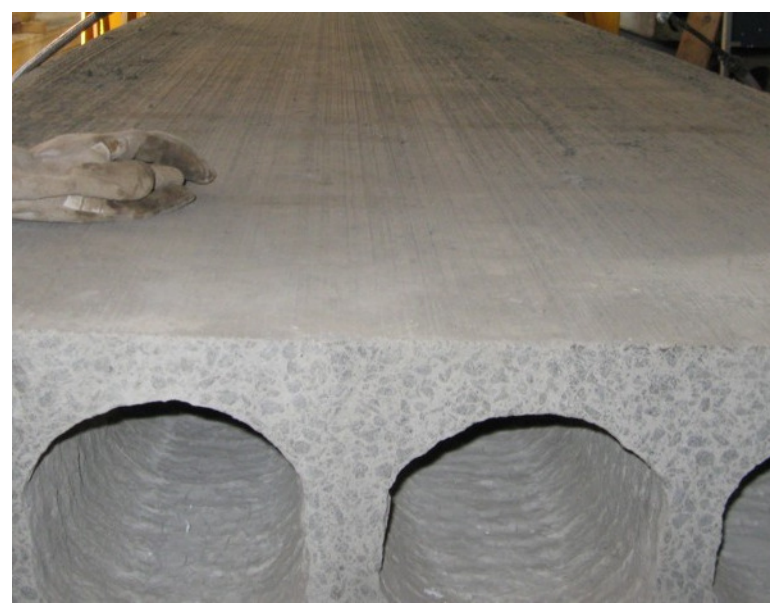

(b)

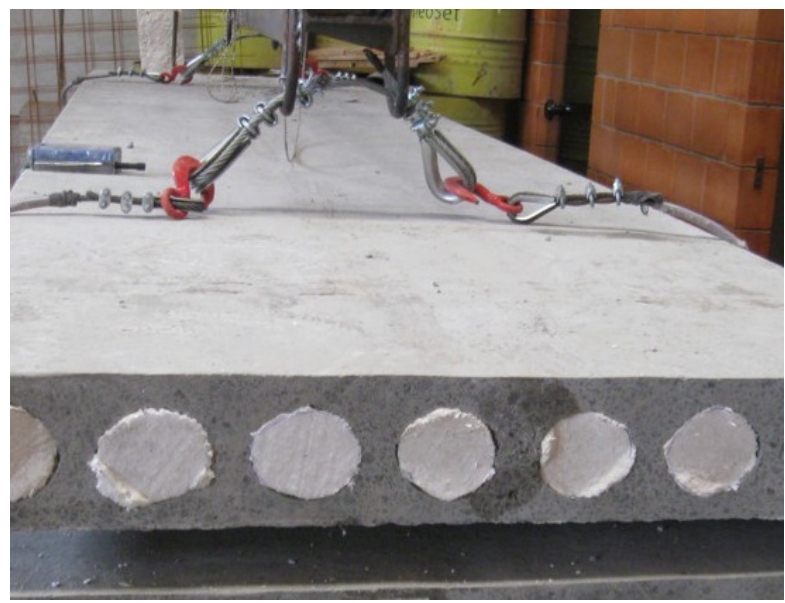

(c)

Figura 5.7 - Superfície superior das lajes: (a) EM1; (b) EM2; (c) EM3.

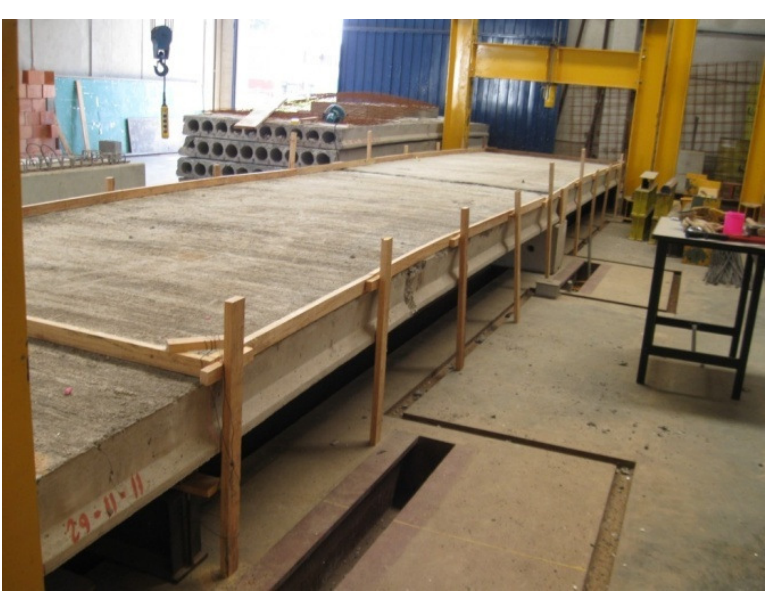

(a)

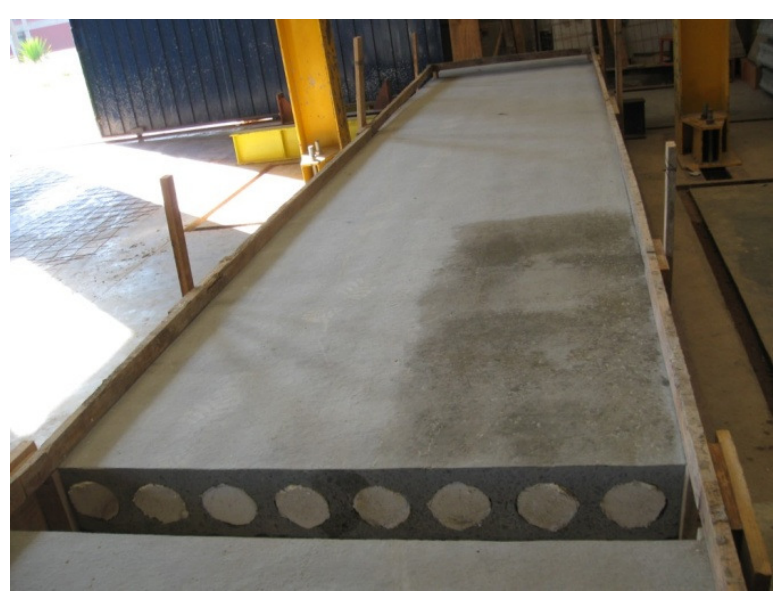

(b)

Figura 5.8 - Preparo das formas e limpeza da superfície da laje: (a) Formas de madeira para concretagem da capa (EM1); (b) Limpeza da superfície com pano úmido (EM3). 
Com as formas prontas e com a superfície limpa, as armaduras passivas e as telas foram colocadas sobre as lajes, utilizando espaçadores. Para o modelo 1 foram utilizadas 17 barras de aço CA50, com bitola de 12,7 mm, com $4 \mathrm{~m}$ de comprimento (Figura 5.9a). Estando as armaduras posicionadas, fez-se uma molhagem da superfície superior por aspersão com água (Figura 5.9b).

O mesmo procedimento foi adotado para os outros modelos. No modelo 2 (Figura 5.9c), foram usadas 11 barras, e no modelo 3 (Figura 5.9d), cinco barras.

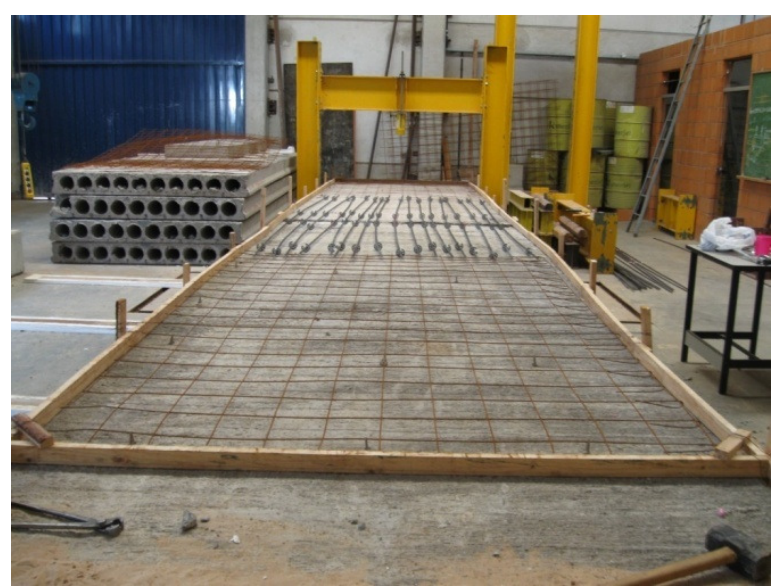

(a)

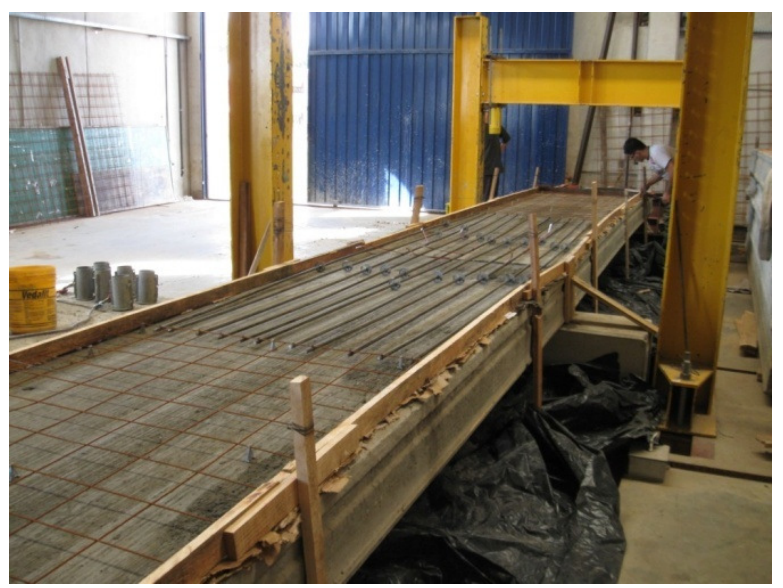

(c)

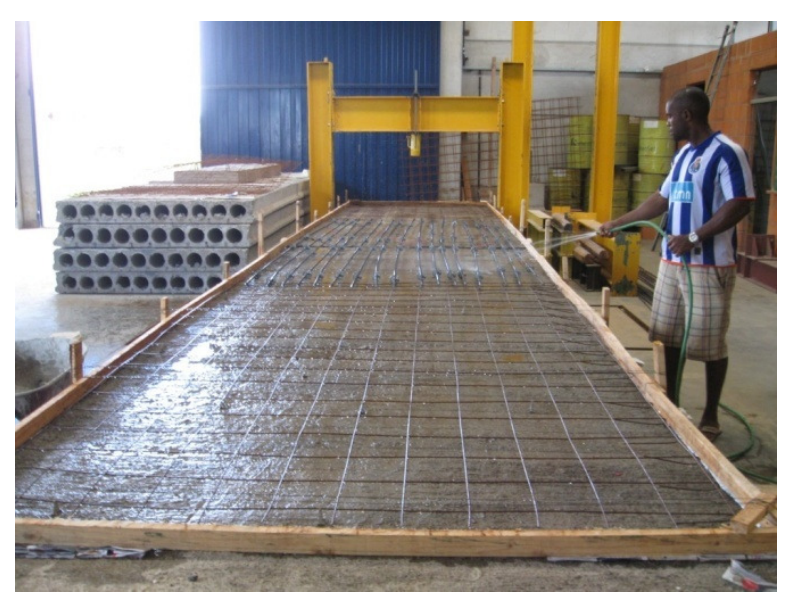

(b)

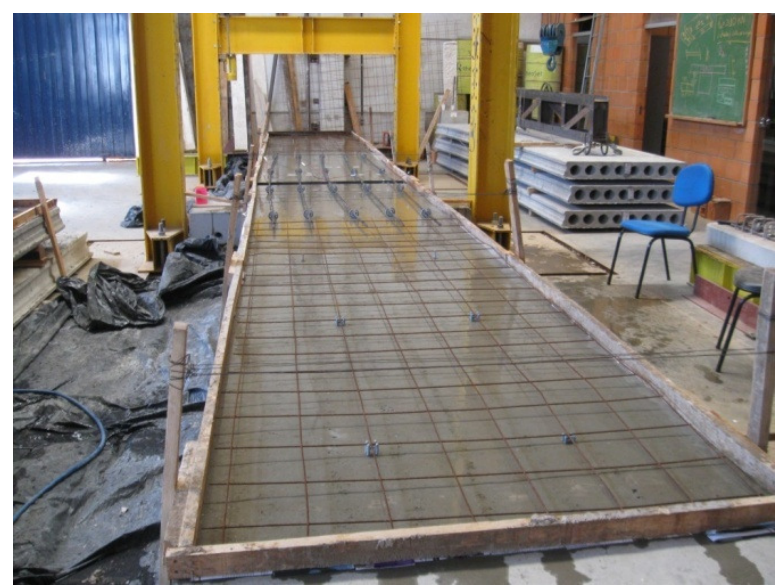

(d)

Figura 5.9 - Colocação da armadura passiva e das telas: (a) EM1 antes da aspersão com água; (b) EM1 após a aspersão com água; (c) EM2 após a aspersão com água; (d) EM3 após a aspersão com água.

Sendo o comprimento da armadura passiva igual a $4 \mathrm{~m}$, foi possível cobrir todo o trecho negativo do diagrama de momento fletor $(1,365 \mathrm{~m}$, cada lado). Com isso, o comprimento de ancoragem foi de 0,635 m em cada lado.

As telas foram posicionadas nas extremidades das lajes com o objetivo de evitar a retração do concreto da capa. Foram utilizados fios com diâmetro de 3,4 mm espaçados a cada $15 \mathrm{~cm}$. O comprimento era de $2,82 \mathrm{~m}$ e se estendia da extremidade do modelo até o 
encontro com as barras da armadura passiva. Já a largura da tela dependia da largura da laje. Em todas as direções foram atendidos cobrimentos de $2,5 \mathrm{~cm}$.

Entretanto, as armaduras passivas foram posicionadas com cobrimento de aproximadamente $1,88 \mathrm{~cm}$, ficando exatamente no meio da altura capa.

Após o preparo da armadura passou-se um desmoldante na forma e logo em seguida procedeu-se a concretagem da capa. Essa concretagem foi feita com concreto usinado. A proximidade do caminhão betoneira com o modelo permitiu um lançamento direto em todo o modelo, sendo necessários poucos lançamentos manuais. A Figura 5.10 ilustra a concretagem dos três modelos: (a) correspondente ao modelo 1, (b) ao modelo 2 e (c) e (d), ao modelo 3.

As datas das concretagem dos modelos 1,2 e 3 foram, respectivamente: $17 / 02 / 2012 ; 20 / 06 / 2012$ e 26/07/2012.

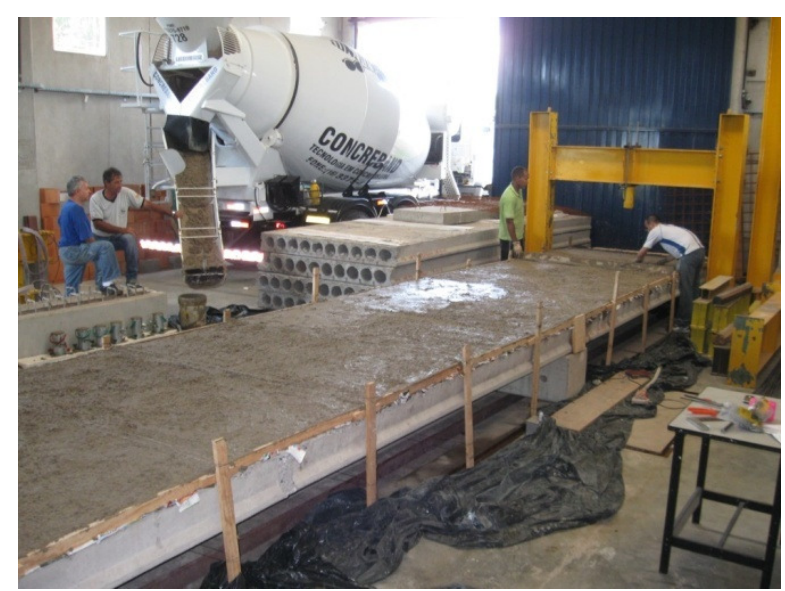

(a)

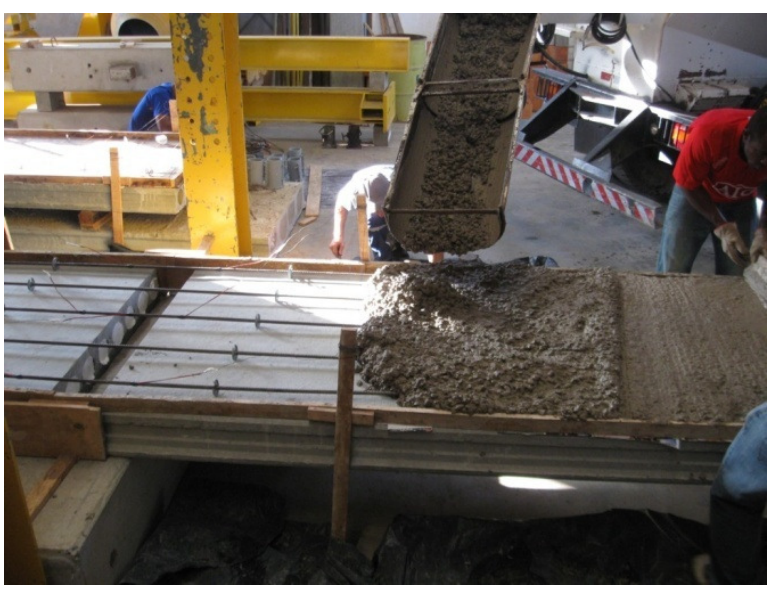

(c)

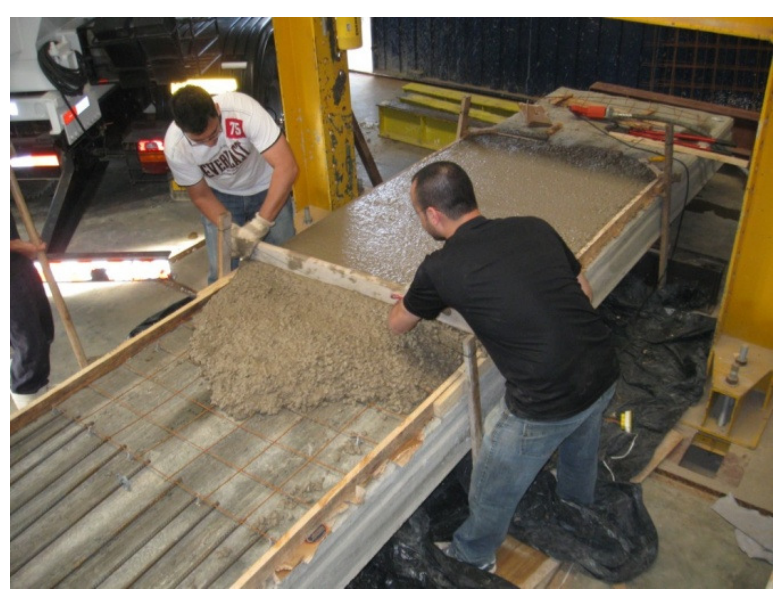

(b)

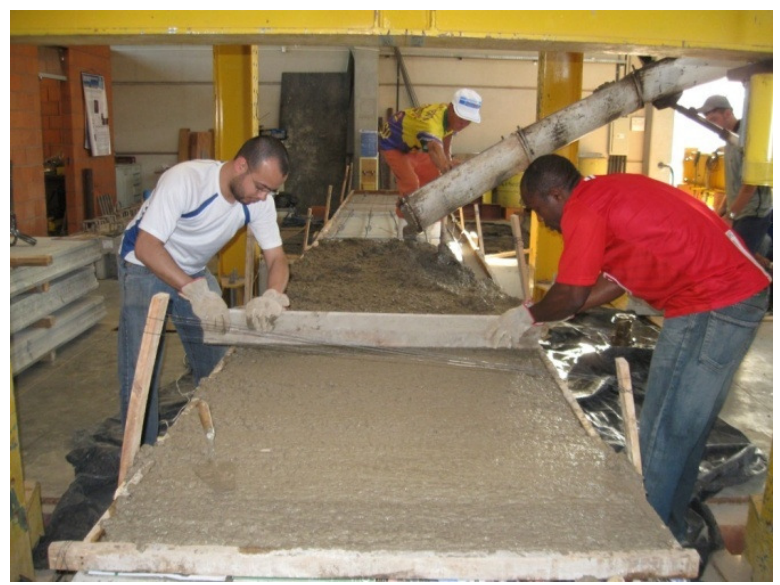

(d)

Figura 5.10 - Concretagem dos modelos: (a) EM1 - 17/02/2012; (b) EM2 - 20/06/2012;

(c) EM3 - 26/07/2012; (d) EM3 - 26/07/2012. 
Após a concretagem da capa, os modelos foram cobertos com plástico preto, como mostram as Figura 5.11a, 5.11b e 5.11c. No primeiro dia após a concretagem, todos os modelos apresentavam superfície úmida (Figura 5.11d). Os modelos foram descobertos e molhados novamente.

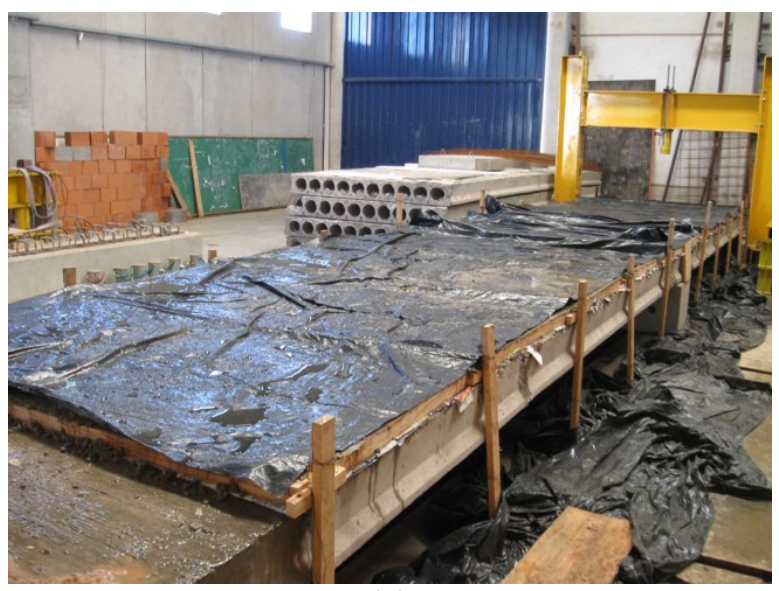

(a)

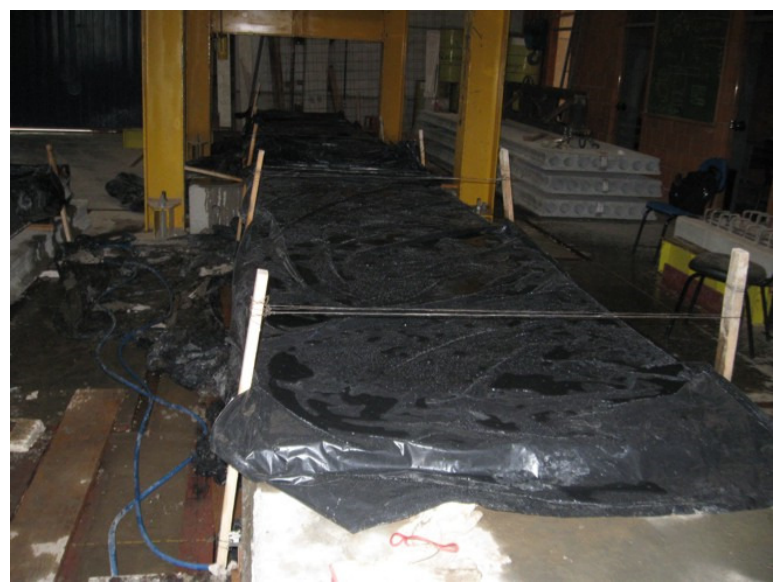

(c)

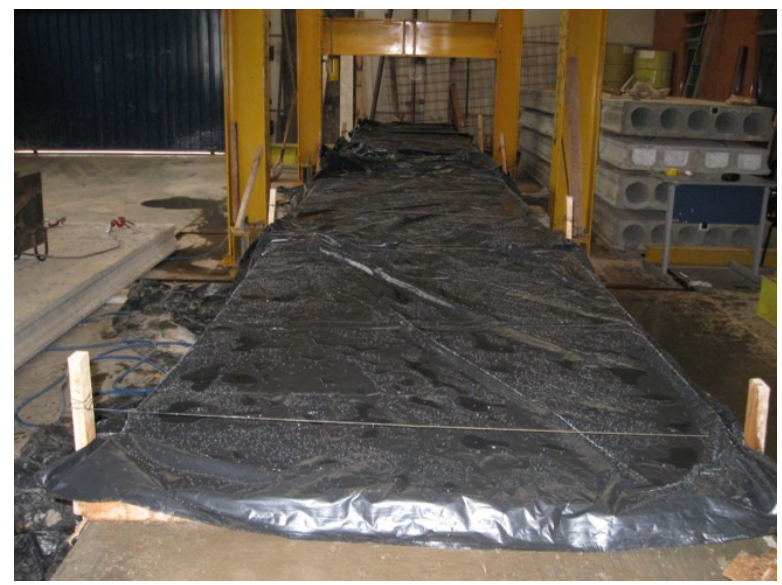

(b)

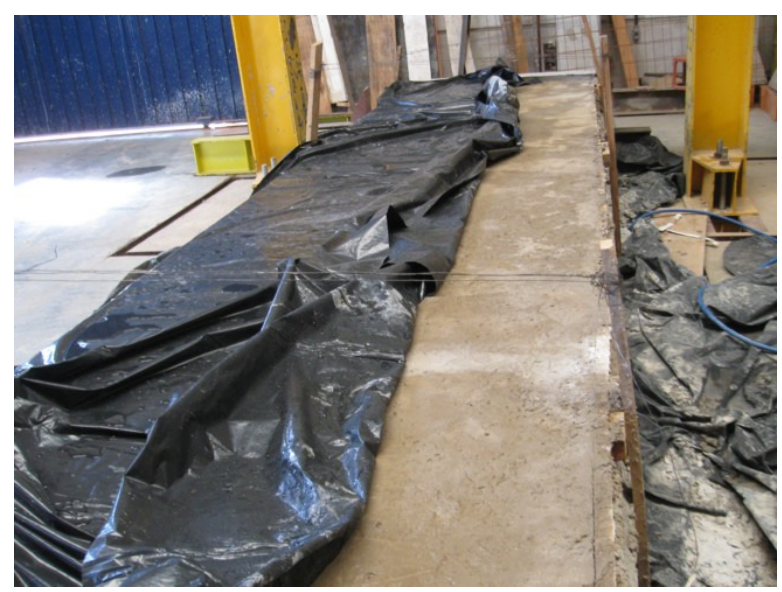

(d)

Figura 5.11 - Cura dos modelos: (a) EM1; (b) EM2; (c) EM3; (d) Superfície se manteve úmida com o passar de um dia após a molhagem.

Esse procedimento (descobrir, molhar e cobrir novamente) foi repetido no segundo e no terceiro dia após a concretagem. Também nesses dois dias os modelos apresentavam superfície úmida.

No sétimo dia os modelos foram descobertos em definitivo e as formas de madeira foram removidas. A seguir, as Figuras 5.12a, 5.12c e 5.12e apresentam, respectivamente, os modelos EM1, EM2 e EM3 após a concretagem da capa. As demais figuras (Figuras $5.12 \mathrm{~b}, 5.12 \mathrm{~d}$ e $5.12 \mathrm{f})$ mostram a regularidade da capa, com relação à sua altura $(5 \mathrm{~cm})$. 


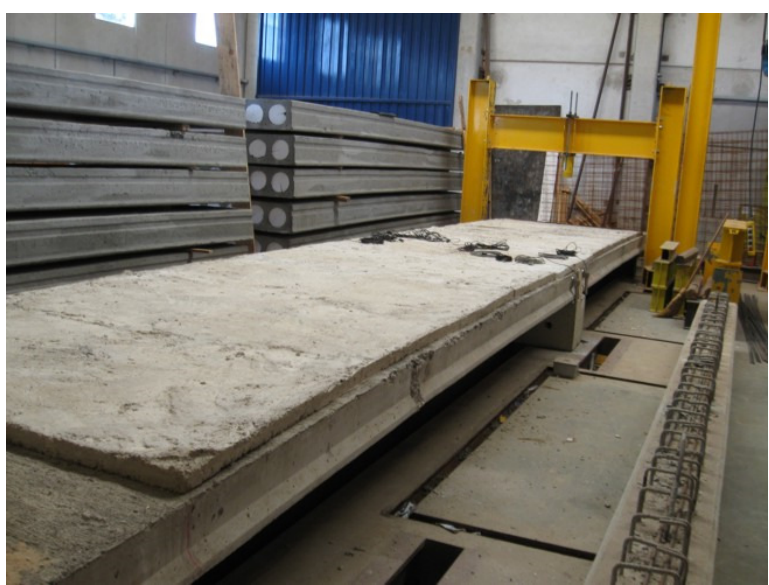

(a)

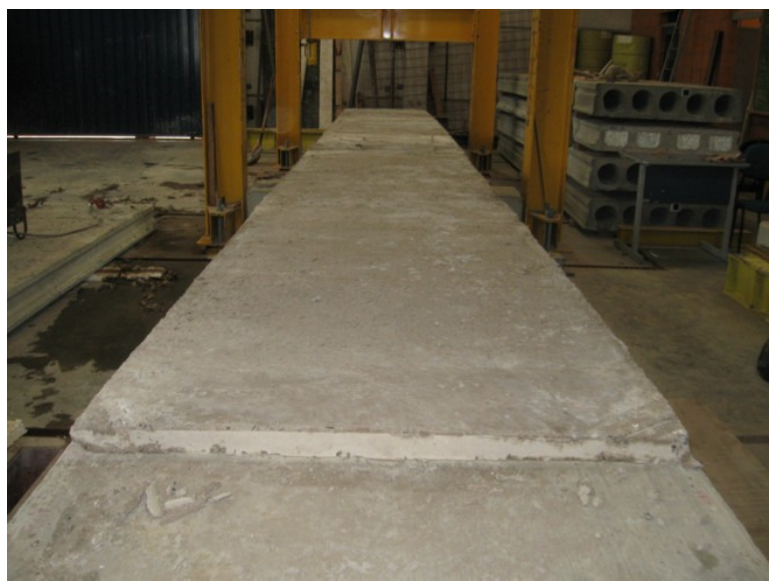

(c)

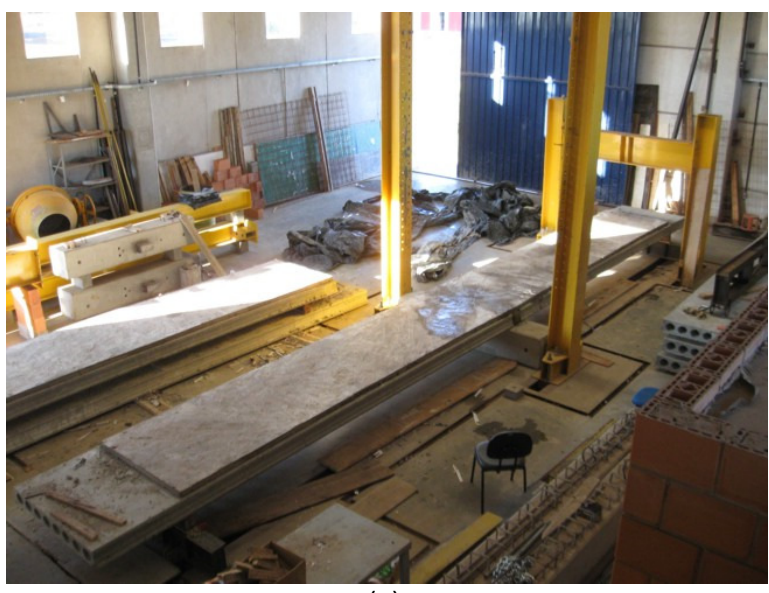

(c)

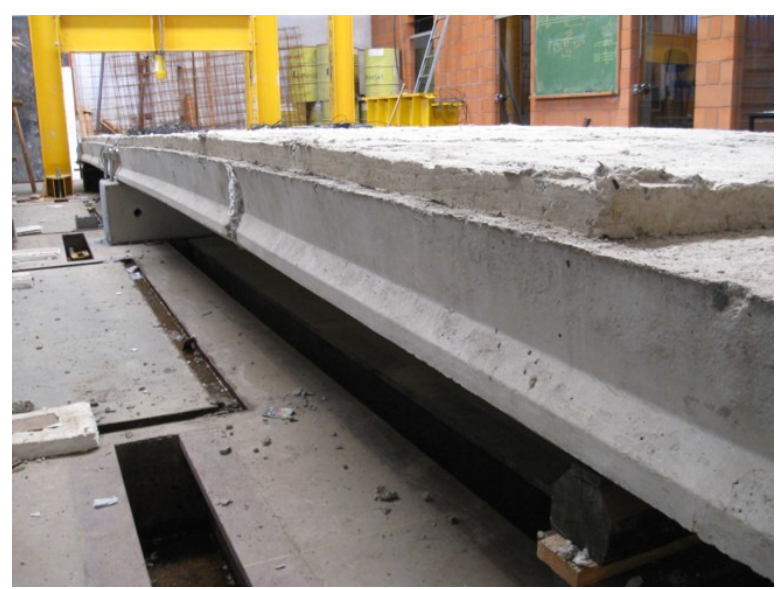

(b)

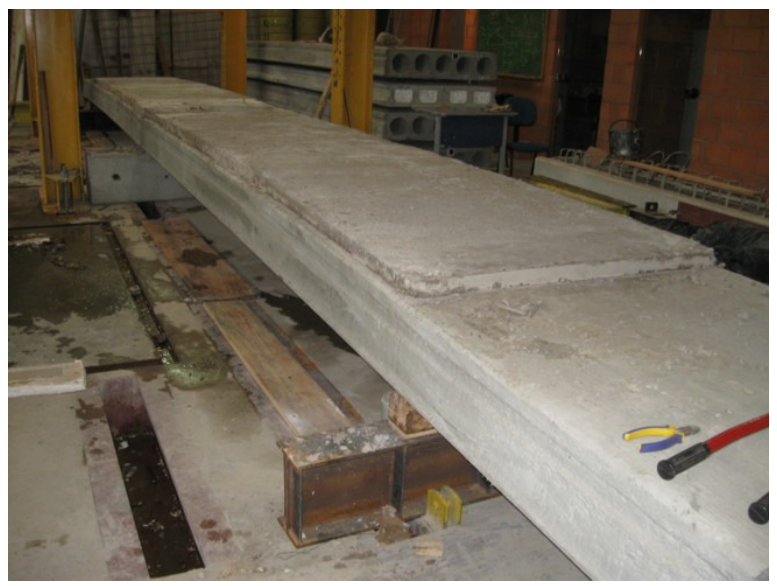

(d)

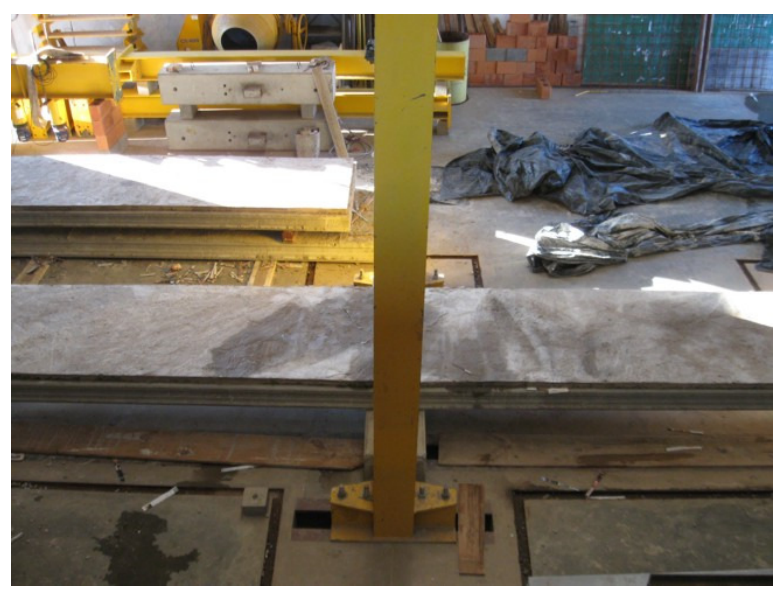

(d)

Figura 5.12 - Modelos após a concretagem da capa: (a) EM1; (b) Regularidade da capa de EM1; (c) EM2; (d) Regularidade da capa de EM2; (e) EM3; (f) Regularidade da capa de EM3.

Logo após a retirada das formas de madeira, iniciou-se a montagem do pórtico de reação com os conjuntos de aplicação das forças (atuadores hidráulicos, células de carga, rótulas) e das vigas de transmissão da força do pórtico de reação para os modelos. As Figuras 5.2, 5.3 e 5.4 apresentadas anteriormente mostram, respectivamente, os modelos 1, 2 e 3 após a montagem desses itens. 


\section{3 - Instrumentação e equipamentos utilizados}

A instrumentação utilizada foi igual para os três modelos. Os pontos de instrumentação são mostrados na Figura 5.13, e as Figura 5.14, 5.15 e 5.16 apresentam fotos com essa instrumentação, sendo que:

- O número 1 corresponde a duas células de carga, utilizadas para a medição da força aplicada por cada atuador hidráulico (Figura 5.14a);

- Os números 2 a 5 correspondem a quatro transdutores de deslocamentos, sendo dois em cada laje, posicionados no meio do vão de ensaio (Figuras 5.14b a 5.14d);

- Os números 6 a 8 correspondem a quatro clinômetros, sendo dois em cada laje (Figura 5.15a até 5.15d);

- Os números 10 a 16 correspondem a sete extensômetros elétricos de resistência, colados em barras da armadura da capa.

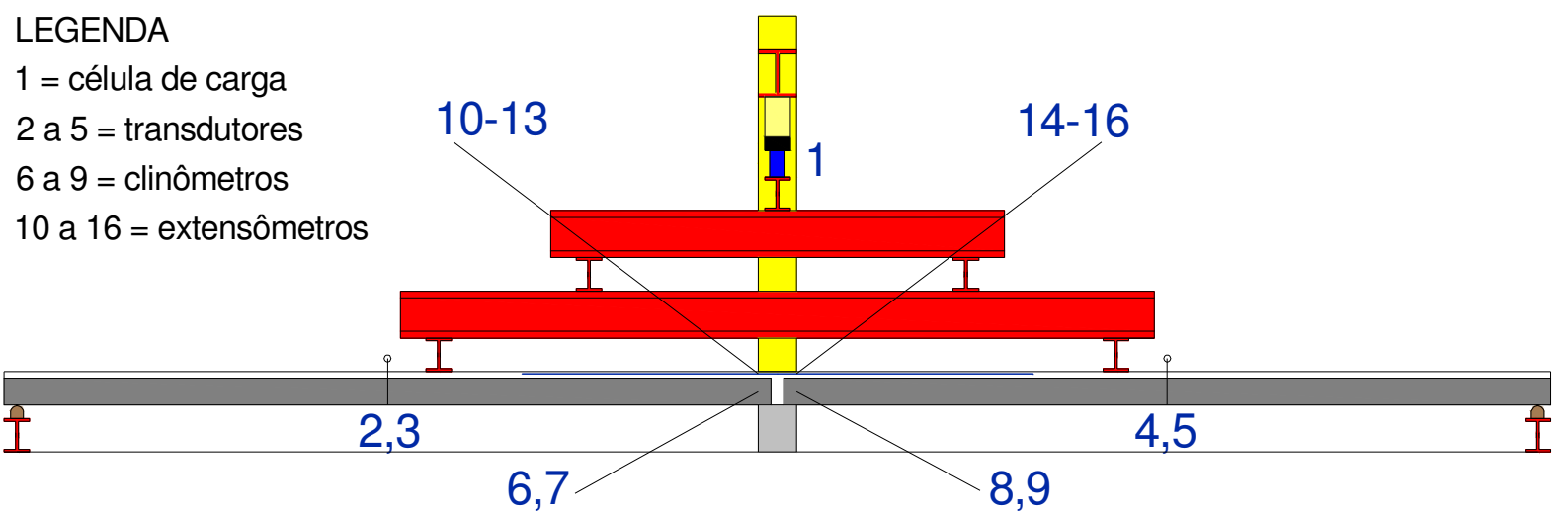

Figura 5.13 - Pontos de instrumentação.

A Figura 5.14a mostra o posicionamento das células de carga que juntamente com os atuadores foram presos à viga do pórtico de reação.

Os transdutores de deslocamentos foram posicionados no meio do vão, sendo dois em cada laje, como mostra a Figura 5.14b (específica do modelo 1). Esses aparelhos foram fixados em suportes verticais presos a vigas metálicas, com o emprego de "sargentos". Além disso, as vigas estavam presas à laje de reação também com "sargentos" (Figura 5.14c). A Figura 5.14d mostra dois transdutores montados sobre uma das lajes do modelo 3. Geometricamente, essa figura corresponde também ao modelo 2. Já a Figura 5.14b ilustra o modelo 1.

No modelo 1 , os clinômetros foram colocados na região do apoio intermediário, como mostram as Figuras 5.15a e 5.15b, somando quatro pontos de instrumentação. 


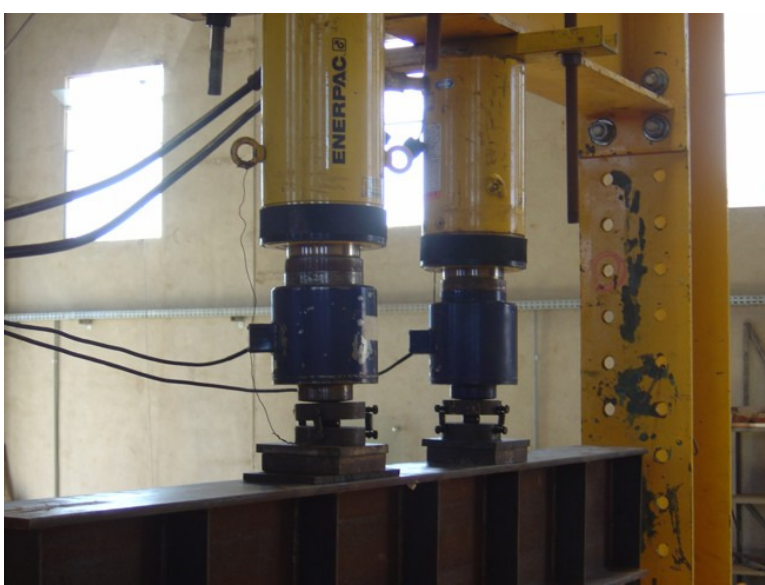

(a)

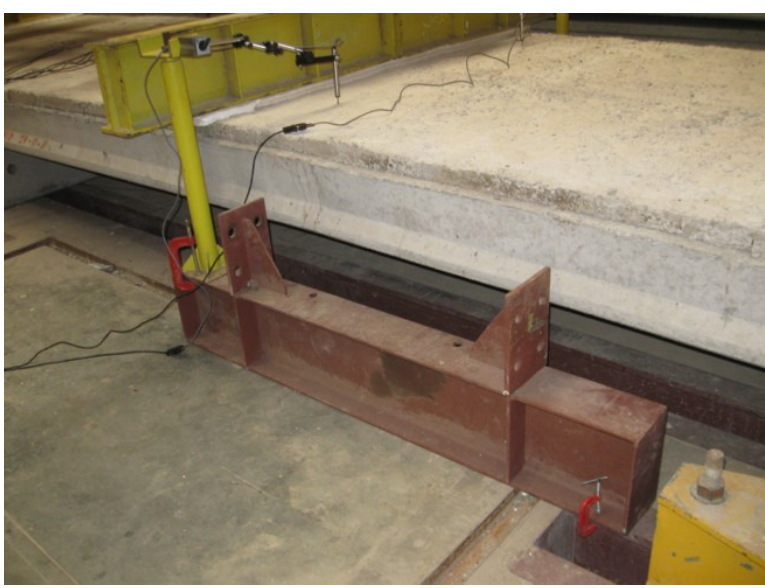

(c)

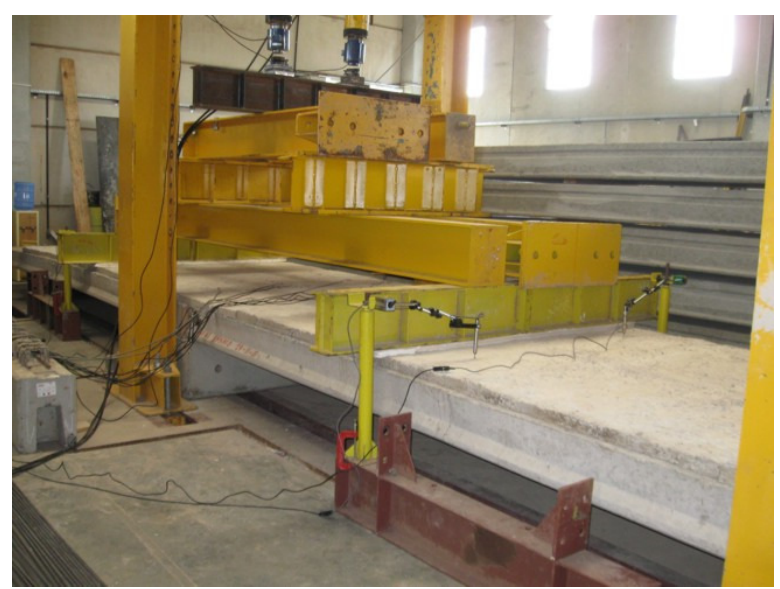

(b)

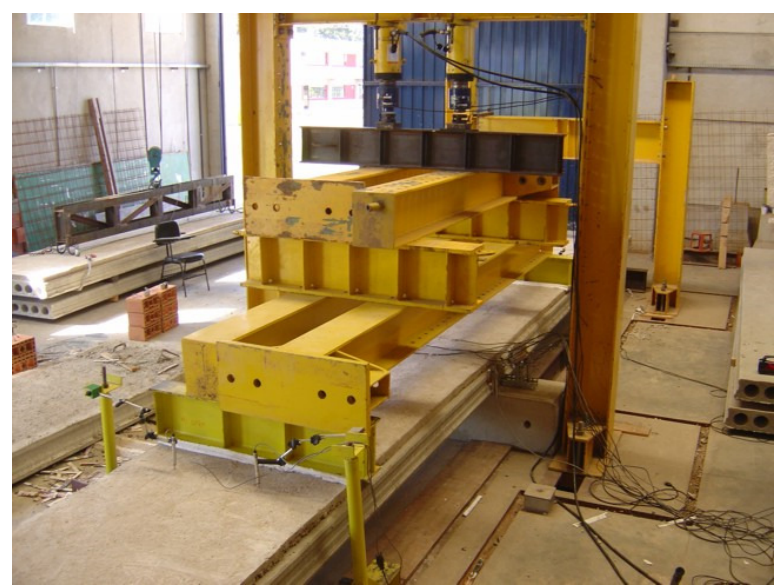

(d)

Figura 5.14 - Pontos de instrumentação (células de carga e transdutores): (a) Células de carga, atuadores hidráulicos e rótulas; (b) Transdutores de deslocamentos em um dos lados do modelo 1; (c) Fixação dos transdutores nos suportes; (d) Posicionamento dos transdutores em um dos lados do modelo 3 (igual ao modelo 2).

Entretanto, durante o ensaio do primeiro modelo, um dos clinômetros deixou de funcionar. Desse modo, as rotações do modelo 1 foram medidas com dois clinômetros em um lado e apenas um no outro lado.

Para os modelos 2 e 3, os três clinômetros foram colocados de forma diferente. Os três aparelhos foram instalados no mesmo lado das lajes, sendo dois posicionados da mesma forma que no modelo 1 , ou seja, na seção da laje que dista $5 \mathrm{~cm}$ do ponto onde a laje começa a se apoiar na viga, e o outro disposto no meio do modelo, entretanto, posicionado de maneira a medir a rotação da viga (Figuras 5.15c e 5.15d). Essa configuração se mostrou vantajosa com relação à do modelo 1 . Foi possível medir as rotações no apoio para as duas lajes e compará-las com a rotação da viga, tendo assim a rotação das lajes com relação ao apoio. 


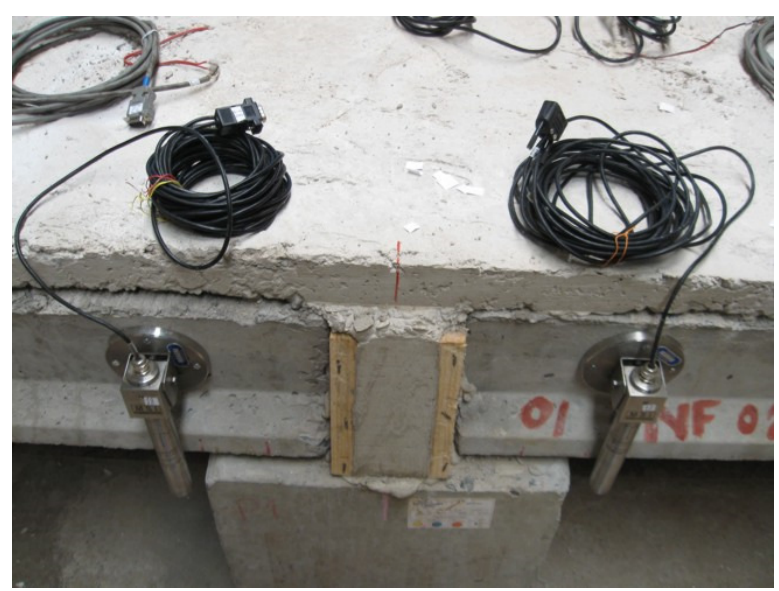

(a)

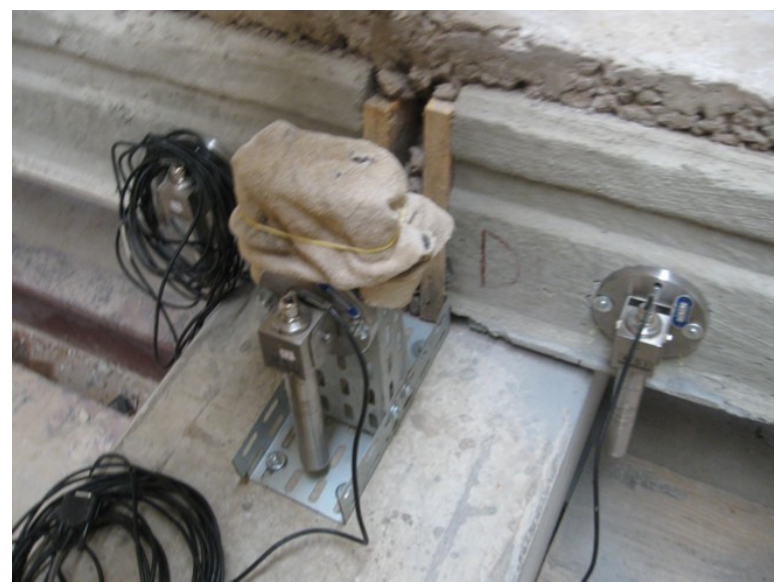

(c)

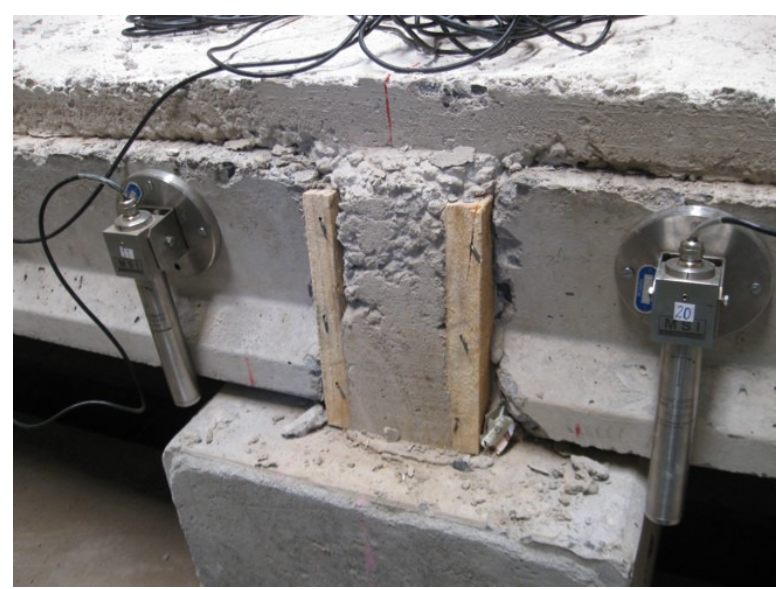

(b)

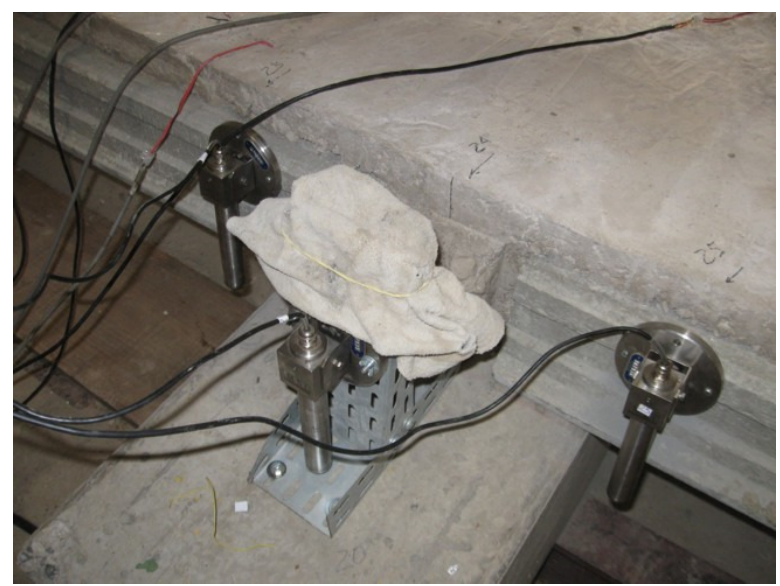

(d)

Figura 5.15 - Pontos de instrumentação (clinômetros): (a) Clinômetros posicionados no EM1; (b) Clinômetros posicionados no EM1 (o da esquerda não funcionou);

(c) Clinômetros posicionados no EM2; (d) Clinômetros posicionados no EM3.

As barras de aço da armadura da capa, (aço CA-50, 12,5 mm) foram instrumentadas de acordo com o projeto básico e as especificações técnicas dos extensômetros, mostrados no APÊNDICE C. A colagem dos extensômetros foi feita no Laboratório de Estruturas do Departamento de Engenharia de Estruturas da Escola de Engenharia de São Carlos.

Foram instrumentadas três barras com três extensômetros e seis barras com dois, totalizando 21 extensômetros. A Figura 5.16a mostra as nove barras e sua instrumentação, enquanto que a Figura 5.16b apresenta uma vista mais próxima de um extensômetro colado em uma barra de aço. As Figuras 5.16c, 5.16d e 5.16e mostram os posicionamentos das barras e dos extensômetros antes da concretagem da capa, respectivamente nos modelos 1 , 2 e 3.

Durante a concretagem da capa os cabos que conectavam os extensômetros foram protegidos e amarrados na fôrma para que as suas pontas não ficassem no interior do concreto da capa (Figura 5.16f). Entretanto no modelo 3 um desses cabos se soltou do extensômetro durante a concretagem da capa, deixando este modelo com seis extensômetros. 


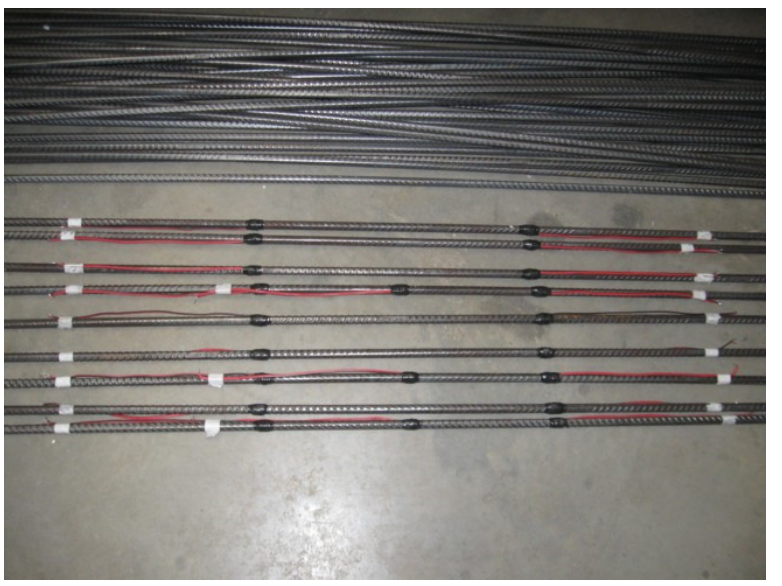

(a)

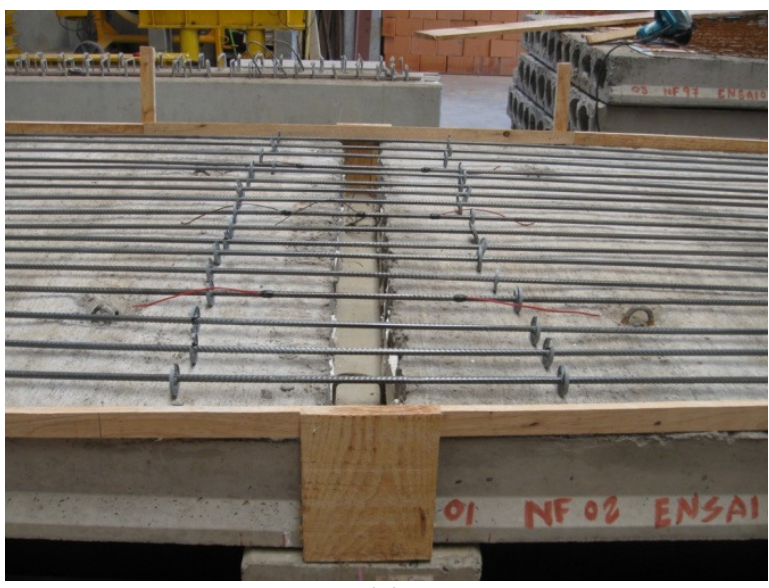

(c)

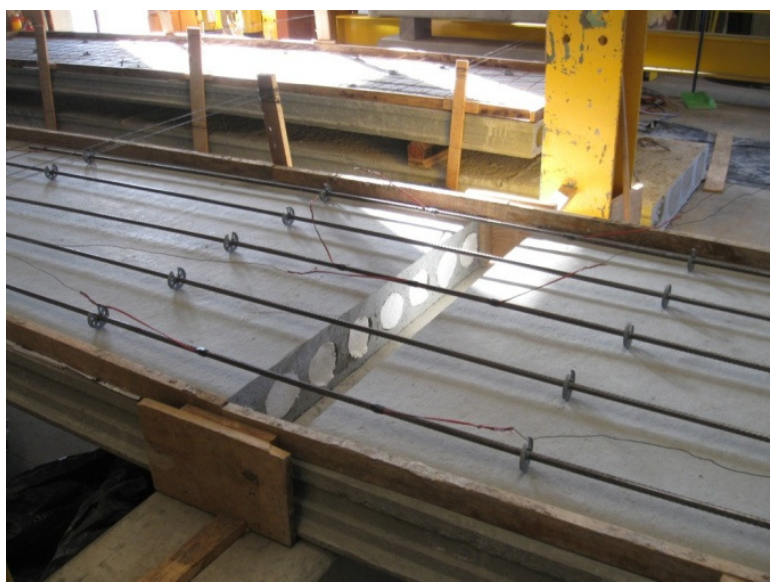

(c)

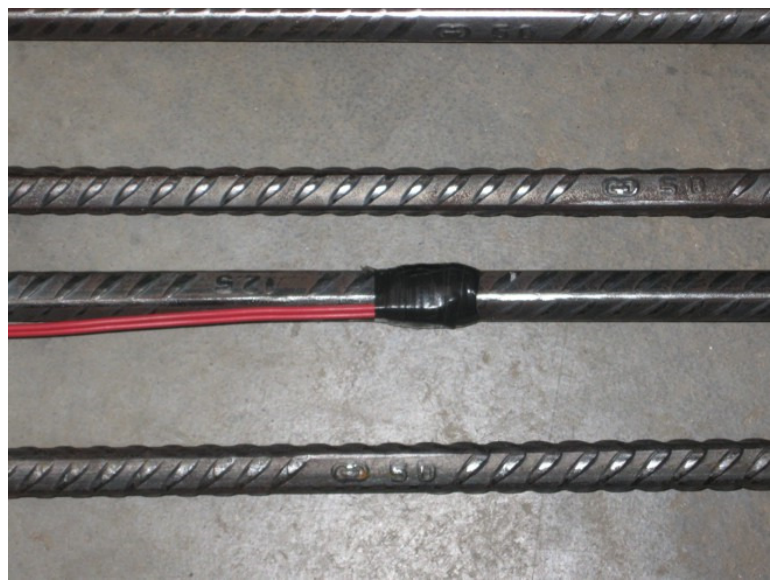

(b)

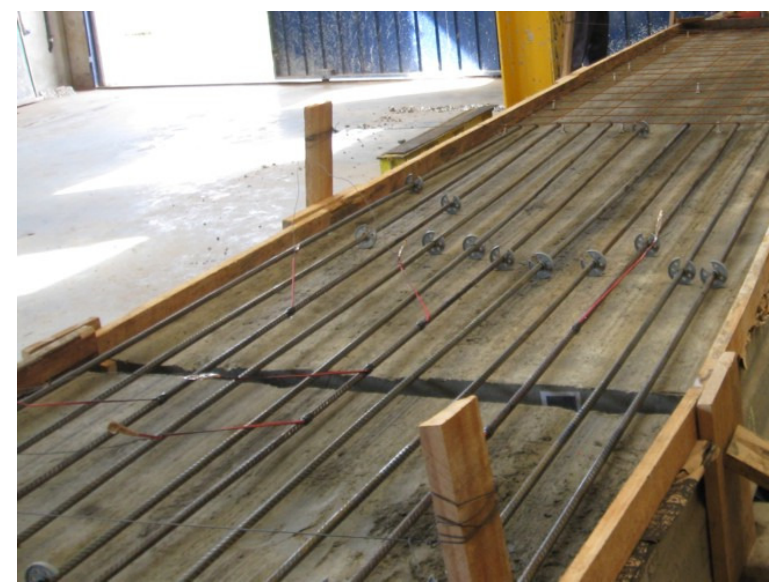

(d)

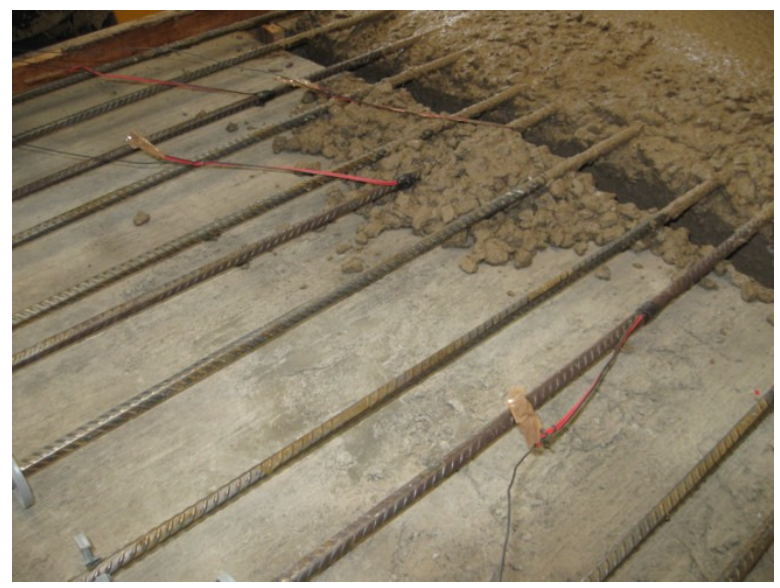

(d)

Figura 5.16 - Pontos de instrumentação (extensômetros): (a) Nove barras após a colagem dos extensômetros; (b) Visão aproximada de um extensômetro colado em uma barra;

(c) Posicionamento das barras e dos extensômetros no EM1; (d) Posicionamento das barras e dos extensômetros no EM2; (e) Posicionamento das barras e dos extensômetros no EM3;

(f) Concretagem da capa na região do apoio intermediário.

A Figura 5.17 mostra o posicionamento dos extensômetros com relação ao apoio intermediário do modelo 3. Nessa figura os pontos 1, 2 e 3 estão posicionados no plano 
correspondente ao início do apoio da laje esquerda. Os pontos 5, 6 e 7 possuem o mesmo posicionamento, entretanto correspondem à laje da direita da figura. Já o ponto 4 está posicionado no plano correspondente ao meio do modelo. Durante a concretagem, perdeu-se o ponto 5 .

O mesmo princípio para a colocação das barras e posicionamento dos extensômetros foi aplicado nos modelos 2 e 3.

Como foi visto no capítulo 3 deste trabalho, o modelo 1 tem 17 barras de armadura passiva (Figura 5.16c), o modelo 2, 11 barras (Figura 5.16d), enquanto que o modelo 3 foi concretado com cinco barras (Figura 5.17).

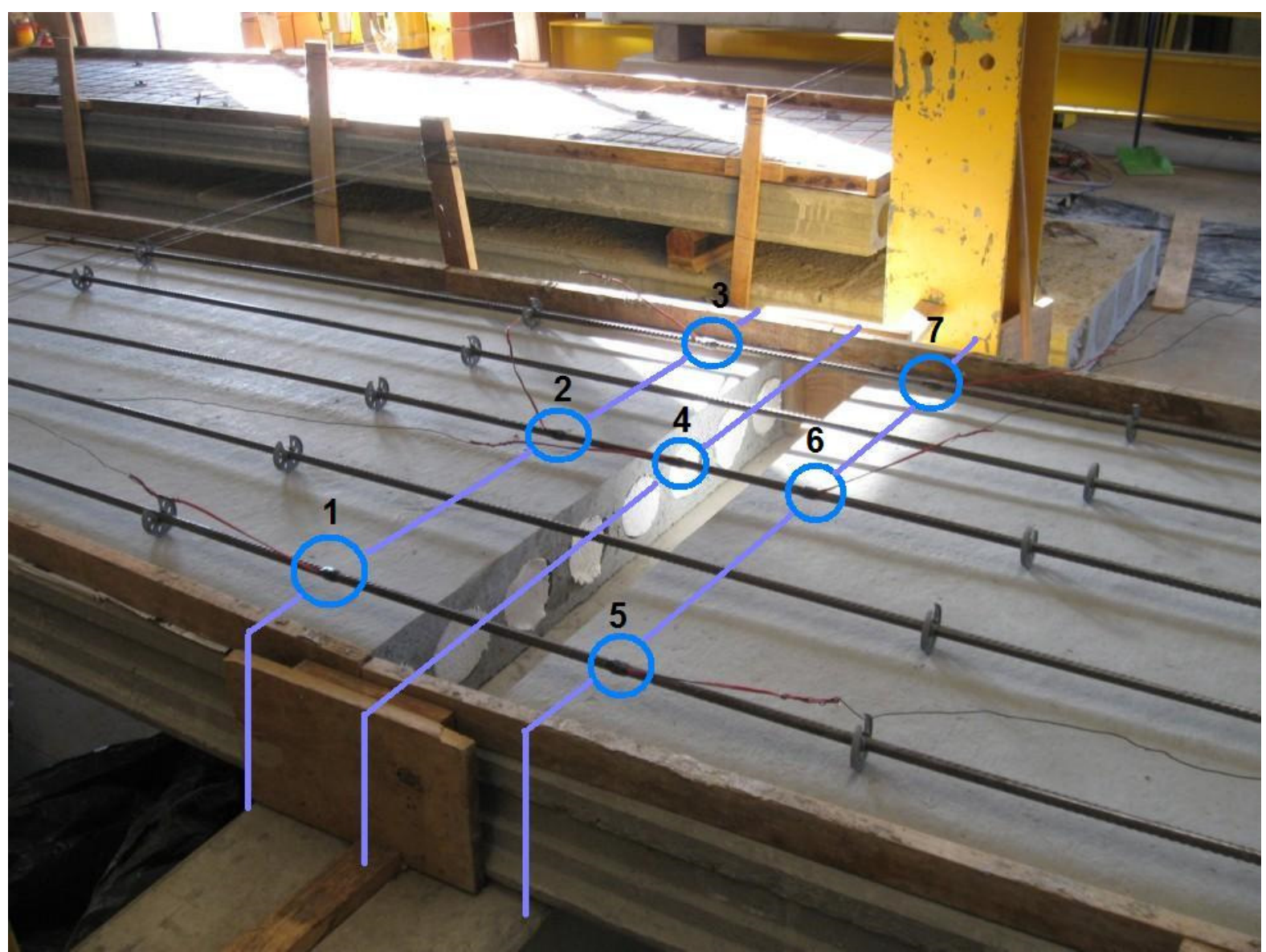

Figura 5.17 - Posição dos extensômetros no modelo EM3 (a mesma dos modelos 2 e 3).

Para a aquisição dos dados, foram utilizados dois aparelhos SYSTEM 5000 (Figura 5.18a), aos quais os dezessete pontos de instrumentação (instrumentos de medição e aplicação do carregamento) foram ligados (Figura 5.18b). A leitura e o registro das informações eram realizados por computador (Figura 5.18c), através do software que acompanha o SYSTEM 5000. 


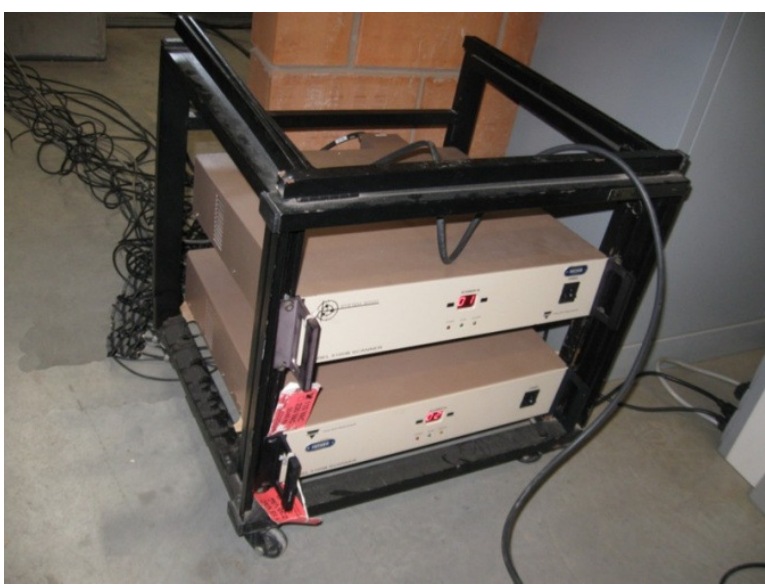

(a)

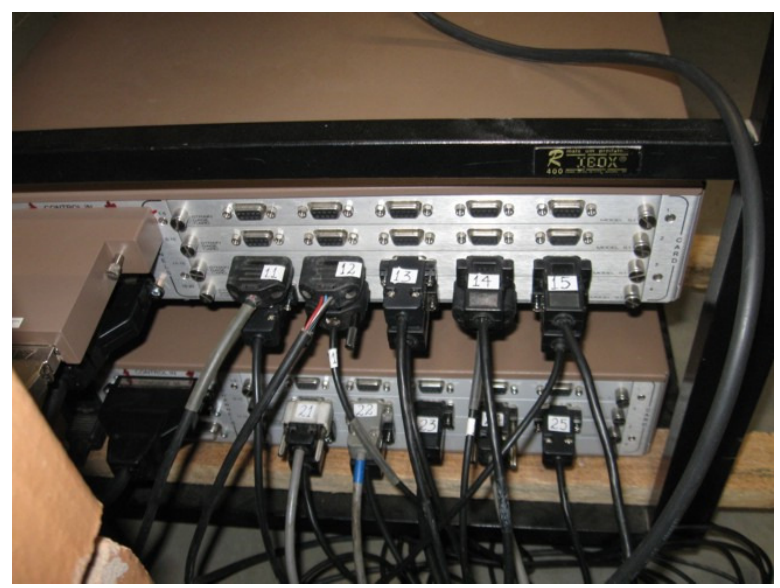

(b)

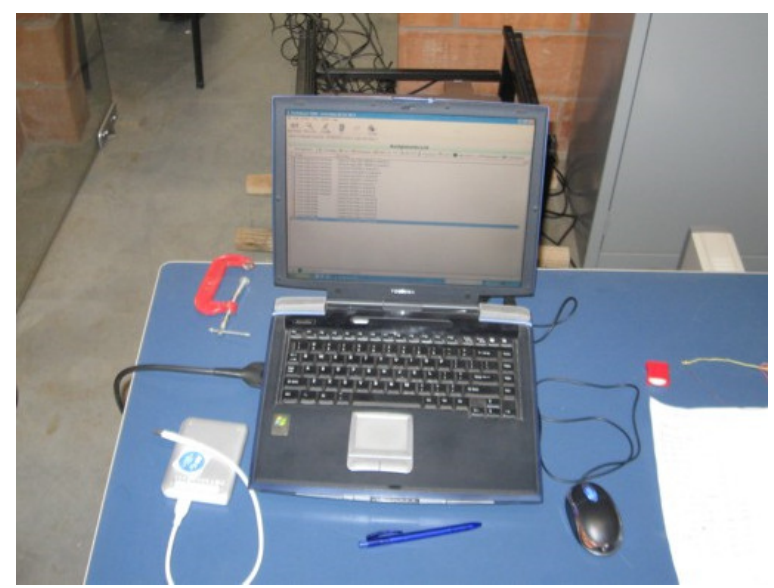

(c)

Figura 5.18 - Equipamentos para aquisição, leitura e registro dos dados: (a) Parte frontal dos aparelhos SYSTEM 5000; (b) Parte traseira dos aparelhos SYSTEM 5000, sendo utilizados 17 canais; (c) Computador com o software que acompanha o sistema.

\section{4 - Mapa da instrumentação}

Com o objetivo de auxiliar o entendimento dos pontos de instrumentação de cada ensaio, a Figura 5.19 apresenta um mapa de instrumentação para cada modelo ensaiado. Nessa figura os números representam o canal do sistema SYSTEM 5000 aos quais os aparelhos de instrumentação foram ligados. Longitudinalmente, os modelos foram divididos em:

- Lado de referência, correspondente àquele onde o sistema de aquisição de dados foi montado;

- Lado oposto (ao lado de referência).

Transversalmente, os modelos foram divididos em:

- Lado direito, representado pela cor vermelha;

- Lado esquerdo, representado pela cor azul. 


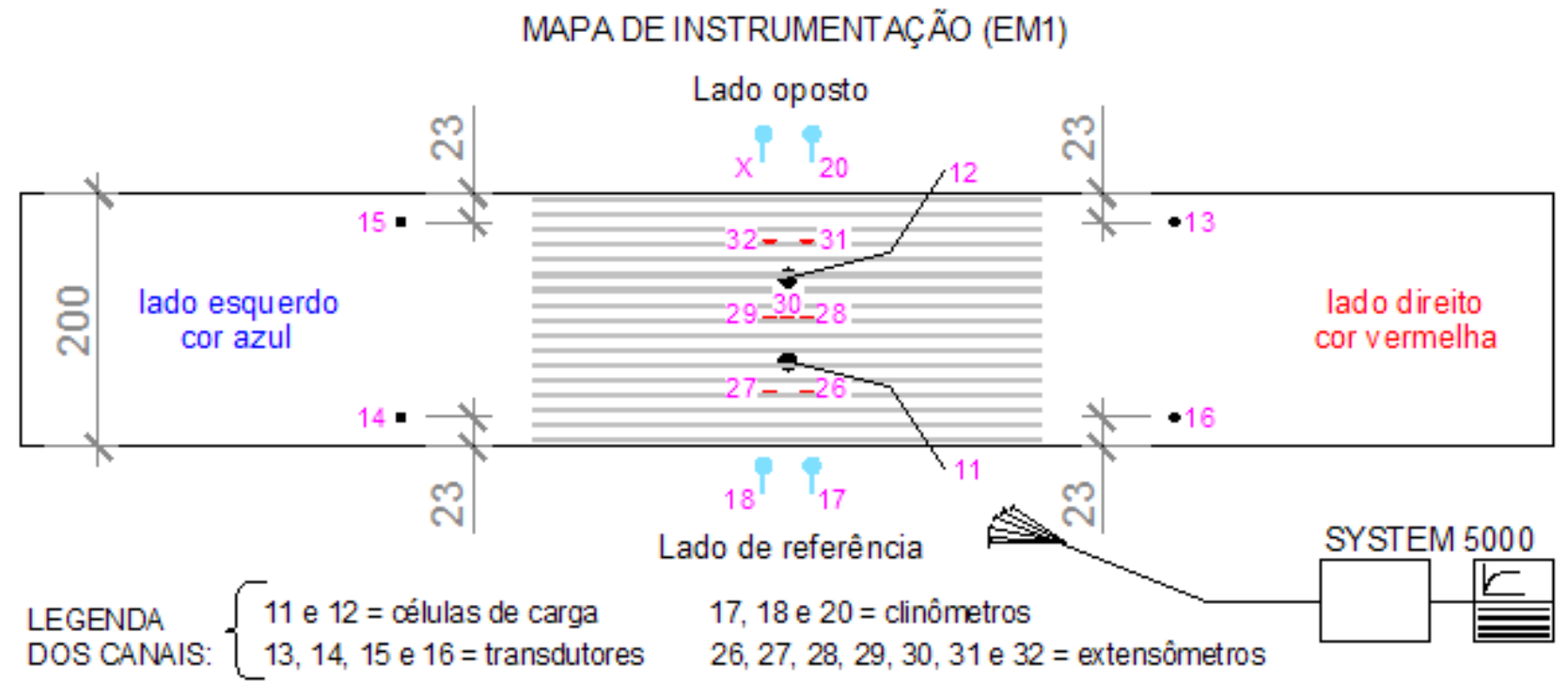

(a)

MAPA DE INSTRUMENTAÇÃO (EM2)

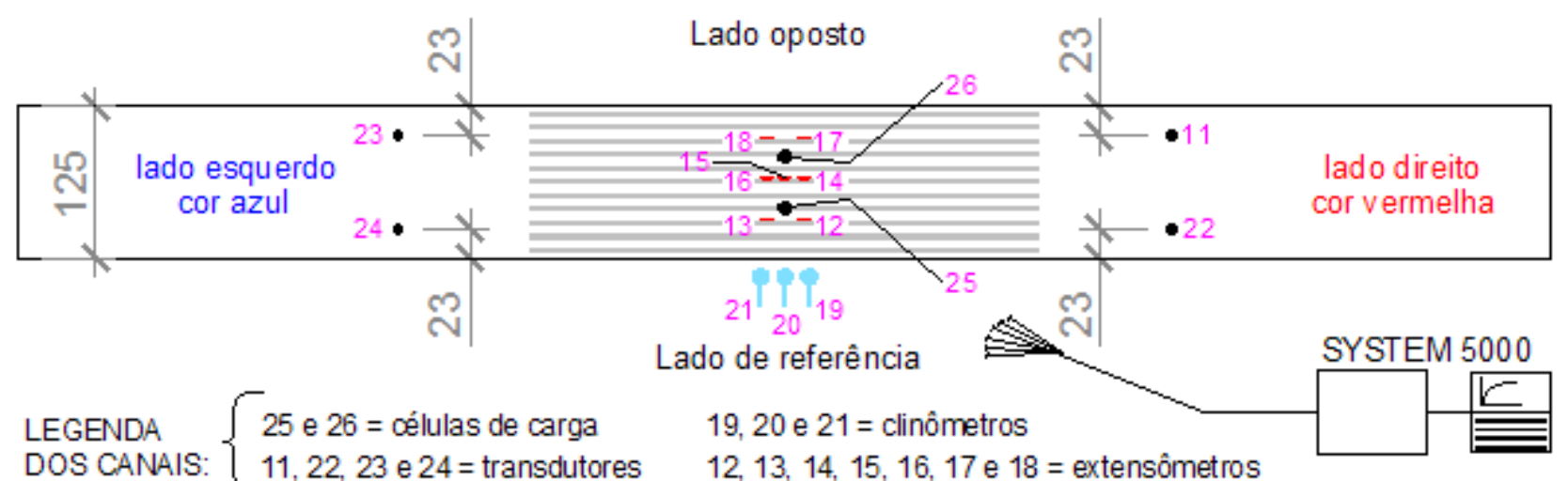

(b)

MAPA DE INSTRUMENTAÇÃO (EM3)

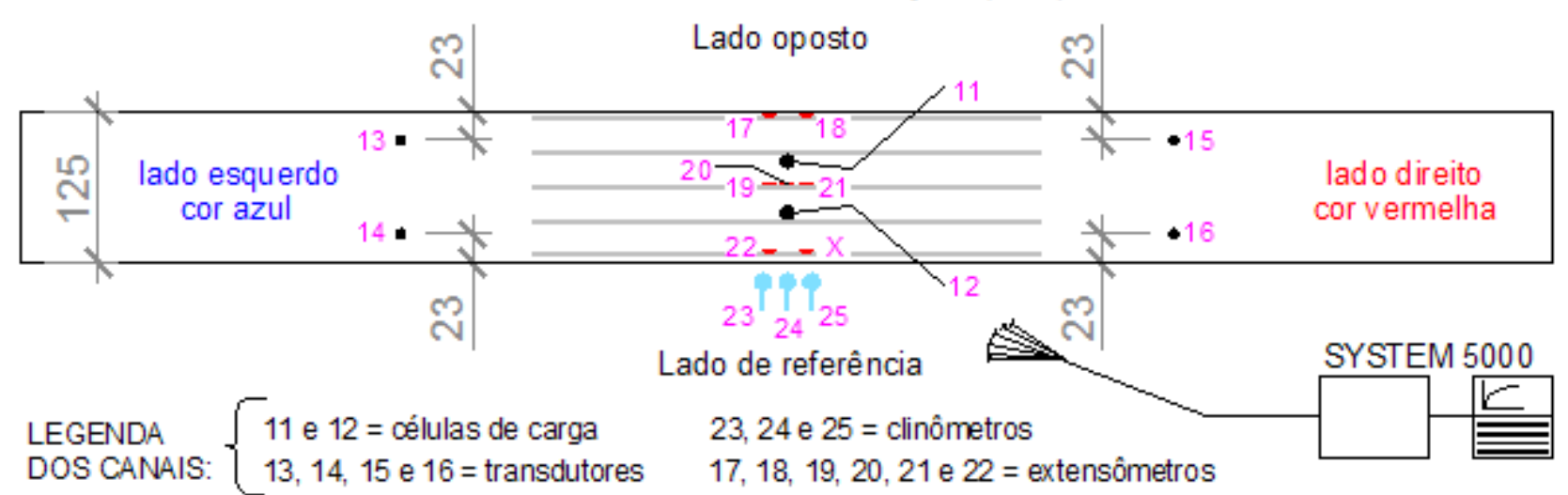

(c)

Figura 5.19 - Mapa de instrumentação: (a) EM1; (b) EM2; (c) EM3. 


\section{5 - Resultados}

A seguir serão apresentados os resultados dos ensaios de continuidades. Os gráficos, mostrados na sequência, foram obtidos a partir dos resultados obtidos pelo sistema de aquisição de dados, e de acordo com os pontos de instrumentação utilizados.

No item 3.7 do capítulo 3, as forças aplicadas nos ensaios de lajes simplesmente apoiadas foram convencionadas como $F_{1}$, nomenclatura que foi seguida no capítulo 4 , que trata dos ensaios de caracterização. De modo semelhante, as forças aplicadas nos ensaios de continuidade foram chamadas de $F_{2}$. Portanto, tal terminologia será mantida neste capítulo.

Como mostrado anteriormente, foram utilizadas vigas metálicas para a aplicação da força no ensaio de continuidade $\left(F_{2}\right)$. No ensaio do modelo 1 (EM1), o peso total das vigas metálicas era de $21,4 \mathrm{kN}$. Isso fez com que cada laje do EM1 fosse carregada com 10,7 kN, antes de se iniciar a aplicação da força pelo atuador. Nos modelos 2 e 3 (EM2 e EM3), o peso total das vigas metálicas era de $20 \mathrm{kN}$. Essa diferença se deu pelo fato de que as lajes do modelo 1 possuírem 2,0 m de largura, sendo necessária a utilização, nesse modelo, de duas vigas metálicas.

Uma vez que a montagem das vigas metálicas sobre as lajes alveolares não foi feita de forma instantânea, e também a instrumentação foi colocada posteriormente, não foi possível fazer a leitura dos deslocamentos, rotações e deformações correspondente ao peso próprio das vigas metálicas.

Vale destacar que, em todos os ensaios realizados, foi feito o escorvamento, considerando aproximadamente $30 \%$ da força de ruptura. Além desse fato, os gráficos que serão apresentados a seguir consideram a força absorvida pelo isopor colocado entre a viga metálica e a face superior da laje alveolar, para distribuir de forma homogênea a força aplicada pela viga. Foram descontados aproximadamente $10 \mathrm{kN}$, de acordo com análise prévia dos gráficos.

As unidades usadas nos gráficos deste capítulo são:

- Força aplicada no ensaio $\left(F_{2}\right)$ : kN;

- Deslocamentos ( $\delta): \mathrm{mm}$;

- $\operatorname{Rotação~}(\phi)$ : graus $\left({ }^{\circ}\right)$;

- Deformação $(\varepsilon)$ : \%o.

Os ensaios de continuidade tiveram as seguintes durações (aproximadamente):

- Modelo 1: 8 minutos;

- Modelo 2: 5 minutos;

- Modelo 3: 10 minutos. 


\subsection{1 - Modelo 1 (EM1)}

A Figura 5.20 mostra uma visão geral do modelo 1, com o objetivo de indicar o lado de referência e o lado oposto convencionado no mapa de instrumentação da Figura 5.19.

Com a aplicação da força, a primeira fissura ocorreu na capa, na seção do apoio, com $F_{2}=107,9$ kN, aproximadamente. Com $F_{2}=210$ kN, ouviram-se ruídos, caracterizados por pequenos estalos. Para $F_{2}=219,1 \mathrm{kN}$, verificou-se o início de uma fissura vertical na face inferior de cada laje. Essas fissuras estavam localizadas próximas à seção de aplicação da força $F_{2}$ (em cada lado), caracterizando fissuração devida ao momento positivo.

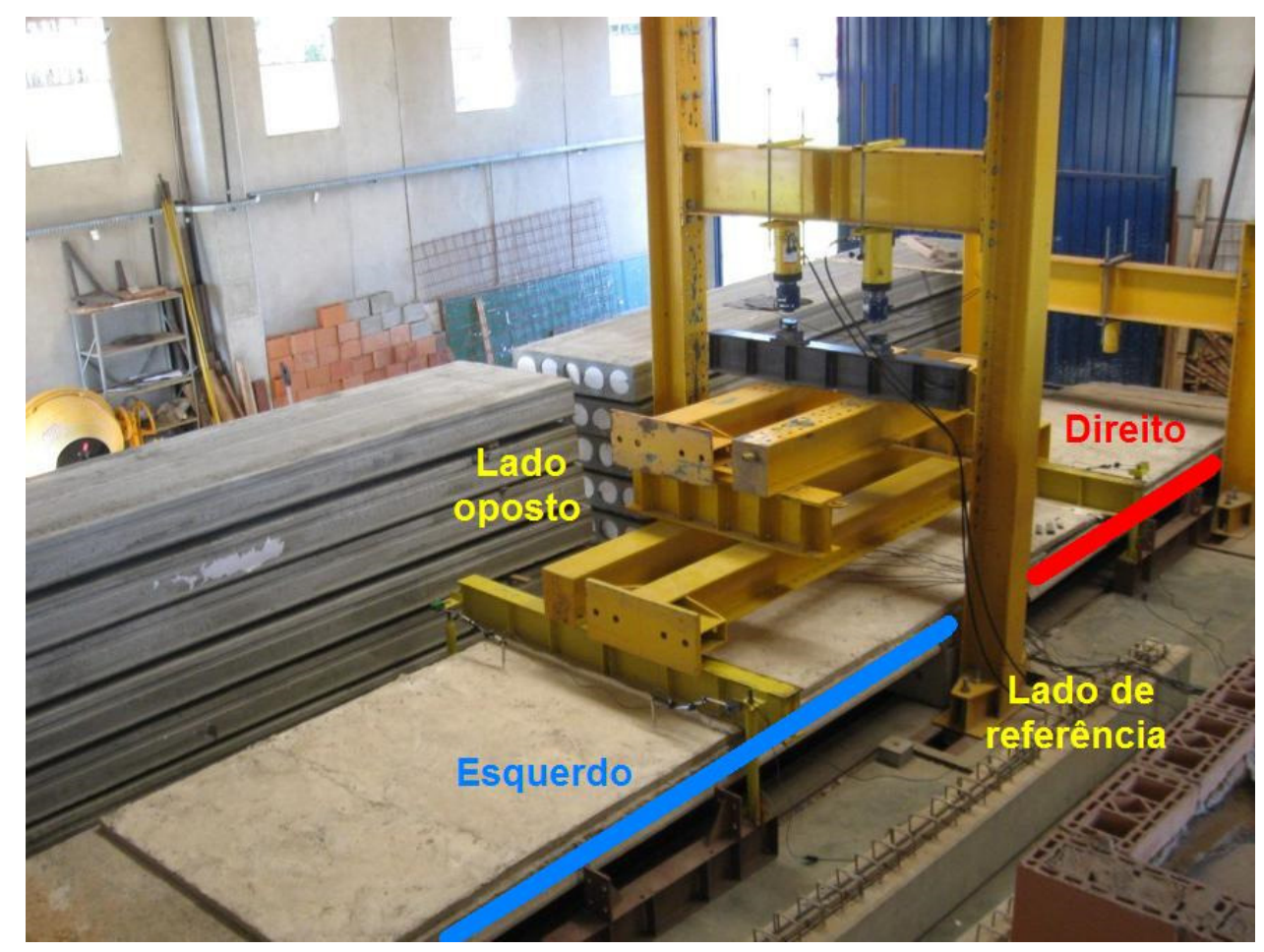

Figura 5.20 - Visão geral do modelo 1 (EM1). Convenção do lado de referência.

Quando $F_{2}$ atingiu $260 \mathrm{kN}$, ouviram-se ruídos mais altos, que continuaram até que, por volta de $F_{2}=272 \mathrm{kN}$, uma das lajes atingiu a ruptura por cisalhamento, (ruptura por tração diagonal do concreto). A laje que sofreu ruptura foi a indicada em vermelho, posicionada no lado direito com relação ao lado de referência. A ruptura ocorreu entre a linha de aplicação da força $F_{2}$ e o apoio intermediário, próximo a este.

Logo após a ruptura da laje por cisalhamento, a laje se deslocou para baixo de forma abrupta, e isso fez com que ela se desprendesse da capa. Esta por sua vez permaneceu na sua posição, antes da ruptura da laje.

A Figura 5.21 apresenta uma vista panorâmica do modelo 1 após a ruptura, correspondente ao lado referência. A Figura 5.22, apresenta uma vista lateral, enfatizando 
o trecho com ruptura do lado de referência. Já a Figura 5.23, mostra uma vista lateral da ruptura, porém no lado oposto.

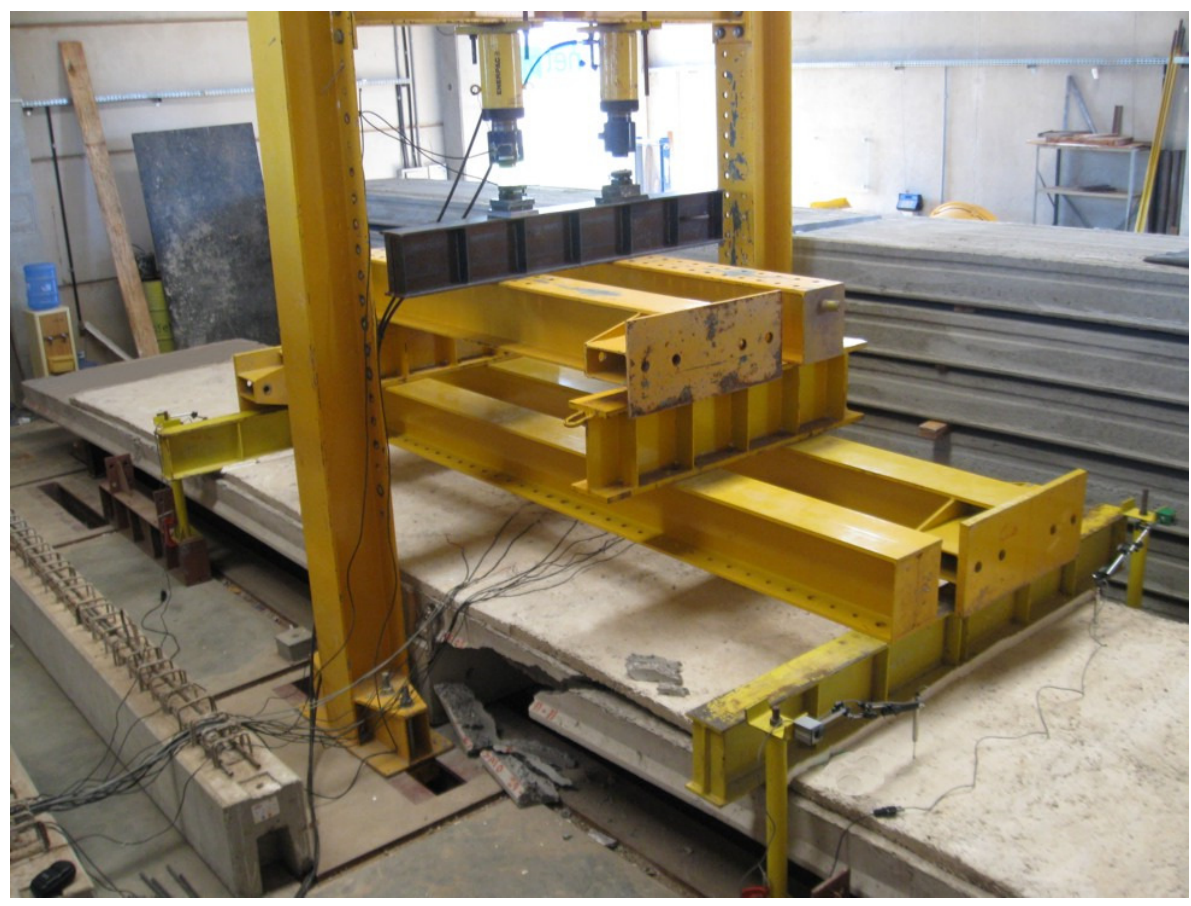

Figura 5.21 - Vista panorâmica do modelo EM1 após a ruptura. Foto tirada no lado de referência.

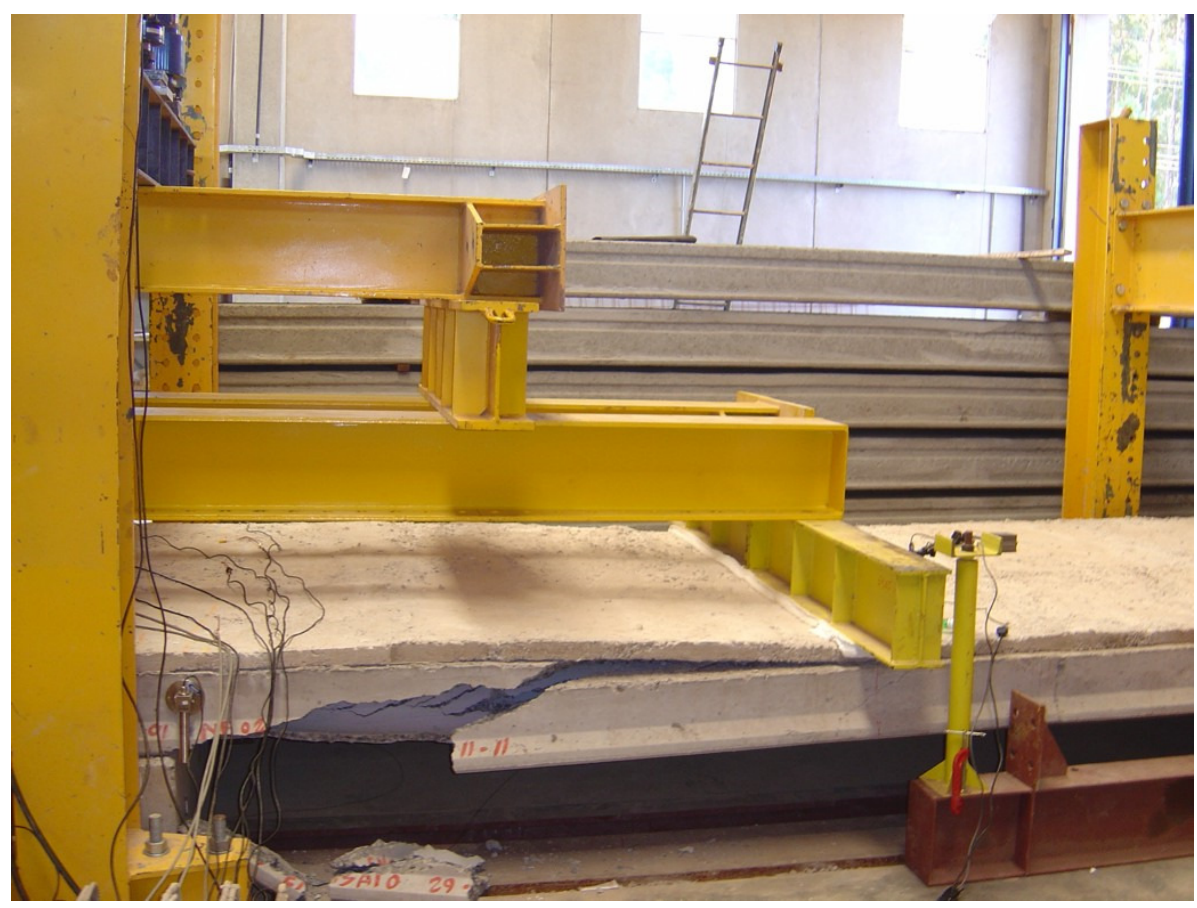

Figura 5.22 - Vista lateral da laje que sofreu ruptura no EM1. Laje da direita com relação ao lado de referência. Foto tirada no lado de referência. 


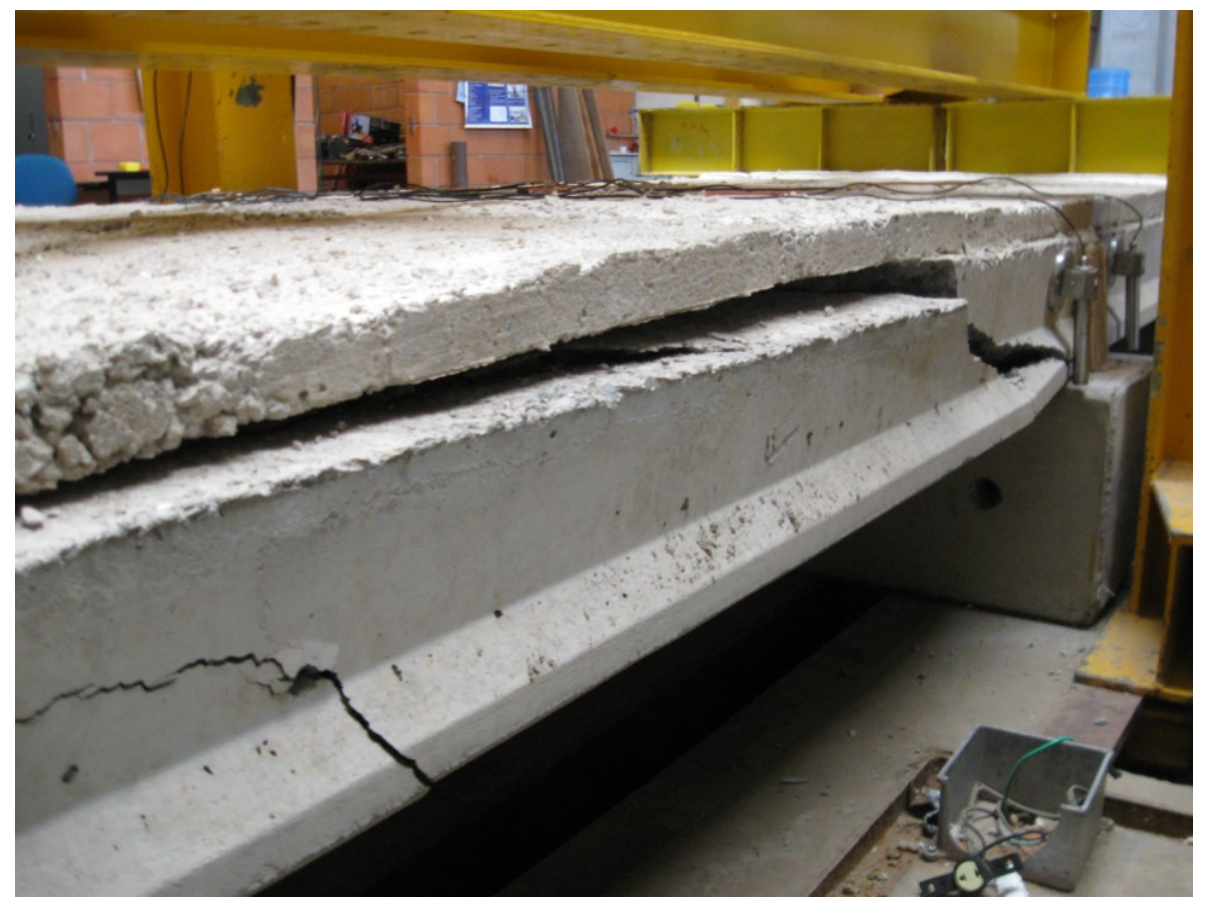

Figura 5.23 - Vista lateral da laje que sofreu ruptura no EM1. Laje da direita com relação ao lado de referência. Foto tirada no lado oposto.

No lado de referência houve um maior desprendimento de concreto, e isso possibilitou visualizar a formação e a inclinação das fissuras. A Figura 5.24 mostra essa região onde houve a ruptura e permite ver a ruptura por solicitação tangencial, com inclinação das fissuras em torno de $30^{\circ}$. No lado oposto também foi possível verificar que a inclinação da fissura diagonal foi de aproximadamente $28^{\circ}$ (Figura 5.25).

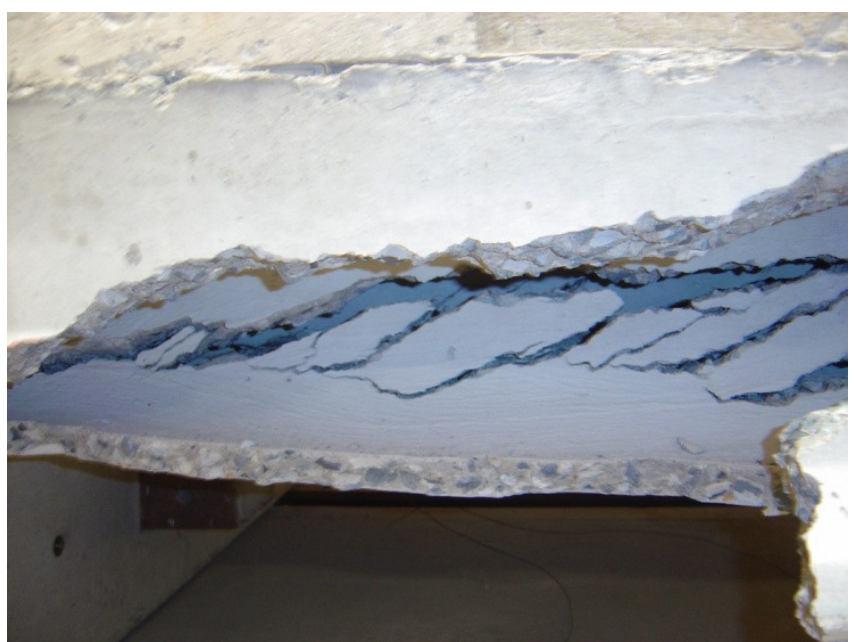

Figura 5.24 - Inclinação das fissuras diagonais decorrentes das solicitações tangenciais para a ruptura de EM1. Foto tirada no lado de referência. 


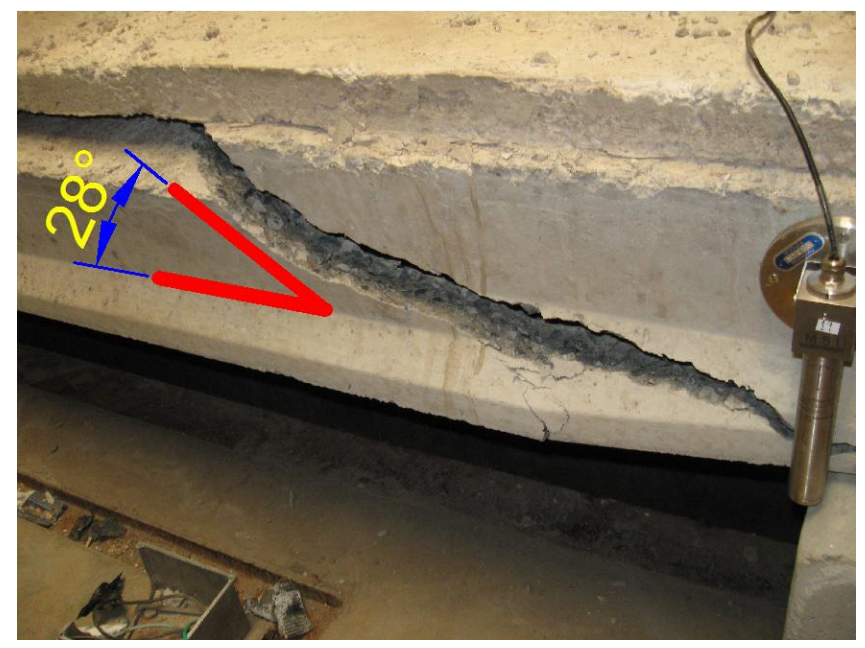

Figura 5.25 - Inclinação das fissuras diagonais decorrentes das solicitações tangenciais para a ruptura de EM1. Foto tirada no lado oposto.

Para a laje que sofreu ruptura, a fissura devida ao momento positivo pode ser vista na Figura 5.26.

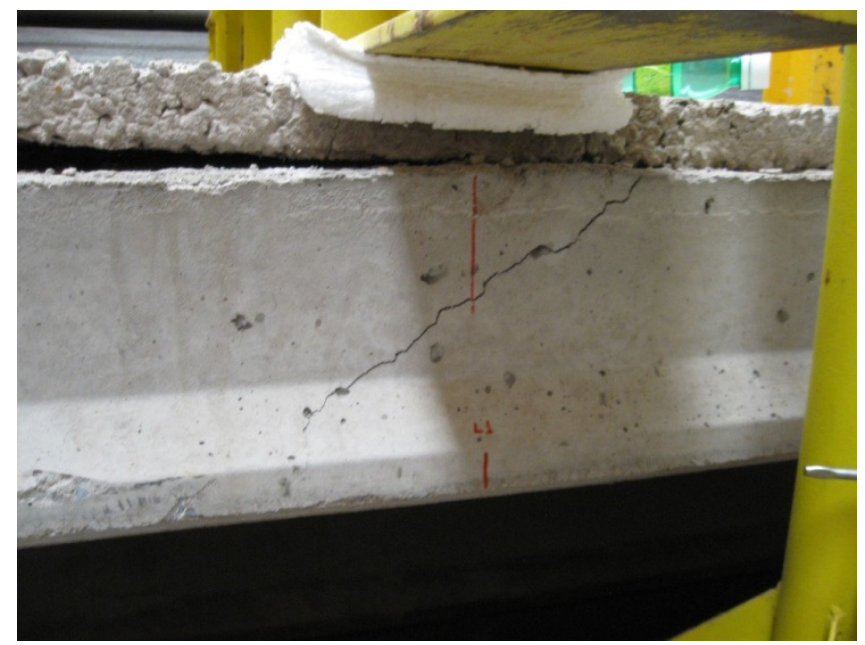

Figura 5.26 - Fissura ocasionada pelo momento positivo (EM1). Foto tirada no lado de referência, na laje que sofreu ruptura.

A seguir serão apresentados os gráficos obtidos através do sistema de aquisição de dados. Os da Figura 5.27 relacionam a força aplicada no ensaio $\left(F_{2}\right)$ com os deslocamentos medidos ( $\delta$ ), para LVDT's do lado esquerdo (em azul) do EM1. A Figura 5.28 mostra o mesmo tipo de gráfico, porém, para LVDT's do lado direito (em vermelho). Já a Figura 5.29 apresenta uma comparação entre os lados direito e esquerdo, feita com valores médios dos LVDT's. 
EM1 - Força (kN) x Deslocamento $(\delta)$

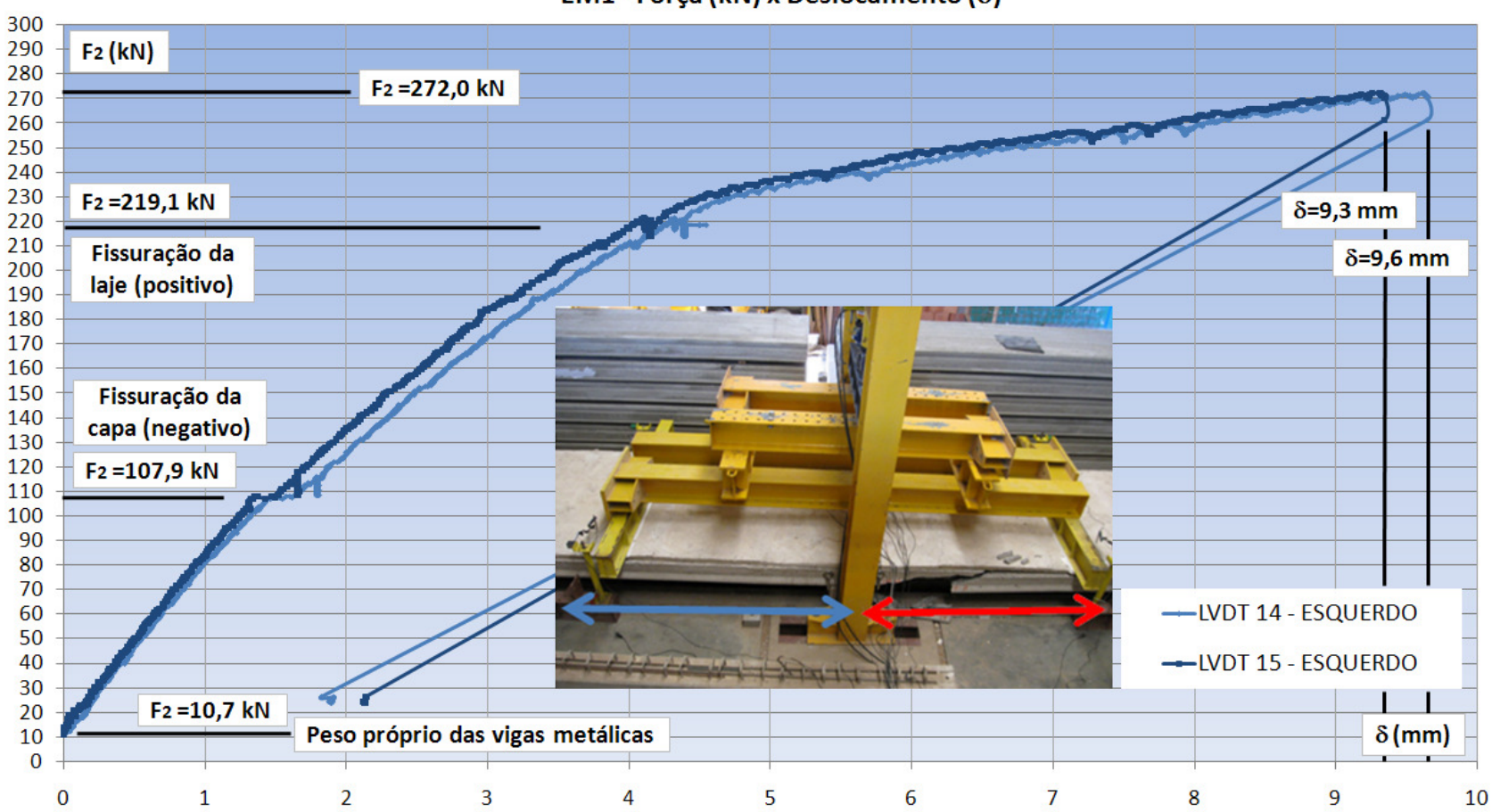

Figura 5.27 - Diagramas Força x Deslocamento do lado esquerdo (azul) de EM1.

EM1 - Força $(k N)$ x Deslocamento $(\delta)$

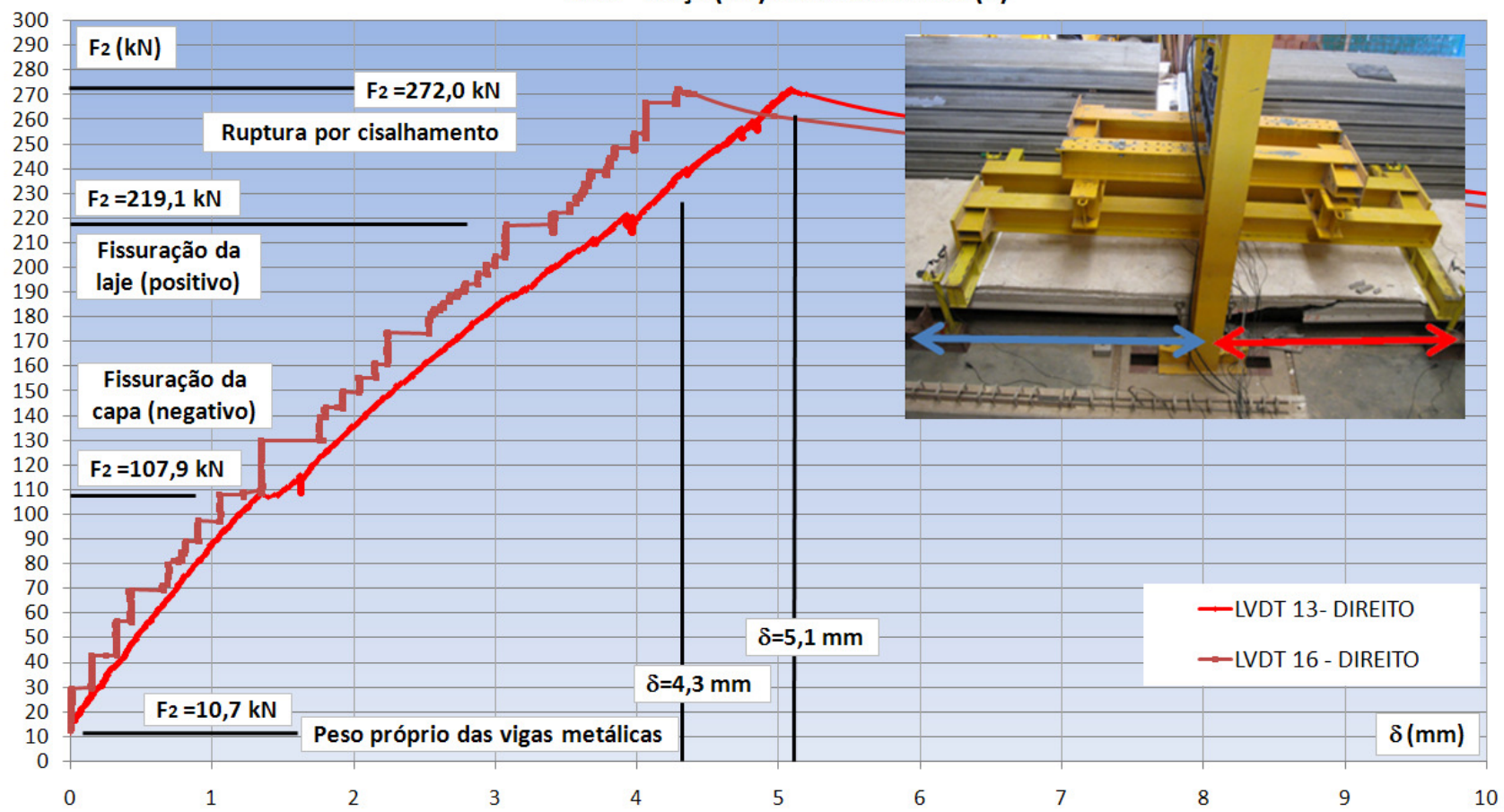

Figura 5.28 - Diagramas Força x Deslocamento do lado direito (vermelho) de EM1. 


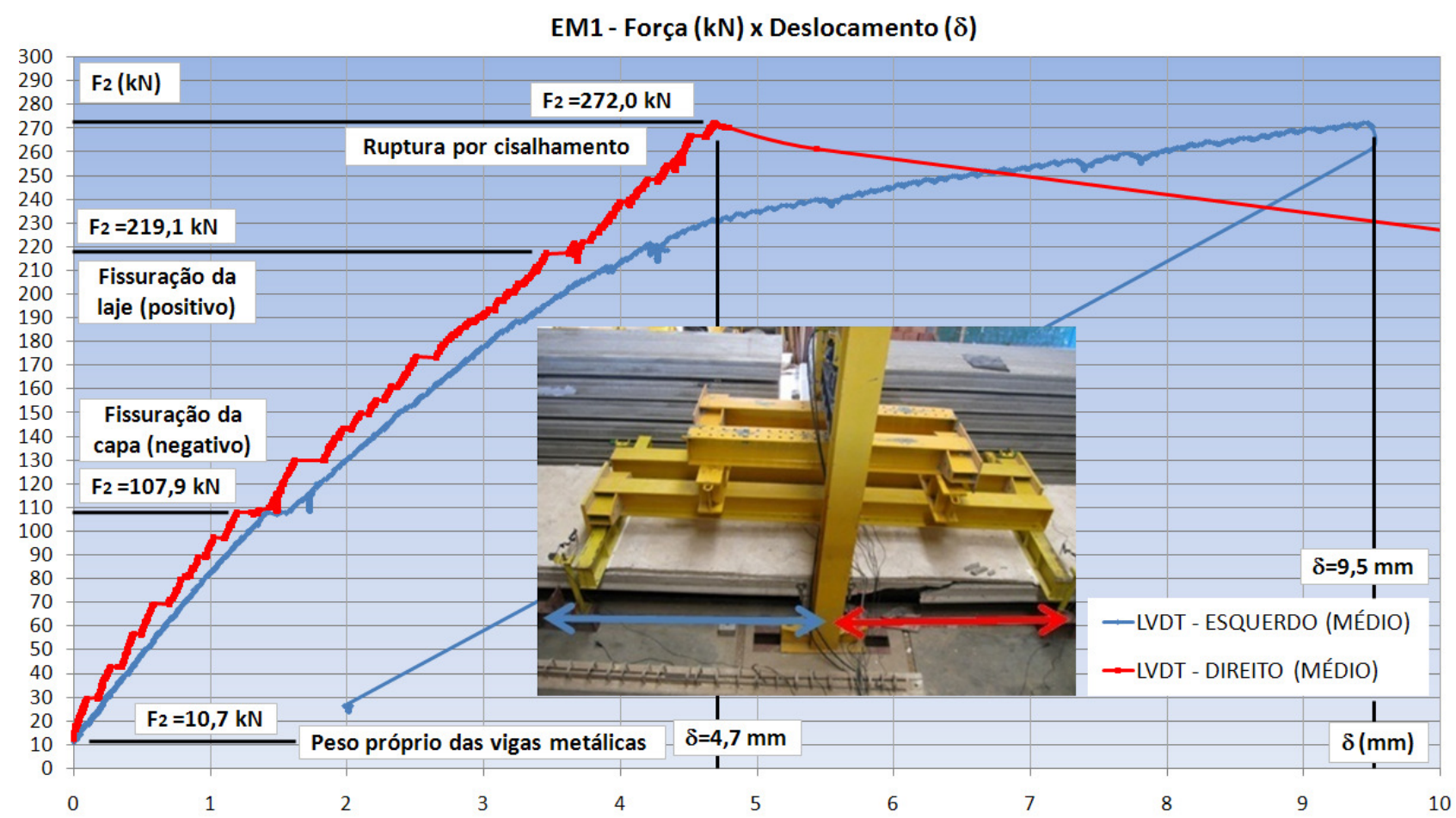

Figura 5.29 - Diagramas Força x Deslocamento dos valores médios de EM1 (ruptura na laje da direita, com indicação em vermelho).

De acordo com a Figura 5.29, a laje da esquerda (em relação ao lado de referência) se deslocou mais que a da direita. A laje da esquerda sofreu um deslocamento de 9,5 $\mathrm{mm}$, enquanto a da direita alcançou a ruptura com $4,7 \mathrm{~mm}$. Isso indica que a laje que atingiu a ruptura por cisalhamento teve um comportamento mais rígido, com deslocamento de, aproximadamente, metade do valor da outra laje. Esse comportamento mais rígido é acentuado após a fissuração da laje pelo momento positivo ( $\left.F_{2}=219,1 \mathrm{kN}\right)$. A laje da esquerda apresentou uma maior fissuração devida a momento positivo que a laje da direita.

Observando a Figura 5.27, percebe-se que a laje da esquerda se deslocou de forma uniforme, uma vez que os resultados dos dois LVDT's ficaram muito próximos entre si. Por outro lado, os LVDT's da laje da direita apontaram comportamentos diferentes entre si. 0 LVDT número 16 (posicionado no lado de referência) apresentou um gráfico com comportamento "serrilhado", e em relação aos deslocamentos, teve um comportamento mais rígido que o LVDT 13, situado no lado oposto

De uma forma geral, todos os gráficos $F_{2} \times \delta$ apresentaram comportamentos que podem ser aproximados por três retas: a primeira começa com o início do carregamento $\left(F_{2}=10,7 \mathrm{kN}\right)$ e vai até a fissuração da capa pelo momento negativo $\left(F_{2}=107,9 \mathrm{kN}\right)$; a segunda vai da fissuração da capa até a fissuração das lajes pelo momento positivo $\left(F_{2}=219,1 \mathrm{kN}\right)$; e a terceira que tem início na fissuração da laje e termina na ruptura por cisalhamento $\left(F_{2}=272,0 \mathrm{kN}\right)$. 
A Figura 5.30 mostra os gráficos que relacionam $F_{2}$ com a rotação no apoio ( $\left.\phi\right)$. Essa figura apresenta os resultados do clinômetro posicionado na laje esquerda (clinômetro 18, resultados em azul), e os da direita (clinômetros 17 e 20, em vermelho). A Figura 5.31 apresenta a comparação do resultado da esquerda com os valores médios da direita.

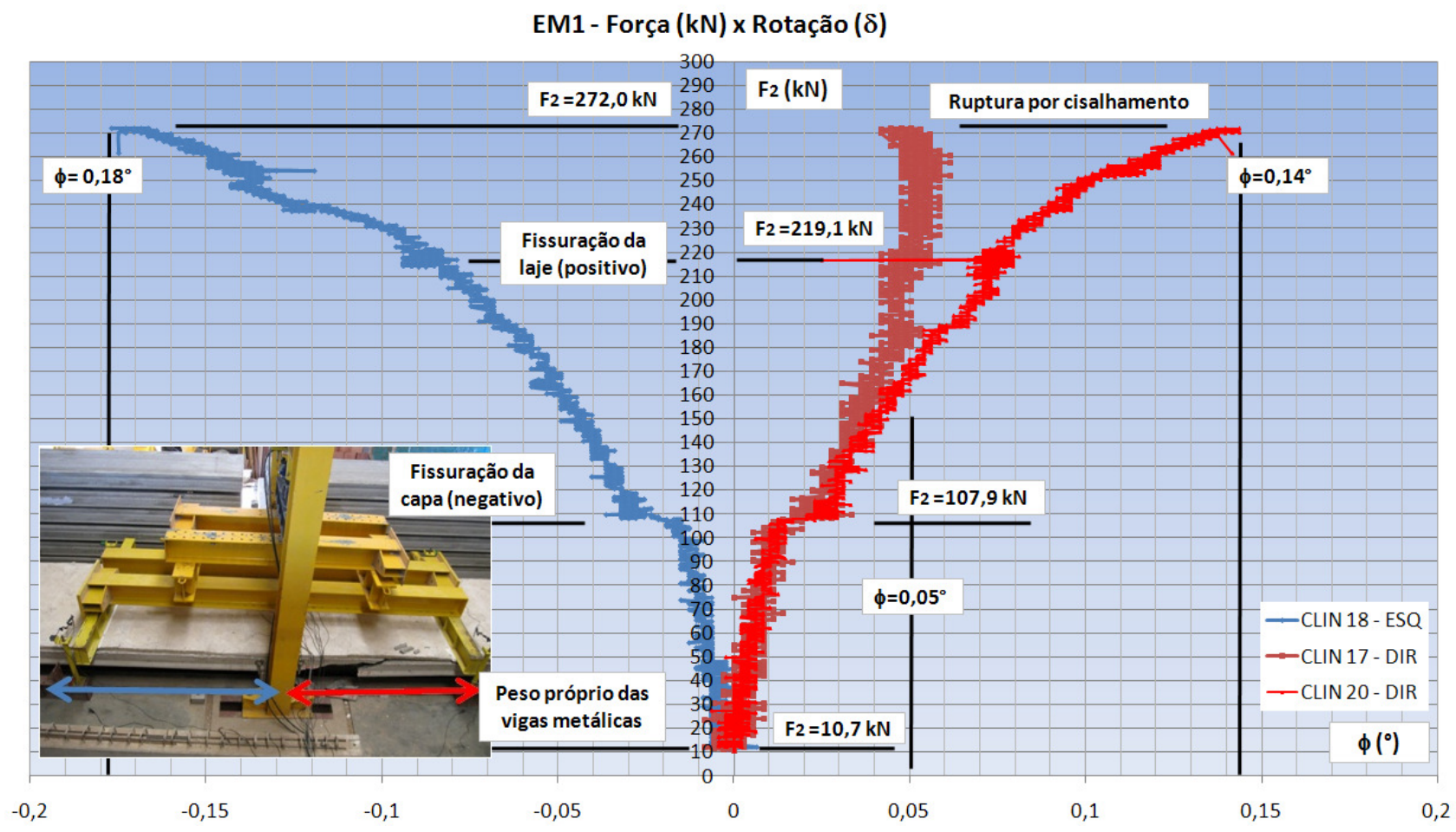

Figura 5.30 - Diagramas Força x Rotação dos clinômetros 17 e 20 (direito) e 18 (esquerdo) de EM1.

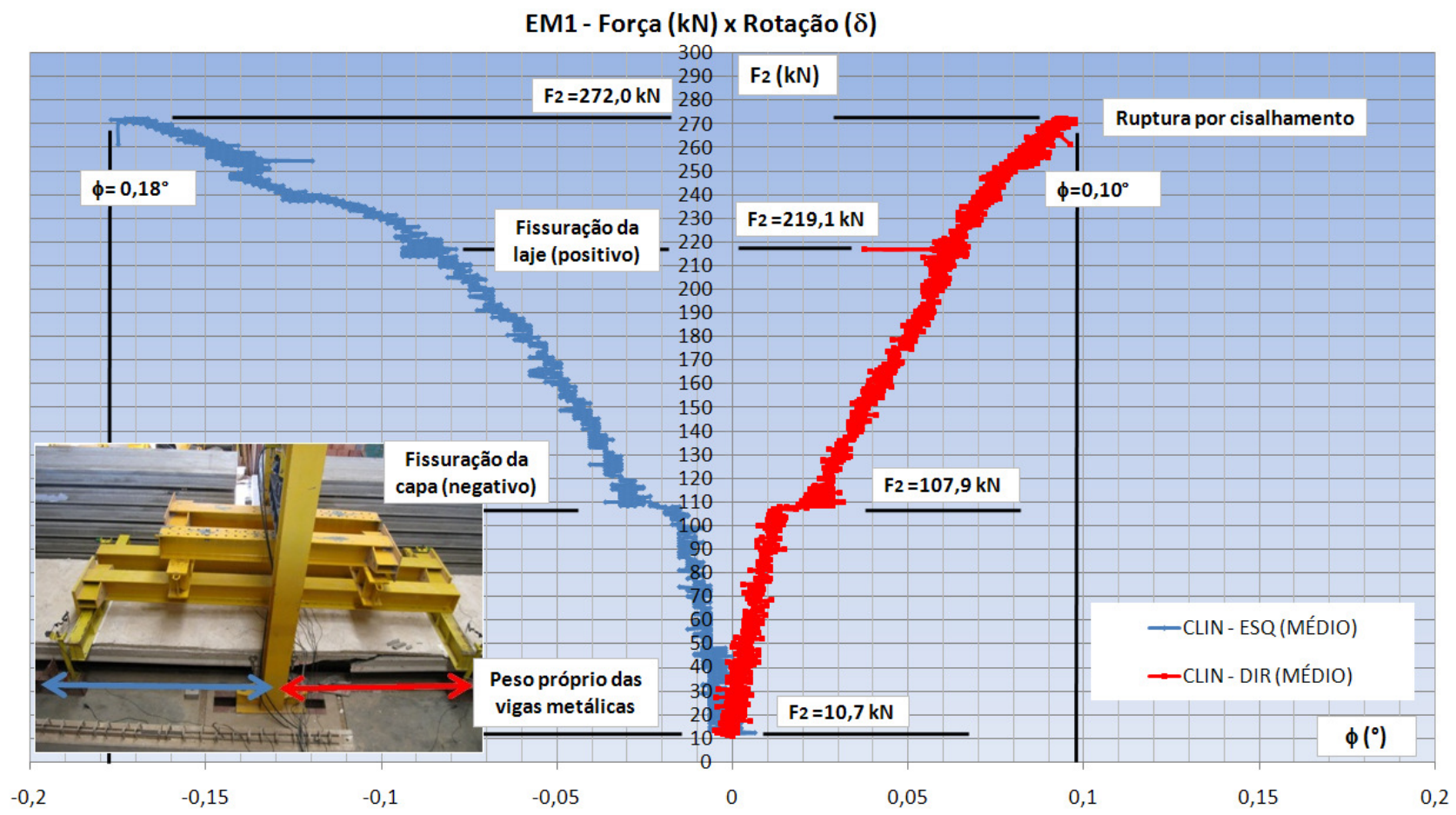

Figura 5.31 - Diagramas Força x Rotação dos clinômetro 18 (esquerdo) e média entre os clinômetros 17 e 20 de EM1. 
De uma forma geral, os resultados da rotação no apoio estão em consonância com os de deslocamentos no meio do vão. Da mesma forma que os gráficos de deslocamentos, os de rotação mostraram que a laje que sofreu ruptura (em vermelho) ficou mais rígida que a da esquerda (em azul), principalmente após a fissuração das lajes pelo momento positivo. Além disso, a comparação entre os dois resultados da laje da direita (em vermelho), mostra que o lado de referência (clinômetro 17) ficou mais rígido que o lado oposto (clinômetro 20).

Os gráficos de rotação no apoio também podem ser descritos por três retas, da mesma forma que os deslocamentos, tendo os mesmos intervalos com relação à força $F_{2}$.

Esses gráficos indicam também que a ligação no apoio intermediário, com a presença de armadura passiva na capa, se mostrou com comportamento rígido, no que diz respeito à transmissão de esforços solicitantes, pois os valores de rotação à esquerda e à direita ficaram muito próximos. Em outras palavras, a rotação nas lajes do modelo 1 foi simétrica, principalmente no primeiro trecho das curvas (início da aplicação da força $F_{2}$ até a fissuração da capa).

Com relação às deformações nas armaduras passivas, a Figura 5.32 mostra as curvas que relacionam a força $\left(F_{2}\right)$ com as deformações medidas $(\varepsilon)$ pelos extensômetros posicionados no lado esquerdo (azul) de EM1. A Figura 5.33 apresenta as mesmas curvas, porém para os extensômetros colocados no lado direito (vermelho). Por fim, a Figura 5.34 exibe, além da comparação entre os valores médios dos lados esquerdo e direito, a curva que representa o extensômetro posicionado no centro do modelo (verde).

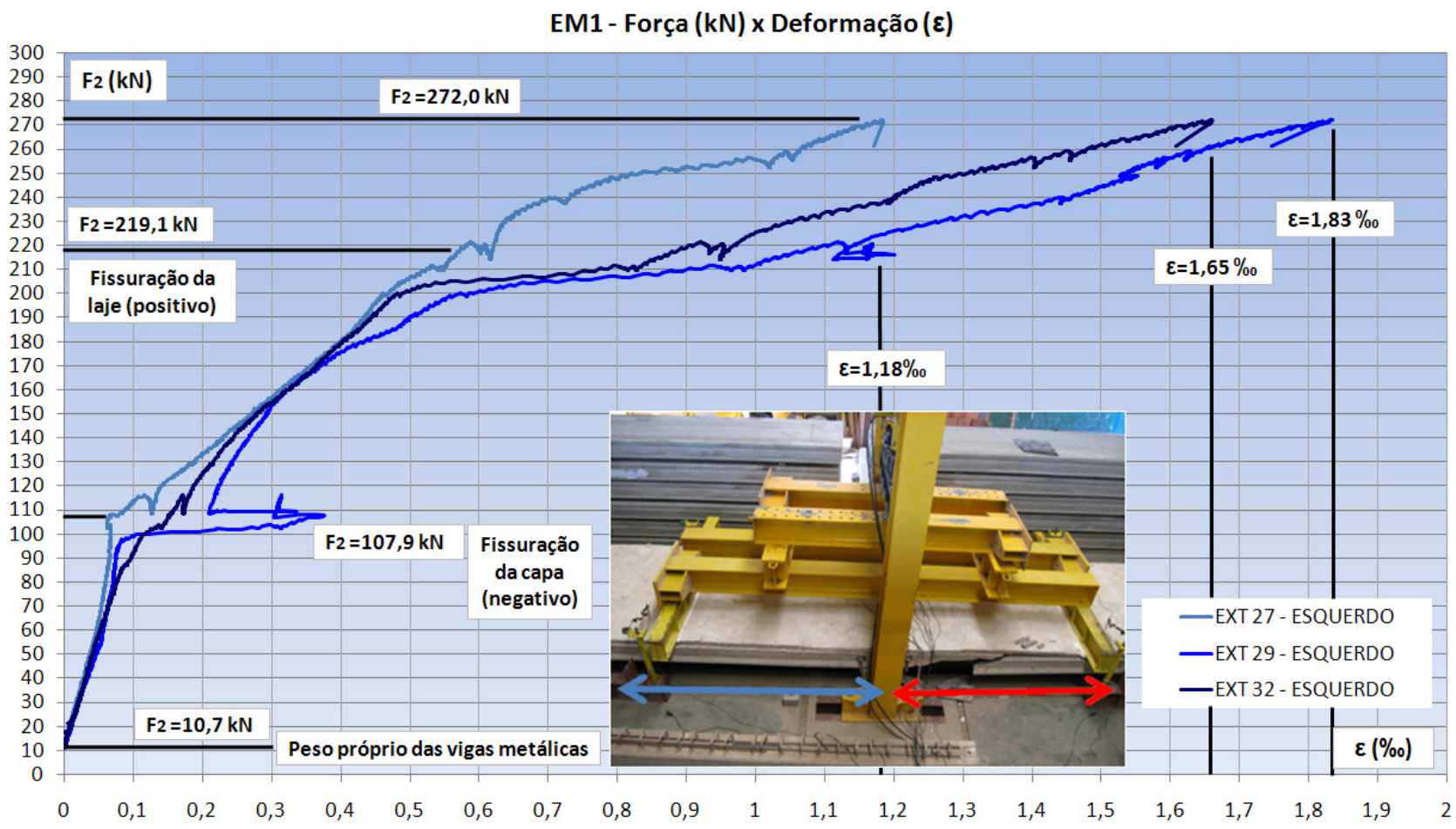

Figura 5.32 - Diagramas Força x Deformação do lado esquerdo (azul) de EM1. 
EM1 - Força $(k N)$ x Deformação $(\varepsilon)$

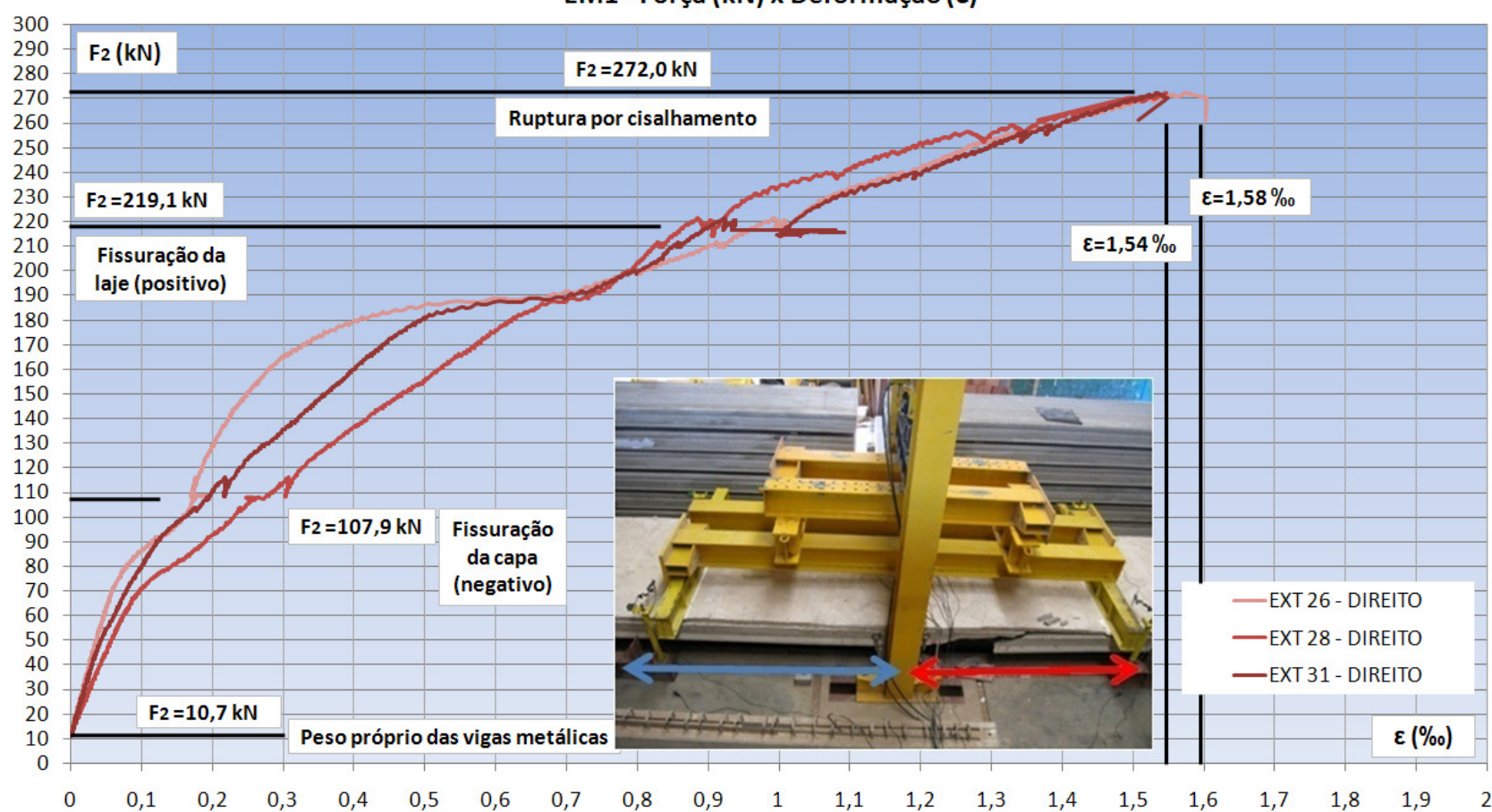

Figura 5.33 - Diagramas Força x Deformação do lado direito (vermelho) de EM1.

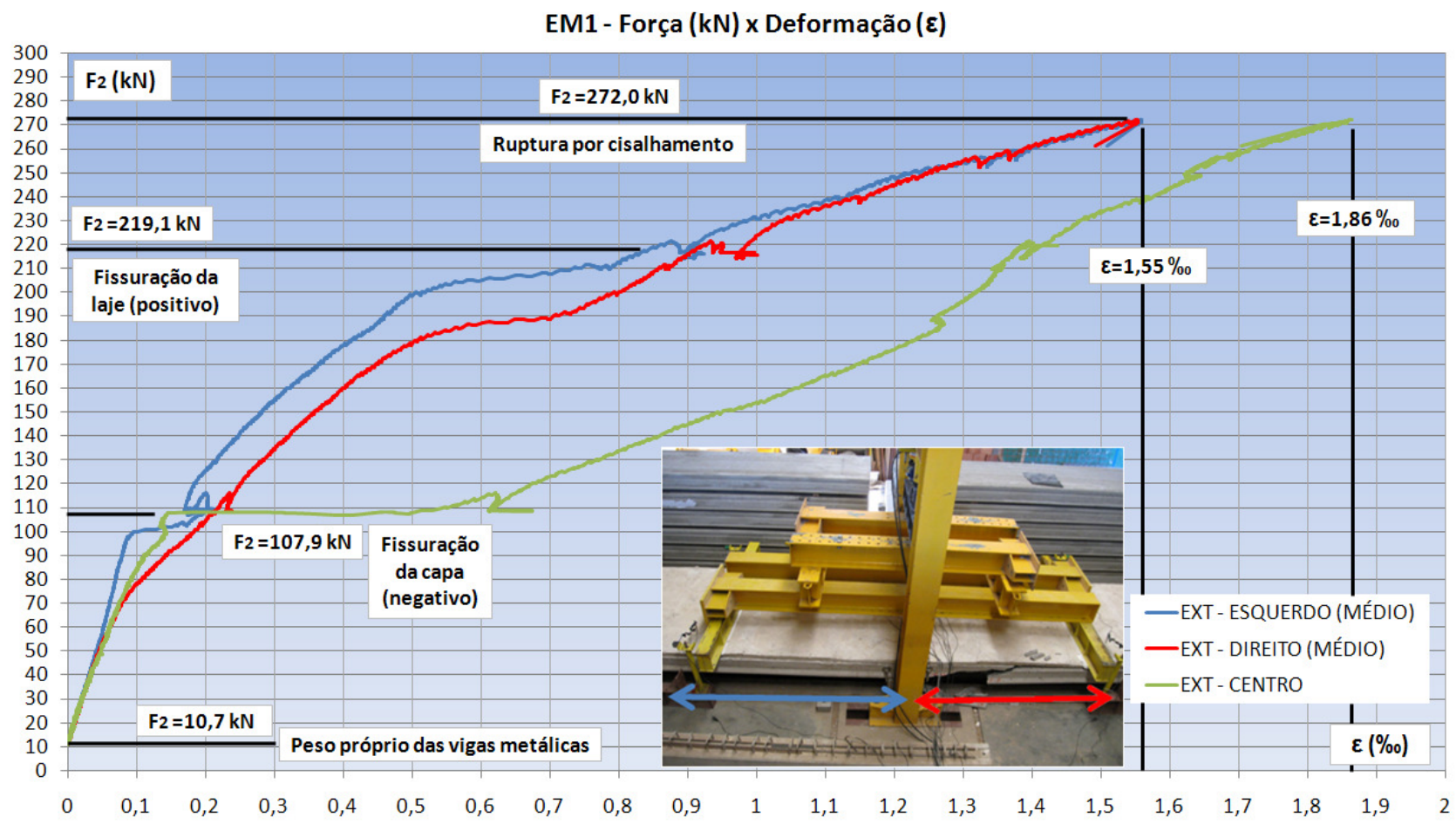

Figura 5.34 - Diagramas Força x Deformação do extensômetro do centro (EXT 30), e valores médios dos extensômetros posicionados nos lados esquerdo e direito de EM1.

Analisando os diagramas da Figura 5.34, nota-se que a deformação no centro do modelo foi maior após a fissuração da capa, enquanto que o comportamento médio dos extensômetros da esquerda ficou bem próximo ao comportamento médio dos da direita. 
A curva do extensômetro relativo ao centro do modelo (destacado em verde) apresentou, basicamente, três trechos distintos:

- O primeiro corresponde ao estádio I, ou seja, região sem fissuras. Inicia-se com a aplicação do carregamento $\left(F_{2}=10,7 \mathrm{kN}\right)$ e termina com a fissuração da capa $\left(F_{2}=107,9 \mathrm{kN}\right)$. Nessa fase a seção do centro do modelo pôde contar com a resistência do concreto à tração;

- O segundo representado por um patamar corresponde ao estádio II. Nesse caso a seção está fissurada e ocorre transferência das tensões de tração do concreto para a armadura. Nessa fase ocorre o efeito de contribuição do concreto entre as fissuras para o aumento da rigidez da seção, conhecido como tension stiffening effect. A aderência entre o concreto e o aço faz com que parte da tensão de tração existente no aço seja transmitida ao concreto vizinho, ocasionando a formação de mais fissuras;

- O terceiro trecho corresponde à fissuração estabilizada, onde novas fissuras não podem surgir e somente as existentes sofrem aumento de abertura em função do aumento do carregamento.

A máxima deformação sofrida pelas barras na seção central do modelo 1 foi de $1,86 \%$. Isso indica que as barras não sofreram escoamento, comprovando que a ruína por flexão estaria longe de acontecer.

Considerando as curvas que representam o comportamento médio dos lados esquerdo (que não sofreu ruptura, representado pelo azul) e direito (lado que sofreu ruptura por cisalhamento, representado pelo vermelho), também é possível observar, basicamente, os mesmos três trechos distintos (estádio I, estádio II com patamar e fissuração estabilizada). Entretanto, esses trechos referem-se a fases diferentes em relação às da seção central.

A primeira fase (estádio I) pode ser dividida em duas partes. Uma em que o comportamento dessas curvas é idêntico ao da curva central, terminando com $F_{2}=60 \mathrm{kN}$, aproximadamente. E uma segunda parte em que o comportamento dessas curvas se distinguem da curva da seção central. Nessa parte já é possível notar que o lado direito (em vermelho) sofre maior deformação que o lado esquerdo. Essa parte termina com $F_{2}=180 \mathrm{kN}$, aproximadamente, para a curva da direita, e com $F_{2}=200 \mathrm{kN}$, aproximadamente, para a curva a esquerda.

A segunda fase (estádio II), representada por um patamar, começa com $F_{2}=180 \mathrm{kN}$ e vai até $F_{2}=190 \mathrm{kN}$, para a laje da direita. Para a laje da esquerda, esse intervalo é de $200 \mathrm{kN}$ até $210 \mathrm{kN}$.

$\mathrm{Na}$ terceira fase, os comportamentos médios das duas curvas são próximos, até atingirem na ruptura o mesmo valor de deformação ( $\varepsilon=1,55 \%$, aproximadamente).

De acordo com as Figuras 5.32 e 5.33, a deformação foi menor no lado de referência, tanto no lado esquerdo quanto no direito. 


\subsection{2 - Modelo 2 (EM2)}

A Figura 5.35 mostra uma visão geral do modelo 2, indicando o lado de referência e o lado oposto convencionado no mapa de instrumentação da Figura 5.19.

Nesse ensaio a primeira fissura na capa aconteceu logo que começou a aplicação da força ( $F_{2}=26 \mathrm{kN}$, aproximadamente).

Próximo a $F_{2}=254,7 \mathrm{kN}$, ouviu-se um forte barulho acompanhado por um descolamento da capa, que ocorreu próximo à seção do apoio, em toda a região de momento negativo na laje, que atingiu a ruína (laje do lado esquerdo, em relação ao lado de referência, indicada em azul na Figura 5.35). Isso foi constatado visualmente, pois a capa aparentou ter "subido". Depois se percebeu que, na verdade, a laje havia se deslocado para baixo em relação à capa.

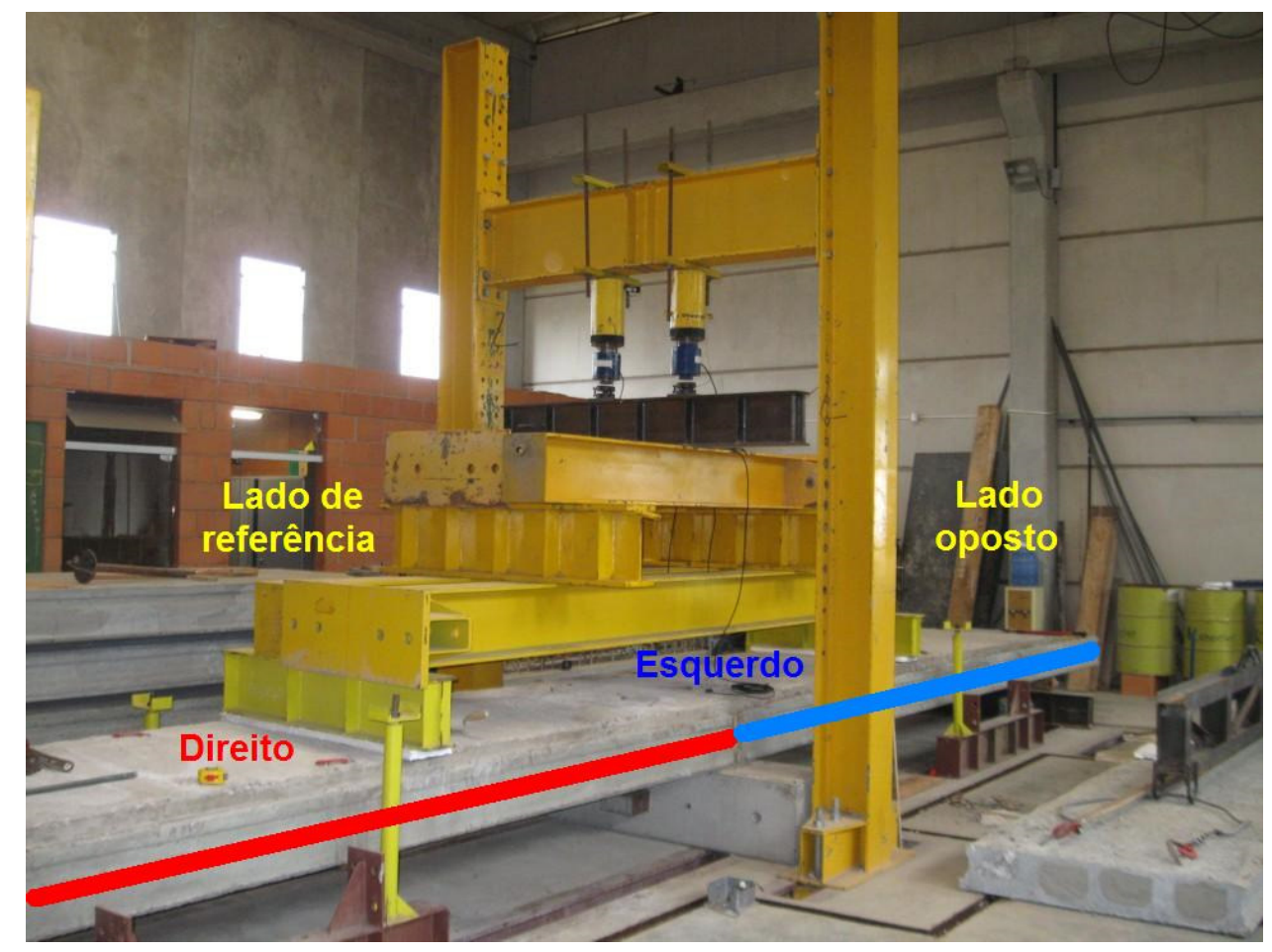

Figura 5.35 - Visão geral do modelo 2 (EM2). Convenção do lado de referência.

O descolamento da capa, em parte da laje esquerda, fez com que a seção da laje, nesse trecho, funcionasse como seção simples, não contando mais com a solidarização da capa com a laje.

Com parte da laje da esquerda trabalhando com seção simples, quando se atingiu $F_{2}=282,3 \mathrm{kN}$, aproximadamente, observou a primeira fissura de cisalhamento na laje, na região do apoio, caracterizando cisalhamento por tração diagonal do concreto. A fissura apresentava inclinação de aproximadamente $30^{\circ}$ no trecho inferior e $60^{\circ}$ no trecho superior, porém era interrompida na interface laje-capa. A ruptura da laje, no trecho de 
seção simples, ocorreu com aproximadamente $F_{2}=297,3 \mathrm{kN}$, não havendo fissuras relativas a momento positivo em nenhuma das duas lajes.

A Figura 5.36 apresenta uma vista panorâmica do modelo 2 após a ruptura, a partir do lado de referência. A Figura 5.37 apresenta uma vista lateral, enfatizando o trecho com ruptura do lado de referência. Já a Figura 5.38 mostra uma vista lateral da ruptura, porém no lado oposto.

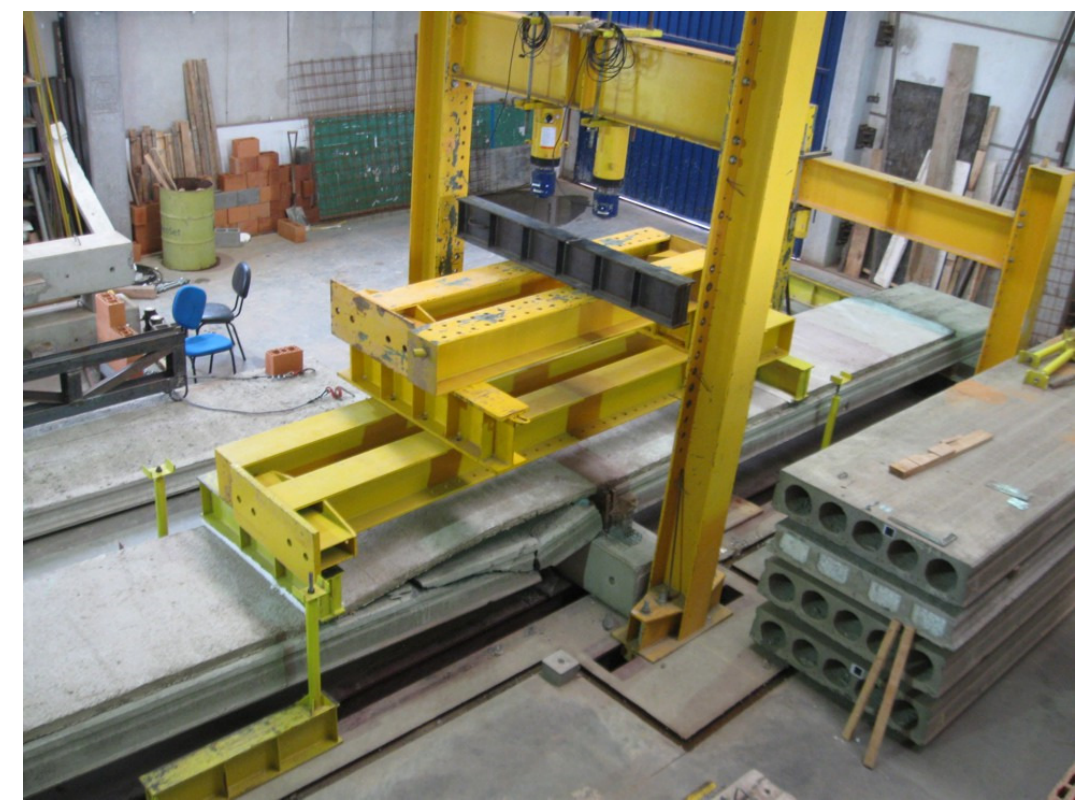

Figura 5.36 - Vista panorâmica de EM2 após a ruptura.

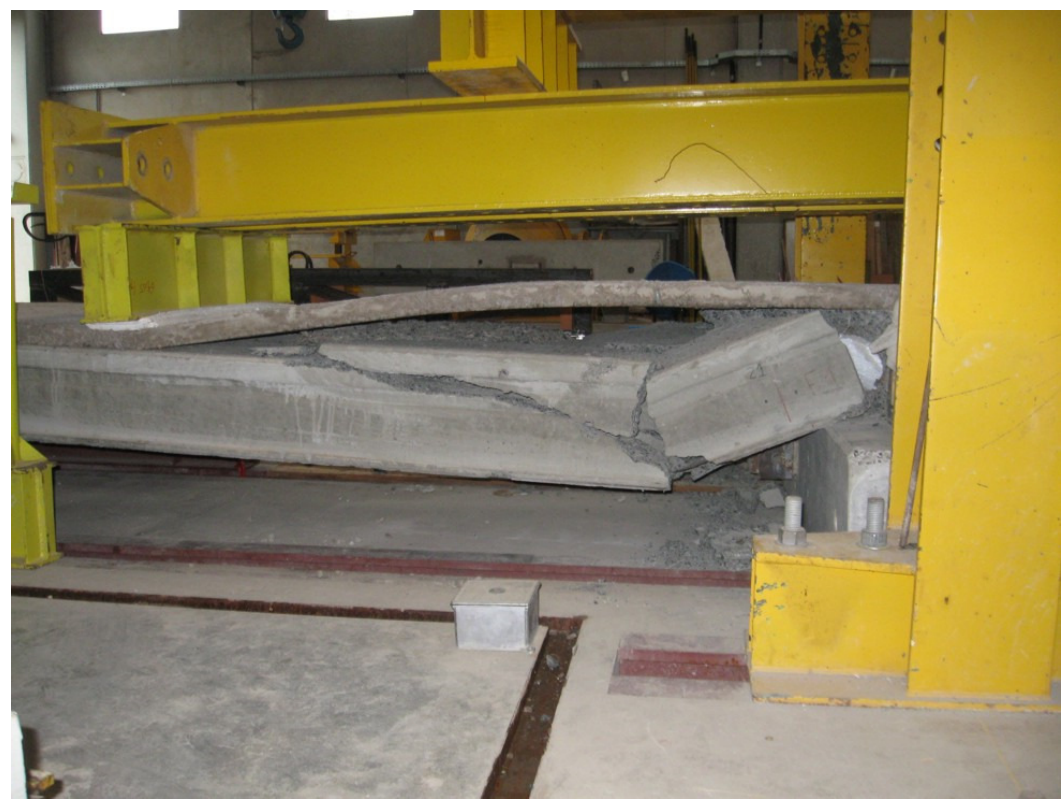

Figura 5.37 - Vista lateral da laje que sofreu ruptura no EM2. Laje da esquerda com relação ao lado de referência. Foto tirada no lado de referência. 


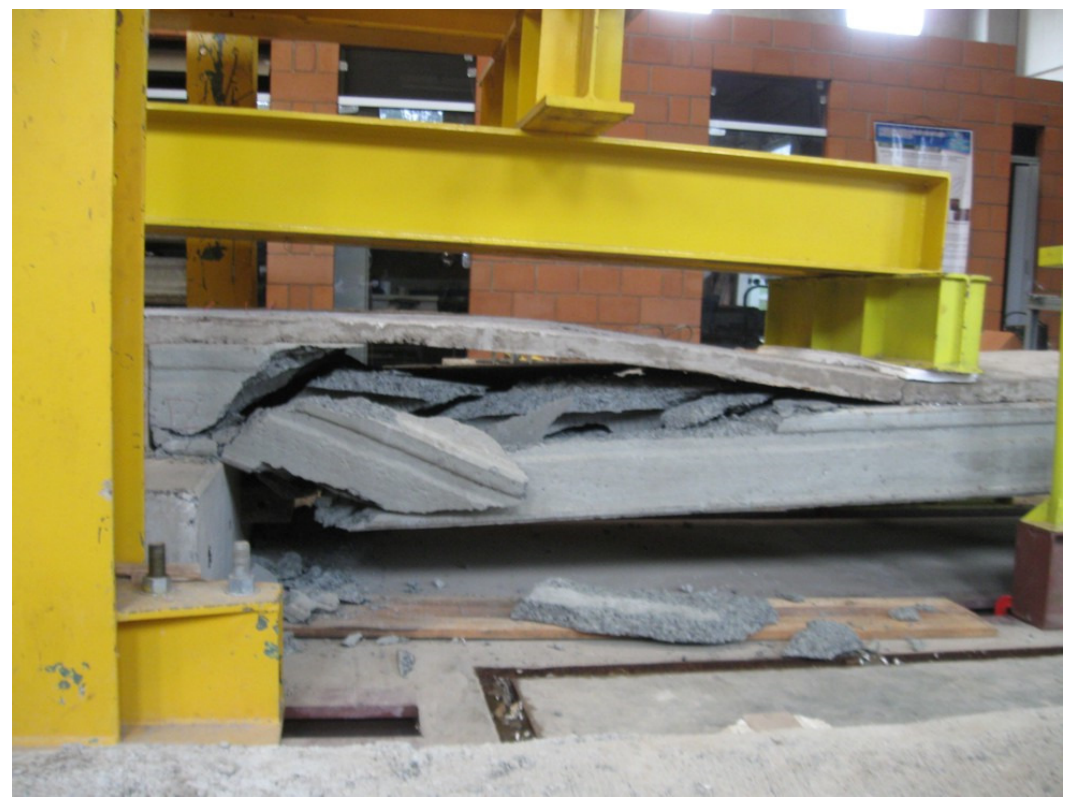

Figura 5.38 - Vista lateral da laje que sofreu ruptura no EM2. Laje da esquerda com relação ao lado de referência. Foto tirada no lado oposto.

As Figuras 5.39 e 5.40 mostram as vistas laterais dos lados de referência e oposto, no instante da ruptura. Essas imagens foram captadas das câmeras utilizadas para a filmagem de ambos os lados. Quando essas filmagens são sincronizadas com relação ao tempo, verifica-se que a ruptura atingiu primeiramente o lado oposto (Figura 5.40) e, instantes depois, alcançou o lado de referência (Figura 5.39).

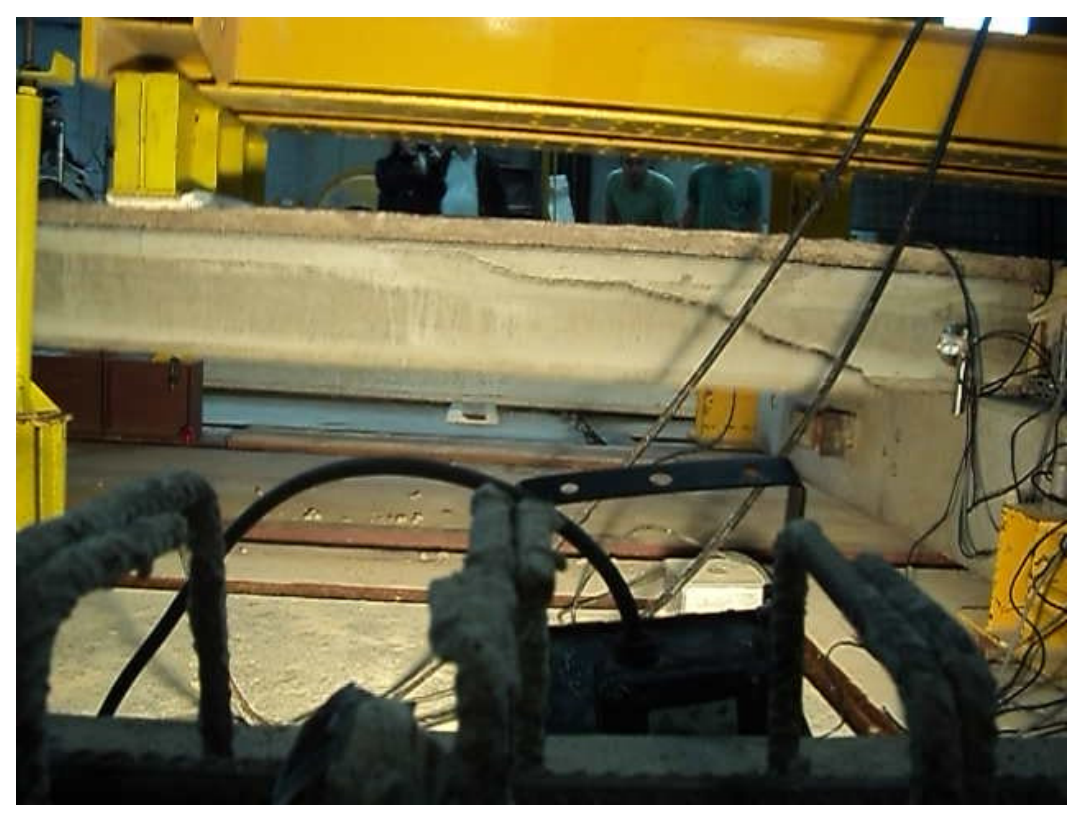

Figura 5.39 - Vista lateral de EM2 no instante da ruptura. Laje da esquerda com relação ao lado de referência. Foto tirada do lado de referência. 


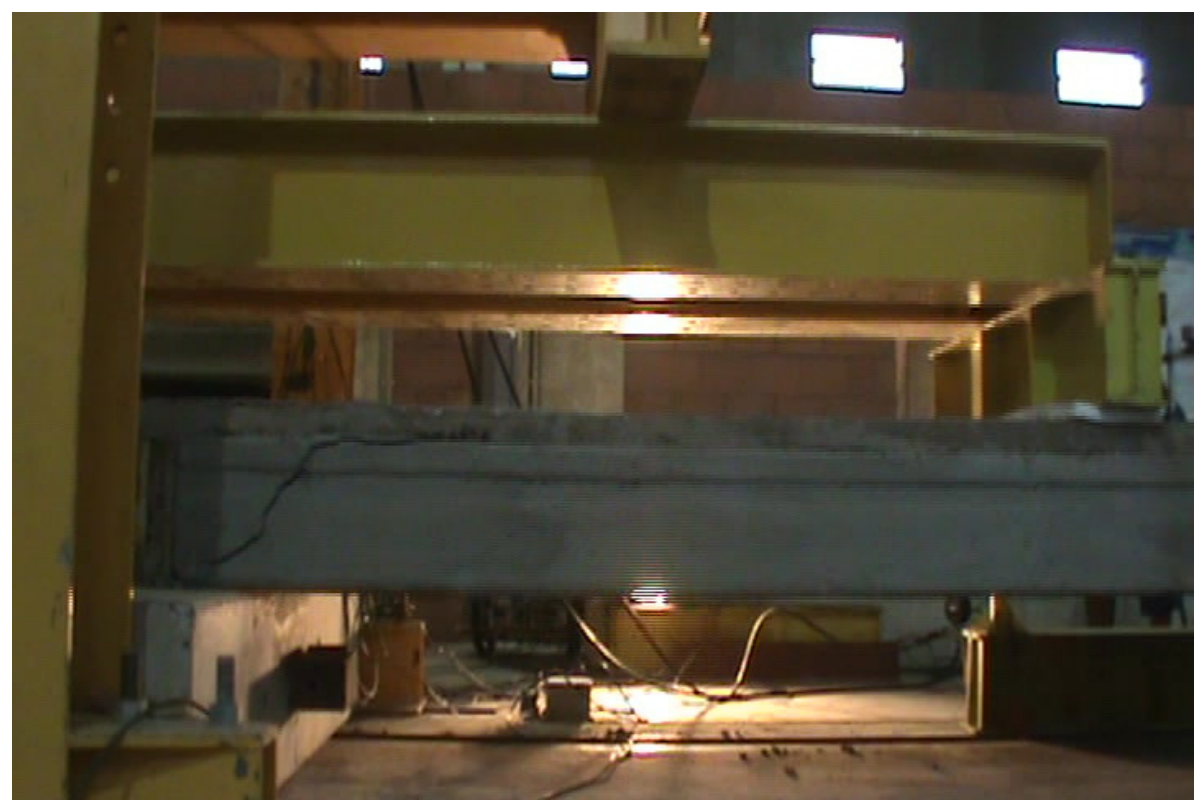

Figura 5.40 - Vista lateral de EM2 no instante da ruptura. Laje da esquerda com relação ao lado de referência. Foto tirada do lado oposto.

Após a ruptura, mediu-se a inclinação das fissuras. O resultado obtido foi que, tanto no lado de referência quanto no lado oposto, as fissuras começaram com um ângulo de $30^{\circ}$ com relação à face inferior da laje alveolar. No lado de referência (Figura 5.41), a inclinação mudou para $45^{\circ}$ e permaneceu até alcançar a capa. Já no lado oposto, a inclinação passou de $30^{\circ}$ para $60^{\circ}$ e posteriormente para $45^{\circ}$, (Figura 5.42), apresentando uma inclinação média de $50^{\circ}$, aproximadamente.

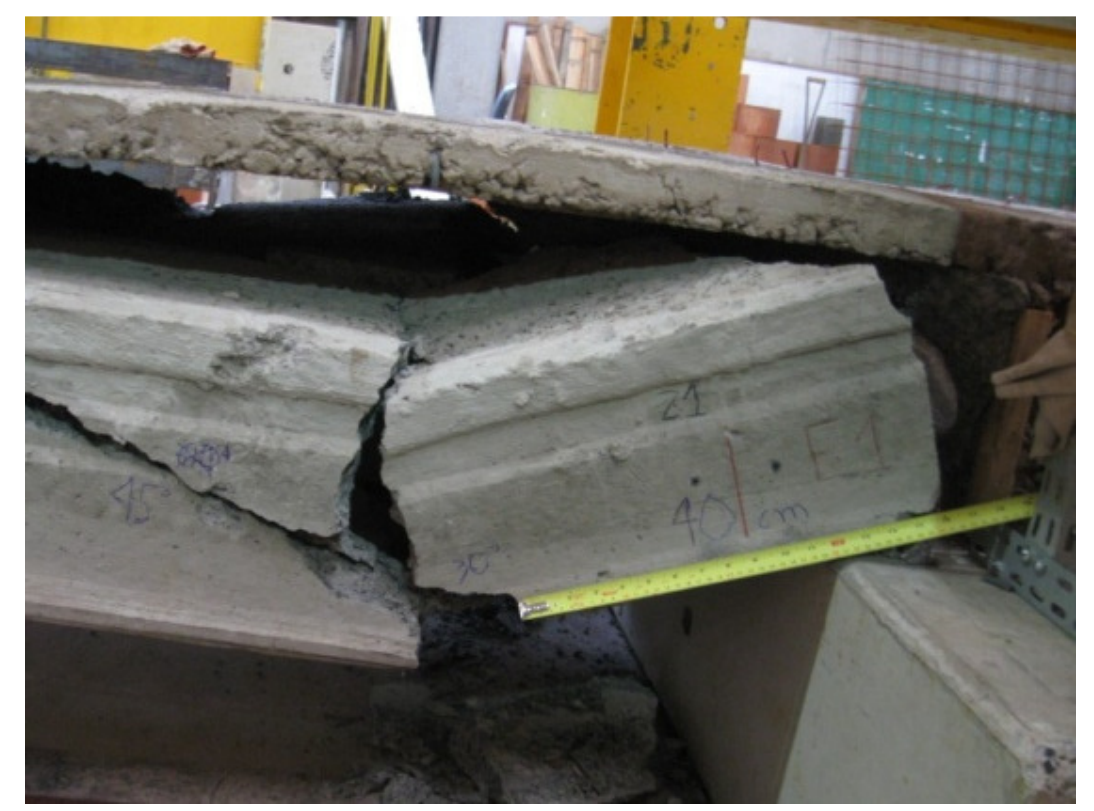

Figura 5.41 - Vista lateral de EM2 após a ruptura, mostrando a inclinação das fissuras. Com relação à face inferior da laje, a fissura começa com $30^{\circ} \mathrm{e}$ depois altera para $45^{\circ}$ até atingir a interface lajecapa. Foto tirada do lado de referência. 


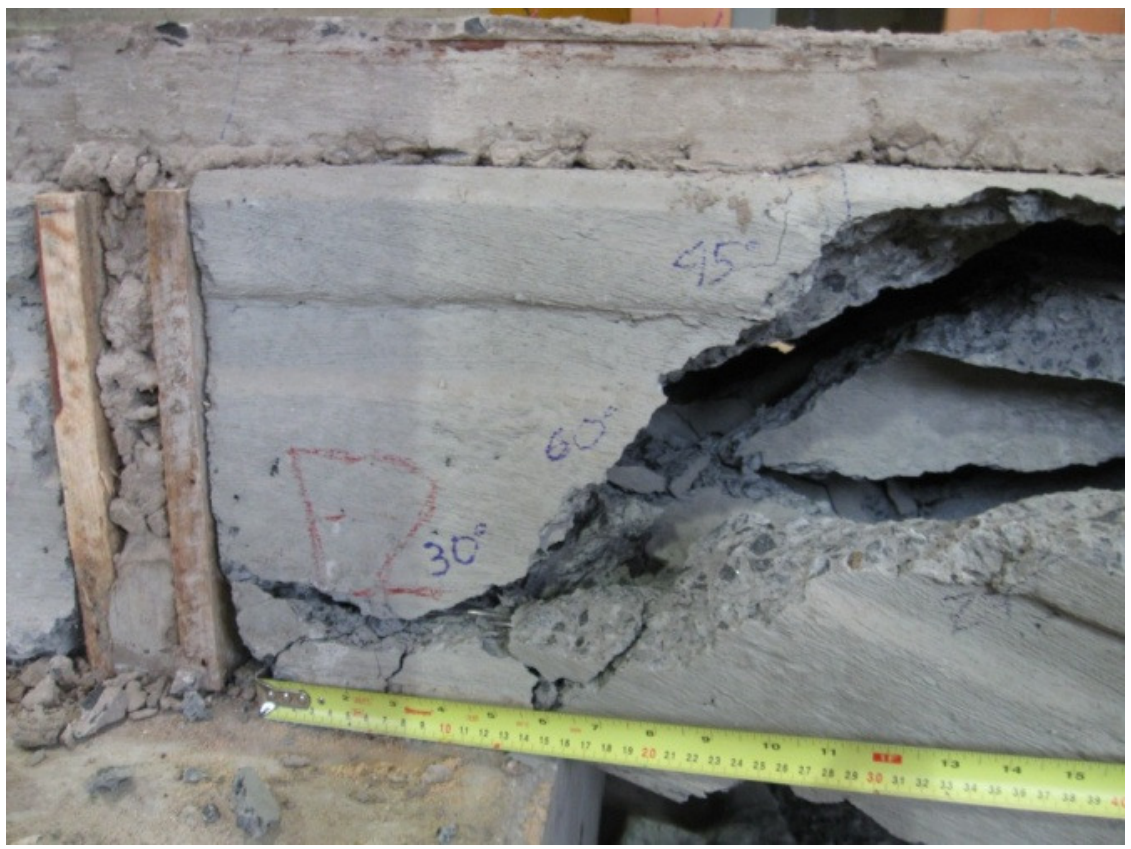

Figura 5.42 - Vista lateral de EM2 após a ruptura, mostrando a inclinação das fissuras. Com relação à face inferior da laje, a fissura começa com $30^{\circ} \mathrm{e}$ depois altera para $60^{\circ} \mathrm{e}$, por fim, para $45^{\circ}$ até atingir a interface laje-capa. Foto tirada do lado oposto.

A Figura 5.43 apresenta os gráficos que relacionam a força aplicada $\left(F_{2}\right)$ com os deslocamentos medidos ( $\delta$ ), para LVDT's do lado esquerdo (em azul) de EM2. A Figura 5.44 mostra o mesmo tipo de gráfico, porém para LVDT's do lado direito (em vermelho). Já a Figura 5.45 apresenta uma comparação com os valores médios de cada lado.

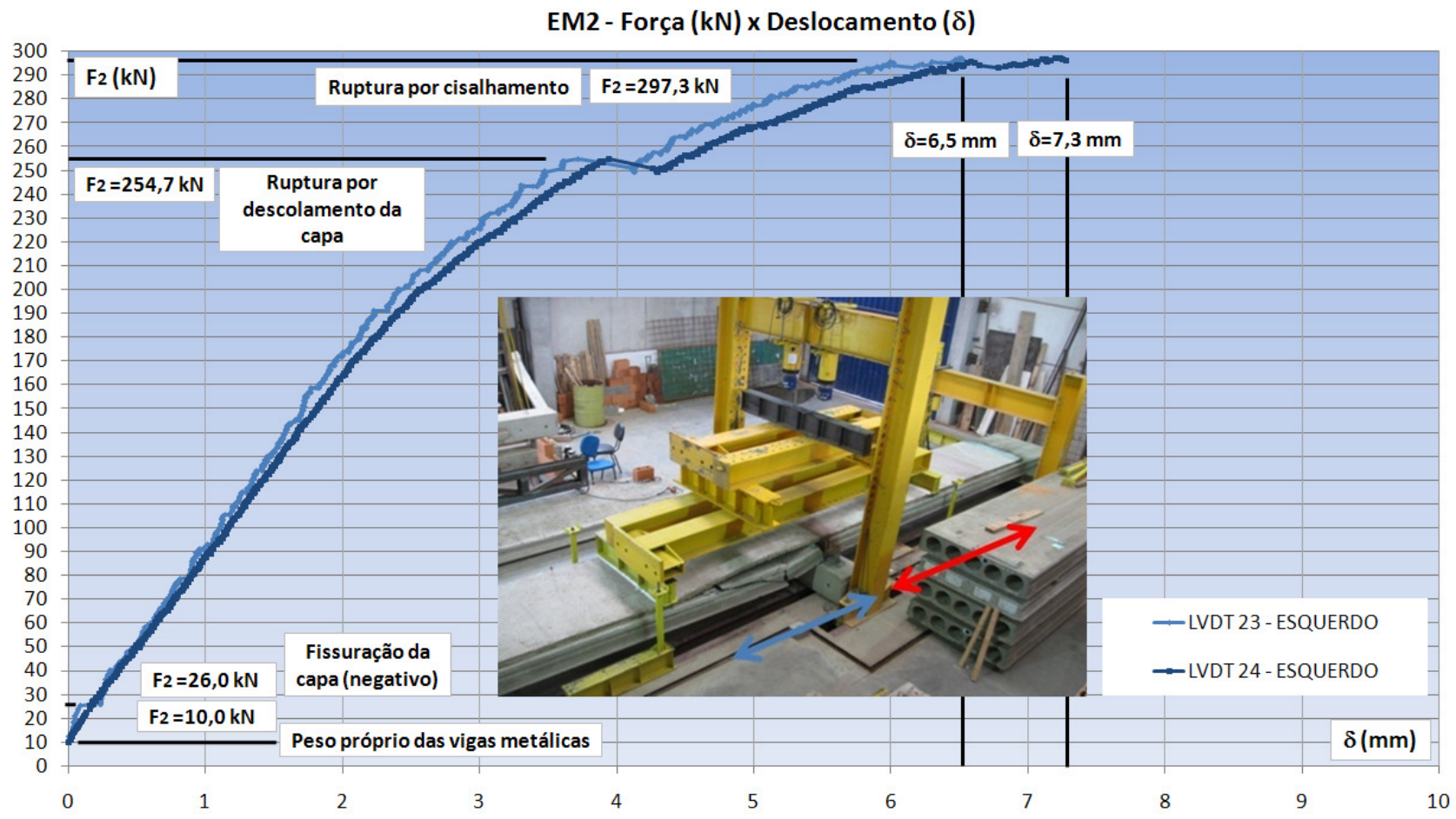

Figura 5.43 - Diagramas Força x Deslocamento do lado esquerdo (azul) de EM2. 
EM2 - Força (kN) x Deslocamento ( $\delta)$

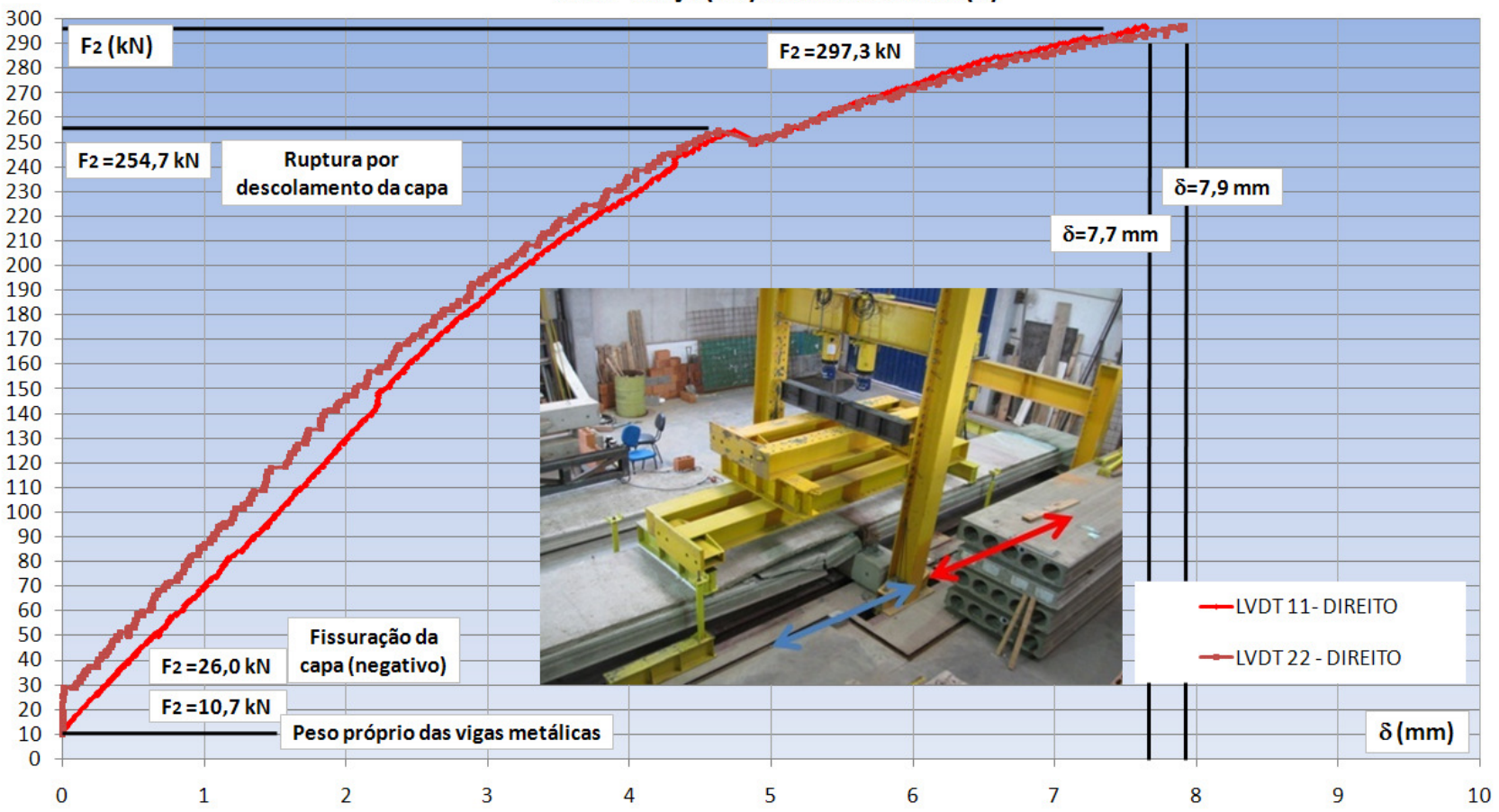

Figura 5.44 - Diagramas Força x Deslocamento do lado direito (vermelho) de EM2.

EM2 - Força $(k N)$ x Deslocamento ( $\delta)$

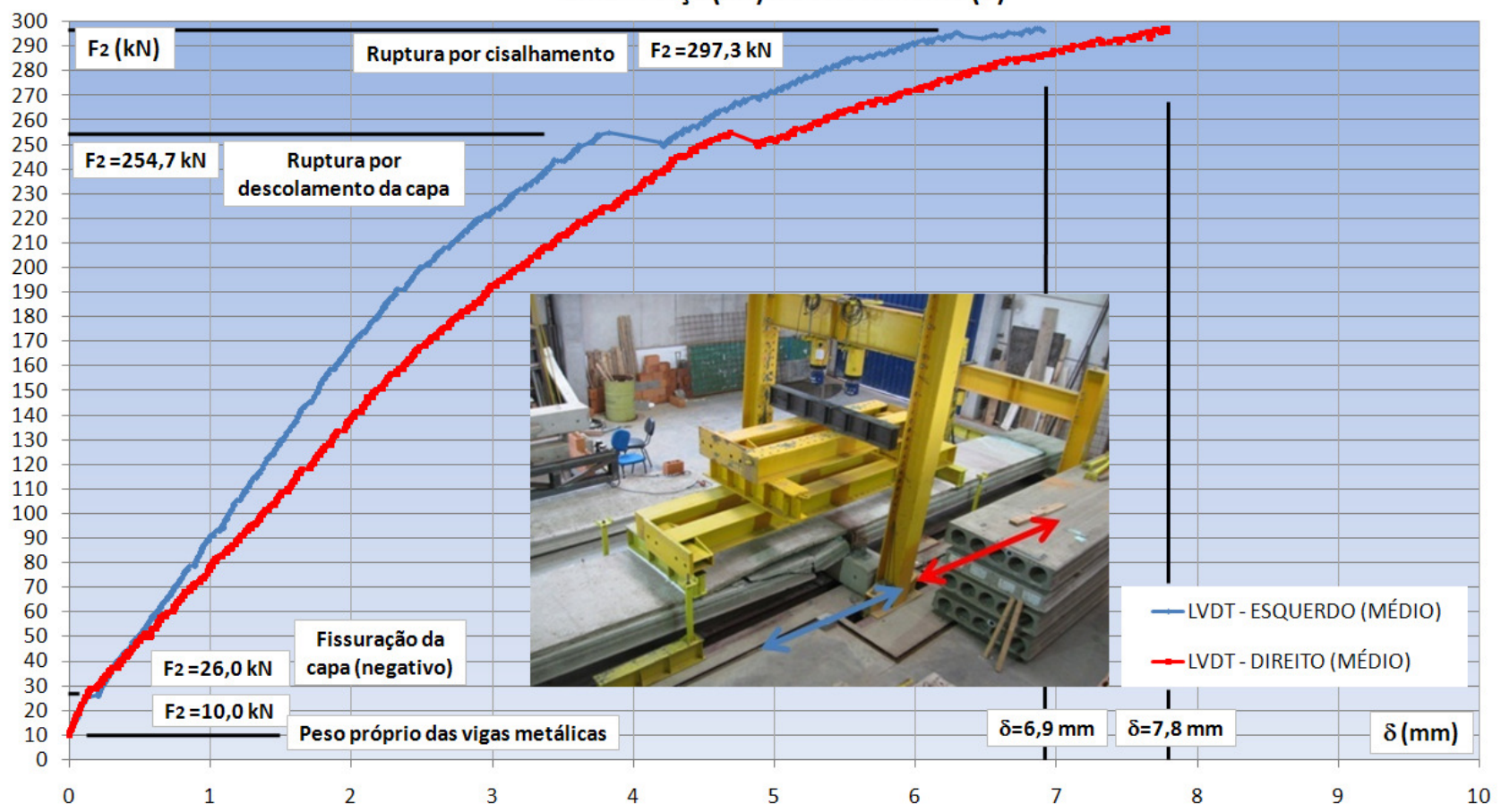

Figura 5.45 - Diagramas Força x Deslocamento dos valores médios de EM2 (ruptura na laje da esquerda, com indicação em azul).

De acordo com a Figura 5.45, a laje da direita (em relação ao lado de referência) se deslocou mais que a laje da esquerda. A laje da direita sofreu um deslocamento de $7,8 \mathrm{~mm}$, enquanto que a laje que alcançou a ruptura, $6,9 \mathrm{~mm}$. 
Assim como aconteceu no modelo 1 , a laje que atingiu a ruptura (primeiramente com o descolamento da capa e depois com a ruptura por cisalhamento) teve um comportamento mais rígido, com deslocamento menor que a da outra laje. Esse comportamento mais rígido é acentuado após a fissuração da capa pelo momento negativo $\left(F_{2}=26,0 \mathrm{kN}\right)$.

Observando as Figuras 5.43 e 5.44, percebe-se que as duas lajes se deslocaram de forma uniforme, uma vez que os resultados dos dois LVDT's (para cada laje) ficaram muito próximos entre si. Entretanto, como curiosidade, destaca-se o fato que os gráficos dos LVDT's do lado oposto, LVDT 23 posicionado na esquerda e LVDT 11 posicionado na direita, apresentaram comportamento do tipo "serrilhado".

De forma geral, todos os gráficos $F_{2} \times \delta$ apresentaram comportamento que pode ser aproximado por três retas: a primeira tem início com a aplicação do carregamento $\left(F_{2}=10,0 \mathrm{kN}\right)$ e vai até a fissuração da capa pelo momento negativo $\left(F_{2}=26,0 \mathrm{kN}\right)$; a segunda começa com a fissuração da capa e termina na ruptura pelo desprendimento da capa $\left(F_{2}=254,7 \mathrm{kN}\right)$; e a terceira vai do descolamento da capa até a ruptura por cisalhamento da laje da esquerda, que nessa etapa resiste aos esforços com seção simples $\left(F_{2}=297,3 \mathrm{kN}\right)$.

Entretanto, no modelo 2, a diferença entre a inclinação da primeira reta (que termina com a fissuração da capa) e a segunda (que começa neste ponto) é pequena. Isso indica que a fissuração da capa foi proporcionalmente menor no modelo 2, quando comparada com o modelo 1.

Vale destacar também que, embora apenas a laje da esquerda (indicada em azul) tenha sofrido colapso por cisalhamento, as duas lajes sofreram ruptura pelo descolamento da capa. Isso aconteceu para um mesmo valor da força aplicada ( $F_{2}=254,7 \mathrm{kN}$ ).

A partir do ensaio do modelo 2 , os clinômetros foram posicionados conforme as Figuras 5.15c e 5.15d, para medir as rotações das lajes com relação à viga (apoio intermediário). Dessa forma, a Figura 5.46 apresenta os resultados das rotações absolutas dos três clinômetros: laje da direita, ponto 19; centro da viga intermediária, 20; e laje da esquerda, 21. A Figura 5.47 mostra as rotações das lajes com relação à viga.

Analisando os resultados da Figura 5.47, nota-se que a laje da direita girou menos em relação à laje da esquerda, até o instante do descolamento da capa, ou seja, a inclinação da curva até esse ponto é maior para a laje da direita. Após esse descolamento, inverteu-se o comportamento das lajes, uma vez que as rotações foram maiores na laje da direita.

Os gráficos de rotação indicam, também, que a ligação no apoio intermediário, com a presença de armadura passiva na capa, se mostrou com comportamento rígido, no que diz respeito à transmissão de esforços solicitantes. Isto porque os valores de rotação dos lados esquerdo e direito ficaram próximos. Entretanto, os gráficos não ficaram simétricos, tal como ocorreu com os do modelo 1. 


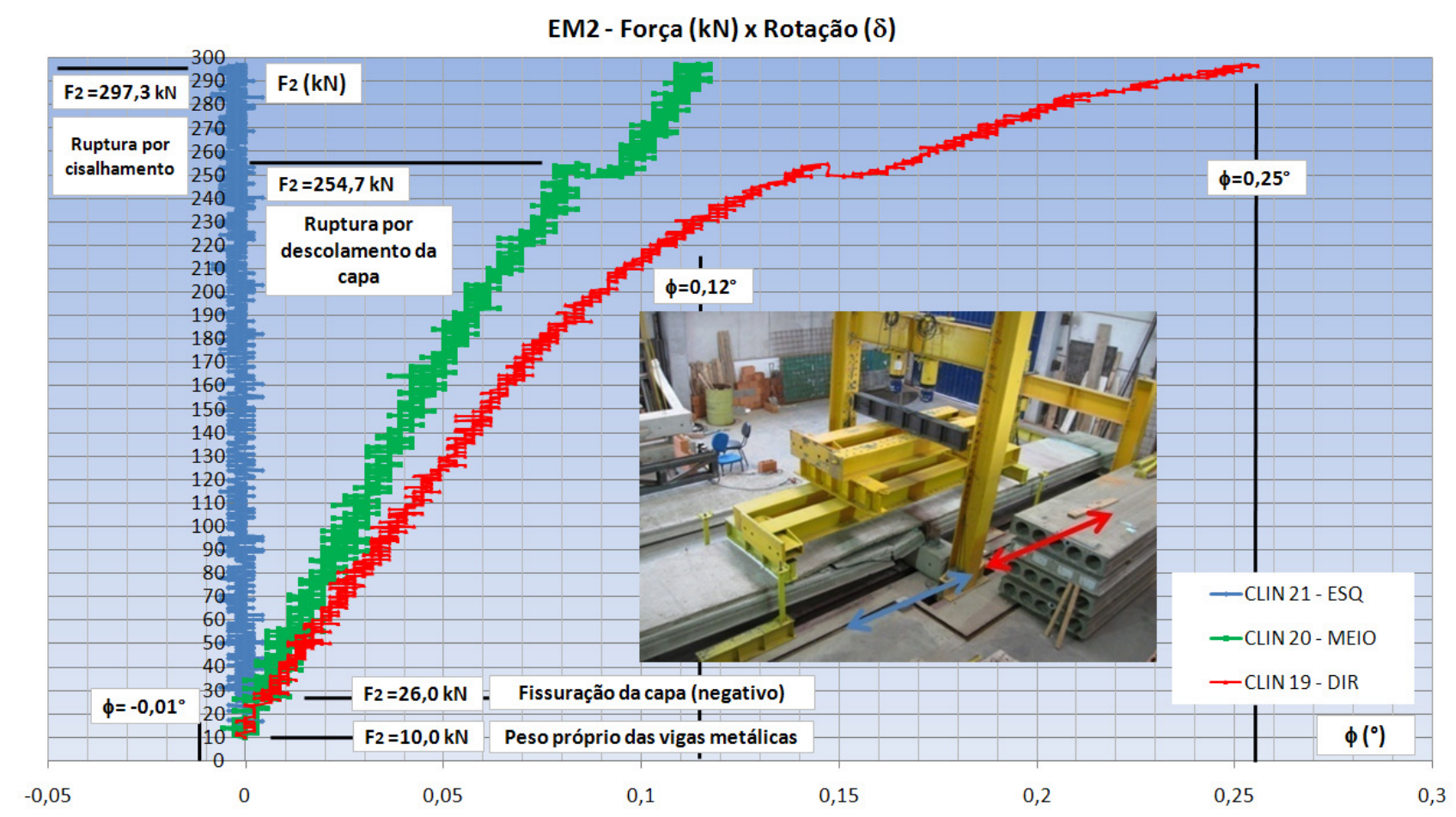

Figura 5.46 - Diagramas Força x Rotação. Valores absolutos dos clinômetros 19 (direito), 20 (apoio) e 21 (esquerdo) de EM2.

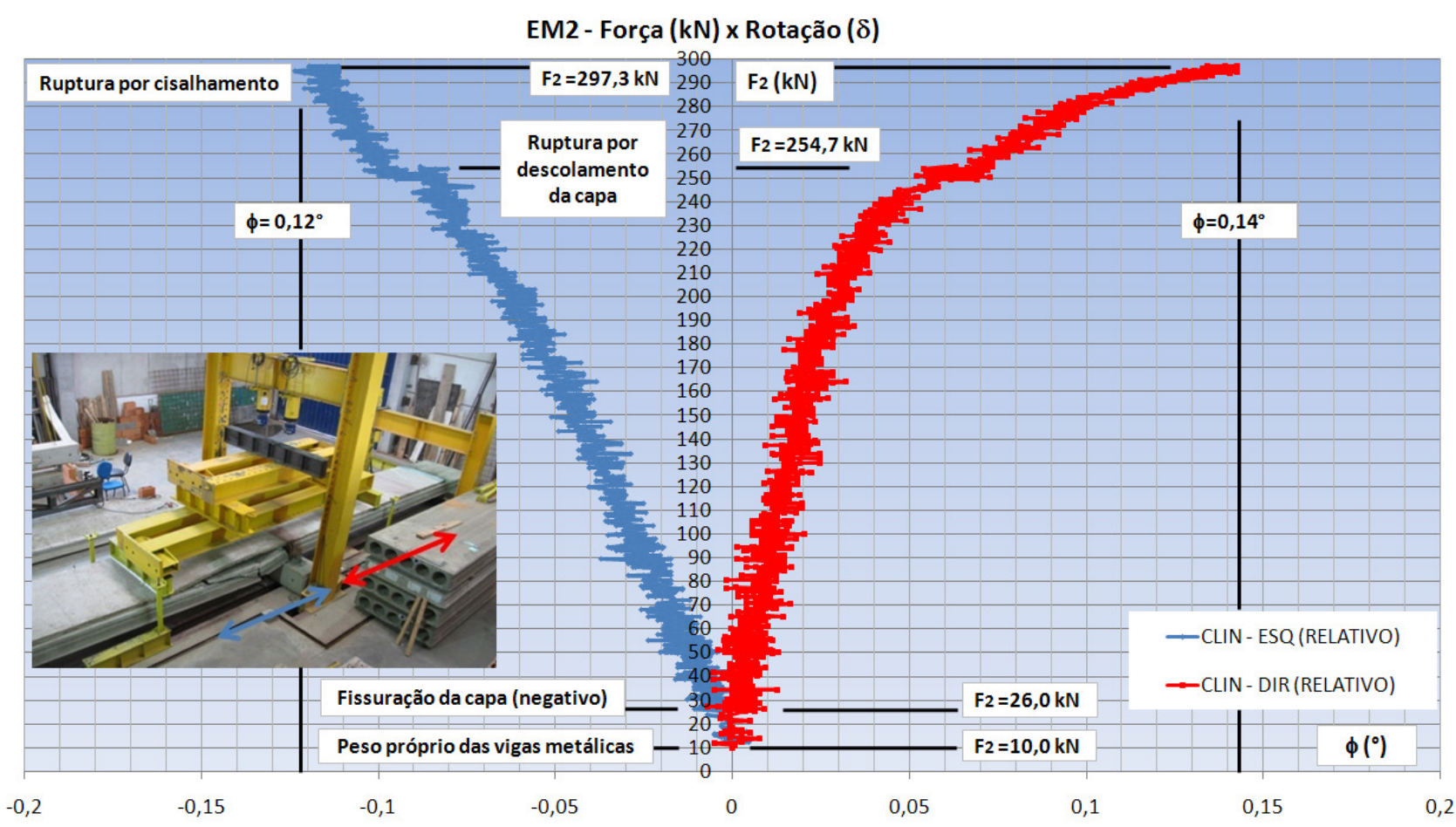

Figura 5.47 - Diagramas Força x Rotação. Valores relativos (descontando a rotação do apoio intermediário) de EM2.

Observando as curvas dos valores absolutos (Figura 5.46), nota-se que houve uma rotação do conjunto no sentido horário de um observador posicionado no lado de referência. Em outras palavras, o conjunto todo girou no sentido da laje da direita. Isso 
afetou os diagramas da Figura 5.45, aumentando os deslocamentos da laje da direita e diminuindo os da esquerda.

Com relação à leitura das deformações nas armaduras passivas, a Figura 5.48 mostra as curvas que relacionam a força aplicada no ensaio $\left(F_{2}\right)$ com as deformações medidas $(\varepsilon)$ pelos extensômetros posicionados no lado esquerdo (azul) do EM2. A figura 5.49 apresenta as mesmas curvas, porém para os extensômetros colocados no lado direito.

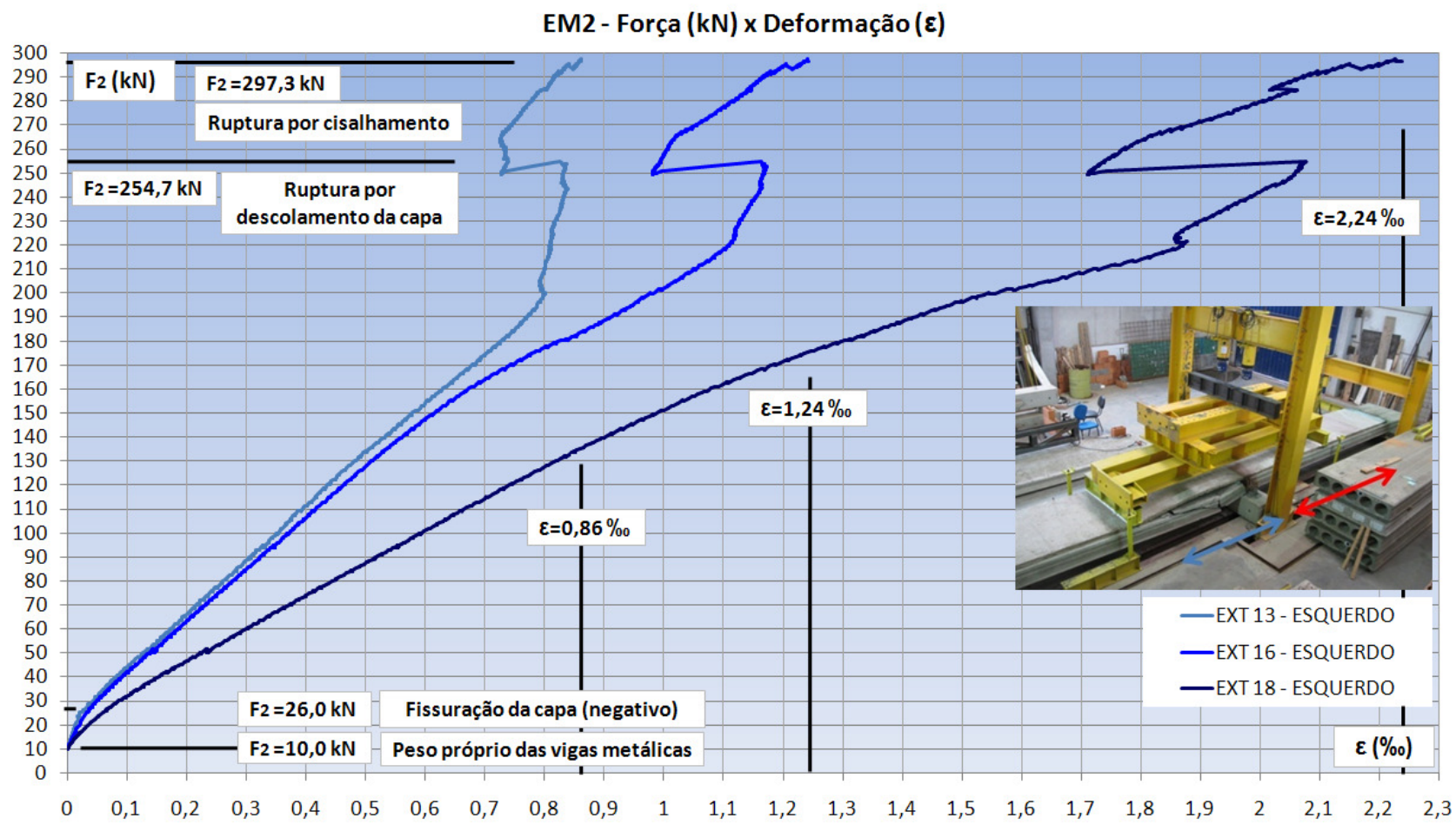

Figura 5.48 - Diagramas Força x Deformação do lado esquerdo (azul) de EM2.

A Figura 5.50 exibe, além da comparação entre os valores médios dos lados esquerdo e direito, a curva que representa o extensômetro posicionado no centro do modelo (verde).

De acordo com a Figura 5.50, as deformações nas barras, tanto a do centro como as dos lados esquerdo e direito, tiveram um comportamento semelhante.

Diferentemente do que ocorreu no modelo 1 , no modelo 2 não houve um comportamento que mostrasse explicitamente as transições do estádio I para o estádio II, principalmente na seção do centro. Isso é mostrado pelas curvas da Figura 5.50, nas quais, que desde o início do carregamento $\left(F_{2}=10,0 \mathrm{kN}\right)$ até instantes antes da ruptura do modelo pelo descolamento da capa ( $F_{2}=220,0 \mathrm{kN}$, aproximadamente), o acréscimo de deformação foi (praticamente) constante, sendo inclusive confundidas com retas.

Além disso, a influência da fissuração no comportamento das deformações das armaduras passivas foi pequena, quase não apresentando mudanças de trajetória nas curvas dessa figura. 
EM2 - Força (kN) x Deformação $(\varepsilon)$

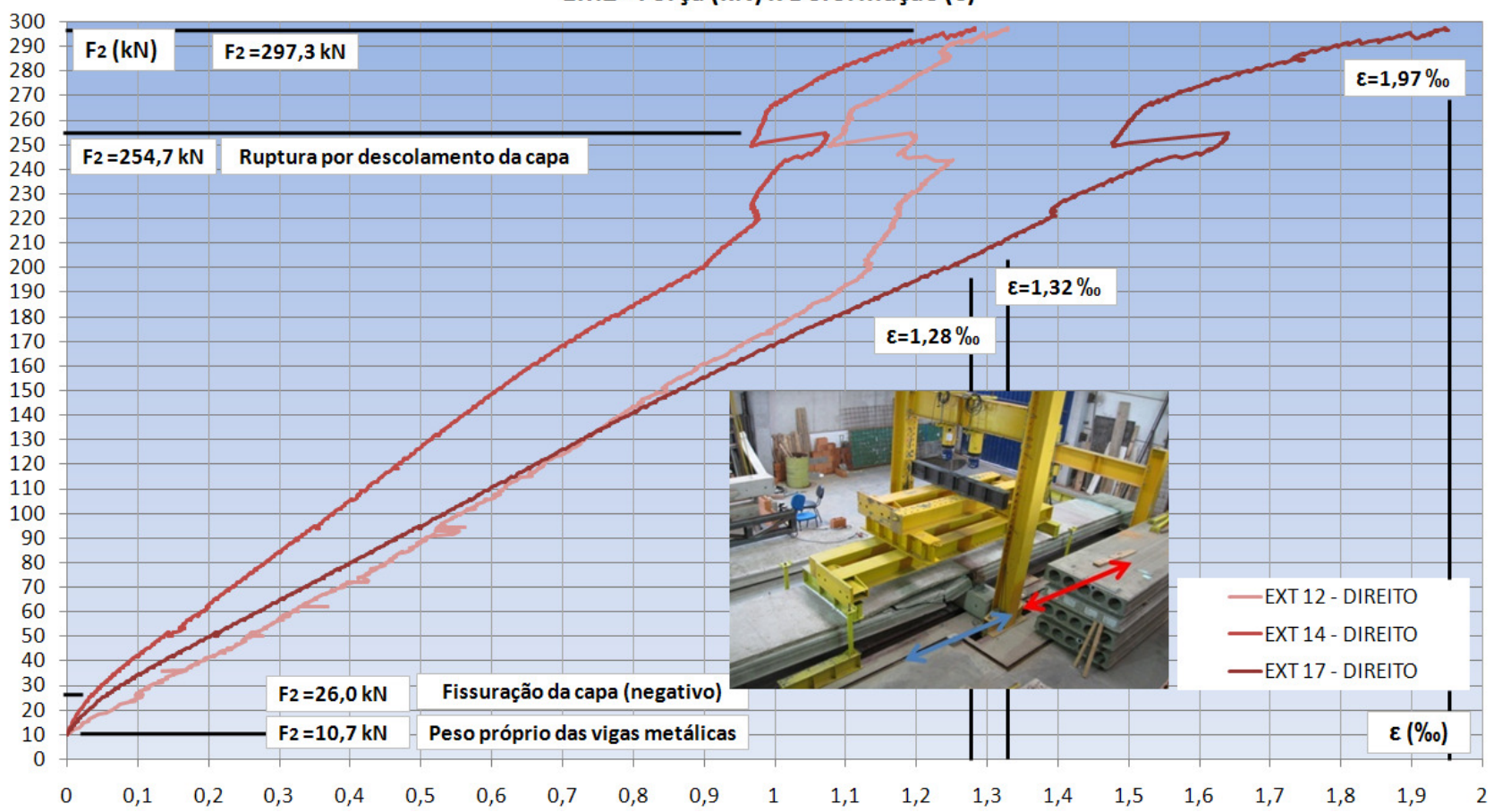

Figura 5.49 - Diagramas Força x Deformação do lado direito (vermelho) de EM2.

EM2 - Força $(k N)$ x Deformação $(\varepsilon)$

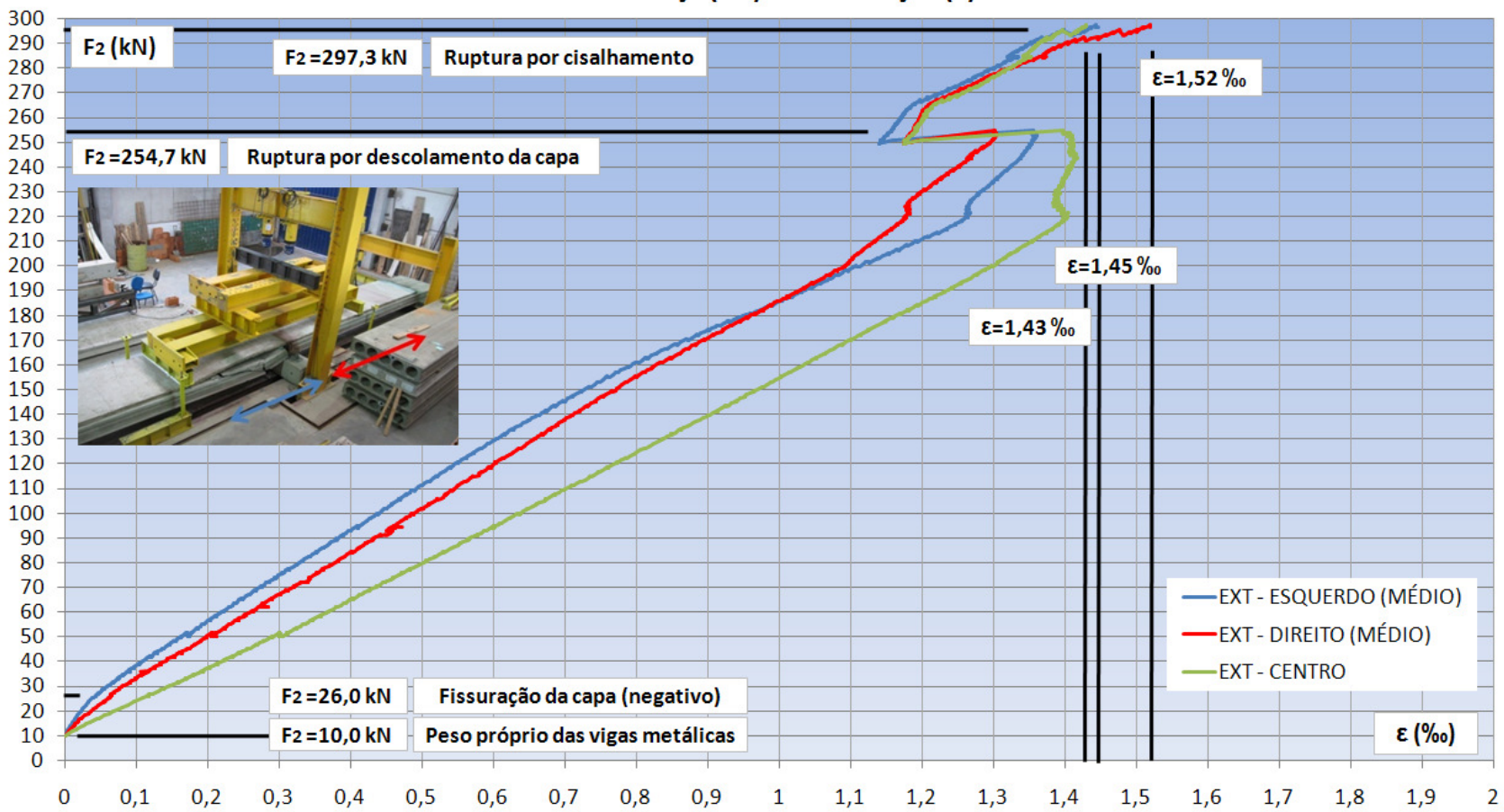

Figura 5.50 - Diagramas Força x Deformação do extensômetro do centro (EXT 15), e valores médios dos extensômetros posicionados nos lados esquerdo e direito de EM2.

$\mathrm{Na}$ Figura 5.50, também se observa o fato que o acréscimo de deformação permanece constante até cerca de $30 \mathrm{kN}$ antes da ruptura por descolamento da capa. Ou seja, por volta de $F_{2}=220,0 \mathrm{kN}$, há uma diminuição brusca nas deformações das barras, 
até que por volta de $F_{2}=254,7 \mathrm{kN}$, ocorre a ruptura do modelo com o descolamento da capa. Após isso, o modelo retoma a trajetória inicial da relação $F_{2} / \varepsilon$, com seção simples entre o apoio intermediário e ponto de aplicação de $F_{2}$ para cada laje.

Analisando as deformações nos gráficos das Figuras 5.48 e 5.49, nota-se que as barras posicionadas no lado oposto, extensômetro 18 na laje da esquerda e extensômetro 17 na laje da direita, sofreram deformações maiores. Esse lado é o mesmo que gerou curvas de $F_{2}$ x $\delta$ com comportamento "serrilhado".

Vale ressaltar que as deformações nas barras não ultrapassaram o valor correspondente ao escoamento $(\varepsilon=2,07 \%$ ), indicando que a ruptura por flexão estava longe de acontecer, com exceção apenas no extensômetro 18, colado no lado esquerdo oposto, onde a armadura sofreu escoamento.

\subsection{3 - Modelo 3 (EM3)}

A Figura 5.51 mostra uma visão geral do modelo 3, indicando o lado de referência e o lado oposto convencionado no mapa de instrumentação da Figura 5.19.

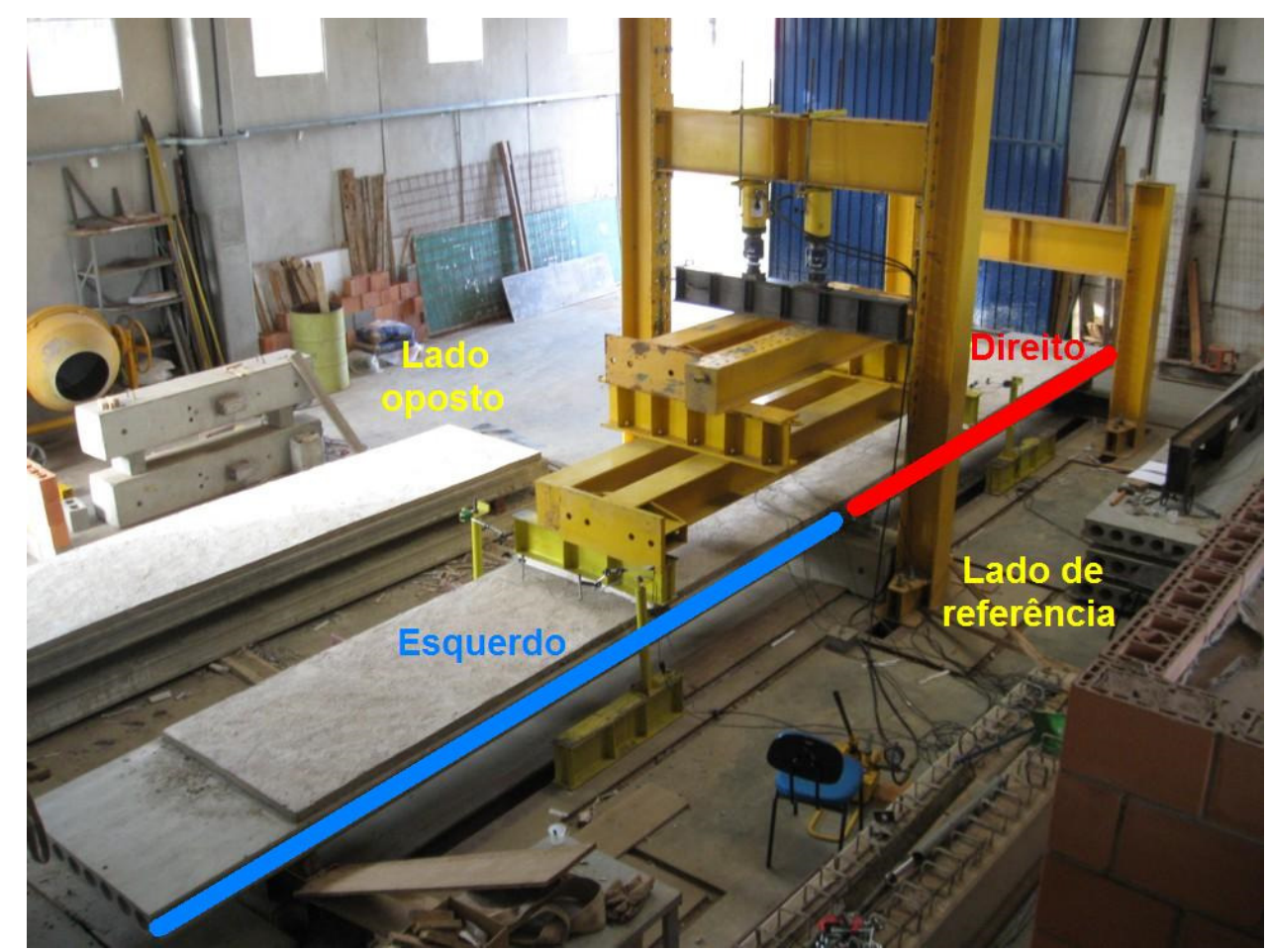

Figura 5.51 - Visão geral do modelo 3 (EM3). Convenção do lado de referência.

O modelo 3 (EM3) apresentou a primeira fissura na capa com $F_{2}=25,1 \mathrm{kN}$. 
A partir de $55 \mathrm{kN}$, as fissuras se intensificaram até que, com $\mathrm{F}_{2}=105 \mathrm{kN}$, houve o escoamento da armadura passiva da seção do centro do modelo, em função do momento negativo.

A partir desse valor da força, percebeu-se que os deslocamentos aumentaram mais, até que a laje fissurou (nas fibras inferiores) por conta do momento positivo, para $F_{2}=137,7 \mathrm{kN}$. As duas lajes do modelo fissuram em decorrência do momento positivo quase que ao mesmo tempo, sendo que as fissuras verticais foram identificadas logo abaixo do ponto de aplicação da força $F_{2}$ (em cada lado).

As fissuras verticais foram avançando na seção até atingirem a mesa superior da laje (mesa de compressão), quando ocorreu a ruptura por flexão com $F_{2}=146,8 \mathrm{kN}$, acompanhada por um estalo forte e repentino.

A laje que sofreu ruptura por flexão foi a posicionada no lado direito (indicada em vermelho), com relação ao lado de referência. Logo após a ruptura a laje se destacou da capa.

A seguir, a Figura 5.52 mostra o modelo 3 na região do apoio intermediário, onde é possível ver as fissuras que se formaram em função do momento negativo. Essa figura se refere ao lado oposto.

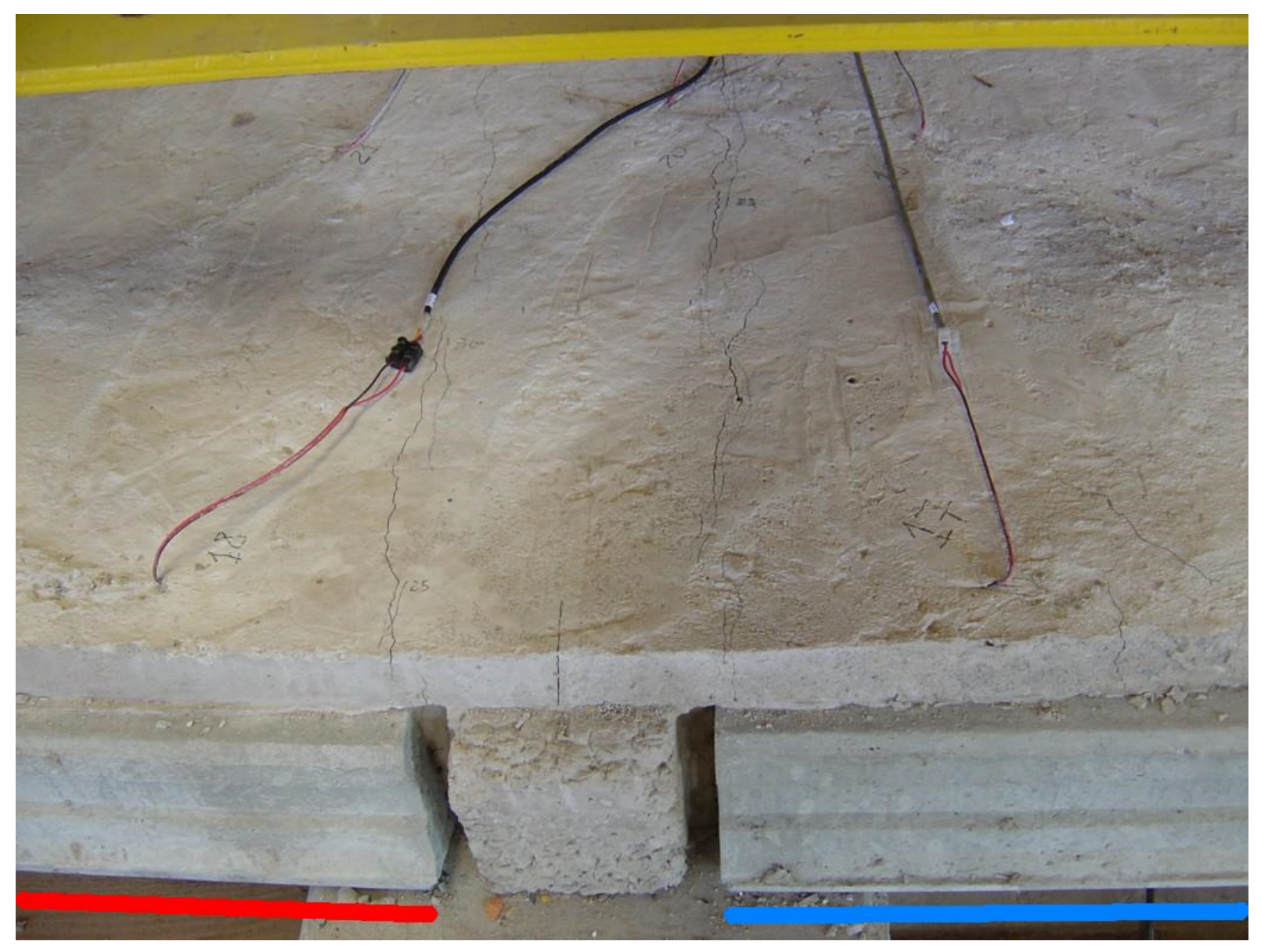

Figura 5.52 - Vista lateral do modelo 3 (EM3) na região do apoio intermediário, mostrando as fissuras na capa. Foto tirada no lado oposto. 
As Figuras 5.53 e 5.54 apresentam as vistas laterais da laje da direita (que sofreu ruptura por flexão). Por essas figuras é possível ver o destacamento entre a laje e a capa, causado no instante da ruptura. A Figura 5.53 se refere ao lado de referência, enquanto que a Figura 5.54, ao lado oposto.

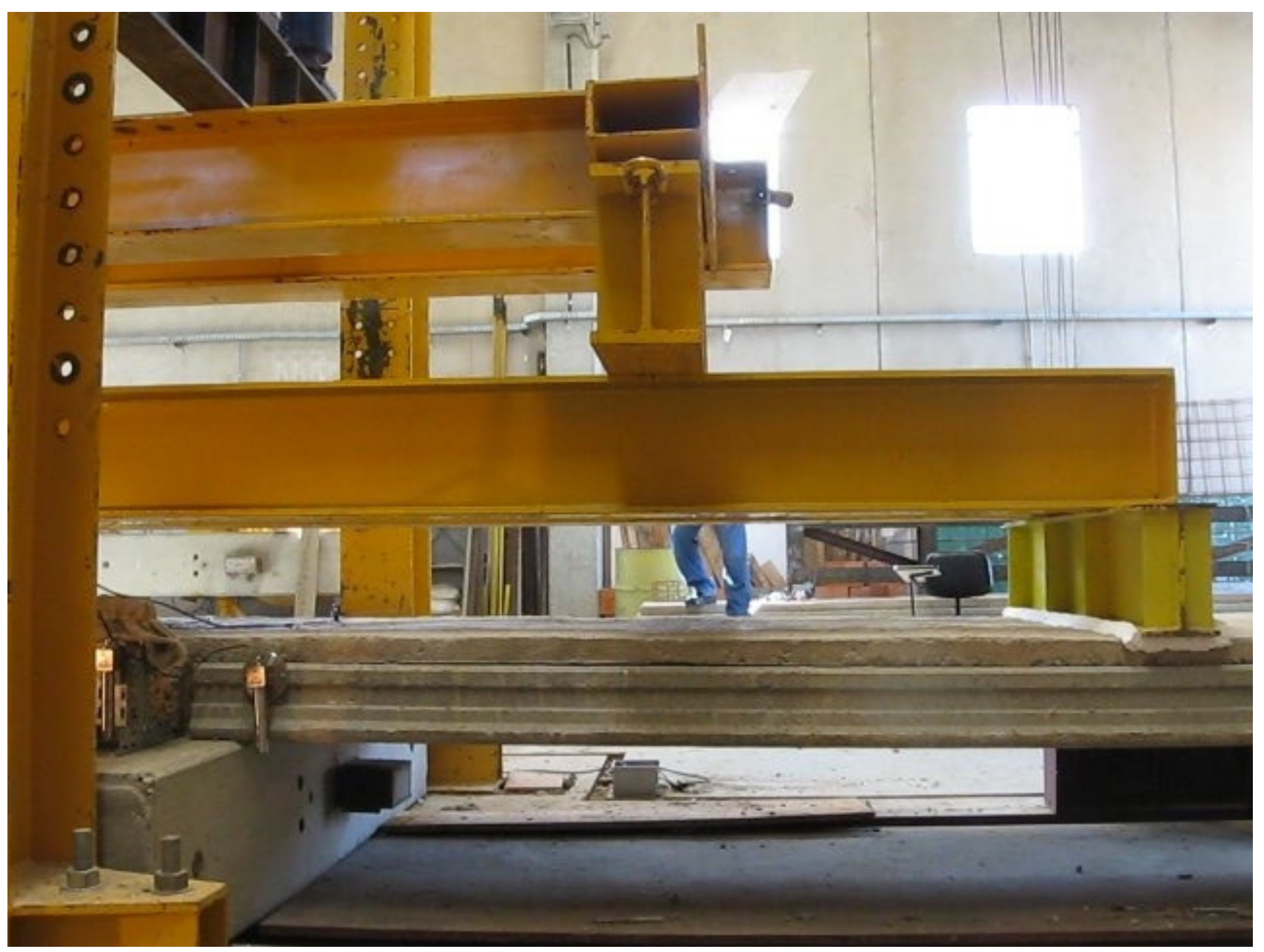

Figura 5.53 - Vista lateral da laje da direita modelo 3 (EM3) no instante da ruptura por flexão. Foto tirada do lado de referência.

Após atingir a ruptura por flexão do modelo 3, descarregou-se o atuador hidráulico até zerar força aplicada $\left(F_{2}\right)$, e por questão de curiosidade, iniciou-se novamente a aplicação da força sem a presença dos clinômetros e dos LVDT's, mas com os extensômetros.

Essa etapa durou cerca de 10 minutos, e a máxima carga atingida foi de, aproximadamente, $100 \mathrm{kN}$. Os deslocamentos alcançados foram visivelmente superiores aos do ensaio propriamente dito, e pelos valores das deformações obtidas pelos extensômetros, verificou-se que em nenhum dos pontos instrumentados o valor da deformação de escoamento (2,07\% ) foi alcançado. Provavelmente isso ocorreu porque a capa já não estava mais aderida à laje. 


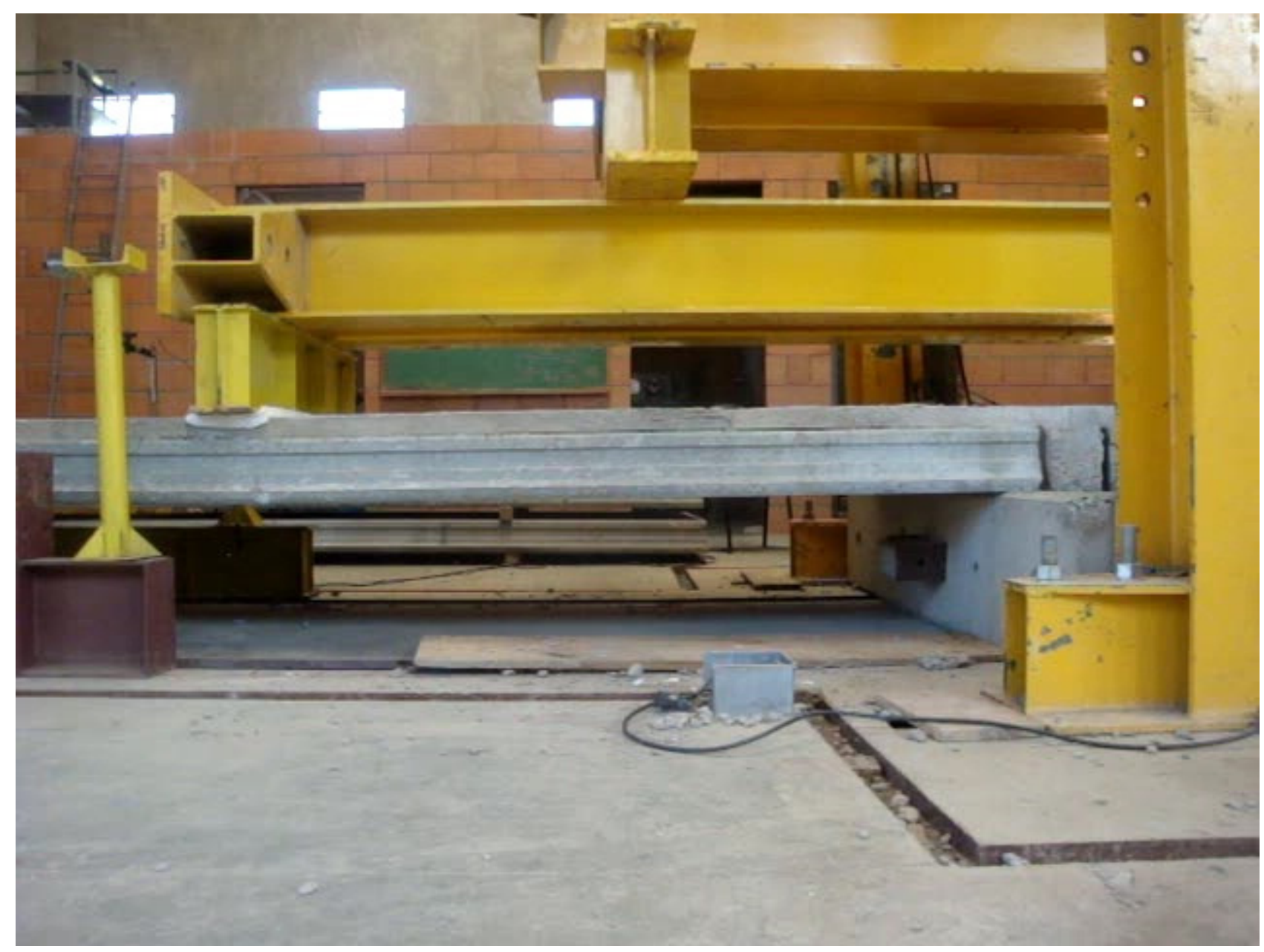

Figura 5.54 - Vista lateral da laje da direita modelo 3 (EM3) no instante da ruptura por flexão. Foto tirada do lado oposto.

Nessa segunda etapa de aplicação da força, as fissuras na capa (devidos ao momento negativo) e na laje (em função do momento positivo) aumentaram significativamente. A Figura 5.55 mostra uma vista lateral do ensaio, na qual é possível ver a laje da direita nessa etapa de aplicação da força. Foi constatado também que nessa segunda etapa as cordoalhas da laje da direita se deslocaram em relação à laje.

A Figura 5.56 apresenta os gráficos que relacionam a força aplicada no ensaio $\left(F_{2}\right)$ com deslocamentos medidos ( $\delta$ ), para LVDT's do lado esquerdo (em azul) do EM3. A Figura 5.57 mostra o mesmo tipo de gráfico, porém para LVDT's do lado direito (em vermelho). Já a Figura 5.58 apresenta uma comparação com os valores médios de cada lado.

De acordo com a Figura 5.58, a laje da direita (em relação ao lado de referência) se deslocou mais que da esquerda. A laje da direita sofreu um deslocamento de $18,5 \mathrm{~mm}$, enquanto que a laje da esquerda alcançou a ruptura, com 15,3 mm.

Ao contrário do que aconteceu nos modelos 1 e 2, a laje que atingiu a ruptura teve um comportamento menos rígido, com deslocamento maior que o da outra laje. 


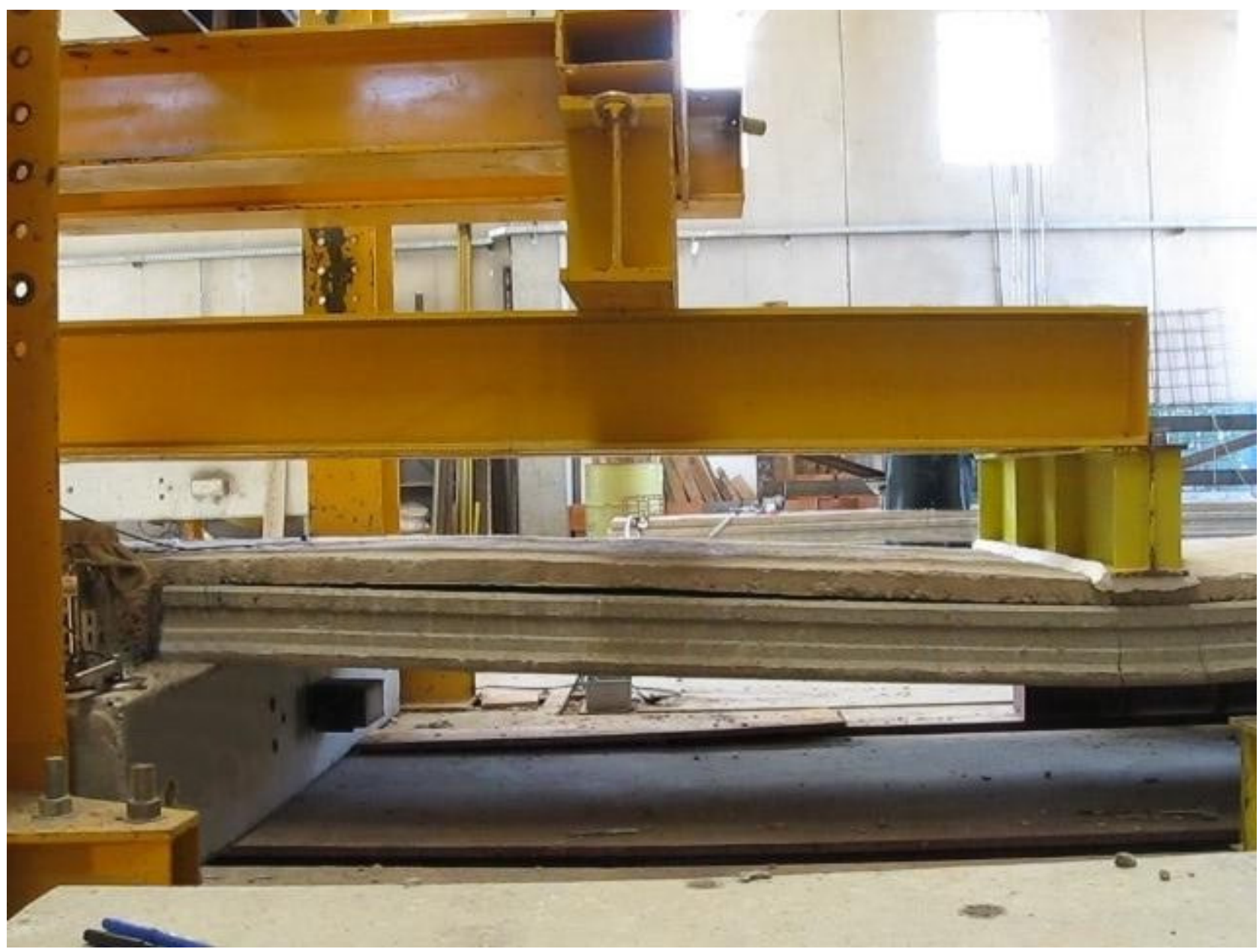

Figura 5.55 - Vista lateral da laje da direita modelo 3 (EM3) quando a força foi aplicada pela segunda vez. Foto tirada do lado de referência.

Observando as Figuras 5.56 e 5.57, percebe-se que as duas lajes se deslocaram de forma uniforme. Em outras palavras, os resultados dos LDT's ficaram muito próximos entre si, sobretudo aos da laje da esquerda.

De uma forma geral, todos os gráficos $F_{2} \times \delta$ apresentaram comportamento que pode ser aproximado por quatro retas:

- A primeira começa com a aplicação do carregamento $\left(F_{2}=10,0 \mathrm{kN}\right)$ e vai até a fissuração da capa pelo momento negativo $\left(F_{2}=25,1 \mathrm{kN}\right)$;

- A segunda começa na fissuração da capa e termina no escoamento da armadura passiva posicionada na capa $\left(F_{2}=105,5 \mathrm{kN}\right.$ para o escoamento da armadura do centro, cujo extensômetro é o de número 20 , e $F_{2}=118,0 \mathrm{kN}$, para o escoamento de uma das armaduras posicionadas no lado esquerdo, cujo extensômetro é o de número 19);

- A terceira etapa começa no escoamento da armadura passiva e termina com a fissuração da laje nas fibras inferiores, pelo momento positivo $\left(F_{2}=137,7 \mathrm{kN}\right)$;

- A quarta e última etapa começa na fissuração da laje e termina com a ruptura por flexão da laje da direita $\left(F_{2}=146,8 \mathrm{kN}\right)$. 


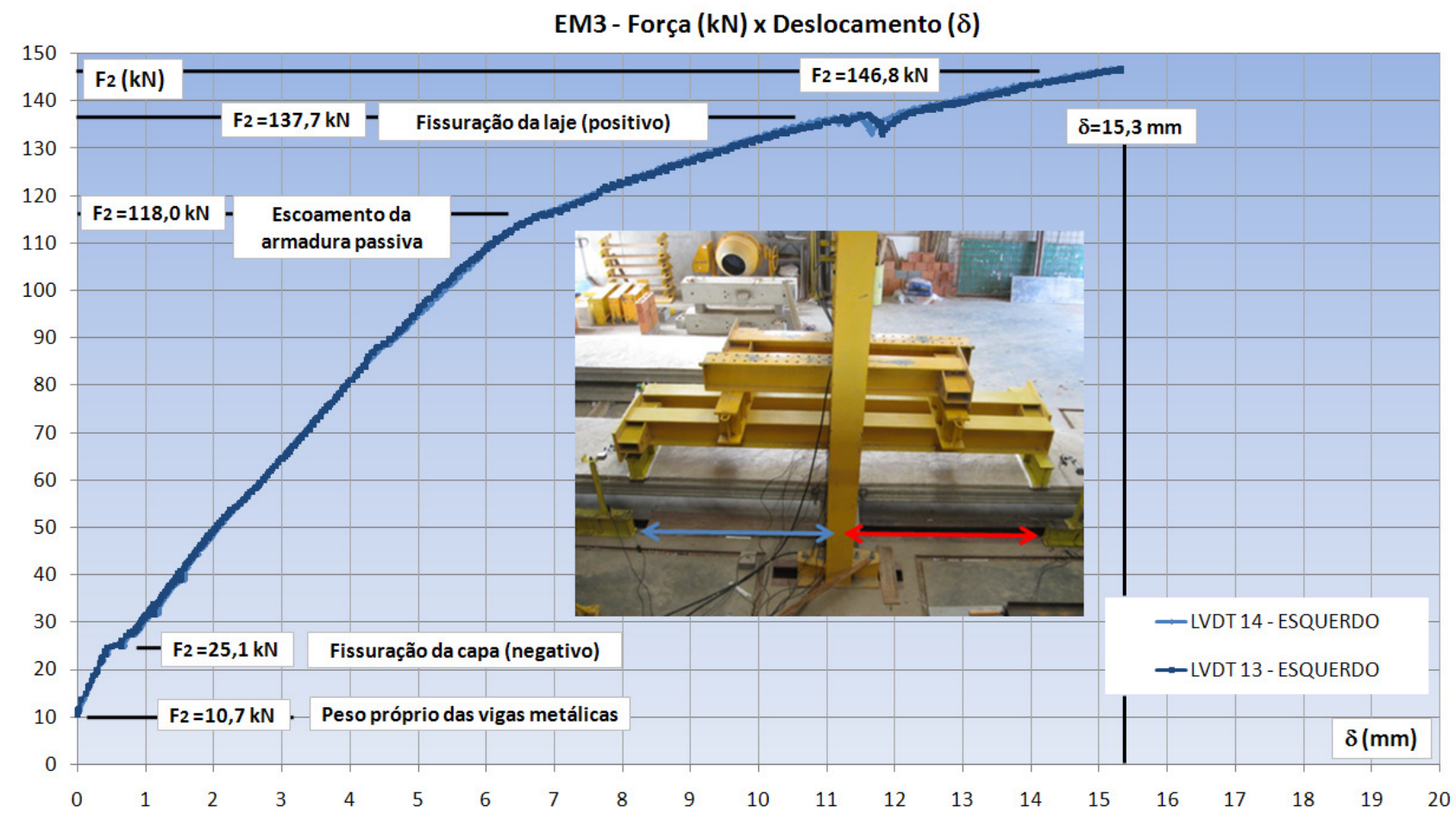

Figura 5.56 - Diagramas Força x Deslocamento do lado esquerdo (azul) de EM3.

EM3 - Força (kN) x Deslocamento ( $\delta)$

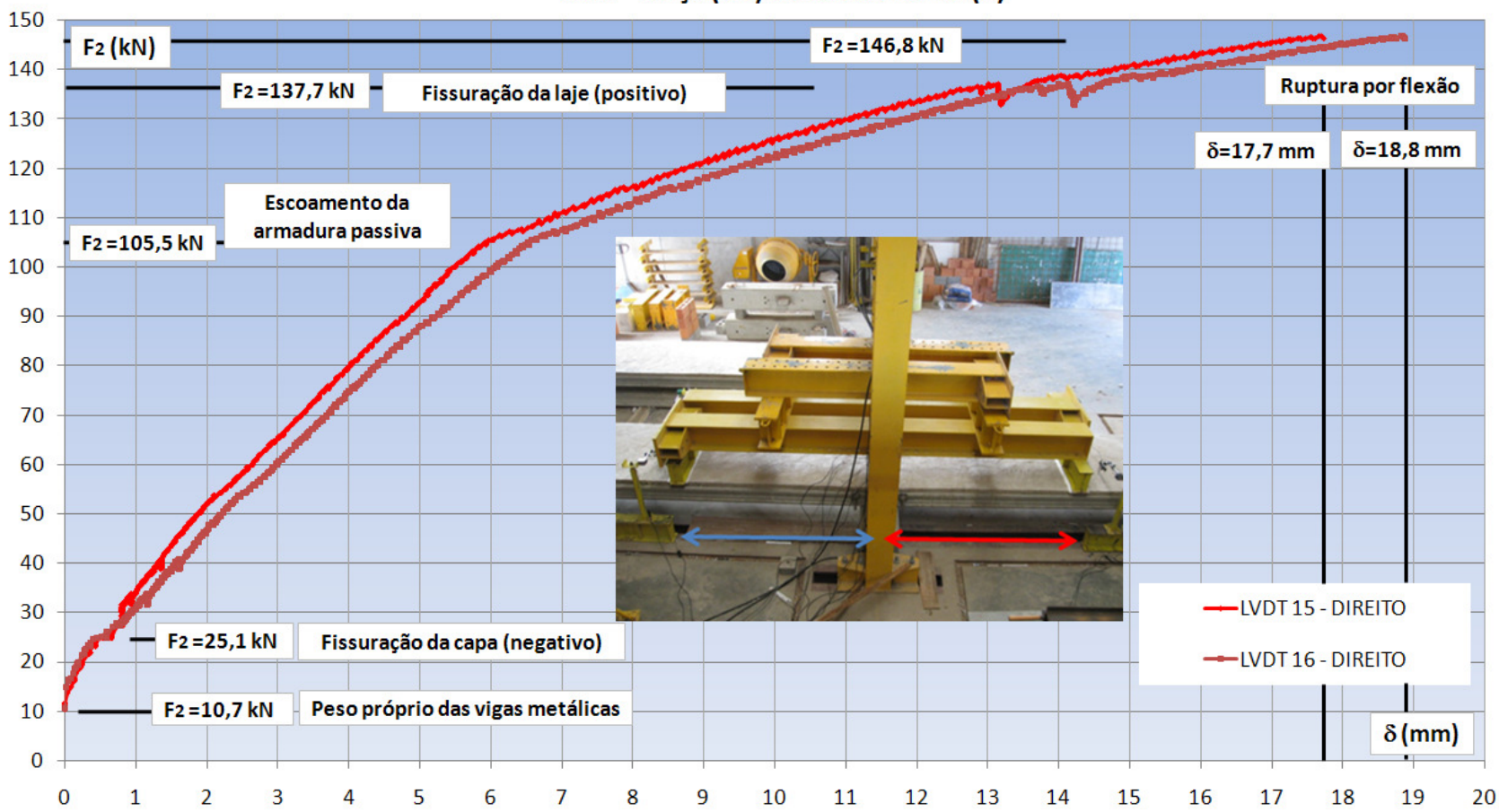

Figura 5.57 - Diagramas Força x Deslocamento do lado direito (vermelho) de EM3. 


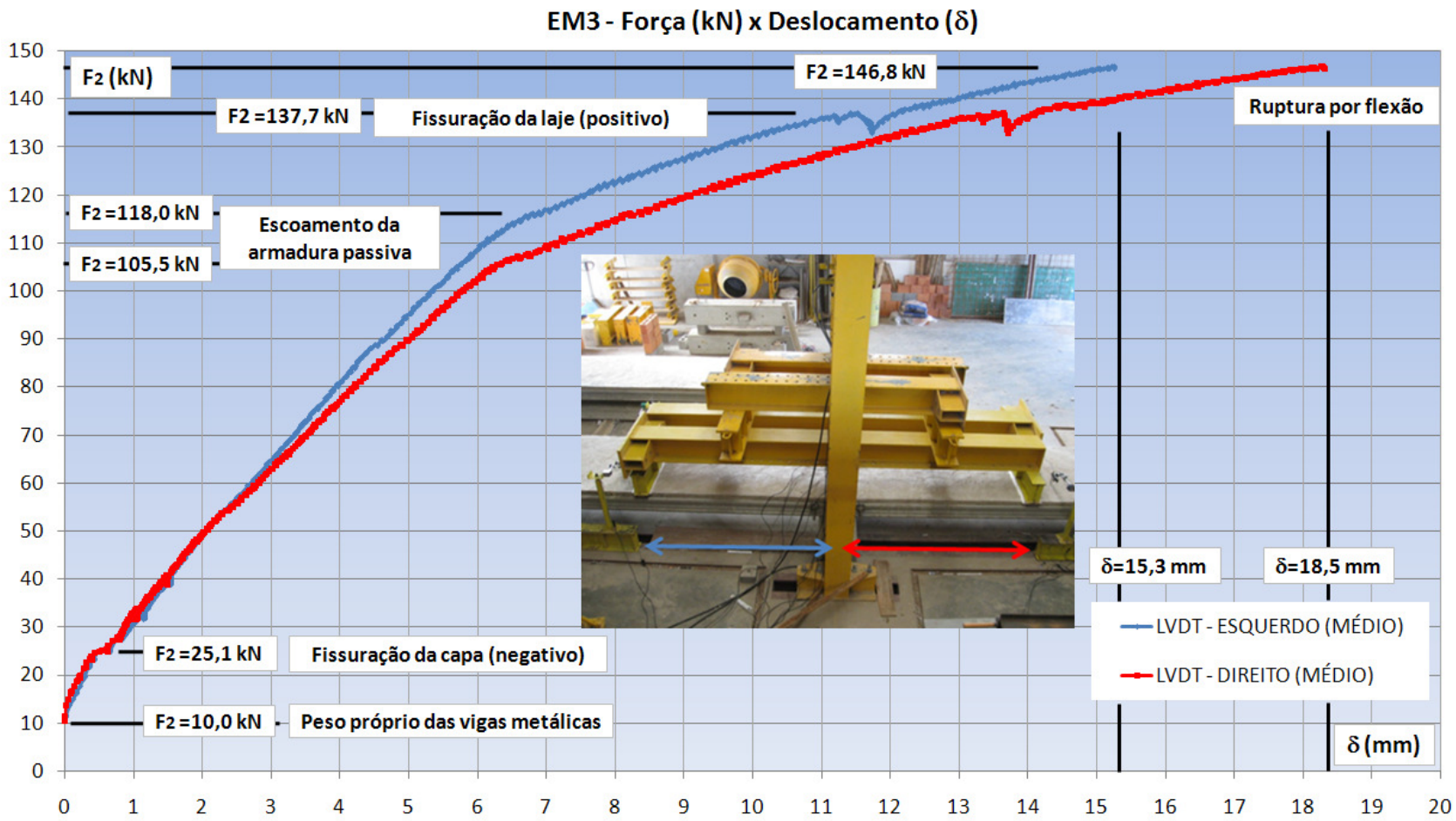

Figura 5.58 - Diagramas Força x Deslocamento dos valores médios de EM3 (ruptura na laje da direita, com indicação em vermelho).

Como foi já dito, a partir do modelo 2 os clinômetros foram posicionados conforme as Figuras 5.15 c e $5.15 \mathrm{~d}$, para medir as rotações relativas entre as lajes e a viga (apoio intermediário). Dessa forma, a Figura 5.59 apresenta os resultados das rotações absolutas dos três clinômetros para o modelo 3: laje da esquerda, clinômetro 23; centro da viga intermediária, 24; e laje da direita, 25. A Figura 5.60 mostra as rotações relativas entre as lajes e a viga.

Analisando a Figura 5.59, percebe-se que quase não houve rotação do apoio, sendo que a curva que o representa se confunde com o eixo das ordenadas. Nesse ensaio, a análise das rotações poderia ser feita sem a consideração da rotação relativa.

Avaliando os resultados da Figura 5.60, que representa as rotações relativas, notase que a laje da direita girou menos em relação à laje da esquerda, a partir de $F_{2}=53,0 \mathrm{kN}$. Esse fato mostra que a ligação no apoio intermediário da laje da direita apresentou um comportamento mais rígido que o da esquerda. Com isso o valor do momento negativo no apoio foi maior para o lado direito, fazendo com que esse lado atingisse a ruptura por flexão.

Como já foi dito, até $F_{2}=53,0 \mathrm{kN}$, os valores da rotação dos lados esquerdo e direito ficaram próximos, sendo que as curvas apresentaram resultados simétricos até esse valor de força. Entre 53,0 kN e 87,0 kN, a laje da direita apresentou comportamento de rotação nula. 


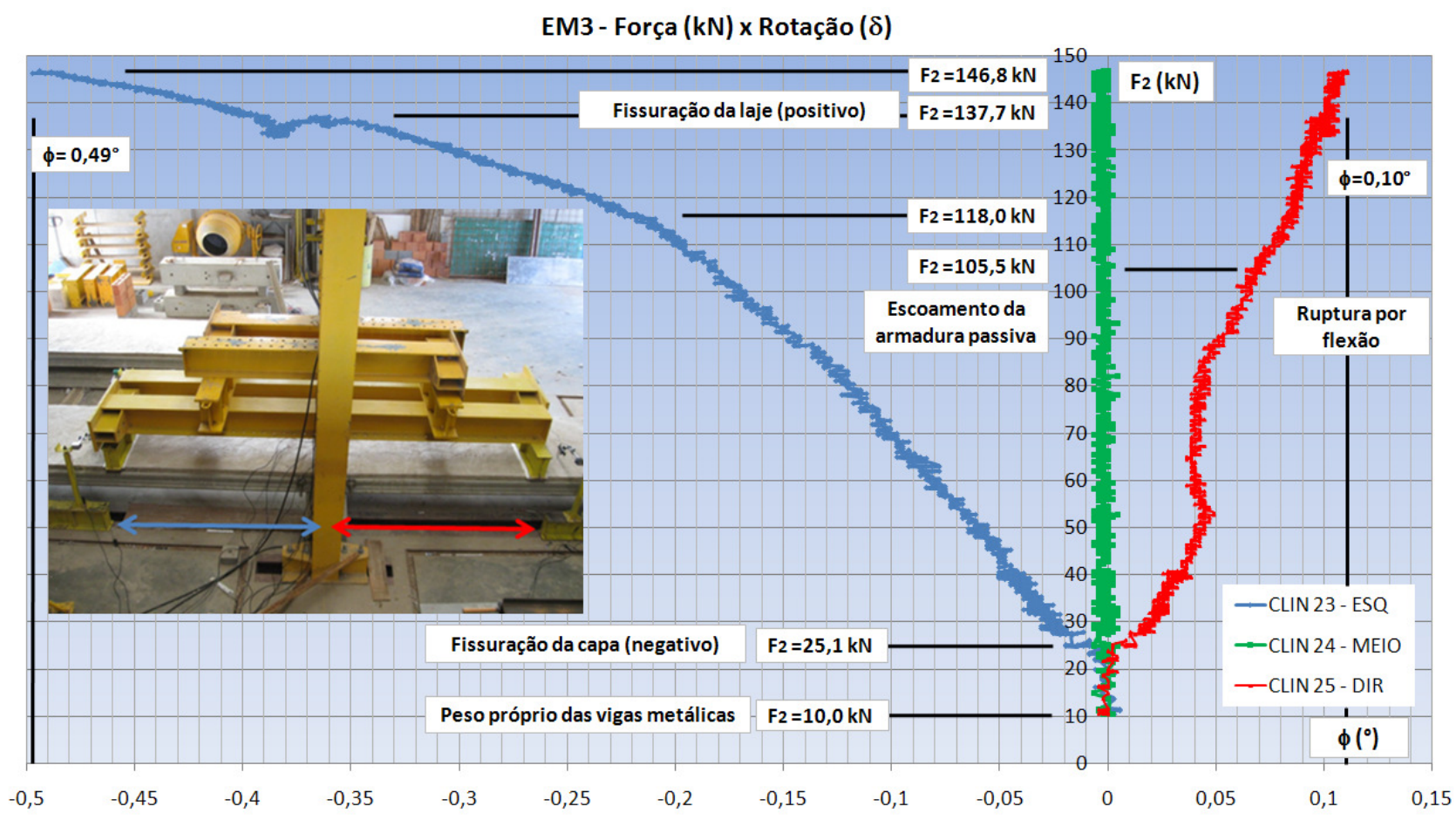

Figura 5.59 - Diagramas Força x Rotação. Valores absolutos dos clinômetros 23 (esquerdo), 24 (apoio) e 25 (direito) de EM3.

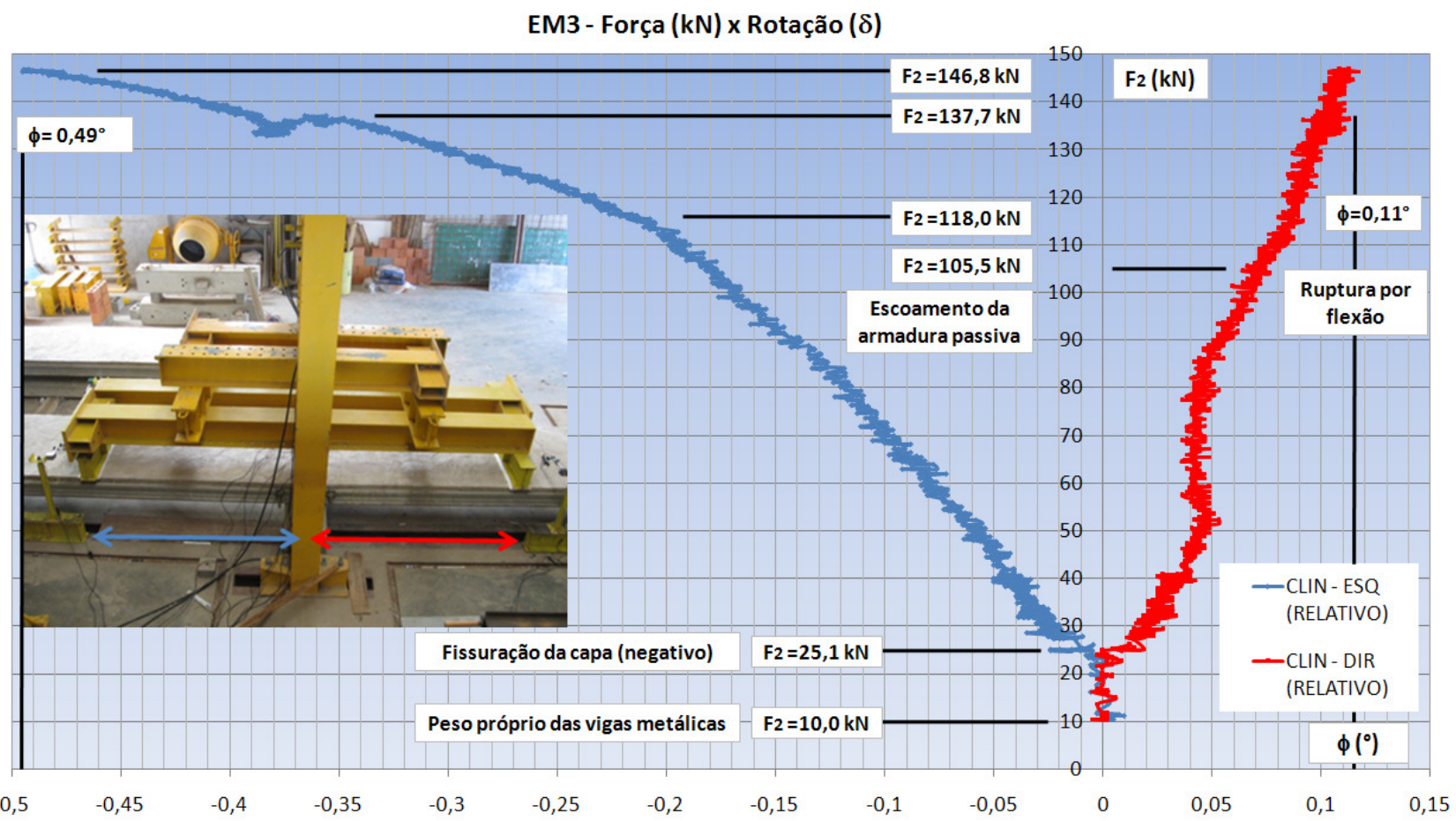

Figura 5.60 - Diagramas Força x Rotação. Valores relativos (descontando a rotação do apoio intermediário) de EM3.

Com relação à leitura das deformações nas armaduras passivas, a Figura 5.61 mostra as curvas que relacionam a força aplicada no ensaio $\left(F_{2}\right)$ com as deformações medidas $(\varepsilon)$ pelos extensômetros posicionados no lado esquerdo (azul) de EM3. A Figura 
5.62 apresenta as mesmas curvas, porém para os extensômetros colocados no lado direito (vermelho).

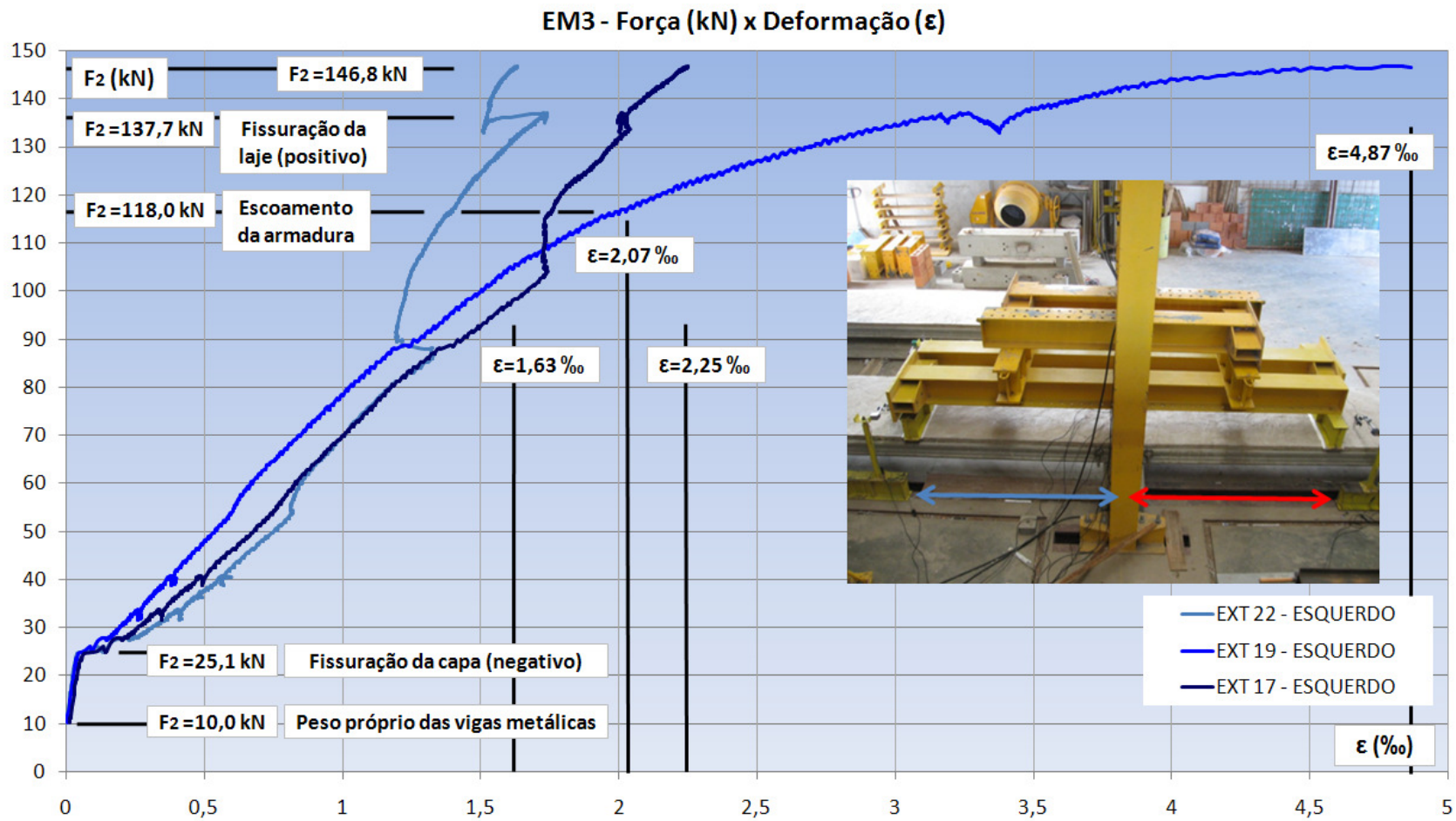

Figura 5.61 - Diagramas Força x Deformação do lado esquerdo (azul) de EM3.

EM3 - Força (kN) x Deformação $(\varepsilon)$

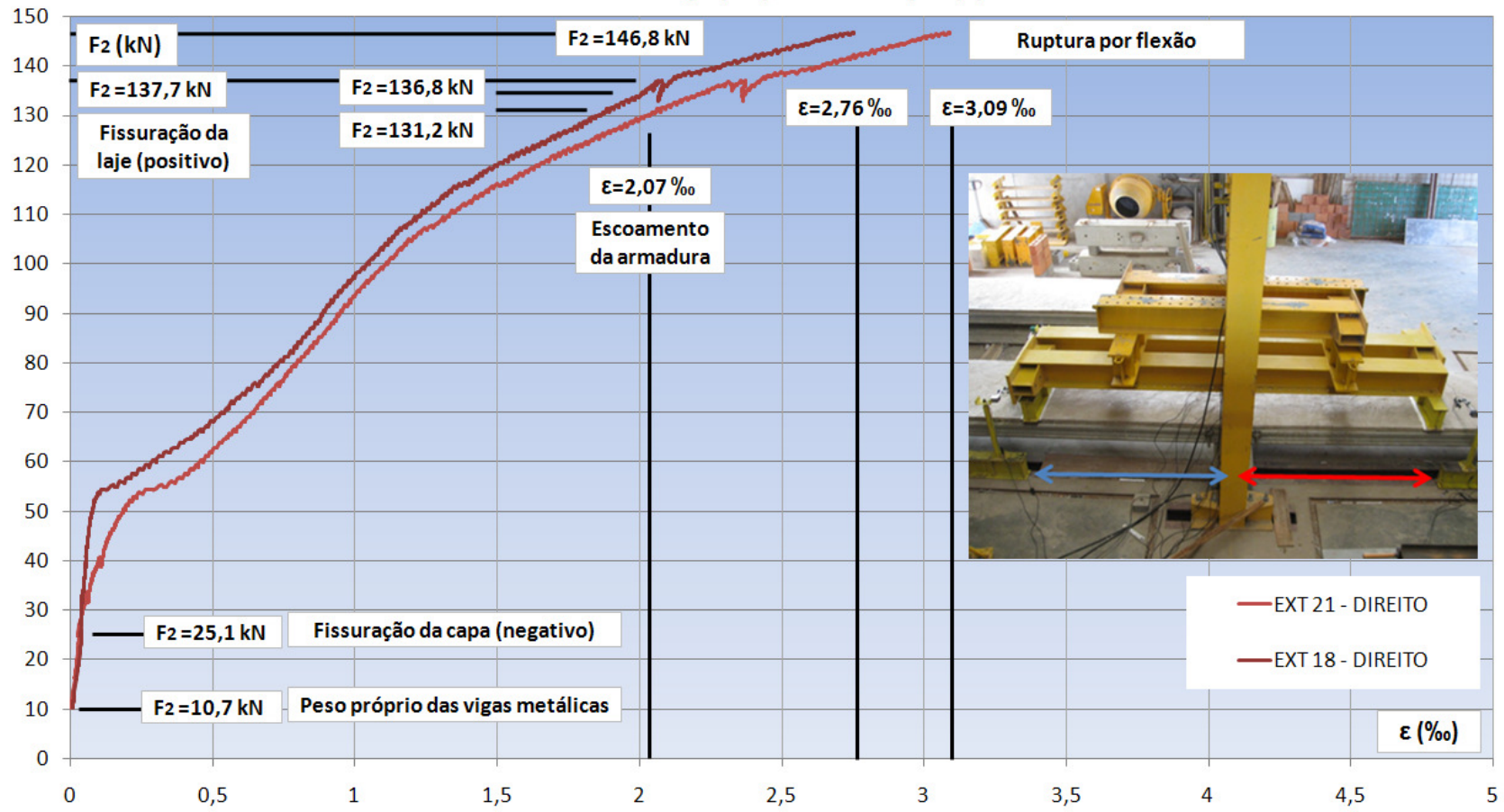

Figura 5.62 - Diagramas Força x Deformação do lado direito (vermelho) de EM3. 
A Figura 5.63, além da comparação entre os valores médios dos lados esquerdo e direito, exibe a curva que representa o extensômetro posicionado no centro do modelo (verde).

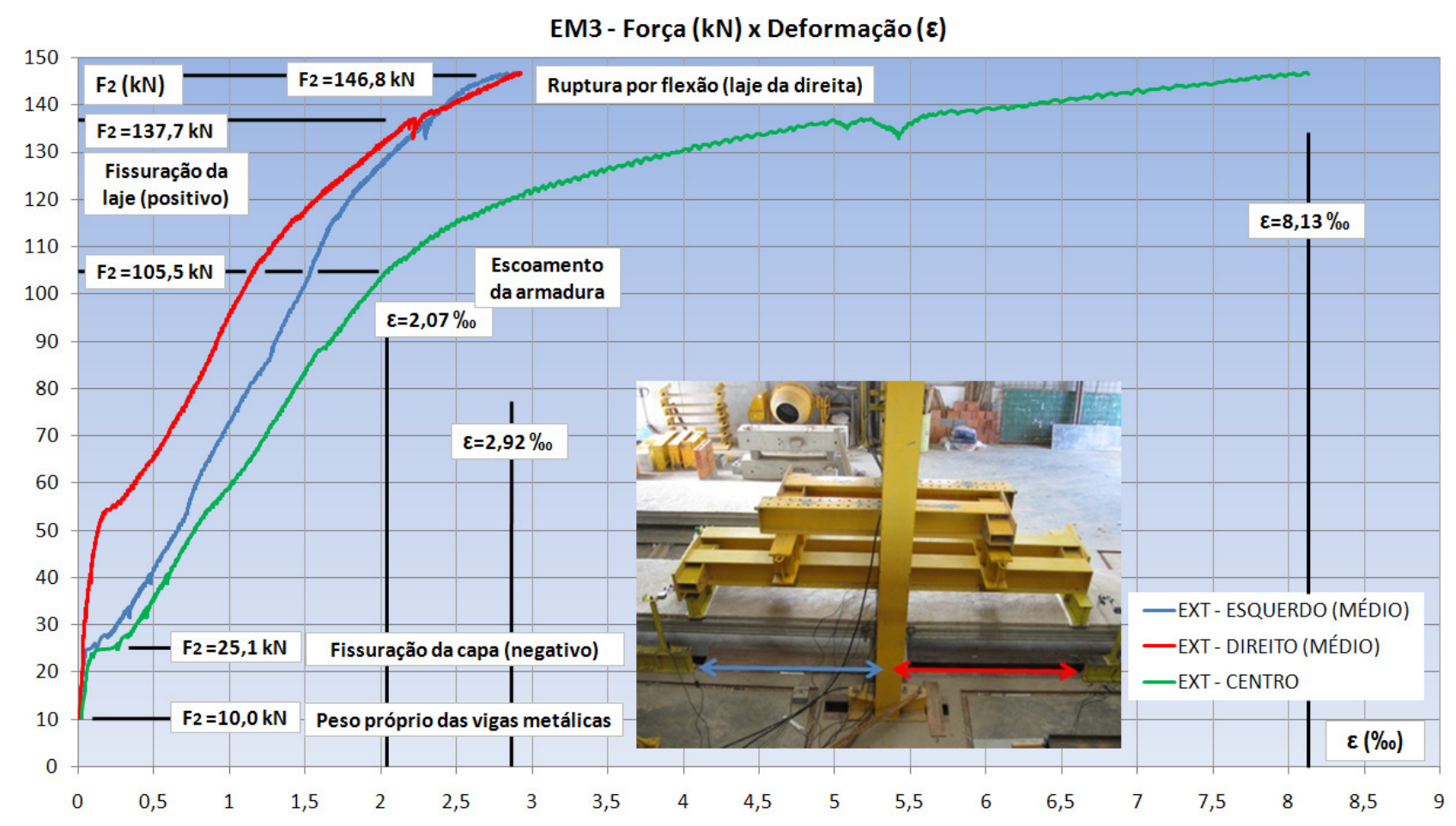

Figura 5.63 - Diagramas Força x Deformação do extensômetro do centro (EXT 20), e valores médios dos extensômetros posicionados nos lados esquerdo e direito de EM3.

Analisando os diagramas da Figura 5.63, nota-se que a deformação no centro do modelo foi maior após a fissuração da capa.

As deformações no lado esquerdo foram maiores que as do lado direito. Tanto é que o lado esquerdo do modelo (em azul) apresentou um patamar no gráfico $F_{2} \times \varepsilon$ para o mesmo nível de força que a curva do centro do modelo, ou seja, $F_{2}=25,1$ kN. Já o lado direito apresentou esse patamar de forma tardia, para $F_{2}=53,0 \mathrm{kN}$, aproximadamente. Esse indica que o lado direito fissurou com aproximadamente o dobro da força que o lado esquerdo e o centro.

A curva do extensômetro relativo ao centro do modelo (destacado em verde) apresentou, basicamente, quatro trechos distintos:

- O primeiro corresponde ao estádio I, ou seja, região sem fissuras. Inicia-se com a aplicação do carregamento $\left(F_{2}=10,0 \mathrm{kN}\right)$ e termina com a fissuração da capa $\left(F_{2}=25,1 \mathrm{kN}\right)$. Nessa fase a seção do centro do modelo pôde contar com a resistência do concreto à tração;

- O segundo, representado por um patamar, corresponde ao estádio II. Nesse caso a seção está fissurada e ocorre transferência das tensões de tração do concreto para a armadura. Nessa fase ocorre o efeito de contribuição do concreto entre 
as fissuras para o aumento da rigidez da seção, conhecido como tension stiffening effect. A aderência entre o concreto e o aço faz com que parte da tensão de tração existente no aço seja transmitida ao concreto vizinho, ocasionando a formação de mais fissuras;

- O terceiro trecho corresponde à fissuração estabilizada, em que novas fissuras não podem surgir e somente as existentes sofrem aumento de abertura em função do amento do carregamento. Esse trecho inicia-se no ponto que representa o final do patamar, também com $F_{2}=25,1 \mathrm{kN}$, e termina com o escoamento da armadura nessa seção, com $F_{2}=105,5 \mathrm{kN}$;

- No quarto trecho, o fenômeno do alongamento ocorre onde o aço não tem aderência, ocorrendo também abertura de fissuras, mas de modo distinto da fase anterior. Nesse ponto a tensão de tração na armadura é igual à tensão de escoamento do aço. Esse último trecho é afetado pela fissuração da laje pelo momento positivo com uma perturbação no gráfico, e encerra-se com a ruptura da laje da direita por flexão na seção onde a força $F_{2}$ é aplicada.

Considerando as curvas que representam o comportamento médio dos lados esquerdo (lado que não sofreu ruptura, representado pelo azul) e direito (lado que sofreu ruptura por cisalhamento, representado pelo vermelho), também é possível observar, basicamente, os mesmos quatro trechos distintos (estádio I, estádio II com patamar, fissuração estabilizada e escoamento da armadura). Entretanto, essas fases ocorrem em fases diferentes das relativas à seção central. 


\section{6 - Resumo dos resultados}

A Tabela 5.1 apresenta o resumo dos resultados relativos aos modelos dos ensaios de continuidade.

Tabela 5.1 - Resumo dos resultados dos modelos de continuidade.

\begin{tabular}{|c|c|c|c|}
\hline Ocorrência & $\begin{array}{c}\text { EM1 - F } 2 \\
(\mathbf{k N})\end{array}$ & $\begin{array}{c}\text { EM2 - F2 } \\
(\mathbf{k N})\end{array}$ & $\begin{array}{c}\text { EM3 - F 2 } \\
(\mathbf{k N})\end{array}$ \\
\hline Início do ensaio & 10,7 & 10,0 & 10,0 \\
\hline $\begin{array}{c}\text { Fissuração da capa } \\
\text { (negativo) }\end{array}$ & 107,9 & 26,0 & 25,1 \\
\hline $\begin{array}{c}\text { Escoamento da armadura } \\
\text { passiva }\end{array}$ & - & - & 105,5 \\
\hline $\begin{array}{c}\text { Fissuração da laje } \\
\text { (positivo) }\end{array}$ & 219,1 & - & 137,7 \\
\hline $\begin{array}{c}\text { Ruptura por flexão } \\
\text { Ruptura por descolamento } \\
\text { da capa }\end{array}$ & - & $\mathbf{1 4 6 , 8}$ \\
\hline \begin{tabular}{c} 
Ruptura por cisalhamento \\
\hline
\end{tabular} & $\mathbf{2 7 2 , 0}$ & $297,3(*)$ & - \\
\hline
\end{tabular}

(*) No modelo 2 a ruptura considerada foi o descolamento da capa. 


\section{NLF COM ELEMENTOS DE VIGA}

Para proceder a análise não linear física de forma analítica, optou-se por utilizar a expressão de Branson, uma vez que ela representa trechos fissurados e não fissurados de um elemento, ou de uma seção de concreto, na obtenção de uma única inércia. Baseia-se em modelo semiprobabilístico, no qual toma a variação da tensão ao longo da seção transversal e ao longo do comprimento de maneira simplificada, utilizando expressões empíricas que fornecem valores médios de inércia. Procura traduzir aproximadamente o efeito da fissuração do concreto, quando submetido à flexão, no cálculo das deformações imediatas.

Foram utilizados elementos de viga para a discretização dos elementos que compõem os modelos ensaiados.

\section{1 - Expressão de Branson}

A expressão de Branson é dada por:

$$
I_{m}=\left(\frac{M_{r}}{M_{a t}}\right)^{n} \cdot I_{I}+\left[1-\left(\frac{M_{r}}{M_{a t}}\right)^{n}\right] \cdot I_{I I}
$$

- $\mathrm{I}_{\mathrm{m}}=$ momento de inércia efetivo para uma seção ou para toda a peça;

- $\mathrm{I}_{\mathrm{I}}=$ momento de inércia no estádio I (da seção bruta ou homogeneizada);

- $\mathrm{I}_{\mathrm{II}}=$ momento de inércia no estádio II puro;

- $\mathrm{M}_{\mathrm{r}}=$ momento de fissuração do concreto;

- $\mathrm{M}_{\mathrm{at}}=$ momento atuante de serviço na seção mais solicitada;

- $\mathrm{n}=$ índice de valor igual a 4, para situações em que a análise é feita em apenas uma seção da peça, ou igual a 3 , quando se faz a análise da peça ao longo de todo seu comprimento.

\subsection{1 - Momento de fissuração}

O momento de fissuração $\mathrm{Mr}_{\mathrm{r}}$ deve ser calculado para duas situações distintas. Uma levando em conta a fissuração da capa e outra, da laje. 
Por se tratar de uma seção em concreto armado, o momento de fissuração da capa pode ser calculado através da expressão 6.2, retirada da NBR 6118:2014.

$$
\mathrm{M}_{\mathrm{r}}=\frac{\alpha \cdot \mathrm{f}_{\mathrm{ct}} \cdot \mathrm{I}_{\mathrm{C}}}{\mathrm{y}_{\mathrm{t}}}
$$

- $\alpha=\left\{\begin{array}{l}1,2 \text { para seções } \mathrm{T} \text { ou duplo T } \\ 1,5 \text { para seções retangulares }\end{array}\right.$

- $\mathrm{f}_{\mathrm{ct}}=\mathrm{f}_{\mathrm{ctk}, \mathrm{inf}}=0,7 \cdot \mathrm{f}_{\mathrm{ct}, \mathrm{m}}=0,7 \cdot 0,3 \cdot \mathrm{f}_{\mathrm{ck}}^{2 / 3}, \operatorname{com} \mathrm{f}_{\mathrm{ck}}$ em MPa;

- $\mathrm{f}_{\mathrm{ct}}=\mathrm{f}_{\mathrm{ctk}, \mathrm{inf}}$ - para formação de fissura;

- $\mathrm{f}_{\mathrm{ct}}=\mathrm{f}_{\mathrm{ct}, \mathrm{m}}$ - para deformação excessiva;

- $\mathrm{I}_{\mathrm{c}}=$ momento de inércia no Estádio I (da seção bruta ou homogeneizada);

- $\mathrm{y}_{\mathrm{t}}=$ distância do centro de gravidade da seção à fibra mais tracionada.

Para a seção em laje alveolar, CARVALHO (2010b) apresenta a expressão 6.3 para o cálculo do momento de fissuração. Além da parcela contida na expressão 6.2 , a fórmula abaixo leva em consideração a parcela do efeito da protensão $\left(N_{p} / A\right)$ e da sua excentricidade $\left[\left(N_{p} \cdot e \cdot y\right) / I_{c}\right]$.

$$
\mathrm{M}_{\mathrm{r}}=\frac{\alpha \cdot \mathrm{f}_{\mathrm{ct}} \cdot \mathrm{I}_{\mathrm{c}}}{\mathrm{y}_{\mathrm{t}}}+\frac{\mathrm{N}_{\mathrm{p}} \cdot \mathrm{I}_{\mathrm{c}}}{\mathrm{A} \cdot \mathrm{y}_{\mathrm{t}}}+N_{p} \cdot e_{p}
$$

- $\mathrm{N}_{\mathrm{p}}=$ força normal de protensão;

- $\mathrm{A}=$ área da seção transversal de concreto, em geral da seção bruta;

- $e_{p}=$ distância do centro de gravidade da seção à fibra mais tracionada.

\subsection{2 - Seção composta equivalente}

No Capítulo 2, item 2.1.2, a redistribuição de momento fletor é feita em função da diferença entre o módulo de elasticidade da capa moldada no local $\left(E_{c m l}\right)$ e o módulo do concreto pré-moldado $\left(E_{c p m}\right)$, sendo que essa redistribuição depende da relação $E_{c m l} / E_{c p m}$. Essa recomendação pode ser encontrada nos manuais: ASSAP (2002) e FIB (2000).

No entanto, para considerar a diferença de material entre os concretos da capa e da laje, foi estabelecida uma seção equivalente na qual uma largura fictícia da capa de concreto foi obtida em função da relação entre os módulos de elasticidade, de acordo com as expressões 6.4 e 6.5 e a Figura 6.1.

$$
\begin{aligned}
& \alpha_{M}=\frac{E_{c m l}}{E_{c p m}} \\
& b_{\text {fic }}=\alpha_{M} \cdot b_{\text {real }}
\end{aligned}
$$




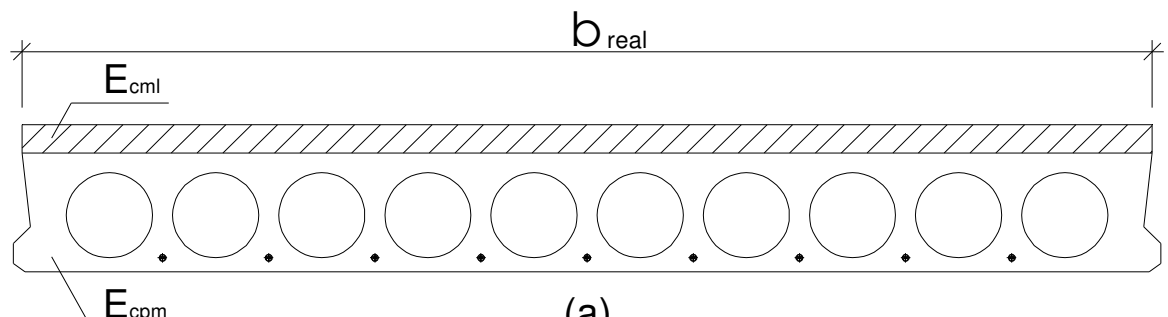

(a)

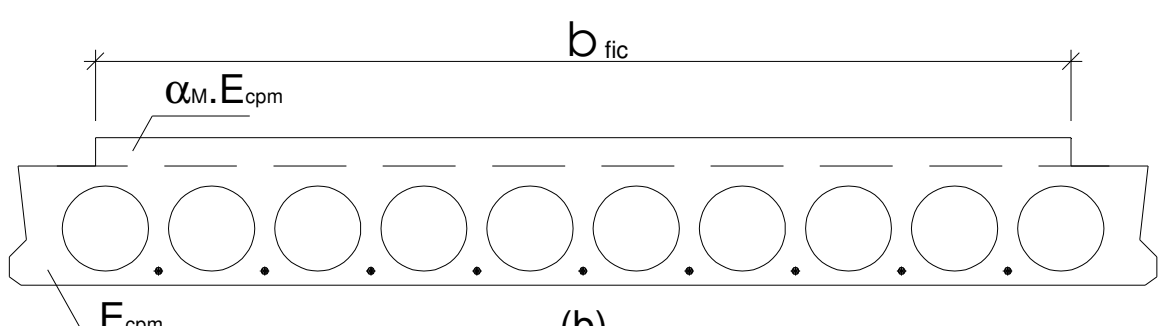

(b)

Figura 6.1 - Largura fictícia da capa - Seção composta equivalente.

\subsection{3 - Características geométricas da seção}

Para realizar a análise não linear utilizando a expressão de Branson, é necessário conhecer as características geométricas da seção, tanto no Estádio I como no Estádio II.

O Estádio I corresponde ao início do carregamento, em que as tensões normais são de baixa intensidade e o concreto consegue resistir às tensões de tração. Nesse caso é válida a lei de Hooke, e o diagrama de tensões é linear ao longo da peça.

No Estádio II, o concreto já não mais resiste à tração, que é resistida somente pela armadura, disposta na região tracionada da seção transversal. Nesse caso existe uma relação linear entre a tensão e a deformação do concreto. Uma vez que se despreza todo o concreto da região fissurada, também é usual chamar de Estádio II puro.

CARVALHO e FIGUEIREDO FILHO (2007) comentam que o Estádio II puro compreende a situação em que um momento maior que o momento de fissuração atua na seção até a situação em que começa a ocorrer o escoamento da armadura e/ou a plastificação do concreto comprimido.

Nesses termos, o Estádio II apresenta as seguintes características:

- Distribuição triangular de tensões de compressão no concreto;

- Esforços de tração resistidos pela armadura situada na região de tração em relação à linha neutra.

Para facilitar os cálculos das propriedades geométricas da seção transversal de uma laje alveolar, pode-se transformá-la em uma seção duplo T fictícia, equivalente à seção original. Para isso sugere-se o método mostrado a seguir e ilustrado na Figura 6.2. 


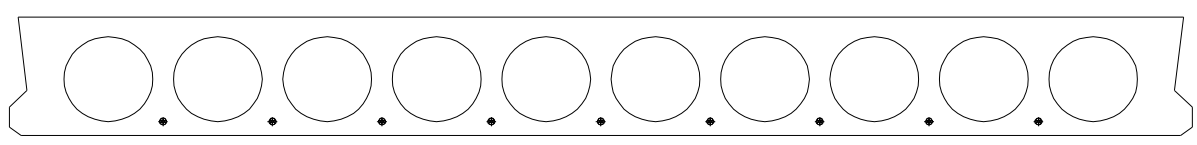

(a)

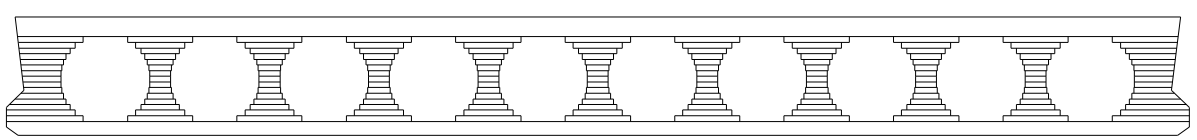

(b)

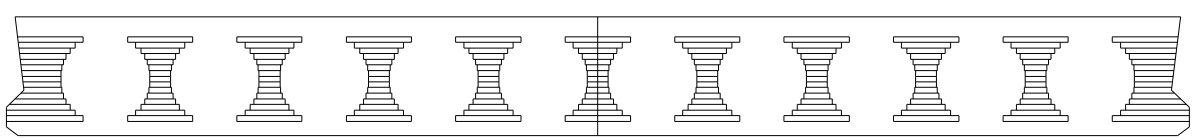

(c)

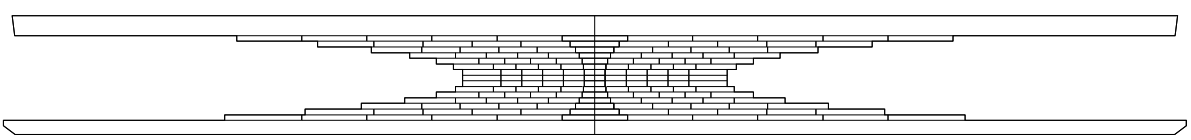

(d)

(e)

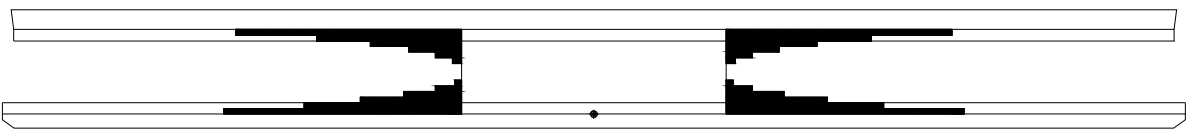

(f)

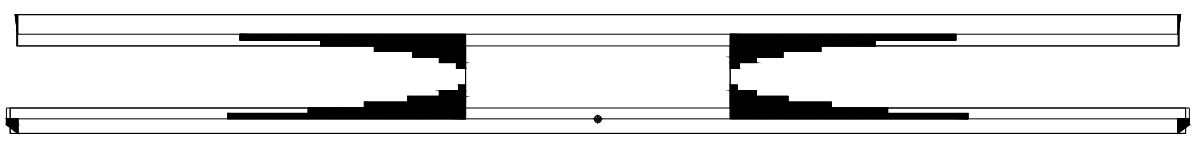

(g)

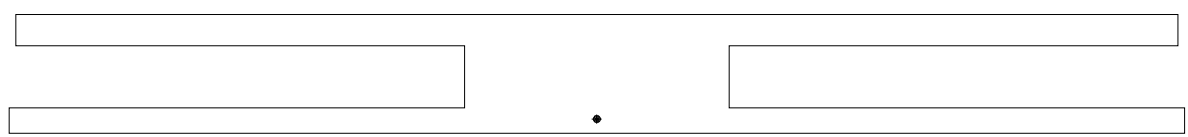

(h)

Figura 6.2 - Seção transversal fictícia de uma laje alveolar.

Dada uma seção de uma laje alveolar como a apresentada na Figura 6.2a, pode-se proceder da seguinte forma:

- Discretizar a seção em faixas, principalmente na região dos alvéolos (Figura 6.2b);

- Somar (geometricamente) as larguras das diferentes faixas de tal forma a obter uma seção duplo T (Figura 6.2c, Figura 6.2d e Figura 6.2e); 
- Transformar as áreas dos triângulos em retângulos equivalentes. Para isso considera-se que a altura do retângulo é igual a um terço da altura do triângulo (Figura 6.2f e Figura 6.2g);

- Por fim, tem-se a seção fictícia em forma de duplo T, em que as armaduras de protensão encontram-se representadas por um único cabo, chamado de cabo representante.

A discretização por faixas representa as propriedades geométricas por somatório ao invés da sua definição por integral. Como exemplo pode-se citar o momento de inércia, dado pela expressão 6.6 .

$$
I_{x}=\int_{A} y^{2} \cdot d A=\sum_{i}^{n} y^{2} \cdot A_{i}
$$

\subsection{4 - Seção composta equivalente fictícia}

Para calcular as características geométricas da seção no Estádio I e no Estádio II, é necessário converter a seção transversal em uma fictícia com as mesmas propriedades da seção composta real. A Figura 6.3 mostra a seção composta equivalente fictícia.

Para isso utilizaram-se os dois artifícios anteriormente apresentados: a seção equivalente, ou seja, obter uma largura equivalente da capa com módulo de elasticidade igual ao da laje alveolar (Figura 6.1); e a transformação da seção da laje em uma seção fictícia (Figura 6.2). Além disso, para compatibilizar as diferentes alturas da mesa superior da seção fictícia da laje e a altura da capa, utilizou-se um critério de tentativa e erro, até que o momento de inércia $\left(I_{x}\right)$ fosse o mesmo (Figura 6.3b).

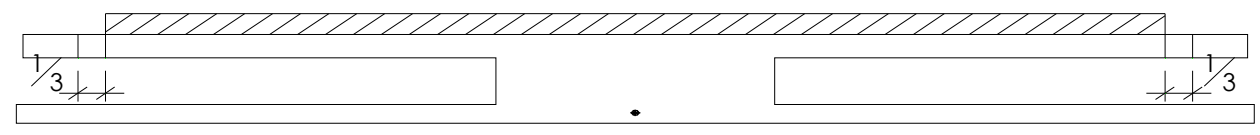

(a) S eção equivalente + seção fictícia

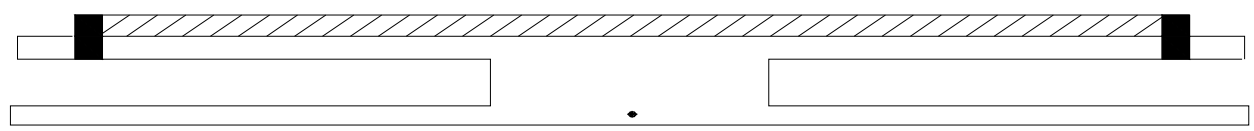

(b) C ritério de $1 / 3$ da largura

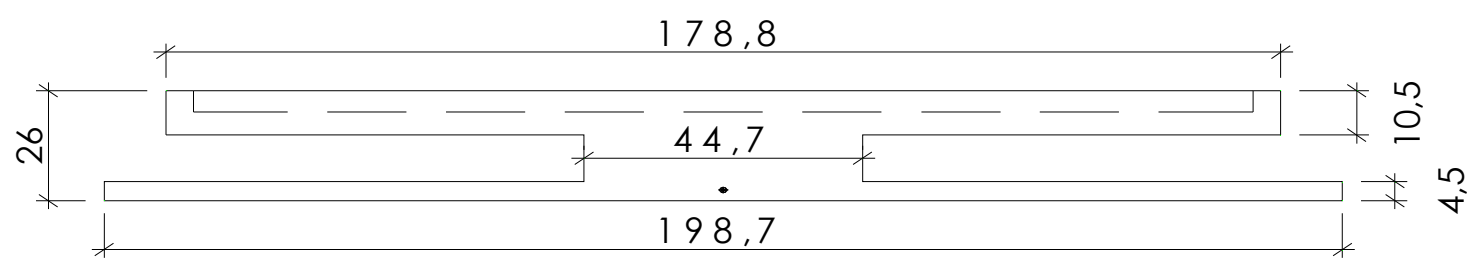

(c) S eção composta equivalente fictícia final-duplo T

Figura 6.3 - Seção transversal - Seção composta equivalente fictícia final. 


\subsection{5 - Expressões para seção homogeneizada nos Estádios I e II}

As expressões mostradas a seguir são adaptadas de CARVALHO e FIGUEIREDO FILHO (2007). A homogeneização da seção é feita substituindo-se a área de aço por uma área correspondente de concreto, obtida pela área de aço $A_{s}$ multiplicada por $\alpha_{e}$, sendo:

$$
\alpha_{\mathrm{e}}=\frac{\mathrm{E}_{\mathrm{s}}}{\mathrm{E}_{\mathrm{c}}}
$$

- $\mathrm{E}_{\mathrm{S}}=$ módulo de elasticidade do aço (armadura ativa ou passiva);

- $\mathrm{E}_{\mathrm{c}}=$ módulo de elasticidade do concreto.

Na Figura 6.4, é mostrada uma seção retangular no Estádio I. As expressões 6.8, 6.9 e 6.10 são relativas à área da seção, posição da linha neutra e momento de inércia da seção retangular homogeneizada no Estádio I.

$$
\begin{gathered}
A_{h}=b \cdot h+A_{s 1} \cdot\left(\propto_{e}-1\right)+A_{s 2} \cdot\left(\propto_{e}-1\right) \\
X_{I}=\frac{b \cdot \frac{h^{2}}{2}+A_{s 1} \cdot\left(\propto_{e}-1\right) \cdot d+A_{s 2} \cdot\left(\propto_{e}-1\right) \cdot d_{2}^{\prime}}{A_{h}} \\
I_{h}=\left[\left(\frac{b \cdot h^{3}}{12}\right)+\text { b.h. }\left(x_{I}-\frac{h}{2}\right)^{2}\right]+\left[A_{s 1} \cdot\left(\propto_{e}-1\right) \cdot\left(x_{I}-d\right)^{2}\right]+\left[A_{s 2} \cdot\left(\propto_{e}-1\right) \cdot\left(x_{I}-d_{2}^{\prime}\right)^{2}\right]
\end{gathered}
$$

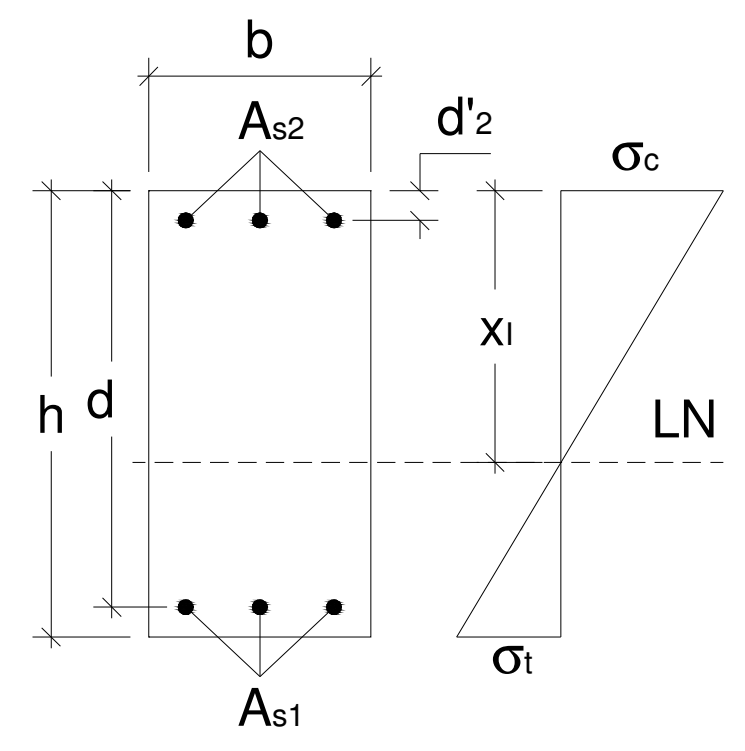

FIGURA 6.4 - Seção retangular no Estádio I.

Da mesma forma, a Figura 6.5 mostra uma seção T no Estádio I. As expressões 6.11, 6.12 e 6.13 são relativas à área da seção, posição da linha neutra e momento de inércia da seção T homogeneizada no Estádio I. 


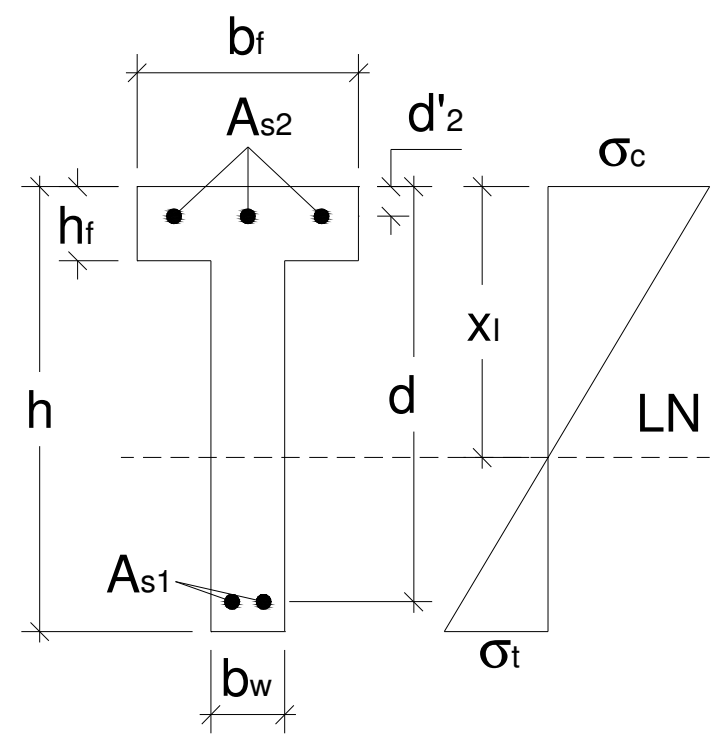

FIGURA 6.5 - Seção T no Estádio I.

$$
\begin{aligned}
& A_{h}=\left(b_{f}-b_{w}\right) \cdot h_{f}+b_{w} \cdot h+A_{s 1} \cdot\left(\propto_{e}-1\right)+A_{s 2} \cdot\left(\propto_{e}-1\right) \\
& x_{I}=\frac{\left(b_{f}-b_{w}\right) \cdot \frac{h_{f}^{2}}{2}+b_{w} \cdot \frac{h^{2}}{2}+A_{s 1} \cdot\left(\alpha_{e}-1\right) \cdot d+A_{s 2} \cdot\left(\alpha_{e}-1\right) \cdot d_{2}^{\prime}}{A_{h}} \\
& I_{h}=\left[\left(\frac{\left(b_{f}-b_{w}\right) \cdot h_{f}^{3}}{12}\right)+\left(b_{f}-b_{w}\right) \cdot h_{f} \cdot\left(x_{I}-\frac{h_{f}}{2}\right)^{2}\right]+\left[\left(\frac{b_{w} \cdot h^{3}}{12}\right)+b_{w} \cdot h \cdot\left(x_{I}-\frac{h}{2}\right)^{2}\right]+ \\
& {\left[A_{s 1} \cdot\left(\propto_{e}-1\right) \cdot\left(x_{I}-d\right)^{2}\right]+\left[A_{s 2} \cdot\left(\propto_{e}-1\right) \cdot\left(x_{I}-d_{2}^{\prime}\right)^{2}\right]}
\end{aligned}
$$

A Figura 6.6, que mostra uma seção duplo T no Estádio I. As expressões 6.14, 6.15 e 6.16 são relativas à área da seção, posição da linha neutra e momento de inércia da seção duplo T homogeneizada no Estádio I.

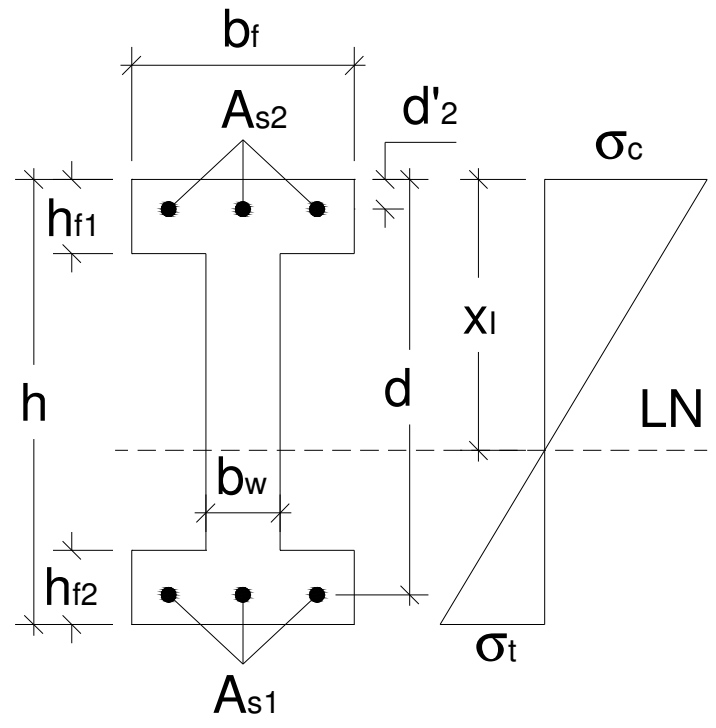

FIGURA 6.6 - Seção duplo T no Estádio I. 


$$
\begin{aligned}
A_{h}= & \left(b_{f}-b_{w}\right) \cdot h_{f 1}+\left(b_{f}-b_{w}\right) \cdot h_{f 2}+b_{w} \cdot h+A_{s 1} \cdot\left(\alpha_{e}-1\right)+A_{s 2} \cdot\left(\propto_{e}-1\right) \\
x_{I}= & \frac{\left(b_{f}-b_{w}\right) \cdot \frac{h_{f 1}{ }^{2}}{2}+\left(b_{f}-b_{w}\right) \cdot h_{f 2} \cdot\left(h-\frac{h_{f 2}}{2}\right)+b_{w} \cdot \frac{h^{2}}{2}}{A_{h}} \\
& +\frac{A_{s 1} \cdot\left(\alpha_{e}-1\right) \cdot d+A_{s 2} \cdot\left(\alpha_{e}-1\right) \cdot d_{2}^{\prime}}{A_{h}} \\
I_{h}= & {\left[\left(\frac{\left(b_{f}-b_{w}\right) \cdot h_{f 1}{ }^{3}}{12}\right)+\left(b_{f}-b_{w}\right) \cdot h_{f 1} \cdot\left(x_{I}-\frac{h_{f 1}}{2}\right)^{2}\right]+\left[\left(\frac{b_{w} \cdot h^{3}}{12}\right)+b_{w} \cdot h \cdot\left(x_{I}-\frac{h}{2}\right)^{2}\right] } \\
& +\left[\left(\frac{\left(b_{f}-b_{w}\right) \cdot h_{f 2}{ }^{3}}{12}\right)+\left(b_{f}-b_{w}\right) \cdot h_{f 2} \cdot\left(x_{I}-\frac{h_{f 2}}{2}\right)^{2}\right]+\left[A_{s 1} \cdot\left(\alpha_{e}-1\right) \cdot\left(x_{I}-d\right)^{2}\right] \\
& +\left[A_{s 2} \cdot\left(\propto_{e}-1\right) \cdot\left(x_{I}-d_{2}^{\prime}\right)^{2}\right]
\end{aligned}
$$

As Figuras 6.7, 6.8 e 6.9 apresentam seções retangular, $T$ e duplo $T$, respectivamente, no Estádio II.

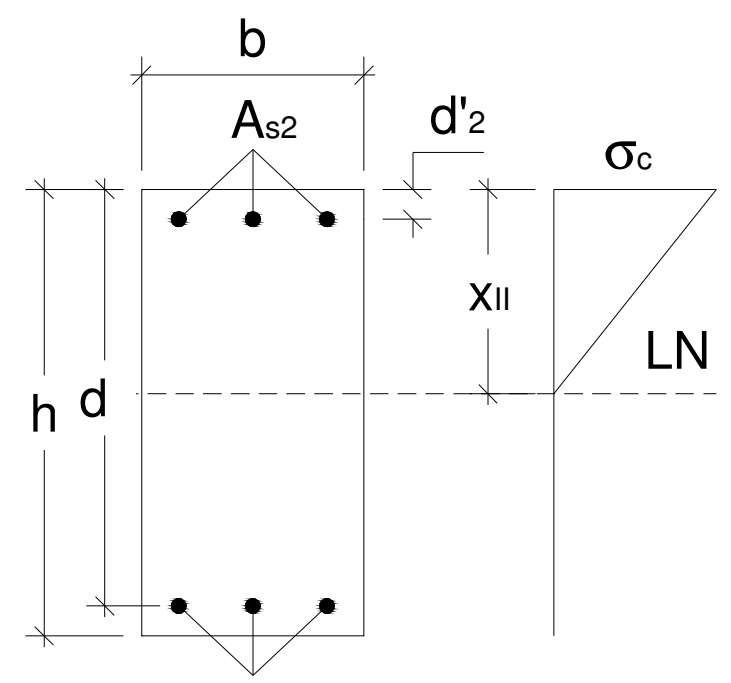

As1

FIGURA 6.7 - Seção retangular no Estádio II.

Para o cálculo da inércia no Estádio II, primeiramente é necessário obter a posição da linha neutra ( $\left.x_{\|}\right)$. CARVALHO e FIGUEIREDO FILHO (2007) apresentam, para seção T, a seguinte equação do segundo grau:

$$
\mathrm{a}_{1} \cdot \mathrm{x}_{\mathrm{II}}^{2}+\mathrm{a}_{2} \cdot \mathrm{x}_{\mathrm{II}}+\mathrm{a}_{3}=0
$$




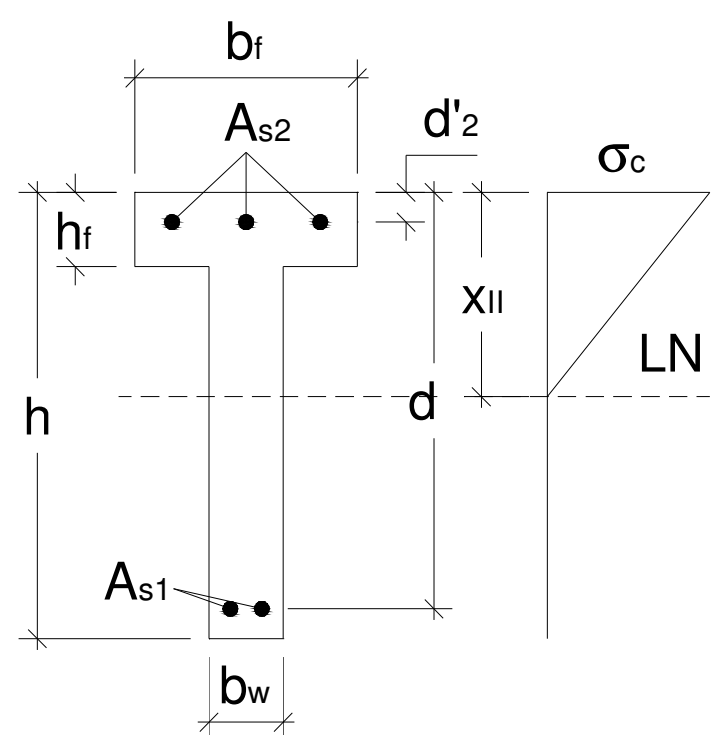

FIGURA 6.8 - Seção T no Estádio II.

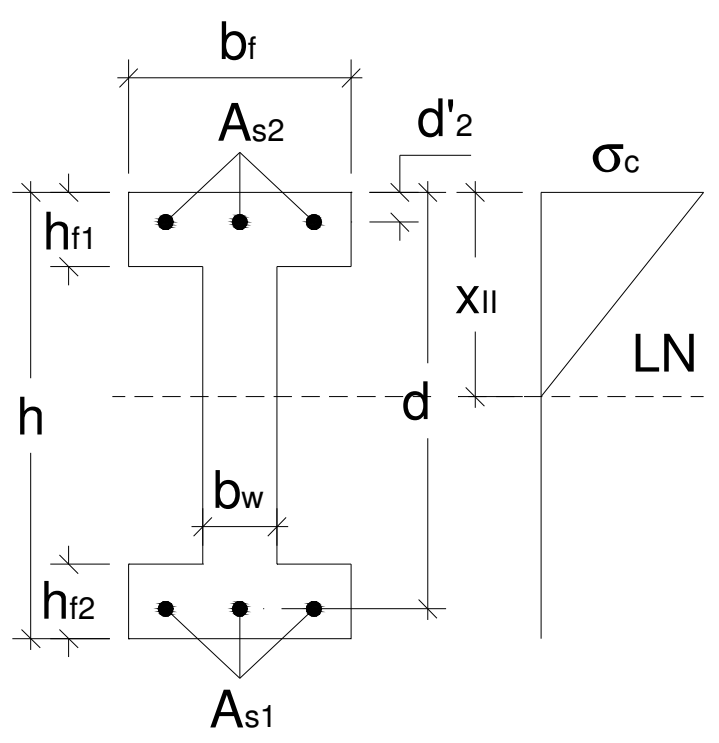

FIGURA 6.9 - Seção duplo T no Estádio II.

A solução para a equação 6.17 é mostrada nas expressões $6.18,6.19,6.20$ e 6.21 :

$$
\begin{aligned}
& \mathrm{x}_{\mathrm{II}}=\frac{-\mathrm{a}_{2} \pm \sqrt{\mathrm{a}_{2}^{2}-4 \cdot \mathrm{a}_{1 \cdot} \mathrm{a}_{3}}}{2 \cdot \mathrm{a}_{1}} \\
& \mathrm{a}_{1}=\frac{\mathrm{b}_{\mathrm{w}}}{2} \\
& a_{2}=h_{f} \cdot\left(b_{f}-b_{w}\right)+\left(\propto_{e}-1\right) \cdot A_{s 2}+b_{w} \cdot h+\propto_{e} \cdot A_{s 1}(6.20) \\
& a_{3}=-d_{2}^{\prime} \cdot\left(\propto_{e}-1\right) \cdot A_{s 2}-d_{1}^{\prime} \cdot \propto_{e} \cdot A_{s 1}-\frac{h_{f}^{2}}{2}\left(b_{f}-b_{w}\right)
\end{aligned}
$$

Para o cálculo do momento de inércia da seção T no Estádio II, tem-se a expressão 6.22, que é válida quando a profundidade da linha neutra é inferior à espessura da mesa $\left(\mathrm{x}_{\|}<\mathrm{h}_{\mathrm{f}}\right)$. Já a expressão 6.23 é válida para os casos em que a profundidade da linha neutra é maior que a espessura da mesa $\left(\mathrm{x}_{\|}>\mathrm{h}_{\mathrm{f}}\right)$.

$$
\begin{aligned}
& I_{I I}=\frac{b_{f} \cdot x_{I I}{ }^{3}}{3}+\alpha_{e} \cdot A_{s 1} \cdot\left(x_{I I}-d\right)^{2}+\left(\alpha_{e}-1\right) \cdot A_{s 2} \cdot\left(x_{I I}-d_{2}^{\prime}\right)^{2} \\
& I_{I I}=\frac{\left(b_{f}-b_{w}\right) \cdot h_{f}^{3}}{12}+\left(b_{f}-b_{w}\right) \cdot h_{f} \cdot\left(x_{I I}-\frac{h_{f}}{2}\right)^{2}+\frac{b_{w} \cdot x_{I I}{ }^{3}}{3}+b_{w} \cdot x_{I I} \cdot\left(\frac{x_{I I}}{2}\right)^{2}+\alpha_{e} \cdot A_{s 1} \cdot\left(x_{I I}-d\right)^{2} \\
& \quad+(\alpha e-1) \cdot A_{s 2} \cdot\left(x_{I I}-d_{2}^{\prime}\right)^{2}
\end{aligned}
$$

Quando a seção transversal da peça for retangular, as equações de 6.18 a 6.21 são válidas, fazendo $b_{w}=b_{f}$ e $h_{f}=0$. 
Nos casos em que a seção transversal for duplo T, as mesmas equações, de 6.18 até 6.21, também são válidas. Para isso basta considerar seção $T$, uma vez que o concreto da mesa tracionada é desprezado.

\subsection{6 - Modelo analítico para a análise da não linearidade física}

Para avaliar a influência e o progresso da fissuração com o carregamento na laje alveolar, foi adotado o procedimento descrito a seguir.

Primeiramente divide-se a estrutura em elementos de barra. Para a modelagem pode-se, por exemplo, utilizar o software FTOOL (Two-dimensional Frame Analysis Tool), disponível para download gratuito em https://web.tecgraf.puc-rio.br/ftool/.

Em segundo lugar a força de ensaio $F_{2}$ é dividida em etapas, para que possa ser aplicado de forma incremental. Neste trabalho essas etapas corresponderam a $10 \mathrm{kN}$.

O terceiro passo consiste em obter as características geométricas de todas as seções no Estádio I, considerando seção bruta. Determinam-se, portanto, para todas as seções, a área e o momento de inércia no Estádio I. Em seguida, calculam-se também as características geométricas de todas as seções no Estádio II, ou seja, área e o momento de inércia no Estádio II.

Feito isso, na quarta fase, aplicam-se as etapas de carregamento.

A Etapa 1 é feita com as propriedades geométricas da seção bruta no Estádio I, obtidas anteriormente.

De posse dos esforços solicitantes (momento fletor e força normal), verifica-se se o momento de fissuração foi atingido. Isso é feito para todas as seções do elemento. A força normal corresponde à força de protensão, considerando as perdas na data do ensaio de continuidade.

Nas seções em que o momento de fissuração foi ultrapassado, calcula-se o momento de inércia efetivo, $I_{m}$, pela expressão de Branson, utilizando-se as inércias previamente calculadas para os Estádios I e II.

Repete-se a Etapa 1 até que haja conversão dos resultados, de forma iterativa.

A Etapa 2 de carregamento é processada considerando para as seções fissuradas o momento de inércia efetivo, calculado na Etapa 1. Para a Etapa 2 repete-se o mesmo procedimento da Etapa 1. Nas seções nas quais o momento atuante é maior que o de fissuração, calcula-se o momento de inércia efetivo.

Esse procedimento é repetido até a última Etapa, que corresponde aplicação do carregamento total.

É importante comentar que para as propriedades geométricas foram considerados os valores obtidos nos ensaios de caracterização dos materiais, indicados no Capítulo 4 
deste trabalho. A Tabela 4.28 mostra os principais valores encontrados na fase de caracterização.

Também é importante ressaltar que os esforços solicitantes (momento fletor e força cortante) da análise da força aplicada $\left(F_{2}\right)$ foram combinados com os relativos ao peso próprio da laje e da capa $\left(g_{1}+g_{2}\right)$, em cada etapa de aplicação de $F_{2}$.

\section{2 - Resultados}

A seguir serão apresentados os resultados obtidos com a modelagem através de elementos de barra associados ao modelo de fissuração pela expressão de Branson.

Para a modelagem a estrutura foi dividida em 34 elementos de barra. A Figura 6.7 ilustra essa divisão. A posição dos nós foi escolhida com base nas seguintes considerações:

- Aplicação da força $F_{2}$;

- Meio de cada laje, ou seja, a 2,72 m de cada extremidade;

- Meio do modelo;

- Centro de giro do apoio;

- Extremidade da laje alveolar, na região do apoio intermediário;

- Divisão das demais barras em tamanhos de $30 \mathrm{~cm}$.

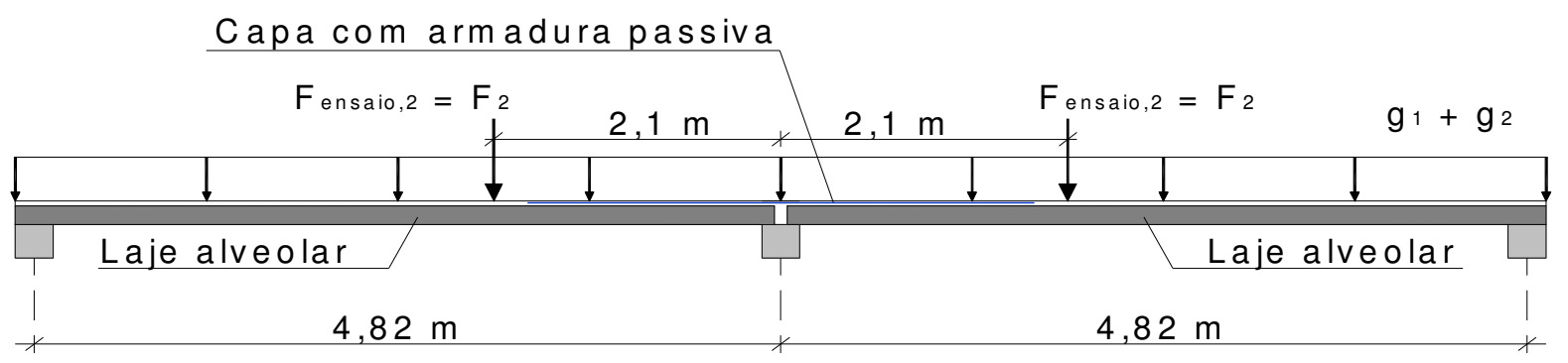

(a)

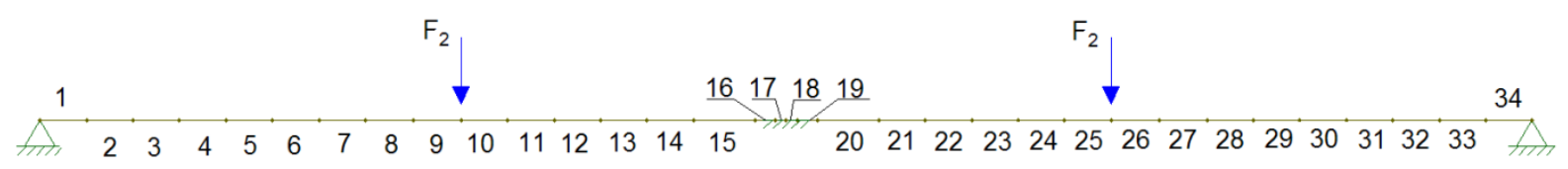

(b)

Figura 6.7 - Modelagem com elementos de barra: (a) Geometria do ensaio; (b) Divisão da estrutura em 34 elementos.

Considera-se a seguinte divisão dos elementos e as seções que eles representam:

- Elementos 17 e 18 - seção tipo 1. Correspondem a uma seção retangular constituída pelo concreto da capa e a armadura passiva. As medidas dessas 
seções são: altura 26,0 cm para EM1, 31,5 cm para EM2 e 21,0 cm para EM3 e largura 2,0 m para EM1 e 1,25m para os modelos EM2 e EM3.

- Elementos 13 a 16 e 19 a 22 - seção tipo 2. Correspondem a seção composta equivalente fictícia, contendo armadura passiva e ativa;

- Elementos 1 a 12 e 23 a 33 - seção tipo 3. Correspondem a seção composta equivalente fictícia, contendo apenas armadura ativa.

Lembra-se que a seção composta equivalente fictícia tem o seguinte significado: composta pela laje mais a capa; - equivalente, fazendo com que o concreto da capa fique igual ao da laje, de acordo com o item 6.1.2; - fictícia, uma vez que representa a seção real por uma seção tipo duplo T (itens 6.1 .3 e 6.1.4).

A Tabela 6.1 mostra as propriedades geométricas das seções compostas equivalentes fictícias, tomando como base as seções transversais dos modelos EM1, EM2 e EM3, apresentadas respectivamente nas Figuras 3.1, 3.3 e 3.5 (Capítulo 3), e de acordo com os itens 6.1.2, 6.1.3 e 6.1.4.

Os valores apresentados na Tabela 6.1 consideram às propriedades dos materiais encontrados nos ensaios de caracterização (Capítulo 4, Tabela 4.28).

Utilizando o item 6.1.5, obtêm-se as propriedades geométricas das seções (tipo 1, tipo 2 e tipo 3) nos Estádios I e II (Tabela 6.2), cuja nomenclatura segue as expressões 6.7 a 6.23 .

De acordo com o item 6.1.1, o momento de fissuração é calculado com a expressão 6.3. A Tabela 6.3 apresenta esses resultados, mantendo a nomenclatura dessa expressão.

Tabela 6.1 - Propriedades geométricas.

\begin{tabular}{|c|c|c|c|c|c|c|c|}
\hline \multirow{2}{*}{ Significado } & $\begin{array}{c}\text { Variá- } \\
\text { veis }\end{array}$ & $\begin{array}{c}\text { Seção } \\
\text { compos- } \\
\text { ta real }\end{array}$ & $\begin{array}{c}\text { Seção } \\
\text { composta } \\
\text { equiva- } \\
\text { lente } \\
\text { fictícia }\end{array}$ & $\begin{array}{c}\text { Seção } \\
\text { compos- } \\
\text { ta real }\end{array}$ & $\begin{array}{c}\text { Seção } \\
\text { composta } \\
\text { equiva- } \\
\text { lente } \\
\text { fictícia }\end{array}$ & $\begin{array}{c}\text { Seção } \\
\text { compos- } \\
\text { ta real }\end{array}$ & $\begin{array}{c}\text { Seção } \\
\text { composta } \\
\text { equiva- } \\
\text { lente } \\
\text { fictícia }\end{array}$ \\
\hline $\begin{array}{c}\text { Área da } \\
\text { armadura de } \\
\text { protensão }\end{array}$ & $\boldsymbol{A}_{\boldsymbol{p}}\left(\boldsymbol{( m m}^{2}\right)$ & 8,91 & 8,91 & 9,90 & 9,90 & 2,63 & 2,63 \\
\hline $\begin{array}{c}\text { Distância da } \\
\text { armadura de } \\
\text { protensão à } \\
\text { fibra } \\
\text { inferior }\end{array}$ & $\boldsymbol{d}^{\prime}(\boldsymbol{m})$ & 0,035 & 0,035 & 0,045 & 0,045 & 0,030 & 0,030 \\
\hline $\begin{array}{c}\text { Área da } \\
\text { seção de } \\
\text { concreto }\end{array}$ & $\boldsymbol{A}_{\boldsymbol{c}}\left(\boldsymbol{m}^{2}\right)$ & 0,3342 & 0,3065 & 0,2462 & 0,2734 & 0,1752 & 0,1790 \\
\hline $\begin{array}{c}\text { Momento de } \\
\text { inércia }\end{array}$ & $\boldsymbol{I}_{\left(\boldsymbol{m}^{4}\right)}$ & 0,0024 & 0,0023 & 0,0027 & 0,0030 & 0,0008 & 0,0008 \\
\hline
\end{tabular}


Tabela 6.2 - Propriedades geométricas das seções nos Estádios l e II.

\begin{tabular}{|c|c|c|c|c|c|c|c|c|c|}
\hline \multirow{2}{*}{ Variáveis } & \multicolumn{3}{|c|}{ EM1 } & \multicolumn{3}{c|}{ EM2 } & \multicolumn{3}{c|}{ EM3 } \\
\cline { 2 - 10 } & $\begin{array}{l}\text { Seção } \\
\text { tipo 1 }\end{array}$ & $\begin{array}{l}\text { Seção } \\
\text { tipo 2 }\end{array}$ & $\begin{array}{l}\text { Seção } \\
\text { tipo 3 }\end{array}$ & $\begin{array}{l}\text { Seção } \\
\text { tipo 1 }\end{array}$ & $\begin{array}{l}\text { Seção } \\
\text { tipo 2 }\end{array}$ & $\begin{array}{l}\text { Seção } \\
\text { tipo 3 }\end{array}$ & $\begin{array}{l}\text { Seção } \\
\text { tipo 1 }\end{array}$ & $\begin{array}{l}\text { Seção } \\
\text { tipo 2 }\end{array}$ & $\begin{array}{c}\text { Seção } \\
\text { tipo 3 }\end{array}$ \\
\hline $\boldsymbol{A}_{\boldsymbol{h}}\left(\mathbf{c m}^{\mathbf{2}}\right)$ & 5189 & 3163 & 3205 & 3970 & 2851 & 2805 & 2549 & 2002 & 1790 \\
\hline $\boldsymbol{x}_{\boldsymbol{I}}(\mathbf{c m})$ & 13,27 & 14,55 & 11,84 & 15,82 & 16,81 & 15,00 & 10,58 & 11,38 & 9,77 \\
\hline $\boldsymbol{I}_{\boldsymbol{h}}\left(\mathbf{c m}^{\mathbf{4}}\right)$ & 296856 & 262918 & 209987 & 327177 & 320484 & 314388 & 94024 & 89452 & 75992 \\
\hline $\boldsymbol{x}_{\boldsymbol{I I}}(\mathbf{c m})$ & 5,44 & 4,59 & 5,43 & 5,29 & 4,99 & 6,40 & 2,88 & 3,12 & 4,58 \\
\hline $\boldsymbol{I}_{\boldsymbol{I I}}\left(\mathbf{c m}^{\mathbf{4}}\right)$ & 52577 & 38056 & 20797 & 38554 & 50742 & 37964 & 7193 & 7291 & 5187 \\
\hline
\end{tabular}

Tabela 6.3- Cálculo do momento de fissuração.

\begin{tabular}{|c|c|c|c|c|c|c|c|c|c|}
\hline \multirow[b]{2}{*}{ Variáveis } & \multicolumn{3}{|c|}{ EM1 } & \multicolumn{3}{|c|}{ EM2 } & \multicolumn{3}{|c|}{ EM3 } \\
\hline & $\begin{array}{l}\text { Seção } \\
\text { tipo } 1\end{array}$ & $\begin{array}{l}\text { Seção } \\
\text { tipo } 2\end{array}$ & $\begin{array}{l}\text { Seção } \\
\text { tipo } 3\end{array}$ & $\begin{array}{l}\text { Seção } \\
\text { tipo } 1\end{array}$ & $\begin{array}{l}\text { Seção } \\
\text { tipo } 2\end{array}$ & $\begin{array}{l}\text { Seção } \\
\text { tipo } 3\end{array}$ & $\begin{array}{l}\text { Seção } \\
\text { tipo } 1\end{array}$ & $\begin{array}{l}\text { Seção } \\
\text { tipo } 2\end{array}$ & $\begin{array}{l}\text { Seção } \\
\text { tipo } 3\end{array}$ \\
\hline$\alpha$ & 1,5 & 1,5 & 1,5 & 1,5 & 1,5 & 1,5 & 1,5 & 1,5 & 1,5 \\
\hline$f_{c k}(M P a)$ & 28 & 54 & 54 & 55 & 38 & 38 & 44 & 55 & 55 \\
\hline$E_{c s}(M P a)$ & 25188 & 34979 & 34979 & 35301 & 29343 & 29343 & 31574 & 35301 & 35301 \\
\hline $\begin{array}{c}f_{c t}^{*} \\
\left(k N / c^{2}\right)\end{array}$ & - & 0,440 & 0,440 & - & 0,335 & 0,335 & - & 0,432 & 0,432 \\
\hline $\begin{array}{c}f_{c t} * * \\
\left(k N / \mathrm{cm}^{2}\right)\end{array}$ & - & - & - & - & - & - & 0,304 & - & - \\
\hline $\begin{array}{c}f_{c t} * * * \\
\left(\boldsymbol{k N} / \mathrm{cm}^{2}\right)\end{array}$ & 0,277 & - & - & 0,434 & - & - & - & - & - \\
\hline $\begin{array}{c}\sigma_{p i} \\
\left(k N / c m^{2}\right)\end{array}$ & 0 & 0 & 142,0 & 0 & 0 & 125,8 & 0 & 0 & $\begin{array}{c}133,0 / \\
13,75\end{array}$ \\
\hline $\begin{array}{c}\text { Perdas } \\
\text { Progressi- } \\
\text { vas }(\%)\end{array}$ & 0 & 0 & 21,91 & 0 & 0 & 21,41 & 0 & 0 & 11,54 \\
\hline $\begin{array}{c}\sigma_{p t} \\
\left(k N / c m^{2}\right)\end{array}$ & 0 & 0 & 110,9 & 0 & 0 & 98,8 & 0 & 0 & $\begin{array}{c}117,7 \text { / } \\
96,8\end{array}$ \\
\hline$N(k N)$ & 0 & 0 & 988,0 & 0 & 0 & 969,6 & 0 & 0 & $\begin{array}{c}309,4+ \\
48,7= \\
358,1 \\
* * * *\end{array}$ \\
\hline$M_{r}(k N . m)$ & 93,0 & $\begin{array}{c}93,0 \\
* * * * *\end{array}$ & 172,0 & 135,0 & $\begin{array}{l}135,0 \\
* * * * *\end{array}$ & 180,0 & 35,0 & $\begin{array}{c}35,0 \\
* * * * *\end{array}$ & 75,0 \\
\hline
\end{tabular}

(*) $f_{c t}=f_{c t m}$ retirado diretamente dos ensaios de caracterização das lajes alveolares (Cap. 4);

$\left.{ }^{(* *}\right) \mathrm{f}_{\mathrm{ct}}=\mathrm{f}_{\mathrm{ctk} \text {,inf, }}$, calculado com base no $\mathrm{f}_{\mathrm{ck}}$ do concreto da capa, sendo o $\mathrm{f}_{\mathrm{ck}}$ retirado dos ensaios de caracterização do concreto da capa. Além disso, $f_{c t k, \text { inf }}$ foi mais representativo que $f_{c t m}$ para este caso;

$\left({ }^{* *}\right) f_{c t}=f_{c t m}$, calculado com base no $f_{c k}$ do concreto da capa, sendo o $f_{c k}$ retirado dos ensaios de caracterização do concreto da capa. Além disso, $\mathrm{f}_{\mathrm{ctm}}$ foi mais representativo que $\mathrm{f}_{\mathrm{ctk} \text {, inf }}$ para estes casos;

$(* * * *)$ Soma das parcelas da protensão das fibras superiores e das inferiores (ver Figura 3.5 e Tabela 3.3);

$(* * * * *)$ Os valores de $\mathrm{M}_{\mathrm{r}}$ das seções tipo 2 foram mais representativos quando estes foram iguais aos da seção tipo 1, o que é coerente, uma vez que o momento negativo solicita a capa tanto nas seções tipo 1 quanto nas tipo 2 . 


\subsection{1 - EM1}

A análise do modelo 1 com elementos de barra combinados com a expressão de Branson (NLF - BRANSON) foi iniciada com $F_{2}=10,0 \mathrm{kN}$ e finalizada com $F_{2}=272,0 \mathrm{kN}$, que corresponde à força de ruptura encontrada no ensaio experimental de EM1.

Como o incremento do carregamento foi de $10,0 \mathrm{kN}$, a fissuração da capa pelo momento negativo ocorreu com $F_{2}=110,0 \mathrm{kN}$, enquanto que a fissuração da laje pelo momento positivo aconteceu com $\mathrm{F}_{2}=210,0 \mathrm{kN}$.

Foram feitas leituras de: força aplicada $\left(F_{2}[k N]\right)$, deslocamento no meio do vão ( $\delta$ [mm]), ou seja, no mesmo local onde os transdutores foram posicionados durante os ensaios de continuidade, e rotação no apoio $\left(\phi\left[^{\circ}\right]\right)$, onde foram posicionados os clinômetros. Através dessas leituras foi possível obter os gráficos $F_{2} \times \delta$ e também $F_{2} \times \phi$, que por sua vez foram sobrepostos aos gráficos com os resultados dos ensaios de continuidade (mostrados no Capítulo 5).

A Figura 6.8 apresenta os gráficos que relacionam a força aplicada no ensaio $\left(F_{2}\right)$ com deslocamentos medidos ( $\delta$ ). Tal figura está relacionada com a Figura 5.29 (Cap. 5).

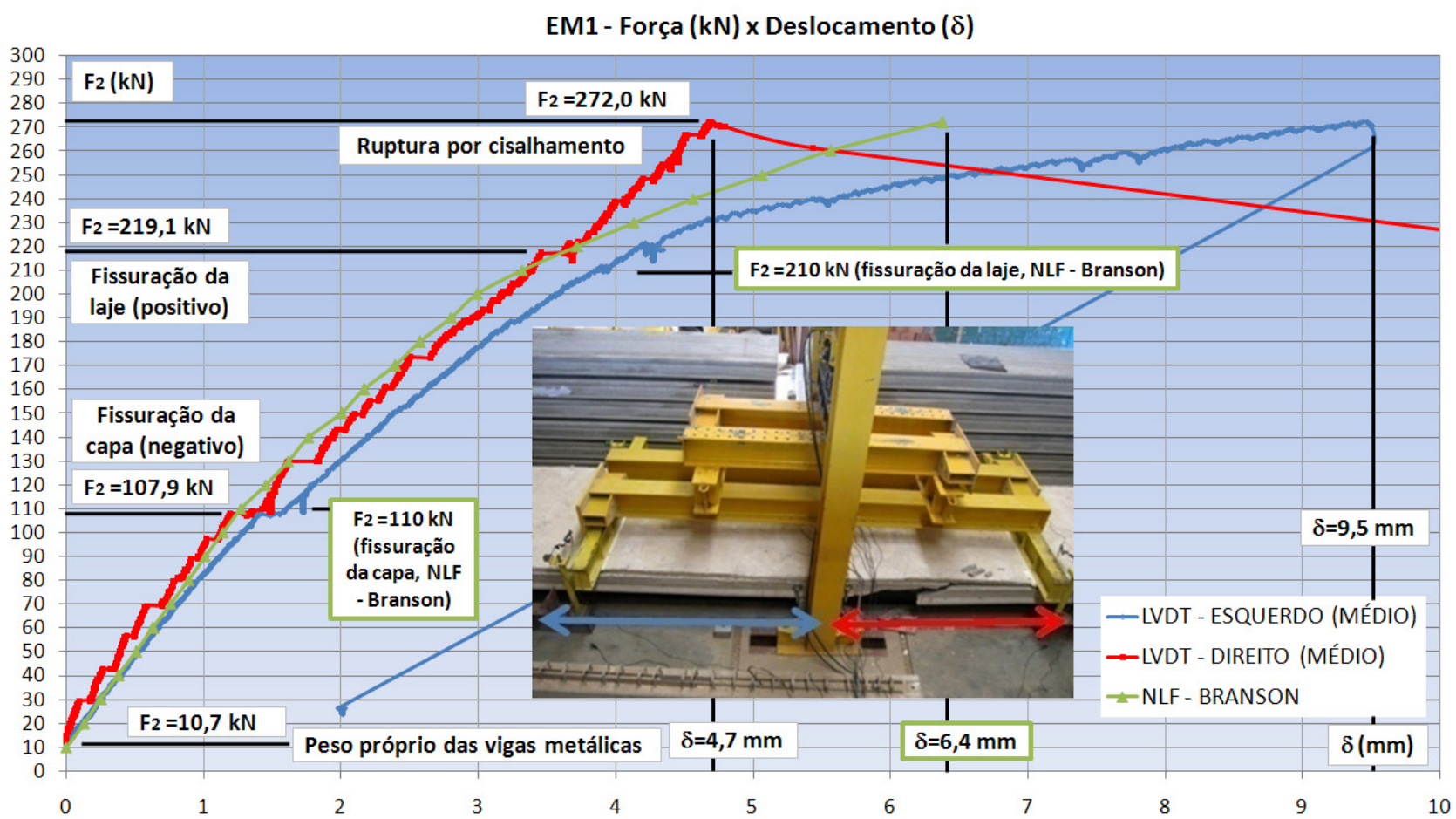

Figura 6.8 - Diagramas Força x Deslocamento dos valores encontrados na análise com elementos de barras combinados com a expressão de Branson para o modelo 1.

De acordo com a Figura 6.8, é possível observar que a curva NLF - BRANSON (traçada a partir dos resultados dos elementos de barra) representou de forma satisfatória o comportamento encontrado no ensaio de EM1. Os resultados da fissuração da capa e da 
laje, respectivamente $F_{2}=110,0 \mathrm{kN}$ e $F_{2}=210,0 \mathrm{kN}$, foram próximos dos encontrados no ensaio $\left(F_{2}=107,9 \mathrm{kN}\right.$ e $\left.F_{2}=219,1 \mathrm{kN}\right)$. Além disso, o deslocamento para $F_{2}=272,0 \mathrm{kN}$, ou seja, $\delta=6,4 \mathrm{~mm}$, é um valor intermediário entre os valores da laje da direita $(\delta=4,7 \mathrm{~mm})$ e da esquerda $(\delta=9,5 \mathrm{~mm})$.

Assim como os gráficos da laje da esquerda e da direita, a curva NLF - BRANSON apresentou um comportamento que pode ser aproximado por três retas. Nos dois primeiros trechos de retas o comportamento da curva NLF - BRANSON se assemelha aos das lajes. Entretanto, no último trecho de reta, a curva NLF - BRANSON apresenta um comportamento intermediário com relação às duas lajes (da esquerda e da direita). Isso ressalta o fato de que a laje que apresentou a ruptura por cisalhamento ficou mais rígida a partir da fissuração das lajes pelo momento positivo.

A Figura 6.9 mostra os gráficos que relacionam a força $F_{2}$ com a rotação no apoio (ф). Essa figura está relacionada com a Figura 5.31 do Capítulo. 5.

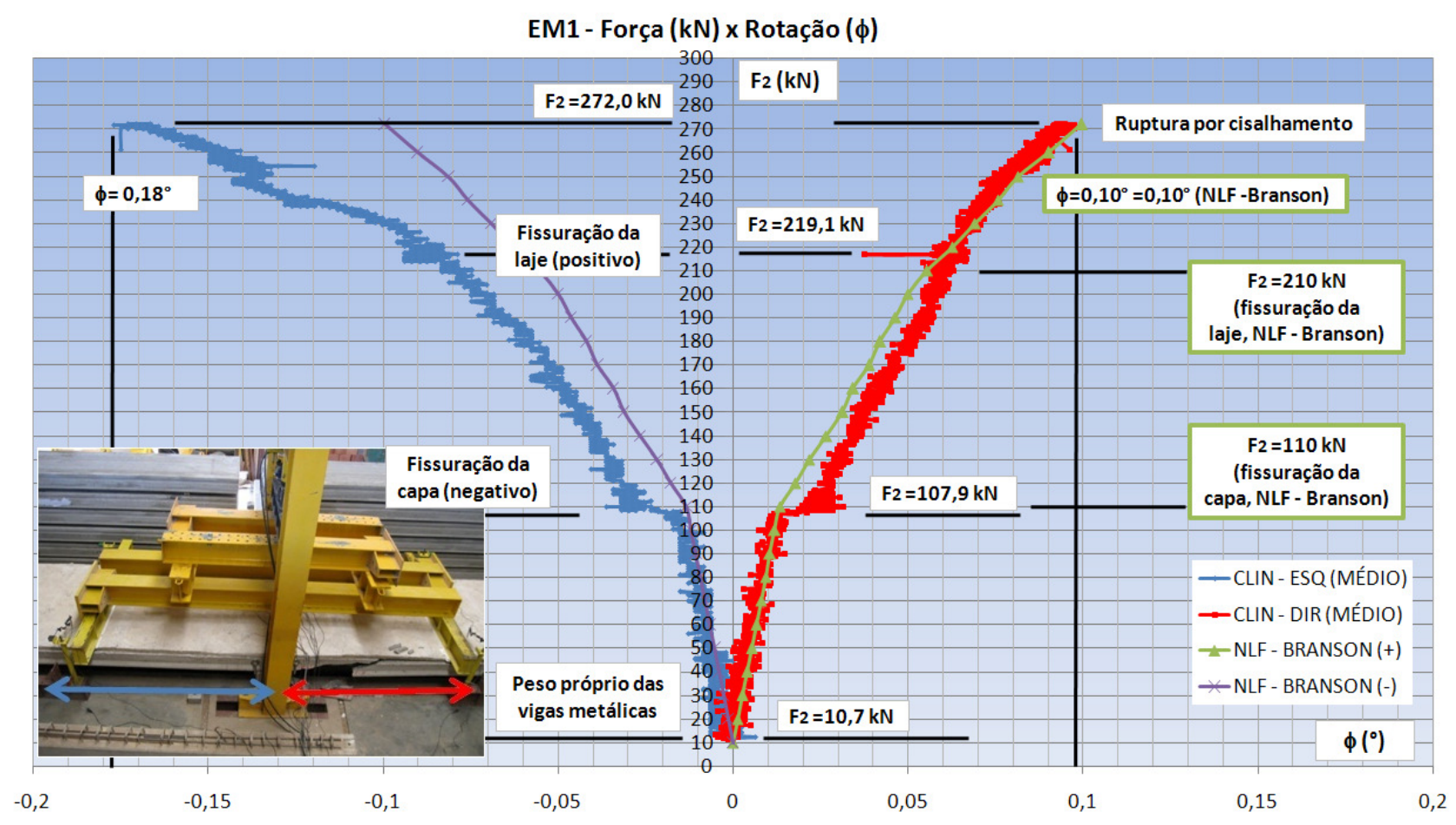

Figura 6.9 - Diagramas Força x Rotação dos valores encontrados na análise com elementos de barras combinados com a expressão de Branson para o modelo 1.

Observando a Figura 6.9 é possível notar que a curva NLF - BRANSON representou de forma satisfatória o comportamento da laje da direita, tendo uma rotação final igual $\left(\phi=0,1^{\circ}\right)$, e teve um comportamento mais rígido que a laje da esquerda, principalmente a partir da fissuração da capa pelo momento negativo. 
A Figura 6.10 apresenta as curvas que relacionam o Momento (M) da análise com elementos de barra e as rotações no apoio $(\phi)$, encontradas nos ensaios e também na análise com elementos de barra (NLF - BRANSON).

\section{Momento x Rotação no apoio - EM1}

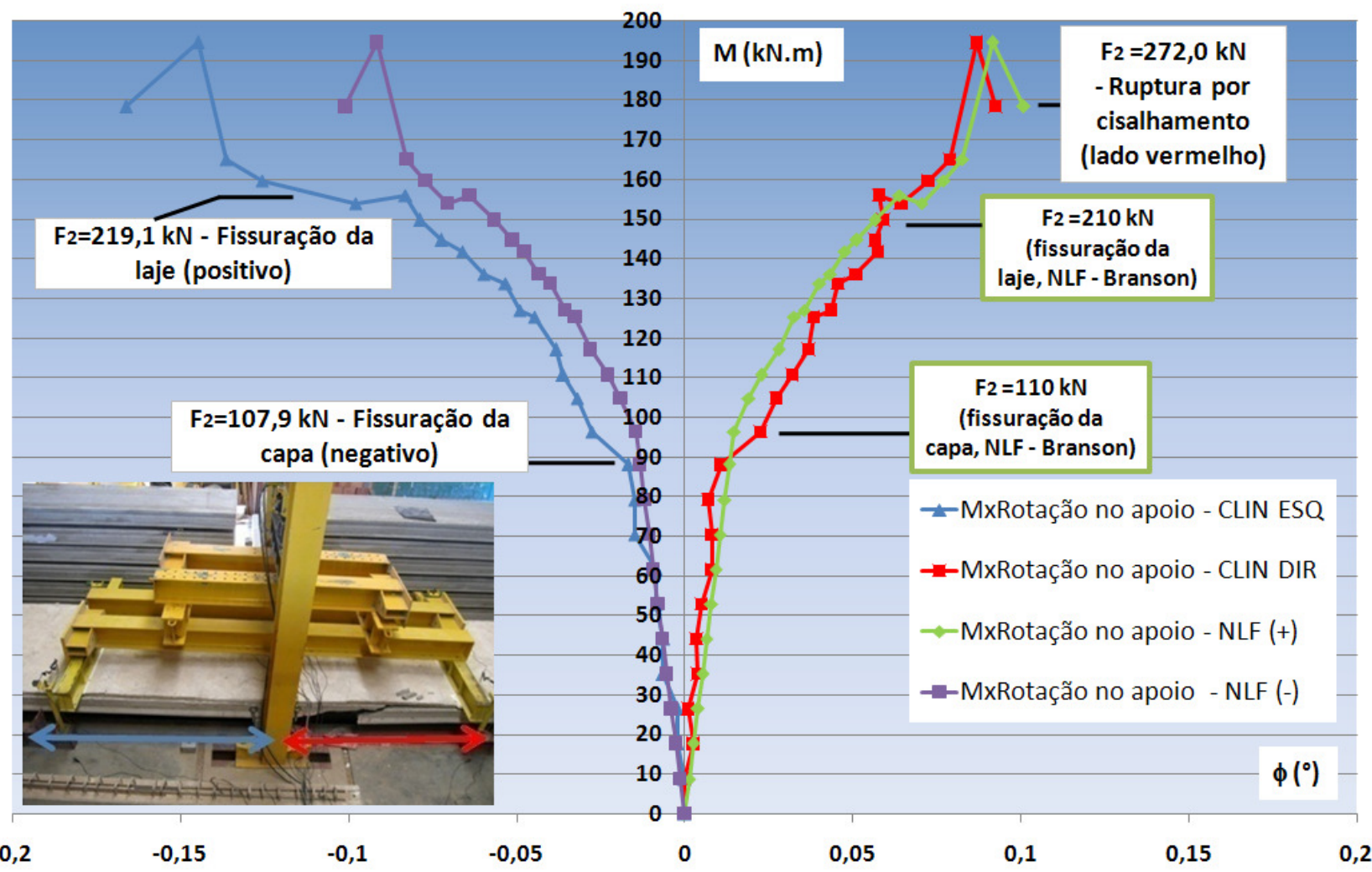

Figura 6.10 - Diagramas Momento x Rotação dos valores encontrados na análise com elementos de barras combinados com a expressão de Branson para o modelo 1.

A Figura 6.10 mostra novamente que a curva NLF - BRANSON representou de forma satisfatória o comportamento do modelo 1. Além disso, essa figura ressalta o fato de que a ligação laje-viga-laje teve um comportamento rígido, principalmente no primeiro trecho, ou seja, até a fissuração da capa pelo momento negativo.

De acordo com os valores dos esforços solicitantes (momento fletor e força cortante) encontrados na análise pelos elementos de barra e a expressão de Branson, foi possível obter a relação Momento Fletor pela Força Cortante em cada seção do modelo. A Figura 6.11 apresenta essa relação para valores de $F_{2}=40$ kN, 80,0 kN, 110,0 kN, 210,0 kN e 272,0 kN. Foram escolhidos apenas alguns valores de $F_{2}$ para não poluir muito o gráfico, e ao mesmo tempo representar de forma satisfatória o comportamento do modelo.

Analisando a Figura 6.11 é possível notar que, na região de momento positivo próximo à aplicação da força $F_{2}$, a relação Momento/Cortante é alta e diminui de acordo com a fissuração do modelo, se estabilizando em um valor de 3,0. Além disso, essa relação é baixa nas seções onde ocorreu a ruptura por cisalhamento (elementos 14 e 15 da Figura 6.7 (b)), ficando próxima de 0,5. 


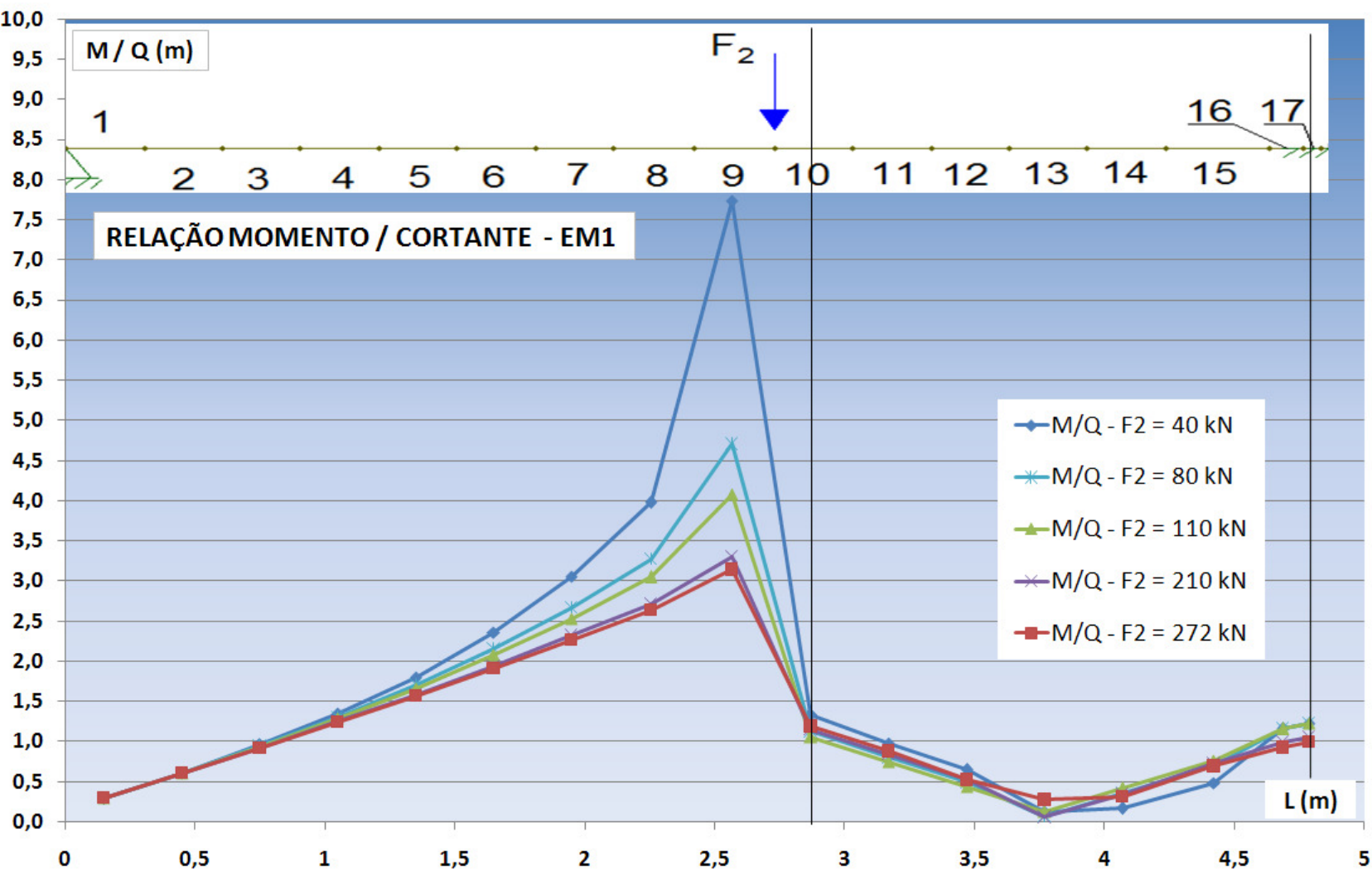

Figura 6.11 - Relação Momento Fletor / Força Cortante dos valores encontrados na análise com elementos de barras combinados com a expressão de Branson para o modelo 1.

Para a força aplicada $F_{2}=272,0 \mathrm{kN}$, a máxima força cortante encontrada foi de $212,7 \mathrm{kN}$. Esse valor corresponde à força cortante de ruptura do modelo teórico, ocorrendo no elemento 15 (ver Figura 6.7 letra b). A seguir a Figura 6.12 relaciona os valores das forças cortantes solicitantes com o valor de $212,7 \mathrm{kN}$.

Analisando essa figura notam-se dois trechos distintos. O primeiro entre o apoio extremo e o local de aplicação de $F_{2}$, e o segundo entre $F_{2}$ e o apoio intermediário. No primeiro trecho a relação se estabiliza próximo de 0,5 , enquanto que o segundo trecho se estabiliza com o valor de 1,0 no elemento 15.

No Capítulo 3, Tabela 3.29, foram apresentados os momentos fletores resistentes das lajes alveolares (positivos e negativos). Para o modelo 1 tem-se os seguintes valores: momento resistente positivo $327,44 \mathrm{kN}$ e momento resistente negativo $219,71 \mathrm{kN}$.

A Figura 6.13 relaciona os valores dos momentos fletores encontrados na análise com elementos de barra e os momentos resistentes. O máximo valor encontrado para essa relação foi de 0,8 para o momento positivo (elementos 9 e 10) e também 0,8 para momento negativo (elemento 15).

As curvas das Figuras 6.12 e 6.13 estão coerentes com o que ocorreu no ensaio de continuidade do modelo 1 , uma vez que a ruptura se deu por cisalhamento. 0 máximo valor encontrado para a relação de força cortante foi de 1,0 , no elemento que sofreu ruptura. 


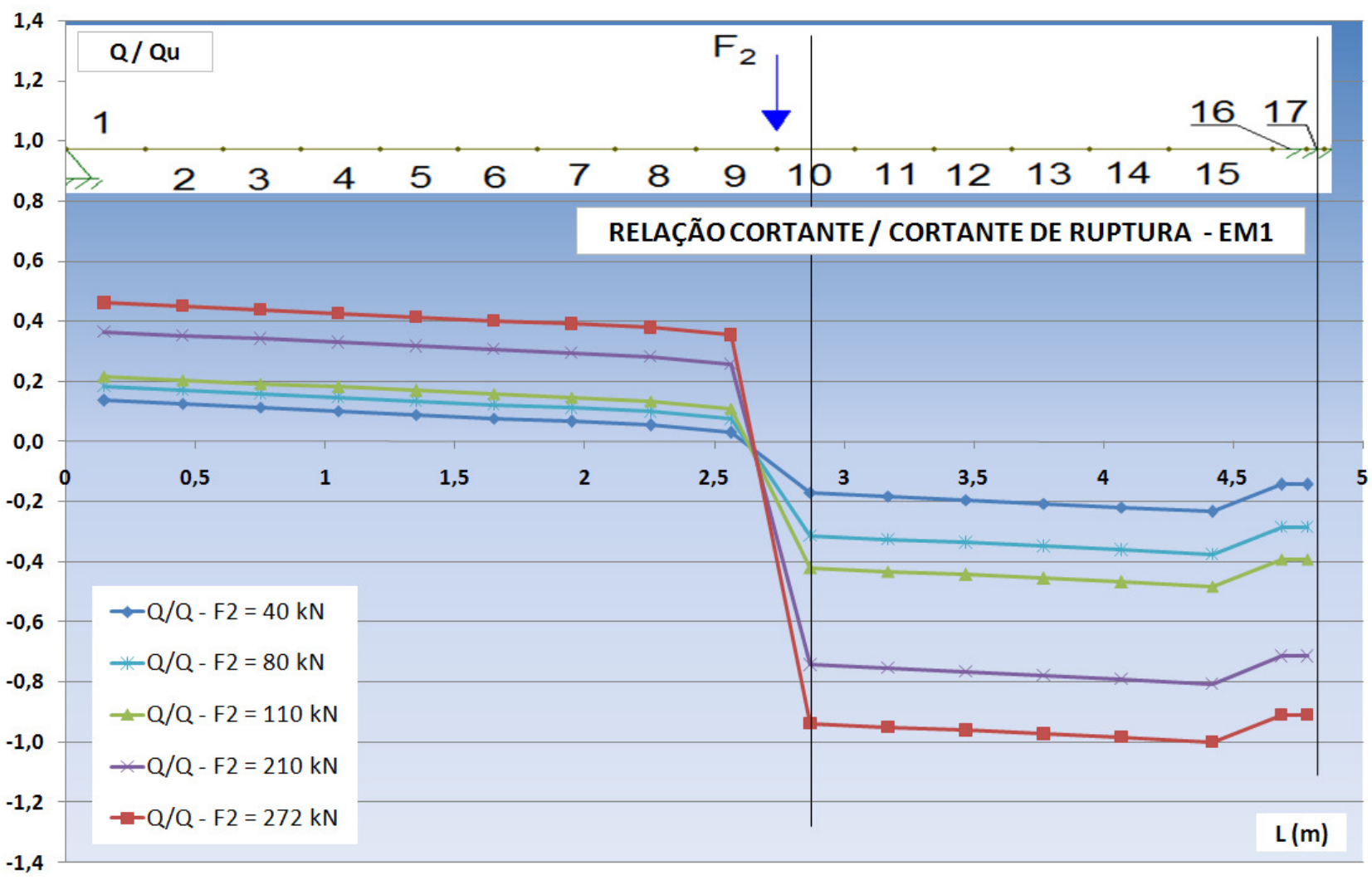

Figura 6.12 - Relação Força Cortante x Força Cortante de Ruptura dos valores encontrados na análise com elementos de barras combinados com a expressão de Branson para o modelo 1.

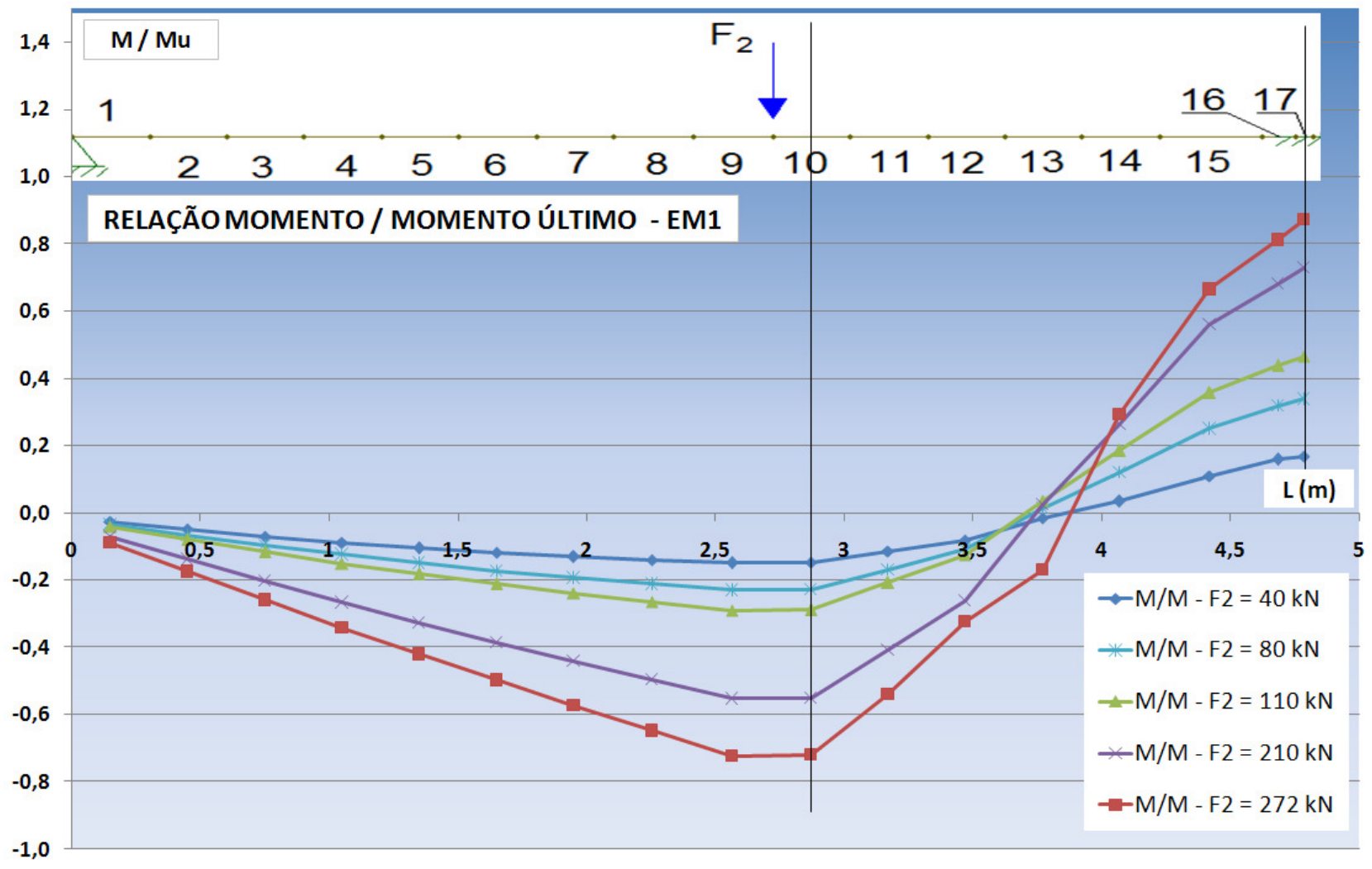

Figura 6.13 - Relação Momento Fletor x Momento Fletor de Ruptura dos valores encontrados na análise com elementos de barras combinados com a expressão de Branson para o modelo 1. 
Já a máxima relação de momento fletor $(0,8)$ é menor que 1,0 , indicando que o modelo ensaiado estava com solicitações de flexão abaixo da resistência, no momento da ruptura por cisalhamento.

\subsection{2 - EM2}

A análise do modelo 2 com elementos de barra combinados com a expressão de Branson (NLF - BRANSON) foi iniciada com $F_{2}=10,0 \mathrm{kN}$ e finalizada com $F_{2}=297,3 \mathrm{kN}$, que corresponde à máxima força aplicada no ensaio experimental de EM2.

Como o incremento do carregamento foi de $10,0 \mathrm{kN}$, a fissuração da capa pelo momento negativo ocorreu com $F_{2}=150,0 \mathrm{kN}$, enquanto que a fissuração da laje pelo momento positivo aconteceu com $\mathrm{F}_{2}=230,0 \mathrm{kN}$.

Da mesma forma que para EM1, foram feitas leituras de força aplicada $\left(F_{2}[k N]\right)$, deslocamento no meio do vão ( $\delta[\mathrm{mm}])$ e rotação no apoio $\left(\phi\left[^{\circ}\right]\right)$.

Através dessas leituras foi possível obter os gráficos $F_{2} \times \delta$ e também $F_{2} \times \phi$, que por sua vez foram sobrepostos aos gráficos com os resultados dos ensaios de continuidade (mostrados no Capítulo 5).

A Figura 6.14 apresenta os gráficos que relacionam a força aplicada no ensaio $\left(F_{2}\right)$ com deslocamentos medidos $(\delta)$. Tal figura está relacionada com a Figura 5.45 (Cap. 5).

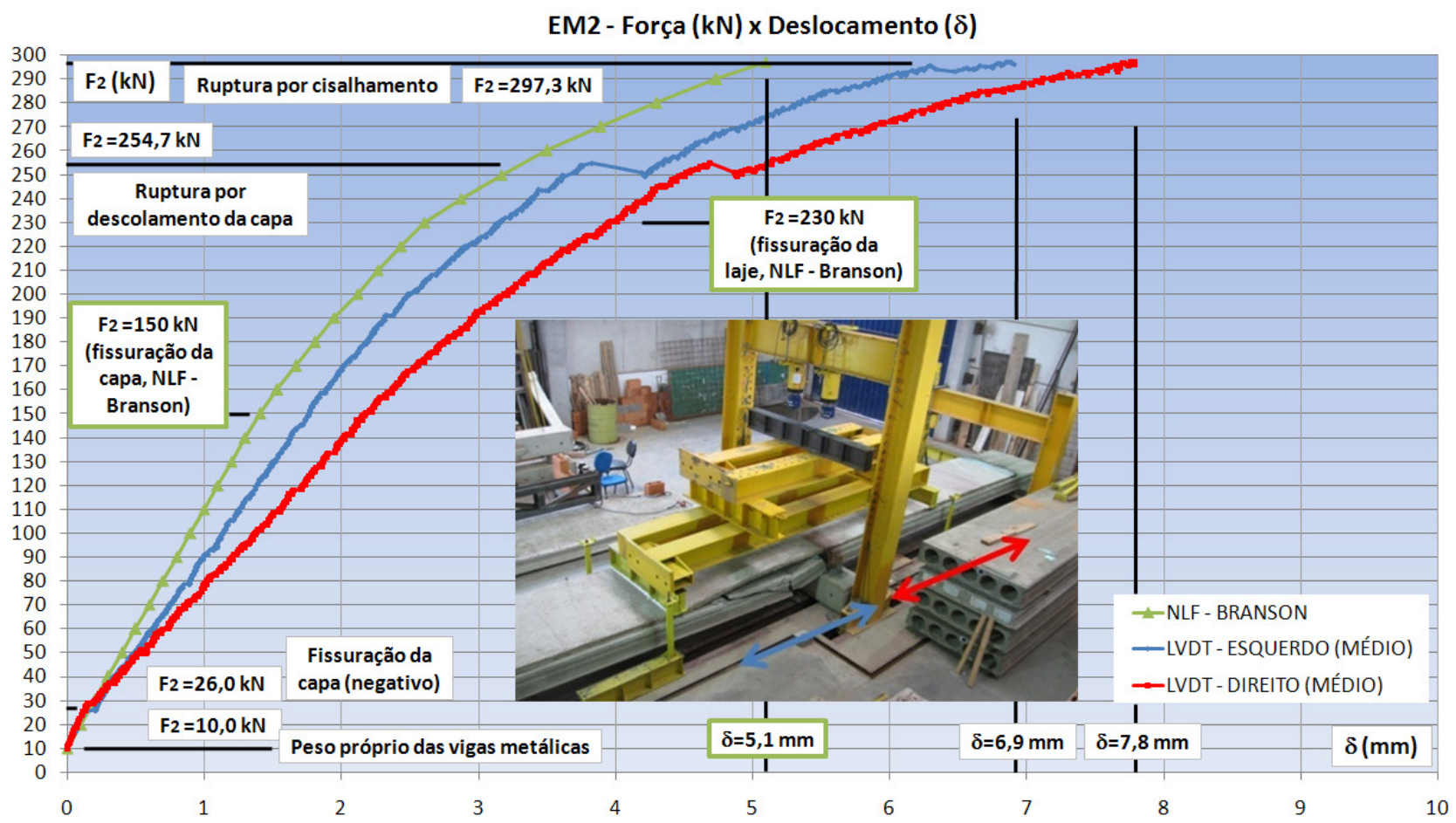

Figura 6.14 - Diagramas Força x Deslocamento dos valores encontrados na análise com elementos de barras combinados com a expressão de Branson para o modelo 2. 
De acordo com a Figura 6.14 é possível observar que a curva NLF - BRANSON representou de forma satisfatória o comportamento encontrado no ensaio de EM2. Entretanto essa curva apresentou um comportamento mais rígido do que as curvas das lajes alveolares (esquerda e direita). No início do último trecho das curvas que representam o ensaio experimental, ou seja, acima da fissuração da laje, ocorreu a ruptura do modelo pelo descolamento da capa com a laje. Isso fez com que a curva teórica com modelo de barras ficasse ainda mais rígida, pois esse modelo teórico não considera o descolamento da capa com a laje.

$O$ resultado da fissuração da capa, $F_{2}=150,0 \mathrm{kN}$, ficou distante do encontrado no ensaio $\left(F_{2}=26,0 \mathrm{kN}\right)$. Além disso, o modelo teórico de barras apresentou fissuração da laje com $F_{2}=230,0 \mathrm{kN}$, enquanto que no ensaio a laje não apresentou fissuração.

A Figura 6.15 mostra os gráficos que relacionam a força $F_{2}$ com a rotação no apoio $(\phi)$. Essa figura está relacionada com a Figura 5.47 do Capítulo 5.

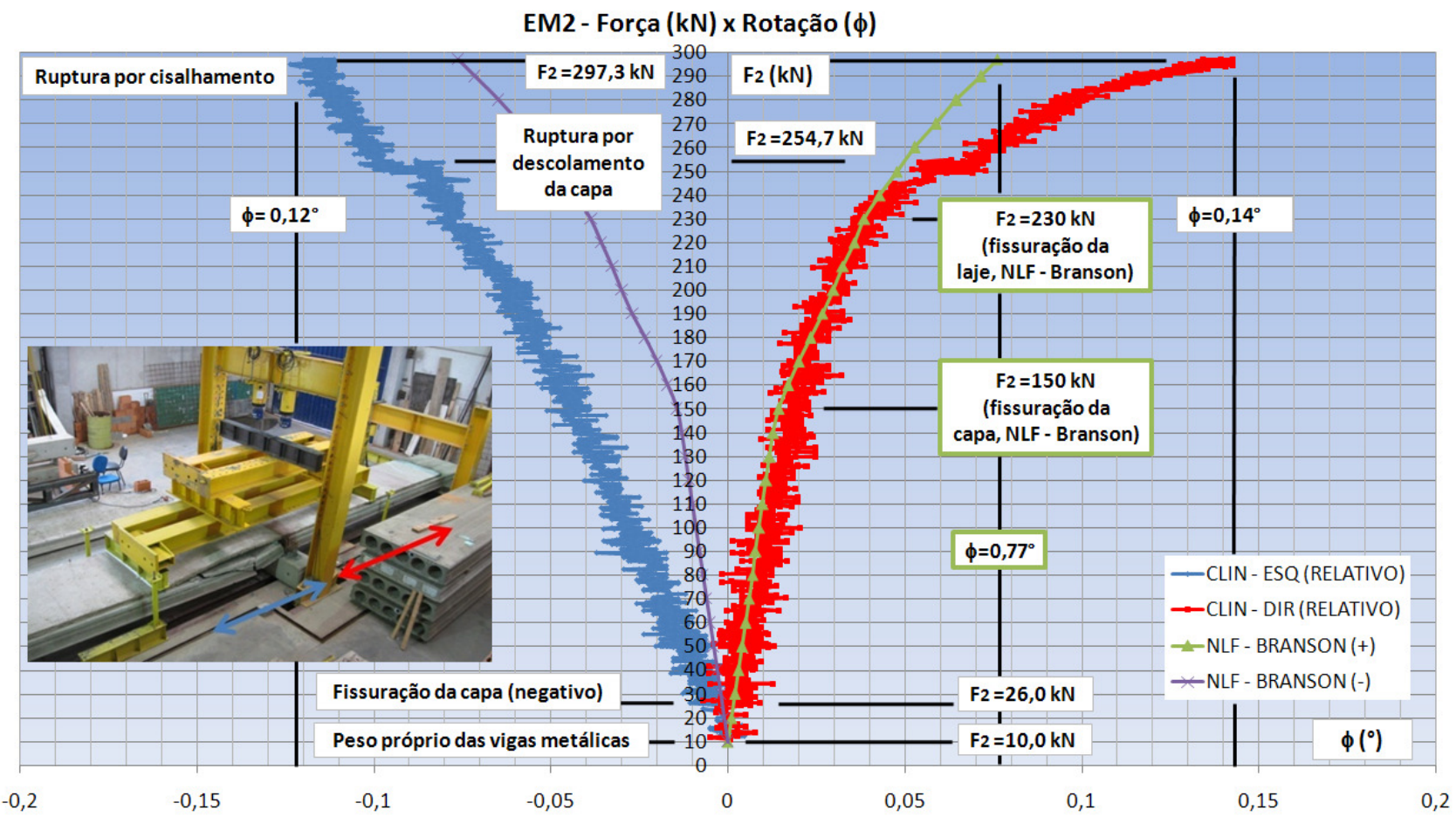

Figura 6.15 - Diagramas Força x Rotação dos valores encontrados na análise com elementos de barras combinados com a expressão de Branson para o modelo 2.

Observando a Figura 6.15 é possível notar que a curva NLF - BRANSON representou de forma satisfatória o comportamento da laje da direita, e teve um comportamento mais rígido que a laje da esquerda. Esse último fato indica que a laje da esquerda pode ter sofrido uma fissuração prematura, e com isso se deslocado mais que a laje da direita. 
Esse fato parece ser contraditório, uma vez que na Figura 5.45 (e 6.14) os deslocamentos da direita são maiores que os da esquerda. No entanto o que ocorreu foi que, como mostra a Figura 5.46, o apoio girou no sentido horário, com relação ao lado de referência, aumentando os deslocamentos da laje da direita e diminuindo os deslocamentos da laje da esquerda.

A Figura 6.16 apresenta as curvas que relacionam o Momento (M) da análise com elementos de barra e as rotações no apoio $(\phi)$, encontradas nos ensaios e também na análise com elementos de barra (NLF - BRANSON).

Novamente existe a indicação de que a curva NLF - BRANSON representou de forma satisfatória o comportamento do modelo 2, sobretudo no lado direito do modelo. Além disso, essa figura ressalta o fato que a ligação laje-viga-laje teve um comportamento rígido, principalmente porque as diferenças entre as curvas da laje da esquerda e da curva teórica (NLF - BRANSON) ficaram distantes, uma vez que ocorreu uma fissuração prematura da laje esquerda na região de momento negativo.

De acordo com os valores dos esforços solicitantes (momento fletor e força cortante) encontrados na análise teórica, foi possível obter a relação Momento Fletor pela Força Cortante em cada seção do modelo. A Figura 6.17 apresenta essa relação para valores de $F_{2}=40 \mathrm{kN}, 80,0 \mathrm{kN}, 150,0 \mathrm{kN}, 230,0 \mathrm{kN}$ e $297,3 \mathrm{kN}$.

\section{Momento x Rotação no apoio - EM2}

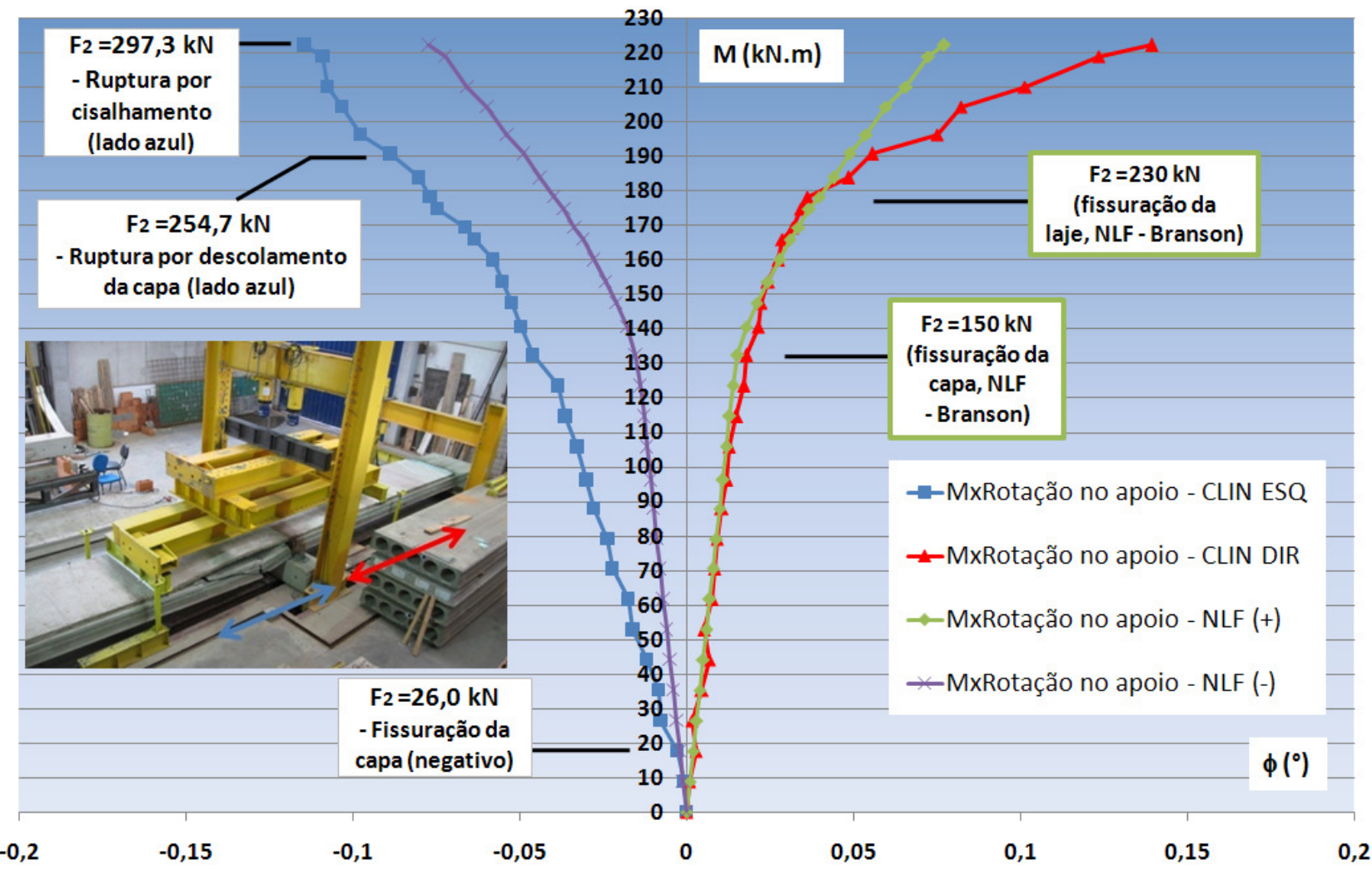

Figura 6.16 - Diagramas Momento x Rotação dos valores encontrados na análise com elementos de barras combinados com a expressão de Branson para o modelo 2. 


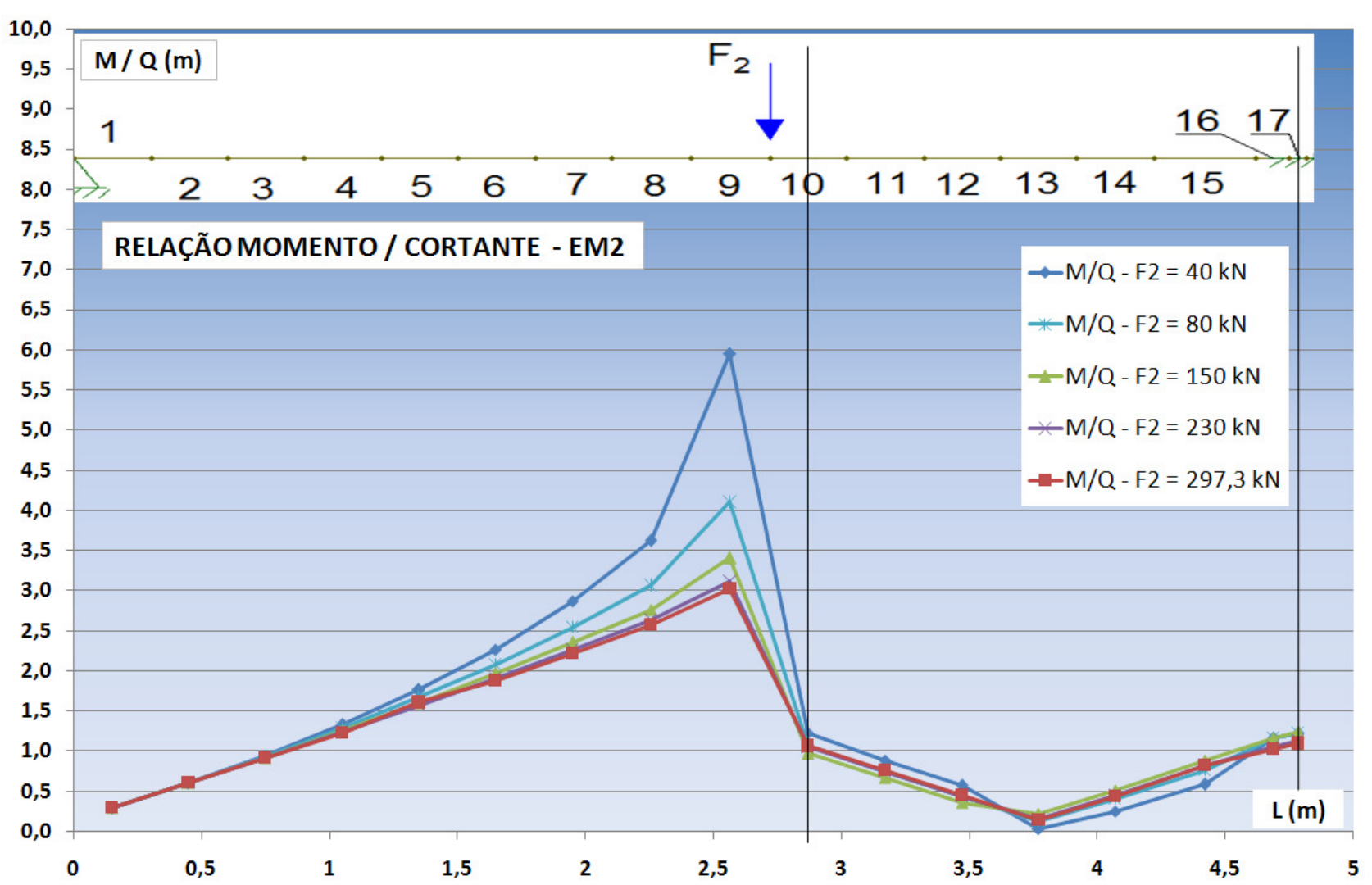

Figura 6.17 - Relação Momento Fletor / Força Cortante dos valores encontrados na análise com elementos de barras combinados com a expressão de Branson para o modelo 2.

Analisando a Figura 6.17 é possível notar que, na região de momento positivo próxima à aplicação da força $F_{2}$, a relação Momento/Cortante é alta e diminui de acordo com a fissuração do modelo, se estabilizando em um valor de 3,0. Além disso, a relação Momento/Cortante é baixa nas seções onde ocorreu a ruptura por cisalhamento (elementos 14 e 15 da Figura 6.7 (b)), ficando próxima de 1,0.

Para a força aplicada $F_{2}=297,3 \mathrm{kN}$, a máxima força cortante encontrada foi de $231,3 \mathrm{kN}$, valor corresponde à máxima força cortante teórica encontrada no modelo 2 , no elemento 15 (ver Figura 6.7, letra b).

A Figura 6.18 relaciona os valores das forças cortantes solicitantes com o valor de 231,3 kN. No entanto, vale ressaltar que para $F_{2}=254,7$ o modelo 2 sofreu ruptura pelo desprendimento da capa, passando a trabalhar como seção simples nos locais onde ocorreu essa ruptura (equivalente aos elementos 10, 11, 12, 13, 14 e 15 da Figura 6.7, letra b).

Analisando essa figura notam-se dois trechos distintos. O primeiro entre o apoio extremo e o local de aplicação de $F_{2}$, e o segundo entre $F_{2}$ e o apoio intermediário. No primeiro trecho a relação se estabiliza próximo de 0,4 , enquanto que o segundo trecho se estabiliza com o valor de 1,0 no elemento 15. 


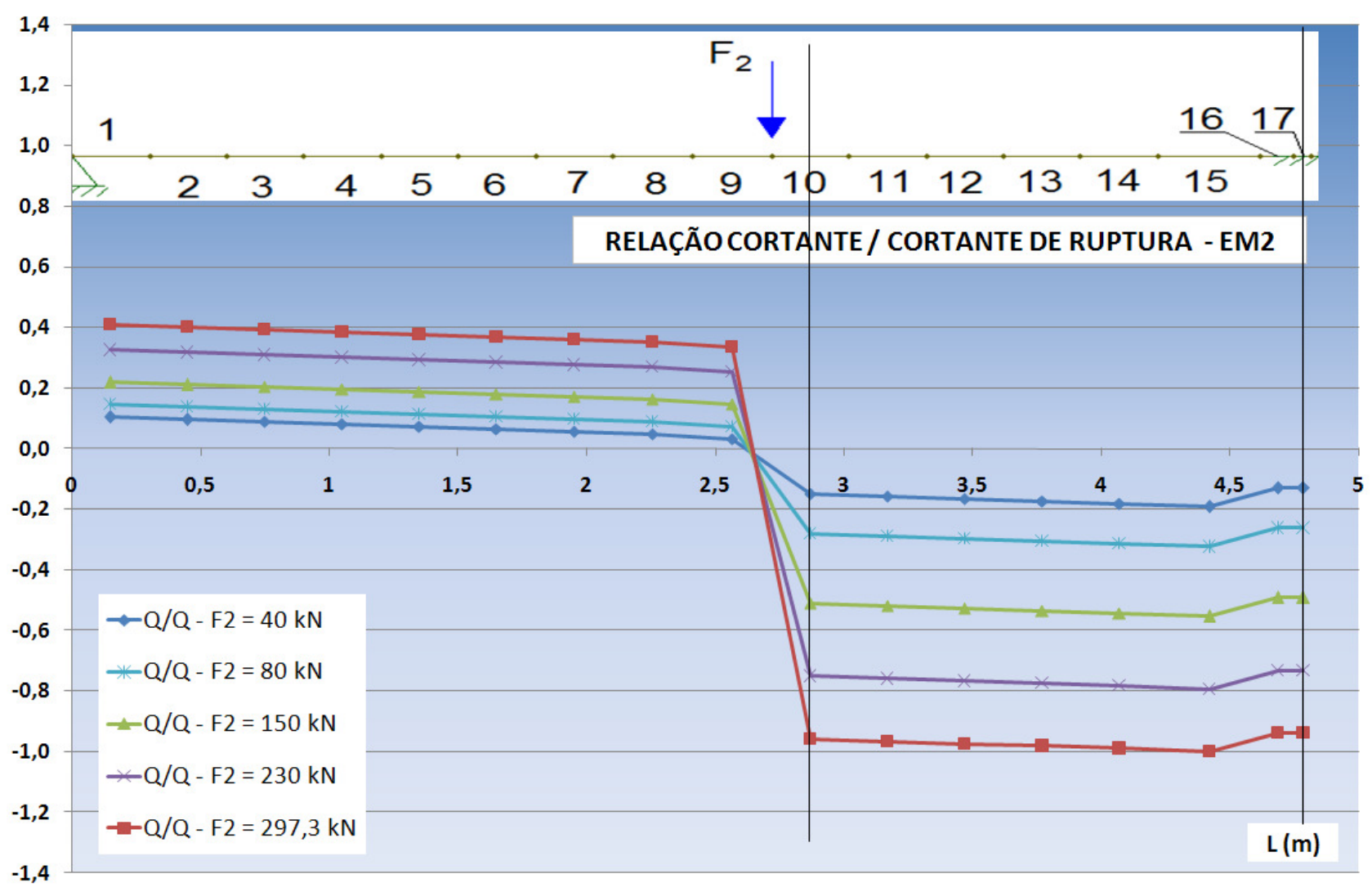

Figura 6.18 - Relação Força Cortante x Força Cortante de Ruptura dos valores encontrados na análise com elementos de barras combinados com a expressão de Branson para o modelo 2.

No Capítulo 3, Tabela 3.29, foram apresentados os momentos fletores resistentes das lajes alveolares (positivo e negativo). Para o modelo 2 tem-se os seguintes valores: momento resistente positivo 445,55 kN e momento resistente negativo 156,20 kN.

A Figura 6.19 relaciona os valores dos momentos fletores encontrados na análise com elementos de barra e os momentos resistentes. O máximo valor encontrado para essa relação foi de 0,6 para o momento positivo (elementos 9 e 10) e 1,5 para momento negativo (elemento 15).

As curvas das Figuras 6.17 e 6.18 estão coerentes com o que ocorreu no ensaio de continuidade do modelo 2 , uma vez que a ruptura não ocorreu por flexão e sim por destacamento da capa, acompanhada pela ruptura por cisalhamento.

Novamente é preciso lembrar que para $F_{2}=254,7$ o modelo 2 sofreu ruptura pelo desprendimento da capa, passando a trabalhar como seção simples nos locais onde ocorreu essa ruptura (equivalente aos elementos 10,11, 12, 13, 14 e 15 da Figura 6.7, letra b). 


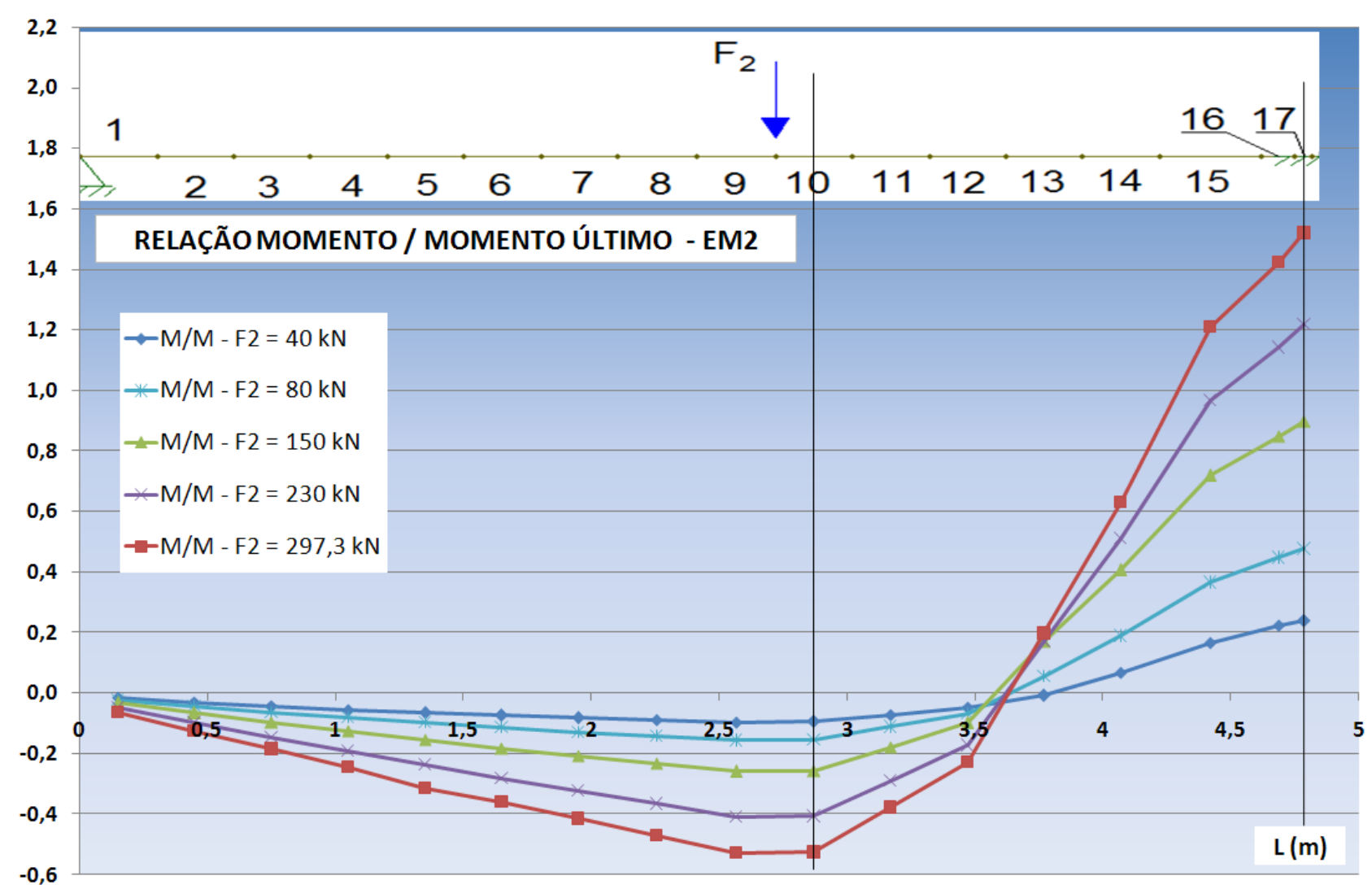

Figura 6.19 - Relação Momento Fletor x Momento Fletor de Ruptura dos valores encontrados na análise com elementos de barras combinados com a expressão de Branson para o modelo 2.

\subsection{3- EM3}

A análise do modelo 3 com elementos de barra combinados com a expressão de Branson (NLF - BRANSON) foi iniciada com $F_{2}=10,0 \mathrm{kN}$ e finalizada com $F_{2}=146,8 \mathrm{kN}$, que corresponde à força de ruptura encontrada no ensaio experimental de EM3.

Como o incremento do carregamento foi de $10,0 \mathrm{kN}$, a fissuração da capa pelo momento negativo ocorreu com $F_{2}=40,0 \mathrm{kN}$, enquanto que a fissuração da laje pelo momento positivo aconteceu com $\mathrm{F}_{2}=80,0 \mathrm{kN}$.

Da mesma forma que para EM1 e EM2, foram feitas leituras de força aplicada $\left(F_{2}[k N]\right)$, deslocamento no meio do vão $(\delta[\mathrm{mm}])$ e rotação no apoio $\left(\phi\left[^{\circ}\right]\right)$.

Através dessas leituras foi possível obter os gráficos $F_{2} \times \delta$ e também $F_{2} \times \phi$, que por sua vez foram sobrepostos aos gráficos com os resultados dos ensaios de continuidade (mostrados no Capítulo 5).

A Figura 6.20 apresenta os gráficos que relacionam a força aplicada no ensaio $\left(F_{2}\right)$ com deslocamentos medidos $(\delta)$. Tal figura está relacionada com a Figura 5.58 (Cap. 5). 


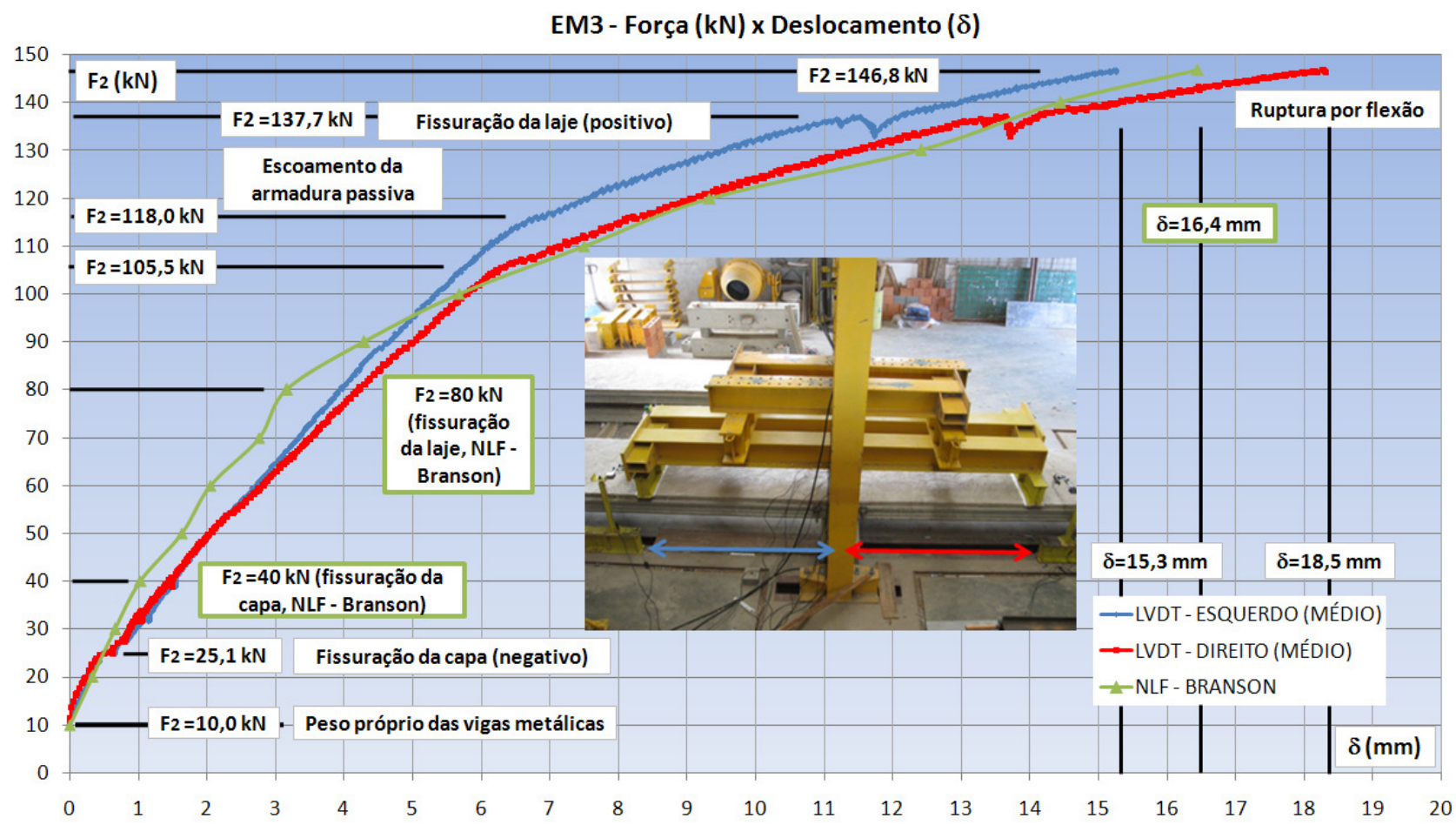

Figura 6.20 - Diagramas Força x Deslocamento dos valores encontrados na análise com elementos de barras combinados com a expressão de Branson para o modelo 3.

De acordo com a Figura 6.20 é possível observar que a curva NLF - BRANSON (traçada a partir dos resultados dos elementos de barra) representou de forma satisfatória o comportamento encontrado no ensaio de EM3.

$O$ resultado da fissuração da capa $F_{2}=40,0 \mathrm{kN}$ ficou próximo do encontrado no ensaio $\left(F_{2}=25,1 \mathrm{kN}\right)$. Já para a fissuração da laje, o valor teórico de $F_{2}=80,0 \mathrm{kN}$, ficou distante do relativo ao ensaio, $F_{2}=137,7 \mathrm{kN}$. Essa diferença pode ter sido causada pelo escoamento da armadura de continuidade ocorrido após a fissuração da capa e antes da fissuração da laje, no ensaio do modelo 3.

Com relação ao deslocamento, o resultado da curva teórica foi de $\delta=16,4 \mathrm{~mm}$, valor próximo e intermediário aos encontrados no ensaio ( $\delta=15,3 \mathrm{~mm}$ para a laje da esquerda e $\delta=18,5 \mathrm{~mm}$ para a laje da direita).

A Figura 6.21 mostra os gráficos que relacionam a força $F_{2}$ com a rotação no apoio $(\phi)$. Essa figura está relacionada com a Figura 5.60 do Capítulo 5.

Observando a Figura 6.21 é possível notar que a curva NLF - BRANSON representou de forma satisfatória o comportamento do modelo 3, tendo resultado melhor quando se considera a laje da esquerda, entretanto com comportamento mais rígido que o dessa laje. De uma forma geral, a laje da direita teve um comportamento mais rígido que a curva teórica. Destaca-se na curva da laje da direita um trecho de recuperação de rigidez para valores de $F_{2}$ entre $50,0 \mathrm{kN}$ e $80,0 \mathrm{kN}$. 


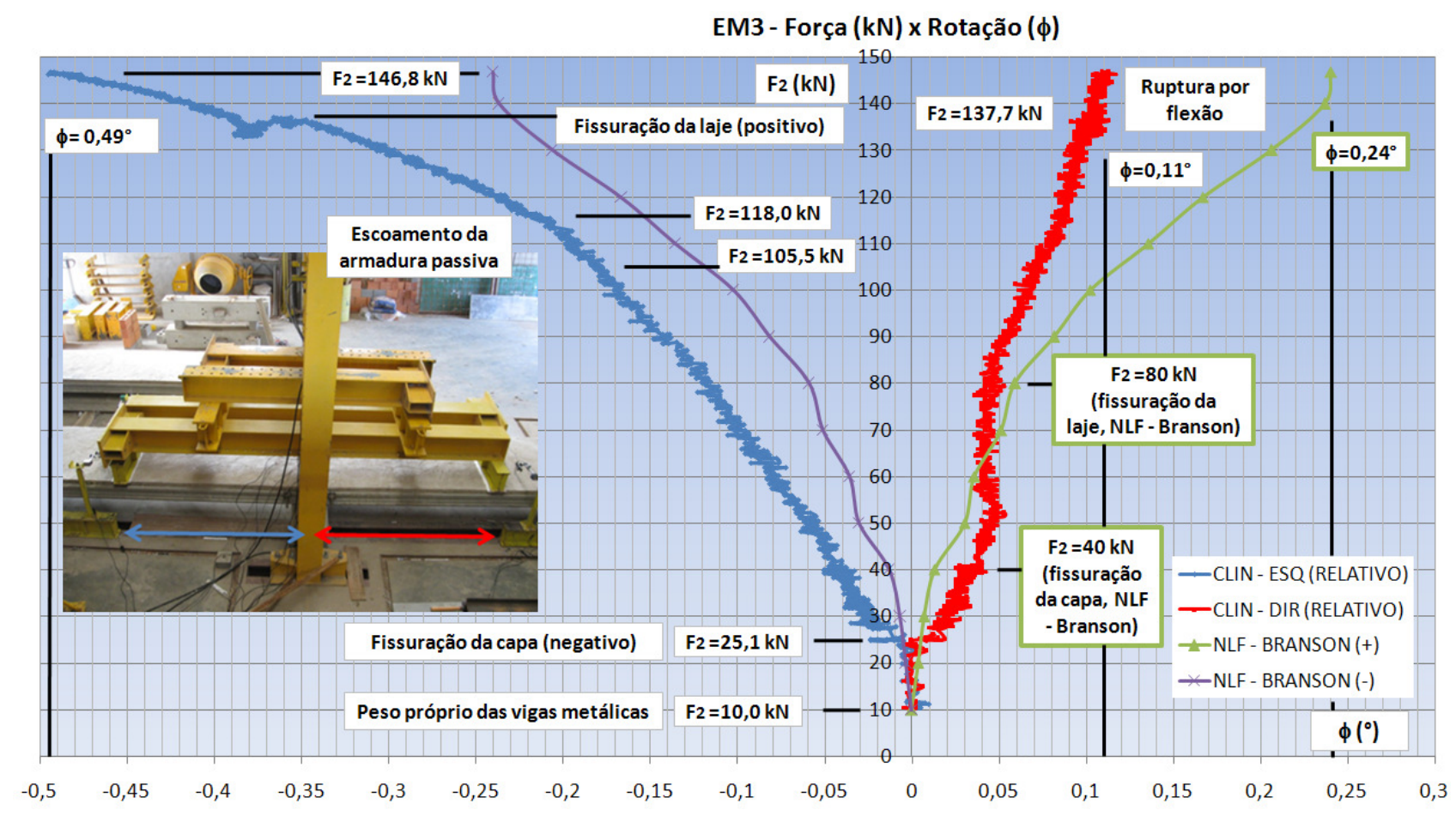

Figura 6.21 - Diagramas Força x Rotação dos valores encontrados na análise com elementos de barras combinados com a expressão de Branson para o modelo 3.

A Figura 6.22 apresenta as curvas que relacionam o Momento $(M)$ da análise com elementos de barra e as rotações no apoio $(\phi)$, encontradas nos ensaios e também na análise com elementos de barra (NLF - BRANSON).

Novamente existe a indicação de que a curva NLF - BRANSON representou de forma satisfatória o comportamento do modelo 3 . Além disso, essa figura ressalta o fato de que a ligação laje-viga-laje teve um comportamento rígido.

De acordo com os valores dos esforços solicitantes (momento fletor e força cortante) encontrados na análise pelos elementos de barra e a expressão de Branson, foi possível obter a relação Momento Fletor pela Força Cortante em cada seção do modelo. A Figura 6.23 apresenta essa relação para valores de $F_{2}=30 \mathrm{kN}, 40,0 \mathrm{kN}, 50,0 \mathrm{kN}, 80,0 \mathrm{kN}$ e $146,8 \mathrm{kN}$.

Analisando a Figura 6.23 é possível notar que, próximo à aplicação da força $F_{2}$, a relação Momento/Cortante é alta e diminui de acordo com a fissuração do modelo, se estabilizando em um valor de 3,0. Além disso, a relação Momento / Cortante é baixa nas seções onde ocorreu a ruptura por cisalhamento (elementos 14 e 15 da Figura 6.7, letra b), ficando próxima de 1,0.

Para a força aplicada $F_{2}=146,8 \mathrm{kN}$, a máxima força cortante encontrada foi de $124,3 \mathrm{kN}$. Esse valor corresponde à máxima força cortante teórica encontrada no modelo 3, no elemento 15 (ver Figura 6.7, letra b). Entretanto a ruptura do modelo não aconteceu por cisalhamento e, portanto, o valor de $124,3 \mathrm{kN}$ não equivale à força cortante de ruptura das lajes do modelo 3 . 
Momento x Rotação no apoio - EM3

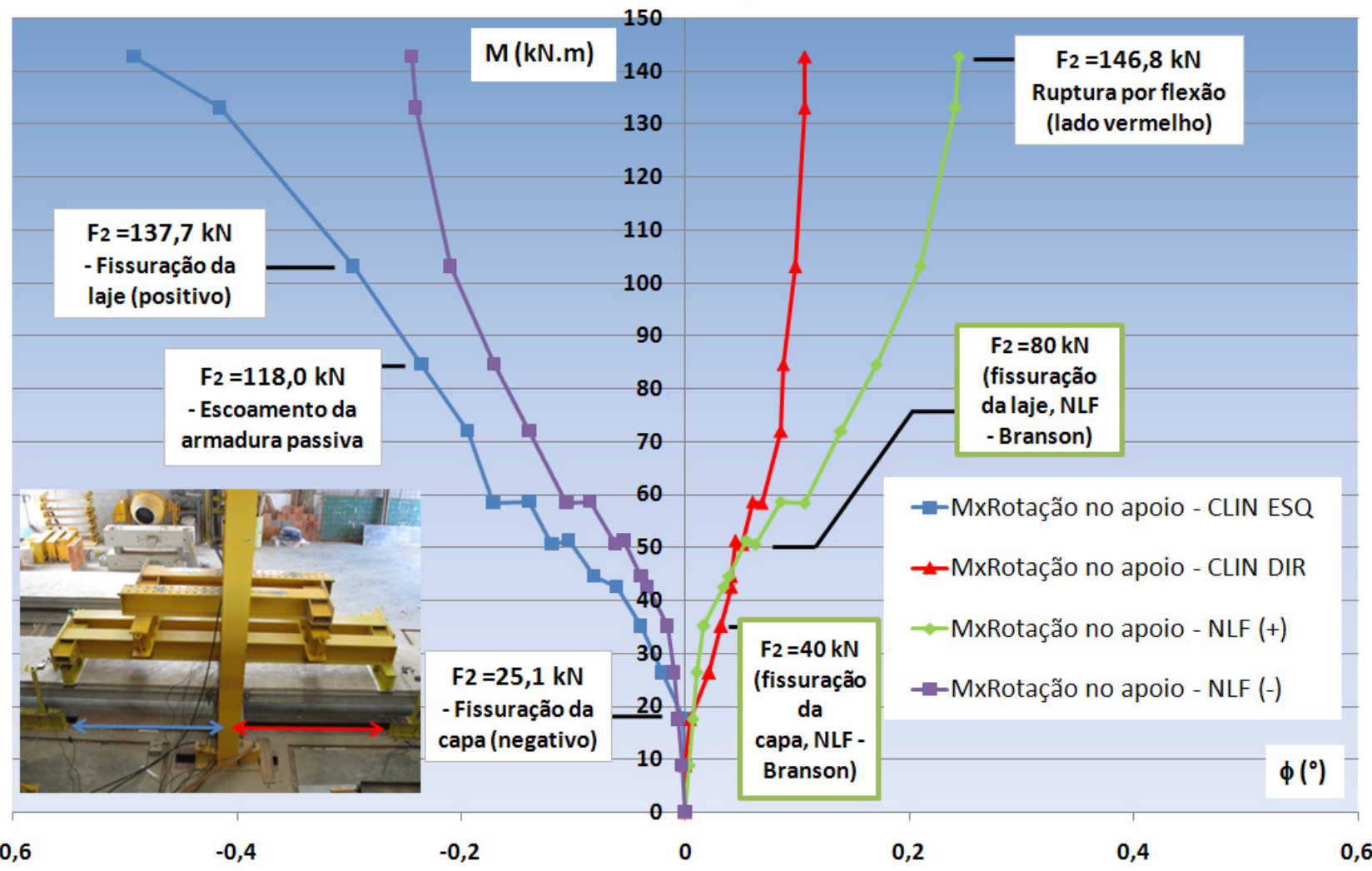

Figura 6.22 - Diagramas Momento x Rotação dos valores encontrados na análise com elementos de barras combinados com a expressão de Branson para o modelo 3.

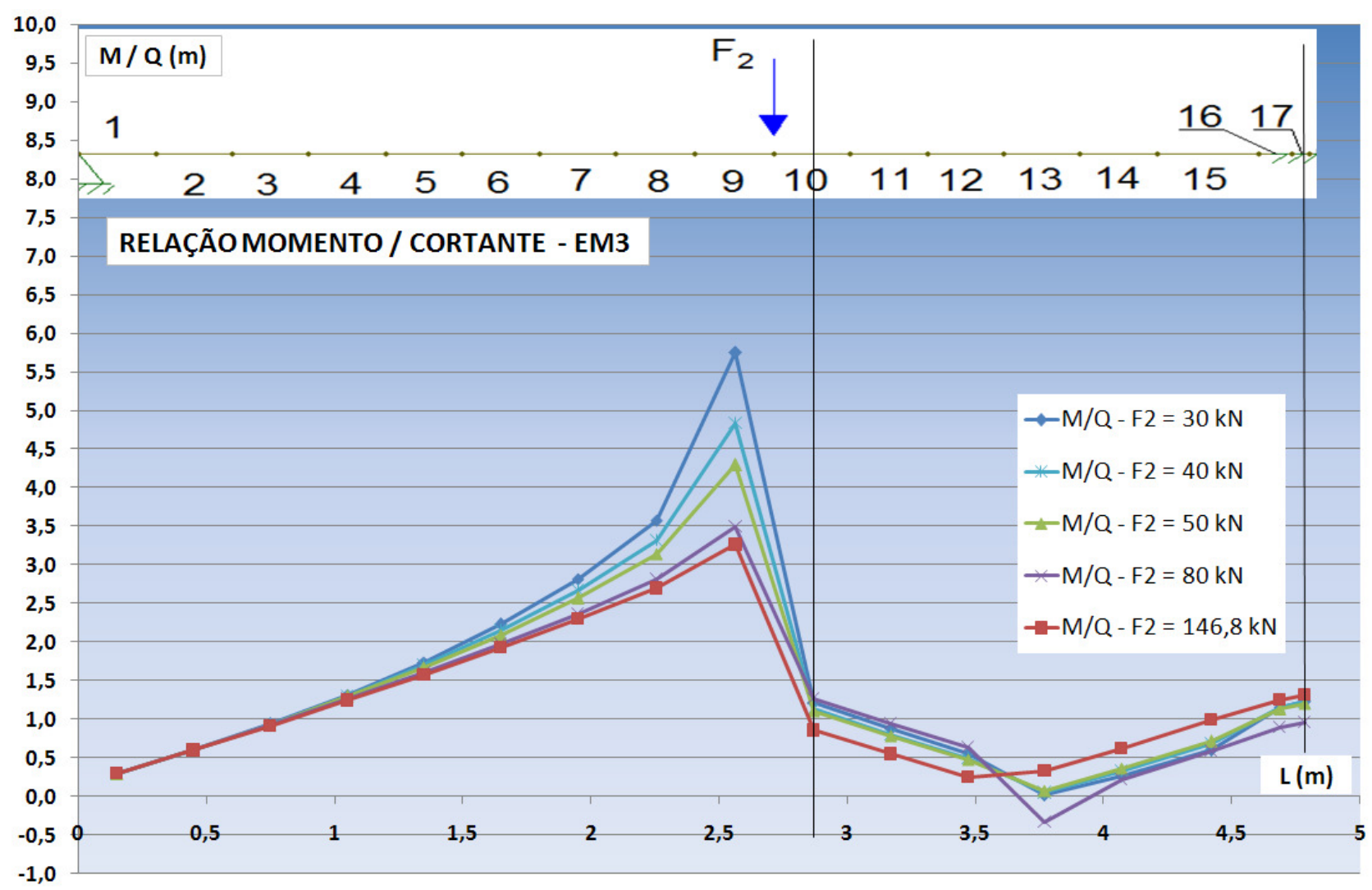

Figura 6.23 - Relação Momento Fletor / Força Cortante dos valores encontrados na análise com elementos de barras combinados com a expressão de Branson para o modelo 3. 
Para relacionar os valores forças cortantes solicitantes com o valor da força cortante resistente é necessário recorrer ao Capítulo 3 e à Tabela 3.29. Observa-se que o valor da força cortante resistente $\left(\mathrm{V}_{\mathrm{Rd} 1}\right)$ estimado foi de 114,54 kN. Entretanto esse valor é menor do que o encontrado na análise teórica $(124,3$ kN).

É possível, ainda, recorrer ao Capítulo 4, e aos ensaios de caracterização do modelo 3, item 4.5.3. A Figura 4.29 mostra os valores de ruptura das forças aplicadas nos ensaios de cisalhamento, realizados conforme as Figuras 4.22 e 4.24. Por esses dados o valor de $\mathrm{V}_{\mathrm{Rd1}}$ é de $161,63 \mathrm{kN}$ e 175,69 kN, respectivamente, para a laje EM3-L4-A e para a laje EM3L4-B. O valor médio é $168,66 \mathrm{kN}$.

A Figura 6.24 relaciona os valores das forças cortantes solicitantes com o valor de $168,66 \mathrm{kN}$.

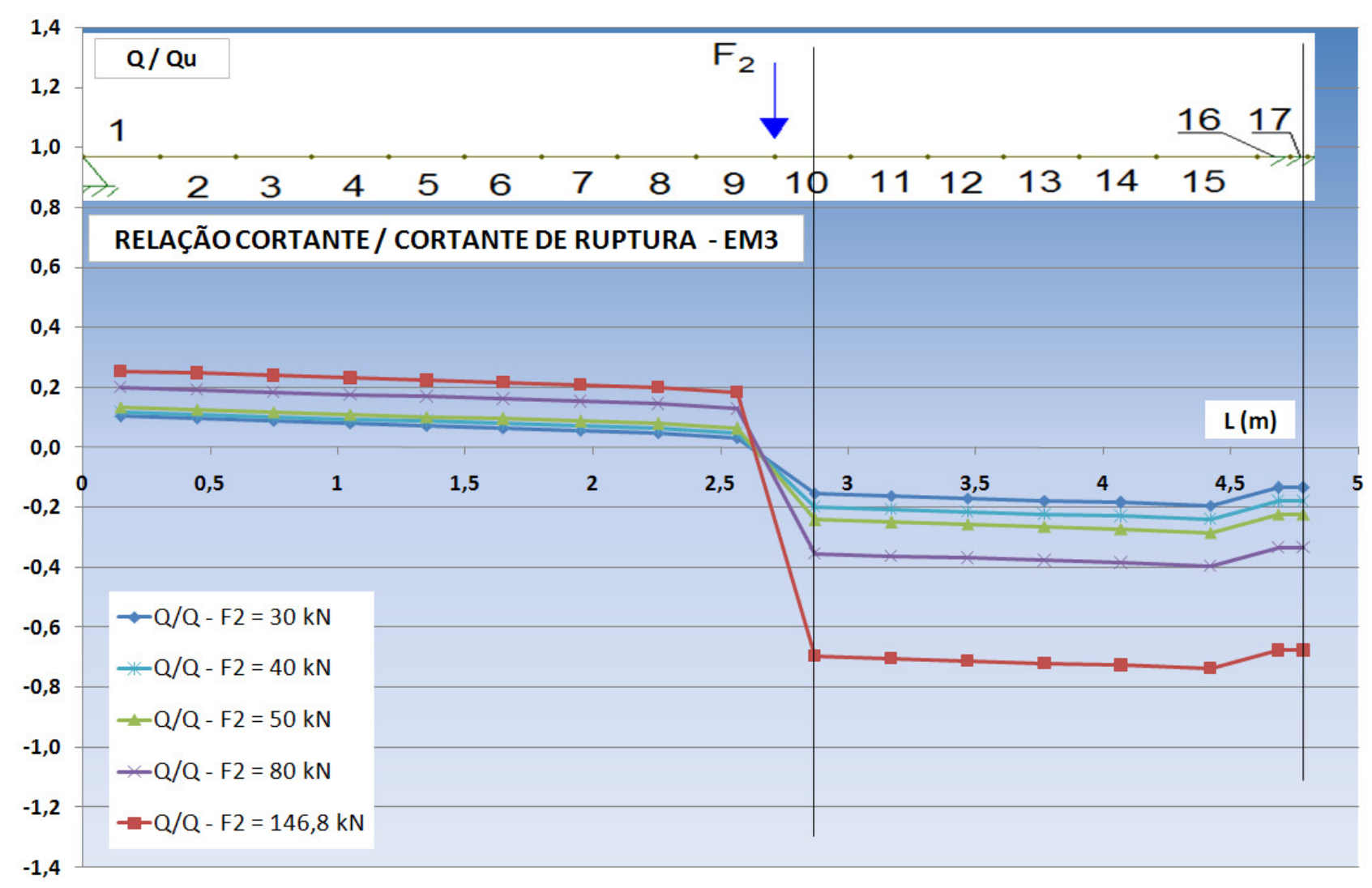

Figura 6.24 - Relação Força Cortante x Força Cortante de Ruptura dos valores encontrados na análise com elementos de barras combinados com a expressão de Branson para o modelo 3.

Analisando essa figura notam-se dois trechos distintos. O primeiro entre o apoio extremo e o local de aplicação de $F_{2}$, e o segundo entre $F_{2}$ e o apoio intermediário. No primeiro trecho a relação se estabiliza próximo de 0,3 , enquanto que o segundo trecho se estabiliza com o valor de 0,8 no elemento 15.

No Capítulo 3, Tabela 3.29, foram apresentados os momentos fletores resistentes das lajes alveolares (positivo e negativo). Para o modelo 3 tem-se os seguintes valores: momento resistente positivo $79,30 \mathrm{kN}$ e momento resistente negativo $80,72 \mathrm{kN}$. 
A Figura 6.25 relaciona os valores dos momentos fletores encontrados na análise com elementos de barra e os momentos resistentes. O máximo valor encontrado para essa relação foi de 1,3 para o momento positivo (elementos 9 e 10) e 1,8 para momento negativo (elemento 15 ).

As curvas das Figuras 6.24 e 6.25 estão coerentes com o que ocorreu no ensaio de continuidade do modelo 3 , uma vez que a ruptura se deu por flexão, e o máximo valor encontrado para a relação de força cortante foi de 0,8 .

Já a máxima relação de momento fletor positivo $(1,3)$ ultrapassou o valor de 1,0 e aconteceu nos elementos que sofreram a ruptura do modelo. Para o momento fletor negativo, a máxima relação encontrada é de 1,8 e ocorreu escoamento da armadura passiva, com deformação do aço $\varepsilon=8,13 \%$ (Figura 5.63).

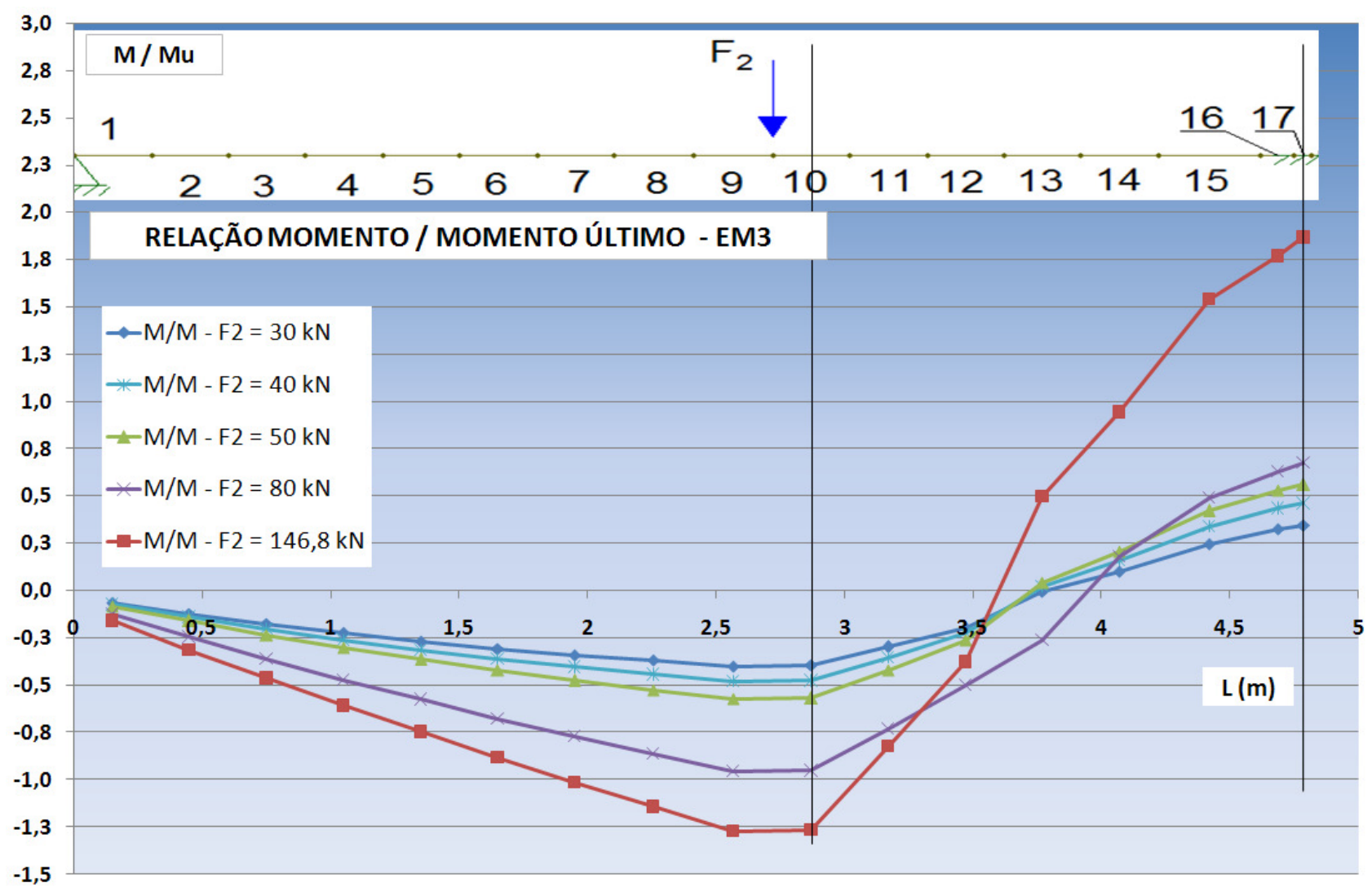

Figura 6.25 - Relação Momento Fletor x Momento Fletor de Ruptura dos valores encontrados na análise com elementos de barras combinados com a expressão de Branson para o modelo 3.

\subsection{4 - Comparações com capítulos anteriores}

De posse das análises teóricas feitas no Capítulo 6, é possível fazer algumas comparações com capítulos anteriores. Para os capítulos 3, 4, 5 e 6, a Tabela 6.4 apresenta os momentos de fissuração $\left(M_{r}\right)$ e as forças aplicadas nos ensaios $\left(F_{2}\right)$ relativas aos momentos de fissuração e de ruptura. 
Tabela 6.4 - Valores de Momento de Fissuração $\left(M_{r}\right)$ e de Força aplicada no ensaio de continuidade relativa à fissuração $\left(F_{2}\right)$ para os capítulos $3,4,5$ e 6.

\begin{tabular}{|c|c|c|c|c|c|c|c|}
\hline \multirow{2}{*}{ Modelo } & \multirow{2}{*}{ Local } & \multicolumn{2}{|c|}{ CAP. 3} & \multirow{2}{*}{$\begin{array}{c}\text { CAP. } 4 \\
M_{r}(k N . m)\end{array}$} & \multirow{2}{*}{$\begin{array}{l}\text { CAP. } 5 \\
F_{2}(\mathrm{kN})\end{array}$} & \multicolumn{2}{|c|}{ CAP. 6} \\
\hline & & $\mathbf{M}_{\mathbf{r}}(\mathbf{k N} \cdot \mathbf{m})$ & $F_{2}(k N)$ & & & $\mathbf{M}_{\mathbf{r}}(\mathbf{k N} . \mathbf{m})$ & $F_{2}(k N)$ \\
\hline \multirow{5}{*}{ EM1 } & \multirow{2}{*}{ CAPA } & $68,84^{*}$ & $82,31 *$ & \multirow{2}{*}{ - } & \multirow{2}{*}{107,9} & \multirow{2}{*}{93,0} & \multirow{2}{*}{110,0} \\
\hline & & $91,21 * *$ & $117,59 * *$ & & & & \\
\hline & \multirow{2}{*}{ LAJE } & $179,9^{*}$ & $234,96^{*}$ & \multirow{2}{*}{-} & \multirow{2}{*}{219,1} & \multirow{2}{*}{172,0} & \multirow{2}{*}{210,0} \\
\hline & & $205,9 * *$ & $274,26 * *$ & & & & \\
\hline & \multicolumn{2}{|c|}{ RUPTURA } & 274,13 & - & 272,0 & - & - \\
\hline \multirow{5}{*}{ EM2 } & \multirow{2}{*}{ CAPA } & $56,50 *$ & $72,84 *$ & \multirow{2}{*}{-} & \multirow{2}{*}{26,0} & \multirow{2}{*}{135,0} & \multirow{2}{*}{150,0} \\
\hline & & $80,72 * *$ & $104,07 * *$ & & & & \\
\hline & \multirow{2}{*}{$L A J E$} & $194,12^{*}$ & $255,44^{*}$ & \multirow{2}{*}{ - } & \multirow{2}{*}{$\begin{array}{c}\text { Não } \\
\text { ocorreu }\end{array}$} & \multirow{2}{*}{180,0} & \multirow{2}{*}{230,0} \\
\hline & & $223,28 * *$ & $300,48 * *$ & & & & \\
\hline & \multicolumn{2}{|c|}{ RUPTURA } & 207,98 & - & 297,3 & - & - \\
\hline \multirow{5}{*}{ EM3 } & \multirow{2}{*}{ CAPA } & $25,55^{*}$ & $32,94 *$ & \multirow{2}{*}{ - } & \multirow{2}{*}{25,1} & \multirow{2}{*}{35,0} & \multirow{2}{*}{40,0} \\
\hline & & $36,50 * *$ & $47,05^{* *}$ & & & & \\
\hline & \multirow{2}{*}{$L A J E$} & $58,67 *$ & $69,23 *$ & & & & \\
\hline & & $69,68 * *$ & $85,88 * *$ & & & & \\
\hline & $R L$ & PTURA & 100,39 & - & 146,8 & - & - \\
\hline
\end{tabular}

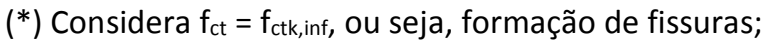

$(* *)$ Considera $f_{c t}=f_{c t k m}$, ou seja, deformação excessiva.

Vale lembrar que no Capítulo 3 foram realizados cálculos preliminares a fim de antever o que aconteceria no ensaio. Nesse capítulo foi utilizada análise linear física e valores nominais para as propriedades dos materiais.

O Capítulo 4 apresentou os valores de ensaios em lajes alveolares para caracterização dos materiais. Apenas no modelo 3 foi realizado um ensaio com a laje biapoiada e composta com a capa. 
No Capítulo 5 foram apresentados os resultados dos ensaios de continuidade. Os resultados do Capítulo 6 consideraram a não-linearidade física pela expressão de Branson e as propriedades dos materiais retiradas do Capítulo 4.

\section{3 - Conclusão}

Os resultados da análise teórica feita com elementos de barra e a expressão de Branson foram satisfatórios na previsão do comportamento global dos ensaios de continuidade.

Essas análises foram feitas antes dos ensaios de continuidade, com o objetivo de saber previamente o comportamento do modelo. Entretanto optou-se por apresentá-las com as propriedades dos materiais retiradas dos ensaios de caracterização (Cap. 4).

O modelo 1 foi o melhor a ser representado, uma vez que seus resultados ficaram mais próximos aos da análise experimental. Nesse ensaio experimental foram utilizados apenas dois clinômetros para a leitura das rotações das lajes alveolares na região dos apoios. Não foi possível ler a rotação do apoio e com isso obter as rotações relativas. No entanto os resultados da análise teórica mostrados nas Figuras 6.8, 6.9 e 6.10 permitem concluir que a rotação relativa no modelo 1 não ocorreu ou não foi significativa. Isso porque nas Figuras 6.9 e 6.10 os resultados das rotações da laje da direita praticamente coincidem com os resultados da análise teórica.

As análises teóricas relativas ao modelo 2 permitiram concluir que houve uma fissuração prematura tanto com relação ao previsto no Capítulo 3 quanto ao calculado nas análises do Capítulo 6. Além disso, foi observado que a rotação relativa que ocorreu no modelo afetou os resultados de deslocamentos, uma vez que os deslocamentos da laje esquerda diminuíram, ficando menores que os da laje da direita.

Para o modelo 3 é possível concluir que as lajes tiveram comportamentos bem distintos entre si, e também distantes do relativo ao modelo teórico. $E$ mesmo ocorrendo o escoamento da armadura nos ensaios, o modelo teórico apresentou resultados satisfatórios.

As análises teóricas apresentadas neste capítulo permitem concluir que os modelos ensaiados não são constituídos de ligação semirrígida. O comportamento dessas estruturas é governado principalmente pela fissuração, ora da capa em função do momento negativo, ora da laje em função do modelo positivo. Os resultados das lajes da direita e da esquerda, embora semelhantes, nem sempre são iguais, sendo que nos três modelos uma laje se apresentou mais rígida que a outra. 
Embora apresentem resultados satisfatórios, que permitem descrever o comportamento dos ensaios realizados, a análise teórica com elementos de barra composta pela expressão de Branson não é capaz de representar outros fenômenos que ocorreram nos ensaios, tais como: destacamento da capa e escoamento da armadura.

Por fim, é importante ressaltar que na análise teórica foram adotadas algumas simplificações. A primeira delas é quanto à influência da protensão no cálculo do momento de inércia no estádio II ( $\left.I_{\|}\right)$, que não foi considerada. A segunda é quanto à modelagem do apoio intermediário, que pode ser melhorada com a influência do apoio na ligação. 


\section{CISALHAMENTO NA INTERFACE}

Quando se utiliza a capa para solidarizar os pavimentos formados por elementos pré-moldados, tal como em lajes alveolares, tem-se o comportamento de elementos compostos.

A transferência de tensões de cisalhamento na interface entre o concreto prémoldado (laje alveolar) e concreto moldado no local (capa) é o item fundamental para garantir o comportamento de seção composta.

Usualmente os concretos do elemento pré-moldado e da capa possuem características mecânicas diferentes. Por essa razão, se faz necessário o emprego de módulos de elasticidades diferentes na análise da seção composta. Além disso, esses concretos normalmente possuem idades distintas e, portanto, estão submetidos a efeitos dependentes do tempo, em função da retração e da fluência. No entanto os efeitos dependentes do tempo serão desprezados, uma vez que a diferença de tempo entre a data da moldagem da capa e a dos ensaios de continuidade foi entre 14 e 19 dias, conforme mostra a Tabela 3.6 do capítulo 3.

Este capítulo trata das tensões de cisalhamento na interface da laje com a capa, mostrando o cálculo das tensões de cisalhamento solicitantes e resistentes. Para o cálculo das tensões resistentes, são utilizadas fórmulas propostas pelos principais códigos nacionais e internacionais e também por IBRAHIM (2008).

\section{1 - Princípios gerais}

A seguir serão comentados os principais assuntos relacionados com a resistência da interface ao cisalhamento.

\subsection{1 - Transferência de cisalhamento na interface}

Quando um elemento composto sofre flexão, existe uma tendência de escorregamento entre a capa e o elemento pré-moldado, como mostra a Figura 7.1, adaptada de IBRAHIM (2008). A tensão de cisalhamento que surge ao longo da interface é responsável por evitar esse escorregamento e garantir o comportamento de seção composta. 


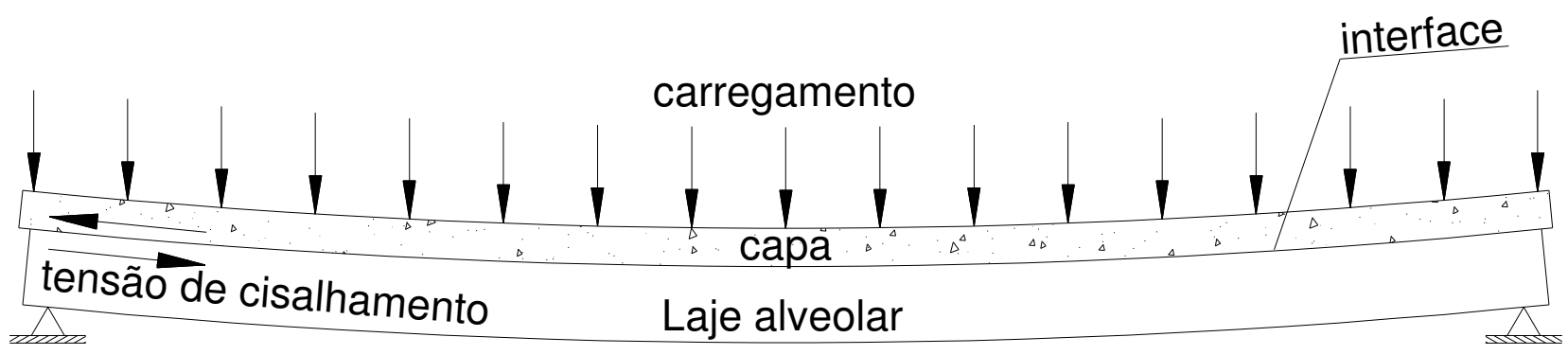

Figura 7.1 - Tensão de cisalhamento ao longo da interface de um elemento composto fletido (IBRAHIM (2008)).

A transferência de cisalhamento pela interface pode ser dividida em dois efeitos (EL DEBS, 2000). O primeiro deles é a transferência por meio de superfície de contato, efeito ao qual estão associadas as seguintes parcelas:

- Adesão. É a primeira parcela a ser mobilizada e se limita a baixas tensões, uma vez que é "vencida" se houver deslizamento;

- Atrito. Manifesta-se após a adesão e depende da tensão normal que atua na interface. Pelos códigos internacionais, é chamada de "friction";

- Mecânica. Parcela associada às saliências na superfície, tratada nos códigos internacionais como: "surface cohesion at the interface".

O segundo efeito é o da armadura cruzando a interface, que possui duas parcelas:

- Efeito de pino. Corresponde à resistência da armadura ao corte direto;

- Tensão normal à interface. Ocorre indiretamente e é mobilizado pela tendência de deslocamento relativo entre os dois concretos.

\subsection{2 - Fatores que influenciam na resistência ao cisalhamento}

A resistência ao cisalhamento na interface entre dois concretos é influenciada, principalmente, por:

- Resistência do concreto. A resistência da interface está diretamente ligada com a resistência do concreto à tração, devido principalmente aos efeitos de transferência mecânica e por efeito de pino. Quanto maior for a resistência do concreto, maior será a resistência da interface, e como na maioria dos casos os concretos da capa e do elemento pré-moldado são diferentes, esse fator é controlado pelo concreto menos resistente;

- Rugosidade da superfície de contato. A rugosidade afeta diretamente a resistência da interface. Quanto maior for a rugosidade do elemento prémoldado, maior será a resistência da interface; 
- Armadura que cruza a interface. Quanto maior a taxa de armadura que cruza a interface, maior será a resistência da interface. No entanto, estudos comprovam que quando a taxa de armadura é muito baixa, a resistência ao cisalhamento é pouco afetada por esse efeito;

- Tensão normal à interface. A tensão normal de compressão, quando existe, aumenta a resistência ao cisalhamento, uma vez que mobiliza a transferência por atrito;

- Ações cíclicas. Quando existem, diminuem a resistência ao cisalhamento, principalmente a parcela correspondente à adesão.

Vale ressaltar que os modelos ensaiados neste trabalho não continham armadura cruzando a interface, tensão normal (a menos da seção onde foi aplicado o carregamento de ensaio) e também ações cíclicas. Portanto, dos fatores acima citados, apenas a resistência do concreto e a rugosidade da superfície serão considerados.

\subsection{3 - Classificação quanto à rugosidade}

A rugosidade da superfície de contato é um fator importante para se determinar a resistência da interface ao cisalhamento. EL DEBS (2000) cita que a rugosidade superficial pode afetar a aderência a ser alcançada entre os dois concretos das seguintes formas:

- Quanto maior a rugosidade, maior a área superficial de contato entre os dois concretos;

- Quanto maior a rugosidade, menos susceptível ela fica à qualidade dos serviços de limpeza e preparo;

- O formato dos picos e vales da rugosidade promove um melhor embricamento entre os dois concretos.

Entre os principais códigos internacionais, não existe, ainda, um consenso quanto à classificação das superfícies dos elementos de concreto pré-moldado, que posteriormente receberão a capa para juntos formarem elementos compostos.

A principal classificação utilizada atualmente, e talvez a mais completa, é a apresentada no documento FIP:1982, que estabelece 10 níveis para a rugosidade:

- Nível 1 - superfície bastante lisa, obtida com o uso de fôrmas metálicas ou de madeira;

- Nível 2 - superfície que foi alisada, atingindo níveis próximos ao Nível 1;

- Nível 3 - superfície que foi alisada (trazendo os finos do agregado à superfície), mas que ainda apresenta pequenas ondulações; 
- Nível 4 - superfície que foi executada com fôrmas deslizantes ou régua vibratória;

- Nível 5 - superfície que foi produzida por alguma forma de extrusão;

- Nível 6 - superfície que foi deliberadamente texturizada pelo escovamento do concreto ainda fresco;

- Nível 7 - como em 6, com maior pronunciamento da texturização;

- Nível 8 - superfície em que o concreto foi perfeitamente vibrado, sem a intenção de fazer superfície lisa, ou fazendo com que os agregados graúdos fiquem expostos;

- Nível 9 - superfície em que o concreto ainda fresco foi jateado com água ou areia, para expor os agregados graúdos;

- Nível 10 - superfície propositadamente rugosa.

Além disso, para facilitar a utilização desses níveis, nos casos de projeto, as superfícies foram divididas no documento FIP:1982, em três casos básicos:

- Superfície lisa - correspondente aos Níveis 1 e 2;

- Superfície naturalmente rugosa - correspondendo aos Níveis 3 a 6;

- Superfície intencionalmente rugosa - correspondendo aos Níveis 7 a 10.

\subsection{4 - Cuidados durante a execução da capa}

Para se ter uma transferência de tensões eficaz na interface é necessário tomar alguns cuidados práticos na execução das capas. Segundo a FIP:1982, esses cuidados práticos podem ser agrupados em três categorias: tratamento da interface, adensamento do concreto e cura do concreto da capa.

A cura do concreto da capa tem grande importância, sobretudo quando a capa for de pequena espessura. EI DEBS (2000) recomenda que em climas secos, quentes ou com presença acumulada de ventos, a capa deve ser protegida com lona, pequena camada de água ou de areia ou membranas de cura. A cura cuidadosa é extremamente necessária, uma vez que auxilia na redução das tensões de cisalhamento e de tração na interface, que ocorrem em função dos efeitos dependentes do tempo (retração e fluência) e da temperatura.

O adensamento da capa é outro fator de grande importância e deve ser feito com cuidado, sempre recorrendo ao equipamento adequado a cada situação e de acordo com a espessura da capa.

O tratamento da interface deve levar em conta os seguintes itens: 
- Limpeza - A superfície que irá receber a capa deverá estar limpa, considerandose a presença de pó, areia, terra, óleo ou outras substâncias que possam prejudicar a transferência de cisalhamento. Além disso, é comum a presença de nata de cimento nas extremidades da laje alveolar, após o corte das unidades (Figura 7.2);

- Umedecimento da interface - O umedecimento da superfície do elemento prémoldado deve ser feito antes da concretagem da capa. Isso evita que o concreto do elemento pré-moldado absorva água do concreto da capa, evitando, portanto, a diminuição da relação água/cimento do concreto da capa, e com isso, seu enfraquecimento. Além disso, é necessário que a superfície do elemento prémoldado não esteja com água livre no momento da concretagem da capa, pelo mesmo motivo de se evitar uma diminuição da relação água/cimento do concreto da capa e, com isso, seu enfraquecimento;

- Pré-tratamento da interface com graute - É um tratamento pouco recomendado devido à dificuldade de execução, principalmente com a presença de armadura que cruza a interface.

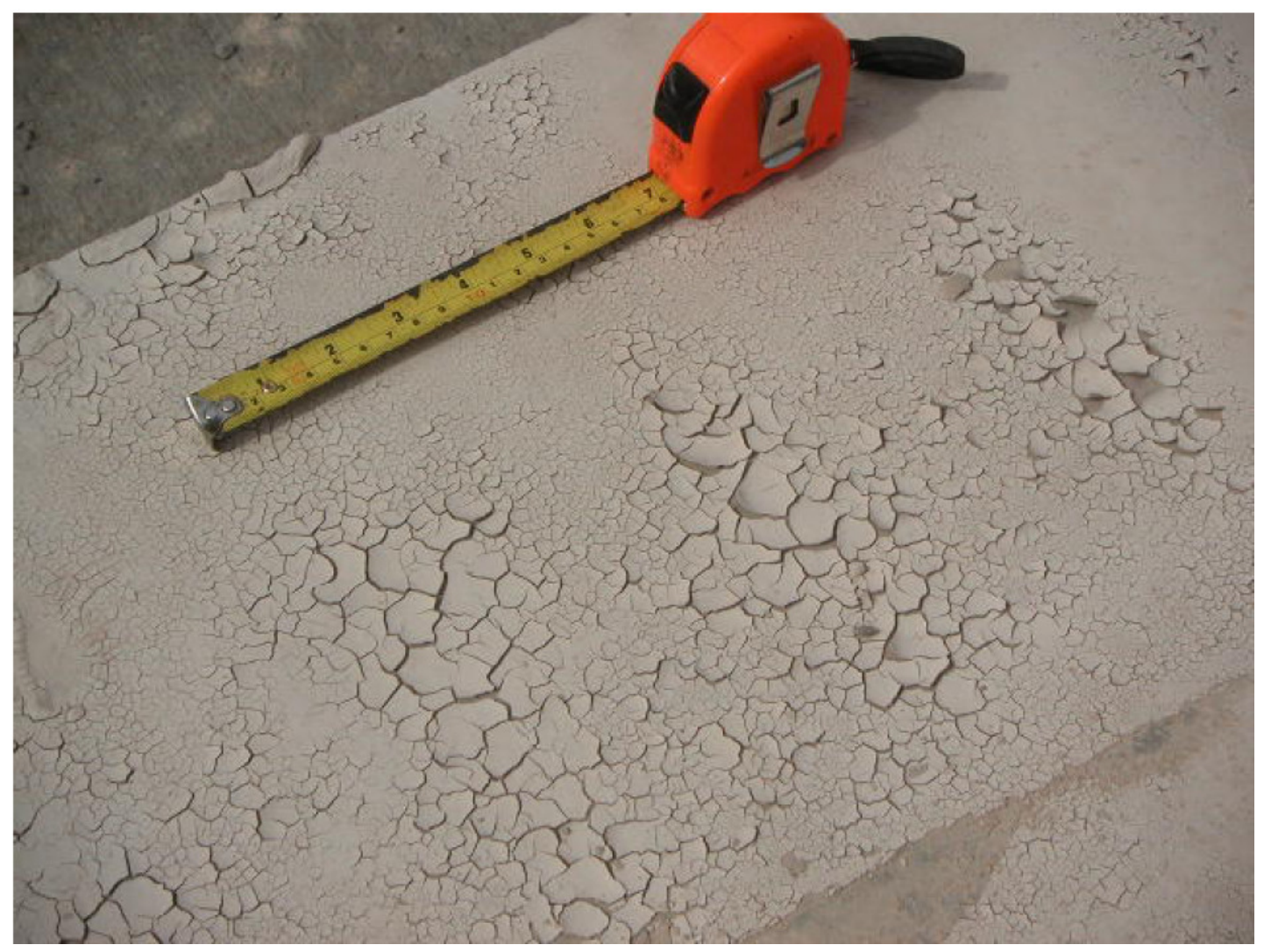

Figura 7.2 - Nata de concreto presente nas extremidades das lajes alveolares devida ao processo de corte das unidades (IBRAHIM (2008)). 


\section{2 - Tensões de cisalhamento solicitantes}

Existem na literatura técnica ao menos duas formas de se calcular as tensões de cisalhamento que atuam na interface: cálculo da tensão de referência e cálculo da tensão média.

\subsection{1 - Tensão de referência}

O cálculo da tensão de referência corresponde ao cisalhamento atuante na interface de uma seção transversal e é derivado da expressão 7.1, que corresponde ao cálculo das tensões médias de cisalhamento para vigas de seções transversais usuais, exemplificada pela Figura 7.3, adaptada de BEER e JOHNSTON (1989). A dedução da expressão 7.1 pode ser encontrada na referência citada anteriormente.

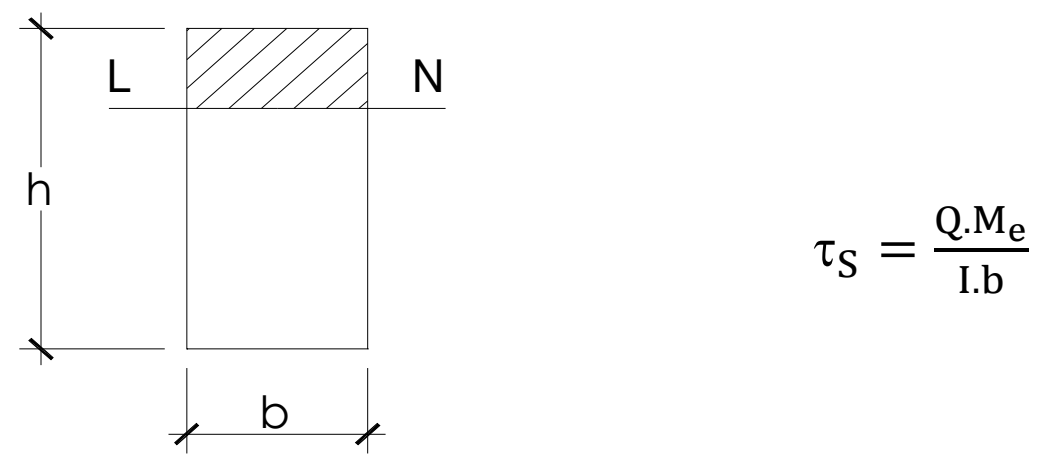

Figura 7.3 - Seção transversal de uma viga retangular. BEER e JOHNSTON (1989).

- $\tau_{\mathrm{S}}=$ tensão solicitante de cisalhamento na fibra da linha neutra;

- $Q=$ força cortante atuante na seção transversal;

- $\mathrm{M}_{\mathrm{e}}=$ momento estático em relação à linha neutra da área sombreada indicada na Figura 7.3;

- I= momento de inércia da seção transversal ;

- $b=$ largura da seção transversal.

Analisando um elemento composto, formado por um elemento pré-moldado (concreto armado e/ou protendido) e a capa (concreto armado), é necessário considerar o estado não fissurado, correspondente ao estádio I, e o estado fissurado, correspondente aos estádios II e III.

Para o estado não fissurado, tem-se a expressão 7.2 e a Figura 7.4, adaptada de EL DEBS (2000). 

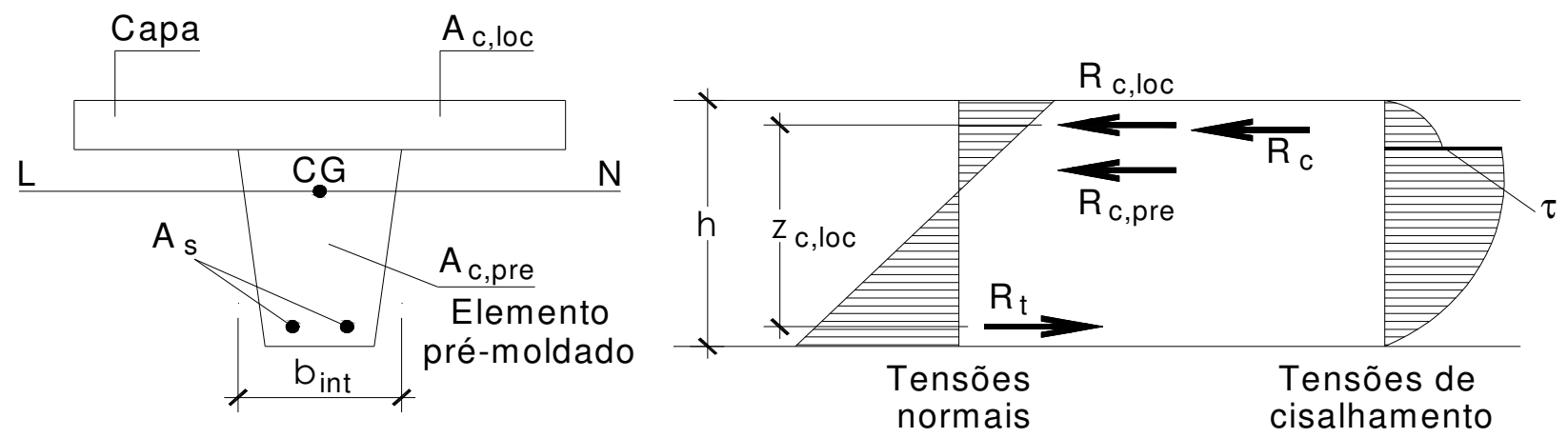

Figura 7.4 - Distribuição de tensões no estado não fissurado (EL DEBS (2000)).

$$
\tau_{\text {ref }}=\frac{\text { Q.M }_{\text {e,c,loc }}}{I_{\text {comp }} \cdot b_{\text {int }}}
$$

- $\tau_{\text {ref }}=$ tensão de referência relativa ao cisalhamento na interface;

- $\mathrm{Q}=$ força cortante atuante na seção transversal;

- $\mathrm{M}_{\mathrm{e}, \mathrm{c}, \mathrm{loc}}=$ momento estático de $\mathrm{A}_{\mathrm{c}, \mathrm{loc}}$ em relação ao CG da seção;

- $\mathrm{I}_{\text {comp }}=$ momento de inércia da seção transversal do elemento composto ;

- $\mathrm{b}_{\text {int }}=$ largura da interface.

O estado fissurado pode ser considerado quando a linha neutra se encontra na capa. Essa situação está ilustrada na Figura 7.5. Além disso, o cálculo das tensões de cisalhamento pode ser feito com a expressão 7.3.
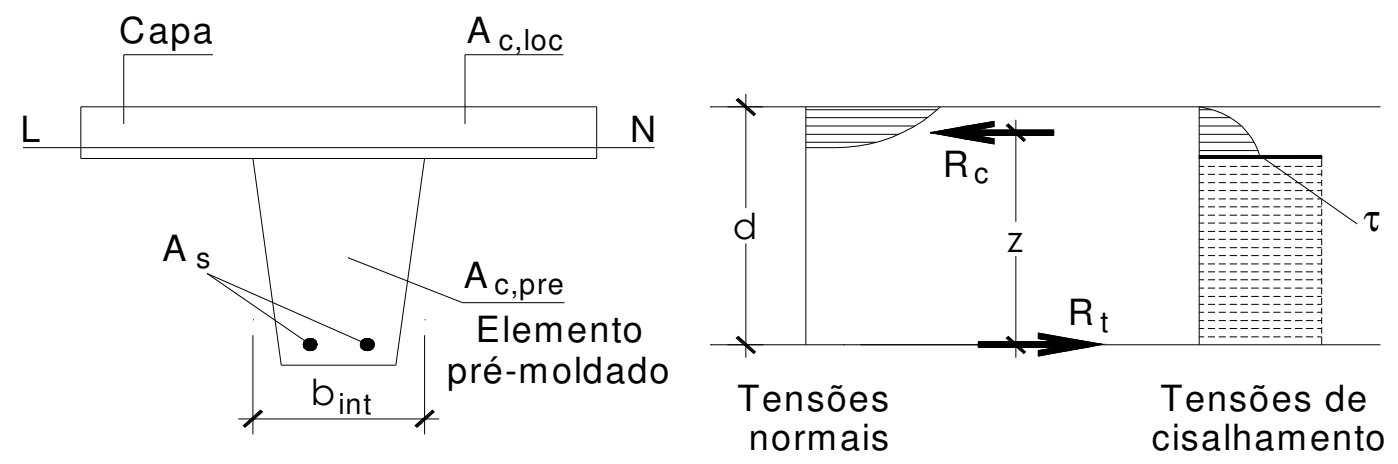

Figura 7.5 - Distribuição de tensões no estado fissurado com linha neutra acima da interface (EL DEBS (2000)).

$$
\tau_{\text {ref }}=\frac{\mathrm{Q}}{\mathrm{z} \cdot \mathrm{b}_{\mathrm{int}}}
$$

- $\mathrm{z}=$ distância entre as resultantes de compressão e de tração; 
O estado fissurado também pode ser considerado quando a linha neutra se encontra abaixo da interface (Figura 7.6). A expressão 7.4, adaptada da expressão 7.3, é utilizada para calcular as tensões de cisalhamento na interface.
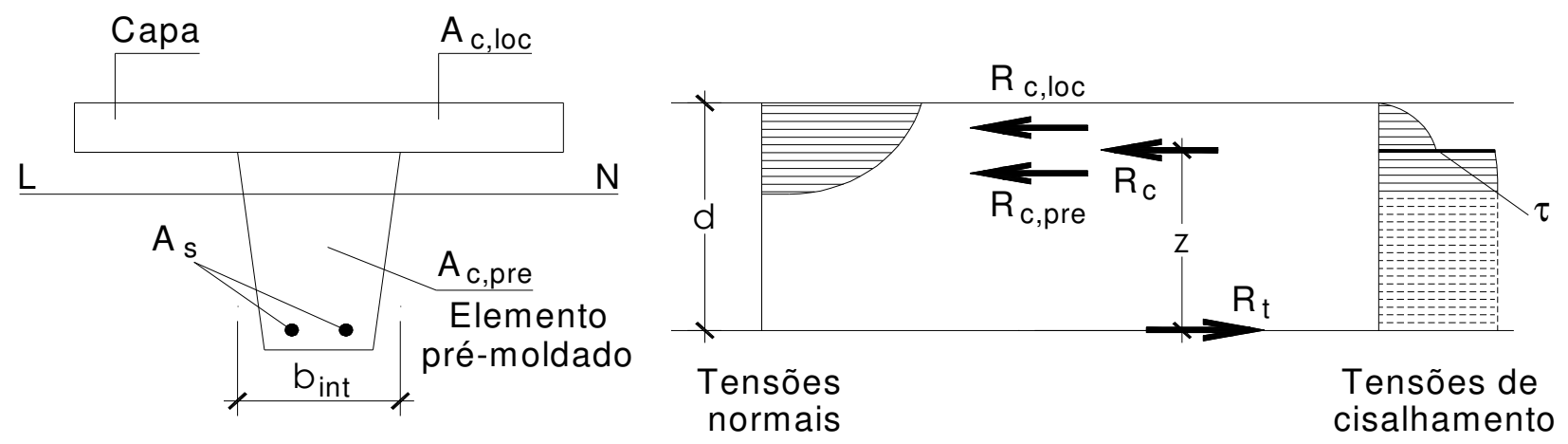

Figura 7.6 - Distribuição de tensões no estado fissurado com linha neutra abaixo da interface (EL DEBS (2000)).

$$
\tau_{\text {ref }}=\frac{\mathrm{Q}}{\mathrm{z} \cdot \mathrm{b}_{\text {int }}}\left(\frac{\mathrm{R}_{\mathrm{c}, \mathrm{loc}}}{\mathrm{R}_{\mathrm{c}}}\right)
$$

- $\mathrm{R}_{\mathrm{c}, \mathrm{loc}}=$ resultante de compressão no concreto da capa;

- $\mathrm{R}_{\mathrm{c}}=$ resultante de compressão no concreto acima da linha neutra;

\subsection{2 - Tensão média}

O cálculo da tensão média ( $\tau_{\text {med }}$ na expressão 7.5 ) é derivado do manual do $P C l: 2010$. A tensão média é calculada a partir da força horizontal solicitante de cálculo ( $\left.F_{\text {hd }}\right)$ atuante na interface, de acordo com a largura da interface ( $b_{\text {int }}$ ) e o comprimento dos trechos relativos ao cisalhamento na interface (lo). A Figura 7.7, adaptada do PCl:2010, ilustra o comprimento lo para casos em que o elemento é simplesmente apoiado ou contínuo. Na Figura 7.7, o comprimento lo corresponde às distâncias entre o momento nulo e o momento máximo (ou mínimo).

A Figura 7.8 apresenta o cálculo de $F_{\text {hd }}$ para as seções com momento fletor positivo ou negativo. Para momento fletor positivo, é necessário considerar o Caso 1, que ocorre quando a linha neutra se encontra acima da interface, e o Caso 2, quando a linha neutra está localizada abaixo da interface.

$$
\tau_{\text {med }}=\frac{\mathrm{F}_{\mathrm{hd}}}{\mathrm{b}_{\mathrm{int}} \cdot \cdot_{0}}
$$




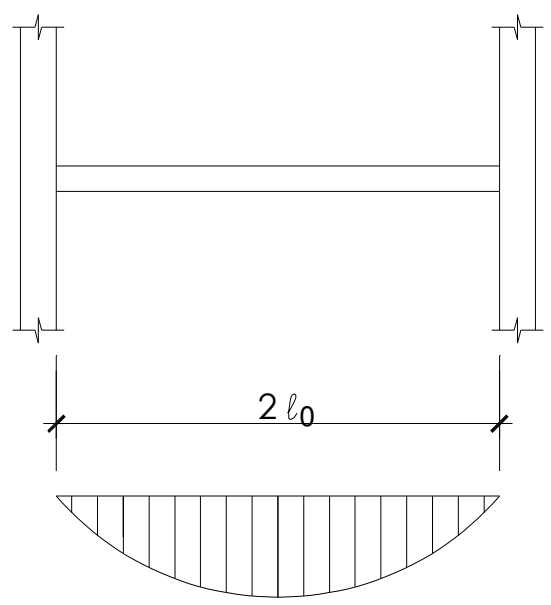

(a) - Elemento simplesmente apoiado

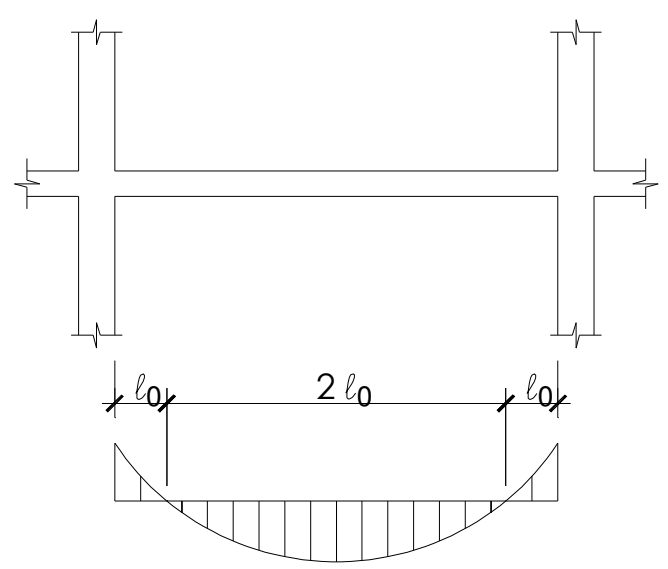

(b) - Elemento contínuo

Figura 7.7 - Exemplo de comprimento dos trechos relativos ao cisalhamento (lo):

(a) Elemento simplesmente apoiado; (b) Elemento com continuidade.

(Adaptado do PCl:2010).
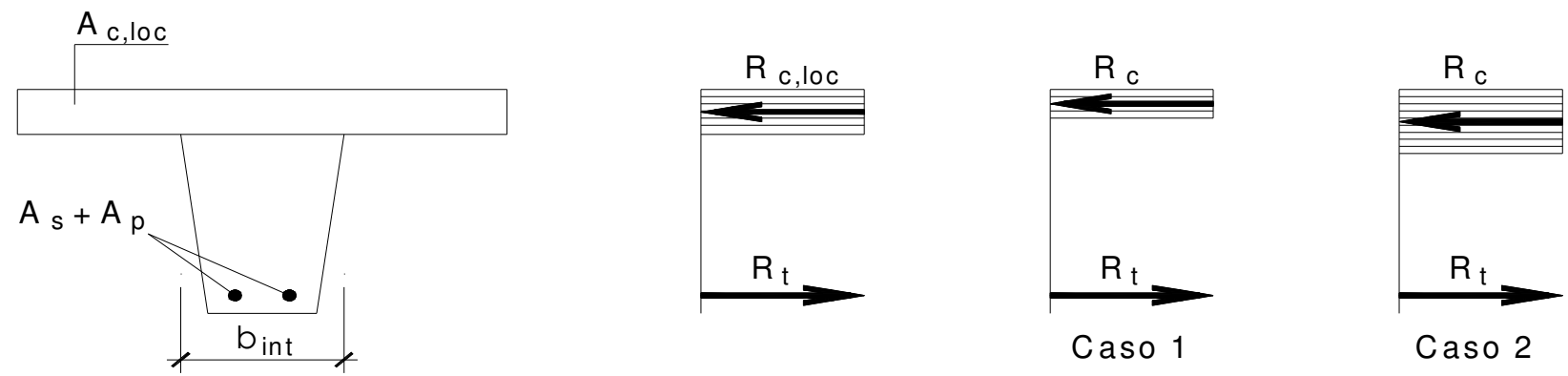

$\mathrm{A}_{\mathrm{c}, \mathrm{loc}}=$ área da seção transversal correspondente ao concreto moldado no local;

$\mathrm{R}_{c, l o c}=$ valor de referência da resultante de compressão na parte do concreto moldado no local, ou seja, $0,85 . f_{c d} \cdot A_{c, l o c}$;

$R_{c}=$ resultante de compressão;

\begin{tabular}{|ll|}
\hline Caso 1 & Caso 2 \\
$R_{t}=R_{c}<R_{c, l o c}$ & $R_{t}=R_{c}>R_{c, l o c}$ \\
$F_{h d}=R_{c}$ & $F_{h d}=R_{c, l o c}$ \\
\hline
\end{tabular}

$\mathrm{F}_{\mathrm{hd}}=$ força horizontal de cisalhamento.

(a) - Seção com momento fletor positivo
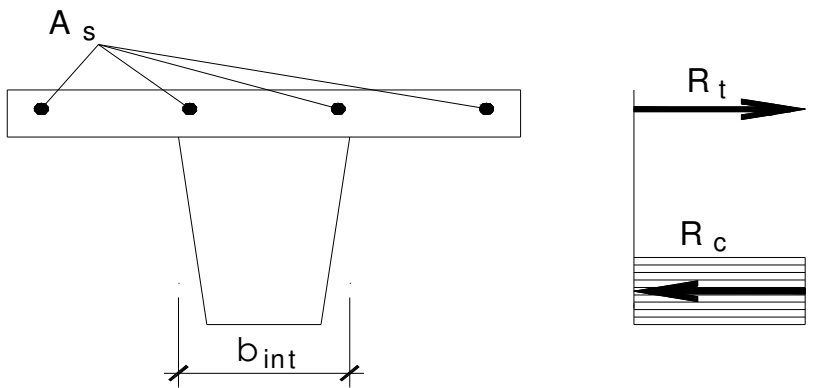

$$
F_{\text {hd }}=R_{t}
$$

(b) - Seção com momento fletor negativo

Figura 7.8 - Cálculo da força horizontal de cisalhamento ( $\left.F_{h d}\right)$ : (a) Seção com momento positivo;

(b) Seção com momento negativo. (Adaptado do PCl:2010). 


\section{3 - Tensões de cisalhamento resistentes segundo códigos}

A seguir será mostrado o cálculo das tensões de cisalhamento resistentes de acordo com os principais códigos internacionais e a NBR 9062:2006.

\subsection{1 - PRECAST/PRESTRESSED CONCRETE INSTITUTE (PCI)}

A metodologia apresentada no manual do $\mathrm{PCl}: 2010$ para a verificação do cisalhamento na interface de elementos compostos é a mesma presente no $\mathrm{ACl} 318$ 08:2008. Esse procedimento é válido tanto para situações em que a interface é comprimida (seção transversal com momento fletor positivo) quanto para situações em que a interface é tracionada (seção com momento negativo).

A resistência ao cisalhamento na interface ocorre quando a força horizontal solicitante de cálculo ( $\left.F_{\text {hd }}\right)$ é menor que a força horizontal resistente última ( $F_{\text {hu}}$ ) (expressão 7.6).

$$
\mathrm{F}_{\mathrm{hd}} \leq \mathrm{F}_{\mathrm{hu}}
$$

A força horizontal solicitante de cálculo $\left(F_{\text {hd }}\right)$ é obtida de acordo o exposto na Figura 7.8, adotando o mesmo princípio do cálculo da tensão média.

O cálculo da força horizontal última resistente $\left(F_{h u}\right)$ considera os seguintes casos:

$$
\begin{aligned}
& \text { Caso } 1 \quad F_{h d} \leq 0,56 . b_{\text {int }} \text { lo (tensão limite de 0,56 MPa) } \\
& \text { Caso } 2 \text { 0,56. } b_{\text {int }} . l_{0}<F_{h d} \leq 2,45 . b_{\text {int }} \text { lo } \quad \text { (entre 0,56 e 2,45 MPa) } \\
& \text { Caso } 3 \quad F_{h d} \geq 2,45 . b_{\text {int }} \text { lo (tensão limite de 2,45 MPa) }
\end{aligned}
$$

No caso 2 é necessária a utilização de armadura mínima. Já no caso 3 deve ser utilizada armadura calculada pela teoria do atrito-cisalhamento.

O caso 1 desobriga a utilização de armadura desde que a superfície seja "intencionalmente rugosa", embora o $\mathrm{PCl}$ não estabeleça de forma explícita as considerações para superfície "normal" ou "intencionalmente rugosa". Há apenas uma nota onde se diz que a experiência prática e ensaios experimentais indicam que os métodos utilizados no acabamento das superfícies dos elementos de concreto prémoldado qualificam essas superfícies como "intencionalmente rugosa". Além disso, o PCI recomenda que nos casos de superfícies pouco rugosas, como é o caso das lajes alveolares fabricadas por extrusora ou moldadora (ver Figura 1.2, letras a e b), a tensão limite de 0,56 MPa seja reduzida pela metade. 


\subsection{2 - CANADIAN PRECAST/PRESTRESSED CONCRETE INSTITUTE (CPCI)}

O manual do $\mathrm{CPCl}: 2007$ apresenta metodologia muito semelhante à do $\mathrm{PCl}$. Contempla situações de compressão e de tração, e a verificação ao cisalhamento é feita comparando a força horizontal solicitante de cálculo $\left(V_{f 1}\right)$ com a força horizontal última resistente $\left(\mathrm{V}_{\mathrm{rd}}\right)$ (expressão 7.7$)$.

$$
\mathrm{V}_{\mathrm{f} 1} \leq \mathrm{V}_{\mathrm{r} 1}
$$

A força solicitante é calculada da mesma forma que no item anterior, através da Figura 7.8 .

Para a força resistente, semelhante ao $\mathrm{PCl}$, o caso 1 considera superfície "intencionalmente rugosa" e sem armadura de cisalhamento. Além disso, é necessário que a superfície de contato esteja limpa e livre de nata superficial.

Caso $1 \quad V_{f 1} \leq 0,70 \phi_{c} . b_{\text {int. }} \quad\left(\phi_{c}=0,65\right)$

Não há indicações para limites da tensão média quando a superfície for pouco rugosa, tal como nas lajes dos modelos EM2 e EM3. Por isso, para esses casos, será utilizada metade do produto $0,70 . \phi_{c}$, assim como no método do $\mathrm{PCl}$.

\subsection{3 - FÉDÉRATION INTERNATIONALE DE LA PRÉCONTRAINTE (FIP)}

O documento da FIP:1982 vale somente para os elementos simplesmente apoiados. No entanto será utilizado neste trabalho, para os trechos de momento positivo.

A expressão 7.8 apresenta a verificação ao cisalhamento na interface, na qual a tensão de referência correspondente ao cisalhamento $\left(\tau_{\text {ref }}\right)$ deve ser menor que a tensão última $\left(\tau_{u}\right)$.

$$
\tau_{\text {ref }} \leq \tau_{\mathrm{u}}
$$

A tensão de referência é obtida conforme o item 7.2.1. Já a tensão última é dada pela expressão 7.9, apresentada a seguir, para situações de alta solicitação de cisalhamento.

$$
\tau_{u}=\beta_{s} \cdot \rho \cdot f_{y d}+\beta_{c} \cdot f_{t d}<0,31 f_{c k}
$$


- $\rho=$ taxa de armadura de cisalhamento, $\rho=\frac{\mathrm{A}_{\mathrm{st}}}{\mathrm{s}_{\mathrm{b}} \mathrm{b}_{\text {int }}} \geq 0,001$;

- $\mathrm{A}_{\mathrm{st}}=$ área de armadura transversal que atravessa a interface e se encontra efetivamente ancorada;

- $\mathrm{s}=$ espaçamento da armadura transversal;

- $\mathrm{f}_{\mathrm{yd}}=$ resistência de cálculo do aço;

- $\mathrm{f}_{\mathrm{td}}=$ resistência de cálculo do concreto à tração;

- $\beta_{\mathrm{s}} \mathrm{e} \beta_{\mathrm{c}}=$ coeficientes multiplicativos para as parcelas do aço e do concreto (ver Tabela 7.1).

Tabela 7.1 - Coeficientes de rugosidade de acordo com FIP:1982.

\begin{tabular}{|c|c|c|}
\hline \multirow{2}{*}{ Coeficiente } & \multicolumn{2}{|c|}{ Categoria da superfície } \\
\cline { 2 - 3 } & $\mathbf{1}$ & $\mathbf{2}$ \\
\hline$\beta_{\mathrm{s}}$ & 0,60 & 0,90 \\
\hline$\beta_{\mathrm{c}}$ & 0,20 & 0,40 \\
\hline
\end{tabular}

As categorias presentes na Tabela 7.1, correspondem à seguinte descrição:

- Superfície naturalmente rugosa = categoria 1 - correspondendo aos Níveis 3 a 6;

- Superfície intencionalmente rugosa = categoria 2 - correspondendo aos Níveis 7 a 10.

Para as superfícies lisas (correspondentes aos Níveis 1 e 2), é sugerido adotar $\beta_{c}=0,10$. De acordo com a Tabela 7.1, as lajes dos ensaios EM2 e EM3 são classificadas como de superfície lisa, enquanto que a do ensaio EM1, superfície naturalmente rugosa (categoria 1).

Segundo a FIP:1982, a resistência de cálculo do concreto à tração pode ser estimada com a expressão 7.10 .

$$
\mathrm{f}_{\mathrm{td}}=0,28 \sqrt{\mathrm{f}_{\mathrm{ck}}}(\mathrm{em} \mathrm{MPa})
$$

Vale ressaltar que, para a aplicação dos modelos ensaiados neste trabalho, a parcela correspondente à armadura de cisalhamento na expressão 7.9 será considerada igual a zero. 


\subsection{4 - EUROPEAN STANDARD (EUROCODE)}

De acordo como o código europeu EUROCODE 2:2004, a tensão de referência correspondente ao cisalhamento na interface $\left(\mathrm{V}_{\mathrm{Edi}}\right)$ deve ser menor que a tensão última $\left(V_{\text {Rdi }}\right)$, o que é indicado na expressão 7.11. Tal verificação é válida para solicitação de momento fletor positivo e negativo.

$$
\mathrm{V}_{\mathrm{Edi}} \leq \mathrm{V}_{\mathrm{Rdi}}
$$

Da mesma forma que na FIP:1982, a tensão de referência $\left(V_{\text {Edi }}\right)$ é obtida conforme o item 7.2.1. Já a tensão última é dada pela expressão 7.12.

$$
V_{\text {Rdi }}=\text { c. } f_{\text {ctd }}+\mu \cdot \sigma_{n}+\rho \cdot f_{y d}(\mu \cdot \operatorname{sen} \alpha+\cos \alpha) \leq 0,5 \cdot v \cdot f_{c t d}
$$

- $\mathrm{c}=$ coeficiente correspondente ao fator de coesão;

- $\mu=$ coeficiente correspondente ao fator de fricção;

- $\rho=$ taxa de armadura de cisalhamento, $\rho=\frac{A_{\text {st }}}{s . b_{\text {int }}} \geq 0,001$;

- $\mathrm{A}_{\mathrm{st}}=$ área de armadura transversal que atravessa a interface e se encontra efetivamente ancorada;

- $\mathrm{s}=$ espaçamento da armadura transversal;

- $\mathrm{f}_{\mathrm{ctd}}=$ resistência de cálculo do concreto à tração, $\mathrm{f}_{\mathrm{ctd}}=\frac{\mathrm{f}_{\mathrm{ctk}, 0,05}}{\gamma_{\mathrm{c}}}$;

- $\sigma_{\mathrm{n}}=$ corresponde à uma eventual tensão de compressão agindo na interface;

- $\alpha=$ inclinação da armadura de cisalhamento que cruza a interface.

- $v=0,6\left[1-\frac{f_{c k}}{250}\right], f_{c k}$ em MPa;

Os coeficientes c e $\mu$ dependem da rugosidade da interface e encontram-se na Tabela 7.2. De acordo com a Tabela 7.2, as lajes dos ensaios EM2 e EM3 são classificadas como muito lisas, enquanto que a laje do ensaio EM1, lisa.

Vale ressaltar que para a aplicação dos modelos ensaiados neste trabalho, as parcelas da força normal e da armadura de cisalhamento na expressão 7.12 serão consideradas iguais a zero.

Consultando a Tabela 3.1 do EUROCODE 2:2004, percebe-se que $f_{c t k, 0,05}$ equivale ao valor de $f_{c t k, \text { inf }}$ presente na norma NBR 6118:2014. Vale ressaltar que a expressão 7.12 será aplicada em modelos ensaiados experimentalmente, e por isso, será considerado que $f_{c t d}=f_{c t k, i n f}$ 
Tabela 7.2 - Coeficientes de rugosidade de acordo com o EUROCODE 2:2004.

\begin{tabular}{|c|c|c|}
\hline \multirow{2}{*}{ Característica da interface } & \multicolumn{2}{|c|}{ Coeficiente } \\
\hline & c & $\mu$ \\
\hline $\begin{array}{c}\text { Muito lisa (formas de aço, plástico ou madeira } \\
\text { tratada) }\end{array}$ & 0,25 & 0,50 \\
\hline $\begin{array}{l}\text { Lisa (superfícies que não receberam tratamentos } \\
\text { após a vibração) }\end{array}$ & 0,35 & 0,60 \\
\hline $\begin{array}{l}\text { Rugosa (superfície em que os agregados ficam } \\
\text { expostos) }\end{array}$ & 0,45 & 0,70 \\
\hline $\begin{array}{c}\text { Muito rugosa (superfícies intencionalmente } \\
\text { rugosas) }\end{array}$ & 0,50 & 0,90 \\
\hline
\end{tabular}

\subsection{5 - FÉDÉRATION INTERNATIONALE DU BÉTON (FIB)}

O boletim 56 da FIB (FIB MODEL CODE 2010) possui a mesma metodologia do EUROCODE 2:2004.

\subsection{6 - BRITISH STANDARD (BS)}

Para a verificação da tensão cisalhante na interface (expressão 7.13) pela norma britânica BS 8110-1:1997, a tensão solicitante de projeto $\left(\tau_{s, \text { med }}\right)$ deve ser menor que a tensão limite $\left(\tau_{\text {lim }}\right)$ apresentada pela Tabela 7.3.

$$
\tau_{\mathrm{S}, \mathrm{med}} \leq \tau_{\mathrm{lim}}
$$

A tensão solicitante ( $\tau_{s, \text { med }}$ ) é calculada da mesma forma que para o $\mathrm{PCl}$. Entretanto, enquanto no $\mathrm{PCl}$ se utiliza uma força horizontal de cisalhamento ( $\left.F_{\text {hd }}\right)$, na norma britânica se emprega o conceito de tensão média, calculada de acordo com a expressão 7.5.

Tabela 7.3- Valores para tensão limite de acordo com a BS 8110-1:1997.

\begin{tabular}{|c|c|c|c|}
\hline \multirow{2}{*}{ Característica da interface } & \multicolumn{3}{|c|}{ Concreto da capa (f $\mathbf{f}_{\text {ck }}$ em MPa) } \\
\cline { 2 - 4 } & $\mathbf{2 5}$ & $\mathbf{3 0}$ & $\mathbf{7 4 0}$ \\
\hline $\begin{array}{c}\text { Concreto moldado e vibrado deixando uma superfície } \\
\text { rugosa }\end{array}$ & 0,40 & 0,55 & 0,65 \\
\hline $\begin{array}{c}\text { Superfície em que os agregados são expostos } \\
\text { utilizando alguma ferramenta, tal como escovação }\end{array}$ & 0,60 & 0,65 & 0,75 \\
\hline Tratamento especial de limpeza e rugosidade & 0,70 & 0,75 & 0,80 \\
\hline
\end{tabular}


A laje do modelo 1 foi moldada e vibrada, ficando com uma superfície rugosa. Além disso, o concreto da capa apresentou $28 \mathrm{MPa}$ de resistência à compressão. Isso implica que a tensão limite do EM1 é igual a 0,63 MPa.

A laje do modelo 2 foi produzida em uma extrusora e, portanto, resultou uma superfície muito lisa. $\mathrm{O}$ concreto da capa apresentou $55 \mathrm{MPa}$ de resistência à compressão. Como a Tabela 7.2 não contempla essa característica de superfície de interface, será utilizado o limite de 0,55 MPa.

A laje do modelo 3 possui as mesmas características de EM2, sendo que o resultado da resistência à compressão do concreto da capa foi de $44 \mathrm{MPa}$. Portanto, também será utilizado o valor de 0,55 MPa para a tensão limite.

\subsection{7 - ASSOCIAÇÃO BRASILEIRA DE NORMAS TÉCNICAS (ABNT)}

A norma brasileira NBR 9062:2006 apresenta metodologia semelhante à dos códigos internacionais, nos quais a tensão de solicitação $\left(\tau_{\varsigma d}\right)$ deve ser menor que a tensão resistente última $\left(\tau_{u d}\right)$, expressão 7.14

$$
\tau_{\mathrm{Sd}} \leq \tau_{\mathrm{ud}}
$$

A tensão de solicitação é calculada da mesma forma que na norma britânica, utilizando os conceitos de tensão média (expressão 7.3) derivados do PCl (Figura 7.8).

A tensão última de resistência apresentada pela expressão 7.15 é derivada da expressão 7.9 da FIP:1982. As únicas diferenças estão nos valores dos coeficientes de rugosidade $\beta_{\mathrm{s}}$ e $\beta_{\mathrm{c}}$, que dependem da taxa de armadura de cisalhamento. Esses coeficientes são mostrados na Tabela 7.4.

$$
\tau_{\mathrm{ud}}=\beta_{\mathrm{s}} \cdot \rho \cdot \mathrm{f}_{\mathrm{yd}}+\beta_{\mathrm{c}} \cdot \mathrm{f}_{\mathrm{ctd}}<0,25 \mathrm{f}_{\mathrm{cd}}
$$

Tabela 7.4- Valores dos coeficientes rugosidade de acordo com a NBR 9062:2006.

\begin{tabular}{|c|c|c|}
\hline \multirow{2}{*}{ Coeficiente } & \multicolumn{2}{|c|}{ Taxa de armadura } \\
\cline { 2 - 3 } & $\boldsymbol{\rho} \leq \mathbf{0 , 2 0}$ & $\boldsymbol{\rho} \geq \mathbf{0 , 5 0}$ \\
\hline$\beta_{\mathrm{s}}$ & 0 & 0,90 \\
\hline$\beta_{\mathrm{c}}$ & 0,30 & 0,60 \\
\hline
\end{tabular}


Vale ressaltar que, para a aplicação dos modelos ensaiados neste trabalho, a parcela correspondente à armadura de cisalhamento na expressão 7.15 será considerada igual a zero.

Os coeficientes da Tabela 7.4 são válidos apenas para superfície de ligação intencionalmente áspera, com rugosidade de 0,50 cm em 3,0 cm. Para superfícies lisas ou naturalmente rugosas, os valores dos coeficientes de rugosidades devem ser obtidos através de ensaios específicos.

Para as lajes dos ensaios EM2 e EM3, cujas superfícies são lisas, foi considerado $\beta_{c}$ igual a 0,1. Para a laje do modelo 1 , cuja superfície é naturalmente rugosa, foi considerado $\beta_{c}$ igual 0,2. Dessa forma os valores dos coeficientes ficam iguais aos da FIP:1982. A única

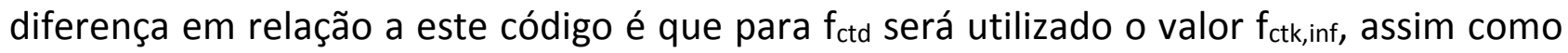
foi explicado no item 7.3.4, correspondente ao EUROCODE 2:2004.

\section{4 - Tensões resistentes de acordo com IBRAHIM (2008)}

IBRAHIM (2008) realizou ensaios chamados "push-off" para medir a resistência ao cisalhamento de interfaces entre a capa e a laje alveolar. Nesse ensaio uma força é aplicada paralela à interface, como mostra a Figura 7.9. A tensão última resistida pela interface equivale à força medida pela célula de carga dividida pela área de contato entre a capa e a laje.

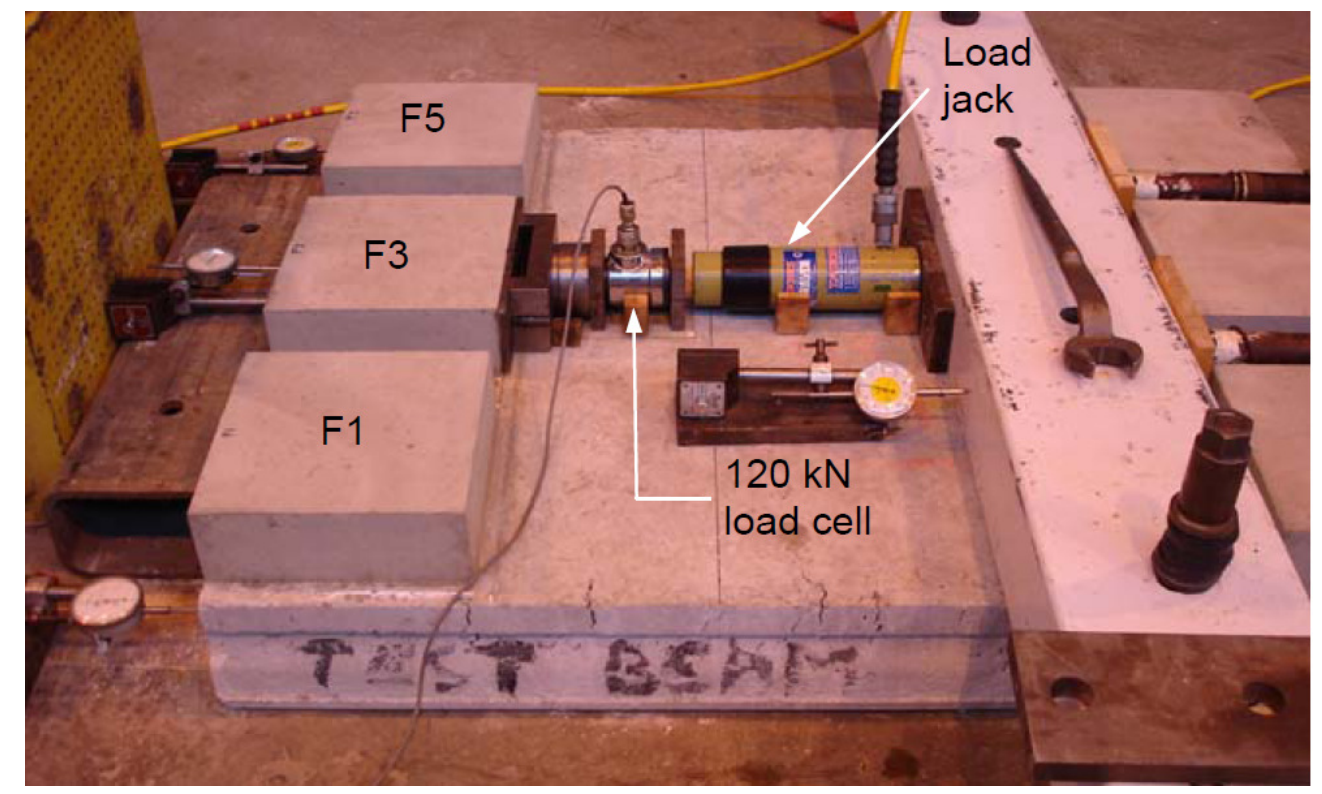

Figura 7.9 - Ensaio de "push-off” realizado por IBRAHIM (2008). 
Foram estudados três parâmetros principais: rugosidade da superfície da laje, condições de preparo da superfície e percentual de área da capa naturalmente ligada à laje.

Entre os tipos de rugosidade da superfície estudados estão: superfície lisa (da forma como a laje alveolar é produzida por moldadoras e extrusoras) e superfície naturalmente rugosa (obtida pelo escovamento do concreto ainda fresco). As condições de preparo consideram a superfície da laje alveolar seca, molhada em condições ótimas ou com água em excesso (água empoçada).

Com relação ao percentual da área da capa naturalmente ligada à laje, foram escolhidos os seguintes valores: $0 \%, 50 \%$ e 100\%. Essas taxas correspondem aos percentuais de nata de cimento (Figura 7.2), poeira, óleo etc. deixados na laje antes da concretagem da capa. Para isso foram utilizadas fbras de polietileno com $0,01 \mathrm{~m}$ de espessura.

O carregamento foi aplicado a uma taxa de $10 \mathrm{kN} / \mathrm{min}$, até ocorrer a ruína. A ruptura ocorreu de forma súbita, e foi considerada quando houve separação entre a capa e a laje. Durante as etapas iniciais da aplicação do carregamento, não houve deslocamento entre a capa e a laje, ou esse deslocamento ficou compreendido entre 0,01 e 0,02 mm.

Seguem algumas conclusões a respeito dos ensaios realizados:

- Foi encontrado um deslocamento maior para as superfícies lisas. Isso mostra que o comportamento é melhor quando a superfície é rugosa;

- Os maiores resultados de resistência da interface foram observados quando a superfície estava molhada na condição ótima, era rugosa e estavam em contato $100 \%$ de área entre os concretos;

- A ligação entre a capa e a laje será fraca se a superfície estiver molhada em excesso. Esse excesso de água atua como uma segunda camada de isolamento entre os concretos. Independente da percentagem da área em contato, e também do tipo de superfície (rugosa e lisa), a situação saturada gerou os piores resultados;

- A resistência ao cisalhamento da interface é maior quando a superfície está seca, quando comparada como a superfície com água em excesso. Isso ocorre porque, mesmo seca, a superfície apresenta umidade estimada entre 12\% e 13\%;

- Quando as superfícies rugosas são comparadas com as lisas, existe um aumento da resistência da interface ao cisalhamento. Isso ocorre quando a superfície está na condição seca ou molhada na condição ótima. Entretanto, não ocorre quando a superfície está com água em excesso. Além disso, esse aumento ocorre para os casos de $50 \%$ e $100 \%$ da área em contato;

- O estudo mostrou que as superfícies com 50\% da área em contato registraram menores deslocamentos durante a ruptura, quando comparados com as situações de $100 \%$ da área em contato; 
- A utilização das fibras de polietileno foi eficiente para simular sujeira ou nata de cimento em excesso;

- Diferentes tipos de superfície não contribuem para aumento da resistência ao cisalhamento, quando se têm $50 \%$ da área da interface em contato;

- Para as situações de $100 \%$ da área em contato e superfície molhada em condição ótima, as resistências ao cisalhamento na interface alcançam valores acima do limite estabelecido pela norma britânica BS 8110-1:1997;

- Quando a área de contato é de $50 \%$, os valores de resistência ao cisalhamento sempre ficam abaixo dos limites de tensão da BS 8110-1:1997;

- Para situações de $100 \%$ da área em contato, foi observada uma relação linear entre a resistência do concreto à compressão e a resistência da interface. Esse aumento foi influenciado pelo tipo de preparo da superfície, sendo que para superfície molhada na condição ótima e $f_{c k}$ acima de $35 \mathrm{MPa}$ a média da resistência da interface é $20 \%$ maior que nas situações seca e água em excesso;

- Os resultados indicaram que, isoladamente, a resistência do concreto à compressão tem pouco efeito na resistência da interface;

- Se área de contato entre os concretos for de 50\%, a amplitude da rugosidade terá pouco efeito na resistência da interface ao cisalhamento;

- Se o coeficiente que determina a média da rugosidade $\left(R_{a}\right)$ for o mesmo para lajes lisas e rugosas, a amplitude da rugosidade terá pouco efeito na resistência ao cisalhamento.

A equação sugerida por IBRAHIM (2008) para o cálculo da resistência da interface ao cisalhamento é derivada da formulação do EUROCODE 2:2004, dada pela expressão 7.12.

Considerando que não exista atuação de tensão normal à interface e que o elemento composto não possua armadura atravessando essa interface, a formulação sugerida por IBRAHIM (2008) é apresentada pelas expressões 7.16a e 7.16b, cujas variáveis são explicadas nos próximos itens.

$$
\begin{aligned}
& \tau=\mathrm{w}_{\mathrm{a}, \mathrm{wet}}\left(\mathrm{c} \cdot \mathrm{s}_{\mathrm{c}} \cdot \mathrm{f}_{\mathrm{t}}+\tau_{\mathrm{r}}\right)\left(\mathrm{R}_{\mathrm{z}} \leq 1,40 \mathrm{~mm} \mathrm{e} 1^{\circ} \leq \alpha<5^{\circ}\right) \\
& \tau=\mathrm{w}_{\mathrm{a}, \mathrm{wet}}\left(\mathrm{c} \cdot \mathrm{s}_{\mathrm{c}} \cdot \mathrm{f}_{\mathrm{t}}-\tau_{\mathrm{r}}\right)\left(\mathrm{R}_{\mathrm{z}}>1,40 \mathrm{~mm} \text { e } 18^{\circ} \leq \alpha<30^{\circ}\right)
\end{aligned}
$$

- $\mathrm{f}_{\mathrm{t}}=$ resistência do concreto à tração (para aplicação nos modelos ensaiados será considerado $\mathrm{f}_{\mathrm{t}}=\mathrm{f}_{\mathrm{ctk} \text {,inf; }}$; 


\subsection{1 - Área de contato (sc)}

$\mathrm{O}$ coeficiente $\mathrm{s}_{\mathrm{c}}$ considera simultaneamente a percentagem da área de contato entre os dois concretos da interface e, também, o tipo de superfície (lisa ou rugosa).

De acordo com os resultados obtidos pelos testes de IBRAHIM (2008), o coeficiente Sc é obtido conforme a Tabela 7.5.

Tabela 7.5 - Valores do coeficiente $s_{c}$ de acordo com IBRAHIM (2008).

\begin{tabular}{|c|c|c|c|c|}
\hline \multirow{2}{*}{$\begin{array}{c}\text { Umidade da } \\
\text { superfície }\end{array}$} & \multicolumn{2}{|c|}{$\mathbf{1 0 0 \%}$ da área em contato } & \multicolumn{2}{|c|}{$\mathbf{5 0 \%}$ da área em contato } \\
\cline { 2 - 5 } & Rugosa & Lisa & Rugosa & Lisa \\
\hline Ótima & 1 & 1 & 0,55 & 0,44 \\
\hline Seca & 0,72 & 0,72 & 0,55 & 0,44 \\
\hline Saturada & 0,44 & 0,42 & 0,55 & 0,44 \\
\hline
\end{tabular}

\subsection{2 - Umidade da interface $\left(w_{a, w e t}\right)$}

O coeficiente $w_{a \text {,wet }}$ considera o efeito da porcentagem de água absorvida pela superfície superior da laje alveolar de forma isolada, e assume como referência a condição em que a laje é molhada na condição ótima. Os valores desse coeficiente são apresentados na Tabela 7.6.

Tabela 7.6 - Valores do coeficiente wa,wet de acordo com IBRAHIM (2008).

\begin{tabular}{|c|c|}
\hline $\begin{array}{c}\text { Umidade da } \\
\text { superfície }\end{array}$ & $\begin{array}{c}\text { Coeficiente } \\
\mathbf{w}_{\mathbf{a}, \text { wet }}\end{array}$ \\
\hline Ótima & 1 \\
\hline Seca & 0,85 \\
\hline Saturada & 0,85 \\
\hline
\end{tabular}

\subsection{3 - Rugosidade da superfície $\left(\tau_{r}\right)$}

A Figura 7.9 ilustra a idealização de uma superfície de contato feita por IBRAHIM (2008). Nessa figura, a rugosidade de uma laje alveolar é influenciada por alguns fatores que incluem: o ângulo de inclinação das ranhuras $(\alpha)$, o comprimento entre dois vales ou dois picos $\left(a_{p}\right)$ e o coeficiente de rugosidade $\left(R_{z}\right)$. 


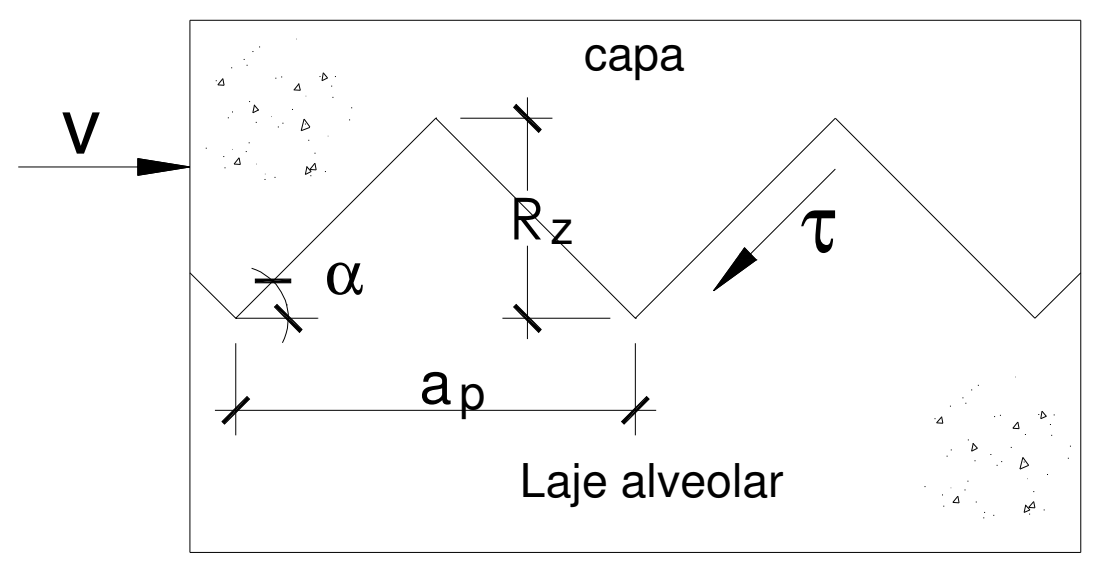

Figura 7.9 - Idealização da superfície de contato de uma interface. (Adaptado de IBRAHIM (2008)).

O coeficiente de rugosidade representa a maior distância entre um pico e um vale $\left(R_{z}\right)$ e foi definida por SANTOS et al (2007) como sendo a média entre cinco valores de máximas distâncias $(z)$ entre picos e vales, ao longo de um comprimento $\ell$ (ver expressão 7.17 e Figura 7.10).

$$
\mathrm{R}_{\mathrm{z}}=\frac{1}{5} \sum_{\mathrm{i}=1}^{5} \mathrm{z}_{\mathrm{i}}
$$

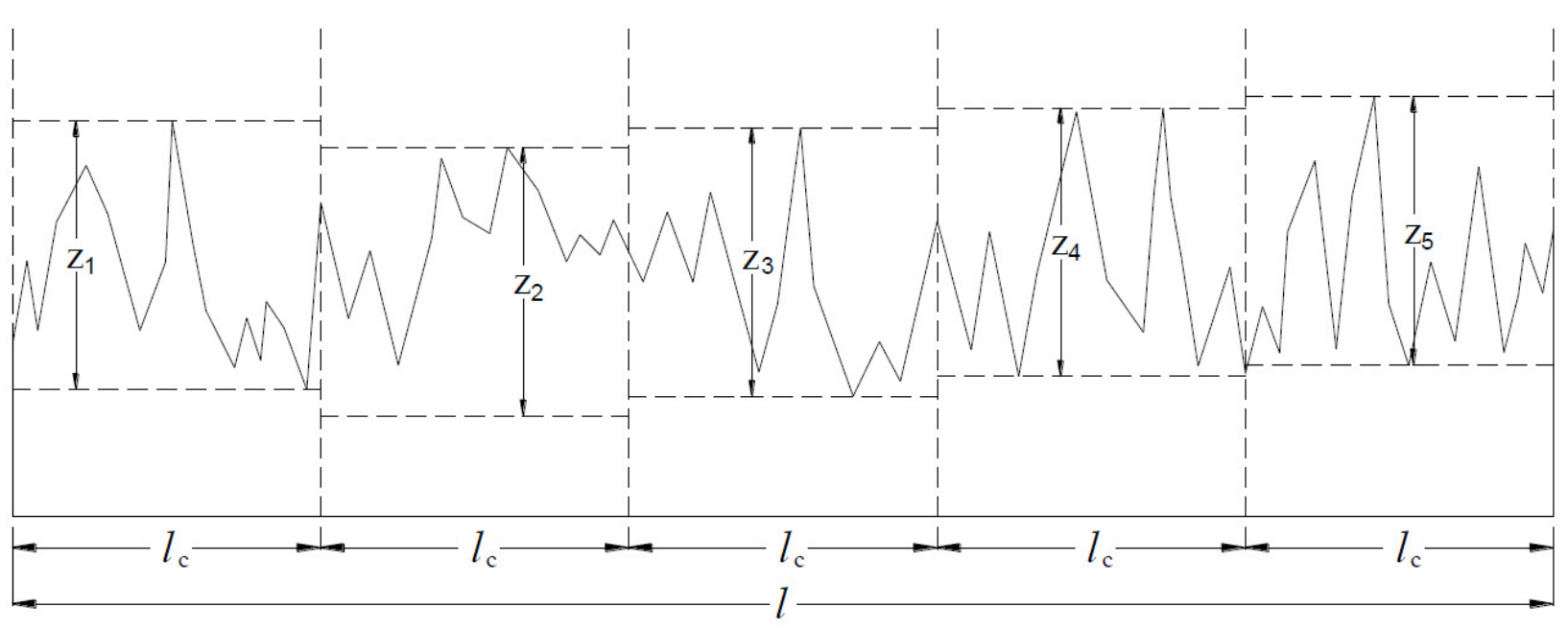

Figura 7.10 - Definição do coeficiente de rugosidade ( $\left.R_{z}\right)$. (Adaptado de IBRAHIM (2008)).

IBRAHIM (2008) concluiu, de acordo com os resultados obtidos, que, para superfícies lisas, $1^{\circ}<\alpha \leq 5^{\circ}$, e que $\mathrm{R}_{\mathrm{z}} \leq 1,40 \mathrm{~mm}$. Para superfícies rugosas, $18^{\circ} \leq \alpha<30^{\circ}$ e $\mathrm{R}_{\mathrm{z}}>1,40 \mathrm{~mm}$. Outra conclusão obtida foi que, nas situações em que o valor de $\alpha$ é menor que $5^{\circ}$, ou seja, para superfícies lisas, existe mais contato entre o concreto da laje e da capa.

Por outro lado, para superfícies rugosas, ou seja, quando o valor de $\alpha$ é maior que $18^{\circ}$, a resistência na interface é reduzida em função da menor área de contato entre os concretos. 
A parcela da resistência ao cisalhamento correspondente à rugosidade $\left(\tau_{r}\right)$ é definida pelas expressões 7.18a e 7.18b.

$$
\begin{aligned}
& \tau_{\mathrm{r}}=\frac{\left(\mathrm{R}_{\mathrm{z}, \text { limit }}-\mathrm{R}_{\mathrm{z}}\right) \cdot \tau_{\text {inc }}}{\mathrm{R}_{\mathrm{z}, \mathrm{inc}}}\left(\mathrm{R}_{\mathrm{z}} \leq 1,40 \mathrm{~mm} \mathrm{e} 1^{\circ} \leq \alpha<5^{\circ}\right) \\
& \tau_{\mathrm{r}}=\frac{\left(\mathrm{R}_{\mathrm{z}}-\mathrm{R}_{\mathrm{z}, \text { limit }}\right) \cdot \tau_{\mathrm{dec}}}{\mathrm{R}_{\mathrm{z}, \mathrm{dec}}}\left(\mathrm{R}_{\mathrm{z}}>1,40 \mathrm{~mm} \text { e } 18^{\circ} \leq \alpha<30^{\circ}\right) \\
& \text { - } \mathrm{R}_{\mathrm{z}, \text { limit }}=1,40 \mathrm{~mm} ; \\
& \text { - } \mathrm{R}_{\mathrm{z}, \text { inc }}=\mathrm{R}_{\mathrm{z}, \mathrm{dec}}=0,10 \mathrm{~mm} ; \\
& \text { - } \tau_{\text {inc }}=\tau_{\mathrm{dec}}=0,04 \mathrm{~N} / \mathrm{mm}^{2} .
\end{aligned}
$$

\subsection{4 - Coeficientes de coesão (c) - EUROCODE 2:2004}

Os coeficientes de coesão (c) são os mesmos encontrados no EUROCODE 2:2004, Tabela 7.2.

\subsection{5 - Observações quanto à formulação utilizada}

IBRAHIM (2008) apresenta duas formulações para o problema tratado. A primeira é relacionada com ensaio "push-off" e considera o coeficiente de friç̧ão $(\mu)$ na parcela da coesão. Além disso, a formulação para o "push-off" desconsidera a parcela de tensão normal à interface.

A segunda formulação é relativa ao ensaio de cisalhamento. Nesse caso o autor considera uma tensão normal à interface e emprega o coeficiente de fricção $(\mu)$, nessa parcela, assim como no EUROCODE 2:2004. Portanto existe uma contradição nas formulações propostas.

É importante ressaltar que, para o emprego da formulação de IBRAHIM (2008), algumas considerações foram feitas:

- Foi adotado que o coeficiente $\mu$ atua somente na parcela da tensão normal, assim como no EUROCODE 2:2004. Entretanto, essa parcela foi zerada, uma vez que não existiu tensão de compressão atuando na interface durante o ensaio de continuidade;

- Para os coeficientes $s_{c}$ e $W_{a}$,wet foram adotados os valores relativos ao ensaio "push-off", uma vez que esse ensaio analisa a interface de forma isolada. 


\section{5 - Resultados}

A seguir serão apresentados os resultados dos cálculos das tensões solicitantes e resistentes para os ensaios de continuidade dos modelos EM1, EM2 e EM3.

\subsection{1 - Tensões de cisalhamento solicitantes na interface}

Para o cálculo das tensões de cisalhamento solicitantes serão empregados os cálculos das tensões de referência e da tensão média.

\subsubsection{1 - Cálculo da tensão de referência}

Considerando o conceito de seção composta homogeneizada, apresentado no item 6.1.2 do capítulo 6 (ver Figura 6.1 e expressões 6.4 e 6.5), é possível obter a largura fictícia $\left(b_{\text {fic }}\right)$ e, em seguida, a largura da interface $\left(b_{\text {int }}\right)$. Para isso tem-se a Tabela 7.7.

Tabela 7.7 - Cálculo da largura da interface (bint).

\begin{tabular}{|c|c|c|c|c|c|c|c|c|}
\hline \multirow{2}{*}{ Modelo } & \multicolumn{2}{|c|}{ CAPA } & \multicolumn{2}{|c|}{ LAJE ALVEOLAR } & \multirow[b]{2}{*}{$\alpha_{m}$} & \multirow{2}{*}{$\begin{array}{l}\mathbf{b}_{\text {real }} \\
(\mathbf{m})\end{array}$} & \multirow{2}{*}{$\begin{array}{c}\mathbf{b}_{\text {fic }} \\
(\mathbf{m})\end{array}$} & \multirow{2}{*}{$\begin{array}{l}\mathbf{b}_{\text {int }} \\
(\mathbf{m})\end{array}$} \\
\hline & $\begin{array}{c}\mathbf{f}_{\mathrm{cj}, \text { continuidade }} \\
\text { (MPa) }\end{array}$ & $\mathbf{E}_{\mathrm{cs}}(\mathbf{M P a})$ & $\begin{array}{c}\mathbf{f}_{\mathrm{cj}, \text { continuidade }} \\
\text { (MPa) }\end{array}$ & $\mathbf{E}_{\mathrm{cs}}(\mathbf{M P a})$ & & & & \\
\hline EM1 & 28 & 29632 & 54 & 41151 & 0,72 & 1,97 & 1,42 & 1,42 \\
\hline EM2 & 55 & 41531 & 38 & 34521 & 1,20 & 1,19 & 1,43 & 1,19 \\
\hline EM3 & 44 & 37146 & 55 & 41531 & 0,89 & 1,18 & 1,06 & 1,06 \\
\hline
\end{tabular}

A largura da interface $\left(b_{\text {int }}\right.$ ) será utilizada para o cálculo das tensões solicitantes nas seções onde atuam o momento fletor positivo. No entanto, para equilíbrio da seção transversal considerando o momento negativo, é necessário utilizar a largura real da laje alveolar na região de compressão. Considerando a mesa inferior comprimida, os valores utilizados são:
- EM1
$\mathrm{b}_{\text {real,mesa_inferior }}=2,00 \mathrm{~m}$;
- $\mathrm{EM} 2 \rightarrow$
$\mathrm{b}_{\text {real,mesa_inferior }}=1,25 \mathrm{~m}$;
- EM3
$\mathrm{b}_{\text {real,mesa_inferior }}=1,25 \mathrm{~m}$.

Para o cálculo da tensão de referência será considerada a força cortante correspondente à aplicação da força de ruptura $F_{2}$. Além disso, os valores da força cortante (Tabela 7.8) foram obtidos da análise não linear física, apresentada no capítulo 6. A Tabela 7.8 mostra, também, em qual elemento ocorreu a máxima força cortante, de acordo com a (Figura 6.7, letra b). 
Tabela 7.8 - Valores das forças cortantes máximas obtidas de acordo com o capítulo 6.

\begin{tabular}{|c|c|c|c|c|c|c|}
\hline \multirow{2}{*}{ Modelo } & \multicolumn{2}{|c|}{ Momento Positivo } & \multicolumn{2}{|c|}{ Momento Negativo } & \multirow{2}{*}{$\begin{array}{c}\mathbf{F}_{2} \\
(\mathbf{k N})\end{array}$} & \multirow{2}{*}{$\begin{array}{l}\text { Tipo de } \\
\text { ruptura }\end{array}$} \\
\hline & $\mathbf{Q}_{\max }(\mathbf{k N})$ & Elemento & $\mathbf{Q}_{\max }(\mathbf{k N})$ & Elemento & & \\
\hline EM1 & 206,8 & 13 & 212,7 & 15 & 272,0 & cisalhamento \\
\hline EM2 & 191,4 & 12 & 197,6 & 15 & 254,7 & interface \\
\hline EM3 & 119,9 & 12 & 124,3 & 15 & 146,8 & flexão \\
\hline
\end{tabular}

O braço de alavanca (z) corresponde à distância entre as resultantes de compressão $\left(R_{c}\right)$ e de tração $\left(R_{t}\right)$ no equilíbrio da seção transversal. O cálculo de $z$ será feito considerando o equilíbrio da seção composta e a discretização de faixas apresentados no capítulo 3, item 3.6, e APÊNDICE A.

Nos trechos correspondentes ao momento fletor positivo, o procedimento consistirá nos seguintes passos:

- Determinar a resultante de tração $\mathrm{R}_{\mathrm{t}}$, correspondente à armadura de protensão $R_{t}=A_{p} \cdot \sigma_{p k}$

- $A_{p}$ é a área da seção da armadura de protensão;

- $\sigma_{p k}$, a tensão na armadura de protensão considerando as perdas isoladas, calculadas no capítulo 3 (ver procedimento no item 3.6.1, Tabela 3.17). Foi adotada uma aproximação, considerando $\varepsilon_{\mathrm{s}}$ igual a $10 \%$. É fato que, quando a deformação total $\left(\varepsilon_{t}\right)$ é maior que a deformação correspondente ao escoamento $\left(\varepsilon_{y k}\right)$, a tensão de cisalhamento na interface pouco se altera, quando se varia o valor de $\varepsilon_{\mathrm{s}}$. Essa variação é menor que $0,5 \mathrm{MPa}$;

- Calcular a resultante de compressão correspondente à capa $\left(\mathrm{R}_{\mathrm{c}, \mathrm{loc}}\right)$ $R_{c, l o c}=0,85 . f_{c d} \cdot A_{c . l o c}$

- $A_{c, \text { loc }}$ é a área de concreto da capa, ou seja: $A_{c . l o c}=h_{c a p a} \cdot b_{f i c}$, sendo $\mathrm{h}_{\text {capa }}$ a altura da capa e $\mathrm{b}_{\text {fic }}$ a largura da interface, considerando a seção equivalente;

- $f_{c d}$ é o valor da resistência do concreto à compressão, na data do ensaio de continuidade $\left(f_{c j}\right.$,continuidade);

- Comparar $R_{t}$ com $R_{c, l o c}$

- Se $R_{t}$ for menor que $R_{c, l o c}$ implica que a linha neutra se encontra acima da interface, ou seja, na capa, como mostra a Figura 7.5. Nesse caso deve-se utilizar a expressão 7.3;

- Caso contrário a linha neutra se encontrará abaixo da interface, ou seja, na laje como ilustra a Figura 7.6. Nesse caso deve-se utilizar a expressão 7.4; 
- De posse de $R_{\mathrm{t}}$, consultar qual faixa corresponde ao equilíbrio, ou seja, $R_{t}=R_{c}$. Automaticamente se obtém a posição da linha neutra $(x)$ e o valor de $y=0,8 . x$;

- Vale destacar que se $R_{t}$ é menor que $R_{c, l o c}$ e a linha neutra encontra-se acima da interface, pode-se obter $z$ diretamente, considerando $y=\frac{R_{t}}{0,85 . f_{c d} \cdot b_{f i c}}$;

- Por fim, $z=\left(h_{t o t}-d^{\prime}\right)-0,4 \cdot x=d-0,5 \cdot y$.

O procedimento correspondente ao momento fletor negativo é semelhante e segue os seguintes passos:

- Determinar a resultante de tração $\mathrm{R}_{\mathrm{t}}$, correspondente à armadura passiva $R_{t}=A_{s} \cdot f_{y k}$

- $A_{s}$ é a área da seção da armadura passiva;

- $f_{y k}$, a tensão na armadura passiva correspondente à deformação encontrada durante a ruptura, se a deformação na armadura for menor que 2,07\%o. Caso contrário é a tensão de escoamento obtida no ensaio de caracterização da barra;

- De posse de $R_{\mathrm{t}}$, consultar qual faixa corresponde ao equilíbrio, ou seja, $R_{t}=R_{c}$. Automaticamente se obtém a posição da linha neutra $(\mathrm{x})$ e o valor de $y=0,8 . x$;

- Por fim, $z=\left(h_{t o t}-d^{\prime}\right)-0,4 . x=d-0,5 . y$.

A Tabela 7.9 mostra o cálculo do valor de $R_{t}$ para as seções com momento positivo.

A Tabela 7.10 apresenta os cálculos para a obtenção do braço de alavanca (z) correspondente às seções submetidas ao momento fletor positivo. Vale ressaltar que o resultado final foi o mesmo quando se considerou os valores das perdas progressivas ao invés das perdas isoladas.

A Tabela 7.11 indica os cálculos de z referentes ao momento fletor negativo.

Por fim, a Tabela 7.12 ilustra os cálculos correspondentes à tensão de referência atuante nos elementos mais solicitados. 
Tabela 7.9 - Cálculo da resultante de tração $\left(R_{t}\right)$ na armadura ativa - seções com momento positivo.

\begin{tabular}{|c|c|c|c|c|}
\hline Var. & EM1 & EM2 & EM3 & Referência \\
\hline$\sigma_{\mathrm{pi}}(\mathrm{MPa})$ & 1420 & 1257,6 & 1330,3 & Tabela 3.15 \\
\hline $\begin{array}{c}\text { PERDAS } \\
\text { ISOLADAS } \\
(\%)\end{array}$ & 24,18 & 31,09 & 12,25 & Tabela 3.15 \\
\hline$\sigma_{\mathrm{pt}, \infty}(\mathrm{MPa})$ & 1076,65 & 866,63 & 1167,40 & Tabela 3.18 \\
\hline $\mathrm{E}_{\mathrm{p}}(\mathrm{MPa})$ & 200387 & 200387 & 201000 & Tabela 4.28 \\
\hline$\varepsilon_{\mathrm{p}}(\% \circ)$ & 5,37 & 4,32 & 5,81 & Tabela 3.16 \\
\hline $\mathrm{A}_{\mathrm{p}}\left(\mathrm{cm}^{2}\right)$ & 8,91 & 9,90 & 2,63 & Tabela 3.15 \\
\hline $\mathrm{A}_{\mathrm{c}}\left(\mathrm{cm}^{2}\right)$ & 0,2357 & 0,1866 & 0,1166 & Tabela 3.1 \\
\hline$N_{p}(\mathrm{kN})$ & 959 & 858 & 285 & Tabela 3.18 \\
\hline$e_{p}(m)$ & 0,0734 & 0,0863 & 0,0493 & Tabela 3.1 \\
\hline$M_{p}(\mathrm{kN})$ & 70,41 & 74,04 & 14,07 & Tabela 3.18 \\
\hline $\mathrm{I}\left(\mathrm{m}^{4}\right)$ & 0,0013 & 0,0016 & 0,0004 & Item 3.1 \\
\hline $\mathrm{f}_{\mathrm{ck}, \mathrm{capa}}(\mathrm{cm})$ & 28 & 55 & 44 & Tabela 4.28 \\
\hline$\varepsilon_{7}(\% \circ)$ & 0,32 & 0,24 & 0,13 & Tabela 3.16 \\
\hline$\varepsilon_{\mathrm{s}}(\% \circ)$ & 10,00 & 10,00 & 10,00 & Tabela 3.16 \\
\hline$\varepsilon_{\mathrm{t}}(\% \circ)$ & 15,69 & 14,57 & 15,94 & Tabela 3.16 \\
\hline $\mathrm{f}_{\mathrm{pyk}}(\mathrm{MPa})$ & 1824 & 1824 & 1817 & Tabela 4.28 \\
\hline $\mathrm{f}_{\mathrm{ptk}}(\mathrm{MPa})$ & 1987 & 1987 & 1963 & Tabela 4.28 \\
\hline$\varepsilon_{\mathrm{pyk}}(\%)$ & 9,10 & 9,10 & 9,04 & Tabela 3.16 \\
\hline$\sigma_{\mathrm{pk}}\left(\mathrm{kN} / \mathrm{cm}^{2}\right)$ & 186,55 & 185,84 & 185,58 & Tabela 3.16 \\
\hline $\mathrm{R}_{\mathrm{t}}=\mathrm{F}_{\mathrm{p}}(\mathrm{kN})$ & 1662 & 1840 & 386 & - \\
\hline
\end{tabular}


Tabela 7.10 - Cálculo do braço de alavanca (z) para momento positivo.

\begin{tabular}{|c|c|c|c|c|}
\hline Var. & EM1 & EM2 & EM3 & Referência \\
\hline $\mathrm{b}_{\text {int }}(\mathrm{m})$ & 1,42 & 1,19 & 1,06 & Tabela 7.7 \\
\hline $\mathrm{b}_{\text {fic }}(\mathrm{m})$ & 1,42 & 1,43 & 1,06 & Tabela 7.7 \\
\hline$N_{p}(\mathrm{kN})$ & 959 & 858 & 285 & Tabela 3.18 \\
\hline $\mathrm{h}_{\text {capa }}(\mathrm{cm})$ & 5,0 & 5,0 & 5,0 & Item 3.1 \\
\hline $\mathrm{A}_{\mathrm{c}, \text { loc }}\left(\mathrm{cm}^{2}\right)$ & 710,0 & 715,0 & 530,0 & - \\
\hline $\mathrm{f}_{\mathrm{cj}, \mathrm{continidade}}$ & 54 & 38 & 55 & Item 4.5 \\
\hline $\mathrm{R}_{\mathrm{t}}=\mathrm{F}_{\mathrm{p}}(\mathrm{kN})$ & 1662 & 1840 & 386 & - \\
\hline $\mathrm{R}_{\mathrm{c}, \mathrm{loc}}(\mathrm{kN})$ & 3259 & 2309 & 2478 & - \\
\hline $0,5 . \mathrm{y}(\mathrm{cm})$ & 1,28 & 2,39 & 0,49 & - \\
\hline $\mathrm{h}_{\text {tot }}(\mathrm{cm})$ & 26,0 & 31,5 & 21,0 & Item 3.1 \\
\hline $\mathrm{d}^{\prime}(\mathrm{cm})$ & 2,5 & 4,5 & 3,0 & Item 3.1 \\
\hline $\mathrm{z}(\mathrm{cm})$ & 22,22 & 24,61 & 17,51 & - \\
\hline
\end{tabular}

Tabela 7.11 - Cálculo do braço de alavanca (z) para momento negativo.

\begin{tabular}{|c|c|c|c|c|}
\hline Var. & EM1 & EM2 & EM3 & Referência \\
\hline $\mathrm{A}_{\mathrm{s}}\left(\mathrm{cm}^{2}\right)$ & 20,86 & 13,75 & 6,25 & Item 3.8 \\
\hline$\varepsilon_{\mathrm{s}}(\%)$ & 1,86 & 2,09 & 8,13 & $\begin{array}{c}\text { Figuras: } 5.34 \\
5.48,5.63\end{array}$ \\
\hline $\mathrm{E}_{\mathrm{s}}(\mathrm{MPa})$ & 200125 & 200125 & 200125 & Tabela 4.28 \\
\hline $\mathrm{f}_{\mathrm{yk}}(\mathrm{MPa})$ & 372 & 595 & 595 & Item 4.7 \\
\hline$R_{t}(\mathrm{kN})$ & 776 & 818 & 372 & - \\
\hline $\left.\mathrm{A}_{\mathrm{c}, \mathrm{loc}}(\mathrm{cm})^{2}\right)$ & 169,2 & 253,3 & 795,6 & Item 3.6 \\
\hline Faixa & 8 & 20 & 6 & Item 3.6 \\
\hline Localização & Mesa inferior & Mesa inferior & Mesa inferior & Item 3.6 \\
\hline $0,5 . \mathrm{y}(\mathrm{cm})$ & 4 & 10 & 3 & - \\
\hline $\mathrm{h}_{\text {tot }}(\mathrm{cm})$ & 26,0 & 31,5 & 21,0 & Item 3.1 \\
\hline $\mathrm{d}$ ' $(\mathrm{cm})$ & 2,5 & 2,5 & 2,5 & Item 3.1 \\
\hline $\mathrm{z}(\mathrm{cm})$ & 19,5 & 19,0 & 15,5 & - \\
\hline
\end{tabular}


Tabela 7.12 - Cálculo da tensão de referência ( $\left.\tau_{\text {ref }}\right)$.

\begin{tabular}{|c|c|c|c|c|c|c|c|c|c|c|}
\hline \multirow{2}{*}{ Modelo } & \multicolumn{4}{|c|}{ Momento Positivo } & \multicolumn{5}{c|}{ Momento Negativo } \\
\cline { 2 - 11 } & Elemento & $\begin{array}{c}\mathbf{b}_{\text {int }} \\
(\mathbf{m})\end{array}$ & $\begin{array}{c}\mathbf{Q}_{\text {max }} \\
(\mathbf{k N})\end{array}$ & $\begin{array}{c}\mathbf{z} \\
(\mathbf{c m})\end{array}$ & $\begin{array}{c}\boldsymbol{\tau}_{\text {ref }} \\
(\mathbf{M P a})\end{array}$ & Elemento & $\begin{array}{c}\mathbf{b}_{\text {real }} \\
(\mathbf{m})\end{array}$ & $\begin{array}{c}\mathbf{Q}_{\text {max }} \\
(\mathbf{k N})\end{array}$ & $\begin{array}{c}\mathbf{z} \\
(\mathbf{c m})\end{array}$ & $\begin{array}{c}\tau_{\text {ref }} \\
(\mathbf{M P a})\end{array}$ \\
\hline EM1 & 13 & 1,42 & 206,8 & $\begin{array}{c}22,2 \\
2\end{array}$ & $\mathbf{0 , 6 6}$ & 15 & 2,00 & 212,7 & 16,5 & $\mathbf{0 , 5 5}$ \\
\hline EM2 & 12 & 1,19 & 191,4 & $\begin{array}{c}24,6 \\
1\end{array}$ & $\mathbf{0 , 6 5}$ & 15 & 1,25 & 197,6 & 19,0 & $\mathbf{0 , 8 3}$ \\
\hline EM3 & 12 & 1,06 & 119,9 & $\begin{array}{c}17,5 \\
1\end{array}$ & $\mathbf{0 , 6 5}$ & 15 & 1,25 & 124,3 & 15,5 & $\mathbf{0 , 6 4}$ \\
\hline
\end{tabular}

\subsubsection{2 - Cálculo da tensão média}

O comprimento dos trechos relativos ao cisalhamento (lo), dados de acordo com Figura 7.7, foi obtido com base na análise não linear física do capítulo 6 . Foi considerado o gráfico da força cortante relacionado com a força de ruptura de cada modelo.

A Tabela 7.13 apresenta lo e também indica os elementos que estão compreendidos entre os momentos máximos e nulos no diagrama de momento fletor. Vale lembrar que a análise não linear física do capítulo 6 considerou duas etapas de carregamento: a primeira considerou a atuação do peso próprio do elemento composto antes da continuidade, ou seja, com o elemento simplesmente apoiado. A segunda etapa considerou a atuação da força $F_{2}$ após a continuidade.

Tabela 7.13- Valores das forças cortantes máximas obtidas de acordo com o capítulo 6.

\begin{tabular}{|c|c|c|c|c|c|c|}
\hline \multirow{2}{*}{ Modelo } & \multicolumn{2}{|c|}{ Momento Positivo } & \multicolumn{2}{|c|}{ Momento Negativo } & \multirow{2}{*}{$\begin{array}{c}\mathbf{F}_{2} \\
(\mathbf{k N})\end{array}$} & \multirow{2}{*}{$\begin{array}{l}\text { Tipo de } \\
\text { ruptura }\end{array}$} \\
\hline & $l_{0}(\mathbf{m})$ & Elementos & $l_{0}(\mathbf{m})$ & Elemento & & \\
\hline EM1 & 1,0 & 10 até 13 & 1,10 & 13 até 17 & 272,0 & cisalhamento \\
\hline EM2 & 1,0 & 10 até 13 & 1,10 & 13 até 17 & 254,7 & interface \\
\hline EM3 & 0,8 & 10 até 12 & 1,30 & 12 até 17 & 146,8 & flexão \\
\hline
\end{tabular}

O cálculo da força horizontal de cisalhamento $\left(F_{h d}\right)$ foi feito de acordo com a Figura 7.8. Entretanto, o cálculo da resultante de tração $\left(R_{t}\right)$ pode ser aproveitado do item anterior (item 7.5.1.1).

As Tabelas 7.9 e 7.10 mostram o cálculo de $N_{p}=R_{t}$ e $R_{c}$,loc para as situações com momento positivo. Para todos os modelos, $R_{t}=N_{p}<R_{c}$,loc. Isso significa que, no equilíbrio da seção, a linha neutra se encontra acima da interface e, portanto, para todos os modelos, $\mathrm{F}_{\mathrm{hd}}=\mathrm{R}_{\mathrm{c}}=\mathrm{R}_{\mathrm{t}}$. 
A Tabela 7.11 apresenta o cálculo de $N_{p}=R_{t}$ para as situações com momento negativo. E de acordo com a Figura 7.8, para esses casos, $F_{h d}=R_{c}=R_{t}$.

O cálculo da tensão média $\left(\tau_{\text {med }}\right)$ para os modelos ensaiados é apresentado na Tabela 7.14.

Tabela 7.14 - Cálculo da força horizontal de cisalhamento $\left(F_{h d}\right)$ e da tensão média $\left(\tau_{m e d}\right)$.

\begin{tabular}{|c|c|c|c|c|c|c|c|c|c|c|}
\hline \multirow{2}{*}{ Modelo } & \multicolumn{4}{|c|}{ Momento Positivo } & \multicolumn{5}{c|}{ Momento Negativo } \\
\cline { 2 - 12 } & Elementos & $\begin{array}{c}\mathbf{b}_{\text {int }} \\
(\mathbf{m})\end{array}$ & $\begin{array}{c}\boldsymbol{l}_{0} \\
(\mathbf{m})\end{array}$ & $\begin{array}{c}\mathbf{F}_{\text {hd }} \\
(\mathbf{k N})\end{array}$ & $\begin{array}{c}\tau_{\text {med }} \\
(\mathbf{M P a})\end{array}$ & Elementos & $\begin{array}{c}\mathbf{b}_{\text {real }} \\
(\mathbf{m})\end{array}$ & $\ell_{\mathbf{0}}(\mathbf{m})$ & $\begin{array}{c}\mathbf{F}_{\text {hd }} \\
(\mathbf{k N})\end{array}$ & $\begin{array}{c}\tau_{\text {med }} \\
(\mathbf{M P a})\end{array}$ \\
\hline EM1 & $10-13$ & 1,42 & 1,0 & $\mathbf{1 6 6 2}$ & $\mathbf{1 , 1 7}$ & $13-17$ & 2,00 & 1,10 & $\mathbf{7 7 6}$ & $\mathbf{0 , 3 5}$ \\
\hline EM2 & $10-13$ & 1,19 & 1,0 & $\mathbf{1 8 4 0}$ & $\mathbf{1 , 5 5}$ & $13-17$ & 1,25 & 1,10 & $\mathbf{8 1 8}$ & $\mathbf{0 , 6 0}$ \\
\hline EM3 & $10-12$ & 1,06 & 0,8 & $\mathbf{4 8 8}$ & $\mathbf{0 , 5 8}$ & $12-17$ & 1,25 & 1,30 & $\mathbf{3 7 2}$ & $\mathbf{0 , 2 3}$ \\
\hline
\end{tabular}

\subsection{2 - Tensões de cisalhamento resistentes na interface}

A seguir serão apresentados os resultados do cálculo das tensões de cisalhamento resistente conforme os códigos nacionais e internacionais e, ainda, segundo a formulação proposta por IBRAHIM (2008).

\subsubsection{1 - Cálculo de acordo com PCl:2010}

A Tabela 7.15 apresenta o cálculo da força horizontal última ( $\left.F_{h u}\right)$, conforme o PCl:2010. Adotou-se como tensão limite o valor de 0,56 MPa para a laje do modelo 1, uma vez que a superfície da laje pode ser considerada como naturalmente rugosa (caso 1 ).

Para as lajes dos modelos 2 e 3, adotou-se a metade da tensão limite do caso 1 (0,56 MPa), como recomendado pelo $\mathrm{PCl}: 2010$.

Tabela 7.15 - Cálculo da força horizontal última (Fhu) conforme o PCI:2010.

\begin{tabular}{|c|c|c|c|c|c|c|c|c|c|c|}
\hline \multirow{2}{*}{ Modelo } & \multicolumn{4}{|c|}{ Momento Positivo } & \multicolumn{5}{c|}{ Momento Negativo } \\
\cline { 2 - 12 } & Elementos & $\begin{array}{c}\mathbf{b}_{\text {int }} \\
(\mathbf{m})\end{array}$ & $\begin{array}{c}\mathbf{l}_{0} \\
(\mathbf{m})\end{array}$ & $\begin{array}{c}\boldsymbol{\tau}_{\text {lim }} \\
(\mathbf{M P a})\end{array}$ & $\begin{array}{c}\mathbf{F}_{\text {hu }} \\
(\mathbf{k N})\end{array}$ & Elementos & $\begin{array}{c}\mathbf{b}_{\text {real }} \\
(\mathbf{m})\end{array}$ & $\begin{array}{c}\mathbf{l}_{0} \\
(\mathbf{m})\end{array}$ & $\begin{array}{c}\tau_{\text {lim }} \\
(\mathbf{M P a})\end{array}$ & $\begin{array}{c}\mathbf{F}_{\text {hu }} \\
(\mathbf{k N})\end{array}$ \\
\hline EM1 & $10-13$ & 1,42 & 1,0 & $\mathbf{0 , 5 6}$ & $\mathbf{7 9 5}$ & $13-17$ & 2,00 & 1,10 & $\mathbf{0 , 5 6}$ & $\mathbf{1 2 3 2}$ \\
\hline EM2 & $10-13$ & 1,19 & 1,0 & $\mathbf{0 , 2 8}$ & $\mathbf{3 3 3}$ & $13-17$ & 1,25 & 1,10 & $\mathbf{0 , 2 8}$ & $\mathbf{3 8 5}$ \\
\hline EM3 & $10-12$ & 1,06 & 0,8 & $\mathbf{0 , 2 8}$ & $\mathbf{2 3 7}$ & $12-17$ & 1,25 & 1,30 & $\mathbf{0 , 2 8}$ & $\mathbf{4 5 5}$ \\
\hline
\end{tabular}




\subsubsection{2 - Cálculo de acordo com o CPCl:2007}

A Tabela 7.16 apresenta o cálculo da força horizontal última $\left(F_{\text {hu }}\right)$, conforme o $\mathrm{CPCl}$ :2007. A diferença entre o método do $\mathrm{CPCl}: 2007$ e o do $\mathrm{PCl}: 2010$ está na tensão limite. No $\mathrm{CPCl}: 2007$ esse valor é de 0,455 $\mathrm{MPa}$, que equivale ao produto de 0,7 pelo coeficiente $\phi_{c}=0,65$. Esse valor foi adotado para o modelo EM1.

Da mesma forma que no $\mathrm{PCl}: 2010$, para as lajes dos modelos 2 e 3, adotou-se a metade da tensão limite.

Tabela 7.16 - Cálculo da força horizontal última $\left(F_{h u}\right)$ conforme o CPCl:2007.

\begin{tabular}{|c|c|c|c|c|c|c|c|c|c|c|}
\hline \multirow{2}{*}{ Modelo } & \multicolumn{4}{|c|}{ Momento Positivo } & \multicolumn{5}{c|}{ Momento Negativo } \\
\cline { 2 - 11 } & Elementos & $\begin{array}{c}\mathbf{b}_{\text {int }} \\
(\mathbf{m})\end{array}$ & $\begin{array}{c}\ell_{0} \\
(\mathbf{m})\end{array}$ & $\begin{array}{c}\tau_{\text {lim }} \\
(\mathbf{M P a})\end{array}$ & $\begin{array}{c}\mathbf{F}_{\text {hu }} \\
(\mathbf{k N})\end{array}$ & Elementos & $\begin{array}{c}\mathbf{b}_{\text {real }} \\
(\mathbf{m})\end{array}$ & $\begin{array}{c}\ell_{\mathbf{0}} \\
(\mathbf{m})\end{array}$ & $\begin{array}{c}\tau_{\text {lim }} \\
(\mathbf{M P a})\end{array}$ & $\begin{array}{c}\mathbf{F}_{\text {hu }} \\
(\mathbf{k N})\end{array}$ \\
\hline EM1 & $10-13$ & 1,42 & 1,0 & $\mathbf{0 , 4 5 5}$ & $\mathbf{6 4 6}$ & $13-17$ & 2,00 & 1,10 & $\mathbf{0 , 4 5 5}$ & $\mathbf{1 0 0 1}$ \\
\hline EM2 & $10-13$ & 1,19 & 1,0 & $\mathbf{0 , 2 2 8}$ & $\mathbf{2 7 0}$ & $13-17$ & 1,25 & 1,10 & $\mathbf{0 , 2 2 8}$ & $\mathbf{3 1 3}$ \\
\hline EM3 & $10-12$ & 1,06 & 0,8 & $\mathbf{0 , 2 2 8}$ & $\mathbf{1 9 2}$ & $12-17$ & 1,25 & 1,30 & $\mathbf{0 , 2 2 8}$ & $\mathbf{3 7 0}$ \\
\hline
\end{tabular}

\subsubsection{3 - Cálculo de acordo com a FIP:1982}

O cálculo da tensão de resistência última, de acordo com FIP:1982, válido para as seções com momento positivo, é mostrado na Tabela 7.17. Como foi comentado anteriormente, na laje do modelo 1 foi considerada superfície naturalmente rugosa e, portanto, o valor de $\beta_{c}$ foi admitido como 0,20.

Para as lajes dos modelos 2 e 3, cujas superfícies eram lisas, foi considerada metade do valor de $\beta_{\mathrm{c}}$ adotado para laje naturalmente rugosa, seguindo o critério do $\mathrm{PCl}$.

O cálculo da resistência do concreto à tração foi feito de acordo com a expressão 7.10.

Tabela 7.17 - Cálculo da tensão resistente conforme a FIP:1982.

\begin{tabular}{|c|c|c|c|c|c|}
\hline \multirow{2}{*}{ Modelo } & \multicolumn{5}{|c|}{ Momento Positivo } \\
\cline { 2 - 6 } & $\begin{array}{c}\mathbf{f}_{\text {cj,continuidade,capa }} \\
\text { (MPa) }\end{array}$ & $\begin{array}{c}\mathbf{f}_{\text {td }} \\
(\mathbf{M P a})\end{array}$ & $\boldsymbol{\beta}_{\mathbf{c}}$ & $\begin{array}{c}\boldsymbol{\tau}_{\mathbf{u}, \text { max }} \\
(\mathbf{M P a})\end{array}$ & $\begin{array}{c}\boldsymbol{\tau}_{\mathbf{u}} \\
(\mathbf{M P a})\end{array}$ \\
\hline EM1 & 28 & 1,48 & 0,20 & $\mathbf{0 , 4 6}$ & $\mathbf{0 , 3 0}$ \\
\hline EM2 & 55 & 2,08 & 0,10 & $\mathbf{0 , 6 4}$ & $\mathbf{0 , 2 1}$ \\
\hline EM3 & 44 & 1,86 & 0,10 & $\mathbf{0 , 5 8}$ & $\mathbf{0 , 1 9}$ \\
\hline
\end{tabular}




\subsubsection{4 - Cálculo de acordo com o EUROCODE 2:2004}

De acordo com o EUROCODE 2:2004, o cálculo da tensão de resistência última ( $\left.V_{\text {Rdi }}\right)$ é mostrado na Tabela 7.18. Foi considerada a seguinte classificação para as lajes:

- EM1, superfície rugosa, $c=0,45$;

- EM2 e EM3, superfície muito lisa, c = 0,25.

Tabela 7.18 - Cálculo da tensão última ( $\left.V_{\text {Rdi }}\right)$ conforme o EUROCODE 2:2004.

\begin{tabular}{|c|c|c|c|c|c|c|c|c|c|c|}
\hline \multirow{2}{*}{ Modelo } & \multicolumn{4}{|c|}{ Momento Positivo } & \multicolumn{5}{|c|}{ Momento Negativo } \\
\cline { 2 - 11 } & Elemento & $\begin{array}{c}\mathbf{f}_{\text {ctk,inf }} \\
(\mathbf{M P a})\end{array}$ & $\mathbf{c}$ & $\begin{array}{c}\mathbf{V}_{\text {Rdi,max }} \\
(\mathbf{M P a})\end{array}$ & $\begin{array}{c}\mathbf{V}_{\text {Rdi }} \\
(\mathbf{M P a})\end{array}$ & $\mathbf{E l e m e n t o}$ & $\begin{array}{c}\mathbf{f}_{\text {ctk,inf }} \\
(\mathbf{M P a})\end{array}$ & $\mathbf{c}$ & $\begin{array}{c}\mathbf{V}_{\text {Rdi,max }} \\
(\mathbf{M P a})\end{array}$ & $\begin{array}{c}\mathbf{V}_{\text {Rdi }} \\
(\mathbf{M P a})\end{array}$ \\
\hline EM1 & 13 & 1,94 & 0,45 & $\mathbf{0 , 5 2}$ & $\mathbf{0 , 8 7}$ & 15 & 1,94 & 0,45 & $\mathbf{0 , 5 2}$ & $\mathbf{0 , 8 7}$ \\
\hline EM2 & 12 & 3,04 & 0,25 & $\mathbf{0 , 7 1}$ & $\mathbf{0 , 7 6}$ & 15 & 3,04 & 0,25 & $\mathbf{0 , 7 1}$ & $\mathbf{0 , 7 6}$ \\
\hline EM3 & 12 & 2,62 & 0,25 & $\mathbf{0 , 6 5}$ & $\mathbf{0 , 6 6}$ & 15 & 2,62 & 0,25 & $\mathbf{0 , 6 5}$ & $\mathbf{0 , 6 6}$ \\
\hline
\end{tabular}

Foi considerado que $f_{c t d}$ é igual a $f_{c t k, 0,05}$, ou seja, igual a $f_{c t k, \text { inf. }}$

\subsubsection{5 - Cálculo de acordo com a BS 8110-1:1997}

Os resultados da tensão última conforme a BS 8110-1:1997 são apresentados na Tabela 7.19.

A BS 8110-1:1997 não considera tensão limite para superfícies lisas, portanto os valores para a tensão limite das lajes EM2 e EM3 foram adotados como sendo 0,55 $\mathrm{MPa}$, considerando uma suposta categoria anterior, que a Tabela 7.3 não contempla.

Tabela 7.19 - Cálculo da tensão última ( $\tau_{\text {im }}$ conforme a BS 8110-1:1997.

\begin{tabular}{|c|c|c|c|c|c|c|c|c|}
\hline \multirow{2}{*}{ Modelo } & \multicolumn{4}{|c|}{ Momento Positivo } & \multicolumn{4}{c|}{ Momento Negativo } \\
\cline { 2 - 9 } & $\begin{array}{c}\text { Ele- } \\
\text { mento }\end{array}$ & $\begin{array}{c}\mathbf{f}_{\text {cj,continu- }} \\
\text { idade,capa } \\
(\mathbf{M P a})\end{array}$ & Categoria & $\begin{array}{c}\tau_{\text {lim }} \\
(\mathbf{M P a})\end{array}$ & $\begin{array}{c}\text { Ele- } \\
\text { mento }\end{array}$ & $\begin{array}{c}\mathbf{f}_{\text {cj,continu- }} \\
\text { idade,capa } \\
\text { (MPa) }\end{array}$ & Categoria & $\begin{array}{c}\tau_{\text {lim }} \\
\text { (MPa) }\end{array}$ \\
\hline EM1 & 13 & 28 & $\begin{array}{c}\text { Superfície com } \\
\text { agregados } \\
\text { Expostos }\end{array}$ & $\mathbf{0 , 6 3}$ & 15 & 28 & $\begin{array}{c}\text { Superfície com } \\
\text { agregados } \\
\text { expostos }\end{array}$ & $\mathbf{0 , 6 3}$ \\
\hline EM3 & 12 & 55 & Superfície lisa & $\mathbf{0 , 5 5}$ & 15 & 55 & Superfície lisa & $\mathbf{0 , 5 5}$ \\
\hline
\end{tabular}




\subsubsection{6 - Cálculo de acordo com NBR 9062:2006}

A Tabela 7.20 apresenta os cálculos para a obtenção da resistência última da interface, de acordo com a NBR 9062:2006. Vale lembrar que, de acordo com essa norma, os coeficientes $\beta_{c}$ são válidos apenas para superfície de ligação intencionalmente áspera, com rugosidade de 0,50 cm em 3,0 cm. Para superfícies lisas ou naturalmente rugosas, os valores dos coeficientes de rugosidades devem ser obtidos através de ensaios específicos.

Tabela 7.20 - Cálculo tensão última ( $\left.\tau_{u d}\right)$ conforme a NBR 9062:2006.

\begin{tabular}{|c|c|c|c|c|c|c|c|c|c|c|}
\hline \multirow{2}{*}{ Modelo } & \multicolumn{4}{|c|}{ Momento Positivo } & \multicolumn{5}{c|}{ Momento Negativo } \\
\cline { 2 - 11 } & Elemento & $\begin{array}{c}\mathbf{f}_{\text {ctk,inf }} \\
(\mathbf{M P a})\end{array}$ & $\boldsymbol{\beta}_{\mathbf{c}}$ & $\begin{array}{c}\boldsymbol{\tau}_{\mathbf{u}, \mathbf{m a x}} \\
(\mathbf{M P a})\end{array}$ & $\begin{array}{c}\boldsymbol{\tau}_{\text {ud }} \\
(\mathbf{M P a})\end{array}$ & Elemento & $\begin{array}{c}\mathbf{f}_{\text {ctk,inf }} \\
(\mathbf{M P a})\end{array}$ & $\boldsymbol{\beta}_{\mathbf{c}}$ & $\begin{array}{c}\boldsymbol{\tau}_{\mathbf{u}, \text { max }} \\
(\mathbf{M P a})\end{array}$ & $\begin{array}{c}\boldsymbol{\tau}_{\text {ud }} \\
(\mathbf{M P a})\end{array}$ \\
\hline EM1 & 13 & 1,94 & 0,20 & $\mathbf{0 , 4 8}$ & $\mathbf{0 , 3 9}$ & 15 & 1,94 & 0,20 & $\mathbf{0 , 4 8}$ & $\mathbf{0 , 3 9}$ \\
\hline EM2 & 12 & 3,04 & 0,10 & $\mathbf{0 , 7 6}$ & $\mathbf{0 , 3 0}$ & 15 & 3,04 & 0,10 & $\mathbf{0 , 7 6}$ & $\mathbf{0 , 3 0}$ \\
\hline EM3 & 12 & 2,62 & 0,10 & $\mathbf{0 , 6 5}$ & $\mathbf{0 , 2 6}$ & 15 & 2,62 & 0,10 & $\mathbf{0 , 6 5}$ & $\mathbf{0 , 2 6}$ \\
\hline
\end{tabular}

Para as lajes dos ensaios EM2 e EM3, cujas superfícies são lisas, foi considerado $\beta_{c}=0,1$. Para a laje do modelo 1 , cuja superfície é naturalmente rugosa, foi admitido $\beta_{c}=0,2$. Dessa forma, os valores dos coeficientes ficam iguais aos da FIP:1982. A única

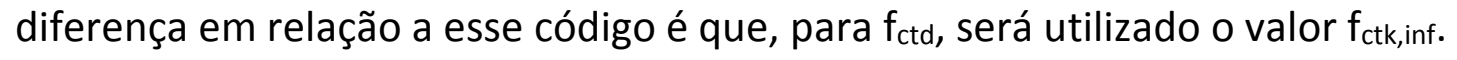

\subsubsection{7 - Cálculo de acordo com IBRAHIM (2008)}

A formulação de IBRAHIM (2008) é derivada do EUROCODE 2:2004 e considera fatores como preparo e limpeza da superfície, quando introduz os coeficientes de área de contato $\left(s_{c}\right)$ e da umidade da interface $\left(w_{a}\right.$,wet). Além disso, introduz um coeficiente que considera a rugosidade da superfície $\left(\tau_{r}\right)$.

Com relação aos modelos ensaiados neste trabalho, todos foram preparados da mesma forma. A umidade aplicada foi a do tipo ótima. Portanto, considerou-se $w_{a, w e t}=1,0$. Foi feita uma limpeza da laje alveolar para remover a nata de cimento e demais sujeiras, fazendo com que $s_{c}=1,0$.

Entretanto, a leitura do coeficiente de rugosidade $\left(R_{z}\right)$ não foi feita. Por conta disso, esses valores foram adotados de acordo com a média dos valores de rugosidade encontrados por IBRAHIM (2008) nas lajes ensaiadas.

- EM1, superfície rugosa: $\mathrm{R}=0,80$. Valor médio entre 0,50 e 1,10;

- $E M 2$ e EM3, superfície muito lisa: $R=1,70$. Valor médio entre 2,00 e 1,40. 
Para o coeficiente de coesão (c) foram considerados os mesmos valores utilizados no item 7.5.2.4, ou seja:

- EM1, superfície rugosa: $c=0,45$;

- EM2 e EM3, superfície muito lisa: $c=0,25$.

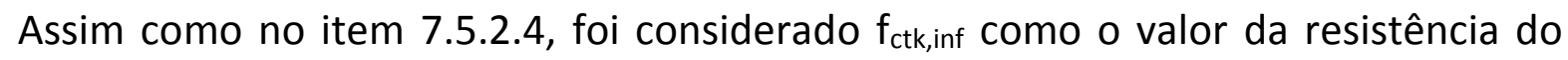
concreto à tração. A Tabela 7.21 mostra o cálculo da tensão resistente de cisalhamento da interface para os modelos ensaiados com continuidade, a partir dos valores dos coeficientes acima mencionados.

Tabela 7.21 - Cálculo tensão última ( $\tau_{u}$ ) conforme IBRAHIM (2008).

\begin{tabular}{|c|c|c|c|c|c|c|c|c|c|}
\hline \multirow{2}{*}{ Modelo } & \multicolumn{8}{|c|}{ Momento Positivo e Momento Negativo } \\
\cline { 2 - 11 } & Superfície & $\begin{array}{c}\mathbf{f}_{\text {cj,continu- }} \\
\text { idade,capa } \\
(\text { MPa) }\end{array}$ & $\begin{array}{c}\mathbf{f}_{\text {ctk,inf }} \\
(\mathbf{M P a})\end{array}$ & $\mathbf{s}_{\mathbf{c}}$ & $\mathbf{w}_{\text {a,wet }}$ & $\mathbf{c}$ & $\mathbf{R}_{\mathbf{z}}$ & $\begin{array}{c}\tau_{\mathbf{r}} \\
(\mathbf{M P a})\end{array}$ & $\begin{array}{c}\tau_{\mathbf{u}} \\
(\mathbf{M P a})\end{array}$ \\
\hline EM1 & Rugosa & 28 & 1,94 & 1 & 1 & 0,45 & $\mathbf{1 , 7 0}$ & $\mathbf{- 0 , 1 2}$ & $\mathbf{0 , 7 5}$ \\
\hline EM2 & Muito lisa & 55 & 3,04 & 1 & 1 & 0,25 & $\mathbf{0 , 8 0}$ & $\mathbf{+ 0 , 2 4}$ & $\mathbf{1 , 0 0}$ \\
\hline EM3 & Muito lisa & 44 & 2,62 & 1 & 1 & 0,25 & $\mathbf{0 , 8 0}$ & $\mathbf{+ 0 , 2 4}$ & $\mathbf{0 , 9 0}$ \\
\hline
\end{tabular}

\section{6 - Conclusão}

A Tabela 7.22 mostra os resultados dos cálculos das tensões de cisalhamento solicitantes e resistentes, anteriormente apresentados no item 7.5. Nessa tabela, os valores das tensões de solicitação e de resistência foram comparados conforme o procedimento de cada código.

É preciso lembrar que, nos ensaios dos modelos 1 e 3, não ocorreu ruptura por cisalhamento na interface. Portanto, para que a formulação apresente resultados coerentes com os ensaios, espera-se que os valores das tensões solicitantes (S) sejam menores que os resistentes (R), ou seja, S/R menor que 1 . No ensaio do modelo 2 ocorreu ruptura por cisalhamento na região de momento negativo. Logo, espera-se que os valores das tensões solicitantes sejam maiores que os resistentes, ou seja, S/R maior que 1 , para momento negativo, e o contrário para momento positivo.

Analisando a Tabela 7.22, conclui-se que a única formulação que apresentou resultados coerentes com os ensaios foi a do EUROCODE 2:2004. Outra vantagem com relação aos demais códigos é que o EUROCODE 2:2004 apresenta mais opções quanto à rugosidade da superfície. Entretanto, os valores das tensões resistentes ficaram maiores que as tensões máximas permitidas, e os valores das tensões máximas não foram coerentes com os ensaios. 
Tabela 7.22 - Comparação entre as tensões de cisalhamento solicitantes e resistentes.

\begin{tabular}{|c|c|c|c|c|c|c|c|}
\hline \multirow{2}{*}{ Código } & \multirow{2}{*}{ Modelo } & \multicolumn{3}{|c|}{ Momento Positivo } & \multicolumn{3}{|c|}{ Momento Negativo } \\
\hline & & $\mathbf{S}$ & $\mathbf{R}$ & \multirow{2}{*}{$\begin{array}{l}\text { Situação / } \\
(\mathbf{S} / \mathbf{R})\end{array}$} & $\mathbf{S}$ & $\mathbf{R}$ & \\
\hline \multirow{4}{*}{ PCI: 2010} & & $\begin{array}{l}\mathbf{F}_{\text {hd }} \\
(\mathbf{k N})\end{array}$ & $\begin{array}{c}\mathbf{F}_{\mathbf{h u}} \\
(\mathbf{k N})\end{array}$ & & $\begin{array}{l}\mathbf{F}_{\text {hd }} \\
(\mathbf{k N})\end{array}$ & $\begin{array}{l}\mathbf{F}_{\mathbf{h u}} \\
(\mathbf{k N})\end{array}$ & $(\mathbf{S} / \mathbf{R})$ \\
\hline & EM1 & 1662 & 795 & REP. / 2,09 & 776 & 1232 & APR. / 0,63 \\
\hline & EM2 & 1840 & 333 & REP./ 5,53 & 818 & 385 & APR. / 2,12 \\
\hline & EM3 & 488 & 237 & REP. / 2,06 & 372 & 455 & APR. / 0,82 \\
\hline \multirow{4}{*}{$\begin{array}{c}\text { CPCI: } \\
2007\end{array}$} & & $\begin{array}{c}\mathbf{F}_{\mathbf{h d}} \\
(\mathbf{k N})\end{array}$ & $\begin{array}{c}\mathbf{F}_{\mathbf{h u}} \\
(\mathbf{k N})\end{array}$ & Situação & $\begin{array}{c}\mathbf{F}_{\mathbf{h d}} \\
(\mathbf{k N})\end{array}$ & $\begin{array}{c}\mathbf{F}_{\mathrm{hu}} \\
(\mathbf{k N})\end{array}$ & Situação \\
\hline & EM1 & 1662 & 646 & REP. / 2,57 & 776 & 1001 & APR. / 0,78 \\
\hline & EM2 & 1840 & 270 & REP. / 6,81 & 818 & 313 & APR. / 2,61 \\
\hline & EM3 & 488 & 192 & REP. / 2,54 & 372 & 370 & REP. / 1,01 \\
\hline \multirow{4}{*}{ FIP: 1982} & & $\begin{array}{c}\tau_{\text {ref }} \\
(\mathbf{M P a})\end{array}$ & $\begin{array}{c}\tau_{\mathrm{u}} \\
(\mathbf{M P a})\end{array}$ & Situação & - & - & - \\
\hline & EM1 & 0,66 & 0,30 & REP. / 2,20 & - & - & - \\
\hline & EM2 & 0,65 & 0,21 & REP./3,10 & - & - & - \\
\hline & EM3 & 0,65 & 0,19 & REP. / 3,42 & - & - & - \\
\hline \multirow{4}{*}{$\begin{array}{c}\text { EURO- } \\
\text { CODE 2: } \\
2004\end{array}$} & & $\begin{array}{c}\tau_{\text {ref }} \\
(\mathbf{M P a})\end{array}$ & $\begin{array}{c}\mathbf{V}_{\text {Rdi }} \\
(\mathrm{MPa})\end{array}$ & Situação & $\begin{array}{c}\tau_{\text {ref }} \\
(\mathbf{M P a})\end{array}$ & $\begin{array}{c}\mathbf{V}_{\mathbf{R d i}} \\
(\mathbf{M P a})\end{array}$ & Situação \\
\hline & EM1 & 0,66 & 0,87 & APR. / 0,76 & 0,55 & 0,87 & APR. / 0,63 \\
\hline & EM2 & 0,65 & 0,76 & APR. / 0,86 & 0,83 & 0,76 & APR. / 1,09 \\
\hline & EM3 & 0,65 & 0,66 & APR. / 0,98 & 0,64 & 0,66 & APR. / 0,97 \\
\hline \multirow{4}{*}{$\begin{array}{c}\text { BS } \\
8110-1: \\
1997\end{array}$} & & $\begin{array}{c}\tau_{\text {med }} \\
(\mathbf{M P a})\end{array}$ & $\begin{array}{c}\tau_{\lim } \\
(\mathbf{M P a})\end{array}$ & Situação & $\begin{array}{c}\tau_{\text {med }} \\
(\mathbf{M P a})\end{array}$ & $\begin{array}{c}\tau_{\lim } \\
(\mathbf{M P a})\end{array}$ & Situação \\
\hline & EM1 & 1,17 & 0,63 & REP. / 1,86 & 0,35 & 0,63 & APR. / 0,56 \\
\hline & EM2 & 1,55 & 0,55 & REP. / 2,82 & 0,60 & 0,55 & APR. / 1,09 \\
\hline & EM3 & 0,58 & 0,55 & REP. / 1,05 & 0,23 & 0,55 & APR. / 0,42 \\
\hline \multirow{4}{*}{$\begin{array}{l}\text { NBR 9062: } \\
\quad 2006\end{array}$} & & $\begin{array}{c}\tau_{\text {med }} \\
(\mathbf{M P a})\end{array}$ & $\begin{array}{c}\tau_{\text {ud }} \\
(\mathbf{M P a})\end{array}$ & Situação & $\begin{array}{c}\tau_{\text {med }} \\
(\mathbf{M P a})\end{array}$ & $\begin{array}{c}\tau_{\text {ud }} \\
(\mathbf{M P a})\end{array}$ & Situação \\
\hline & EM1 & 1,17 & 0,39 & REP./3,00 & 0,35 & 0,39 & APR. / 0,90 \\
\hline & EM2 & 1,55 & 0,30 & REP./ 5,17 & 0,60 & 0,30 & APR. / 2,00 \\
\hline & EM3 & 0,58 & 0,26 & REP. / 2,23 & 0,23 & 0,26 & APR. / 0,88 \\
\hline \multirow{4}{*}{$\begin{array}{l}\text { IBRA-HIM } \\
\qquad(2008)\end{array}$} & & $\begin{array}{c}\tau_{\text {ref }} \\
(\mathbf{M P a})\end{array}$ & $\begin{array}{c}\tau_{\mathrm{u}} \\
(\mathbf{M P a})\end{array}$ & Situação & $\begin{array}{c}\tau_{\text {ref }} \\
(\mathbf{M P a})\end{array}$ & $\begin{array}{c}\tau_{\mathbf{u}} \\
(\mathbf{M P a})\end{array}$ & Situação \\
\hline & EM1 & 0,66 & 0,75 & APR. / 0,88 & 0,55 & 0,75 & APR. / 0,73 \\
\hline & EM2 & 0,65 & 1,00 & APR. / 0,65 & 0,83 & 1,00 & REP. / 0,83 \\
\hline & EM3 & 0,65 & 0,90 & APR. / 0,72 & 0,64 & 0,90 & APR. / 0,71 \\
\hline
\end{tabular}

LEGENDA: REP. = reprovado; $A P R$. = aprovado; $S$ = solicitação; $\mathrm{R}=$ resistência. 
A formulação presente no $\mathrm{PCl}: 2010$ possui valores limites para o cálculo da tensão resistente de cisalhamento. No entanto, os valores limites desse código contemplam apenas a situação de superfície intencionalmente rugosa. Para que essa formulação produzisse resultados coerentes com os encontrados nos ensaios, os valores limites da tensão resistente de cisalhamento deveriam ser maiores. No entanto, mesmo que esses valores fossem aumentados, ainda seria difícil de atender o modelo 2, uma vez que ele apresentou ruptura somente na região de momento negativo.

A análise feita para o $\mathrm{PCl}: 2010$ também é válida para o $\mathrm{CPCl}: 2007$, pois suas formulações são semelhantes. A única diferença está nos valores limites para a tensão resistente de cisalhamento, sendo que os do $\mathrm{CPCl}: 2007$ são menores que os do $\mathrm{PCl}: 2010$.

O código da FIP:1982, que considera o cálculo da tensão resistente de cisalhamento apenas para situações de momento positivo, apresentou resultados de tensão resistente bem abaixo das tensões solicitantes. Para que essa formulação apresentasse resultados coerentes com os ensaios, os valores limites da tensão resistente de cisalhamento deveriam ser maiores. Além disso, vale ressaltar que os coeficientes não contemplam todas as categorias de superfícies encontradas nas lajes alveolares.

A norma britânica BS 8110-1:1997 utiliza o mesmo princípio que o modelo americano, comparando as tensões médias com as tensões limites. Os valores limites para as tensões resistentes são maiores que nos códigos $\mathrm{PCl}, \mathrm{CPCl}$ e $\mathrm{FIP}$, entretanto os resultados não foram compatíveis com os dos ensaios. Embora apresente mais categorias quanto aos tipos de superfícies que as normas $\mathrm{PCl}, \mathrm{CPCl}$ e $\mathrm{FIP}$, ainda falta definir coeficientes para as superfícies lisas e muito lisas.

A norma brasileira NBR 9062:2006 apresenta as mesmas limitações que os códigos $\mathrm{PCl}, \mathrm{CPCl}$ e FIP, ou seja, possui coeficientes para a determinação das tensões cisalhantes resistentes com valores baixos e não contemplam as várias situações possíveis para as superfícies das lajes alveolares.

A formulação de IBRAHIM (2008) não apresentou resultados coerentes com o ensaio do modelo 2. Dentre as melhorias propostas, a única que afetou os resultados foi o coeficiente de rugosidade $\left(R_{z}\right)$, uma vez que os outros dois, $s_{z}$ e $W_{a}$,wet, foram considerados iguais a 1,0. É necessário analisar o coeficiente de rugosidade com maior cautela, uma vez que ele vai de encontro ao princípio básico de que quanto maior a rugosidade da superfície da laje, maior será a resistência da interface ao cisalhamento.

Comparando os valores das tensões solicitantes, tensão de referência e tensão média com os resultados dos ensaios, conclui-se que o método que apresentou resultados mais coerentes foi o da tensão de referência. Vale ressaltar que, para EM2, o método da tensão média apresentou tensão de solicitação maior na região de momento positivo $\left(\tau_{\text {med }}=1,55 \mathrm{MPa}\right)$ do que na região de momento negativo ( $\left.\tau_{\mathrm{med}}=0,60 \mathrm{MPa}\right)$. Esperava-se que esses resultados fossem invertidos, uma vez que a ruptura aconteceu na região de momento negativo. 


\section{CISALHAMENTO NA SEÇÃO TRANSVERSAL}

O comportamento das lajes alveolares sob ação das forças cortantes é mais complexo do que quando elas são submetidas a momentos fletores. Diferentemente da ruptura por flexão, que ocorre de forma dúctil, a ruptura das lajes alveolares por cisalhamento é abrupta (sem aviso). Por isso, o cisalhamento tem sido objeto de estudo nos grandes centros de pesquisas, conforme destacado no capítulo 2.

Diversos ensaios experimentais com o objetivo de estudar o cisalhamento têm sido realizados desde a segunda metade do século XX. Além disso, as formulações para se determinar o valor da resistência ao cisalhamento têm apresentado diferenças consideráveis quando são feitas comparações entre si, e também com análises experimentais.

Essas diferenças ocorrem principalmente pelo fato de que a resistência ao cisalhamento é influenciada por diversos fatores. LEONHARDT (1977) relata 21 fatores, dos quais alguns têm importância primária, e outros, secundária. Além do mais, há na literatura técnica atual dois mecanismos principais para descrever a ruptura de lajes alveolares por cisalhamento: tração diagonal, que ocorre em regiões não fissuradas por flexão, e flexocortante, que se verifica em regiões fissuradas por flexão.

Neste capítulo estuda-se o cisalhamento nas lajes alveolares, considerando os resultados obtidos nos ensaios com continuidade, e as principais formulações para a determinação da resistência ao cisalhamento, propostas pelos principais códigos nacionais e internacionais.

\section{1 - Conceitos básicos}

Diferentemente da flexão pura, quando só atuam as tensões normais $(\sigma)$, na flexão não pura atuam simultaneamente as tensões normais e as tensões tangenciais $(\tau)$. Isso faz com que se tenha um estado biaxial de tensões, com tensões principais de tração e compressão, em geral, inclinadas em relação ao eixo do elemento estrutural.

Dada a complexidade da solução envolvendo as solicitações de flexão e de cisalhamento de forma simultânea, é preferível tratá-las de forma independente. No entanto, é desejável que as peças fletidas alcancem a ruína por meio do momento fletor, uma vez que, dessa forma, ocorrem grandes deformações antes da ruptura. 
A respeito da separação entre a determinação das tensões normais e das tangenciais, FUSCO (2008) comenta que é dessa simplificação que surge a ideia de que, nas vigas de seção constante, possam ser imaginados dois banzos paralelos ao eixo longitudinal da peça. A Figura 8.1 mostra trajetórias de tensões, em regime elástico, determinadas por métodos precisos e pela teoria usual de flexão. Considerando o método preciso, nota-se que existe uma certa inclinação da trajetória das tensões nos apoios, havendo portanto um banzo comprimido inclinado.

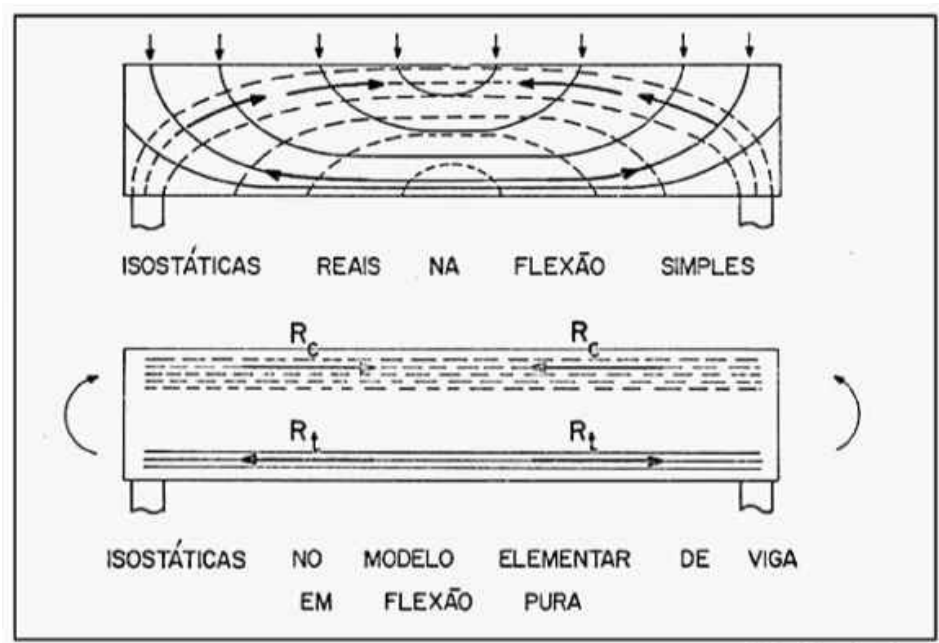

Figura 8.1 - Trajetórias de tensões (FUSCO (2008)).

Considerando uma viga retangular (Figura 8.2) constituída por material homogêneo, isotrópico e em regime elástico-linear, submetida a um carregamento externo de forma distribuída (q), a distribuição das tensões normais e das tangenciais pode ser descrita de acordo com a Figura 8.3.

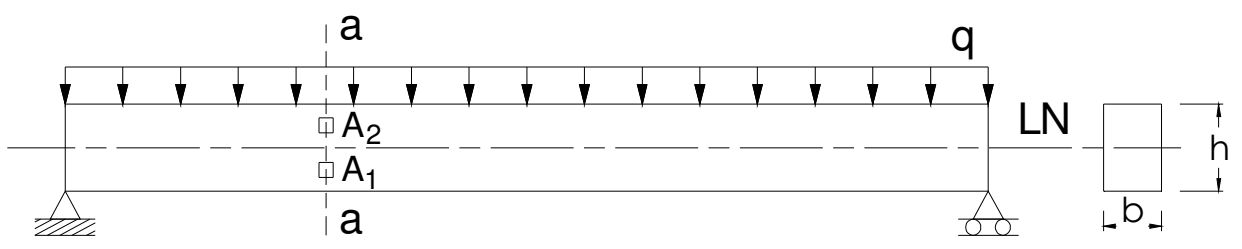

Figura 8.2 - Elementos infinitesimais $A_{1}$ e $A_{2}$ em uma viga retangular de material em regime elásticolinear (adaptada de NAWY (1996)).

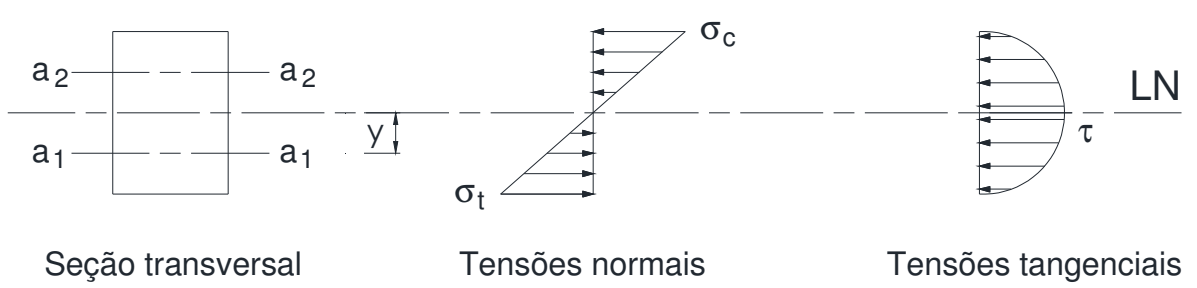

Figura 8.3 - Distribuição das tensões normais e das tangenciais (adaptada de NAWY (1996)). 
Na viga da Figura 8.2 são destacados dois elementos infinitesimais $A_{1}$ e $A_{2}$, de forma que o elemento $A_{2}$ está situado na região de compressão, enquanto que o elemento $A_{1}$, na região de tração. A tensão normal de tração e a tensão tangencial no elemento $A_{1}$ são consideradas de acordo com o plano $a_{1}-a_{1}$ posicionado a uma distância y da linha neutra (Figura 8.3). Dessa forma, a tensão solicitante normal $\left(\sigma_{s}\right)$ e a tangencial $\left(\tau_{s}\right)$ para o elemento $A_{1}$ pode ser escrita de acordo com as expressões 8.1 e 8.2.

$$
\begin{gathered}
\sigma_{\mathrm{s}}=\frac{\mathrm{M}}{\mathrm{I}} y \\
\tau_{\mathrm{s}}=\frac{\mathrm{V}_{\mathrm{M}} \mathrm{M}_{\mathrm{e}}}{\mathrm{I} \cdot \mathrm{b}}
\end{gathered}
$$

- $\mathrm{M}, \mathrm{V}=$ momento fletor e força cortante atuante na seção $\mathrm{a}_{1}-\mathrm{a}_{1}$;

- $\mathrm{M}_{\mathrm{e}}=$ momento estático em relação à linha neutra, da parte situada de um dos lados da fibra na qual é calculada a tensão $\tau_{\mathrm{s}}$;

- I= momento de inércia da seção transversal em relação à linha neutra ;

- $b=$ largura da seção transversal na fibra considerada;

- $\mathrm{y}=$ distância do elemento $\mathrm{A}_{1}$ à linha neutra.

Considerando o estado plano de tensões, mostrado na Figura 8.4, e de acordo com o círculo de Mohr, as tensões principais podem ser calculadas com as expressões 8.3 a 8.5.

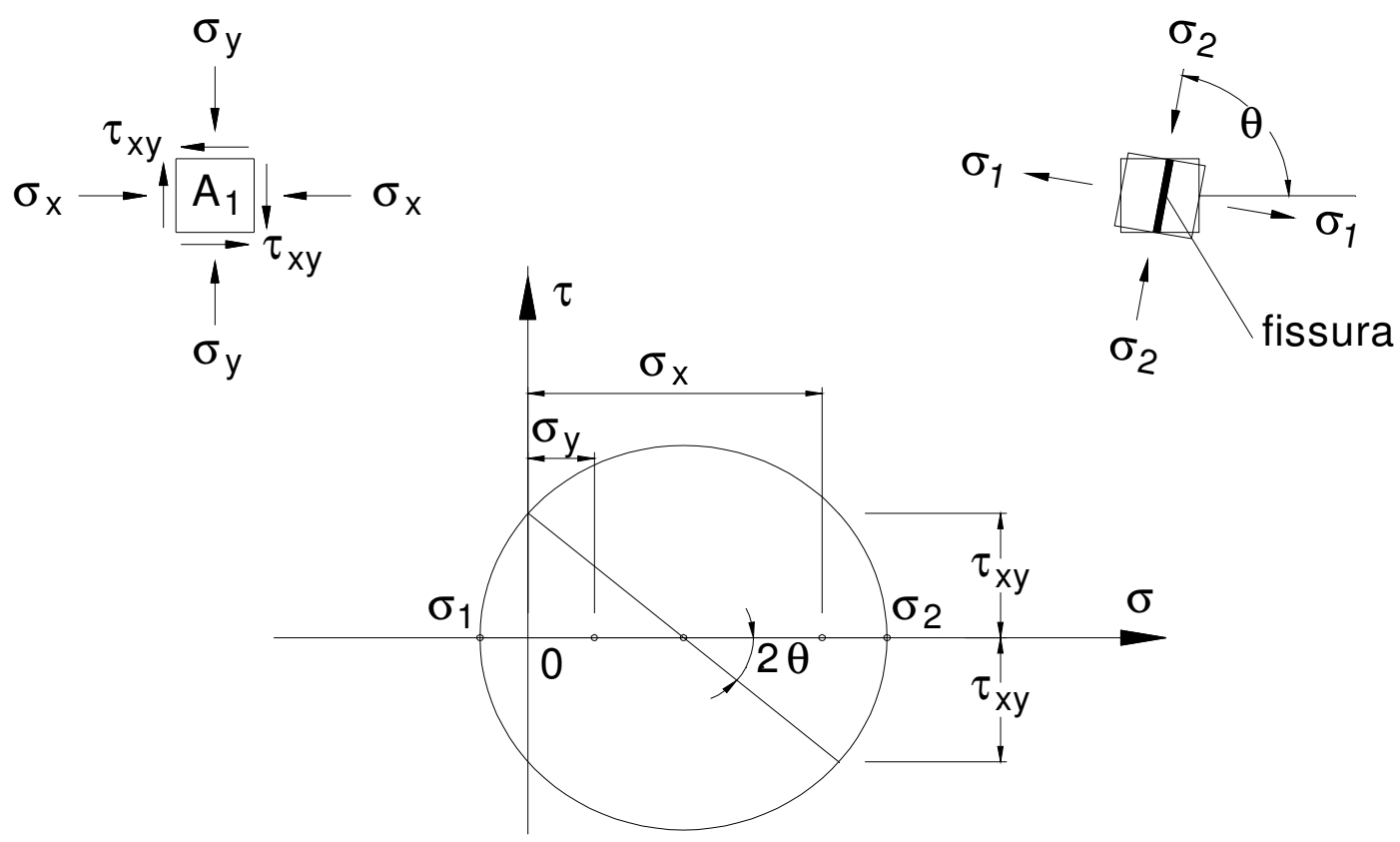

Figura 8.4 - Estado plano de tensões (adaptada de CARVALHO e FIGUEIREDO FILHO (2007)). 


$$
\begin{aligned}
& \sigma_{1}=\frac{\sigma_{x}+\sigma_{y}}{2}-\sqrt{\left(\frac{\sigma_{x}-\sigma_{y}}{2}\right)^{2}+\tau_{x y}^{2}} \\
& \sigma_{2}=\frac{\sigma_{x}+\sigma_{y}}{2}+\sqrt{\left(\frac{\sigma_{x}-\sigma_{y}}{2}\right)^{2}+\tau_{x y}{ }^{2}} \\
& \operatorname{tg} 2 \theta=\frac{2 \cdot \tau_{x y}}{\sigma_{x}-\sigma_{y}}
\end{aligned}
$$

A distribuição das tensões de cisalhamento em uma seção delgada como, por exemplo, a da seção duplo T pode auxiliar no entendimento do que ocorre em uma seção típica de laje alveolar. Ao longo da alma da seção duplo T, a distribuição das tensões de cisalhamento ocorre como mostra a Figura 8.5.

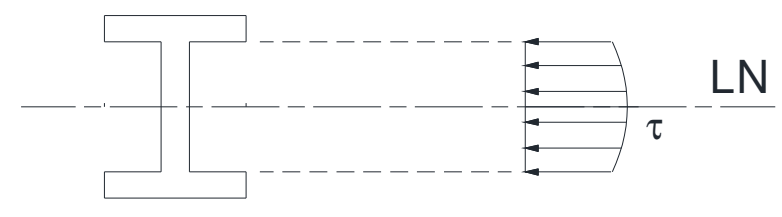

Seção transversal Tensões tangenciais

Figura 8.5 - Distribuição das tensões de cisalhamento em seções delgadas tipo duplo $T$ (adaptada de FUSCO (2008)).

De acordo com FUSCO (2008), nesses elementos as tensões perpendiculares à linha média das abas (mesas) são sempre de pequena intensidade, pois elas partem do zero em uma borda e chegam a zero na outra, como consequência de serem nulas as tensões na superfície externa do elemento. Por esse motivo, essas tensões são sempre desprezadas, considerando-se apenas as componentes paralelas à linha média do perfil.

Com isso é possível concluir que nas lajes alveolares os máximos valores de tensões cisalhantes ocorrem nas nervuras, e que nas mesas a tensão cisalhante é de pequena intensidade (Figura 8.6).

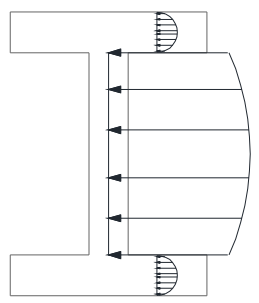

Seção - Duplo T

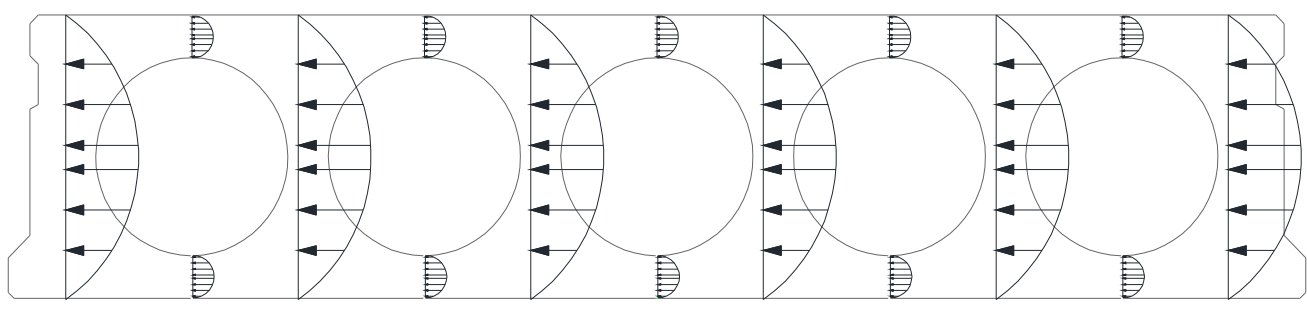

Seção - laje alveolar

Figura 8.6 - Distribuição das tensões de cisalhamento em seções típicas de laje alveolar. 


\section{2 - Comportamento de vigas submetidas ao cisalhamento}

Para descrever o comportamento de vigas fletidas submetidas a cisalhamento utilizou-se a referência teórica do livro do professor Fusco (FUSCO (2008)), uma vez que é abordado o cisalhamento, de forma completa.

\subsection{1 - Comportamento de viga e de treliça}

Considerando uma viga de concreto armado, existem dois modelos simultâneos que caracterizam o comportamento da peça: o comportamento de viga e o comportamento de treliça. Admitindo uma viga submetida a uma força suficientemente elevada, alcançando as proximidades do estado limite último, ocorrerá uma intensa fissuração (Figura 8.7).

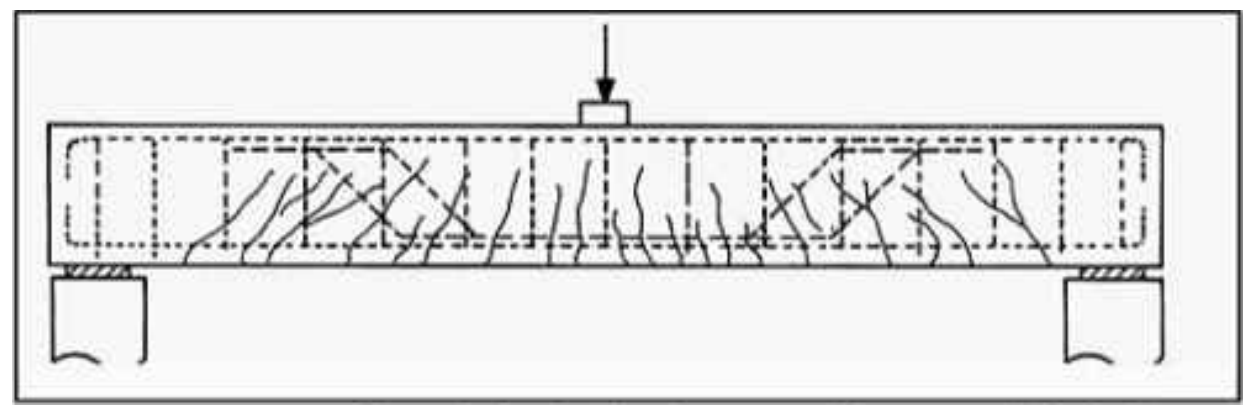

Figura 8.7 - Fissuração intensa de uma viga nas proximidades do ELU (FUSCO (2008)).

No estado fissurado, o comportamento da viga é comparado ao de uma treliça, no qual as bielas diagonais delimitadas pelas fissuras formam as diagonais comprimidas, e as armaduras transversais, os tirantes que ligam os banzos da treliça (Figura 8.8).

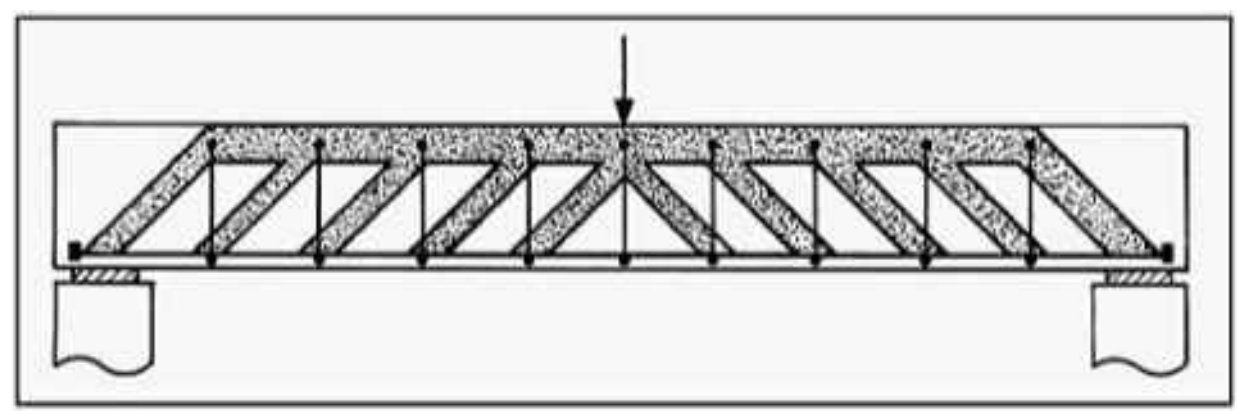

Figura 8.8 - Analogia de treliça (FUSCO (2008)).

No entanto o comportamento de treliça não ocorre desde o início do carregamento. Nessa fase o comportamento das vigas de concreto armado se aproxima muito ao das vigas feitas de material homogêneo resistente à tração. 
À medida que o carregamento aumenta, o mecanismo se altera, passando do comportamento de viga para o de treliça.

Nas vigas de concreto armado não há grande interesse no estudo dos mecanismos resistentes ao cisalhamento, antes que ocorra a fissuração por flexão, uma vez que a armadura transversal é obrigatória. Portanto, os comportamentos resistentes alternativos ao de treliça têm interesse apenas para esclarecer a influência da presença de forças normais de compressão, uma vez que elas têm a capacidade de adiar o início do progresso de fissuração da viga.

Entretanto, nas vigas com protensão, sobretudo nas peças sem estribos, esses mecanismos são importantes, uma vez que a ruptura por cisalhamento é frágil, e na grande maioria dos casos, ocorre com cargas elevadas. Nessas vigas o processo de transição do comportamento de viga para o de treliça é semelhante ao encontrado nas vigas armadas, sendo que a principal diferença é que nas vigas protendidas o comportamento de treliça, que começa somente após a formação de fissuras, é retardado pela protensão.

\subsection{2 - A formação do leque de fissuração}

A Figura 8.9 mostra a fissuração real de vigas contínuas submetidas a cargas concentradas, em situações próximas ao ELU para as solicitações normais. É possível distinguir, junto às cargas concentradas, uma distribuição das fissuras em forma de leque.

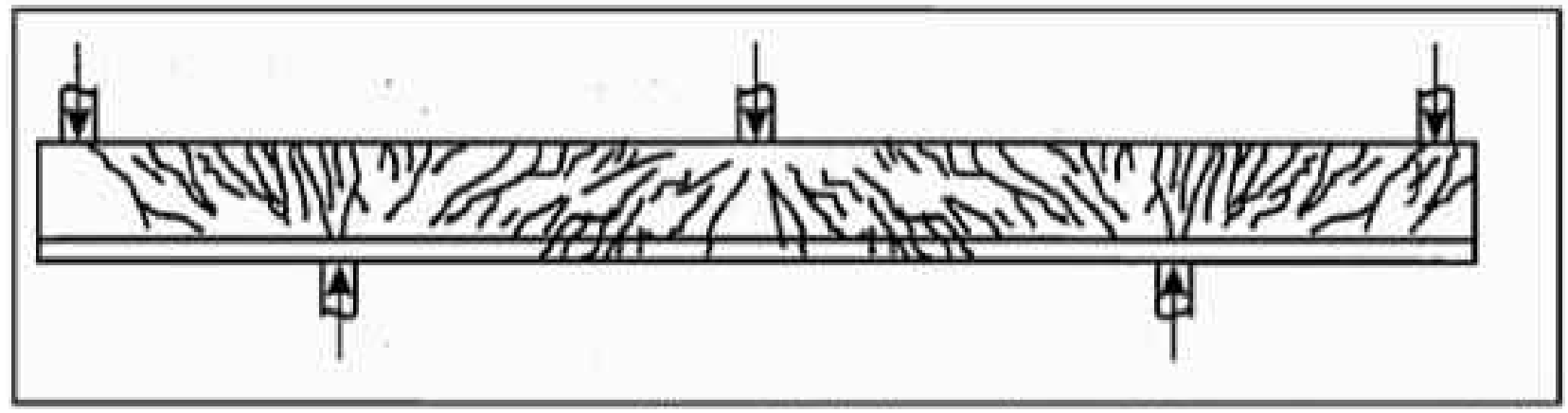

Figura 8.9 - Fissuração de vigas contínuas sujeitas a cargas concentradas (FUSCO (2008)).

A Figura 8.10 mostra o modelo geral de comportamento admitido para vigas de concreto armado. Nesse modelo distinguem-se as regiões de introdução de forças concentradas, caracterizadas pela distribuição das fissuras em forma de leque, das regiões cujo comportamento se aproxima do de treliça. 


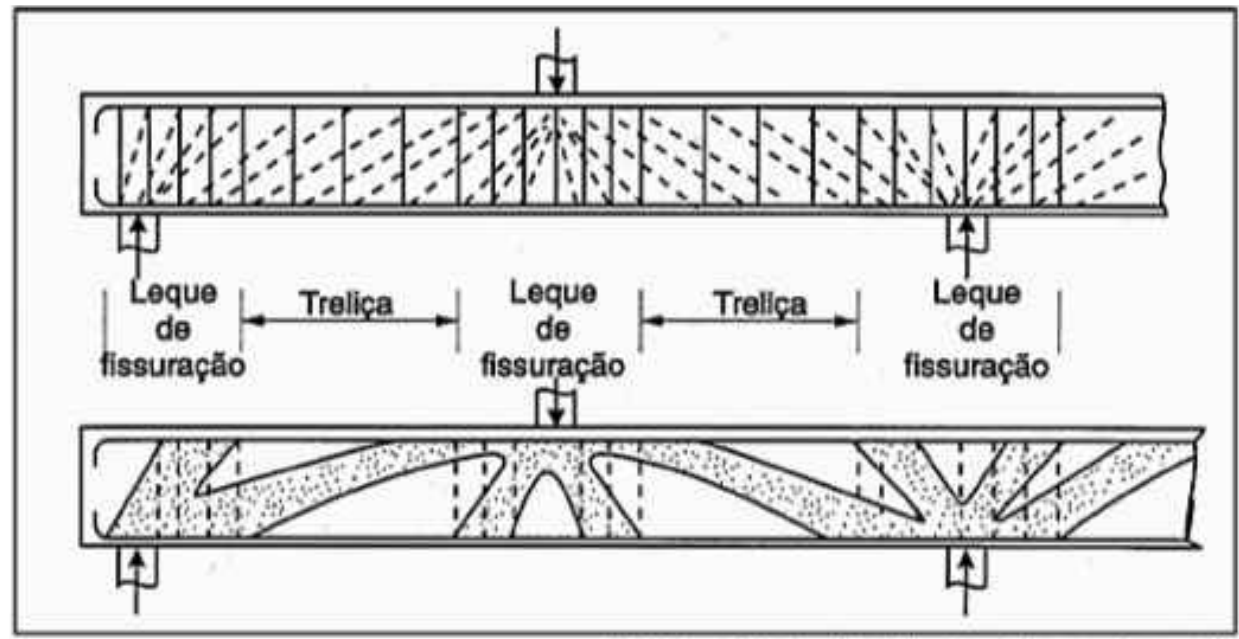

Figura 8.10 - Modelo geral de comportamento admitido para as vigas armadas (FUSCO (2008)).

NAWY (1996) apresenta conceitos semelhantes em relação aos tipos de fissuração de uma viga de concreto armado, sem armadura de cisalhamento. Em regiões com alta solicitação por momento fletor, as fissuras se desenvolvem perpendiculares ao eixo da viga. Essas fissuras são chamadas de fissuras por flexão. Porém, em regiões com elevadas solicitações por cortante, as fissuras são inclinadas e podem ocorrer próximas às fissuras por flexão, chamadas de fissuras por flexo-cortante, ou distantes dessas, chamadas de fissuras por tração diagonal. A Figura 8.11 apresenta os tipos de fissuras e suas distribuições, conforme o autor mencionado.

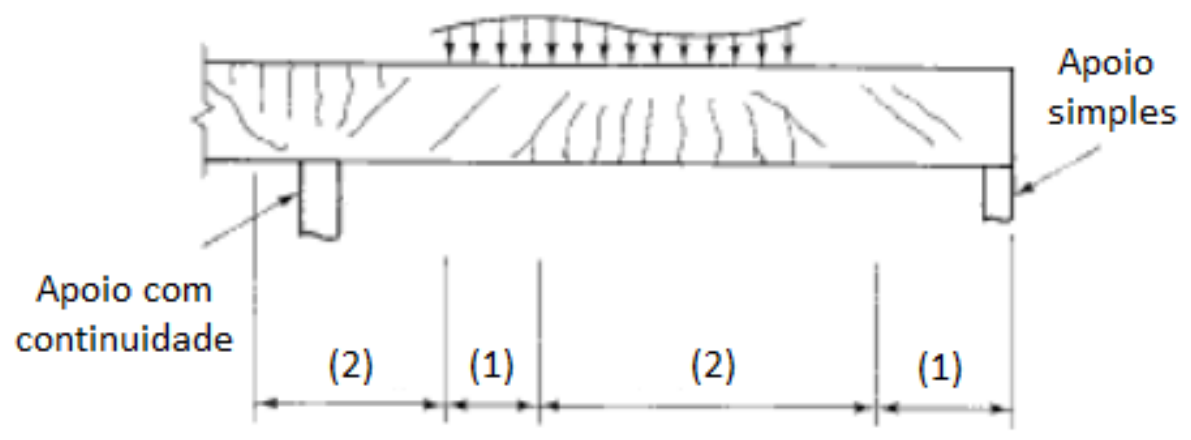

(1) - Fissuras por tração diagonal

(2) - Fissuras por flexão ou por flexo-cortante

Figura 8.11 - Tipos de fissura (NAWY (1996)).

\subsection{3 - Modos de ruptura}

FUSCO (2008) descreve os modos de ruptura divididos de três formas:

- Ruptura na ausência de armaduras transversais eficazes;

- Ruptura na presença de armaduras transversais eficazes;

- Ruptura por deficiência das ancoragens. 
Como as lajes alveolares estudadas neste trabalho não apresentam armaduras transversais, são descritos apenas os modos de ruptura relacionados ao primeiro item ora indicado. Os demais modos encontram-se na referência citada.

Nos três modos de ruptura mostrados na Figura 8.12, a ausência de uma armadura transversal eficiente, que intercepte a possível superfície de fratura, faz que a resistência da peça dependa da resistência do concreto à tração e de outros fenômenos resistentes associados à estrutura interna da peça.

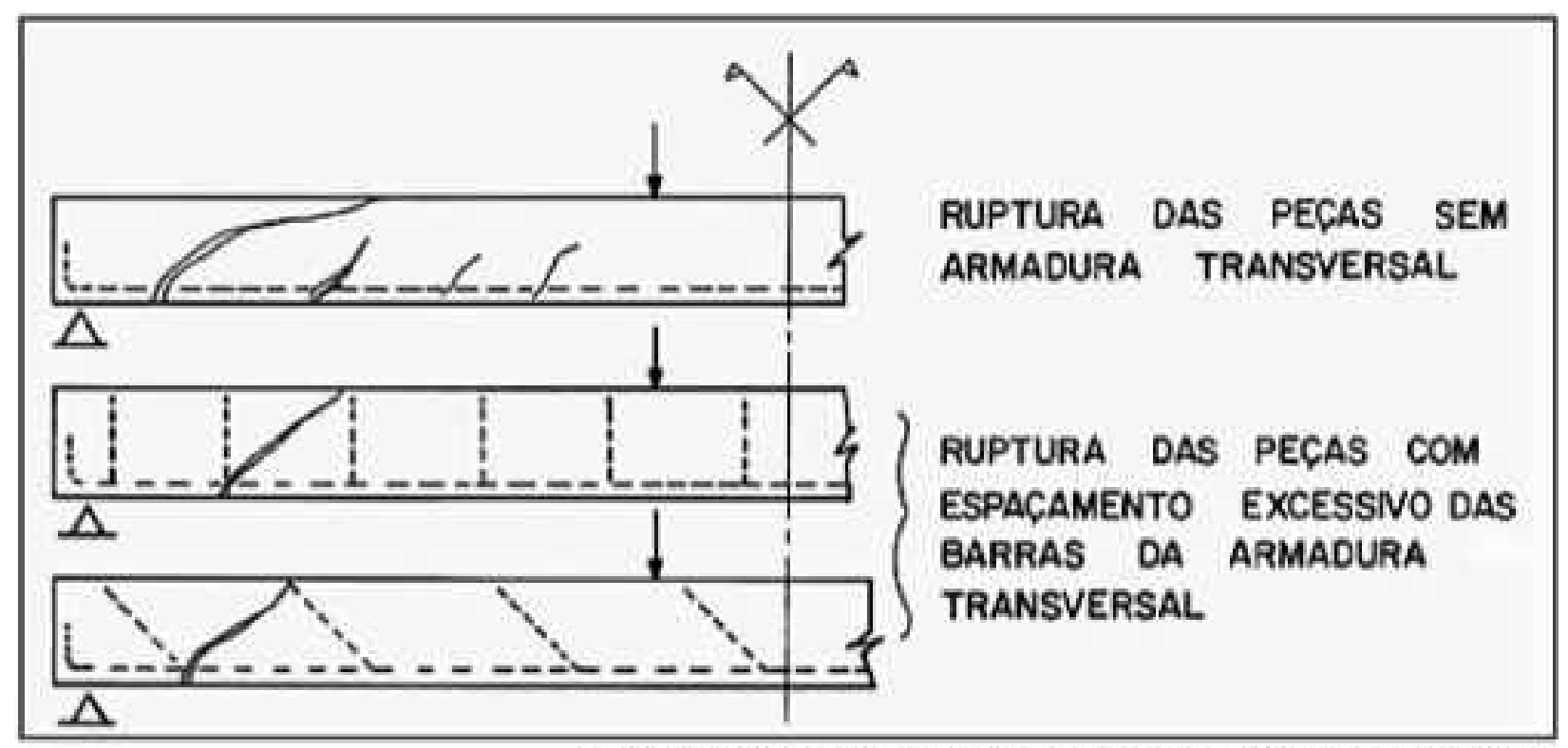

Figura 8.12 - Modos de ruptura na ausência de armadura transversal eficiência (FUSCO (2008)).

Conforme FUSCO (2008), a ausência de uma armadura transversal é permitida apenas em vigas de dimensões muito pequenas e nas peças estruturais de superfície, como as lajes e as cascas. Nesses casos, a segurança depende apenas da manutenção dos outros comportamentos resistentes, que não sejam o de treliça. Com relação aos elementos de concreto protendidos, os que dispõem de armadura transversal são: as lajes alveolares e as terças utilizadas em galpões.

De acordo com NAWY (1996), os modos de ruptura de uma viga sem armadura de cisalhamento (Figura 8.13) podem ocorrer segundo três formas (ou pela combinação delas):

- Ruptura por flexão (Figura 8.13, letra a). Ocorre quando as tensões de flexão alcançam a tensão principal de tração e são dominantes com relação às tensões de cisalhamento. À medida que o carregamento aumenta, as fissuras avançam em direção à linha neutra, ocorrendo um aumento na flecha da viga. Essa forma de ruptura, geralmente, acontece de forma dúctil, com aviso, antes que o ocorra o colapso. Para as cargas concentradas, a relação a/d é maior que 5,5; 
- Ruptura por tração diagonal do concreto (Figura 8.13, letra b). Acontece quando as tensões resistentes de cisalhamento são de baixas magnitudes, quando comparadas com as tensões resistentes de flexão. A relação $a / d$, para as cargas concentradas, varia entre 2,5 e 5,5. No início do carregamento, as fissuras de flexão se desenvolvem no meio do vão, seguidas pela ruptura da aderência entre a armadura de flexão e o concreto na região do apoio. Após isso, duas ou três fissuras diagonais se desenvolvem a uma distância do apoio de cerca de $1,5 \mathrm{~d}$ a $2 \mathrm{~d}$. Quando elas se estabilizam, uma se torna a fissura principal e se estende até a região de compressão (acima da linha neutra). A ruptura ocorre sem aviso prévio e com baixos valores de deslocamentos;

- Ruptura por compressão do concreto (Figura 8.13, letra c). Essa forma de ruptura ocorre para relação a/d menor que 2,5 (para cargas concentradas). A ruptura por compressão do concreto ocorre nas fibras acima da linha neutra.
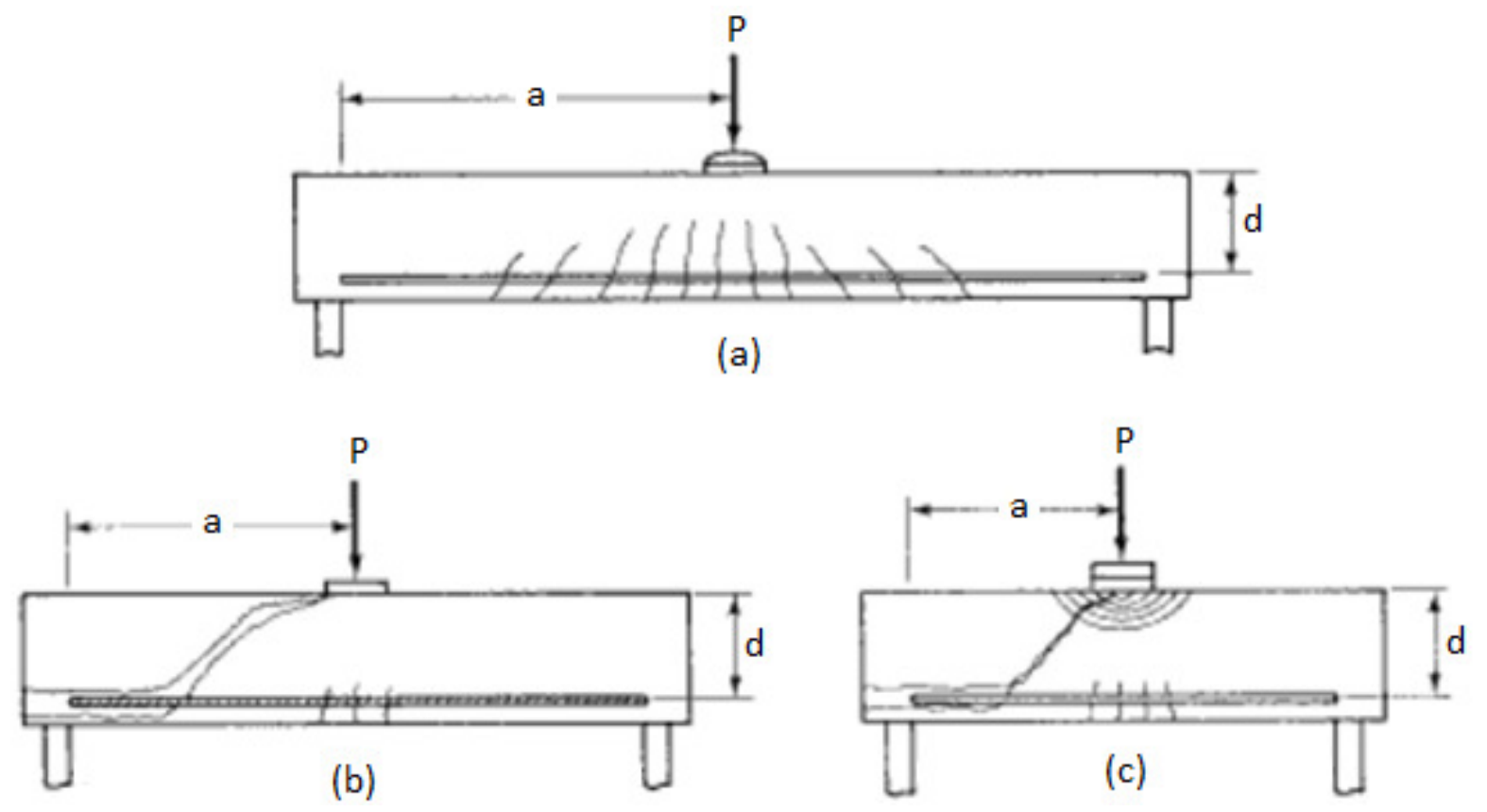

Figura 8.13- Modos de ruptura de uma viga sem armadura de cisalhamento: (a) ruptura por flexão; (b) ruptura por tração diagonal; (c) ruptura por compressão (NAWY (1996)).

\subsection{4 - Mecanismo resistente em peças sem armadura de cisalhamento}

Diferentes mecanismos resistentes garantem a resistência ao cisalhamento em peças de concreto armado sem armadura transversal. Nos trechos em que as forças cortantes não são muito elevadas, tem-se comportamento semelhante ao de flexão pura, com banzos praticamente paralelos ao eixo da peça. As possíveis fissuras nesses trechos são perpendiculares ao eixo longitudinal e se iniciam na face tracionada. 
FUSCO (2008) explica que a resistência ao cisalhamento pode ser justificada por meio de dois modelos, que dependem do funcionamento da região de concreto situada entre duas fissuras adjacentes. A Figura 8.14 ilustra esses dois modelos em que se admite, no primeiro, a cooperação máxima, e, no segundo, a cooperação mínima do concreto entre fissuras.

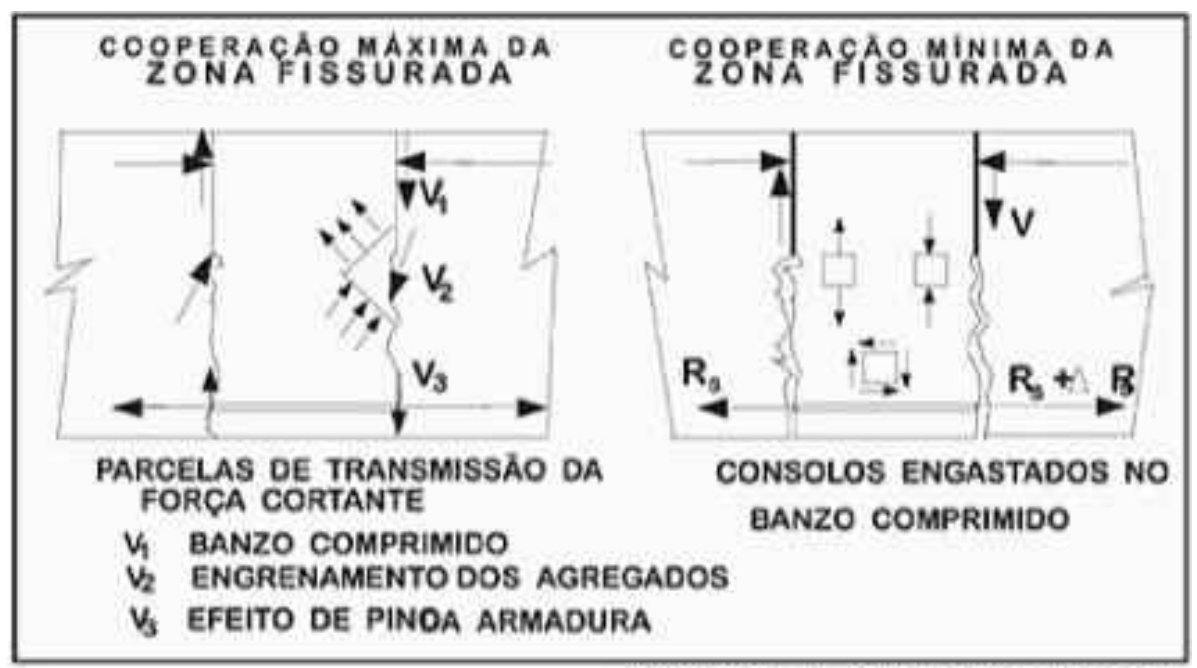

Figura 8.14- Modelos de mecanismos resistentes (FUSCO (2008)).

O modelo de cooperação mínima do concreto entre as fissuras admite que a força cortante seja transmitida inteiramente pelo banzo comprimido, e que os trechos da alma entre duas fissuras adjacentes tenham o comportamento de consolos engastados no banzo comprimido. Esse modelo admite que o mecanismo de viga subsista até a ruptura da peça, após a formação da fissura crítica.

No modelo de cooperação máxima do concreto entre as fissuras, admite-se que o mecanismo de funcionamento da peça fletida se altere, a partir do mecanismo de viga, até se organizar um comportamento global análogo ao mecanismo de treliça, no qual as tensões diagonais de tração permitem a resistência da peça.

Nesse modelo, admite-se que a transmissão da força cortante ao longo do elemento possa ser feita por meio de três parcelas:

- V1 corresponde à parcela transmitida pelo banzo comprimido;

- V2 é igual à parcela transmitida através da fissura de flexão, em função do engrenamento existente entre os grãos do agregado graúdo, e retransmitida por tensões de tração na alma da peça;

- V3 é a parcela transmitida através da fissura de flexão por meio da armadura de flexão, que se comporta como um pino de ligação entre as duas faces da fissura, sendo retransmitida adiante por tração, no trecho da alma entre duas fissuras adjacentes. 


\subsection{5 - Cisalhamento na flexo-tração e na flexo-compressão}

Nas peças sem armadura de cisalhamento, a presença de uma força normal de tração não altera significativamente sua resistência à força cortante, de forma que os modos de ruptura são os mesmos das peças submetidas a flexão simples. Quando as armaduras longitudinais estão corretamente ancoradas, a ruptura ocorre depois do aparecimento da fissura crítica inclinada.

Porém, com a presença de uma força normal de compressão, a resistência ao cisalhamento é aumentada, uma vez que a compressão retarda o aparecimento das fissuras de flexão na região de maiores forças cortantes. Enquanto essas fissuras não existem, os mecanismos resistentes alternativos garantem a segurança da peça. Somente após a fissuração do banzo tracionado é que começa a se manifestar o mecanismo resistente de treliça, com a mobilização de esforços significativos.

\section{3 - Comportamento de lajes alveolares ao cisalhamento}

A literatura atual sobre cisalhamento em lajes alveolares descreve quatro formas típicas de ruptura, decorrentes de:

- Flexo-cortante;

- Tração diagonal;

- Falha na ancoragem da armadura de protensão;

- Compressão.

PALMER e SCHULTZ (2009) citam que as rupturas mais comuns são por flexo-cortante e por tração diagonal. Diversos são os fatores que influenciam o tipo de ruptura. De acordo com esses autores, a tração diagonal ocorre frequentemente em elementos com nervuras relativamente finas, com consideráveis níveis de protensão, e situações onde o carregamento é concentrado próximo ao apoio. Já a ruptura por flexo-cortante ocorre em situações contrárias.

\subsection{1 - Ruptura por flexo-cortante}

O mecanismo de flexo-cortante (Figura 8.15) acontece quando as tensões de cisalhamento e de flexão são elevadas ao ponto de fazer com que a ruptura por cisalhamento sofra influência da flexão. Nesse caso as tensões de flexão ocasionam muitas fissuras ao longo do vão, e isso faz com que alguns autores denominem esse mecanismo como ruptura por cisalhamento em elementos fissurados. 


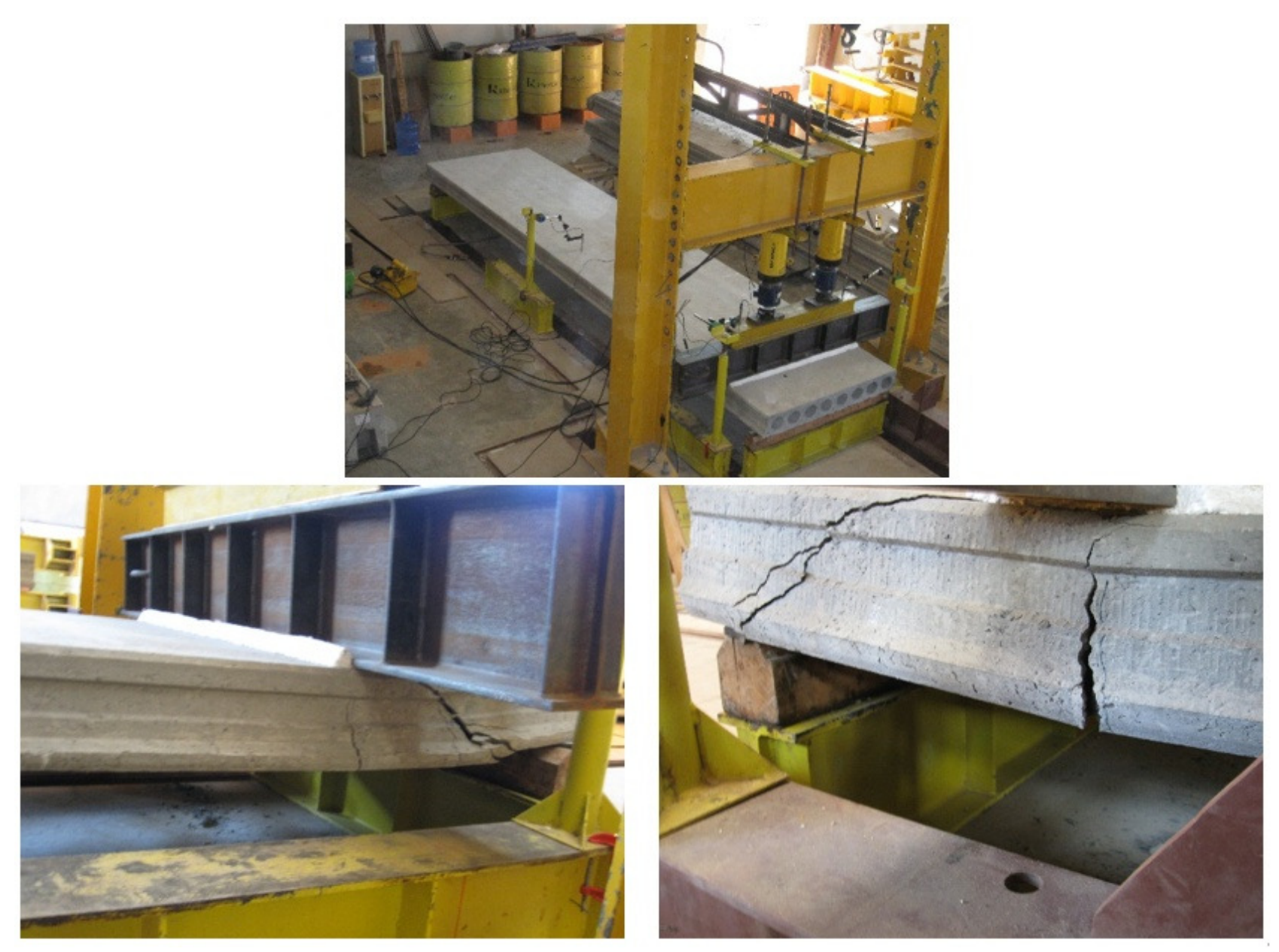

Figura 8.15 - Ruptura por flexo-cortante (ensaios de caracterização da laje EM3-L4-A).

Como não há estribos, não existe resistência à propagação das fissuras, e estas podem ultrapassar a linha neutra, atingindo o banzo comprimido.

Esse mecanismo considera que as tensões internas são transmitidas entre as fissuras, que é semelhante ao mecanismo descrito por FUSCO (2008) como cooperação máxima da zona fissurada para vigas de concreto armado.

Entretanto essa transmissão interna depende de diversos fatores. WIGHT e MACGREGOR (2012) elencaram cinco principais fatores que afetam diretamente a resistência de elementos sem armadura de cisalhamento:

- Tensão de tração do concreto;

- Taxa de armadura longitudinal (efeito pino);

- Relação entre a distância de aplicação da força concentrada e a altura útil da seção;

- Tipo e tamanho dos agregados;

- Fator escala;

- Força axial (por exemplo, protensão). 
Tentando descrever esse mecanismo, diversos autores formularam equações empíricas, com base em ensaios, para a calibração dos fatores que julgaram ser mais importantes.

Nas formulações mais utilizadas para lajes alveolares, destacam-se as seguintes: tensão de tração do concreto; taxa de armadura longitudinal; efeito escala e efeito da protensão. A Figura 8.16 exemplifica a presença desses fatores em algumas fórmulas. É interessante notar que, no exemplo da fórmula do EUROCODE 2:2004, o efeito da tensão de tração do concreto está computado de forma indireta, através da raiz cúbica da resistência à compressão.

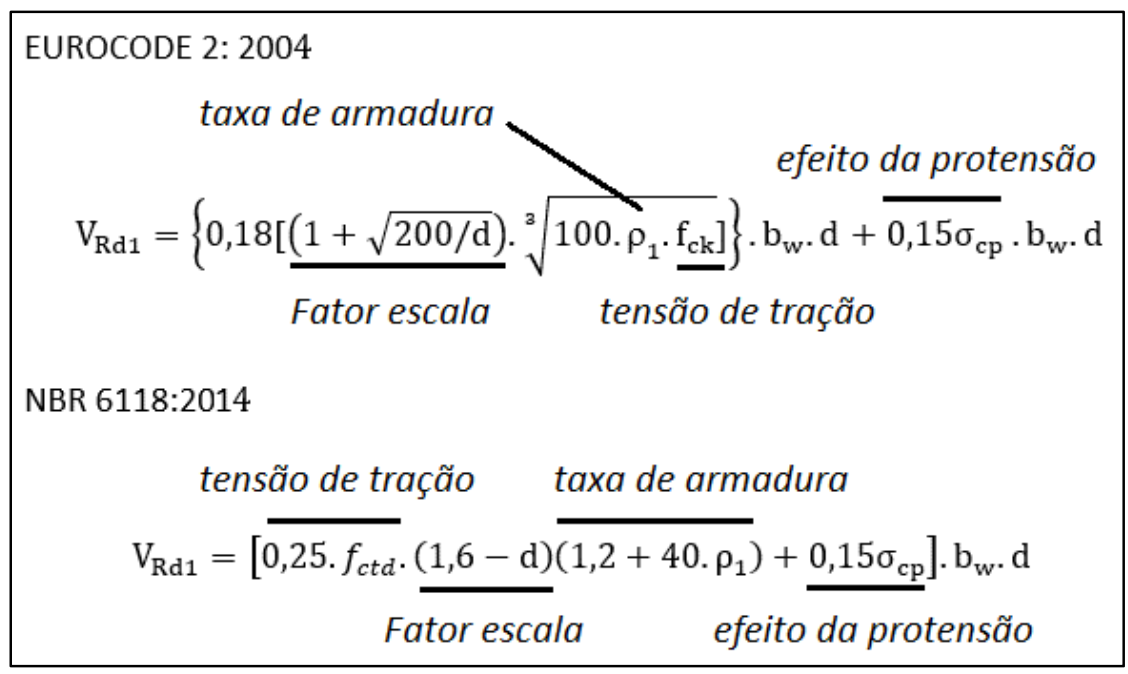

Figura 8.16 - Exemplo de fatores que influenciam no mecanismo de flexo-cortante.

\subsection{2 - Ruptura por tração diagonal}

O mecanismo de ruptura por tração diagonal do concreto (Figura 8.17) é o mais frequente nos ensaios de laje alveolar. Ocorre quando a tensão principal de tração atinge o valor da resistência à tração. É caracterizada pela fissura inclinada que ocorre repentinamente e próxima ao apoio. Esse mecanismo é chamado por alguns autores de ruptura por cisalhamento em elementos não fissurados, uma vez que, próximo ao colapso, não existe fissura na região do apoio.

Os modelos tradicionais do mecanismo de tração diagonal consideram as coordenadas do ponto crítico como sendo: distância $l_{x}$ entre a extremidade da laje alveolar e a seção onde ocorre a ruptura, e $y_{c g}$ coincidente com o centro de gravidade da seção (Figura 8.18). No entanto, neste trabalho, $\mathrm{y}_{c g}$ será considerado como a altura que corresponde à menor largura da seção transversal, ou seja, no centro dos alvéolos. Isto porque as lajes estudadas neste trabalho possuem alvéolos circulares, e que com a menor largura tem-se a menor resistência ao cisalhamento. 


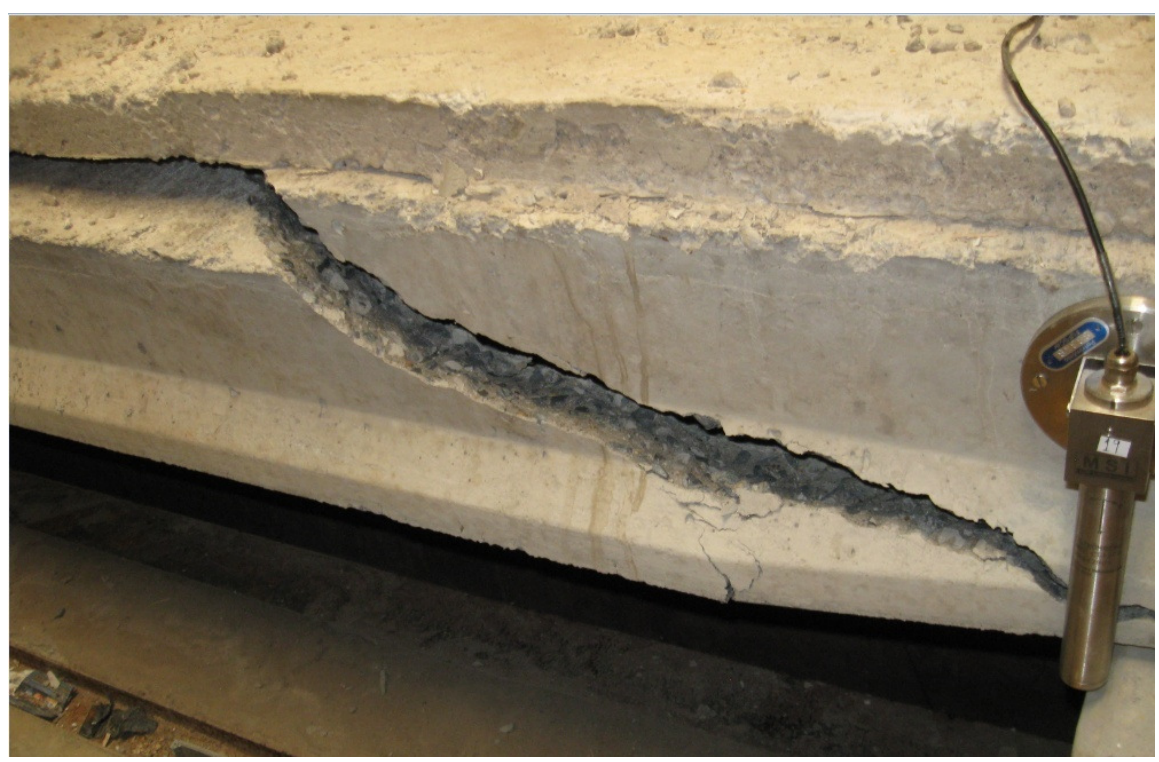

Figura 8.17 - Ruptura por tração diagonal (ensaio de continuidade de EM1).

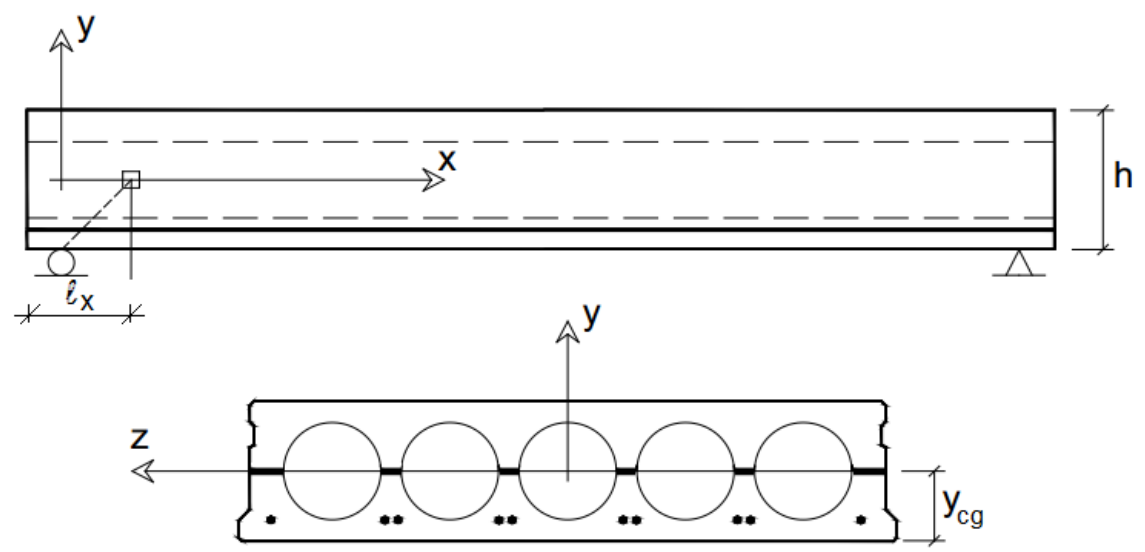

Figura 8.18 - Posição do ponto crítico utilizado no modelo de tração diagonal (adaptada de: MARQUESI, 2014).

Levando em conta as expressões 8.1 e 8.2, a tensão principal de tração pode ser calculada utilizando o círculo de Mohr. Considerando a tensão perpendicular à linha neutra igual a zero $\left(\sigma_{y}=0\right)$ e a tensão $\sigma_{x}$ de tração, ou seja, negativa, a expressão 8.3 pode ser reescrita conforme mostra a expressão 8.6.

$$
\sigma_{1}=-\frac{\sigma_{x}}{2}+\sqrt{\left(-\frac{\sigma_{x}}{2}\right)^{2}+\tau_{x y}^{2}}
$$

Considerando:

$$
\begin{aligned}
& \sigma_{1}=\mathrm{f}_{\mathrm{ct}} \\
& \sigma_{\mathrm{x}}=\alpha_{\mathrm{f}} \cdot \sigma_{\mathrm{cp}}=\frac{l_{x}}{l_{p t 2}} \cdot \sigma_{\mathrm{cp}} \\
& \tau_{\mathrm{xy}}=\tau_{\mathrm{Rd}}=\frac{\mathrm{V}_{\mathrm{Rd}, \mathrm{c}} \cdot \mathrm{M}_{\mathrm{e}}}{\mathrm{I} \cdot \mathrm{b}_{\mathrm{w}}}
\end{aligned}
$$


Tem-se:

$\mathrm{f}_{\mathrm{ctd}}=-\frac{1}{2} \cdot \alpha_{\mathrm{f} \cdot} \cdot \sigma_{\mathrm{cp}}+\sqrt{\left(-\frac{\alpha_{\mathrm{f}} \cdot \sigma_{\mathrm{cp}}}{2}\right)^{2}+\left(\frac{\mathrm{V}_{\mathrm{Rd}, \mathrm{c}} \cdot \mathrm{M}_{\mathrm{e}}}{\mathrm{I} \cdot \mathrm{b}_{\mathrm{w}}}\right)^{2}}$

Elevando-se os dois lados da expressão ao quadrado, encontra-se a expressão utilizada pelos códigos normativos europeus para o cálculo da força cortante resistente ao cisalhamento (expressão 8.11).

$$
V_{\text {Rd,c }}=\frac{I \cdot b_{w}}{M_{e}} \sqrt{\left(f_{c t}\right)^{2}+\alpha_{f} \cdot \sigma_{c p} \cdot f_{c t}}
$$

Como mencionado anteriormente, a expressão 8.11 é utilizada por códigos normativos europeus, principalmente na adoção das igualdades presentes nas expressões 8.7 e 8.8. A diferença com relação ao código americano ( $\mathrm{ACl}$ 318-08:2008) está exatamente nestas expressões.

Para o $\mathrm{ACl}$ 318-08:2008, a resistência do concreto à de tração é dada pela raiz quadrada da resistência à compressão (expressão 8.12). Além disso, são adotadas as simplificações mostradas na expressões 8.13 e 8.14, resultando a expressão 8.15.

$$
\begin{aligned}
& \sigma_{1}=\mathrm{f}_{\mathrm{ct}}=0,29 \sqrt{\mathrm{f}_{\mathrm{c}}^{\prime}} \\
& \mathrm{d}=\frac{\mathrm{I}}{\mathrm{M}_{\mathrm{e}}} \\
& \sigma_{\mathrm{x}}=0,3 \cdot \sigma_{\mathrm{cp}}=0,3 \cdot \mathrm{f}_{\mathrm{pc}} \\
& \mathrm{V}_{\mathrm{cw}}=\left(0,29 \sqrt{\mathrm{f}_{\mathrm{c}}^{\prime}}+0,3 \cdot \mathrm{f}_{\mathrm{pc}}\right) \mathrm{b}_{\mathrm{w}} \cdot \mathrm{d}
\end{aligned}
$$

\section{4 - Resistência ao cisalhamento sem armadura transversal}

O cálculo da resistência ao cisalhamento para elementos sem armadura transversal pode ser feito de acordo com alguns autores e com os principais códigos internacionais e nacionais.

A seguir apresenta-se uma relação de alguns autores e dos códigos considerados para o cálculo da força cortante resistente, indicando o respectivo mecanismo resistente e o local onde esse cálculo foi apresentado e empregado:

- HEDMAN e LOSBERG - flexo-cortante - Europa;

- REAGAN - flexo-cortante - Europa;

- MODEL CODE 90 - flexo-cortante - Europa;

- EUROCODE 2:2004 - flexo-cortante - Europa; 
- NBR 6118:2014 - flexo-cortante - Brasil;

- NBR 14861:2011 - flexo-cortante - Brasil;

- $\mathrm{ACl}$ 318-08:2008 - flexo-cortante - E.U.A.;

- $\mathrm{ACl}$ 318-08:2008 - tração diagonal - E.U.A.;

- FIB MODEL CODE 2010 - tração diagonal - Europa;

- EUROCODE 2:2004 - tração diagonal - Europa;

- EN 1168:2005 - tração diagonal - Europa.

\subsection{1 - Flexo-cortante - Europa}

Apresentam-se a seguir os cálculos da força cortante resistente, considerando o mecanismo de flexo-cortante. Nesse item são consideradas as formulações europeias, que utilizam o conceito do mecanismo resistente da cooperação máxima da zona fissurada (item 8.2.4), considerando também a resistência do concreto à tração.

A força cortante resistente segundo o mecanismo de flexo-cortante é derivada da expressão 8.16. No entanto, essa formulação não contempla a contribuição da protensão (efeito da compressão), e, por isso, nas formulações apresentadas neste item, será incluída a parcela da protensão, através da expressão 8.17 .

$$
\begin{aligned}
& V_{R d 1}=V_{c}=\tau_{r d 1} \cdot b_{w} \cdot d \\
& V_{p}=0,15 \cdot \sigma_{c p} \cdot b_{w} \cdot d
\end{aligned}
$$

FUSCO (2008) descreve duas formulações apresentadas por pesquisadores europeus ao longo da segunda metade do século XX.

A primeira é a de HEDMAN e LOSBERG ${ }^{1}$ apud FUSCO (2008), que considera forças concentradas em linha, suficientemente afastadas do apoio (expressão 8.18).

$$
V_{\mathrm{Rd} 1}=\left\{0,070 \cdot\left(1+50 \cdot \rho_{1}\right) \cdot(1,6-d) \cdot \sqrt{f_{c k}}\right\} \cdot b_{w} \cdot d+0,15 \cdot \sigma_{c p} \cdot b_{w} \cdot d
$$

A segunda formulação é a de REAGAN² apud FUSCO (2008), indicada na expressão 8.19.

$$
V_{R d 1}=\left\{0,16 \cdot\left[(1+\sqrt{200 / d}) \cdot \sqrt[3]{100 \cdot \rho_{1} \cdot f_{c k}}\right]\right\} \cdot b_{w} \cdot d+0,15 \cdot \sigma_{c p} \cdot b_{w} \cdot d
$$

\footnotetext{
${ }^{1}$ HEDMAN, O.; LOSBERG, A. Design of concrete structures with regard to shear forces. In Shear and Torsion. CEB Bulletin d'Information no 126. Paris, 1978.

2 REAGAN, P. Ultimate limit states principles. In Structural Concrete vol. 2. FIB CEB-FIP Bulletin no 2. Stuttgart, 1999.
} 
A terceira formulação é a do MODEL CODE 90, expressão 8.20, que apenas modifica o primeiro coeficiente da formulação de REAGAN para 0,12.

$$
V_{\mathrm{Rd} 1}=\left\{0,12 \cdot\left[(1+\sqrt{200 / d}) \cdot \sqrt[3]{100 \cdot \rho_{1} \cdot f_{c k}}\right]\right\} \cdot b_{w} \cdot d+0,15 \cdot \sigma_{c p} \cdot b_{w} \cdot d
$$

A quarta formulação é a do EUROCODE 2:2004, expressão 8.21.

$$
V_{R d 1}=\left\{0,18 \cdot\left[(1+\sqrt{200 / d}) \cdot \sqrt[3]{100 \cdot \rho_{1} \cdot f_{c k}}\right]\right\} \cdot b_{w} \cdot d+0,15 \cdot \sigma_{c p} \cdot b_{w} \cdot d
$$

- $\mathrm{V}_{\mathrm{Rd} 1}=$ força cortante resistente;

- $\mathrm{V}_{\mathrm{c}}=$ parcela da resistência correspondente ao concreto armado;

- $\mathrm{V}_{\mathrm{p}}=$ parcela da resistência correspondente à protensão;

- $\tau_{\mathrm{Rd} 1}=$ tensão resistente de cálculo;

- $\mathrm{b}_{\mathrm{w}}=$ largura mínima da seção ao longo da altura útil d;

- $d=$ altura útil da seção;

- $\sigma_{\mathrm{cp}}=$ tensão de compressão no concreto devida à força de protensão, levando em conta as perdas na data do ensaio de continuidade: $\sigma_{c p}=N_{s d} / A_{c}$;

- $\rho_{1}=$ taxa de aço, considerando a armadura que contribui para o efeito pino: $\rho_{1}=A_{s 1} /\left(b_{w} \cdot d\right) \leq 0,02$;

- $\mathrm{f}_{\mathrm{ck}}=$ resistência do concreto à compressão .

\subsection{2 - Flexo-cortante - Brasil}

A formulação brasileira para o cálculo da força cortante resistente representa o mecanismo de flexo-cortante de forma semelhante à formulação europeia. Inclusive, foi adotada na Europa, e o EUROCODE 2 COMMENTARY:2008 cita dois argumentos para a utilização dessa formulação com cautela.

O primeiro deles é com relação à resistência do concreto. Se ela for alta, os desvios com relação aos resultados são consideráveis. O segundo argumento é que essa formulação foi derivada de vigas que alcançam a ruptura por flexo-cortante, e não são válidas para estruturas com ruptura por tração diagonal, tal como as lajes alveolares, "que quase sempre sofrem ruptura por tração diagonal, em regiões que não ocorrem fissuras por flexão".

De acordo com a NBR 6118:2014, a força cortante resistente para lajes sem armadura transversal pode ser calculada de acordo com a expressão 8.22. Essa formulação é a mesma utilizada no capítulo 3 (item 3.7.4) para a obtenção das armaduras de continuidade utilizadas nos ensaios.

$$
\mathrm{V}_{\mathrm{Rd} 1}=\left[\tau_{\mathrm{Rd} 1} \cdot \mathrm{k}\left(1,2+40 \cdot \rho_{1}\right)+0,15 \sigma_{\mathrm{cp}}\right] \cdot \mathrm{b}_{\mathrm{w}} \cdot \mathrm{d}
$$

- $\tau_{\mathrm{Rd} 1}=$ tensão cisalhante resistente de cálculo: $\tau_{\mathrm{Rd} 1}=0,25 . \mathrm{f}_{\mathrm{ctd}}$; 
- $\mathrm{f}_{\mathrm{ctd}}=$ resistência de cálculo do concreto à tração, $\mathrm{f}_{\mathrm{ctd}}=\frac{\mathrm{f}_{\text {ctk,inf }}}{\gamma_{\mathrm{c}}}$;

- $\mathrm{k}=|1,6-\mathrm{d}| \geq 1$ (d em metros).

A NBR 14861:2011 apresenta a mesma formulação que a NBR 6118:2014. Entretanto, faz uma modificação na forma de considerar a contribuição da protensão, introduzindo um coeficiente $\alpha$ na expressão 8.17 (ver expressão 8.23).

$V_{p}=0,15 \cdot\left(\sigma_{c p} \cdot \alpha\right) \cdot b_{w} \cdot d$

O coeficiente $\alpha$ é calculado de acordo com a expressão 8.24.

$$
\alpha=\frac{\mathrm{l}_{\mathrm{x}}}{\mathrm{l}_{\mathrm{pt} 2}} \leq 1
$$

- $\mathrm{l}_{\mathrm{x}}=$ distância da seção $\mathrm{x}$ a partir do final da laje;

- $\mathrm{l}_{\mathrm{pt2}}=$ valor superior de projeto para o comprimento de transmissão (fixado em 85 $\phi$ ).

\subsection{3 - Flexo-cortante e tração diagonal - Estados Unidos}

O ACl 318-08:2008 apresenta duas expressões para o cálculo da resistência ao cisalhamento para elementos protendidos. Uma expressão considera a o mecanismo de flexo-cortante e a outra o de tração diagonal. O menor valor encontrado é considerado como sendo a força cortante resistente.

A unidade utilizada pelo ACl é o psi. Já COLLINS e MITCHEL (1997) apresentam essas formulações também em MPa, como mostrado a seguir.

A expressão 8.25 apresenta o cálculo da força cortante resistente considerando o mecanismo de flexo-cortante $\left(\mathrm{V}_{\mathrm{c}}\right)$. Essa formulação não contempla a contribuição da protensão (efeito da compressão), e, por isso, é necessário incluir a parcela da protensão, através da expressão 8.17 .

$$
V_{c i}=\left(0,05 \sqrt{f_{c}^{\prime}} \cdot b_{w} \cdot d\right)+\frac{v}{M} \cdot M_{c r} 0,15 \cdot \sigma_{c p} \cdot b_{w} \cdot d
$$

A expressão 8.26 mostra a formulação da força cortante resistente para o mecanismo de tração diagonal $\left(V_{\mathrm{cw}}\right)$. A parcela da protensão está contemplada pela parcela 0,3. $\mathrm{f}_{\mathrm{pc}}$.

$$
V_{c w}=\left(0,29 \sqrt{f_{c}^{\prime}}+0,3 \cdot f_{p c}\right) b_{w} \cdot d
$$


- $\mathrm{V} / \mathrm{M}=$ relação entre a força cortante e o momento fletor atuantes na seção;

- $\mathrm{f}_{\mathrm{c}}^{\prime}=$ resistência do concreto à compressão $\left(\mathrm{f}_{\mathrm{cj}}\right)$;

- $\mathrm{M}_{\mathrm{cr}}=$ momento de fissuração;

- $\mathrm{f}_{\mathrm{pc}}=$ tensão de compressão no centro de gravidade da seção, $\mathrm{f}_{\mathrm{pc}}=\sigma_{\mathrm{cp}}$;

\subsection{4 - Tração diagonal - Europa}

A formulação europeia para calcular a força cortante resistente de acordo com o mecanismo de tração diagonal (expressão 8.27) é equivalente à expressão 8.11 deduzida anteriormente.

$$
V_{R d, c t}=\frac{I \cdot b_{w}}{M_{e}} \sqrt{\left(f_{c t d}\right)^{2}+\alpha_{f} \cdot \sigma_{c p} \cdot f_{c t d}}
$$

Essa formulação está presente nos seguintes códigos: FIB MODEL CODE 2010, EUROCODE 2:2004 e EN1168:2005. A diferença entre os dois primeiros códigos está no coeficiente $\alpha_{\mathrm{f}}$, e na forma como calculam o comprimento de transferência l lbpt (ver expressões 8.28 e 8.29 ).

$$
\begin{aligned}
& \alpha_{\mathrm{f}}=\mathrm{l}_{\mathrm{x}} /\left(1,2 \cdot \mathrm{l}_{\mathrm{bd}, 0}\right)=\mathrm{l}_{\mathrm{x}} /\left(1,2 \cdot \mathrm{l}_{\mathrm{bpt}}\right), \quad \text { FIB MODEL CODE } 2010 \\
& \alpha_{\mathrm{f}}=\mathrm{l}_{\mathrm{x}} /\left(\mathrm{l}_{\mathrm{pt} 2}\right)=\mathrm{l}_{\mathrm{x}} /\left(\mathrm{l}_{\mathrm{bpt}}\right), \quad \text { EUROCODE } 2: 2004
\end{aligned}
$$

O comprimento de transferência é discutido no próximo item deste trabalho.

A EN1168:2005, que tem como base a formulação do EUROCODE 2:2004, acrescenta coeficientes redutores, globais e na parcela da protensão, em função da altura da laje (h), tal como mostram as expressões 8.30 e 8.31 .

$$
\begin{aligned}
& \mathrm{V}_{\mathrm{Rd}, \mathrm{ct}}=0,80 \cdot \frac{\mathrm{I} \cdot \mathrm{b}_{\mathrm{w}}}{\mathrm{M}_{\mathrm{e}}} \sqrt{\left(\mathrm{f}_{\mathrm{ctd}}\right)^{2}+0,9 \cdot \alpha_{\mathrm{f}} \cdot \sigma_{\mathrm{cp}} \cdot \mathrm{f}_{\mathrm{ctd}}}, \quad h \leq 45 \mathrm{~cm} \\
& \mathrm{~V}_{\mathrm{Rd}, \mathrm{ct}}=0,72 \cdot \frac{\mathrm{I} \cdot \mathrm{b}_{\mathrm{w}}}{\mathrm{M}_{\mathrm{e}}} \sqrt{\left(\mathrm{f}_{\mathrm{ctd}}\right)^{2}+0,9 \cdot \alpha_{\mathrm{f}} \cdot \sigma_{\mathrm{cp}} \cdot \mathrm{f}_{\mathrm{ctd}}}, \quad h \geq 45 \mathrm{~cm}
\end{aligned}
$$




\section{5 - Comprimento de transferência}

Além das diferentes formulações para o cálculo da força cortante resistente, cada código normativo possui uma forma para calcular o comprimento de transferência.

O comprimento de transferência é aquele necessário para transferir, por aderência, a totalidade da força de protensão ao fio, no interior da massa de concreto.

\subsection{1 -NBR 6118:2014 (lbpt)}

De acordo com a NBR 6118:2014, o comprimento de transferência l bpt $_{\text {é calculado }}$ com a expressão 8.32, desde que a liberação da protensão seja gradual. Caso contrário, os valores obtidos pela expressão 8.32 devem ser multiplicados por 1,25.

$\mathrm{l}_{\mathrm{bpt}}=0,7 . \mathrm{l}_{\mathrm{bp}} \cdot \frac{\sigma_{\mathrm{pi}}}{\mathrm{f}_{\mathrm{pyd}}}, \quad$ (cordoalhas de três ou sete fios)

- $\mathrm{l}_{\mathrm{bp}}=\frac{7 . \phi}{36} \cdot \frac{\mathrm{f}_{\mathrm{pyd}}}{\mathrm{f}_{\mathrm{bpd}}}$, (cordoalhas de três ou sete fios);

- $\mathrm{f}_{\mathrm{bpd}}=\eta_{\mathrm{p} 1} \cdot \eta_{\mathrm{p} 2} \cdot \mathrm{f}_{\mathrm{ctd}}$;

- $\eta_{\mathrm{p} 1}=1,2$ para cordoalhas de três ou sete fios;

- $\eta_{\mathrm{p} 2}=1,0$ para situações de boa aderência;

- $\mathrm{f}_{\mathrm{ctd}}=$ resistência de cálculo do concreto à tração, $\mathrm{f}_{\mathrm{ctd}}=\frac{\mathrm{f}_{\mathrm{ctk} \text {,inf }}}{\gamma_{\mathrm{c}}}$;

- $\sigma_{\mathrm{pi}}=$ tensão inicial de protensão;

- $\phi=$ diâmetro da armadura de protensão.

\subsection{2 -NBR 14861:2011 ( $\left.\mathrm{l}_{\mathrm{pt} 2}\right)$}

A NBR 14861:2011 considera o comprimento de transferência igual a $85 \phi$. No entanto, considera-se que esse valor equivale à situação com coeficiente de segurança. Portanto, adota-se 85 $\phi / 1,4$ para se ter a situação sem coeficiente de segurança.

\subsection{3 - FIB MODEL CODE $2010\left(\mathrm{l}_{\mathrm{bpt}, 95 \%}\right)$}

O FIB MODEL CODE 2010 apresenta a seguinte formulação para o cálculo do comprimento de transferência $\left(I_{\mathrm{bpt}, 95 \%)}\right.$ :

$\mathrm{l}_{\mathrm{bpt}, 95 \%}=0,10 . \phi \cdot \frac{\sigma_{\mathrm{pi}}}{\mathrm{f}_{\mathrm{ctd}}}, \quad$ (cordoalhas de três ou sete fios) 


\subsection{4 - EUROCODE 2:2004 ( $\left.I_{\mathrm{pt} 2}\right)$}

Conforme o EUROCODE 2:2004, o comprimento de transferência é considerado como o mais desfavorável entre $I_{p t 1}$ e $l_{p t 2}$. Entretanto, para o cálculo da força cortante resistente, deve-se considerar apenas o valor de $I_{\mathrm{pt2}}$, de acordo com a expressão 8.34.

$l_{\mathrm{pt} 2}=1,2 \cdot \mathrm{l}_{\mathrm{pt}}$

- $\mathrm{l}_{\mathrm{bt}}=\alpha_{1} \cdot \alpha_{2} \cdot \phi \cdot \frac{\sigma_{\mathrm{pm} 0}}{\mathrm{f}_{\mathrm{bpt}}}$;

- $\alpha_{1}=1,0$ (liberação gradual) ou 1,25 (liberação não gradual);

- $\alpha_{2}=0,19$ para cordoalhas de três ou sete fios;

- $\sigma_{\mathrm{pm}}=\sigma_{\mathrm{pi}}$

- $\mathrm{f}_{\mathrm{bpt}}=\eta_{\mathrm{p} 1} \cdot \eta_{1} \cdot \mathrm{f}_{\mathrm{ctd}}$

- $\eta_{\mathrm{p} 1}=3,2$ para cordoalhas de três ou sete fios;

- $\eta_{1}=1,0$ para situações de boa aderência.

\section{6 - Resultados}

A seguir são apresentados os resultados dos cálculos da força cortante para os ensaios de continuidade dos modelos EM1, EM2 e EM3.

\subsection{1 - Tensões de cisalhamento solicitantes nos ensaios de continuidade}

Após a análise estrutural feita no capítulo 6, utilizando a expressão de Branson, e a discretização mostrada na figura 6.7, aqui reproduzida, os valores de solicitação relativos à força cortante máxima são os mostrados na Tabela 8.1.

A laje do EM1 sofreu ruína por cisalhamento com a seção composta. A laje fissurou junto à face superior (na capa), e depois na face inferior (na laje), e em seguida houve a ruptura.

A laje do EM2 sofreu ruína na interface da capa com a laje, na região de momento negativo, e em seguida houve a ruptura por cisalhamento como seção simples. Antes disso, ocorreu a fissuração da capa na região de momento negativo.

A laje do EM3 rompeu por flexão nos elementos 9 e 10. Antes disso, ocorreu fissuração na capa, por conta do momento negativo, escoamento da armadura passiva, também pelo momento negativo e a fissuração da laje, pelo momento positivo.

Em todos os casos, a máxima força cortante ocorreu no elemento 15. 


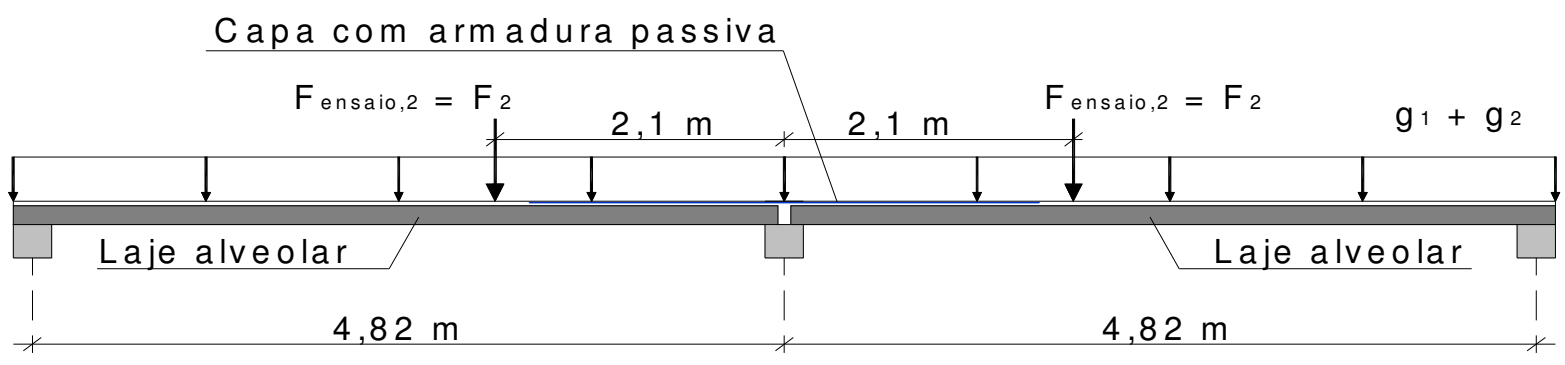

(a)

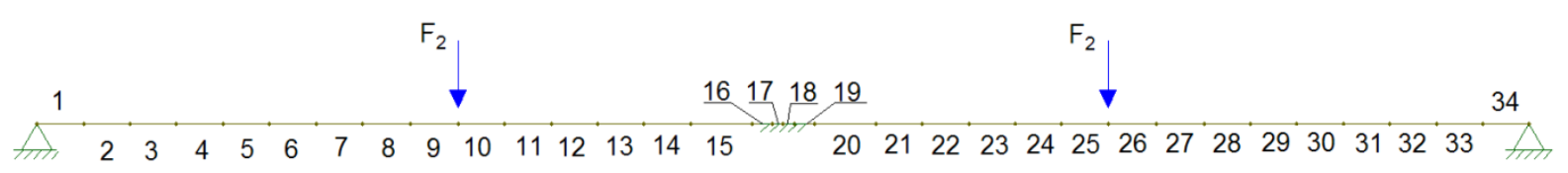

(b)

Figura 6.7 - Modelagem com elementos de barra: (a) Geometria do ensaio; (b) Divisão da estrutura em 34 elementos.

Tabela 8.1 - Valores das máximas forças cortantes solicitantes.

\begin{tabular}{|c|c|c|c|c|c|c|c|}
\hline \multirow{2}{*}{ Modelo } & \multicolumn{2}{|c|}{$\begin{array}{c}\text { Momento } \\
\text { Positivo }\end{array}$} & \multicolumn{2}{|c|}{ Momento Negativo } & \multirow{2}{*}{$\begin{array}{c}\mathbf{F}_{2} \\
(\mathbf{k N})\end{array}$} & \multirow{2}{*}{$\begin{array}{l}\text { Tipo de } \\
\text { ruptura }\end{array}$} & \multirow{2}{*}{$\begin{array}{c}\text { Tipo de } \\
\text { seção }\end{array}$} \\
\hline & $\begin{array}{l}\mathbf{Q}_{\max } \\
(\mathbf{k N})\end{array}$ & Elemento & $\begin{array}{l}\mathbf{Q}_{\max } \\
(\mathbf{k N})\end{array}$ & Elemento & & & \\
\hline EM1 & 206,8 & 13 & 212,7 & 15 & 272 & Cisalhamento & Composta \\
\hline EM2-a & 191,4 & 12 & 197,6 & 15 & 254,7 & Interface & Composta \\
\hline EM2-a & 225,1 & 12 & 231,3 & 15 & 297,3 & Cisalhamento & Simples \\
\hline EM3 & 119,9 & 12 & 124,3 & 15 & 146,8 & Flexão & Composta \\
\hline
\end{tabular}

\subsection{2 - Caracterização do concreto da laje alveolar}

Os valores utilizados para as resistências do concreto das lajes são mostrados na Tabela 8.2. Os valores de $\mathrm{f}_{\mathrm{cj}}$ e de $\mathrm{f}_{\mathrm{ctm}}$ foram tirados do capítulo 4 , que trata da caracterização dos modelos.

A NBR 6118:2014 apresenta uma equação relacionando a resistência à tração com a de compressão, para concretos com resistência entre $50 \mathrm{MPa}$ e $90 \mathrm{MPa}$. O EUROCODE 2:2004 também apresenta uma equação com o mesmo propósito. MARQUESI (2014) analisou tais equações e notou que existe uma descontinuidade na equação da norma brasileira, para concretos com resistência próximas a $50 \mathrm{MPa}$, tal como mostra a Figura 8.19. 
Tabela 8.2- Valores utilizados para as resistências do concreto das lajes (capítulo 4).

\begin{tabular}{|c|c|c|c|c|c|}
\hline MODELO & $\begin{array}{c}\mathbf{f}_{\mathrm{cj}, \text { continuidade }} \\
\text { (MPa) }\end{array}$ & $\begin{array}{c}\mathbf{f}_{\mathrm{tcm}} \\
\mathbf{( M P a )}\end{array}$ & $\begin{array}{c}\mathbf{f}_{\mathrm{tck}, \text { inf }} \\
(\mathbf{M P a})\end{array}$ & $\boldsymbol{\gamma}_{\mathbf{c}}$ & $\begin{array}{c}\mathbf{f}_{\mathrm{tcd}} \\
(\mathbf{M P a})\end{array}$ \\
\hline $\mathrm{EM} 1$ & 54 & 4,32 & 3,024 & 1,00 & 3,024 \\
\hline $\mathrm{EM} 2$ & 38 & 3,40 & 2,38 & 1,00 & 2,38 \\
\hline $\mathrm{EM} 3$ & 55 & 4,32 & 3,024 & 1,00 & 3,024 \\
\hline
\end{tabular}

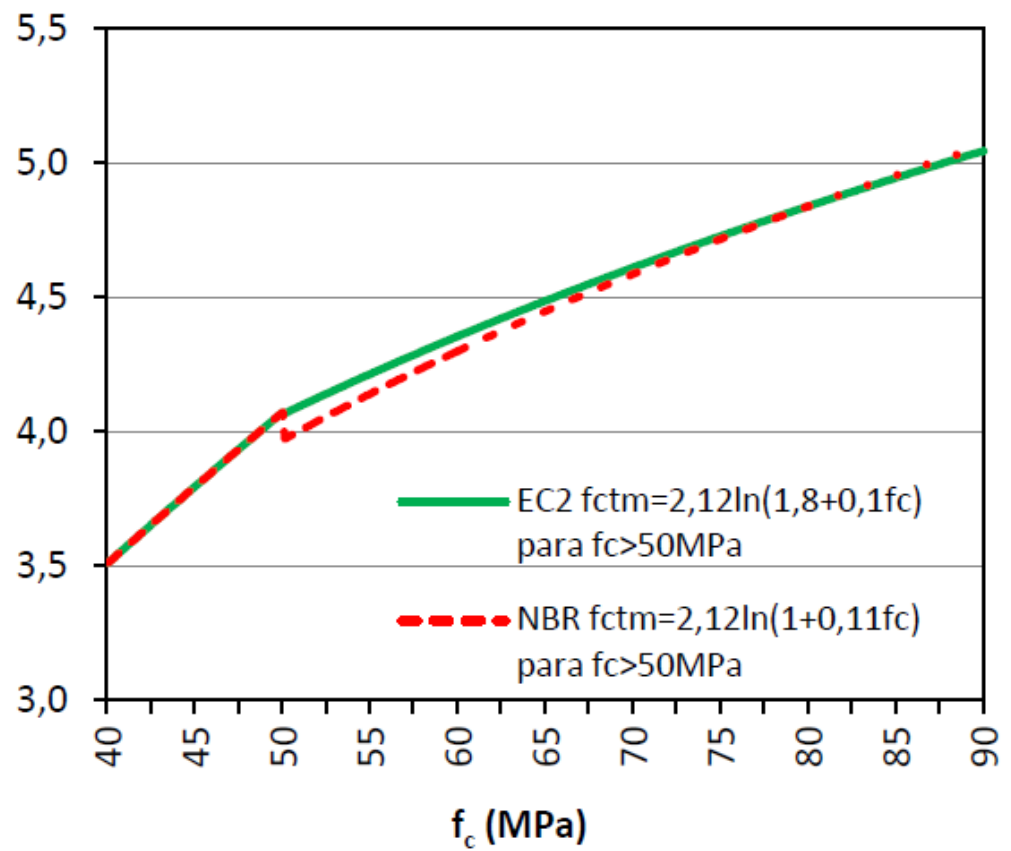

Figura 8.19 - Comparação entre os valores de $f_{c t m}$ da NBR 6118:2014 e do EUROCODE 2:2004 para concretos com resistências entre 50 MPa e 90 MPa (MARQUESI, 2014).

A Tabela 8.3 apresenta uma comparação entre os resultados das fórmulas que relacionam o valor de $\mathrm{f}_{\mathrm{ctm}}$ com $\mathrm{f}_{\mathrm{cj}}$, para a NBR 6118:2014 com $\mathrm{f}_{\mathrm{c}}<50 \mathrm{MPa}$, NBR 6118:2014 com $\mathrm{f}_{\mathrm{c}}>50 \mathrm{MPa}$ e também para o EUROCODE 2:2004 com $\mathrm{f}_{\mathrm{c}}>50 \mathrm{MPa}$.

Nessa tabela foi utilizado o valor de $f_{c t m}$ obtido no capítulo 4 (caracterização) e calculado o valor de $f_{c j}$ usando as expressões de 8.35 a 8.37:

$$
\begin{aligned}
& f_{c t m}=0,3 \cdot f_{c k}^{2 / 3}-\text { ABNT NBR 6118: } 2014-f_{c k} \leq 50 \mathrm{MPa} \\
& f_{c t m}=2,12 \cdot \ln \left(1,8+0,1 \cdot f_{c}\right)-\text { EUROCODE } 2: 2004-f_{c k}>50 \mathrm{MPa} \\
& f_{c t m}=2,12 \cdot \ln \left(1,0+0,11 \cdot f_{c}\right)-A B N T \text { NBR } 6118: 2014-f_{c k}>50 \mathrm{MPa}
\end{aligned}
$$


Tabela 8.3 - Comparação entre as formulações para cálculo de $f_{c t m}$ para concretos com resistência entre $50 \mathrm{MPa}$ e $90 \mathrm{MPa}$.

\begin{tabular}{|c|c|c|c|c|c|}
\hline MODELO & $\mathbf{f}_{\mathrm{cj}}(\mathrm{MPa})$ & $\begin{array}{c}\mathbf{f}_{\mathrm{tcm}} \\
(\mathrm{MPa})\end{array}$ & $\begin{array}{c}\boldsymbol{f}_{c j} \text { usando } \boldsymbol{f}_{c t m} \boldsymbol{e} \\
\mathbf{N B R}(<\mathbf{5 0} \mathbf{M P a})\end{array}$ & $\begin{array}{c}\boldsymbol{f}_{c j} \text { usando } \boldsymbol{f}_{c t m} \boldsymbol{e} \\
\mathbf{E C 2}(>\mathbf{5 0} \mathbf{M P a})\end{array}$ & $\begin{array}{c}\boldsymbol{f}_{c j} \text { usando } \boldsymbol{f}_{c t m} \boldsymbol{e} \\
\mathbf{N B R}(>\mathbf{5 0} \mathbf{M P a})\end{array}$ \\
\hline $\mathrm{EM} 1$ & 54 & 4,32 & $\mathbf{5 5}$ & $\mathbf{5 9}$ & $\mathbf{6 1}$ \\
\hline $\mathrm{EM} 2$ & 38 & 3,40 & $\mathbf{3 8}$ & - & - \\
\hline $\mathrm{EM} 3$ & 55 & 4,32 & $\mathbf{5 5}$ & $\mathbf{5 9}$ & $\mathbf{6 1}$ \\
\hline
\end{tabular}

Analisando os valores da Tabela 8.3, percebe-se que os valores de $f_{c j}$ que mais se aproximam dos encontrados dos ensaios de caracterização são os da expressão da NBR 6118:2014 para $\mathrm{f}_{\mathrm{ck}} \leq 50 \mathrm{MPa}$, ou seja, os valores da coluna 2 são praticamente iguais aos da coluna 4.

Além disso, no ensaio de caracterização de EM1, consideraram-se valores médios entre as três lajes, e uma delas possuía $\mathrm{f}_{\mathrm{c}}<50 \mathrm{MPa}$.

Outro fator é que, para EM1, os valores obtidos na caracterização ficaram coerentes utilizando duas metodologias distintas: a expressão da fissuração e a que considera a força cortante.

Portanto, os valores utilizados para o cálculo da força cortante resistente foram os encontrados nos ensaios de caracterização (coluna 2 da Tabela 8.3). Além disso, esses valores se aproximaram mais da formulação para $\mathrm{f}_{\mathrm{c}}<50 \mathrm{MPa}$, da NBR 6118:2014.

\subsection{3 - Comprimento de transferência}

A seguir são apresentados os cálculos dos comprimentos de transferência, de acordo com o item 8.5.

As Tabelas 8.4 e 8.5 apresentam os cálculos do comprimento de transferência ( $\left.I_{b p t}\right)$ de acordo com a ANBT NBR 6118:2014. A diferença entre elas é que a primeira considera liberação gradual da protensão, e a segunda supõe liberação não gradual.

Tabela 8.4 - Cálculo do comprimento de transferência (l ${ }_{\text {bpt }}$ ) de acordo com a NBR 6118:2014 (liberação gradual da protensão).

\begin{tabular}{|c|c|c|c|c|c|c|c|c|c|c|c|}
\hline MODELOS & $\boldsymbol{\eta}_{\mathbf{p} 1}$ & $\boldsymbol{\eta}_{\mathbf{p 2}}$ & $\begin{array}{c}\mathbf{f}_{\mathbf{b p d}} \\
(\mathbf{M P a})\end{array}$ & $\boldsymbol{\phi} \mathbf{( \mathbf { c m } )}$ & $\begin{array}{c}\mathbf{f}_{\mathbf{p y k}} \\
(\mathbf{M P a})\end{array}$ & $\boldsymbol{\gamma}_{\mathbf{s}}$ & $\begin{array}{c}\mathbf{f}_{\mathbf{p y d}} \\
(\mathbf{M P a})\end{array}$ & $\begin{array}{c}\mathbf{I}_{\mathbf{p b}} \\
(\mathbf{c m})\end{array}$ & $\begin{array}{c}\text { LIBE- } \\
\mathbf{R A C ̧ A ̃ O}\end{array}$ & $\begin{array}{c}\boldsymbol{\sigma}_{\mathbf{p i}} \\
(\mathbf{M P a})\end{array}$ & $\begin{array}{c}\mathbf{I}_{\mathbf{b p t}} \\
(\mathbf{c m})\end{array}$ \\
\hline $\mathrm{EM} 1$ & 1,2 & 1 & 3,63 & 1,27 & 1824 & 1,00 & 1824 & 124 & 1 & 1420 & $\mathbf{4 8}$ \\
\hline $\mathrm{EM} 2$ & 1,2 & 1 & 2,86 & 1,27 & 1824 & 1,00 & 1824 & 158 & 1 & 1258 & $\mathbf{5 5}$ \\
\hline $\mathrm{EM} 3$ & 1,2 & 1 & 3,63 & 0,65 & 1817 & 1,00 & 1817 & 65 & 1 & 1330 & $\mathbf{2 4}$ \\
\hline
\end{tabular}


Tabela 8.5 - Cálculo do comprimento de transferência (lbpt) de acordo com a NBR 6118:2014 (liberação não gradual da protensão).

\begin{tabular}{|c|c|c|}
\hline MODELOS & LIBERAÇÃO & $\mathbf{l}_{\mathbf{b p t}}(\mathbf{c m})$ \\
\hline EM1 & 1,25 & $\mathbf{6 0}$ \\
\hline$E M 2$ & 1,25 & $\mathbf{6 8}$ \\
\hline$E M 3$ & 1,25 & $\mathbf{3 0}$ \\
\hline
\end{tabular}

Os resultados de acordo com a NBR 14861:2011 são apresentados na Tabela 8.6.

Tabela 8.6 - Cálculo do comprimento de transferência ( $\left.I_{\text {pt2 }}\right)$ de acordo com a NBR 14861:2011.

\begin{tabular}{|c|c|c|c|}
\hline MODELOS & $\phi(\mathrm{cm})$ & $I_{p t 2, d}(\mathrm{~cm})$ & $I_{p t 2, k}(\mathrm{~cm})$ \\
\hline EM1 & 1,27 & 107,95 & 77 \\
\hline EM2 & 1,27 & 107,95 & 77 \\
\hline EM3 & 0,65 & 55,25 & 39 \\
\hline
\end{tabular}

Os resultados de acordo com o FIB MODEL CODE 2010 são apresentados na Tabela 8.7. É possível notar que os valores obtidos com essa formulação são próximos aos valores encontrados com a NBR 6118:2014, considerando liberação não gradual da protensão, Tabela 8.5.

Tabela 8.7 - Cálculo do comprimento de transferência (lbpt,95\%) segundo o FIB MODEL CODE 2010.

\begin{tabular}{|c|c|c|c|c|}
\hline MODELOS & $\boldsymbol{\phi} \mathbf{( c m )}$ & $\boldsymbol{\sigma}_{\mathbf{p i}}$ (MPa) & $\mathbf{f}_{\mathbf{t c d}}$ (MPa) & $\begin{array}{c}\mathbf{I}_{\text {bpt,95\% }} \\
(\mathbf{c m})\end{array}$ \\
\hline EM1 & 1,27 & 1420 & 3,024 & $\mathbf{6 0}$ \\
\hline$E M 2$ & 1,27 & 1258 & 2,38 & $\mathbf{6 7}$ \\
\hline$E M 3$ & 0,65 & 1330 & 3,024 & $\mathbf{2 9}$ \\
\hline
\end{tabular}

Os resultados de acordo com o EUROCODE 2:2004 são apresentados nas Tabelas 8.8 e 8.9. A Tabela 8.8 considera a liberação gradual da protensão, enquanto que a Tabela 8.9, liberação não gradual.

Tabela 8.8 - Cálculo do comprimento de transferência ( $\left.I_{p t 2}\right)$ de acordo com o EUROCODE 2:2004 (liberação gradual da protensão).

\begin{tabular}{|c|c|c|c|c|c|c|c|c|c|c|}
\hline MODELOS & $\boldsymbol{\phi}(\mathbf{c m})$ & $\boldsymbol{\alpha}_{\mathbf{1}}$ & $\boldsymbol{\alpha}_{\mathbf{2}}$ & $\boldsymbol{\sigma}_{\mathbf{p i}}(\mathbf{M P a})$ & $\boldsymbol{\eta}_{\mathbf{p} \mathbf{1}}$ & $\boldsymbol{\eta}_{\mathbf{1}}$ & $\begin{array}{c}\mathbf{f}_{\mathbf{t c d}} \\
(\mathbf{M P a})\end{array}$ & $\mathbf{I}_{\mathbf{p t}}(\mathbf{c m})$ & $\mathbf{C O E F}$ & $\mathbf{I}_{\mathbf{p t 2} \mathbf{2}}(\mathbf{c m})$ \\
\hline $\mathrm{EM} 1$ & 1,27 & 1 & 0,19 & 1420 & 3,2 & 1 & 3,024 & 35,41 & 1,2 & 42 \\
\hline $\mathrm{EM} 2$ & 1,27 & 1 & 0,19 & 1258 & 3,2 & 1 & 2,38 & 39,84 & 1,2 & 48 \\
\hline $\mathrm{EM} 3$ & 0,65 & 1 & 0,19 & 1330 & 3,2 & 1 & 3,024 & 16,98 & 1,2 & 20 \\
\hline
\end{tabular}


Tabela 8.9 - Cálculo do comprimento de transferência (l $I_{p t 2}$ de acordo com o EUROCODE 2:2004 (liberação não gradual da protensão).

\begin{tabular}{|c|c|c|c|c|}
\hline MODELOS & $\boldsymbol{\alpha}_{\mathbf{1}}$ & $\boldsymbol{I}_{\mathbf{p t}}(\mathbf{c m})$ & COEF & $\boldsymbol{I}_{\mathbf{p t 2}}(\mathbf{c m})$ \\
\hline EM1 & 1,25 & 44,26 & 1,2 & 53 \\
\hline EM2 & 1,25 & 49,81 & 1,2 & 60 \\
\hline EM3 & 1,25 & 21,22 & 1,2 & 25 \\
\hline
\end{tabular}

A Tabela 8.10 apresenta o resumo dos valores dos comprimentos de transferência.

Tabela 8.10 - Resumo dos comprimentos de transferência.

\begin{tabular}{|c|c|c|c|c|c|c|}
\hline MODELOS & $\begin{array}{c}\text { NBR } \\
\mathbf{6 1 1 8 ,} \\
\text { liberação } \\
\text { gradual }\end{array}$ & $\begin{array}{c}\text { NBR 6118, } \\
\text { liberação } \\
\text { não } \\
\text { gradual }\end{array}$ & $\begin{array}{c}\text { NBR } \\
\mathbf{1 4 8 6 1 : 2 0 1 1}\end{array}$ & $\begin{array}{c}\text { FIB } \\
\text { MODEL } \\
\text { CODE } \\
\mathbf{2 0 1 0}\end{array}$ & $\begin{array}{c}\text { EC2 2004, } \\
\text { liberação } \\
\text { gradual }\end{array}$ & $\begin{array}{c}\text { EC2 2004, } \\
\text { liberação } \\
\text { não } \\
\text { gradual }\end{array}$ \\
\hline EM1 & 48 & 60 & 77 & 60 & 42 & 53 \\
\hline EM2 & 55 & 68 & 77 & 67 & 48 & 60 \\
\hline EM3 & 24 & 30 & 39 & 29 & 20 & 25 \\
\hline
\end{tabular}

\subsection{4 - Resistência ao cisalhamento - Flexo-cortante - Europa}

As tabelas a seguir apresentam os resultados das formulações europeias de flexocortante. Nessas tabelas, a parcela da protensão $V_{p}$ foi calculada separadamente de $V_{c}$, relativa ao concreto.

No modelo 1, a laje sofreu ruptura por cisalhamento com $V_{s}=212,7$ kN. Portanto, espera-se que o valor encontrado para resistência $\left(V_{R}\right)$ esteja próximo e abaixo do valor de 212,7 kN. Em outras palavras, S/R um pouco maior que 1, onde $S$ equivale ao valor de solicitação e R de resistência. Se o valor estiver abaixo, porém muito menor que 212,7 kN, reprova-se a expressão.

A laje do modelo 2 sofreu ruptura na interface, com $V_{s}=197,6 \mathrm{kN}$. A partir disso, a laje passou a ter comportamento de seção simples e sofreu ruptura por cisalhamento com $V_{s}=231,3 \mathrm{kN}$. Portanto, espera-se que os valores encontrados sejam, no primeiro momento, um valor acima de 197,6 kN, pois a seção composta não sofre ruptura por cisalhamento, em outras palavras, S/R menor que 1 . No segundo momento, espera-se que a força cortante resistente $\left(V_{R}\right)$ esteja próxima e abaixo de $231,3 \mathrm{kN}$, ou seja, $S / R$ um pouco maior que 1

No ensaio 3, a ruptura se deu por flexão, com $V_{s}=124,3$ kN. Portanto, espera-se valores de $V_{R}$ maiores que $124,3 \mathrm{kN}$, independentemente se estiverem próximos ou não desse valor, portanto, S/R menor que 1.

A Tabela 8.11 mostra os dados comuns às expressões 8.18, 8.19, 8.20 e 8.21. 
As tabelas seguintes $(8.12,8.13,8.14$ e 8.15$)$ mostram os resultados relativos aos autores e normas: HEADMAN e LOSBERG, REAGAN, MODEL CODE 90 e EUROCODE 2:2004, respectivamente.

Tabela 8.11 - Dados gerais - Flexo-cortante - Europa.

\begin{tabular}{|c|c|c|c|c|c|c|c|c|c|c|c|}
\hline $\begin{array}{c}\text { MODE- } \\
\text { LOS }\end{array}$ & $\begin{array}{l}d_{\text {comp }} \\
(\mathrm{cm})\end{array}$ & $\begin{array}{c}b_{w} \\
(\mathrm{~cm})\end{array}$ & $\begin{array}{c}A_{p} \\
\left(\mathrm{~cm}^{2}\right)\end{array}$ & $0_{1}$ & $\begin{array}{c}\sigma_{\mathrm{pt}, \infty} \\
\left(\mathrm{kN} / \mathrm{cm}^{2}\right)\end{array}$ & $\begin{array}{l}N_{s d} \\
(k N)\end{array}$ & $A_{c}\left(m^{2}\right)$ & $\begin{array}{c}\sigma_{\mathrm{cp}} \\
\left(\mathrm{kN} / \mathrm{m}^{2}\right)\end{array}$ & $\begin{array}{c}f_{c j} \\
\left(k N / m^{2}\right)\end{array}$ & $\begin{array}{c}f_{\mathrm{tcm}} \\
\left(\mathrm{kN} / \mathrm{m}^{2}\right)\end{array}$ & $\begin{array}{c}f_{\mathrm{tcd}} \\
\left(\mathrm{kN} / \mathrm{m}^{2}\right)\end{array}$ \\
\hline EM1 & 22,5 & 44,00 & 8,9 & כ & 0,77 & 987,00 & 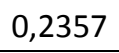 & 2 & 4000 & 4320 & 3024 \\
\hline EM2-a & 28,5 & 28,30 & 9,9 & 012 & 99 & 910,74 & 0,1866 & 4880,68 & 38000 & 3400 & 2380 \\
\hline EM2-b & 23,5 & 28,30 & או, & 0,015 & 91,99 & 910,74 & 0,1866 & 4880,68 & 38000 & 3400 & 2380 \\
\hline EM3 & 18,0 & 30,80 & 2,63 & 0,005 & 117,68 & 309,49 & 0,1166 & 2654,32 & 55000 & 4320 & 3024 \\
\hline
\end{tabular}

Tabela 8.12 - HEADMAN e LOSBERG - Flexo-cortante - Europa.

\begin{tabular}{|c|c|c|c|c|c|c|}
\hline MODELOS & $\mathbf{V}_{\mathbf{c}}(\mathbf{k N})$ & $\mathbf{C}$ & $\mathbf{V}_{\mathbf{p}} \mathbf{( k N )}$ & $\mathbf{V}_{\text {Rd1 }}(\mathbf{k N})$ & $\mathbf{V}_{\mathbf{s}}(\mathbf{k N})$ & SIT / (S/R) \\
\hline EM1 & 3,21 & 0,15 & 62,18 & $\mathbf{6 5 , 4 0}$ & $\mathbf{2 1 2 , 7 0}$ & REP. / 3,25 \\
\hline EM2-a & 2,34 & 0,15 & 59,05 & $\mathbf{6 1 , 3 8}$ & $\mathbf{1 9 7 , 6 0}$ & REP. / 3,22 \\
\hline EM2-b & 2,16 & 0,15 & 48,69 & $\mathbf{5 0 , 8 5}$ & $\mathbf{2 3 1 , 3 0}$ & REP. / 4,55 \\
\hline EM3 & 1,60 & 0,15 & 22,07 & $\mathbf{2 3 , 6 7}$ & $\mathbf{1 2 4 , 3 0}$ & REP. / 5,25 \\
\hline
\end{tabular}

LEGENDA: REP. = reprovado; $A P R$. = aprovado; $S$ = solicitação; $\mathrm{R}=$ resistência.

Tabela 8.13 - REAGAN - Flexo-cortante - Europa.

\begin{tabular}{|c|c|c|c|c|c|c|}
\hline MODELOS & $\mathbf{V}_{\mathbf{c}}$ (kN) & $\mathbf{C}$ & $\mathbf{V}_{\mathbf{p}}(\mathbf{k N})$ & $\mathbf{V}_{\mathbf{R d} 1}(\mathbf{k N})$ & $\mathbf{V}_{\mathbf{s}}(\mathbf{k N})$ & $\mathbf{S I T} / \mathbf{( S / R )}$ \\
\hline EM1 & 17,81 & 0,15 & 62,18 & $\mathbf{8 0 , 0 0}$ & $\mathbf{2 1 2 , 7 0}$ & REP. / 2,66 \\
\hline EM2-a & 12,77 & 0,15 & 59,05 & $\mathbf{7 1 , 8 2}$ & $\mathbf{1 9 7 , 6 0}$ & REP. / 2,75 \\
\hline EM2-b & 12,32 & 0,15 & 48,69 & $\mathbf{6 1 , 0 1}$ & $\mathbf{2 3 1 , 3 0}$ & REP. / 3,79 \\
\hline EM3 & 9,03 & 0,15 & 22,07 & $\mathbf{3 1 , 1 1}$ & $\mathbf{1 2 4 , 3 0}$ & REP. / 4,00 \\
\hline
\end{tabular}

LEGENDA: $R E P$. = reprovado; $A P R$. = aprovado; $S$ = solicitação; $\mathrm{R}=$ resistência.

Tabela 8.14 - MODEL CODE 90 - Flexo-cortante - Europa.

\begin{tabular}{|c|c|c|c|c|}
\hline MODELOS & $\mathbf{V}_{\mathbf{c}} \mathbf{( k N )}$ & $\mathbf{V}_{\text {Rd1 }}(\mathbf{k N})$ & $\mathbf{V}_{\mathbf{s}}(\mathbf{k N})$ & SIT / (S/R) \\
\hline EM1 & 13,36 & $\mathbf{7 5 , 5 4}$ & $\mathbf{2 1 2 , 7 0}$ & REP./ 2,82 \\
\hline EM2-a & 9,58 & $\mathbf{6 8 , 6 3}$ & $\mathbf{1 9 7 , 6 0}$ & REP./ 2,88 \\
\hline EM2-b & 9,24 & $\mathbf{5 7 , 9 3}$ & $\mathbf{2 3 1 , 3 0}$ & REP./ 3,99 \\
\hline EM3 & 6,77 & $\mathbf{2 8 , 8 5}$ & $\mathbf{1 2 4 , 3 0}$ & REP./ 4,31 \\
\hline
\end{tabular}

LEGENDA: REP. = reprovado; APR. = aprovado; $\mathrm{S}=$ solicitação; $\mathrm{R}=$ resistência.

Tabela 8.15 - EUROCODE 2:2004 - Flexo-cortante - Europa.

\begin{tabular}{|c|c|c|c|c|}
\hline MODELOS & $\mathbf{V}_{\mathbf{c}} \mathbf{( k N )}$ & $\mathbf{V}_{\mathbf{R d} \mathbf{1}} \mathbf{( k N )}$ & $\mathbf{V}_{\mathbf{s}}(\mathbf{k N})$ & SIT / (S/R) \\
\hline EM1 & 20,04 & $\mathbf{8 2 , 2 2}$ & $\mathbf{2 1 2 , 7 0}$ & REP. / 2,59 \\
\hline EM2-a & 14,37 & $\mathbf{7 3 , 4 1}$ & $\mathbf{1 9 7 , 6 0}$ & REP. / 2,69 \\
\hline EM2-b & 13,87 & $\mathbf{6 2 , 5 5}$ & $\mathbf{2 3 1 , 3 0}$ & REP. / 3,70 \\
\hline EM3 & 10,16 & $\mathbf{3 2 , 2 4}$ & $\mathbf{1 2 4 , 3 0}$ & REP. / 3,86 \\
\hline
\end{tabular}

LEGENDA: REP. = reprovado; APR. = aprovado; $S$ = solicitação; $\mathrm{R}=$ resistência. 


\subsection{5 - Resistência ao cisalhamento - Flexo-cortante - Brasil}

As tabelas 8.16 a 8.22 apresentam os cálculos considerando a formulação da NBR 6118:2014 e da NBR 14861:2011.

Além disso, foram consideradas as seguintes variações: $f_{c t d}$ para todas as lajes, $f_{c t m}$ para as lajes feitas em extrusoras, coeficiente $\alpha$ para a NBR 6118:2014, considerando l $_{\text {bpt, }}$ e por fim coeficiente $\alpha$ da NBR 14861:2011, considerando $I_{p t 2}$.

A Tabela 8.16 mostra os dados comuns às formulações brasileiras, e os dados das demais são indicados a seguir:

- Tabela 8.17 = NBR 6118:2014, considerando $f_{\text {ctd }}$ para todas as lajes, sem utilizar o coeficiente $\alpha$;

- Tabela 8.18 = NBR 6118:2014, considerando $f_{c t m}$ para as lajes feitas em extrusoras, $f_{\text {ctd }}$ para EM1, sem utilizar o coeficiente $\alpha$;

- Tabela 8.19 = NBR 6118:2014, considerando $f_{\text {ctd }}$ para todas as lajes, utilizando o coeficiente $\alpha$;

- Tabela 8.20 = NBR 6118:2014, considerando $f_{c t m}$ para as lajes feitas em extrusoras, $f_{\text {ctd }}$ para EM1, utilizando o coeficiente $\alpha$;

- Tabela 8.21 = NBR 14861:2011, considerando $\mathrm{f}_{\mathrm{ctd}}$ para todas as lajes, utilizando o coeficiente $\alpha$;

- Tabela 8.22 = NBR 14861:2011, considerando $f_{c t m}$ para as lajes feitas em extrusoras, $f_{c t d}$ para EM1, utilizando o coeficiente $\alpha$.

Tabela 8.16 - Dados gerais - Flexo-cortante - Brasil.

\begin{tabular}{|c|c|c|c|c|c|c|c|c|}
\hline MODELOS & $\begin{array}{c}\mathbf{d}_{\text {comp }} \\
(\mathbf{c m})\end{array}$ & $\mathbf{b}_{\mathbf{w}}(\mathbf{c m})$ & $\mathbf{k}$ & $\left.\mathbf{A}_{\mathbf{p}} \mathbf{( c m}^{\mathbf{2}}\right)$ & $\boldsymbol{\rho}_{\mathbf{1 , p}}$ & $\mathbf{A}_{\mathbf{s}} \mathbf{( c m}^{\mathbf{2})}$ & $\boldsymbol{\rho}_{\mathbf{1 , \mathbf { s }}}$ & $\begin{array}{c}\boldsymbol{\sigma}_{\mathbf{p t}, \mathbf{\infty}} \\
\left(\mathbf{k N} / \mathbf{c m}^{\mathbf{2}}\right)\end{array}$ \\
\hline EM1 & 22,5 & 44,00 & 1,375 & 8,91 & 0,009 & 19,56 & 0,020 & 110,77 \\
\hline EM2-a & 28,5 & 28,30 & 1,315 & 9,9 & 0,012 & 12,26 & 0,015 & 91,99 \\
\hline EM2-b & 23,5 & 28,30 & 1,365 & 9,9 & 0,015 & 9,90 & 0,015 & 91,99 \\
\hline EM3 & 18,0 & 30,80 & 1,420 & 2,63 & 0,005 & 6,50 & 0,012 & 117,68 \\
\hline
\end{tabular}

Tabela 8.16-continuação - Dados gerais - Flexo-cortante - Brasil.

\begin{tabular}{|c|c|c|c|c|c|c|c|}
\hline MODELOS & $N_{s d}(k N)$ & $A_{c}\left(m^{2}\right)$ & $\begin{array}{c}\sigma_{c p} \\
\left(k N / m^{2}\right)\end{array}$ & C & $\begin{array}{c}f_{\mathrm{cj}} \\
\left(\mathrm{kN} / \mathrm{m}^{2}\right)\end{array}$ & $\begin{array}{c}\mathbf{f}_{\mathrm{tcm}} \\
\left(\mathrm{kN} / \mathrm{m}^{2}\right)\end{array}$ & $\begin{array}{c}\mathbf{f}_{\mathrm{tcd}} \\
\left(\mathrm{kN} / \mathrm{m}^{2}\right)\end{array}$ \\
\hline EM1 & 987,00 & 0,2357 & 4187,52 & 0,15 & 54000 & 4320 & 3024 \\
\hline EM2-a & 910,74 & 0,1866 & 4880,68 & 0,15 & 38000 & 3400 & 2380 \\
\hline EM2-b & 910,74 & 0,1866 & 4880,68 & 0,15 & 38000 & 3400 & 2380 \\
\hline EM3 & 309,49 & 0,1166 & 2654,32 & 0,15 & 55000 & 4320 & 3024 \\
\hline
\end{tabular}


Tabela 8.17 - NBR 6118:2014, considerando $f_{c t d}$ para todas as lajes, sem $\alpha$.

\begin{tabular}{|c|c|c|c|c|c|c|}
\hline MODELOS & $\tau_{\text {Rd }}\left(\mathbf{k N} / \mathbf{m}^{\mathbf{2}}\right)$ & $\mathbf{V}_{\mathbf{c}}(\mathbf{k N})$ & $\mathbf{V}_{\mathbf{p}} \mathbf{( k N )}$ & $\mathbf{V}_{\mathbf{R d 1}}(\mathbf{k N})$ & $\mathbf{V}_{\mathbf{s}}(\mathbf{k N})$ & SIT / (S/R) \\
\hline EM1 & 756 & 160,54 & 62,18 & $\mathbf{2 2 2 , 7 3}$ & $\mathbf{2 1 2 , 7 0}$ & REP. / 0,95 \\
\hline EM2-a & 595 & 106,71 & 59,05 & $\mathbf{1 6 5 , 7 6}$ & $\mathbf{1 9 7 , 6 0}$ & REP. / 1,20 \\
\hline EM2-b & 595 & 96,98 & 48,69 & $\mathbf{1 4 5 , 6 7}$ & $\mathbf{2 3 1 , 3 0}$ & REP. / 1,59 \\
\hline EM3 & 756 & 82,71 & 22,07 & $\mathbf{1 0 4 , 7 9}$ & $\mathbf{1 2 4 , 3 0}$ & REP. / 1,19 \\
\hline
\end{tabular}

LEGENDA: $R E P$. = reprovado; $A P R$. = aprovado; $S$ = solicitação; $\mathrm{R}=$ resistência.

Tabela 8.18 - NBR 6118:2014, considerando $f_{c t m}$ para as lajes feitas em extrusoras, $f_{\text {ctd }}$ para EM1, sem $\alpha$.

\begin{tabular}{|c|c|c|c|c|c|c|}
\hline MODELOS & $\boldsymbol{\tau}_{\mathbf{R d}}\left(\mathbf{k N} / \mathbf{m}^{\mathbf{2}}\right)$ & $\mathbf{V}_{\mathbf{c}}(\mathbf{k N})$ & $\mathbf{V}_{\mathbf{p}} \mathbf{( k N )}$ & $\mathbf{V}_{\mathbf{R d 1}}(\mathbf{k N})$ & $\mathbf{V}_{\mathbf{s}}(\mathbf{k N})$ & $\mathbf{S I T} / \mathbf{( S / R )}$ \\
\hline EM1 & 756 & 160,54 & 62,18 & $\mathbf{2 2 2 , 7 3}$ & $\mathbf{2 1 2 , 7 0}$ & REP. / 0,95 \\
\hline EM2-a & 850 & 152,45 & 59,05 & $\mathbf{2 1 1 , 4 9}$ & $\mathbf{1 9 7 , 6 0}$ & REP. / 0,93 \\
\hline EM2-b & 850 & 138,54 & 48,69 & $\mathbf{1 8 7 , 2 3}$ & $\mathbf{2 3 1 , 3 0}$ & REP. / 1,24 \\
\hline EM3 & 1080 & 118,16 & 22,07 & $\mathbf{1 4 0 , 2 3}$ & $\mathbf{1 2 4 , 3 0}$ & APR. / 0,89 \\
\hline
\end{tabular}

LEGENDA: REP. = reprovado; $A P R .=$ aprovado; $S$ = solicitação; $\mathrm{R}=$ resistência.

Tabela 8.19 - NBR 6118:2014, considerando $f_{c t d}$ para todas as lajes, com $\alpha$.

\begin{tabular}{|c|c|c|c|c|c|c|c|c|c|}
\hline MODELOS & $\begin{array}{c}\boldsymbol{\tau}_{\text {Rd }} \\
\left(\mathbf{k N} / \mathbf{m}^{\mathbf{2}}\right)\end{array}$ & $\mathbf{V}_{\mathbf{c}}(\mathbf{k N})$ & $\mathbf{I}_{\mathbf{x}}(\mathbf{c m})$ & $\mathbf{I}_{\text {bpt }}(\mathbf{c m})$ & $\boldsymbol{\alpha}$ & $\mathbf{V}_{\mathbf{p}}(\mathbf{k N})$ & $\mathbf{V}_{\text {Rd1 }}(\mathbf{k N})$ & $\mathbf{V}_{\mathbf{s}}(\mathbf{k N})$ & SIT / (S/R) \\
\hline EM1 & 756 & 160,54 & 26 & 60 & 0,430 & 26,77 & $\mathbf{1 8 7 , 3 1}$ & $\mathbf{2 1 2 , 7 0}$ & REP./1,14 \\
\hline EM2-a & 595 & 106,71 & 28 & 68 & 0,411 & 24,26 & $\mathbf{1 3 0 , 9 7}$ & $\mathbf{1 9 7 , 6 0}$ & REP./1,51 \\
\hline EM2-b & 595 & 96,98 & 28 & 68 & 0,411 & 20,01 & $\mathbf{1 1 6 , 9 8}$ & $\mathbf{2 3 1 , 3 0}$ & REP./1,98 \\
\hline EM3 & 756 & 82,71 & 21 & 30 & 0,707 & 15,62 & $\mathbf{9 8 , 3 3}$ & $\mathbf{1 2 4 , 3 0}$ & REP./1,26 \\
\hline
\end{tabular}

LEGENDA: REP. = reprovado; $A P R$. = aprovado; $S$ = solicitação; $R=$ resistência.

Tabela 8.20 - NBR 6118:2014, considerando $f_{c t m}$ para as lajes feitas em extrusoras, $f_{c t d}$ para EM1, com $\alpha$.

\begin{tabular}{|c|c|c|c|c|c|c|}
\hline MODELOS & $\begin{array}{c}\tau_{\text {Rd }} \\
\left(\mathbf{k N} / \mathbf{m}^{\mathbf{2}}\right)\end{array}$ & $\mathbf{V}_{\mathbf{c}}(\mathbf{k N})$ & $\mathbf{V}_{\mathbf{p}}(\mathbf{k N})$ & $\mathbf{V}_{\text {Rd1 }}(\mathbf{k N})$ & $\mathbf{V}_{\mathbf{s}}(\mathbf{k N})$ & SIT / (S/R) \\
\hline EM1 & 756 & 160,54 & 26,77 & $\mathbf{1 8 7 , 3 1}$ & $\mathbf{2 1 2 , 7 0}$ & REP. / 1,14 \\
\hline EM2-a & 850 & 152,45 & 24,26 & $\mathbf{1 7 6 , 7 1}$ & $\mathbf{1 9 7 , 6 0}$ & REP. / 1,12 \\
\hline EM2-b & 850 & 138,54 & 20,01 & $\mathbf{1 5 8 , 5 5}$ & $\mathbf{2 3 1 , 3 0}$ & REP./ 1,46 \\
\hline EM3 & 1080 & 118,16 & 15,62 & $\mathbf{1 3 3 , 7 8}$ & $\mathbf{1 2 4 , 3 0}$ & APR. / 0,93 \\
\hline
\end{tabular}

LEGENDA: REP. = reprovado; $A P R$. = aprovado; $S$ = solicitação; $R=$ resistência.

Tabela 8.21 - NBR 14861:2011, considerando $f_{c t d}$ para todas as lajes, com $\alpha$.

\begin{tabular}{|c|c|c|c|c|c|c|c|c|c|}
\hline MODELOS & $\begin{array}{c}\boldsymbol{\tau}_{\mathbf{R d}} \\
\left(\mathbf{k N} / \mathbf{m}^{\mathbf{2}}\right)\end{array}$ & $\mathbf{V}_{\mathbf{c}}(\mathbf{k N})$ & $\mathbf{l}_{\mathbf{x}}(\mathbf{c m})$ & $\mathbf{l}_{\mathbf{p t 2} \mathbf{k} \mathbf{k}}(\mathbf{c m})$ & $\boldsymbol{\alpha}$ & $\mathbf{V}_{\mathbf{p}}(\mathbf{k N})$ & $\mathbf{V}_{\mathbf{R d} \mathbf{1}}(\mathbf{k N})$ & $\mathbf{V}_{\mathbf{s}}(\mathbf{k N})$ & $\mathbf{S I T} /(\mathbf{S} / \mathbf{R})$ \\
\hline EM1 & 756 & 160,54 & 26 & 77 & 0,337 & 20,97 & $\mathbf{1 8 1 , 5 1}$ & $\mathbf{2 1 2 , 7 0}$ & REP./1,17 \\
\hline EM2-a & 595 & 106,71 & 28 & 77 & 0,363 & 21,44 & $\mathbf{1 2 8 , 1 5}$ & $\mathbf{1 9 7 , 6 0}$ & REP./1,54 \\
\hline EM2-b & 595 & 96,98 & 28 & 77 & 0,363 & 17,68 & $\mathbf{1 1 4 , 6 6}$ & $\mathbf{2 3 1 , 3 0}$ & REP. /2,02 \\
\hline EM3 & 756 & 82,71 & 21 & 39 & 0,532 & 11,75 & $\mathbf{9 4 , 4 6}$ & $\mathbf{1 2 4 , 3 0}$ & REP./1,32 \\
\hline
\end{tabular}

LEGENDA: REP. = reprovado; $A P R .=$ aprovado; $S=$ solicitação; $R=$ resistência. 
Tabela 8.22 - NBR 14861:2011, considerando $f_{c t m}$ para as lajes feitas em extrusoras, $f_{c t d}$ para EM1, com $\alpha$.

\begin{tabular}{|c|c|c|c|c|c|c|}
\hline MODELOS & $\begin{array}{c}\tau_{\mathrm{Rd}} \\
\left(\mathrm{kN} / \mathrm{m}^{2}\right)\end{array}$ & $\mathrm{V}_{\mathrm{c}}(\mathrm{kN})$ & $V_{p}(k N)$ & $\mathrm{V}_{\mathrm{Rd} 1}(\mathrm{kN})$ & $\mathrm{V}_{\mathrm{s}}(\mathrm{kN})$ & SIT / (S/R) \\
\hline EM1 & 756 & 160,54 & 20,97 & 181,51 & 212,70 & REP. / 1,17 \\
\hline EM2-a & 850 & 152,45 & 21,44 & 173,89 & 197,60 & REP. / 1,14 \\
\hline EM2-b & 850 & 138,54 & 17,68 & 156,22 & 231,30 & REP. / 1,48 \\
\hline EM3 & 1080 & 118,16 & 11,75 & 129,91 & 124,30 & APR. / 0,96 \\
\hline
\end{tabular}

LEGENDA: REP. = reprovado; $A P R .=$ aprovado; $S$ = solicitação; $\mathrm{R}=$ resistência.

8.6.6 - Resistência ao cisalhamento - Flexo-cortante e tração diagonal - E.U.A.

As tabelas 8.23 e 8.23-continuação apresentam os valores para tração diagonal.

Tabela 8.23 - ACl 318-08:2008, tração diagonal.

\begin{tabular}{|c|c|c|c|c|c|c|c|c|}
\hline MODELOS & $\mathrm{f}_{\mathrm{c}}^{\prime}(\mathrm{MPa})$ & $\begin{array}{c}\sigma_{\mathrm{pt}, \infty} \\
\left(\mathrm{kN} / \mathrm{cm}^{2}\right)\end{array}$ & $A_{p}\left(\mathrm{~cm}^{2}\right)$ & $\mathbf{N}_{\mathrm{sd}}(\mathrm{kN})$ & $A_{c}\left(m^{2}\right)$ & $\begin{array}{c}\sigma_{\mathrm{cp}} \\
(\mathrm{MPa})\end{array}$ & $b_{w}(\mathrm{~cm})$ & $\mathrm{d}_{\text {comp }}(\mathrm{cm})$ \\
\hline EM1 & 54 & 110,8 & 8,91 & 987,0 & 0,2357 & 4,19 & 44,0 & 22,5 \\
\hline EM2-a & 38 & 92,0 & 9,9 & 910,7 & 0,1866 & 4,88 & 28,3 & 28,5 \\
\hline EM2-b & 38 & 92,0 & 9,9 & 910,7 & 0,1866 & 4,88 & 28,3 & 23,5 \\
\hline EM3 & 55 & 117,7 & 2,63 & 309,5 & 0,1166 & 2,65 & 30,8 & 18 \\
\hline
\end{tabular}

Tabela 8.23-continuação - ACl 318-08:2008, tração diagonal.

\begin{tabular}{|c|c|c|c|c|c|}
\hline MODELOS & $\mathbf{V}_{\text {cw,conc }}(\mathbf{k N})$ & $\mathbf{V}_{\text {cw,prot }}(\mathbf{k N})$ & $\mathbf{V}_{\mathrm{cw}}(\mathbf{k N})$ & $\mathbf{V}_{\mathbf{s}}(\mathbf{k N})$ & SIT / (S/R) \\
\hline EM1 & $\mathbf{2 1 0 , 9 7}$ & 124,37 & 335,34 & 212,70 & REP. , 0,63 \\
\hline EM2-a & 144,19 & 118,10 & 262,28 & 197,60 & APR. / 0,75 \\
\hline EM2-b & 118,89 & 97,38 & 216,27 & 231,30 & APR. / 1,07 \\
\hline EM3 & 119,23 & 44,15 & 163,38 & 124,30 & APR. / 0,76 \\
\hline
\end{tabular}

LEGENDA: REP. = reprovado; $A P R .=$ aprovado; $S$ = solicitação; $\mathrm{R}=$ resistência.

As tabelas 8.24 e 8.24-continuação apresentam os valores da força cortante resistente para flexo-cortante. Foram considerados os momentos de fissuração da laje e da capa.

Tabela 8.24 - ACI 318-08:2008, flexo-cortante.

\begin{tabular}{|c|c|c|c|c|c|c|c|}
\hline MODELOS & $\mathbf{f}_{\mathbf{c}}$ (MPa) & $\mathbf{V}_{\mathbf{u}} \mathbf{( k N )}$ & $\begin{array}{c}\mathbf{M}_{\mathbf{u}} \\
(\mathbf{k N . m})\end{array}$ & $\begin{array}{c}\mathbf{M}_{\mathbf{r}, \text { LAJE }} \\
\mathbf{( k N . m )}\end{array}$ & $\begin{array}{c}\mathbf{M}_{\mathbf{r}, \text { CAPA }} \\
(\mathbf{k N . m})\end{array}$ & $\mathbf{b}_{\mathbf{w}} \mathbf{( c m )}$ & $\begin{array}{c}\mathbf{d}_{\text {comp }} \\
\mathbf{( \mathbf { c m } )}\end{array}$ \\
\hline EM1 & 54 & 212,7 & 146 & 172 & 93 & 44 & 22,5 \\
\hline EM2-a & 38 & 197,6 & 161,7 & 180 & 135 & 28,3 & 28,5 \\
\hline EM2-b & 38 & 231,3 & 188,7 & 180 & 135 & 28,3 & 23,5 \\
\hline EM3 & 55 & 124,3 & 124,1 & 78 & 35 & 30,8 & 18 \\
\hline
\end{tabular}


Tabela 8.24-continuação - ACl 318-08:2008, flexo-cortante.

\begin{tabular}{|c|c|c|c|c|c|c|}
\hline MODELOS & $\begin{array}{c}\mathbf{V}_{\text {ci }}(\mathbf{k N})- \\
\mathbf{M}_{\mathbf{r}} \text { LAJE }\end{array}$ & $\mathbf{V}_{\mathbf{s}}(\mathbf{k N})$ & SIT / (S/R) & $\begin{array}{c}\mathbf{V}_{\text {ci }}(\mathbf{k N})- \\
\mathbf{M}_{\mathbf{r}} \text { CAPA }\end{array}$ & $\mathbf{V}_{\mathbf{s}}(\mathbf{k N})$ & SIT / (S/R) \\
\hline EM1 & $\mathbf{2 8 6 , 9 5}$ & $\mathbf{2 1 2 , 7 0}$ & REP. / 0,74 & $\mathbf{1 7 1 , 8 6}$ & $\mathbf{2 1 2 , 7 0}$ & REP. / 1,24 \\
\hline EM2-a & $\mathbf{2 4 4 , 8 2}$ & $\mathbf{1 9 7 , 6 0}$ & APR. / 0,81 & $\mathbf{1 8 9 , 8 3}$ & $\mathbf{1 9 7 , 6 0}$ & REP. / 1,04 \\
\hline EM2-b & $\mathbf{2 4 1 , 1 3}$ & $\mathbf{2 3 1 , 3 0}$ & REP. / 0,96 & $\mathbf{2 4 1 , 1 3}$ & $\mathbf{2 3 1 , 3 0}$ & REP. / 0,96 \\
\hline EM3 & $\mathbf{9 8 , 6 8}$ & $\mathbf{1 2 4 , 3 0}$ & REP. / 1,26 & $\mathbf{5 5 , 6 1}$ & $\mathbf{1 2 4 , 3 0}$ & REP. / 2,24 \\
\hline
\end{tabular}

LEGENDA: REP. = reprovado; $A P R$. = aprovado; $S=$ solicitação; $R=$ resistência.

\subsection{7 - Resistência ao cisalhamento - Tração diagonal - Europa}

Para o cálculo da tração diagonal, é preciso considerar a seção transversal do elemento 15. Para o cálculo do $b_{w}$ será considerada a metade da altura do alvéolo, como mostrado na Figura 8.20.
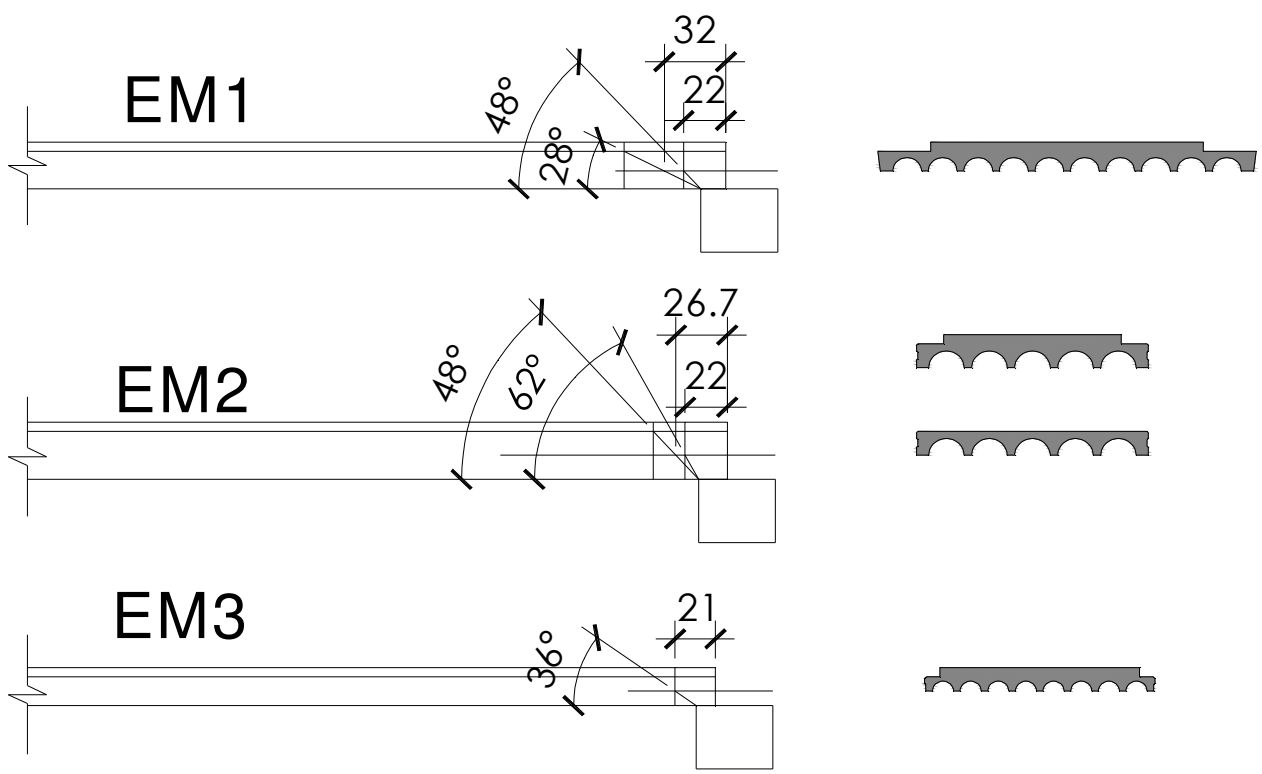

Figura 8.20 - Posição do ponto crítico, considerando metade do alvéolo.

A seguir, a Tabela 8.25 apresenta os dados comuns utilizados nas formulações para o cálculo da força cortante resistente com tração diagonal, seguindo a linha europeia. Os dados das demais tabelas são indicados a seguir:

- Tabela 8.26 = FIB MODEL CODE 2010, considerando $f_{\text {ctd }}$ para todas as lajes;

- Tabela 8.27 = FIB MODEL CODE 2010, considerando $f_{c t m}$ para as lajes feitas em extrusoras, $\mathrm{f}_{\mathrm{ctd}}$ para EM1;

- Tabela 8.28 = EUROCODE 2:2004, considerando $f_{\text {ctd }}$ para todas as lajes e liberação gradual da protensão;

- Tabela 8.29 = EUROCODE 2:2004, considerando $f_{c t d}$ para todas as lajes e liberação não gradual da protensão; 
- Tabela 8.30 = EUROCODE 2:2004, considerando $f_{c t m}$ para as lajes feitas em extrusoras, $f_{c t d}$ para EM1 e liberação gradual da protensão;

- Tabela 8.31 = EUROCODE 2:2004, considerando $f_{c t m}$ para as lajes feitas em extrusoras, $\mathrm{f}_{\mathrm{ctd}}$ para EM1 e liberação não gradual da protensão;

- Tabela 8.32 = EN 1168:2005, considerando $f_{\text {ctd }}$ para todas as lajes e liberação gradual da protensão;

- Tabela 8.33 = EN 1168:2005 considerando $\mathrm{f}_{\text {ctd }}$ para todas as lajes e liberação não gradual da protensão;

- Tabela 8.34 = EN 1168: 2005, considerando $f_{\text {ctm }}$ para as lajes feitas em extrusoras, $\mathrm{f}_{\mathrm{ctd}}$ para EM1 e liberação gradual da protensão;

- Tabela 8.35 = EN 1168: 2005, considerando $f_{c t m}$ para as lajes feitas em extrusoras, $f_{c t d}$ para EM1 e liberação não gradual da protensão.

Tabela 8.25 - Dados gerais - Tração diagonal - Europa.

\begin{tabular}{|c|c|c|c|c|c|c|c|}
\hline MODELOS & $\begin{array}{c}\mathbf{f}_{\mathbf{j}} \\
\left(\mathbf{k N} / \mathbf{m}^{\mathbf{2}}\right)\end{array}$ & $\mathbf{I}\left(\mathbf{m}^{\mathbf{4}}\right)$ & $\mathbf{b}_{\mathbf{c g}} \mathbf{( m )}$ & $\begin{array}{c}\text { Área }\left(\mathbf{m}^{\mathbf{2}}\right) \mathbf{~} \\
\mathbf{M}_{\mathbf{e}}\end{array}$ & $\mathbf{Y}_{\mathbf{c g}}(\mathbf{m}) / \mathbf{M}_{\mathbf{e}}$ & $\mathbf{M}_{\mathbf{e}}\left(\mathbf{m}^{\mathbf{3}}\right)$ & CONST $\left(\mathbf{m}^{\mathbf{2}}\right)$ \\
\hline EM1 & 54000 & 0,0024 & 0,4533 & 0,1979 & 0,0942 & 0,0186 & 0,0584 \\
\hline EM2-a & 38000 & 0,0027 & 0,283 & 0,1382 & 0,1098 & 0,0152 & 0,0504 \\
\hline EM2-b & 38000 & 0,0016 & 0,283 & 0,0921 & 0,0859 & 0,0079 & 0,0572 \\
\hline EM3 & 55000 & 0,0008 & 0,308 & 0,1094 & 0,0767 & 0,0084 & 0,0294 \\
\hline
\end{tabular}

Tabela 8.25-continuação - Dados gerais - Tração diagonal - Europa.

\begin{tabular}{|c|c|c|c|c|c|}
\hline MODELOS & $\mathbf{A}_{\mathbf{p}}\left(\mathbf{c m}^{\mathbf{2}}\right)$ & $\boldsymbol{\sigma}_{\mathbf{p t}, \infty}\left(\mathbf{k N} / \mathbf{c m}^{\mathbf{2}}\right)$ & $\mathbf{N}_{\mathbf{s d}}(\mathbf{k N})$ & $\mathbf{A}_{\mathbf{c}}\left(\mathbf{m}^{\mathbf{2}}\right)$ & $\boldsymbol{\sigma}_{\mathrm{cp}}\left(\mathbf{k N} / \mathbf{m}^{\mathbf{2}}\right)$ \\
\hline $\mathrm{EM} 1$ & 8,91 & 110,774 & 987,00 & 0,2357 & 4187,52 \\
\hline $\mathrm{EM} 2-\mathrm{a}$ & 9,9 & 91,993 & 910,74 & 0,1866 & 4880,68 \\
\hline $\mathrm{EM} 2-\mathrm{b}$ & 9,9 & 91,993 & 910,74 & 0,1866 & 4880,68 \\
\hline $\mathrm{EM} 3$ & 2,63 & 117,678 & 309,49 & 0,1166 & 2654,32 \\
\hline
\end{tabular}

Foi considerada a diferença entre $f_{c t d}$ e $f_{c t m}$ (para EM2 e EM3), uma vez que as lajes EM2 e EM3 foram feitas em extrusoras. Será considerada também a formulação do comprimento de transferência, com liberação gradual e não gradual da protensão.

Tabela 8.26 - FIB MODEL CODE 2010, considerando $f_{c t d}$ para todas as lajes.

\begin{tabular}{|c|c|c|c|c|c|c|c|c|}
\hline MODELOS & $\begin{array}{c}f_{\text {ctd }} \\
\left(k N / \mathrm{m}^{2}\right)\end{array}$ & $\mathrm{I}_{\mathrm{x}}(\mathrm{cm})$ & $\begin{array}{l}I_{\text {bpt }} \\
(\mathrm{cm})\end{array}$ & $\alpha_{1}$ & Ângulo & $\mathrm{V}_{\mathrm{Rd1}}(\mathrm{kN})$ & $\mathrm{V}_{\mathrm{s}}(\mathrm{kN})$ & SIT / (S/R) \\
\hline EM1 & 3024 & 22 & 60 & 0,307 & 48 & 210,72 & 212,70 & APR. / 1,01 \\
\hline EM2-a & 2380 & 22 & 67 & 0,273 & 62 & 149,70 & 197,60 & REP. / 1,32 \\
\hline EM2-b & 2380 & 22 & 67 & 0,273 & 62 & 170,15 & 231,30 & REP. / 1,36 \\
\hline EM3 & 3024 & 21 & 29 & 0,612 & 36 & 110,10 & 124,30 & REP. / 1,13 \\
\hline
\end{tabular}


Tabela 8.27 - FIB MODEL CODE 2010, $f_{c t m}$ para as lajes feitas em extrusoras, $f_{c t d}$ para EM1.

\begin{tabular}{|c|c|c|c|c|c|}
\hline MODELOS & $\mathbf{f}_{\mathrm{ctd}}\left(\mathbf{k N} / \mathbf{m}^{\mathbf{2}}\right)$ & $\mathbf{f}_{\mathrm{ctm}}\left(\mathbf{k N} / \mathbf{m}^{\mathbf{2}}\right)$ & $\mathbf{V}_{\mathrm{Rd} 1}(\mathbf{k N})$ & $\mathbf{V}_{\mathbf{s}}(\mathbf{k N})$ & $\mathrm{SIT} / \mathbf{( S / R )}$ \\
\hline$E M 1$ & 3024 & - & $\mathbf{2 1 0 , 7 2}$ & $\mathbf{2 1 2 , 7 0}$ & APR. / 1,01 \\
\hline$E M 2-a$ & - & 3400 & $\mathbf{2 0 2 , 0 1}$ & $\mathbf{1 9 7 , 6 0}$ & APR. / 0,98 \\
\hline$E M 2-b$ & - & 3400 & $\mathbf{2 2 9 , 6 0}$ & $\mathbf{2 3 1 , 3 0}$ & APR. / 1,01 \\
\hline$E M 3$ & - & 4320 & $\mathbf{1 4 8 , 8 1}$ & $\mathbf{1 2 4 , 3 0}$ & APR. / 0,84 \\
\hline
\end{tabular}

Tabela 8.28 - EUROCODE 2:2004, $f_{c t d}$ para todas as lajes e liberação gradual da protensão.

\begin{tabular}{|c|c|c|c|c|c|c|c|c|}
\hline MODELOS & $\begin{array}{c}\mathbf{f}_{\text {ctd }} \\
\left(\mathbf{k N} / \mathbf{m}^{\mathbf{2}}\right)\end{array}$ & $\mathbf{I}_{\mathbf{x}}(\mathbf{c m})$ & $\begin{array}{c}\mathbf{I}_{\text {pt2 }} \\
(\mathbf{c m})\end{array}$ & $\boldsymbol{\alpha}_{\mathbf{l}}$ & Ângulo & $\mathbf{V}_{\mathbf{R d 1}} \mathbf{( k N )}$ & $\begin{array}{c}\mathbf{V}_{\mathbf{s}} \\
(\mathbf{k N})\end{array}$ & SIT / (S/R) \\
\hline EM1 & 3024 & 22 & 42 & 0,518 & 48 & $\mathbf{2 3 1 , 2 4}$ & $\mathbf{2 1 2 , 7 0}$ & REP. / 0,92 \\
\hline EM2-a & 2380 & 22 & 48 & 0,460 & 62 & $\mathbf{1 6 7 , 0 8}$ & $\mathbf{1 9 7 , 6 0}$ & REP. / 1,18 \\
\hline EM2-b & 2380 & 22 & 48 & 0,460 & 62 & $\mathbf{1 8 9 , 9 0}$ & $\mathbf{2 3 1 , 3 0}$ & REP. / 1,22 \\
\hline EM3 & 3024 & 21 & 20 & 1,000 & 36 & $\mathbf{1 2 1 , 6 8}$ & $\mathbf{1 2 4 , 3 0}$ & REP. / 1,02 \\
\hline
\end{tabular}

Tabela 8.29 - EUROCODE 2:2004, fctd para todas as lajes e liberação não gradual da protensão.

\begin{tabular}{|c|c|c|c|c|c|}
\hline MODELOS & $\mathbf{I}_{\mathbf{p t 2}}(\mathbf{c m})$ & $\boldsymbol{\alpha}_{\mathbf{l}}$ & $\mathbf{V}_{\mathbf{R d} 1} \mathbf{( k N )}$ & $\mathbf{V}_{\mathbf{s}}(\mathbf{k N})$ & SIT / (S/R) \\
\hline EM1 & 53 & 0,414 & $\mathbf{2 1 7 , 6 8}$ & $\mathbf{2 1 2 , 7 0}$ & REP. / 0,98 \\
\hline EM2-a & 60 & 0,368 & $\mathbf{1 5 8 , 7 6}$ & $\mathbf{1 9 7 , 6 0}$ & REP. / 1,24 \\
\hline EM2-b & 60 & 0,368 & $\mathbf{1 8 0 , 4 5}$ & $\mathbf{2 3 1 , 3 0}$ & REP. / 1,28 \\
\hline EM3 & 25 & 0,825 & $\mathbf{1 1 6 , 5 9}$ & $\mathbf{1 2 4 , 3 0}$ & REP. / 1,07 \\
\hline
\end{tabular}

Tabela 8.30 - EUROCODE 2:2004, considerando $f_{c t m}$ para as lajes feitas em extrusoras, $f_{c t d}$ para EM1 e liberação gradual da protensão.

\begin{tabular}{|c|c|c|c|c|c|}
\hline MODELOS & $\mathbf{f}_{\mathrm{ctd}}\left(\mathbf{k N} / \mathbf{m}^{\mathbf{2}}\right)$ & $\mathbf{f}_{\mathrm{ctm}}\left(\mathbf{k N} / \mathbf{m}^{\mathbf{2}}\right)$ & $\mathbf{V}_{\text {Rd1 }}(\mathbf{k N})$ & $\mathbf{V}_{\mathbf{s}}(\mathbf{k N})$ & SIT / (S/R) \\
\hline EM1 & 3024 & - & $\mathbf{2 3 1 , 2 4}$ & $\mathbf{2 1 2 , 7 0}$ & REP. / 0,92 \\
\hline EM2-a & - & 3400 & $\mathbf{2 2 0 , 6 2}$ & $\mathbf{1 9 7 , 6 0}$ & APR. / 0,90 \\
\hline$E M 2-b$ & - & 3400 & $\mathbf{2 5 0 , 7 6}$ & $\mathbf{2 3 1 , 3 0}$ & REP. / 0,89 \\
\hline$E M 3$ & - & 4320 & $\mathbf{1 6 1 , 1 8}$ & $\mathbf{1 2 4 , 3 0}$ & APR. / 0,77 \\
\hline
\end{tabular}

Tabela 8.31 - EUROCODE 2:2004, considerando $f_{c t m}$ para as lajes feitas em extrusoras, $f_{c t d}$ para EM1 e liberação não gradual da protensão.

\begin{tabular}{|c|c|c|c|}
\hline MODELOS & $\mathbf{V}_{\mathbf{R d} 1}(\mathbf{k N})$ & $\mathbf{V}_{\mathbf{s}}(\mathbf{k N})$ & SIT / (S/R) \\
\hline EM1 & $\mathbf{2 1 7 , 6 8}$ & $\mathbf{2 1 2 , 7 0}$ & REP. / 0,98 \\
\hline EM2-a & $\mathbf{2 1 1 , 6 6}$ & $\mathbf{1 9 7 , 6 0}$ & APR. / 0,93 \\
\hline EM2-b & $\mathbf{2 4 0 , 5 8}$ & $\mathbf{2 3 1 , 3 0}$ & REP. / 0,96 \\
\hline EM3 & $\mathbf{1 5 5 , 7 1}$ & $\mathbf{1 2 4 , 3 0}$ & APR. / 0,80 \\
\hline
\end{tabular}

Tabela 8.32 - EN 1168:2005, considerando $f_{c t d}$ para todas as lajes e liberação gradual da protensão.

\begin{tabular}{|c|c|c|c|c|c|}
\hline MODELOS & GLOBAL & PROT. & $\mathbf{V}_{\text {Rd1 }}(\mathbf{k N})$ & $\mathbf{V}_{\mathbf{s}}(\mathbf{k N})$ & SIT / (S/R) \\
\hline EM1 & 0,8 & 0,9 & $\mathbf{1 8 1 , 0 8}$ & $\mathbf{2 1 2 , 7 0}$ & REP. / 1,17 \\
\hline EM2-a & 0,8 & 0,9 & $\mathbf{1 3 0 , 3 8}$ & $\mathbf{1 9 7 , 6 0}$ & REP. / 1,52 \\
\hline EM2-b & 0,8 & 0,9 & $\mathbf{1 4 8 , 1 9}$ & $\mathbf{2 3 1 , 3 0}$ & REP. / 1,56 \\
\hline EM3 & 0,8 & 0,9 & $\mathbf{9 5 , 0 4}$ & $\mathbf{1 2 4 , 3 0}$ & REP. / 1,31 \\
\hline
\end{tabular}


Tabela 8.33 - EN 1168:2005, considerando $f_{c t d}$ para todas as lajes e liberação não gradual da protensão.

\begin{tabular}{|c|c|c|c|}
\hline MODELOS & $\mathbf{V}_{\text {Rd1 }}(\mathbf{k N})$ & $\mathbf{V}_{\mathbf{s}}(\mathbf{k N})$ & SIT / (S/R) \\
\hline EM1 & $\mathbf{1 7 3 , 8 4}$ & $\mathbf{2 1 2 , 7 0}$ & REP. / 1,22 \\
\hline EM2-a & $\mathbf{1 2 4 , 2 5}$ & $\mathbf{1 9 7 , 6 0}$ & REP. / 1,59 \\
\hline EM2-b & $\mathbf{1 4 1 , 2 2}$ & $\mathbf{2 3 1 , 3 0}$ & REP. / 1,64 \\
\hline EM3 & $\mathbf{9 1 , 2 9}$ & $\mathbf{1 2 4 , 3 0}$ & REP. / 1,36 \\
\hline
\end{tabular}

Tabela 8.34 - EN 1168:2005, considerando $f_{c t m}$ para as lajes feitas em extrusoras, $f_{c t d}$ para EM1 e liberação gradual da protensão.

\begin{tabular}{|c|c|c|c|}
\hline MODELOS & $\mathbf{V}_{\text {Rd1 }}(\mathbf{k N})$ & $\mathbf{V}_{\mathbf{s}}(\mathbf{k N})$ & SIT / (S/R) \\
\hline EM1 & $\mathbf{1 8 1 , 0 9}$ & $\mathbf{2 1 2 , 7 0}$ & REP. / 1,17 \\
\hline EM2-a & $\mathbf{1 7 2 , 9 5}$ & $\mathbf{1 9 7 , 6 0}$ & REP. / 1,14 \\
\hline EM2-b & $\mathbf{1 9 6 , 5 7}$ & $\mathbf{2 3 1 , 3 0}$ & REP. / 1,18 \\
\hline EM3 & $\mathbf{1 2 6 , 4 7}$ & $\mathbf{1 2 4 , 3 0}$ & REP. / 0,98 \\
\hline
\end{tabular}

Tabela 8.35 - EN 1168:2005, considerando $f_{c t m}$ para as lajes feitas em extrusoras, $f_{c t d}$ para EM1 e liberação não gradual da protensão.

\begin{tabular}{|c|c|c|c|}
\hline MODELOS & $\mathbf{V}_{\text {Rd1 }}(\mathbf{k N})$ & $\mathbf{V}_{\mathbf{s}}(\mathbf{k N})$ & SIT / (S/R) \\
\hline EM1 & $\mathbf{1 7 3 , 8 4}$ & $\mathbf{2 1 2 , 7 0}$ & REP. / 1,22 \\
\hline EM2-a & $\mathbf{1 6 6 , 3 7}$ & $\mathbf{1 9 7 , 6 0}$ & REP. / 1,19 \\
\hline EM2-b & $\mathbf{1 8 9 , 1 0}$ & $\mathbf{2 3 1 , 3 0}$ & REP. / 1,22 \\
\hline EM3 & $\mathbf{1 2 2 , 4 6}$ & $\mathbf{1 2 4 , 3 0}$ & REP. / 1,02 \\
\hline
\end{tabular}

\section{7 - Conclusão}

Analisando os resultados apresentados, conclui-se que as lajes dos modelos 1 e 2 sofreram ruptura por tração diagonal do concreto.

A única metodologia que apresentou resultados compatíveis com os ensaios foi a do FIB MODEL CODE 2010, que considera o comprimento de transferência de acordo com o item 8.5.3 e a expressão 8.33. Além disso, os resultados só foram considerados aprovados com a utilização de $f_{c t m}$ como resistência do concreto à tração para as lajes fabricadas com extrusoras.

O mecanismo de tração diagonal também levou a resultado positivo quando foi utilizado o $\mathrm{ACl}$ 318-08:2008, nas lajes dos modelos 2 e 3.

Além disso, a formulação brasileira que considera o mecanismo de flexo-cortante apresentou resultados próximos ao esperado, para a laje do modelo 1. 


\section{CONCLUSÃO}

A continuidade em pavimentos formados por laje alveolar é um tema vasto e complexo, e ainda precisa ser amplamente investigado. Acredita-se que este trabalho tenha cumprido seu objetivo principal, que foi estudar o comportamento das lajes alveolares com continuidade, e com isso, tenha contribuído para o desenvolvimento do conhecimento neste assunto.

Tendo em vista que algumas conclusões foram apresentadas anteriormente, este capítulo procura abordá-las por tópicos, a fim de fornecer uma visão global do trabalho.

\section{1 - Objetivos específicos}

A princípio, interessava o comportamento da ligação laje-viga-laje, sobretudo no que diz respeito à semirrigidez. Em nenhum dos três ensaios realizados constatou-se, de forma significativa, um giro relativo entre as lajes e a viga. Acredita-se, portanto, que a ligação tem um comportamento rígido, ou muito próximo de rígido.

Já o fenômeno da formação de uma rótula plástica não foi observado. As fissuras que surgiram na capa se estabilizavam, conforme explicação da Figura 4.11, e, além disso, não alcançavam a interface capa-laje.

Outra meta proposta foi a de sugerir um critério para o cálculo da armadura de continuidade para se utilizar nos ensaios experimentais. Esse critério foi proposto no capítulo 3 e utilizado neste trabalho. Os valores foram coerentes com os resultados da análise experimental.

Também foi proposto, nos objetivos específicos, comparar o efeito da continuidade com as situações de lajes simplesmente apoiadas. Através deste trabalho, essa comparação foi feita, principalmente, nos capítulos 2 e 3 . Observou-se que a continuidade proporciona um melhor desempenho às lajes alveolares, pois diminui os deslocamentos no meio do vão, e aumenta a capacidade portante. Entretanto, a continuidade altera o diagrama de força cortante, aumentando a força cortante no apoio onde existe continuidade, em comparação com apoio simples.

Conclui-se que a continuidade, se corretamente dimensionada, gera benefícios ao pavimento constituído por lajes alveolares, sobretudo em países como o Brasil, que já utiliza a capa para solidarização do pavimento. 


\section{2 - Cálculo da armadura passiva para ensaio experimental}

A metodologia para o cálculo da armadura passiva para se utilizar nos ensaios experimentais mostrou-se eficiente, pois foi possível saber de antemão o aumento real da capacidade portante da laje alveolar e, além disso, prever o modo de ruptura. Com o uso desse método foi possível aproveitar melhor a capacidade portante das lajes alveolares ensaiadas e aproximar mais os esforços solicitantes dos resistentes.

Se essa metodologia não fosse aplicada, seria considerado apenas o momento negativo resistente pela seção próxima ao apoio, comumente chamado de momento elástico.

Isso resultaria em se utilizar, de acordo com a Tabela 3.29, os seguintes valores para armadura passiva: $33,51 \mathrm{~cm}^{2}$ para EM1, 40,72 $\mathrm{cm}^{2}$ para EM2 e $8,92 \mathrm{~cm}^{2}$ para EM3. Em outras palavras, seriam utilizados valores muito altos para essas armaduras nos ensaios de EM1 e EM2, em comparação com o que foi realmente usado $\left(19,56 \mathrm{~cm}^{2}\right.$ e $\left.12,26 \mathrm{~cm}^{2}\right)$. 0 resultado seria um custo excessivo em armadura que não iria interferir nos resultados, uma vez que, de qualquer forma, essas lajes iriam romper por cisalhamento na seção transversal (casos de EM1 e EM2) e na interface (caso de EM2). Vale ressaltar que, para os casos de 33,51 $\mathrm{cm}^{2}$ para EM1 e $40,72 \mathrm{~cm}^{2}$ para EM2, seria fisicamente impossível alojar as barras na capa.

Para o modelo 1, a metodologia empregada no capítulo 3 permitiu fazer as seguintes previsões: a fissuração da capa aconteceria entre 82,31 kN e 117,59 kN de força aplicada; a fissuração da laje ocorreria entre 234,96 kN e 274,26 kN e, por fim, que a ruptura por cisalhamento da seção transversal seria com $274,13 \mathrm{kN}$. Os resultados obtidos no ensaio experimental foram 107,9 kN, 219,1 kN e 272,0 kN, respectivamente para fissuração da capa, fissuração da laje e ruptura. Esse fato permite concluir que a metodologia aplicada representou com precisão o comportamento do modelo 1.

No modelo 2, os resultados de previsão eram: fissuração da capa entre 72,84 kN e 104,07 kN; fissuração da laje entre 255,44 kN e 300,48 kN e, por fim, ruptura por cisalhamento na seção transversal com 207,98 kN. Portanto a previsão era de que não ocorreria fissuração da laje pelo momento positivo. Os resultados da análise experimental foram de: $26,0 \mathrm{kN}$ para a fissuração da capa, 254,7 kN para a ruptura na interface e 297,3 kN para a ruptura por cisalhamento na seção transversal. Portanto a previsão pode ser considerada como satisfatória, uma vez que não ocorreu a fissuração da laje, e se a interface fosse mais resistente, a ruptura do modelo seria igual à prevista, ou seja, por cisalhamento da seção transversal. 
No entanto, os resultados obtidos para o modelo 2 indicam que são necessários dois ajustes na metodologia do capítulo 3. O primeiro diz respeito à expressão para o cálculo da resistência ao cisalhamento da seção transversal, e o segundo se refere à resistência da interface ao cisalhamento.

O capítulo 8 mostrou que a expressão da NBR 6118:2014 para o cálculo resistência da seção transversal ao cisalhamento não foi satisfatória para o modelo 2, como foi para o modelo 1. Além disso, o capítulo 4 mostrou também que a expressão brasileira gerou um resultado incoerente na caracterização da laje do modelo 2 , na obtenção do $f_{\text {ck. Portanto, }}$ conclui-se que a metodologia do capítulo 3 deve ser ajustada, no que diz respeito à resistência da seção transversal ao cisalhamento. Sugere-se a substituição da expressão da NBR 6118:2014, adotada no capítulo 3, pela expressão que melhor representou a ruptura da seção ao cisalhamento, ou seja, a do FIB MODEL CODE 2010.

Com relação à interface, existem duas opções de ajuste. A primeira é utilizar um material aderente, por exemplo, uma resina epóxi, com o objetivo de garantir que a ruptura não ocorra na interface. A segunda opção é considerar no método a ruptura na interface como uma possível forma de ruína. Para isso, é necessário introduzir nos cálculos uma expressão que determine a resistência na interface. Como visto no capítulo 7, é indicada a expressão do EUROCODE 2:2004.

Considerando o modelo 3, os resultados de previsão eram: fissuração da capa entre 32,94 kN e 47,05 kN; fissuração da laje entre 69,23 kN e 85,88 kN e, por fim, ruptura por flexão com 100,39 kN. Os resultados da análise experimental foram: 25,1 kN para a fissuração da capa, 137,7 kN para a fissuração da laje; e 146,8 kN para a ruptura por flexão. Mais uma vez, a previsão pode ser considerada como satisfatória, uma vez que descreveu de forma correta o comportamento e previu a forma de ruptura do modelo.

Vale ressaltar que a metodologia do capítulo 3 não considera a influência da fissuração no modelo, ou seja, faz uma análise linear física. Esse motivo reforça a ideia de que esse modelo prevê de forma satisfatória a comportamento das lajes com continuidade.

Considerando que a metodologia sugerida no capítulo 3 para o cálculo da armadura passiva é satisfatória, e, além disso, tendo em mãos uma ferramenta capaz de processar os cálculos de forma rápida, é intuitivo gerar diagramas de iteração, tal como foi feito no capítulo 3. Esses diagramas de iteração são úteis para pré-dimensionamento, e podem ser melhorados com a consideração de outras variáveis, como, por exemplo, a resistência às ações dinâmicas, a resistência às altas temperaturas e a outros tipos de carregamento. 


\section{3 - Ensaios para a caracterização de laje alveolar}

De acordo com o exposto no capítulo 4, conclui-se que a caracterização feita em ensaios nas próprias lajes gera resultados satisfatórios e atendem o seu propósito.

Na grande maioria dos ensaios de laboratório realizados em lajes alveolares, as lajes são produzidas em fábricas e não no laboratório especializado. Portanto, é recomendável realizar a caracterização desses elementos de forma indireta, como foi mostrado no capítulo 4. Sugere-se que esses ensaios de caracterização, feitos nos próprios elementos, sejam realizados pelo menos para fins de comparação com resultados dos corpos de prova fornecidos pelos fabricantes.

Dos três métodos utilizados para a caracterização das lajes alveolares, o que apresentou resultados coerentes, nos três modelos, foi o método do momento de fissuração. O método do módulo de elasticidade foi aplicado nos modelos 2 e 3, e só gerou resultados coerentes para o modelo 2.

Com relação ao procedimento de utilizar a força cortante, este só foi satisfatório no modelo 1. Nos modelos 2 e 3, os resultados obtidos com esse método foram incoerentes. Sugere-se, novamente, substituir a expressão da ABNT NBR 6118:2014 pela expressão do FIB MODEL CODE 2010, que considera ruptura por tração diagonal do concreto.

Como era de se esperar, as formulações para a teoria de flexão geram resultados melhores que as de cisalhamento, dada a variabilidade de expressões e resultados que existem na teoria de cisalhamento. Isso explica o fato do método do momento de fissuração ter apresentado resultados melhores que os demais. Sugere-se, portanto, utilizar as expressões da teoria da flexão, ou seja, o método do momento de fissuração e também o do momento resistente, para a caracterização das lajes alveolares. O primeiro já está difundido no meio técnico, como mostrado no capítulo 4 . O segundo ainda não é utilizado, porém mostrou-se adequado, conforme os resultados do capítulo 3.

No entanto, é importante considerar o tamanho da laje alveolar nos ensaios de flexão, uma vez que, dependendo do comprimento, os resultados podem sofrer interferência do mecanismo de flexo-cortante, como mostrado no capítulo 4.

\section{4 - Análise experimental utilizando continuidade}

Como previsto, os ensaios experimentais com continuidade são mais complexos que os de lajes simplesmente apoiadas, pois demandam mais espaço no laboratório e mais tempo para montagem. Sugere-se, por exemplo, o uso de pelo menos quatro câmeras filmadoras e uma fotográfica para o registro completo dos ensaios, pois o registro visual é muito importante para auxiliar na interpretação dos resultados indicados pela instrumentação. 
Durante a moldagem da capa, é muito importante evitar que o concreto caia nos alvéolos, pois isso pode alterar o comportamento do modelo sem que se tenha controle sobre essa mudança. Em outras palavras, pode acontecer o fato de se ter alvéolos preenchidos, ou semipreenchidos, e isso não ser levado em conta.

Também durante a concretagem da capa, é necessário tomar os cuidados necessários para não se ter uma interface com resistência baixa.

O que foi observado nos ensaios experimentais é que a capa sofreu fissuração em função do momento fletor negativo, e isso fez com que o comportamento dos modelos fosse governado pela não linearidade do material. Em outras palavras, à medida que a capa fissurava, os esforços solicitantes eram redistribuídos no modelo ensaiado. Esse fato foi observado também na fissuração da laje pelo momento fletor positivo.

Foram identificadas três formas de ruína nos modelos ensaiados. O primeiro sofreu ruptura por cisalhamento da seção transversal. O segundo, por cisalhamento da interface capa-laje, e o terceiro, por flexão. Esse fato comprova o que foi divulgado por GIRHAMMAR e PAJARI (2008) (ver Figura 4.10), e reafirma a necessidade de se considerar, no projeto estrutural, essas formas de ruptura.

De forma geral, o comportamento das lajes alveolares com continuidade, submetidas a cargas concentradas próximas ao meio do vão, acontece de forma variada e depende muito da forma de ruptura associada.

Tão logo se inicia a aplicação da força, a capa irá fissurar em serviço. A partir desse ponto, os fenômenos que antecedem a ruptura, como por exemplo o escoamento da armadura passiva e a fissuração da laje na região de momento positivo, irão ocorrer dependendo da taxa de armadura passiva, ou ativa, que o modelo apresenta. Da mesma forma, o tipo de ruptura irá ocorrer dependendo de fatores como: taxa de armadura (passiva e ativa), resistência da interface e largura total das nervuras.

\section{5 - Análise teórica com elementos de barra}

A análise teórica com elementos de barra e a expressão de Branson para considerar o comportamento não linear físico do material descreveram de forma satisfatória o desempenho dos modelos ensaiados, sendo que os resultados ficaram próximos dos obtidos nos ensaios.

Por isso, é possível concluir que a seção composta equivalente fictícia, representada por um duplo $\mathrm{T}$, representou bem o comportamento da seção real da laje alveolar. Além disso, o procedimento utilizado para aplicar a força de forma incremental e iterativa foi satisfatório, sendo que na maioria das etapas foi necessária apenas uma iteração. 
De posse dos resultados da análise teórica com elementos de barra, foi possível traçar as curvas que relacionam momento fletor negativo com as rotações no apoio. A observação dessas curvas e a comparação entre os resultados teóricos com os dos ensaios reforçaram o fato de que a ligação com continuidade tem um comportamento rígido, principalmente antes da fissuração da capa.

Foi possível, também, relacionar a força cortante solicitante com o valor de ruptura para cada elemento discretizado. Da mesma forma, relacionou-se o momento fletor com o de ruptura. Observou-se que, para os modelos 1 e 2, houve predominância das solicitações tangenciais sobre as normais. Em outras palavras, os modelos 1 e 2 estavam sujeitos à ruptura por cisalhamento e dificilmente iria ocorrer a ruptura pela interação da força cortante com o momento fletor. Esse fato foi coerente com os resultados relativos ao capítulo 8.

No modelo 3, observou-se que as solicitações normais eram predominantes em relação às tangenciais, resultados que são coerentes com os encontrados no capítulo 8.

\section{6 - Resistência ao cisalhamento na interface}

Para o cálculo da resistência da interface ao cisalhamento, existem muitas formulações propostas, como foi mostrado no capítulo 7. Todos os seus resultados foram comparados com os dos ensaios experimentais, e a formulação que apresentou resultados coerentes para todos os três modelos foi a do EUROCODE 2: 2004.

No entanto, outras formulações também apresentaram resultados satisfatórios, como é o caso da indicada por IBRAHIM (2008), que apresentou apenas um resultado negativo, além daquelas que apresentaram resultados coerentes para todos os três modelos para situação de momento negativo, como é o caso das relativas aos códigos: PCl:2010, BS 8110-1:1997 e ABNT NBR 9062:2006.

Para o cálculo da tensão solicitante de cisalhamento, foram apresentados dois métodos: da tensão de referência e da tensão média. O que apresentou resultados mais coerentes foi o da tensão de referência.

De acordo com o cálculo da tensão de referência (Tabela 7.12), em todos os modelos, a tensão solicitante de cisalhamento, na região de momento positivo, foi de aproximadamente $0,65 \mathrm{MPa}$. Já para a região de momento negativo essa tensão foi de 0,55 MPa para EM1, 0,83 MPa para EM2 e de 0,64 MPa para EM3. Conclui-se que em todos os casos a tensão de cisalhamento foi de magnitude considerável, sendo que o valor de 0,83 MPa ocasionou a ruptura da interface para o modelo 2.

Considerando a formulação do EUROCODE 2:2004, a tensão resistente de cisalhamento foi de 0,87 MPa para EM1, 0,76 MPa para EM2 e 0,66 MPa para EM3. Esses 
valores foram coerentes com as características das lajes alveolares de cada modelo. As lajes do modelo 1 tinham superfícies muito rugosas, uma vez que foram concretadas em formas e posteriormente vibradas. As lajes dos modelos 2 e 3 foram fabricadas com extrusoras, e por isso apresentavam superfícies mais lisas que as lajes do EM1. E além disso, como foi mencionado no capítulo 5, as lajes do modelo 3 continham uma camada muito fina de nata, que provavelmente a limpeza não foi capaz de remover $100 \%$.

Recomenda-se que o estudo da resistência da interface seja aprofundado, de preferência sob a forma estatística, com a realização de um número bem maior de ensaios, a fim de se obter a melhor formulação capaz de representar a resistência da interface.

É necessário melhorar os valores dos coeficientes para se considerar os mais variados tipos de superfícies. Além disso, faz-se necessário determinar um limite de tensão capa-laje que garanta a seção composta. Para isso, é necessário um exaustivo estudo experimental com continuidade. Posteriormente, esse limite deverá incluir os coeficientes de segurança.

\section{7 - Resistência da seção transversal ao cisalhamento}

A formulação que apresentou resultados mais coerentes com os ensaios foi a do FIB MODEL CODE 2010, sendo que a diferença entre essa formulação e a do EUROCODE 2:2004 é a forma de se calcular o comprimento de transferência. Além disso, os melhores resultados foram aqueles que utilizaram o valor de $f_{\text {ctm }}$ como resistência à tração para o concreto das lajes produzidas com extrusoras.

Uma das dúvidas que se tinha com relação ao comportamento das lajes ensaiadas com continuidade era se as fissuras devidas ao momento negativo avançavam pela capa, alcançando a seção da laje alveolar e configurando um mecanismo de flexo-cortante invertido. A conclusão é que isso não ocorreu, uma vez que as fissuras não alcançaram as lajes alveolares, nos três ensaios realizados.

Outra dúvida que se tinha era se a fissuração na ligação mudaria a configuração do ensaio (com continuidade) para uma situação biapoiada. A conclusão é que ocorreu ruptura por tração diagonal do concreto, com seção composta (EM1) e com seção simples (EM2). Entretanto, quando o modelo EM1 sofreu ruptura por cisalhamento, a laje não passou a se comportar como biapoiada.

No modelo EM2, isso pode ter acontecido, uma vez que, houve ruptura da ligação capa-laje. Conclui-se que, se houver garantia de que a capa não se descolará, o mecanismo se mantém com continuidade, e a laje nunca se torna biapoiada. Entretanto, devido à fissuração da capa, e depois, da laje, o modelo que melhor retrata esse comportamento é o que considera a não linearidade do material. 
Através dos ensaios realizados é possível concluir que não ocorreu um mecanismo invertido de cisalhamento, quando se considera a laje biapoiada e, depois, com continuidade.

O que ocorreu, na verdade, foi que a continuidade fez com que o arco de compressão mudasse de lugar (não ocorrendo inversão). Com isso, as fissuras também mudaram de posição (considerando as situações biapoiadas e com continuidade).

Para explicar isso, têm-se as figuras mostradas na sequência. A Figura 9.1, adaptada do $\mathrm{ACl}$ 318-08:2008, mostra o mecanismo de cisalhamento com continuidade. Nessa figura existem fissuras de flexão, de flexo-cortante e de tração diagonal.

A Figura 9.2 mostra a comparação entre o arco de compressão existente na situação biapoiada e naquela em que há continuidade. A diferença entre essas duas situações é a posição da biela inclinada, que na situação biapoiada está apoiada diretamente sobre a região do apoio. Já na situação com continuidade, essa biela é deslocada para o interior da laje, e no apoio onde há continuidade surge um arco invertido, em função do momento fletor negativo.

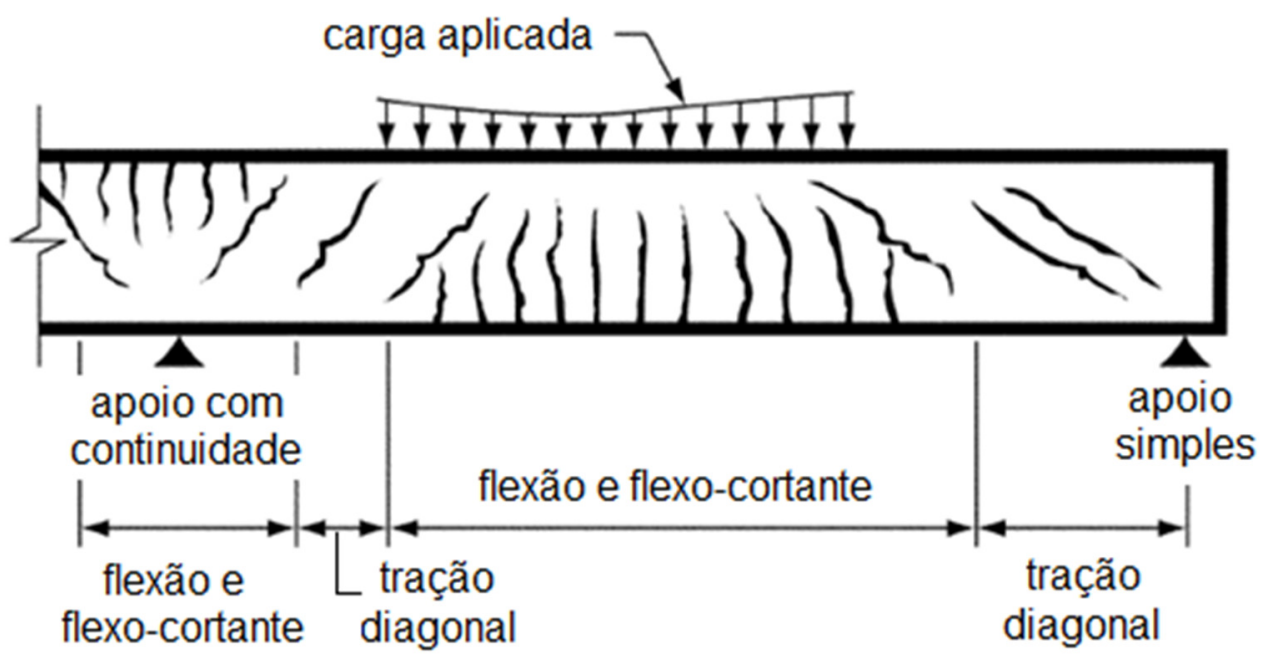

Figura 9.1 - Tipos de fissuras em vigas de concreto (adaptada do ACI 318-08:2008).

BIAPAPADAD A

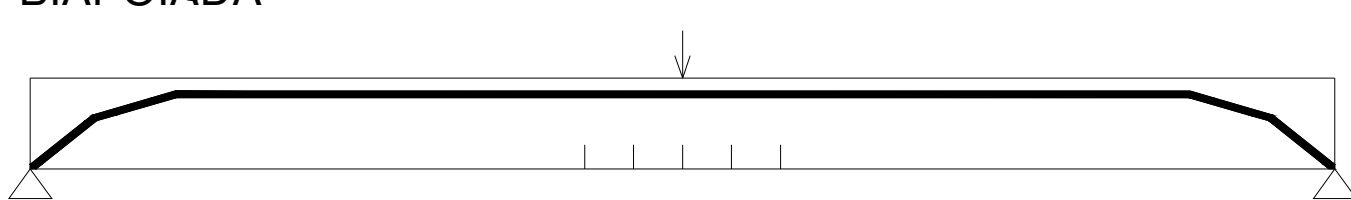

\section{CONNININDLADAD E}

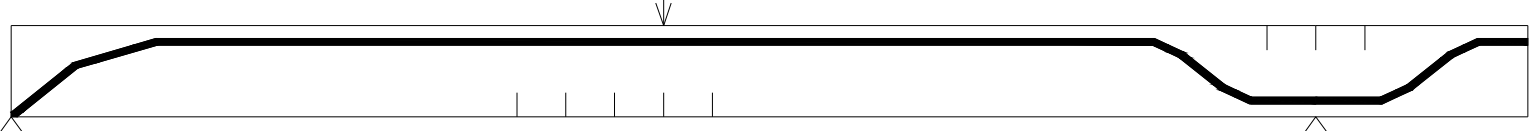

Figura 9.2 - Comparação entre o arco de compressão na situação biapoiada e na que existe continuidade. 
Além disso, para que existisse uma inversão da biela, seria necessário que o apoio mudasse de lugar, como mostra a figura 9.3 (MECANISMO INVERTIDO - HIPOTÉTICO). Portanto essa inversão não ocorreu no ensaio com continuidade.

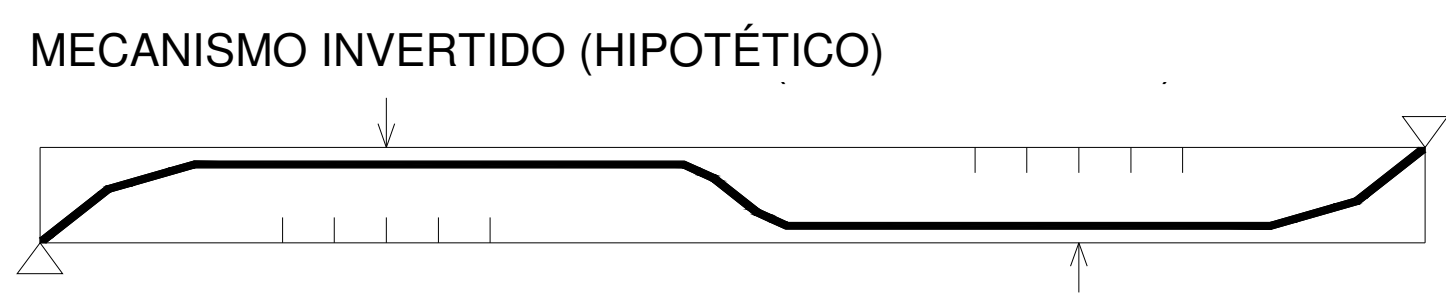

Figura 9.3 - Mecanismo invertido (hipotético) que mostra a inversão da biela.

A teoria de que a biela se movimenta para o interior da laje pode ser comprovada com a comparação entre a posição da ruptura por cisalhamento entre os modelos EM1 e EM2. No modelo EM1, a ruptura se deu por cisalhamento com seção composta, ou seja, com continuidade. No modelo EM2, a ruptura por cisalhamento ocorreu com a seção simples, ou seja, com a situação de biapoiada (ver figuras 5.25 e 5.40, reproduzidas a seguir).

Além disso, é possível notar que a inclinação da biela é maior na situação biapoiada, por volta de $45^{\circ}$. Já com continuidade, essa inclinação diminui para algo em torno de $30^{\circ}$.

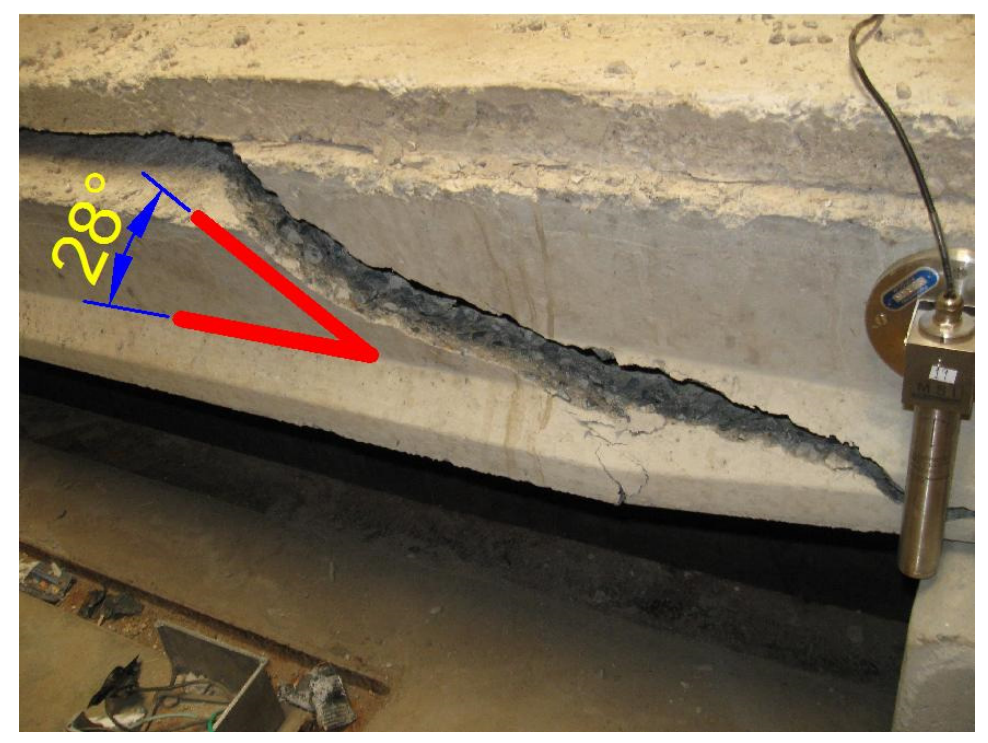

Figura 5.25 - Ruptura por tração diagonal do EM1. Seção composta. 


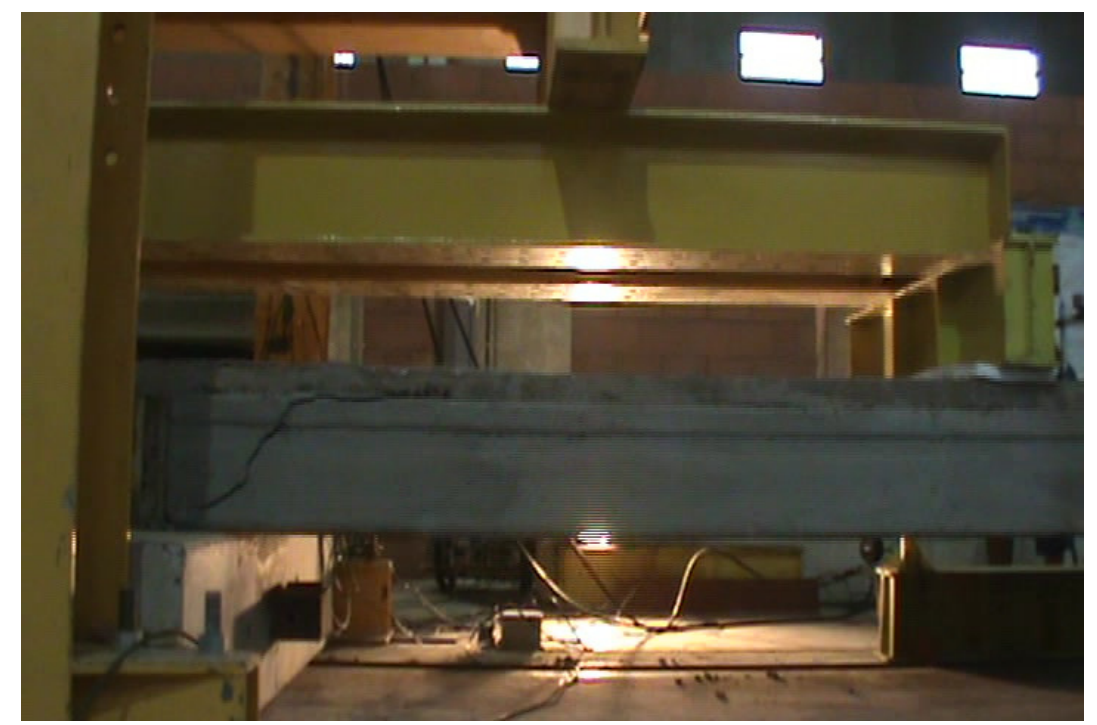

Figura 5.40 - Ruptura por tração diagonal do EM2. Seção simples.

\section{8 - Sugestões para trabalhos futuros}

Apresentam-se a seguir algumas sugestões para futuras pesquisas. Para as análises experimentais com continuidade, sugerem-se as seguintes variações dos ensaios realizados neste trabalho, considerando:

- carregamentos distribuídos;

- alvéolos preenchidos.

Outras variações de ensaios podem ser feitas com continuidade, como, por exemplo, utilizando quatro elementos de lajes alveolares e carregamentos transversais. Além disso, pode-se, também, repetir todos os ensaios já citados, considerando a continuidade com aberturas nos alvéolos.

Todas as formas de continuidade sugeridas para os ensaios também podem ser estudadas de forma teórica, com simulações numéricas considerando elementos de casca, de placa ou, até mesmo, elementos de barra. 


\section{REFERÊNCIAS BIBLIOGRÁFICAS}

AMERICAN CONCRETE INSTITUTE. ACI 318-08: Building code requirements for structural concrete and commentary. Farmington Hill, MI, U.S.A, 2008.

ARAÚJO, C. A. M. Estudo de lajes alveolares pré-tracionadas com auxílio de programa computacional. 2007. 128p. Dissertação (Mestrado em Engenharia Civil) Universidade Federal de Santa Catarina, Florianópolis, 2007.

ARAÚJO, C. A. M. Contribuições para projeto de lajes alveolares protendidas. 2011. 222p. Tese (Doutorado em Engenharia Civil) - Universidade Federal de Santa Catarina, Florianópolis, 2011.

ASSOCIAÇÃO BRASILEIRA DE NORMAS TÉCNICAS. NBR 6118: Projeto de estruturas de concreto. Rio de Janeiro, 2014.

. NBR 7483: Cordoalhas de aço para o concreto protendido - requisitos. Rio de Janeiro, 2004.

. NBR 9062: Projeto e execução de estruturas de concreto pré-moldado. Rio de Janeiro, 2006.

NBR 5739: Concreto - Ensaio de compressão de corpos de prova cilíndricos. Rio de Janeiro, 2007.

. NBR 8522: Concreto - Determinação do módulo estático de elasticidade à compressão. Rio de Janeiro, 2008.

NBR 7222: Concreto e argamassa - Determinação da resistência à tração por compressão diametral de corpos de prova cilíndricos. Rio de Janeiro, 2011.

. NBR 6892: Materiais metálicos - Ensaio de tração. Parte 1: Método de ensaio à temperatura ambiente. Rio de Janeiro, 2013.

. NBR 14861: Laje pré-fabricada - painel alveolar de concreto protendido Requisitos e procedimentos. Rio de Janeiro, 2011.

AJDUKIEWICZ, A. B.; KLISZCZEWICZ, A. T.; WEGLORZ, M. Behaviour of pre-tensioned hollow-core slabs with in-situ concrete topping. In: FIB Symposium Dubrovnik 2007, Dubrovnik, Croatia, 20-23 May 2007. 
ASSOCIATION OF MANUFACTURERS OF PRESTRESSED HOLLOW CORE FLOORS (ASSAP). The hollow core floor design and applications.1.ed. Belfiore, Verona, Italy, 2002.

BAILEY. C. G.; LENNON, T. Full-scale fire tests on hollow core floors. The Structural Engineer. The Institution of Structural Engineers. London, United Kingdom, v.86, n.6, p.33-39, Mar. 2008. Disponível em:

<http://www.istructe.org/thestructuralengineer/>. Acesso em maio 2011.

BARBIRI, R. A.; GASTAL F. P. S. L. Análise numérico-experimental de elementos prémoldados protendidos com continuidade posterior por adição de armadura. In: Congresso Brasileiro do Concreto, 41 - IBRACON. Salvador. Set.-out. 1999.

BEER, F. P. Resistência dos materiais. 2.ed. São Paulo: McGraw-Hill, 1989.

BERTAGNOLI, G.; MANCINI, G. Failure analysis of hollow core slabs tested in shear. Structural Concrete, Journal of the FIB. International Federation for Structural Concrete (FIB) - Lausanne, Switzerland. v.10, n.3, p.139-152, Sep. 2009.

BRITISH STANDARD. BS 8110-1. Structural use of concrete - Part 1: Code of practice for design and construction. London, United Kingdom, 1997.

CAMILLO, C. A. Continuidade de painéis de laje alveolar em edifícios. 2012. 162p. Dissertação (Mestrado em Estruturas e Construção Civil) - Departamento de Engenharia Civil, Universidade Federal de São Carlos, São Carlos, 2012.

CANADIAN PRECAST/PRESTRESSED CONCRETE INSTITUTE. CPCI. Design Manual 4. 4.ed. Ottawa, ON, Canada, 2007.

CARVALHO, R. C. (a). Estruturas de concreto pré-moldado. Notas de aula. Departamento de Engenharia Civil, Universidade Federal de São Carlos, São Carlos, 2010.

CARVALHO, R. C. (b). Estruturas em concreto protendido - pós-tração - pré-tração cálculo e detalhamento. 1.ed. São Paulo: PINI, 2012.

CARVALHO, R. C; FIGUEIREDO FILHO, J. R. Cálculo e detalhamento de estruturas usuais de concreto armado segundo a NBR 6118:2003. 3.ed. São Carlos: EdUFSCar, 2007.

CATOIA, B. Lajes alveolares protendidas: cisalhamento em região fissurada por flexão. 2011. Tese (Doutorado em Engenharia de Estruturas) - Escola de Engenharia de São Carlos, Universidade de São Paulo, São Carlos, 2011. 
CATOIA, B.; CARVALHO, R. C.; PINHEIRO, L. M.; FERREIRA, M. A. Análise da resistência ao cisalhamento de lajes alveolares protendidas com capa de concreto. In: Congresso Brasileiro do Concreto, 51 - IBRACON. Curitiba. Out. 2009.

COLLINS, M. P; MITCHELL, D. Prestressed concrete structures. 1.ed. Ontario, Canada. Response Publications, 1997.

COMITÉ EURO-INTERNATIONAL DU BÉTON. CEB-FIP Model Code 1990. CEB Bulletin d'Information n213/214. 1993.

COMITÉ EUROPÉEN DE NORMALISATION. EN 1168: Precast concrete products hollow core slabs. May 2005.

COMITÉ EUROPÉEN DE NORMALISATION. EN 1992-1: Eurocode 2: design of concrete structures. Dez. 2004.

COSTA, O. O. Avaliação de desempenho de elementos de lajes alveolares protendidas pré-fabricadas. 2009. 132p. Dissertação (Mestrado em Construção Civil) - Departamento de Engenharia Civil, Universidade Federal de São Carlos, São Carlos, 2009.

DAVIES, G.; ELLIOT, K. S.; OMAR, W. Horizontal diaphragm action in precast concrete floors. The Structural Engineer. The Institution of Structural Engineers. London, United Kingdom, v.68, n.2, p.25-33, Jan. 1990.

ECHO PRECAST ENGINEERING. Houthalen, Bélgica. Publicação eletrônica. Disponível em: <http://http://www.echoprecast.com/en/the-company.html>. Acesso em maio 2011.

EL DEBS, M. K. Concreto pré-moldado: fundamentos e aplicações. 1.ed. São Carlos: Edusp, 2000.

ELLIOT, K. S. Precast concrete structures. 1.ed. Woburn, MA, United Kingdom: Butterworth-Heinemann, 2002.

ELLIOT, K. S.; DAVIES, G.; OMAR, W. Experimental and theoretical investigation of precast concrete hollow core slabs used as horizontal floor diaphragms. The Structural Engineer. The Institution of Structural Engineers. London, United Kingdom, v.70, n.10, p.175-187, May 1992.

EUROPEAN CONCRETE PLATAFORM. Eurocode 2 Commentary. Brussels, Belgium. June 2008. Disponível em: <http://www.europeanconcrete.eu/publications/ eurocodes/114-commentarytoeurocode2>. Acesso em: 30 jun. 2014. 
FTOOL Two-dimensional frame analysis tool. Disponível em:

<https://web.tecgraf.puc-rio.br/ftool/>. Acesso em: 13 jan. 2012.

FERNANDES, N. S. Cisalhamento em lajes alveolares pré-fabricadas em concreto protendido: ensaio padrão de apoio para controle de qualidade. 2007. 127p. Dissertação (Mestrado em Construção Civil) - Departamento de Engenharia Civil, Universidade Federal de São Carlos, São Carlos, 2007.

FERREIRA, M. A.; FERNANDES, N. S.; CARVALHO. R. C.; ORTENZI, A.; DONIAK, I. L. O.; LIVI, L. O. B. Avaliação de desempenho da resistência ao cisalhamento em lajes alveolares pré-fabricadas em concreto protendido. Concreto \& Construções, IBRACON, São Paulo. n.48, p.46-51, out.-nov.-dez. 2007.

FERREIRA, R. A. A pesquisa científica nas ciências sociais: caracterização e procedimentos. Universidade Federal de Pernambuco, Recife, 1998.

FÉDÉRATION INTERNATIONALE DE LA PRÉCONTRAINTE (FIP). Guide to good practice - shear at the interface of precast and in-situ concrete. Wrexham Springs, England, 1982.

FÉDÉRATION INTERNATIONALE DE LA PRÉCONTRAINTE (FIP). Guide to good practice: quality assurance of hollow core slab. London, England, 1992.

FÉDÉRATION INTERNATIONALE DE LA PRÉCONTRAINTE (FIP). Planning and design handbook on precast building structures. London, England, 1994.

FÉDÉRATION INTERNATIONALE DU BÉTON (FIB). Model code 2010 - First complete draft. Lausanne, Switzerland, 2010.

FUSCO, P. B. Estruturas de concreto: solicitações tangenciais. 1.ed. São Paulo: Pini, 2008.

GASTAL F. P. S. L. Instantaneous and time-dependent response and strength of jointless bridge beams. 1986. 289p. These. North Carolina State University, Raleigh, North Carolina, U.S.A, 1986.

GIRHAMMAR, U. A. Design principles for simply supported prestressed hollow core slabs. Structure Engineering. Oxford, England, 4 (4), p. 301-316, 1992.

GIRHAMMAR, U. A.; PAJARI, M. Tests and analysis on shear strength of composite slabs of hollow core units and concrete topping. Construction and Building Materials. v.22, n.8, p.1708-1722, Aug. 2008. 
GYLLTOFT, K. Bond properties of strands in fatigue loading. Research report TULEA. Division of Structural Engineering, Luleå University of Tecnology. Luleå, Sweden. v.22. 1979.

HEDMAN, O.; LOSBERG, A. Design of concrete structures with regard to shear forces. In Shear and Torsion. CEB Bulletin d'Information no 126. Paris, 1978.

HEGGER, J.; ROGGENDORF, T.; KERKENI, N. Shear capacity of prestressed hollow core slabs in slim floor constructions. Engineering Structures. v.31, n.6, p.551-559, 2009.

HOSNY, A.; SAYED-AHMED, E. Y.; ABDELRAHMAN, A. A.; ALHABY, N. A. Strengthening precast-prestressed hollow core slabs to resist negative moments using carbon fibre reinforced polymer strips: an experimental investigation and a critical review of Canadian Standards Association S806-02. Canadian Journal of Civil Engineering. v.33, n.8, p.955-967, ago. 2006.

IBRAHIM, I. S. Interface shear strength of hollow core slabs with concrete toppings. 2008. These. University of Nottingham, Nottingham, United Kingdom, 2008.

IBRAHIM, I. S.; ELLIOTT, K. S.; COPELAND, S. Bending capacity of precast prestressed hollow core slabs with concrete toppings. Malaysian Journal of Civil Engineering. University of Technology Malaysia. Malaysia. v.20, n.2, p.260-283. 2008.

INTERNATIONAL FEDERATION FOR STRUCTURAL CONCRETE (FIB). Special design considerations for precast prestressed hollow core floors. Lausanne, Switzerland, 2000.

KONG, F. K.; EVANS, R. H. Reinforced and prestressed concrete. Spon Press, United Kingdom, 2001.

LEONHARDT, F. Construções de concreto: princípios básicos do dimensionamento de estruturas de concreto armado. 1.ed. v.1. Rio de Janeiro: Interciência, 1977.

MARCELLINO, N. A. Ligação laje-viga de estruturas pré-fabricadas de concreto. 2001. 182p. Tese (Doutorado em Engenharia Civil) - Escola Politécnica, Universidade de São Paulo, São Paulo, 2001.

MARQUESI, M. L. G. Contribuição ao estudo dos mecanismos resistentes à força cortante em lajes alveolares protendidas. 2014. 144p. Dissertação (Mestrado em Construção Civil) - Departamento de Engenharia Civil, Universidade Federal de São Carlos, São Carlos, 2014.

MELO, C. E. E. Manual Munte de projetos em pré-fabricados de concreto. 2.ed. São Paulo: Pini, 2007. 
MENEGOTTO, M.; MONTI G. Waved joint for seismic-resistant precast floor diaphragms. Journal of Structural Engineering. American Society of Civil Engineers (ASCE). Reston, VA, U.S.A. p.1515-1525, Oct. 2005.

MICALLEF, P. Assessment of shear capacity of prestressed hollow core floor units in the local construction industry. Buildingindustryconsultativecouncil (BICC). Malta, 2005. Disponível em: <http://www.bicc.gov.mt/bicc/files_folder/P\%20Micallef.pdf>. Acesso em 15 maio 2011.

MOSS, R. M. Load testing of hollow plank concrete floors. The Structural Engineer. The Institution of Structural Engineers. London, United Kingdom, v.73, n.10, p.161168, May 1995.

NAWY, E. G. Reinforced concrete: a fundamental approach. 3.ed. New Jersey, U.S.A. Prentice Hall, 1996.

PAJARI, M. Design of prestressed hollow core slabs. Technical research center of Finland. Espoo, Finland. Rep 567, 1989.

PAJARI, M.; KOUKKARI, H. Shear resistance of PHC slabs supported on beans. I: tests. Journal of Structural Engineering. American Society of Civil Engineers (ASCE). Reston, VA, U.S.A. p.1050-1061, Sep. 1998.

PALMER, K. D.; SCHULTZ, A. E. Web shear strength of precast, prestressed concrete hollow core slab units: a final report. Department of Civil Engineering. University of Minnesota. Minneapolis, MN, U.S.A. July 2009.

PET CIVIL - UFJF. Publicação eletrônica. Disponível em: <http://blogdopetcivil.com/2011/08/18/lajes-alveolares/>. Acesso em mai. 2011.

PETRUCELLI, N. S. Considerações sobre projeto e fabricação de lajes alveolares protendidas. 2009. 103p. Dissertação (Mestrado em Construção Civil) Departamento de Engenharia Civil, Universidade Federal de São Carlos, São Carlos, 2009.

PETRUCELLI, N. S.; CARVALHO, R. C. O uso de continuidade em pavimentos com lajes alveolares protendidas. In: Congresso Brasileiro do Concreto, 52 - IBRACON. Fortaleza. out. 2010.

PRECAST/PRESTRESSED CONCRETE INSTITUTE. PCI. Manual for the design of hollow core slabs. 7.ed. Chicago, IL, U.S.A., 2010. 
RAYMUNDO, R. Análise de pavimentos de edifícios em concreto pré-fabricado considerando o efeito diafragma. 2012. 245p. Dissertação (Mestrado em Construção Civil) - Departamento de Engenharia Civil, Universidade Federal de São Carlos, São Carlos, 2012.

REAGAN, P. Ultimate limit states principles. In Structural Concrete, vol. 2. FIB CEB-FIP Bulletin nํ2. Stuttgart, 1999.

RETTNE, L.; EDEKLING, K. Improved design method for webs shear tension failure in hollow core units. Master's Thesis - Department of Civil and Environmental Engineering, Division of Structural Engineering, Chalmers University of Technology, Göterborg, Sweden, 2006.

RESENDE, R. S.; GASTAL, F. P. S. L. Análise numérico-experimental de lajes prémoldadas protendidas com continuidade posterior por adição de sobrecamada de concreto armado. In: Congresso Brasileiro do Concreto, 41 - IBRACON. Salvador. Set.out. 1999.

SANTOS, L. C. A questão do método na investigação científica. Tecbaia Revista Baiana de Tecnologia, v.19, Maio/dez., 2004, p.5-12.

SANTOS, P. M. D.; JULIO, E. N. B. S.; SILVA, V. D. Correlation between concrete-toconcrete bond strength and the roughness of the substrate surface. Constructionandbuildingmaterials. Endereço. v.21, n.28, p.1688-1695, ago. 2007.

SOARES L. F. S. Efeitos dependentes do tempo em vigas pré-moldadas compostas com lajes alveolares e vinculações semi-rígidas. 2011. 179p. Dissertação (Mestrado em Engenharia de Estruturas) - Escola de Engenharia de São Carlos, Universidade de São Paulo, São Carlos, 2011

SCHOKBETON INC. Québec, Canada. Publicação eletrônica. Disponível em: <http://www.schokbeton.com/eng/dalles.html>. Acesso em maio 2011.

SILVA, E. L; MENEZES, E. M. Metodologia da pesquisa e elaboração de dissertação. 4 ed. Florianópolis: UFSC, 2005. Cap 2-4, p. 19-36.

TAPE, W.; KENNEDY, J.; MADUGULA, M.; COLLAVINO, L. Bearing Capacity of grouted and ungrouted recessed ends in hollow core slabs. $\mathrm{PCl}$ Journal. Precast/Prestressed Concrete Institute, Chicago, IL, U.S.A. p.88-95, Nov.-Dec. 2005.

TAN, K.; ZHENG, L.; PARAMASIVAM, P. Designing hollow core slabs for continuity. $\mathrm{PCl}$ Journal. Precast/Prestressed Concrete Institute, Chicago, IL, U.S.A. v.41, n.1, p.8291, Jan.-Feb. 1996. 
TASSI, G. Bond properties of prestressing strands. Proceedings of the FIP symposium. Jerusalem, Israel. 1988.

TKALČIĆ, D.; BANIĆ, D.; ZUPČIĆ, M.; PERIĆ, Z. Prestressed hollow core slabs - shear resistance test according to HRN EN 1168:2005. In: FIB Symposium Dubrovnik 2007, Dubrovnik, Croatia, 20-23 May 2007.

UEDA, T.; STITMANNAITHUM, B. Shear strength of precast prestressed hollow slabs with concrete topping. $\mathrm{ACl}$ Structural Journal. American Concrete Institute $(\mathrm{ACl})$, Farmington Hills, MI, U.S.A. v.88, n.4, p.402-410, July-Aug. 1991.

WEILER C. HOLZBERGER. Rio Claro, Brasil. Publicação eletrônica. Disponível em: <http://weiler.com.br>. Acesso em maio 2011.

WIGHT, J. K; MACGREGOR, J. G. Reinforced concrete: mechanics \& design. 6.ed. New Jersey, U.S.A. Pearson, 2012.

YANG, L. Design of prestressed hollow core slabs with reference to web shear failure. Journal of Structural Engineering. American Society of Civil Engineers (ASCE). Reston, VA, U.S.A. v.120, n.9, p.2675-2696, Sep. 1994. 


\section{APÊNDICE A}

\section{APA1 - Tabelas de discretização da laje EM1}

Tabela APA1.1 - Valores da discretização em faixas: EM1 MOMENTO POSITIVO - SEÇÃO COMPOSTA

\begin{tabular}{|c|c|c|c|c|c|c|c|c|c|c|c|c|c|c|c|c|c|c|}
\hline & \multicolumn{12}{|c|}{ CAPA } & \multicolumn{6}{|c|}{ MESA SUPERIOR } \\
\hline$\frac{\bar{\xi}}{\underline{\underline{a}}}$ & 㫕 & 㫕 & $\begin{array}{l}\frac{n}{2} \\
\text { \% } \\
8 \\
0\end{array}$ & 농 & 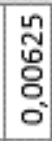 & & $\begin{array}{l}\text { n } \\
\text { o } \\
0 \\
0\end{array}$ & $\begin{array}{l}\text { 㔯 } \\
0 \\
0 \\
0 \\
0 \\
0\end{array}$ & I: & 는 & & 0 & ร & $\left(\begin{array}{l}\infty \\
0 \\
0\end{array}\right.$ & & & $\begin{array}{l}\hat{1} \\
\hat{0} \\
0 \\
0 \\
0\end{array}$ & $0^{\circ}$ \\
\hline $\begin{array}{l}\bar{\xi} \\
\bar{\alpha}\end{array}$ & 영 & 옹 & 용 & 옹 & 응 & & 융 & $\begin{array}{l}\text { 옹 } \\
\text { o } \\
0\end{array}$ & $\begin{array}{l}\text { 워 } \\
\text { סू } \\
\text { 응 }\end{array}$ & $\begin{array}{l}\text { O } \\
\text { D. } \\
\text { ס. }\end{array}$ & $\begin{array}{l}\text { ğ } \\
\text { o. } \\
\text { o. }\end{array}$ & & 5 & & $\begin{array}{l}\text { go } \\
\text { : } \\
0\end{array}$ & & $\begin{array}{l}\mathscr{0} \\
\text { 号 } \\
0 \\
0\end{array}$ & \\
\hline 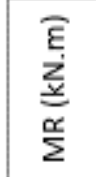 & 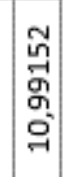 & 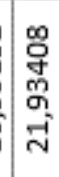 & $\begin{array}{l}0 \\
0 \\
2 \\
\infty \\
\text { ల } \\
\text { ల్ }\end{array}$ & 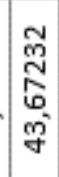 & 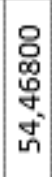 & & 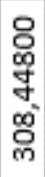 & 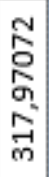 & 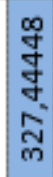 & 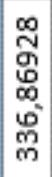 & 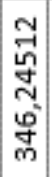 & กุ & ํำ & 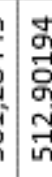 & 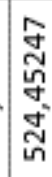 & 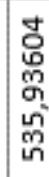 & 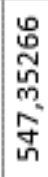 & $\begin{array}{l}\square \\
0 \\
0 \\
4\end{array}$ \\
\hline हु & 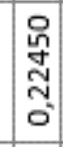 & 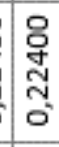 & 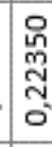 & 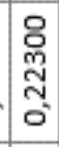 & 号 & & 음 & 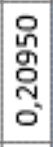 & $\begin{array}{l}\text { 음 } \\
\text { 오 } \\
\text { 。 }\end{array}$ & 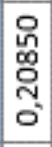 & 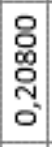 & 号 & 0 & 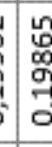 & गु & 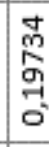 & 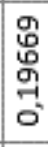 & 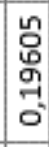 \\
\hline 总 & 응 & $\frac{8}{8}$ & $\begin{array}{l}\text { 음 } \\
\text { 늠 } \\
\text { - }\end{array}$ & 음 & 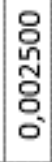 & & 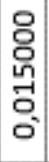 & 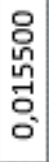 & $\begin{array}{l}\text { 음 } \\
\text { 으 } \\
\text { - } \\
\text { - }\end{array}$ & 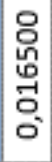 & 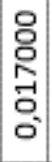 & -7 & $\underline{\tilde{z}}$ & $\begin{array}{l}9 \\
8 \\
0 \\
0 \\
0\end{array}$ & 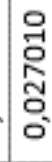 & ส & 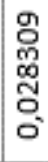 & : \\
\hline « & $\mid$\begin{tabular}{c}
0 \\
\multirow{z}{*}{} \\
$\vdots$ \\
0 \\
0
\end{tabular} & 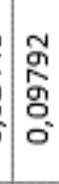 & 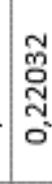 & \begin{tabular}{l}
0 \\
0 \\
\multicolumn{1}{|c}{} \\
m. \\
0
\end{tabular} & 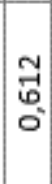 & & $\begin{array}{l}\text { Ñ } \\
\text { స̃ } \\
\text { స̃ }\end{array}$ & $\begin{array}{l}\text { స్ } \\
\text { స్ } \\
\text { స్ } \\
\text { సે }\end{array}$ & 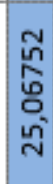 & 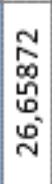 & $\begin{array}{c}\infty \\
\infty \\
\infty \\
2 \\
\\
\infty^{\circ}\end{array}$ & $\begin{array}{l}\infty \\
\infty \\
\sigma \\
\text { gे } \\
\text { Ni }\end{array}$ & $\begin{array}{l}5 \\
0 \\
\infty \\
5 \\
5 \\
0\end{array}$ & 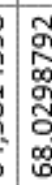 & 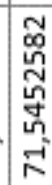 & 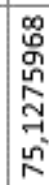 & 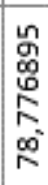 & 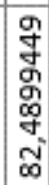 \\
\hline $\begin{array}{l}\overline{\mathrm{E}} \\
\overline{\mathrm{g}} \\
\mathrm{E}\end{array}$ & ठ্. & రั & 응 & 志 & 응 & & $\stackrel{\circ}{\circ}$ & $\begin{array}{l}\text { ") } \\
\text { סू } \\
0\end{array}$ & กี & 吕 & 离 & 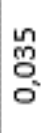 & 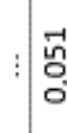 & 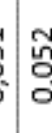 & 哭 & ్ㅡㅇ & 贶 & \\
\hline$\frac{z}{x}$ & 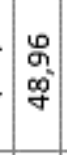 & ๙ু & 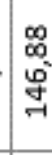 & 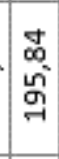 & 竎 & & 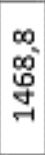 & 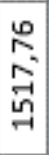 & N & 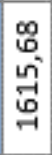 & 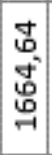 & 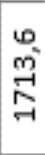 & in & 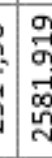 & 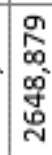 & 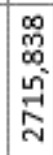 & 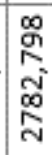 & 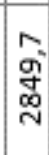 \\
\hline & . & 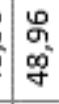 & 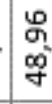 & 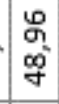 & $\begin{array}{l}\mathscr{0} \\
\text { ô } \\
\text { ơ }\end{array}$ & & 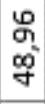 & $\begin{array}{l}\text { o } \\
\text { ơ } \\
\text { of }\end{array}$ & 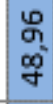 & $\begin{array}{l}\stackrel{8}{9} \\
\text { go } \\
\text { go }\end{array}$ & $\begin{array}{c}0 \\
\alpha \\
o g \\
q\end{array}$ & \% & 5 & $\begin{array}{l}\mathscr{\sigma} \\
0\end{array}$ & $\begin{array}{l}\stackrel{0}{0} \\
8 \\
8\end{array}$ & \%ุ & 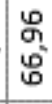 & $\begin{array}{l}9 \\
0 \\
0 \\
0\end{array}$ \\
\hline $4 \sum_{\underline{z}}^{\frac{\pi}{\tilde{z}}}$ & . & 응 & 음 & 응 & రి & & 응 & 일 & 음 & 8 & 음 & & 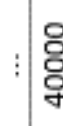 & 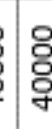 & 8 & 암 & 음 & 옹 \\
\hline$\frac{\bar{\xi}}{\bar{s}}$ & $\begin{array}{l}\text { 응 } \\
\text { 응 } \\
\circ\end{array}$ & 늠 & 논 & 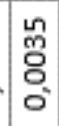 & 号 & & 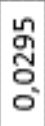 & $\begin{array}{l}\text { 号 } \\
\text { Oे } \\
\text { ○. }\end{array}$ & 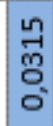 & है & $\begin{array}{l}\text { L } \\
\text { m } \\
\text { O } \\
0 \\
0\end{array}$ & 亗 & 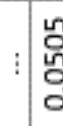 & 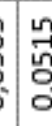 & 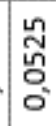 & P & 喈 & $\begin{array}{l}\text { 岁 } \\
\mathrm{u} \\
\mathrm{C}\end{array}$ \\
\hline$\underset{\bar{E}}{\bar{E}}$ & 용 & 응 & 응 & 응 & 용 & & 응 & 뭉 & 옹 & 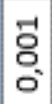 & ठ্ & $\gamma$ & 응 & 0 & 응 & 0 & 용 & 형 \\
\hline 드 & - & శ్ & శ్ & જ్ & สิ & & శ్ & ๙ָ & & S. & ๙ิ & 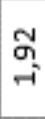 & वั & & 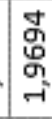 & 4 & 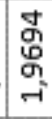 & 萹 \\
\hline 3 & -1 & $N$ & $m$ & & n) & & $\bar{m}$ & $\overrightarrow{\mathrm{m}}$ & $\mathrm{m}$ & $\mathrm{m}$ & m & $\mathrm{m}$ & แก & & in & & & \\
\hline
\end{tabular}


Tabela APA1.2 - Valores da discretização em faixas: EM1 - MOMENTO NEGATIVO - SEÇÃO COMPOSTA

\begin{tabular}{|c|c|c|c|c|c|c|c|c|c|c|c|c|c|c|c|c|}
\hline & \multicolumn{6}{|c|}{ ALVÉolos } & \multicolumn{10}{|c|}{ MESA INFERIOR } \\
\hline$\frac{\widehat{\xi}}{x}$ & 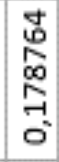 & 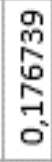 & 总 & 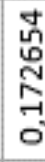 & 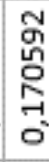 & & $\begin{array}{l}\text { ñ } \\
\text { m } \\
\text { - } \\
0 \\
0\end{array}$ & 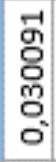 & 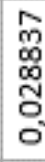 & 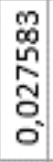 & T & 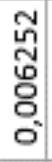 & $\begin{array}{l}5 \\
\text { 웅 } \\
\text { 응 }\end{array}$ & 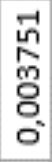 & 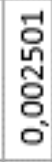 & 논 \\
\hline$\underset{>}{\widehat{\underline{E}}}$ & 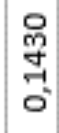 & 告 & 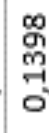 & 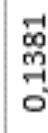 & $\begin{array}{l}\text { ڤ } \\
\text { o } \\
\text { - }\end{array}$ & & 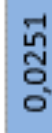 & : & 离 & ปี & & $\begin{array}{l}\text { 응 } \\
\text { 응 }\end{array}$ & 옹 & $\begin{array}{l}\text { 유 } \\
\text { రั }\end{array}$ & ్ㅗㅁ & 옹 \\
\hline 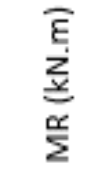 & 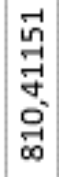 & $\begin{array}{l}-1 \\
-1 \\
\infty \\
0 \\
\infty \\
\infty \\
\infty \\
\infty\end{array}$ & 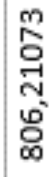 & 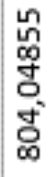 & $\begin{array}{l}\text { స్ } \\
\text { † } \\
\vdots \\
-1\end{array}$ & & 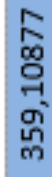 & $\begin{array}{l}\hat{f} \\
\text { f } \\
\text { f } \\
\text { 号 }\end{array}$ & 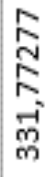 & 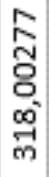 & & 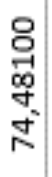 & 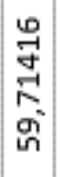 & 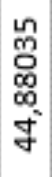 & 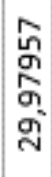 & $\begin{array}{l}2 \\
0 \\
7 \\
0 \\
\text { ù } \\
-1\end{array}$ \\
\hline$\underbrace{\bar{E}}_{\bar{N}}$ & 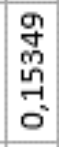 & 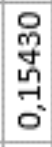 & $\begin{array}{l}7 \\
\text { นñ } \\
\text { ? }\end{array}$ & 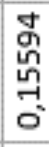 & 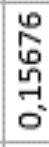 & & 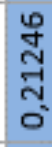 & 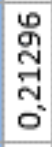 & $\begin{array}{l}\text { f } \\
\text { m } \\
\text { స్ } \\
\text { o }\end{array}$ & $\begin{array}{l}\text { बू } \\
\text { लె } \\
\text { స్ } \\
\text { o }\end{array}$ & & 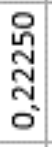 & $\begin{array}{l}\text { \& } \\
\text { ग्र } \\
\text { స్ } \\
\text { - }\end{array}$ & 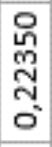 & 옹 & 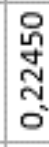 \\
\hline 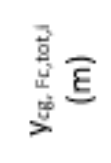 & 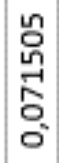 & 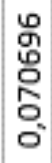 & $\begin{array}{l}-1 \\
0 \\
0 \\
0 \\
0 \\
0 \\
0\end{array}$ & 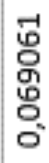 & 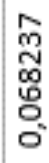 & & 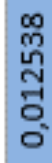 & 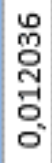 & 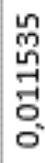 & 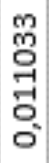 & & 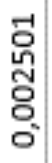 & 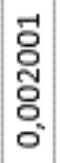 & 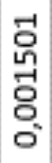 & 음 & $\begin{array}{l}\text { 응 } \\
\text { 응 } \\
\text { 응 }\end{array}$ \\
\hline $\begin{array}{l}\frac{3}{3} \\
\frac{1}{3}\end{array}$ & 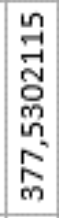 & $\begin{array}{l}0 \\
0 \\
0 \\
0 \\
0 \\
0 \\
0 \\
0 \\
0 \\
0 \\
m\end{array}$ & $\begin{array}{l}\text { g } \\
\text { o } \\
90 \\
0 \\
9 \\
0 \\
0 \\
0\end{array}$ & 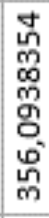 & 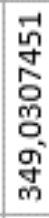 & & $\begin{array}{l}\text { nี } \\
\text { - } \\
0 \\
\text { न } \\
\text { न } \\
-1 \\
-1\end{array}$ & 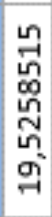 & 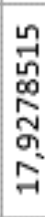 & 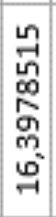 & & 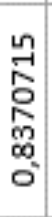 & 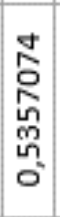 & 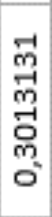 & $\begin{array}{l}D \\
\infty \\
\infty \\
\infty \\
0 \\
0 \\
0 \\
-1 \\
0 \\
0\end{array}$ & 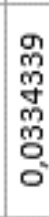 \\
\hline $\bar{E} \bar{E}$ & 朵 & 売 & 奈 & స̃ & 형 & & 응 & 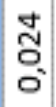 & జ̃ & ฐ̃ & & 옹 & : & : & ชั & 옹 \\
\hline 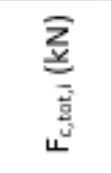 & 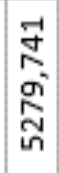 & 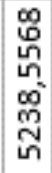 & 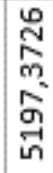 & 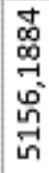 & 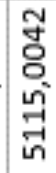 & & 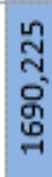 & 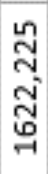 & 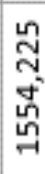 & 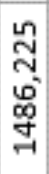 & & 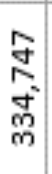 & 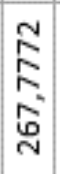 & 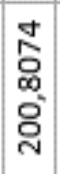 & $\begin{array}{l}0 \\
\mathbb{1} \\
\infty \\
\infty \\
\infty \\
m \\
-1\end{array}$ & 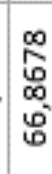 \\
\hline$\frac{\widehat{\bar{z}}}{\underline{\bar{v}}}$ & 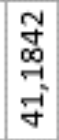 & 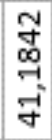 & \begin{tabular}{l}
$\mathcal{F}$ \\
\multirow{2}{*}{} \\
\multirow{F}{*}{} \\
$\mathcal{y}$
\end{tabular} & 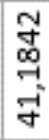 & $\underset{\sim}{\stackrel{\sim}{\sim}}$ & & $\ddot{\circ}$ & \% & $\stackrel{8}{\circ}$ & $\stackrel{\infty}{\circ}$ & & 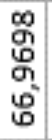 & $\begin{array}{l}0 \\
0 \\
0 \\
0 \\
0 \\
0\end{array}$ & $\begin{array}{l}0 \\
0 \\
0 \\
0 \\
0 \\
0\end{array}$ & $\begin{array}{l}\infty \\
80 \\
0 \\
0 \\
0 \\
0\end{array}$ & $\begin{array}{l}\infty \\
0 \\
0 \\
0 \\
0 \\
0 \\
0\end{array}$ \\
\hline $4 \sum_{\underline{\underline{z}}}^{\frac{\pi}{\xi}}$ & ষั & 음 & 음 & 음 & 守 & & 응 & 응 & 음 & 응 & & 응 & 옹 & 응 & 응 & 음 \\
\hline$\underset{\mathrm{s}}{\overline{\mathrm{E}}}$ & 虫 & 旡 & 望 & 告 & 望 & & $\begin{array}{l}\text { ก } \\
\text { ปั } \\
\text { О }\end{array}$ & 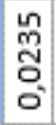 & ปี & 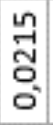 & & 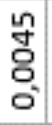 & 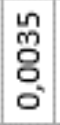 & 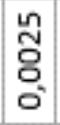 & ำ & 응 \\
\hline 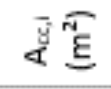 & & & & & & & & & & & & & & & & \\
\hline$\underset{\underline{E}}{\bar{E}}$ & ס્ & 응 & 음 & 응 & 15 & & 응 & ס̊ & 응 & ס्: & : & ס्: & ס् & 吾 & 응 & 음 \\
\hline$\frac{\widehat{E}}{\bar{B}}$ & $\underset{7}{\stackrel{m}{二}}$ & $\underset{\stackrel{m}{ت}}{\stackrel{m}{-1}}$ & 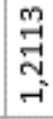 & $\begin{array}{l}3 \\
-7 \\
-1\end{array}$ & $\stackrel{m}{7}$ & & i & ì & 어 & i & : & $\begin{array}{l}\text { 今̀ } \\
\text { ơ } \\
\text { - }\end{array}$ & $\begin{array}{c}\text { ô } \\
\text { o. } \\
\text { on } \\
\text { - }\end{array}$ & $\begin{array}{l}\text { o } \\
\text { o. } \\
\text { o. } \\
\text { - }\end{array}$ & 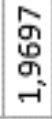 & 总 \\
\hline$\frac{\mathbb{x}}{\mathbb{4}}=$ & 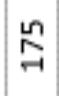 & $\rightarrow$ & | & & & & $\stackrel{\Perp}{2}$ & N & $N$ & i & & (5) & ब & $m$ & $N$ & -1 \\
\hline
\end{tabular}




\section{APA2 - Tabelas de discretização da laje EM2}

Tabela APA2.1 - Valores da discretização em faixas: EM2 - MOMENTO POSITIVO - SEÇÃO COMPOSTA

\begin{tabular}{|c|c|c|c|c|c|c|c|c|c|c|c|c|c|c|c|c|c|c|c|c|c|c|}
\hline & \multicolumn{14}{|c|}{ CAPA } & \multicolumn{8}{|c|}{ MESA SUPERIOR } \\
\hline$\frac{\widehat{\underline{\xi}}}{x}$ & 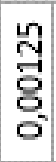 & 웡 & $\begin{array}{l}\text { n } \\
\text { \% } \\
\text { ठ․ } \\
\text { o }\end{array}$ & 녕 & 岇 & & 능 & $\begin{array}{l}\text { N్ } \\
\text { O్ } \\
0 \\
0 \\
0\end{array}$ & $\begin{array}{l}\text { ñ } \\
\text { mo } \\
0 \\
0\end{array}$ & 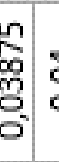 & t: & & & & 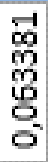 & & & 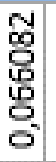 & 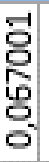 & 응 & & \\
\hline $\begin{array}{l}\underline{\underline{E}} \\
>\end{array}$ & & ్. & & 웅 & & & : & ปี & ஜृ & 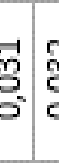 & 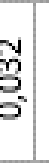 & שֶ. & 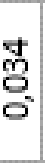 & & $\begin{array}{l}\text { 농 } \\
\text { 응 } \\
\text { 응 } \\
\text { ᄋ }\end{array}$ & 봉 & ถู & 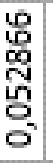 & & 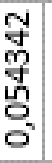 & 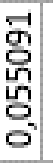 & \\
\hline$\stackrel{\alpha}{\Sigma} \bar{\varepsilon}_{j}$ & ? & 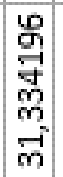 & 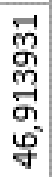 & 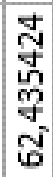 & 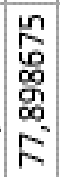 & & 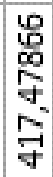 & 昌 & 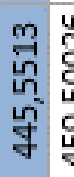 & 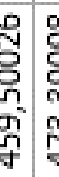 & 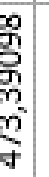 & 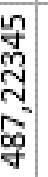 & $\begin{array}{l}\text { S. } \\
\text { s. } \\
8\end{array}$ & & 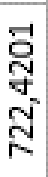 & 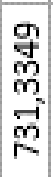 & 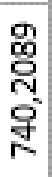 & 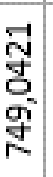 & 永 & 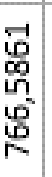 & है & क \\
\hline$\underline{\underline{\Xi}}$ & & 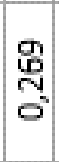 & $\begin{array}{l}\text { 员 } \\
\text { 总 } \\
\text { 。' }\end{array}$ & 总 & 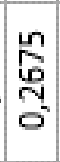 & & 亗 & 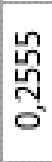 & 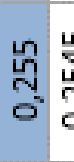 & 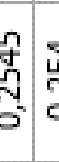 & 志 & 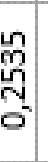 & 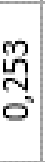 & & $\begin{array}{l}\text { 号 } \\
\text { 导 } \\
\text { 영 }\end{array}$ & 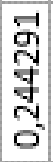 & 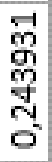 & 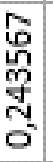 & 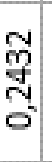 & 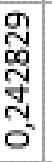 & 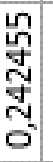 & $\mathfrak{c}$ \\
\hline${ }_{\bar{y}}^{\bar{g}} \overline{\underline{y}}$ & ? & $\begin{array}{l}8 \\
8 \\
8 \\
8 \\
8 \\
\\
\\
0\end{array}$ & 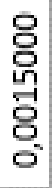 & 응 & $\begin{array}{l}8 \\
\text { 윰 } \\
\text { ปั } \\
8 \\
0\end{array}$ & & 응 & 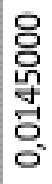 & 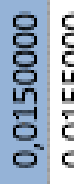 & 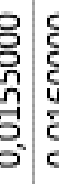 & $\begin{array}{l}8 \\
8 \\
8 \\
8 \\
0 \\
0 \\
0 \\
0\end{array}$ & 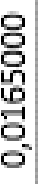 & 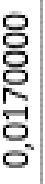 & & 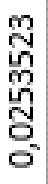 & 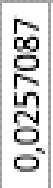 & 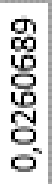 & 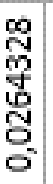 & 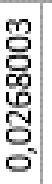 & 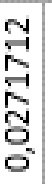 & 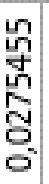 & 2 \\
\hline 3 & 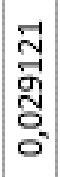 & 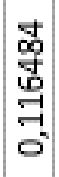 & 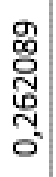 & 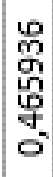 & 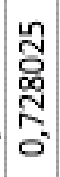 & & $\begin{array}{l}\mathbb{U} \\
\mathbb{0} \\
0 \\
\mathbb{\mathscr { D }} \\
\mathbb{N} \\
\mathbb{N}\end{array}$ & 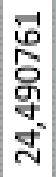 & 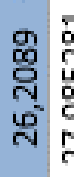 & 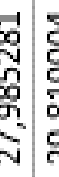 & 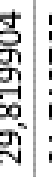 & 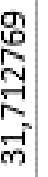 & 范 & & 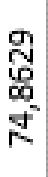 & 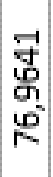 & 年 & $\begin{array}{c}\text { g } \\
\text { శ్ } \\
\underset{\infty}{-\infty}\end{array}$ & $\begin{array}{l}\text { స్ } \\
\text { กี } \\
\tilde{\infty}\end{array}$ & 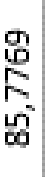 & 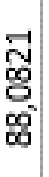 & \& \\
\hline & & 응 & 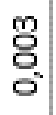 & 응 & 능 & & 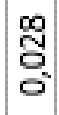 & 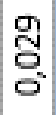 & "ூ & 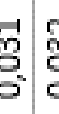 & $\begin{array}{l}2 \\
z \\
0 \\
0\end{array}$ & $\begin{array}{l}\tilde{m} \\
\ddot{0} \\
0\end{array}$ & 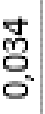 & & 콩 & กู & $\begin{array}{l}\text { 艿 } \\
\text { 응 }\end{array}$ & $\begin{array}{l}\text { 志 } \\
\text { О. }\end{array}$ & $\begin{array}{l}\text { ్․ } \\
\text { 응 }\end{array}$ & 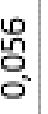 & $\begin{array}{l}\text { 농 } \\
\text { 웅 }\end{array}$ & $0^{\circ}$ \\
\hline & & 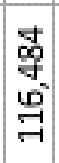 & 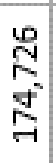 & 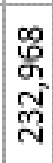 & $\overrightarrow{\tilde{N}}$ & & 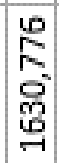 & 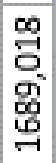 & 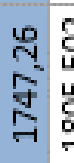 & 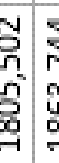 & 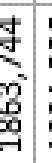 & 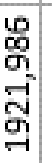 & $\begin{array}{c}\text { ב̃ } \\
\text { §ิ }\end{array}$ & & 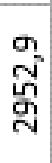 & कू & 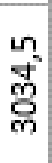 & $\begin{array}{c}m \\
\tilde{n} \\
\tilde{m}\end{array}$ & $\begin{array}{l}-1 \\
6 \\
\frac{1}{6} \\
\frac{7}{m}\end{array}$ & 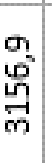 & ब. & กี่ \\
\hline & & 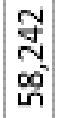 & 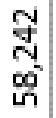 & $\begin{array}{l}\mathcal{N} \\
\text { Z } \\
\text { ơ }\end{array}$ & $\begin{array}{l}\mathcal{y} \\
\mathcal{u} \\
\text { og } \\
\text { und }\end{array}$ & & 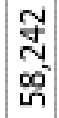 & 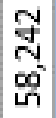 & 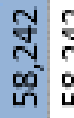 & 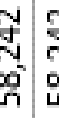 & 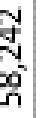 & \begin{tabular}{l}
$\mathcal{Y}$ \\
\multirow{2}{*}{} \\
of \\
$\mathfrak{n}^{\circ}$
\end{tabular} & & & $\stackrel{\infty}{\text { gे }}$ & $\begin{array}{l}\infty \\
\text { gे }\end{array}$ & $\begin{array}{l}\infty \\
\sigma^{\circ}\end{array}$ & 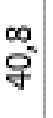 & 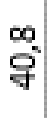 & $\begin{array}{c}\infty \\
o \\
o\end{array}$ & $\begin{array}{c}\infty \\
\stackrel{\sigma}{q}\end{array}$ & $\begin{array}{l}\infty \\
\stackrel{+}{q}\end{array}$ \\
\hline $4 \sum_{\underline{z}}^{\bar{E}}$ & & 8 & 8 & 8 & 8 & & 8 & $\varepsilon$ & 8 & 8 & 8 & 8 & & & 요 & 용 & $\begin{array}{l}8 \\
8 \\
8\end{array}$ & $\begin{array}{l}8 \\
\text { gृ }\end{array}$ & $\begin{array}{l}8 \\
\text { gे }\end{array}$ & $\begin{array}{l}8 \\
\text { gृ } \\
\text { g }\end{array}$ & & প্ণ \\
\hline$\xi$ & & 궁 & 눙 & $\begin{array}{l}2 \\
\tilde{0} \\
8 \\
0\end{array}$ & 告 & $\vdots$ & $\begin{array}{l}\text { กิ } \\
\text { ธิ } \\
0 \\
0\end{array}$ & 亗 & & 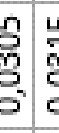 & $\begin{array}{l}0 \\
0 \\
0 \\
0 \\
0\end{array}$ & ฮู & & & 농 & 는 & 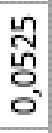 & 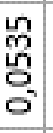 & 0 & 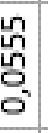 & $\begin{array}{l}\text { 员 } \\
\text { 另 } \\
\text { ○ }\end{array}$ & 0 \\
\hline$\underset{\underline{\xi}}{\bar{\xi}}$ & & 웅 & 웅 & 웅 & 웅 & $\vdots$ & 웅 & 8 & 용 & 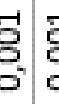 & 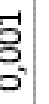 & 영 & & & 웅 & 웅 & 영 & 용 & -1 & 영 & & $0^{\circ}$ \\
\hline & & $\underset{\mathcal{F}}{\stackrel{\mathcal{F}}{二}}$ & $\underset{\mathcal{F}}{\mathcal{Z}}$ & $\underset{\mathcal{Y}}{\stackrel{\mathcal{H}}{-}}$ & $\stackrel{+}{-1}$ & $\vdots$ & $\underset{\mathcal{F}}{\stackrel{\mathcal{F}}{-}}$ & $\underset{\mathcal{F}}{\mathcal{F}}$ & $\underset{\mathcal{F}}{\mathcal{F}}$ & & $\begin{array}{l}y \\
y \\
-1\end{array}$ & $\Rightarrow$ & & & 오 & 오 & 고 & 고- & $\underset{ }{-}$ & 고- & 곡 & -1 \\
\hline 永 & & $N$ & $m$ & ४ & เn & & $\tilde{N}$ & 금 & 요 & s) & लె & $m$ & ले & & ที่ & กี & พิ่ & 思 & & 㔛 & ถั่ & นั \\
\hline
\end{tabular}


Tabela AP2.2 - Valores da discretização em faixas: EM2 - MOMENTO NEGATIVO - SEÇÃO COMPOSTA

\begin{tabular}{|c|c|c|c|c|c|c|c|c|c|c|c|c|c|c|c|c|c|c|c|c|c|c|}
\hline & \multicolumn{10}{|c|}{ ALVÉolos } & \multicolumn{12}{|c|}{ MESA INFERIOR } \\
\hline$\frac{\bar{g}}{x}$ & 경 & 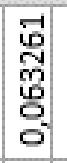 & & & & & & 뭉 & & s. & $\begin{array}{l}\text { 오 } \\
\text { 足 } \\
0\end{array}$ & $\begin{array}{l}\text { 耑 } \\
0\end{array}$ & 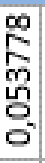 & & 0 & 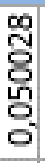 & & 음 & & & 농 & \\
\hline$\underline{\mathrm{g}}$ & 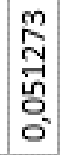 & $\begin{array}{l}9 \\
0 \\
0 \\
0 \\
0 \\
0\end{array}$ & 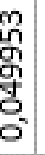 & & & & 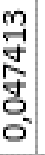 & 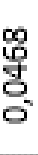 & & S. & 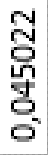 & 封 & 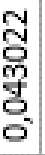 & & 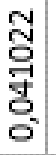 & : & & 웅 & 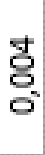 & ס्: & ర్ & c \\
\hline$\stackrel{\propto}{\Sigma} \underset{\Sigma}{\Sigma}$ & 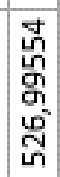 & 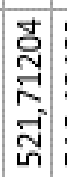 & 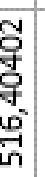 & & 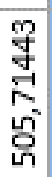 & & t. & 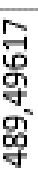 & O & 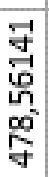 & 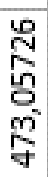 & 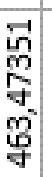 & 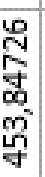 & 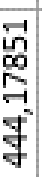 & 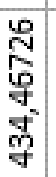 & 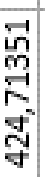 & & & 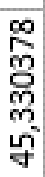 & 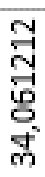 & 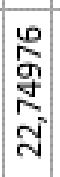 & है \\
\hline$s$ & 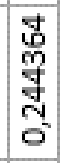 & 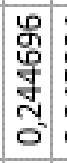 & 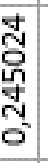 & ) & : & & . & 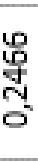 & 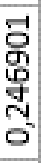 & 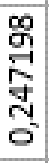 & $\begin{array}{l}\text { g } \\
\text { o } \\
\text { 守 } \\
\text { ป }\end{array}$ & 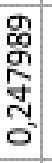 & 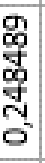 & $t$ & 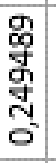 & 守 & & o' & $\begin{array}{l}\infty \\
\text { : } \\
\text { ․ } \\
0\end{array}$ & 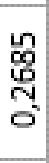 & 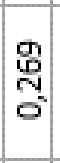 & $\tilde{o}$ \\
\hline $\begin{array}{l}5 \\
5 \\
5\end{array}$ & 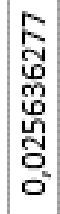 & 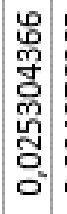 & 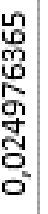 & 员 & S. & 호 & 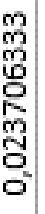 & 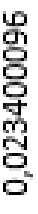 & 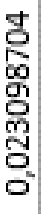 & 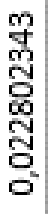 & 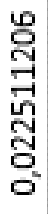 & 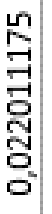 & 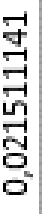 & -1 & 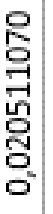 & 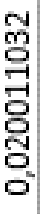 & & & 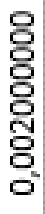 & $\begin{array}{l}\text { 응 } \\
\text { 웅 } \\
\text { 응 }\end{array}$ & 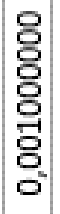 & 응 \\
\hline 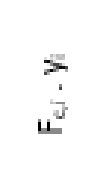 & 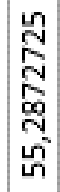 & 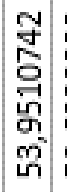 & 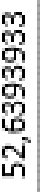 & స్ల్ & 'ת & & 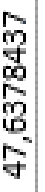 & 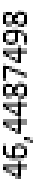 & 2 & 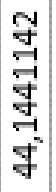 & 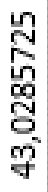 & 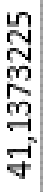 & 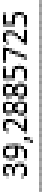 & $\infty$ & 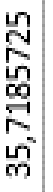 & 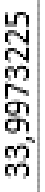 & & & 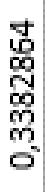 & 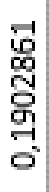 & 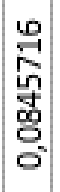 & 5 \\
\hline & 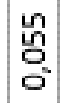 & 荅 & 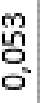 & & & & & 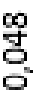 & वे & 㝵 & 告 & $\begin{array}{l}\text { 寺 } \\
\text { : }\end{array}$ & 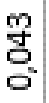 & g & 5 & $0^{\circ}$ & & & 형 & : & రั & 0 \\
\hline 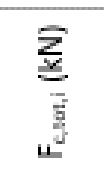 & 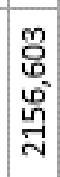 & 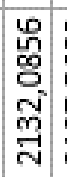 & 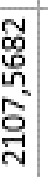 & ci & & $N$ & & 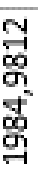 & R & 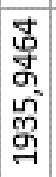 & 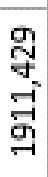 & 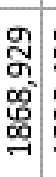 & 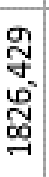 & ֻ & th & 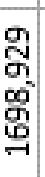 & & N & 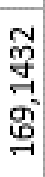 & 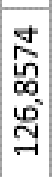 & $\begin{array}{l}0 \\
0 \\
5 \\
0 \\
\infty \\
0\end{array}$ & สู \\
\hline & 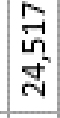 & \begin{tabular}{l} 
ज. \\
ป̂. \\
\multirow{2}{*}{}
\end{tabular} & 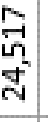 & & & & & $\begin{array}{l}\text { जે } \\
\text { ปे } \\
\text { ते }\end{array}$ & 7 & 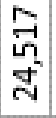 & นุ & $\sim$ & ֶָ) & & 虫 & ปี & & 8 & 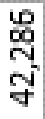 & 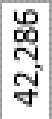 & 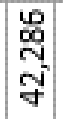 & 8 \\
\hline $4 \underset{\underline{Z}}{\widetilde{E}}$ & ষ্ট & ষ্ট & ষ্ট & S & & & & ষ্ট & & 응 & ষ্ট & & ষ্ & & 守 & ষ্ট & & & ষ্ট & ষ্ট & ষ্ট & 于 \\
\hline $\bar{\xi}$ & S & $\begin{array}{l}\stackrel{4}{0} \\
\text { 员 } \\
0\end{array}$ & 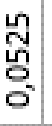 & $0^{\circ}$ & & & & 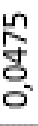 & 紫 & 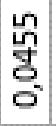 & 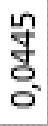 & 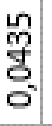 & 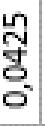 & $\sigma^{\circ}$ & 客 & 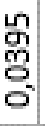 & & & 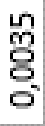 & ปั & 능 & 잉 \\
\hline & & & & & & & & & & & & & & & & & & & & & & \\
\hline s & & 형 & 흥 & & & & & 용 & 8 & 형 & 흥 & 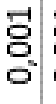 & 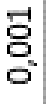 & & $5^{2}$ & : & & & 형 & 응 & 8 & 8 \\
\hline$\widehat{\underline{\mathrm{g}}}$ & & 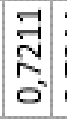 & $\begin{array}{l}\vec{Z} \\
\frac{7}{\sigma} \\
\sigma\end{array}$ & & & & 8 & $\begin{array}{l}\vec{Z} \\
\stackrel{Z}{*} \\
\sigma^{\prime}\end{array}$ & $F$ & $\begin{array}{l}\vec{Z} \\
\stackrel{2}{N} \\
\sigma^{\prime}\end{array}$ & $\stackrel{\text { ㄱ }}{-}$ & $\stackrel{\text { 学 }}{-}$ & 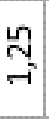 & $\lambda$ & $-i$ & $\stackrel{2}{-}$ & & & 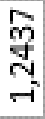 & 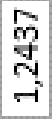 & 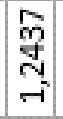 & 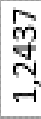 \\
\hline & & nก & & & & & & 8 & & 导 & v & f & \% & & 寸 & ㅇ & & & $\nabla$ & $m$ & $N$ & \\
\hline
\end{tabular}




\section{APA3 - Tabelas de discretização da laje EM3}

\section{Tabela APA3.1 - Valores da discretização em faixas: EM3 - MOMENTO POSITIVO - SEÇÃO COMPOSTA}

\begin{tabular}{|c|c|c|c|c|c|c|c|c|c|c|c|c|c|c|c|c|c|c|c|c|c|}
\hline & \multicolumn{11}{|c|}{ CAPA } & \multicolumn{10}{|c|}{ MESA SUPERIOR } \\
\hline$\frac{\widehat{\underline{\xi}}}{\frac{a}{x}}$ & t. & ปூ & 8 & 능 & 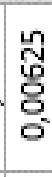 & & & : & ปี & 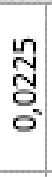 & $\begin{array}{l}\text { ñ } \\
\tilde{n} \\
\delta \\
\delta \\
\delta\end{array}$ & 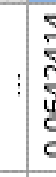 & 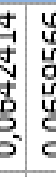 & 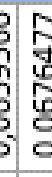 & $\begin{array}{l}0 \\
0 \\
0\end{array}$ & & 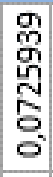 & 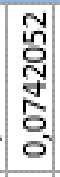 & & & 5 \\
\hline 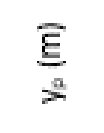 & & 옹 & 윰 & 옹 & 늉 & & & $\begin{array}{l}\text { 유. } \\
\text { 응 } \\
0\end{array}$ & $\begin{array}{l}\text { 음 } \\
\text { : } \\
\text { - }\end{array}$ & $\begin{array}{l}\text { 品 } \\
\stackrel{0}{0} \\
\text { ठ }\end{array}$ & & 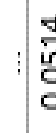 & 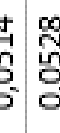 & : & 㞫 & $\infty$ & 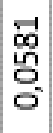 & 弯 & $0^{\circ}$ & & $0^{\circ}$ \\
\hline 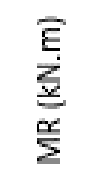 & y. & 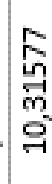 & 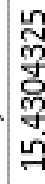 & 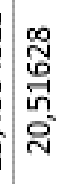 & 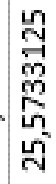 & & 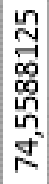 & 总 & 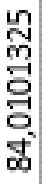 & 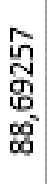 & 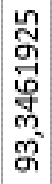 & $\begin{array}{l}\alpha \\
\alpha \\
4 \\
ي \\
\alpha \\
\alpha \\
\delta \\
\delta\end{array}$ & 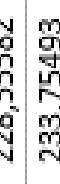 & 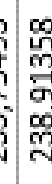 & 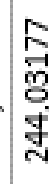 & 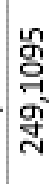 & 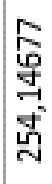 & 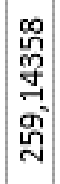 & 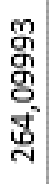 & 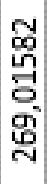 & 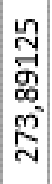 \\
\hline$\underset{N^{2}}{\bar{E}}$ & & g & $\begin{array}{l}\stackrel{n}{0} \\
\stackrel{9}{7} \\
0\end{array}$ & 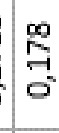 & $\begin{array}{l}\text { n } \\
\text { f } \\
\text { o }\end{array}$ & $\vdots$ & 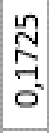 & \begin{tabular}{c}
\multirow{G}{*}{} \\
G
\end{tabular} & 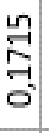 & 공 & & ñ & 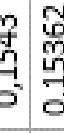 & 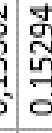 & సิ & 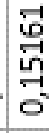 & 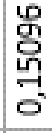 & 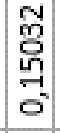 & 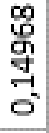 & $\begin{array}{l}\text { nू } \\
\text { 竎 } \\
\text { - } \\
\end{array}$ & $0^{\circ}$ \\
\hline 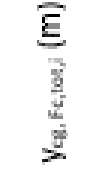 & ?5 & $\begin{array}{l}8 \\
80 \\
8 \\
8\end{array}$ & 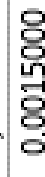 & $\begin{array}{l}8 \\
8 \\
8 \\
8 \\
8 \\
0\end{array}$ & $\begin{array}{l}8 \\
8 \\
8 \\
8\end{array}$ & & 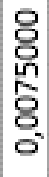 & $\begin{array}{l}8 \\
8 \\
8 \\
8 \\
8 \\
8 \\
\text { 8. }\end{array}$ & 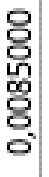 & $\begin{array}{l}8 \\
8 \\
8 \\
8 \\
8 \\
\circ\end{array}$ & 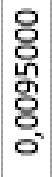 & 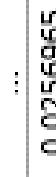 & 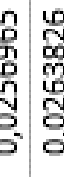 & $\begin{array}{l}5 \\
5 \\
5 \\
5 \\
8\end{array}$ & 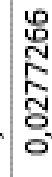 & $\begin{array}{l}\text { ज } \\
\text { סू } \\
\mathbb{0} \\
\text { ర్ }\end{array}$ & 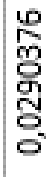 & 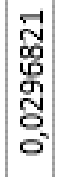 & 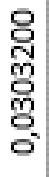 & 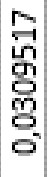 & $\begin{array}{l}\frac{1}{2} \\
\overline{8} \\
0 \\
0\end{array}$ \\
\hline $\begin{array}{l}> \\
4\end{array}$ & 㝵 & ஜ & 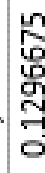 & 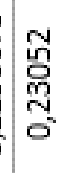 & 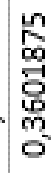 & & 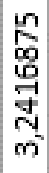 & $\begin{array}{l}\text { N } \\
0 \\
0 \\
0 \\
0 \\
\tilde{n}^{\prime}\end{array}$ & 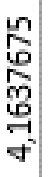 & 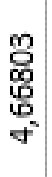 & 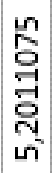 & 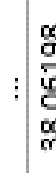 & $\begin{array}{l}0 \\
0 \\
0 \\
0\end{array}$ & 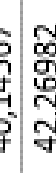 & $\begin{array}{l}\text { J } \\
\text { m } \\
\text { 寸 } \\
\text { J }\end{array}$ & 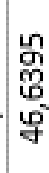 & 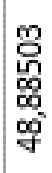 & 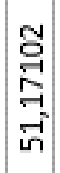 & 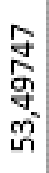 & 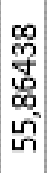 & 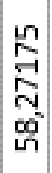 \\
\hline$\frac{\widehat{\underline{\xi}}}{\underline{\underline{g}}}$ & & 8 & & 영 & 능 & : & 뚱 & 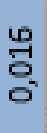 & 긍 & $\begin{array}{l}\infty \\
\stackrel{\infty}{0} \\
0\end{array}$ & 9 & ப் & 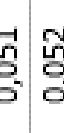 & 象 & 壱 & 出 & 号 & 농 & $\begin{array}{l}\text { 㔛 } \\
\text { ○' }\end{array}$ & $\begin{array}{l}\text { 㔛 } \\
\text { - }\end{array}$ & 웅 \\
\hline 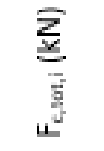 & & 菖 & & $\begin{array}{l}\text { N } \\
\text { ר్ } \\
\text { רે }\end{array}$ & $\begin{array}{l}\text { 㔯 } \\
\text { 过 } \\
\text { 寸 }\end{array}$ & $\vdots$ & $\begin{array}{l}\text { ป̂ } \\
\text { Ñ } \\
\text { 豸్ }\end{array}$ & 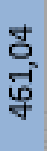 & $\begin{array}{l}\text { 岇 } \\
\text { व. } \\
\text { g }\end{array}$ & $\begin{array}{l}\text { b. } \\
\infty 0^{\circ} \\
\text { जn }\end{array}$ & 岇 & ร. & 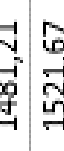 & 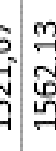 & 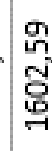 & 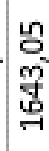 & 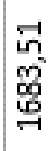 & 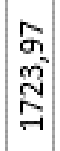 & $\begin{array}{l}\frac{m}{f} \\
\text { d } \\
\text { fે }\end{array}$ & 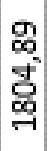 & 亗 \\
\hline $\bar{z}$ & & \begin{tabular}{l}
\multicolumn{1}{c}{} \\
0 \\
0 \\
09
\end{tabular} & \begin{tabular}{l}
\multicolumn{2}{c}{} \\
$\infty$ \\
0 \\
0
\end{tabular} & \begin{tabular}{l}
\multicolumn{1}{c}{} \\
$\infty$ \\
0 \\
00
\end{tabular} & $\vdots$ & $\vdots$ & & 离 & 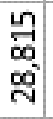 & 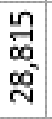 & $\ddot{L}$ & 4 & 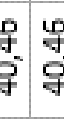 & 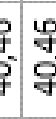 & $\begin{array}{l}\text { 守 } \\
\text { ơ }\end{array}$ & 告 & $\begin{array}{l}\text { 昌 } \\
\text { 品 }\end{array}$ & 昌 & 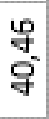 & 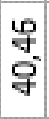 & 0 \\
\hline $4 \sum_{\underline{\underline{z}}}^{\overline{\tilde{E}}}$ & క్ & 응 & & $\frac{8}{8}$ & 8 & & 욤 & 용 & 용 & 용 & 8 & . & 8 & $\frac{8}{8}$ & 8 & 음 & 8 & 8: & 安 & ষ্ণ & 8 \\
\hline $\bar{\xi}$ & 5 & 긍 & ڤ్ & 品 & 눙 & : & 4 & $\begin{array}{l}\text { 出 } \\
\text { 응 } \\
\text { - }\end{array}$ & & 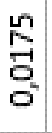 & 感 & , & $\begin{array}{l}0 \\
0\end{array}$ & $\begin{array}{l}9 \\
5 \\
5 \\
5\end{array}$ & 영 & แ้ & 出 & 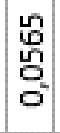 & 농 & 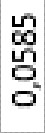 & 응 \\
\hline$\xi$ & & 8 & 8 & 8 & 8 & & 웅 & 형 & 용 & : & & 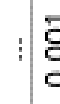 & 8 & 5 & 8 & 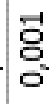 & 응 & 응 & 용 & 8 & . \\
\hline 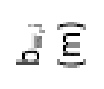 & & m & $\stackrel{m}{\rightarrow}$ & $\stackrel{m}{\rightarrow}$ & 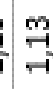 & ; & & $\underset{\rightarrow}{\stackrel{m}{-1}}$ & $\stackrel{9}{\underset{7}{-}}$ & $\underset{\rightarrow}{\stackrel{9}{\rightarrow}}$ & $\stackrel{m}{7}$ & g & g & $\frac{9}{7}$ & $\stackrel{9}{\stackrel{9}{7}}$ & 9 & $\underset{7}{9}$ & $\underset{7}{9}$ & $\underset{7}{9}$ & 각 & $\stackrel{7}{-1}$ \\
\hline$\frac{\pi}{x}=$ & & $N$ & $m$ & 寸 & nn & & 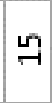 & & 7 & $\underset{-}{\infty}$ & -1 & I & กิ & กิ & ตา & 出 & 罢 & nn & 品 & ूㅣ & 8 \\
\hline
\end{tabular}


Tabela APA3.2 - Valores da discretização em faixas: EM3 - MOMENTO NEGATIVO - SEÇÃO COMPOSTA

\begin{tabular}{|c|c|c|c|c|c|c|c|c|c|c|c|c|c|c|c|c|c|c|c|}
\hline & \multicolumn{9}{|c|}{ ALVÉolos } & \multicolumn{10}{|c|}{ MESA INFERIOR } \\
\hline$\frac{\overline{\underline{\xi}}}{x}$ & 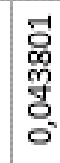 & $\begin{array}{l}m \\
0 \\
0 \\
\tilde{y} \\
0 \\
0\end{array}$ & 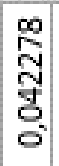 & 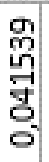 & 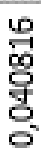 & & & 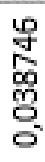 & $\begin{array}{l}\text { ஜू } \\
\text { ס्र } \\
0 \\
0 \\
0\end{array}$ & 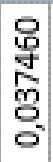 & 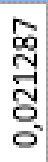 & 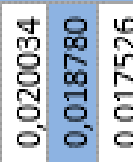 & 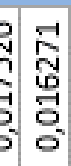 & & 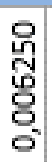 & $\begin{array}{l}\text { 응 } \\
\text { फ़े } \\
\text { 웅 }\end{array}$ & : & 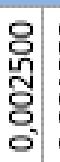 & $\begin{array}{l}\text { 율 } \\
\text { 영 } \\
8\end{array}$ \\
\hline$\underset{\mathrm{E}}{\overline{\mathrm{E}}}$ & $\begin{array}{l}\text { 웅 } \\
\text { \% } \\
\text { 은 }\end{array}$ & 音 & $\begin{array}{l}\infty \\
0 \\
0 \\
0 \\
0 \\
0\end{array}$ & $\begin{array}{l}\text { \%̃ } \\
\text { סू } \\
\text { ס. }\end{array}$ & 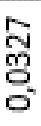 & & & $\begin{array}{l}\text { 을 } \\
\text { 응 } \\
\text { 인 }\end{array}$ & 농 & $\begin{array}{l}\text { 옹 } \\
\text { o. } \\
\text { - }\end{array}$ & 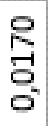 & 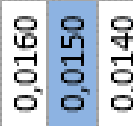 & 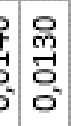 & & $\begin{array}{l}\text { 융 } \\
\text { 응 }\end{array}$ & $\begin{array}{l}\text { 웅 } \\
\text { 응 }\end{array}$ & $\begin{array}{l}\text { 유. } \\
\text { 응 }\end{array}$ & ్. & 응 \\
\hline $\begin{array}{l}\widehat{\widehat{E}} \\
\underset{\sum}{\dot{\alpha}} \\
\stackrel{\alpha}{\Sigma}\end{array}$ & $\begin{array}{l}\infty \\
0 \\
0 \\
\tilde{ల} \\
0 \\
\tilde{0} \\
\tilde{N}\end{array}$ & 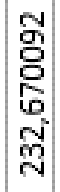 & 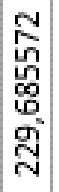 & 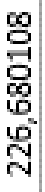 & 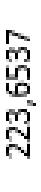 & 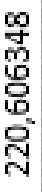 & V & 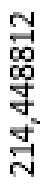 & 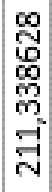 & 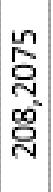 & 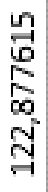 & 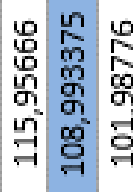 & 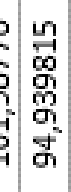 & & 空 & 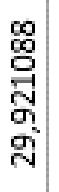 & 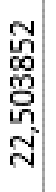 & 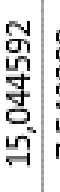 & 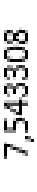 \\
\hline$\frac{\widehat{\underline{E}}}{\mathrm{~N}}$ & 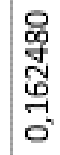 & 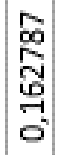 & 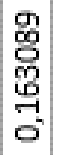 & 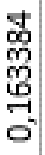 & 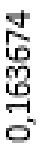 & ñ & $\ddot{m}$ & 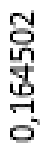 & 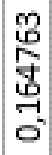 & 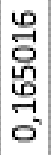 & 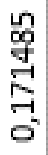 & 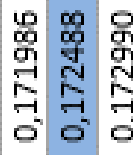 & 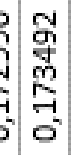 & & 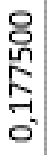 & $\begin{array}{c}8 \\
8 \\
\text { g } \\
7 \\
0 \\
0\end{array}$ & 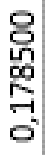 & 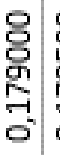 & 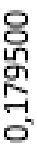 \\
\hline 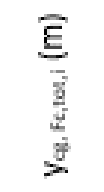 & 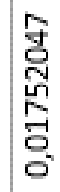 & 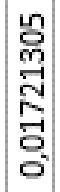 & 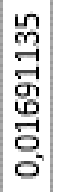 & 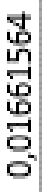 & 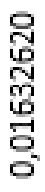 & 范 & $\begin{array}{l}\text { ปे } \\
\frac{0}{0} \\
\frac{0}{0}\end{array}$ & 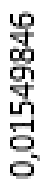 & 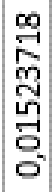 & 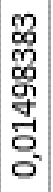 & 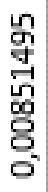 & 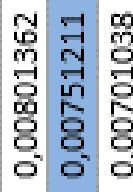 & 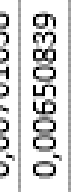 & & 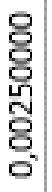 & 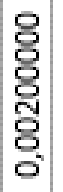 & $\begin{array}{l}8 \\
8 \\
\text { फ़े } \\
\frac{4}{8} \\
0\end{array}$ & $\begin{array}{l}8 \\
8 \\
8 \\
8 \\
8 \\
\end{array}$ & 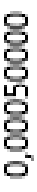 \\
\hline 交 & 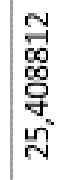 & 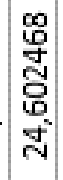 & 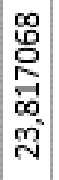 & 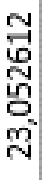 & 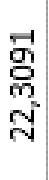 & 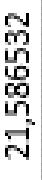 & 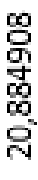 & 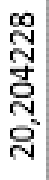 & 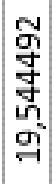 & $\begin{array}{l}\text { 능 } \\
\text { ơ } \\
\text { कo } \\
\rightarrow\end{array}$ & 兄 & 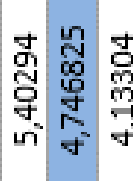 & 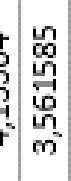 & & 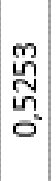 & 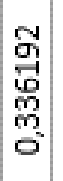 & 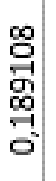 & 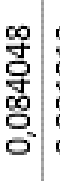 & 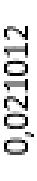 \\
\hline $\bar{g}$ & 品 & 离 & \%ิ & $\begin{array}{l}0 \\
0 \\
0 \\
0\end{array}$ & 哭 & $\begin{array}{l}\text { है } \\
\text { : }\end{array}$ & n & ֻี & 络 & $\stackrel{\circ}{\circ}$ & 킁 & 뜽명ㅁㅇㅇㅇㅇㅇ & $\begin{array}{c}0 \\
3 \\
0\end{array}$ & & 농 & : & : & : & 용 \\
\hline 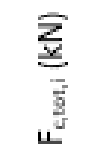 & 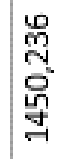 & $\begin{array}{l}\text { న్ } \\
\text { ปั } \\
\text { ปે }\end{array}$ & 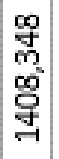 & 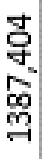 & 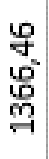 & 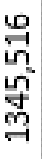 & 5 & 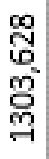 & 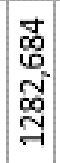 & \begin{tabular}{l}
\multirow{2}{*}{} \\
$\overrightarrow{\mathrm{D}}$ \\
\multirow{4}{*}{}
\end{tabular} & $\begin{array}{l}\text { 资 } \\
\text { 吾 } \\
\text { ה }\end{array}$ & 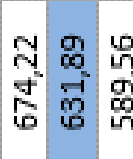 & 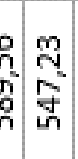 & & בี & 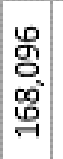 & 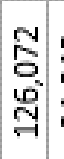 & $\begin{array}{l}0 \\
\text { वे } \\
\text { वें }\end{array}$ & 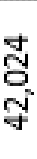 \\
\hline 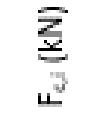 & $\begin{array}{l}\text { 寸 } \\
\text { 今ू } \\
\text { 尺े }\end{array}$ & 寺 & $\begin{array}{l}\text { Jे } \\
\text { ô. } \\
\text { ते }\end{array}$ & $\begin{array}{l}\text { जे } \\
\text { तें }\end{array}$ & & $\begin{array}{l}\text { 高 } \\
\text { तें }\end{array}$ & 8 & $\begin{array}{l}\text { 志 } \\
\text { ते }\end{array}$ & 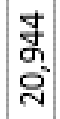 & $\begin{array}{l}\stackrel{1}{\infty} \\
\stackrel{-}{-1}\end{array}$ & \begin{tabular}{l}
$\stackrel{m}{m}$ \\
\multirow{q}{*}{}
\end{tabular} & 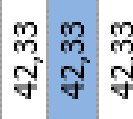 & 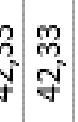 & & 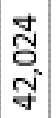 & 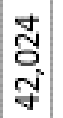 & I & 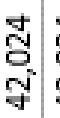 & 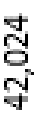 \\
\hline $4 \sum_{\underline{\underline{z}}}^{\widetilde{\xi}}$ & 8 & 8 & 8 & $\begin{array}{l}8 \\
8 \\
\end{array}$ & ठ8. & $\begin{array}{l}8 \\
8 \\
\end{array}$ & & ठ8. & 8 & 8) & ठ․ & ৪ి & 8 & & 8 & 8 & 8 & $\begin{array}{l}8 \\
8 \\
8\end{array}$ & 8 \\
\hline$\underset{\overline{\mathrm{E}}}{\bar{\lambda}}$ & $\begin{array}{l}\text { L } \\
0 \\
0 \\
0 \\
0\end{array}$ & $\begin{array}{l}n \\
0 \\
0 \\
0 \\
0\end{array}$ & 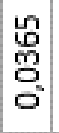 & 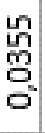 & 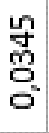 & 0 & 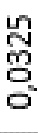 & 뭉 & 눙 & 亗 & 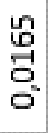 & 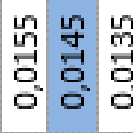 & مُ & & 告 & $\begin{array}{l}\text { m } \\
0 \\
0 \\
0 \\
0\end{array}$ & 嵌 & 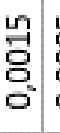 & $\begin{array}{l}\text { 능 } \\
8\end{array}$ \\
\hline$\varangle E$ & & & & & & & & & & & & & & & & & & & \\
\hline$\underset{\underline{E}}{\bar{E}}$ & 응 & 음 & ठ․ & : & ठั. & চ̈ & & ठ․ & 응 & 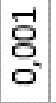 & 용 & 홍용응 & s. & & 응 & ठ․ & 0 & ठ̈. & ठ̈. \\
\hline$\frac{\widehat{E}}{\bar{z}}$ & $\begin{array}{l}0 \\
0 \\
0 \\
0 \\
0\end{array}$ & 量 & $\begin{array}{l}\varphi \\
0 \\
0 \\
0 \\
0\end{array}$ & $\begin{array}{l}0 \\
\stackrel{9}{0} \\
0 \\
0\end{array}$ & $\begin{array}{l}\text { 명 } \\
0 \\
0 \\
0\end{array}$ & 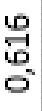 & & $\begin{array}{l}\text { प्र } \\
0 \\
0 \\
0\end{array}$ & $\begin{array}{l}0 \\
0 \\
0 \\
0 \\
0\end{array}$ & $\begin{array}{c}2 \\
-1\end{array}$ & $\underset{\mathrm{f}}{\stackrel{\text { f }}{-}}$ & 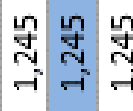 & 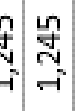 & & 品 & 品 & 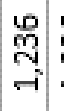 & 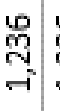 & $\begin{array}{l}\mathscr{D} \\
\text { ָָ } \\
-1\end{array}$ \\
\hline$\frac{\pi}{x}=$ & ले & $\stackrel{\infty}{m}$ & $\widehat{m}$ & $m$ & ल & ল & & ले & $\vec{m}$ & 이 & 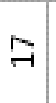 & $\stackrel{9}{9}$ & 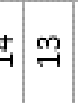 & & แn & ष & $m$ & $N$ & -1 \\
\hline
\end{tabular}




\section{APÊNDICE B}

\section{APB1 - Caracterização do concreto das lajes alveolares}

Tabela APB1.1 - Resultados dos ensaios à compressão dos corpos de prova correspondentes ao concreto das lajes alveolares do ensaio EM1.

\begin{tabular}{|l|c|c|c|c|c|c|c|}
\hline \multicolumn{1}{|c|}{ LAJE TRELIÇADA IND. E COM LTDA } \\
OBRA: Estádio
\end{tabular}

Tabela APB1.2 - Resultados dos ensaios à compressão dos corpos de prova correspondentes ao concreto das lajes alveolares do ensaio EM2.

\begin{tabular}{|c|c|c|c|c|c|c|c|c|c|}
\hline \multicolumn{9}{|c|}{ LABORATÓRIO DE CONTROLE TECNOLÓGICO - CASSOL } & Pág.: \\
\hline \multicolumn{10}{|c|}{ ENSAIO : CONCRETO - ENSAIO DE COMPRESSÃO DE CORPOS DE PROVA CILÍNDRICOS } \\
\hline \multicolumn{6}{|c|}{ NORMA APLICÁVEL : } & \multicolumn{4}{|c|}{ PROCEDIMENTO: } \\
\hline \multicolumn{4}{|c|}{$\begin{array}{l}\text { OBRA : UNIVERSIDADE FEDERAL DE SAO CARLOS } \\
\text { PRODUTO : BLOCO P/PISO CONCR.L26.5 }\end{array}$} & \multicolumn{5}{|c|}{$\begin{array}{l}\text { Período: } 15 \text { à } 15 \text { de Fevereiro de } 2012 \\
\text { (fck } 30 \mathrm{MPa} \text { ) }\end{array}$} & \\
\hline \multirow{3}{*}{$\begin{array}{c}\text { DATA } \\
\text { DA } \\
\text { PRODUÇÃO }\end{array}$} & \multirow{3}{*}{ PEÇA } & \multirow{3}{*}{$\begin{array}{c}\text { ORDEM } \\
\text { DE } \\
\text { PRODUÇÃO }\end{array}$} & \multirow{3}{*}{$\begin{array}{l}\text { QTDE. } \\
\text { O.P. }\end{array}$} & \multicolumn{5}{|c|}{ RESISTÊNCIA(MPa) } & \\
\hline & & & & \multicolumn{3}{|c|}{ LIBERAÇÃO } & \multirow{2}{*}{\multicolumn{2}{|c|}{$\begin{array}{r}28 \text { DIAS } \\
\text { CP-1 }\end{array}$}} & \\
\hline & & & & Ruptura & CP-1 & CP-2 & & & CP-2 \\
\hline $15 / 02 / 2012$ & UFCA-LA-000001 & 479.748 & 12 & 25 Horas & 17,1 & 21,0 & $14 / 03 / 2012$ & 42,4 & 40,9 \\
\hline
\end{tabular}

OBSERVAÇÃO : As peças foram produzidas na Unidade Fabril de CASSOL MONTE MOR - SP

Data da Última Aferição da Prensa : 00/00/0000 Realizada por

Periodicidade de Aferição: Anual 


\section{APB2 - Ensaios de resistência à compressão}

Tabela APB2.1 - Resultados dos ensaios à compressão dos corpos de prova correspondentes ao concreto da capa do ensaio EM1.

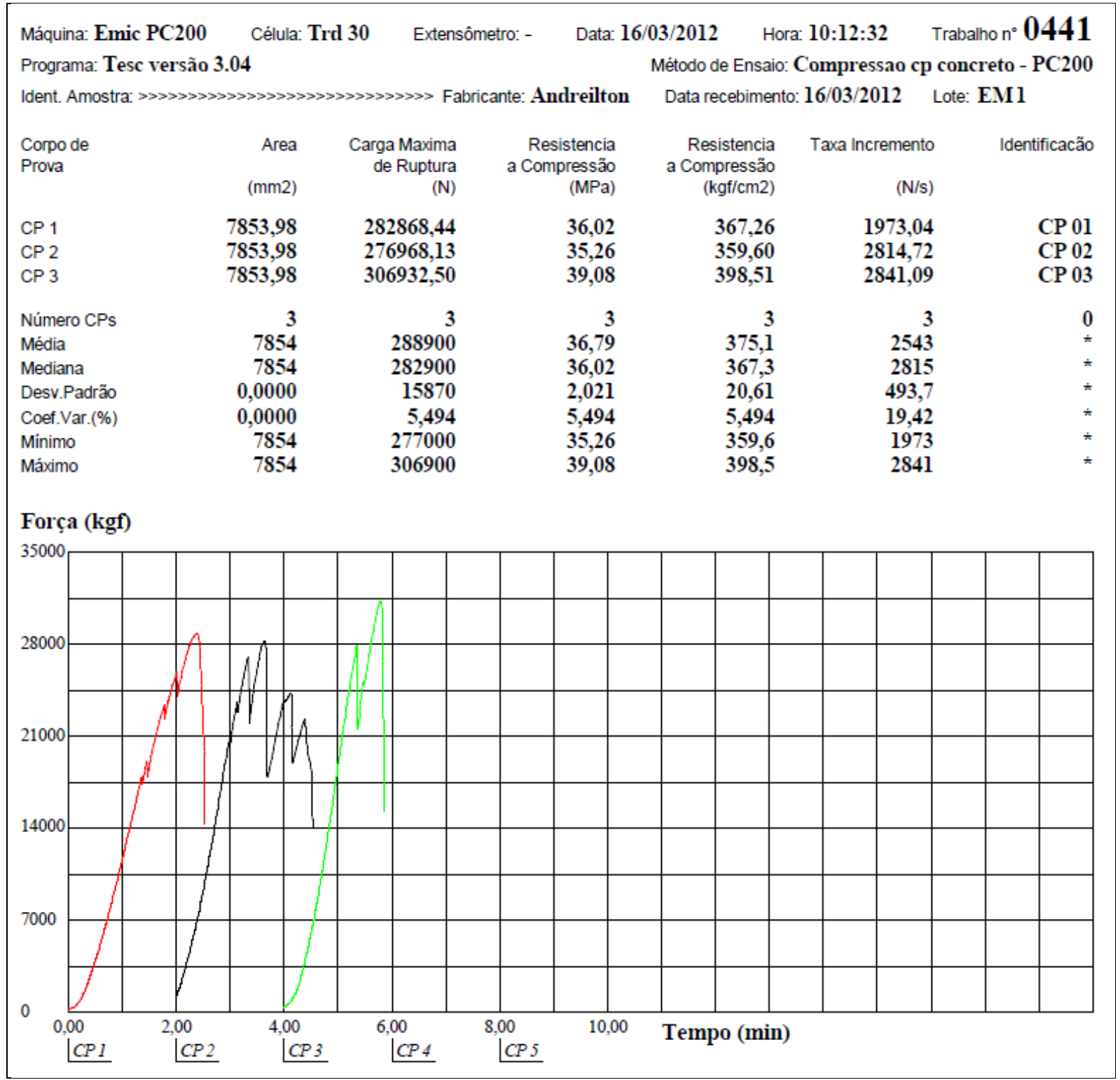


Tabela APB2.2 - Resultados dos ensaios à compressão dos corpos de prova correspondentes ao concreto da capa do ensaio EM2.

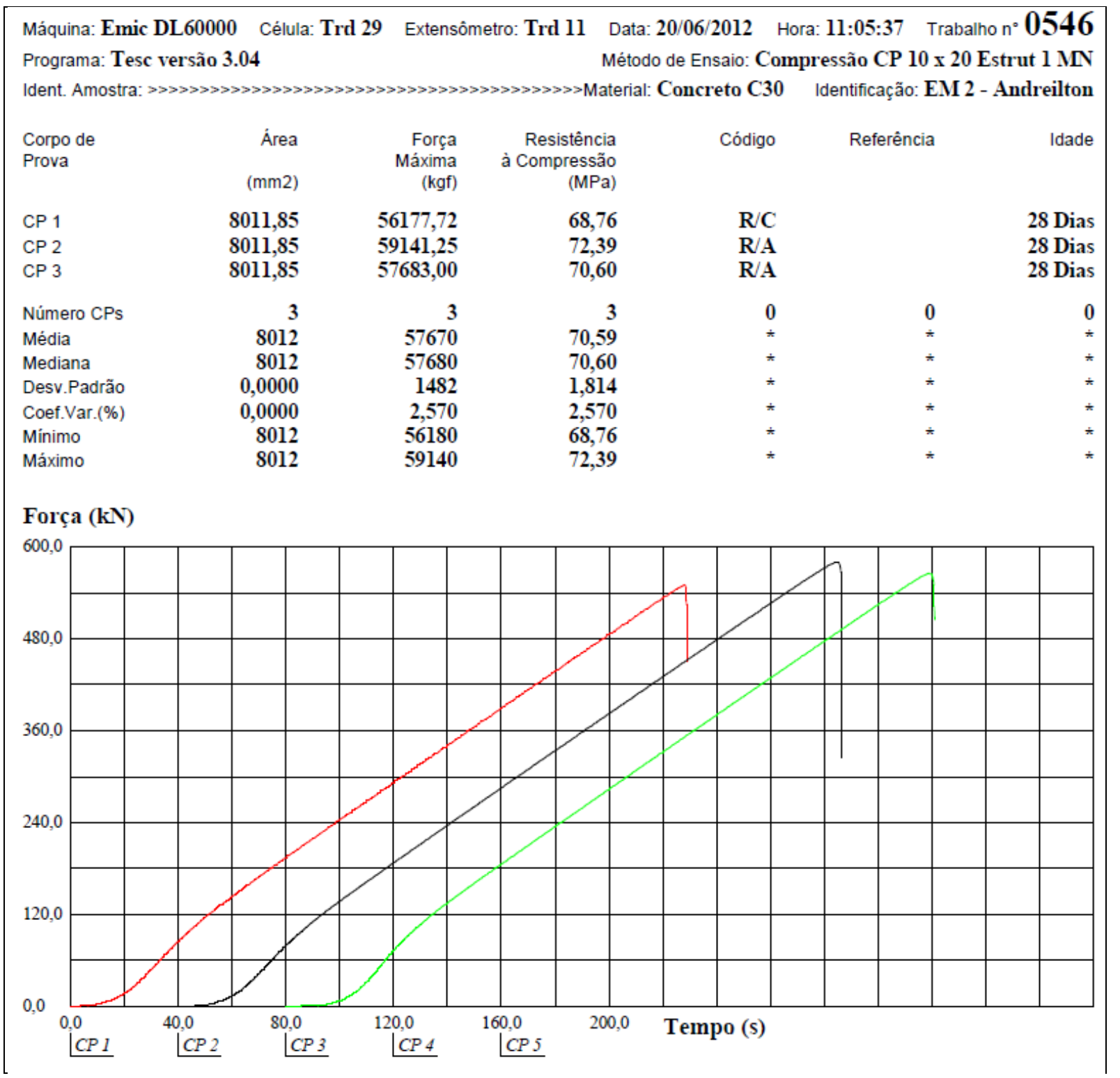


Tabela APB2.3 - Resultados dos ensaios à compressão dos corpos de prova correspondentes ao concreto da capa do ensaio EM3.

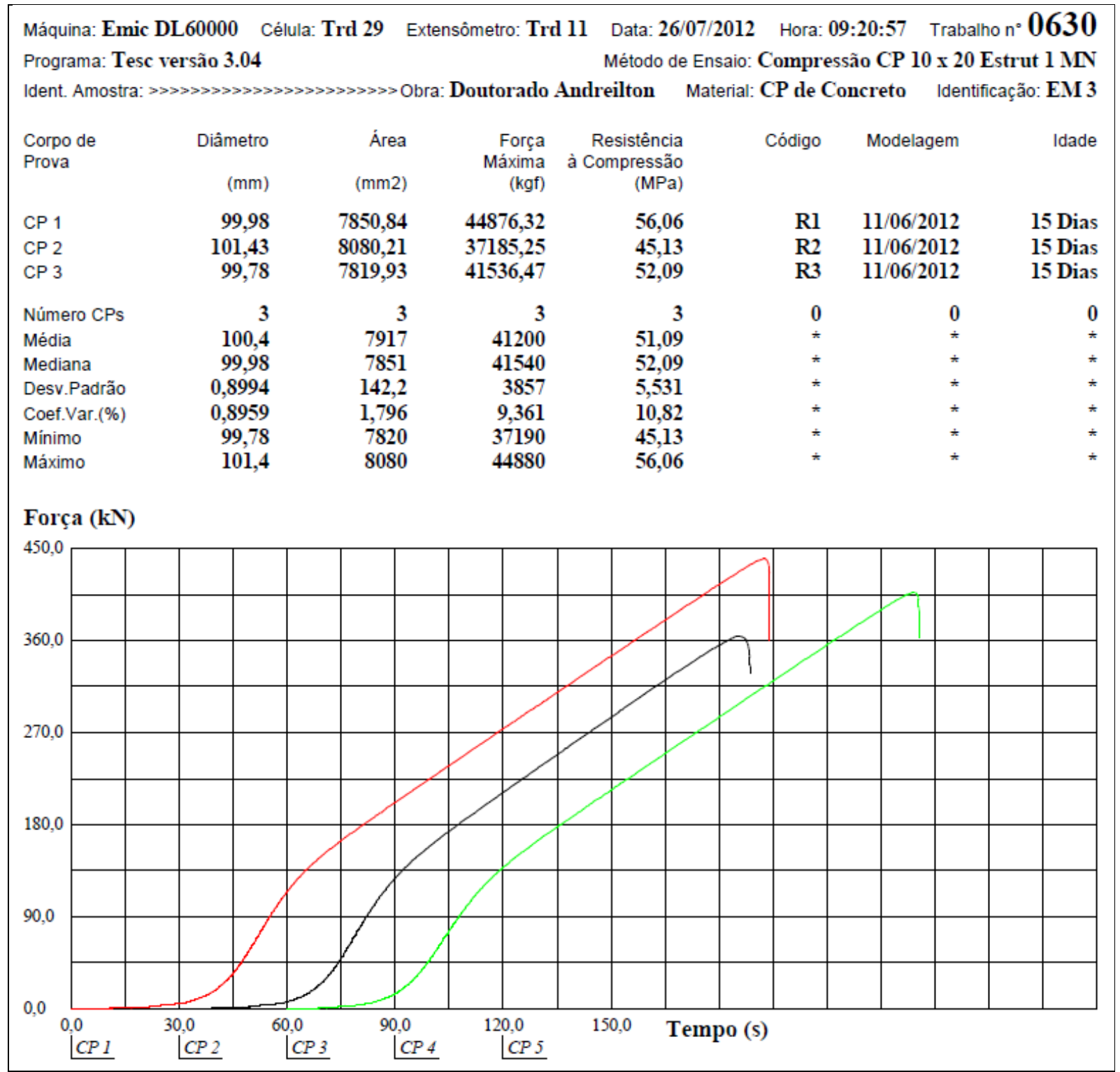




\section{APB3 - Determinação do módulo de elasticidade}

\section{Tabela APB3.1 - Resultados dos ensaios de determinação do módulo de elasticidade dos corpos de} prova correspondentes ao concreto da capa do ensaio EM3.

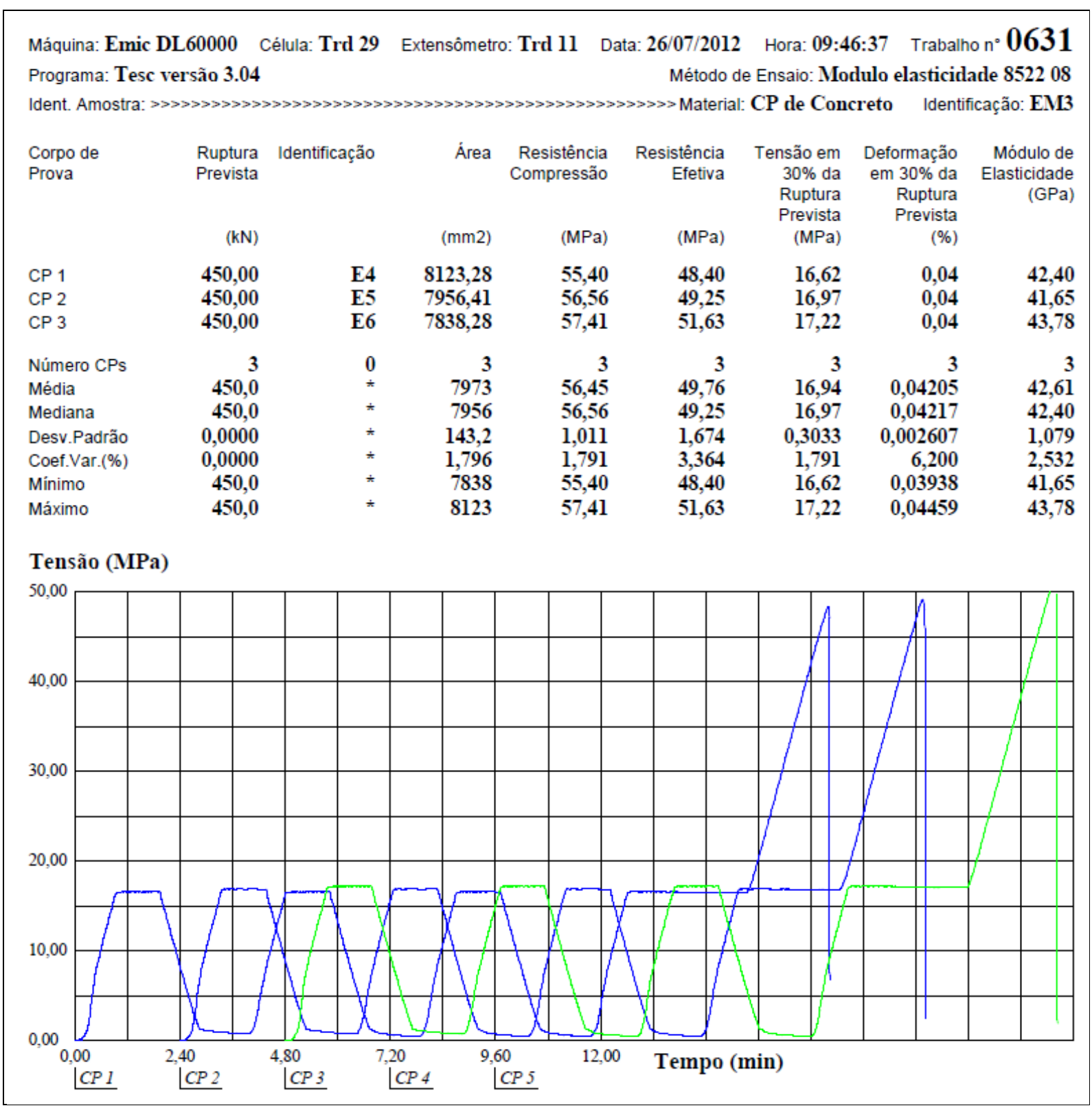




\section{APB4 - Resistência à tração por compressão diametral}

Tabela APB4.1 - Resultados dos ensaios de resistência à tração por compressão diametral dos corpos de prova correspondentes ao concreto da capa do ensaio EM3.

Máquina: Emic DL60000 Célula: Trd 29 Extensômetro: Trd 11 Data: 26/07/2012 Hora: 11:19:41 Trabalho n 0632 Programa: TesıMétodo de Ensaio: NBR 7222 Determinação da Resistência à Tração por Compressão Diametral-DL100T Ident. Amostra: >>>>>>>>>>>>>>>>>>>>>>>>>>>>>>>>>>Obra: Doutorado Andreilton Identificação: EM3 Idade: 15 Dias

\begin{tabular}{|c|c|c|c|c|}
\hline $\begin{array}{l}\text { Corpo de } \\
\text { Prova }\end{array}$ & Identificação & & $\begin{array}{r}\text { Força } \\
\text { Máxima } \\
(\mathrm{N})\end{array}$ & $\begin{array}{r}\text { Resistência } \\
(\mathrm{MPa})\end{array}$ \\
\hline $\mathrm{CP} 1$ & 7 & 18,88 & 150270,0 & 4,88371 \\
\hline $\mathrm{CP} 2$ & 8 & 14,03 & 114057,6 & 3,67160 \\
\hline $\mathrm{CP} 3$ & 9 & 18,76 & 145657,0 & 4,83957 \\
\hline Número $\mathrm{CPs}$ & 3 & 3 & 3 & 3 \\
\hline Média & 8,000 & 17,22 & 136700 & 4,465 \\
\hline Mediana & 8,000 & 18,76 & 145700 & 4,840 \\
\hline Desv.Padrão & 1,000 & 2,765 & 19710 & 0,6874 \\
\hline Coef.Var.(\%) & 12,50 & 16,05 & 14,42 & 15,40 \\
\hline Mínimo & 7,000 & 14,03 & 114100 & 3,672 \\
\hline Máximo & 9,000 & 18,88 & 150300 & 4,884 \\
\hline
\end{tabular}

Força (kN)

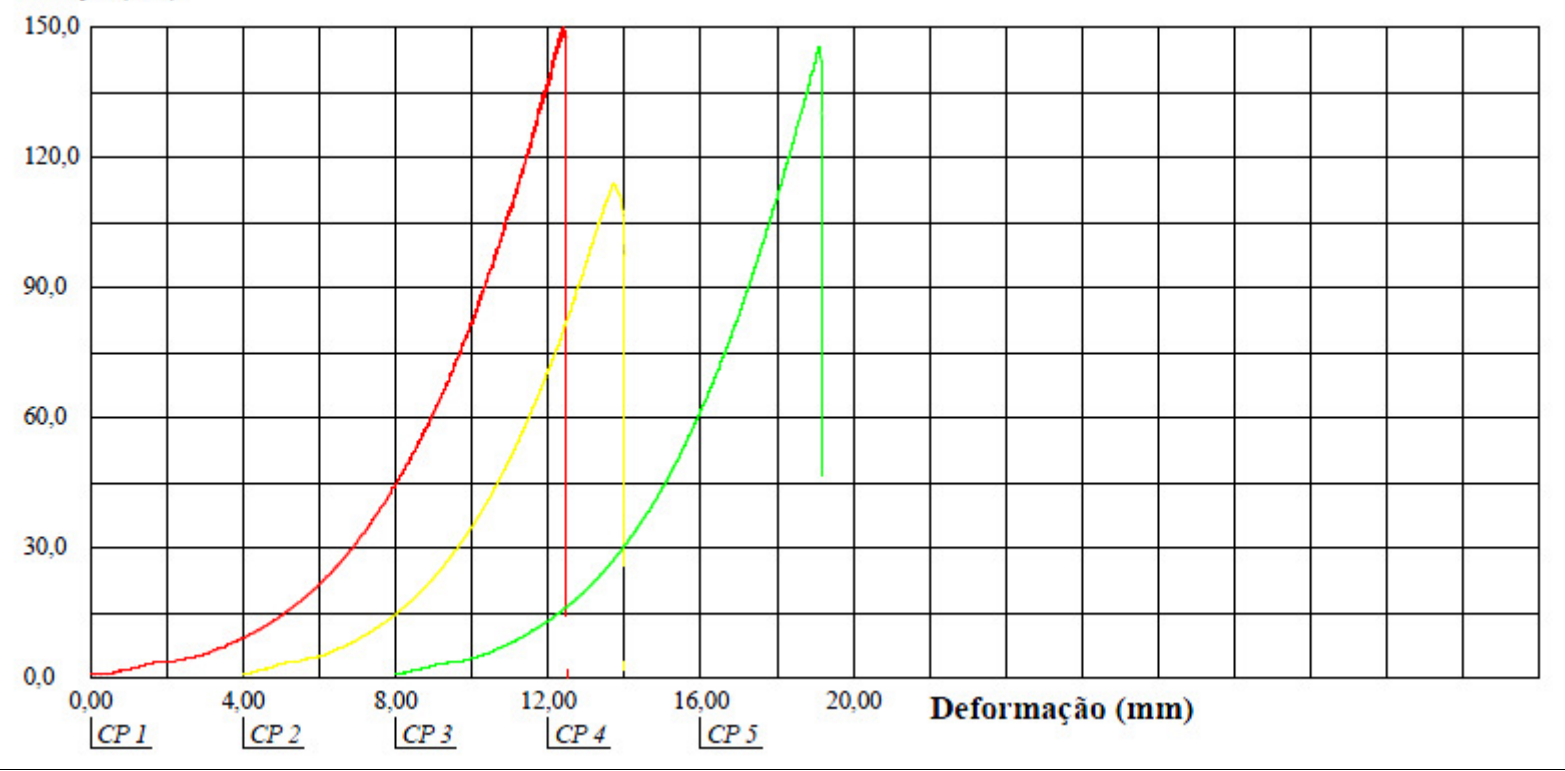




\section{APB5 - Resistência à tração por compressão diametral}

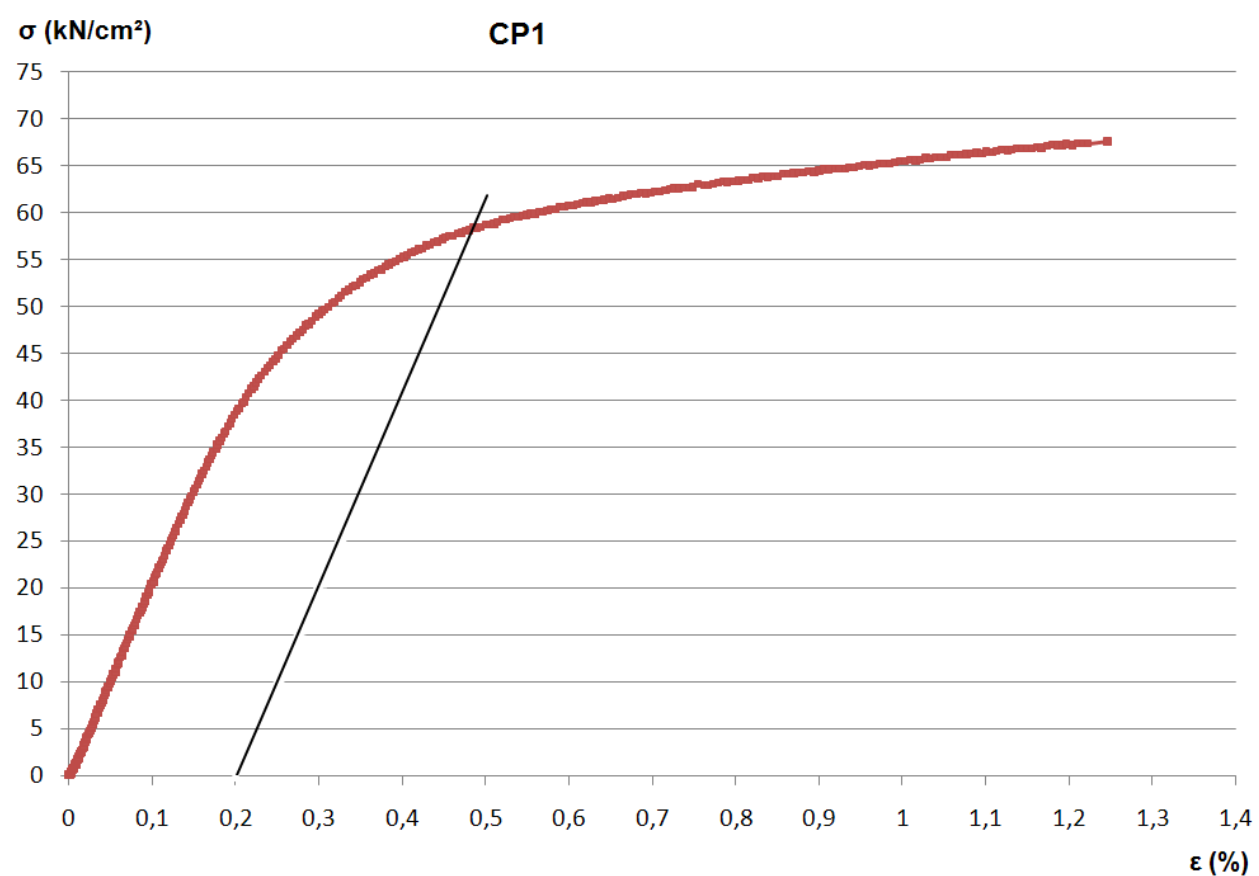

Figura APB5.1 - Ensaio de resistência à tração direta em barras de aço de armadura passiva (CP1).

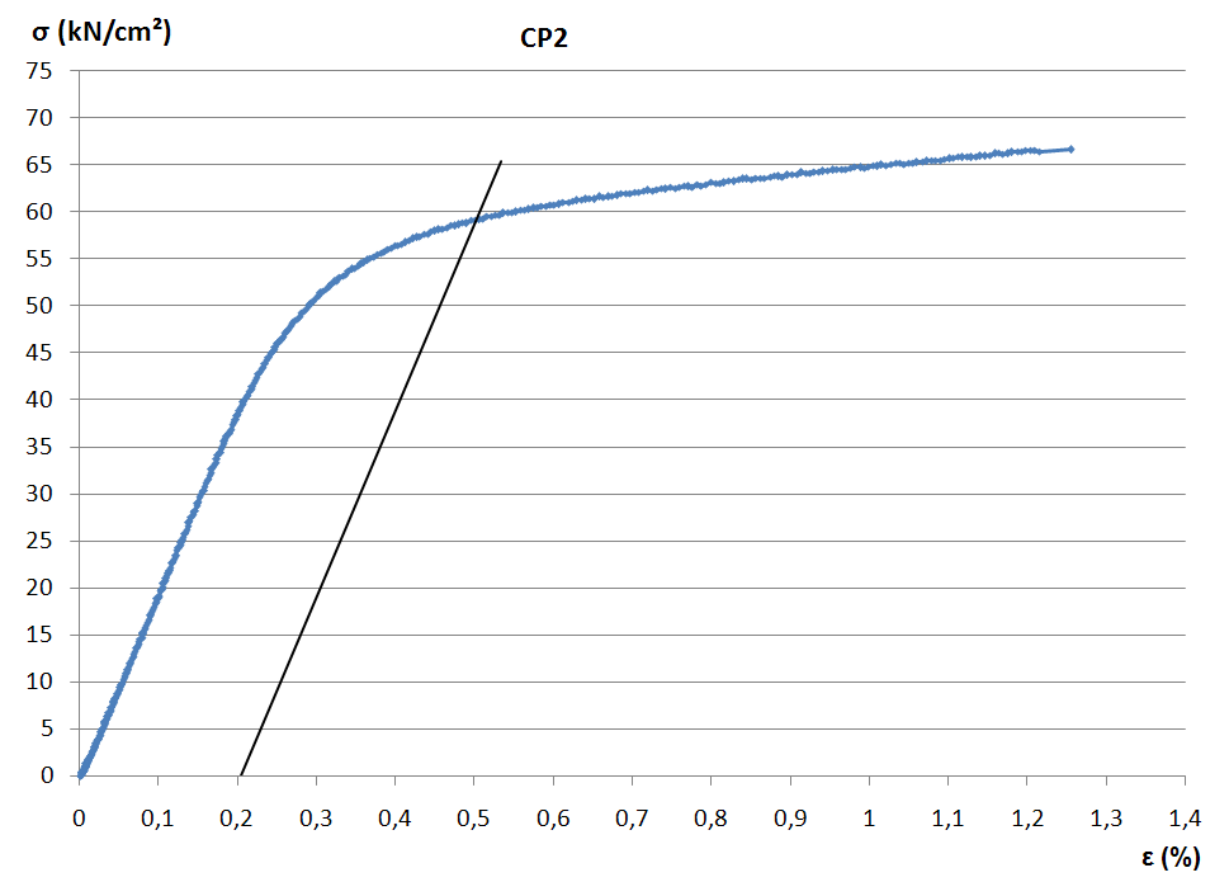

Figura APB5.2 - Ensaio de resistência à tração direta em barras de aço de armadura passiva (CP2). 


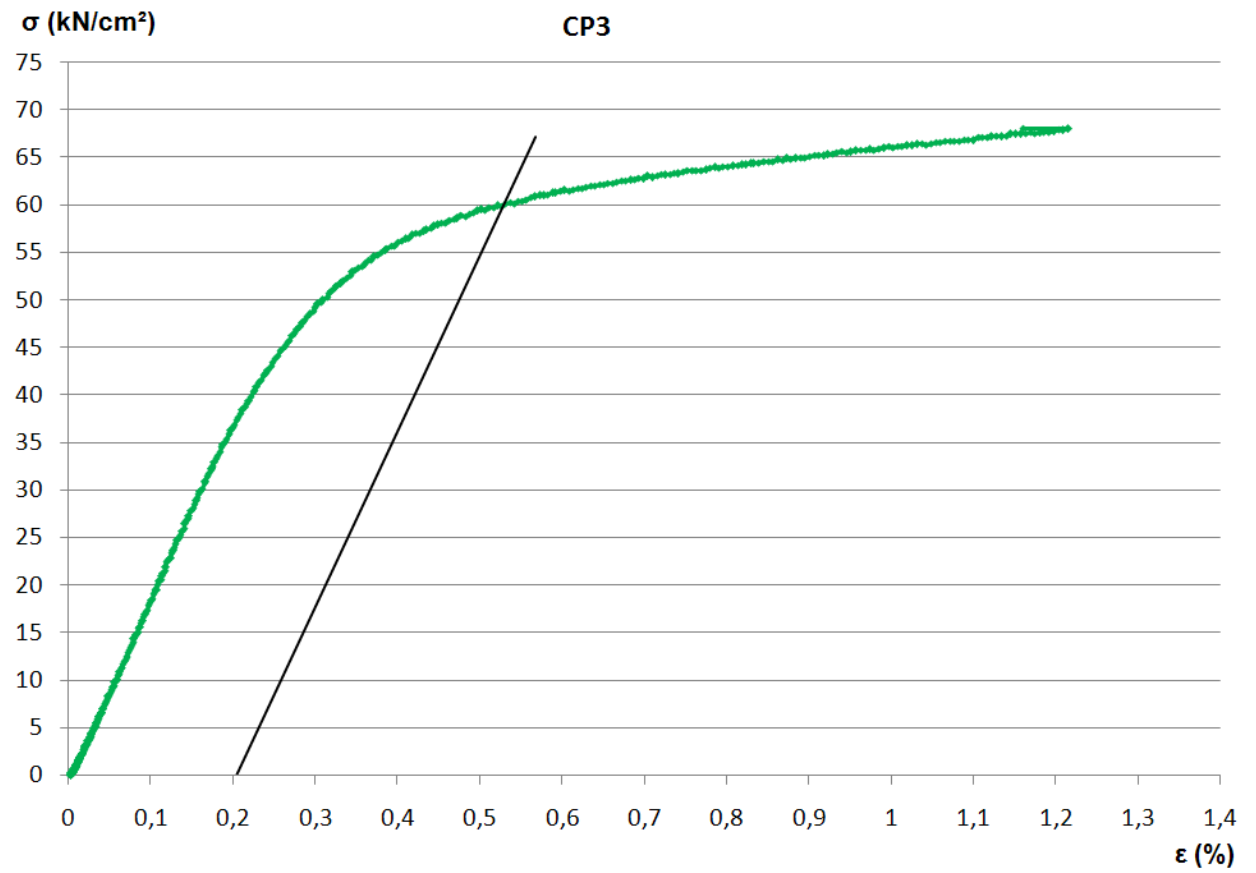

Figura APB5.3 - Ensaio de resistência à tração direta em barras de aço de armadura passiva (CP3). 


\section{APB6 - Relatórios de ensaios da armadura ativa - EM1}

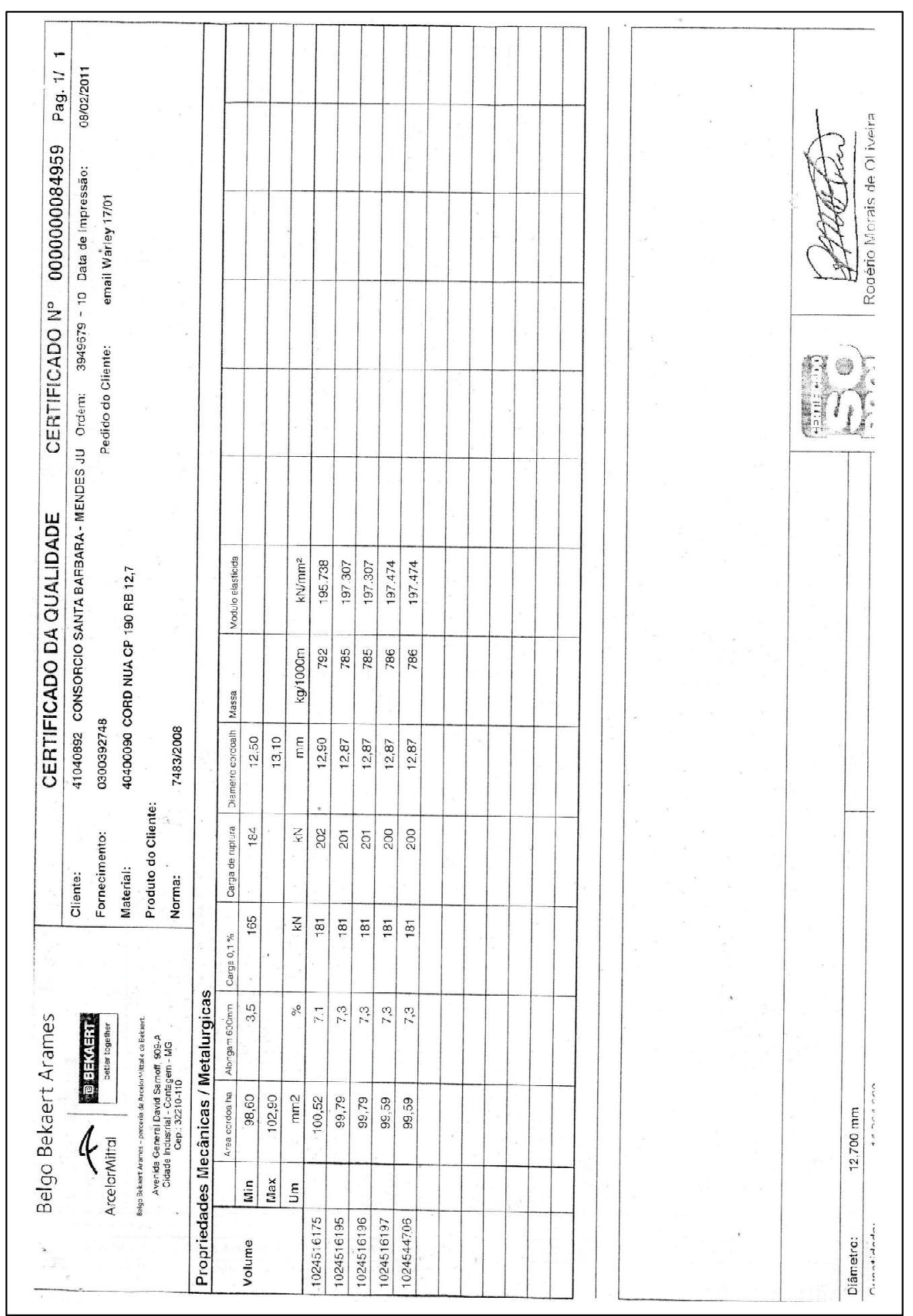

Figura APB6.1 - Relatório da armadura ativa fornecido pelo fabricante do modelo EM1. FOLHA 1/4. 


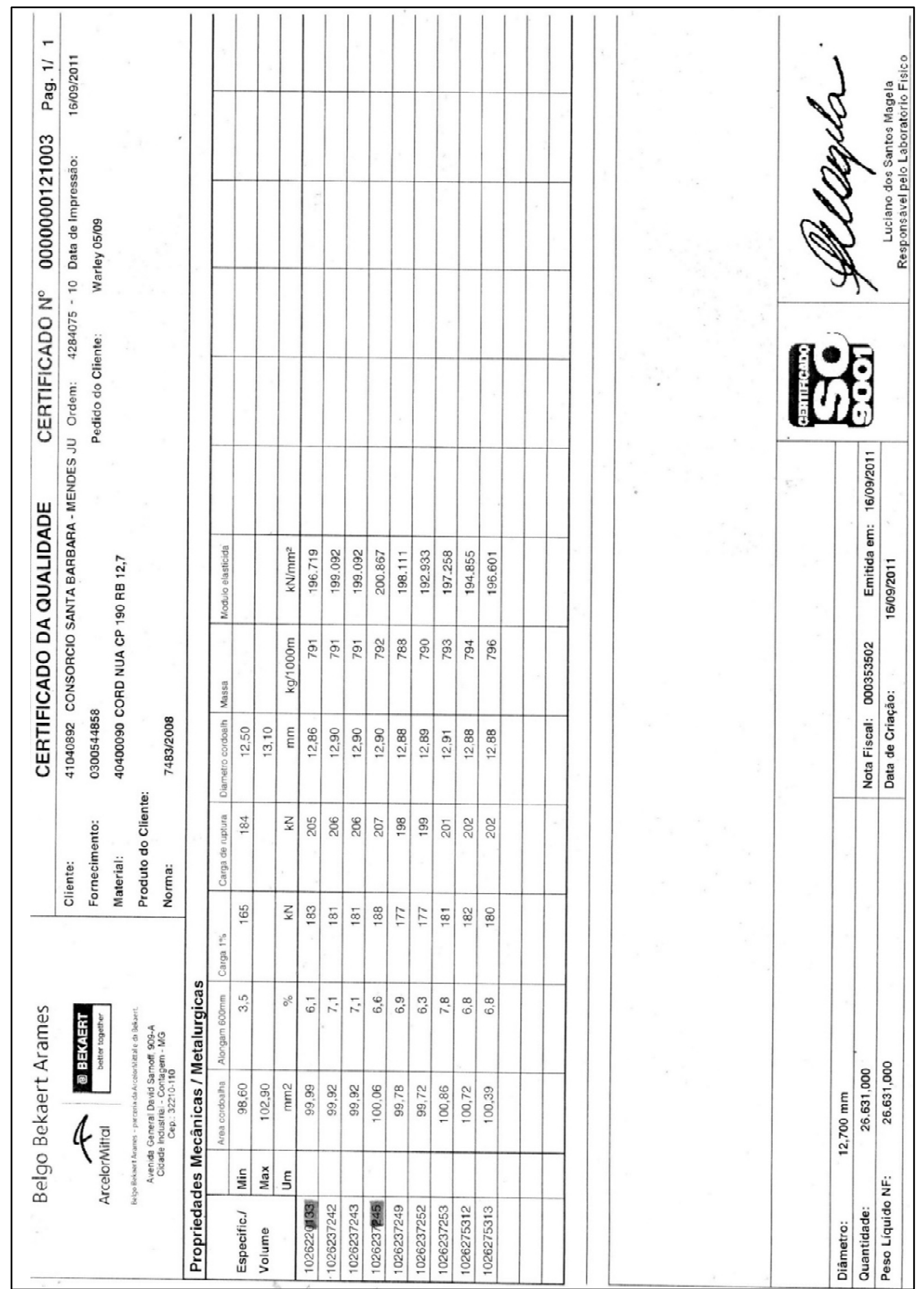

Figura APB6.2 - Relatório da armadura ativa fornecido pelo fabricante do modelo EM1. FOLHA 2/4. 


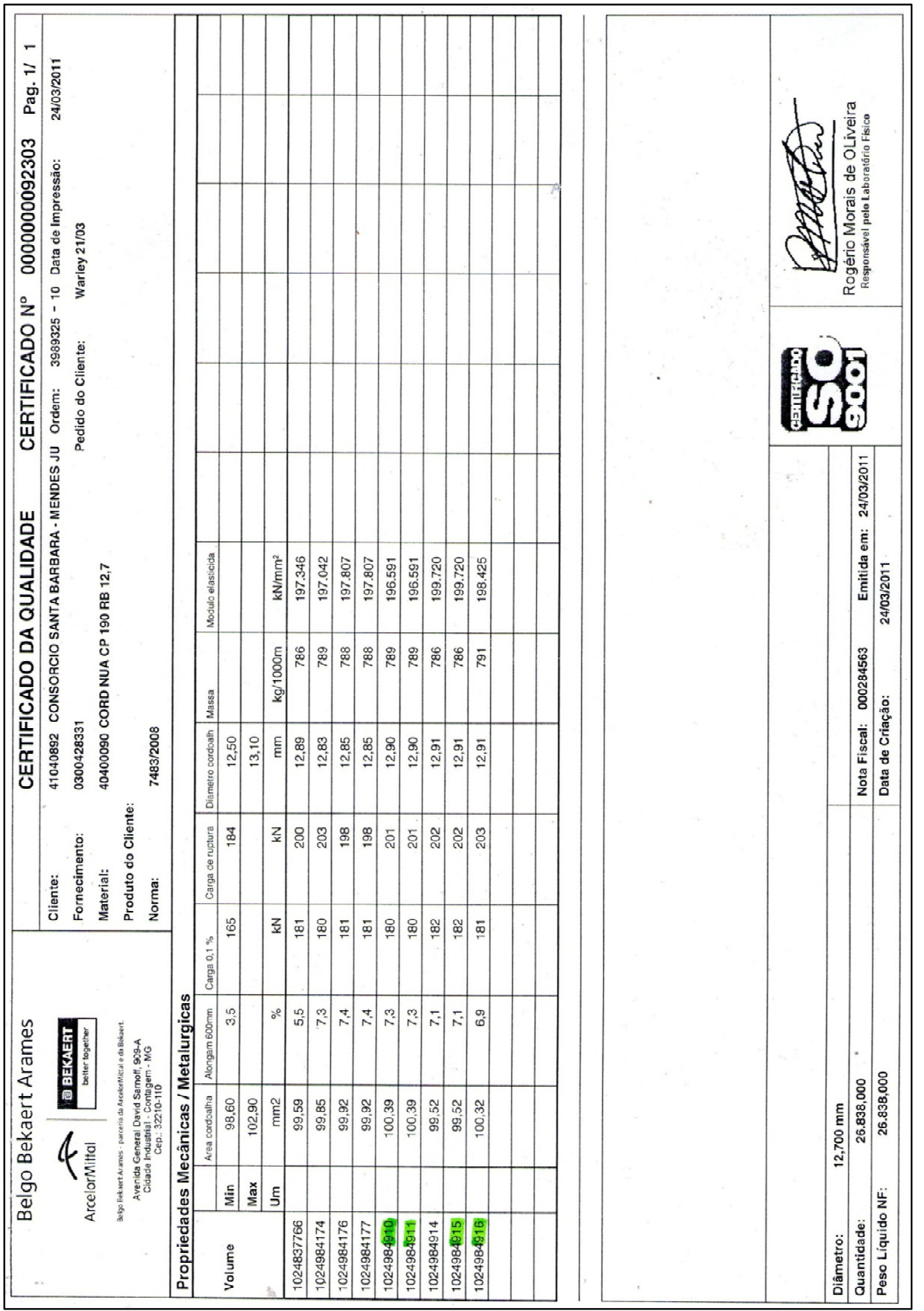

Figura APB6.3 - Relatório da armadura ativa fornecido pelo fabricante do modelo EM1. FOLHA 3/4. 


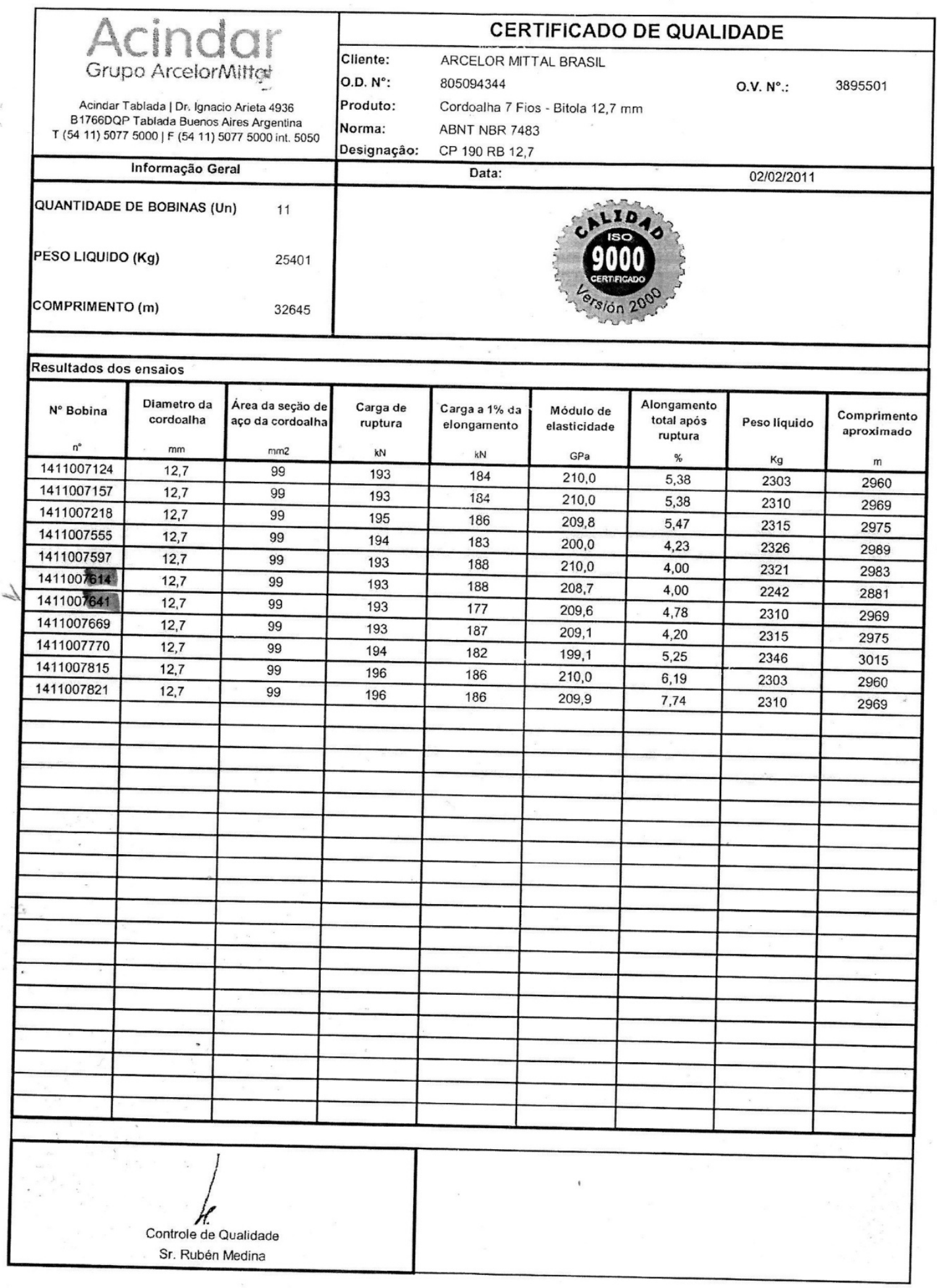

Figura APB6.4 - Relatório da armadura ativa fornecido pelo fabricante do modelo EM1. FOLHA 4/4. 
APB7 - Relatórios de ensaios da armadura ativa - EM2

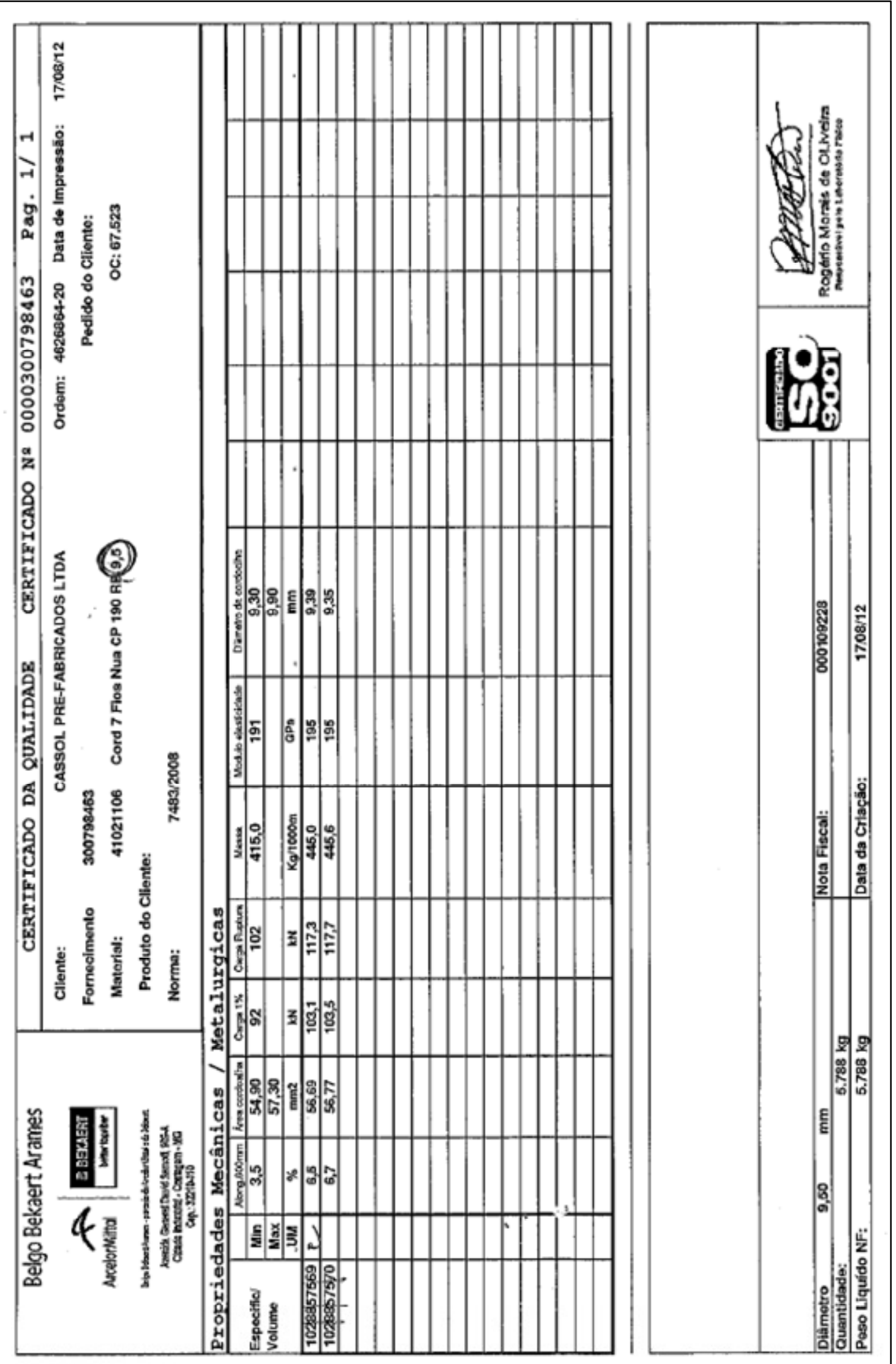

Figura APB7.1 - Relatório da armadura ativa fornecido pelo fabricante do modelo EM2. FOLHA 1/10. 


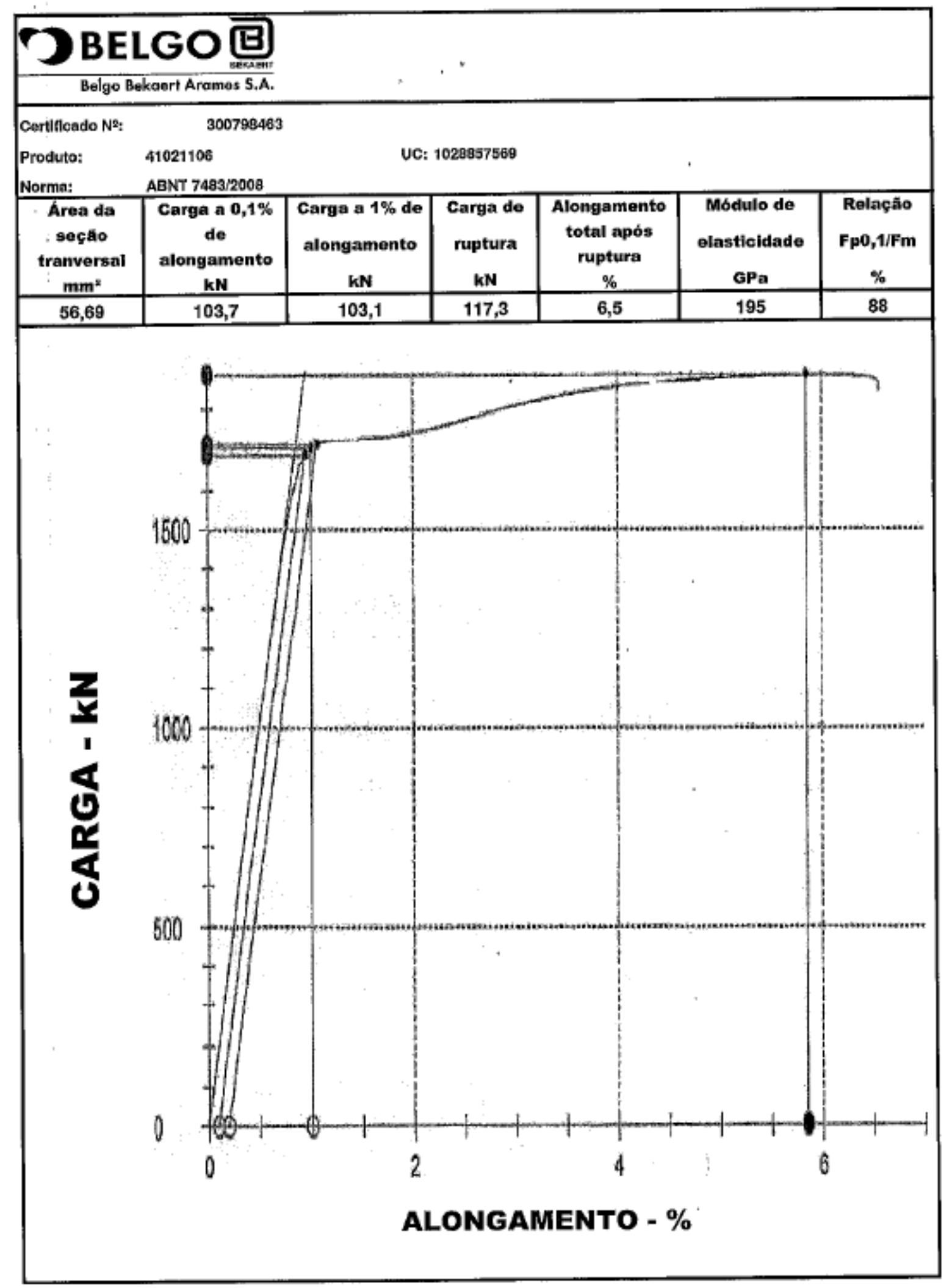

Figura APB7.2 - Relatório da armadura ativa fornecido pelo fabricante do modelo EM2. FOLHA 2/10. 


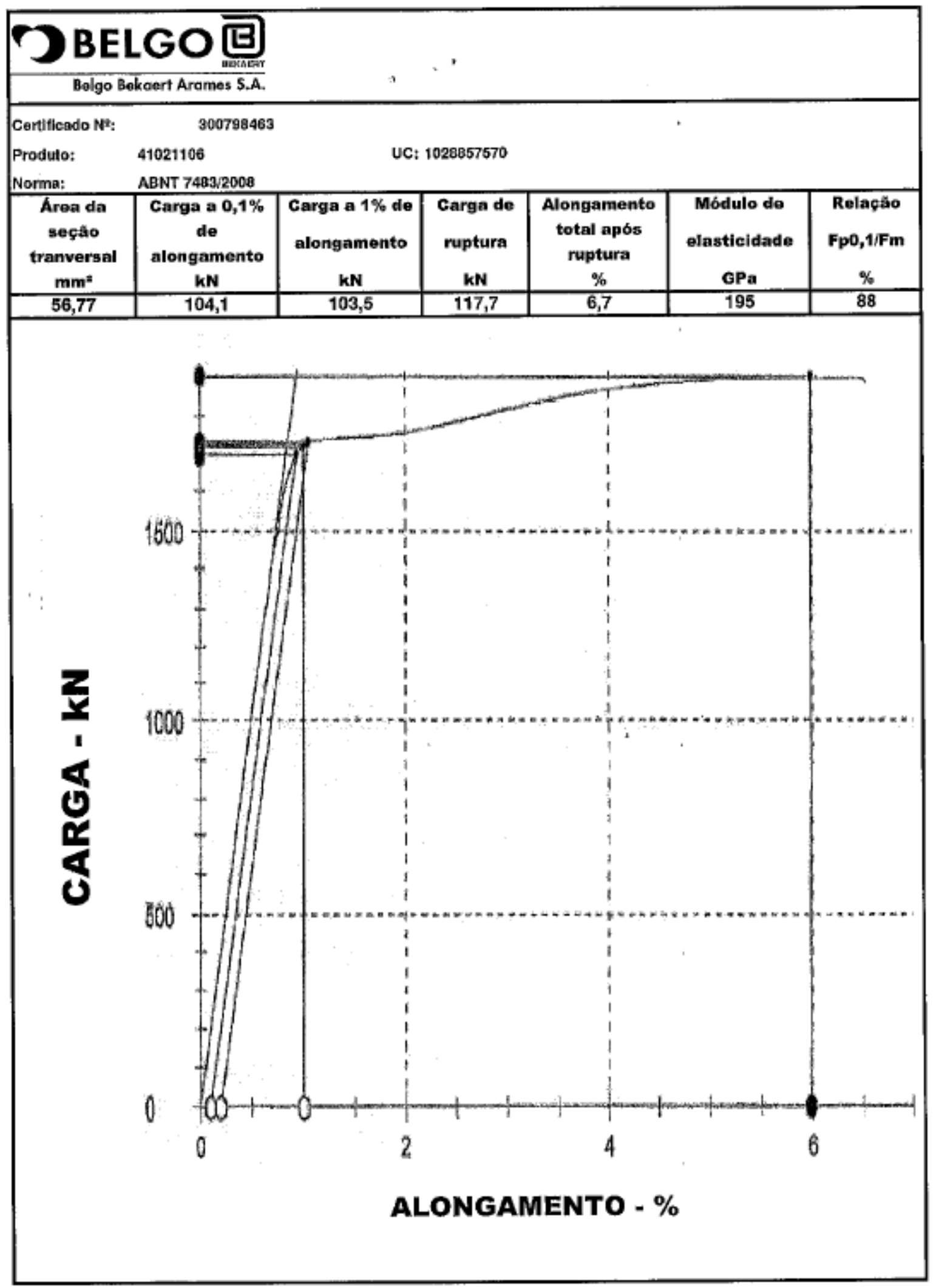

Figura APB7.3 - Relatório da armadura ativa fornecido pelo fabricante do modelo EM2. FOLHA 3/10. 
TIANJIN SHENGTE PRESTRESSED CONCRETE STEEL STRAND CO., LTD

\section{TEST REPORT OF MECHANICAL PROPERTIES}

NO. 29

ROLL NO. A0726-306-4

TEST DATE: 2011.7 .26

\begin{tabular}{|c|c|c|c|c|c|c|c|c|}
\hline Dia & Area & $\begin{array}{c}\text { Tensile } \\
\text { Strength }\end{array}$ & $\begin{array}{c}\text { Breaking } \\
\text { Load }\end{array}$ & Elongation & $\begin{array}{c}\text { Yeild } \\
\text { Strength }\end{array}$ & $\begin{array}{c}\text { Net } \\
\text { Weight }\end{array}$ & $\begin{array}{c}\text { Approximate } \\
\text { Length }\end{array}$ & $\begin{array}{c}\text { Modulus } \\
\text { of } \\
\text { Elasticity } \\
\mathbf{m m}\end{array}$ \\
$\mathbf{m m} \mathbf{2}$ & $\mathbf{M p a}$ & $\mathbf{K N}$ & $\%$ & $\mathbf{K N}$ & $\mathbf{K G}$ & $\mathbf{M}$ & $\mathbf{\text { Gpa }}$ \\
\hline 9.65 & 56.7 & 1950 & 110 & 4.5 & 105 & 2310 & 5190 & 194 \\
\hline
\end{tabular}

\section{STRESS-STRAIN CURVES}

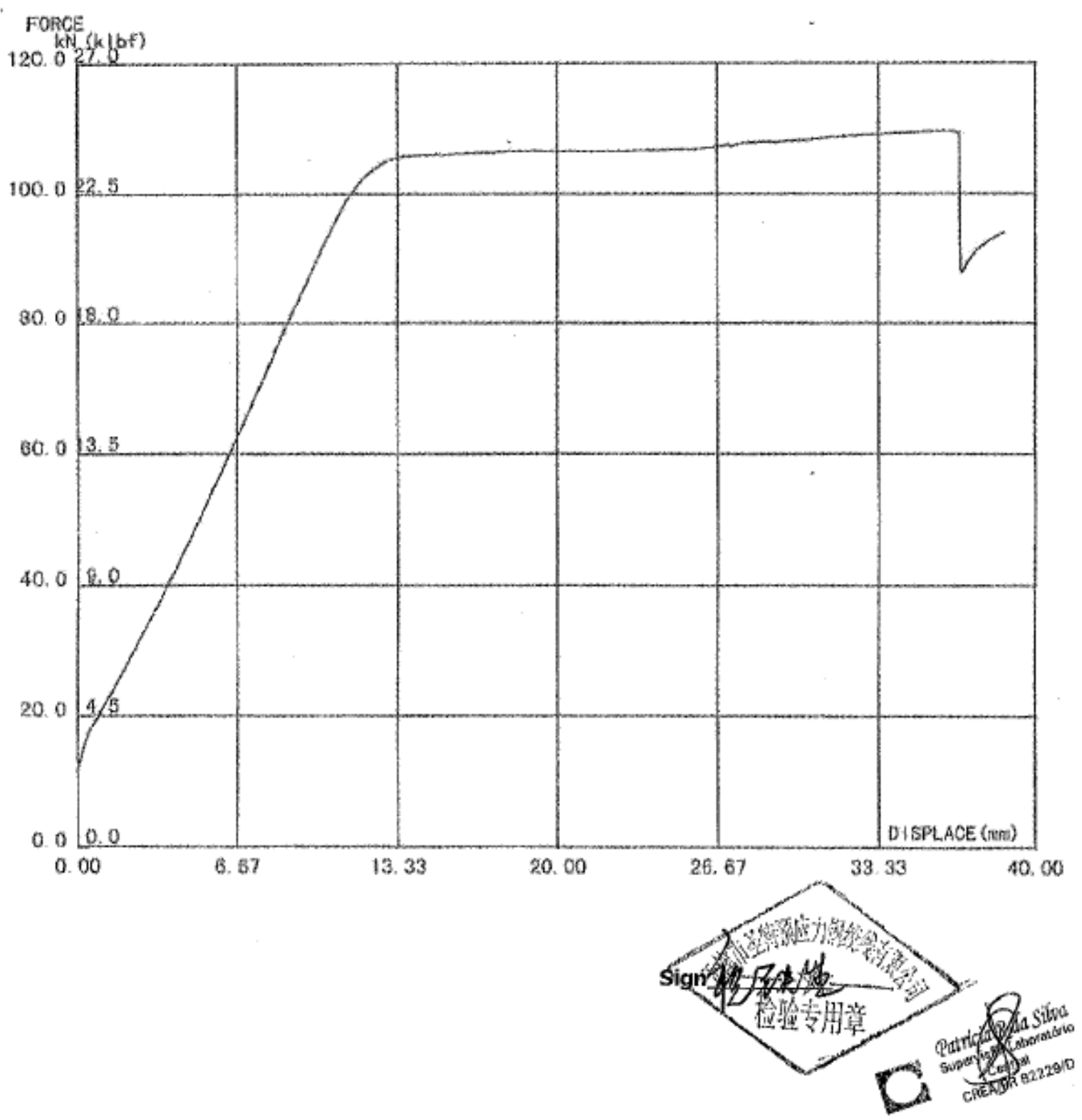

Figura APB7.4 - Relatório da armadura ativa fornecido pelo fabricante do modelo EM2. FOLHA 4/10. 
TIANJIN SHENGTE PRESTRESSED CONCRETE STEEL STRAND CO., LTD

\section{TEST REPORT OF MECHANICAL PROPERTIES}

NO. 32

\begin{tabular}{|c|c|c|c|c|c|c|c|c|}
\hline \multicolumn{3}{|c|}{$\begin{array}{l}\text { ROLL NO. A0727-308-1 } \\
\text { TEST DATE; } \quad 2011.7 .27\end{array}$} & \multicolumn{4}{|c|}{$\begin{array}{l}\text { SAMPLE NAME: PC STRAND } \\
\text { STANDARD; NBR 7483: } 2008\end{array}$} & \multicolumn{2}{|c|}{$\begin{array}{l}\text { SPEC:9.5MM } \\
\text { GRADE: } 1900 \mathrm{Mpa}\end{array}$} \\
\hline Dia & Area & $\begin{array}{c}\text { Tensile } \\
\text { Strength } \\
\text { Mpa }\end{array}$ & $\begin{array}{c}\text { Breaking } \\
\text { Load } \\
\text { KN }\end{array}$ & Elongation & $\begin{array}{c}\text { Yeild } \\
\text { Strength } \\
\text { KN }\end{array}$ & $\begin{array}{c}\text { Net } \\
\text { Weight } \\
\text { KG }\end{array}$ & $\begin{array}{c}\text { Approximate } \\
\text { Length } \\
\text { M }\end{array}$ & $\begin{array}{c}\text { Modulus } \\
\text { of } \\
\text { Elasticity } \\
\text { Gpa }\end{array}$ \\
\hline 9.71 & 57.1 & 1970 & 111 & 4.5 & 107 & 2873 & 6411 & 198 \\
\hline
\end{tabular}

\section{STRESS-STRAIN CURVES}

4 FORCE

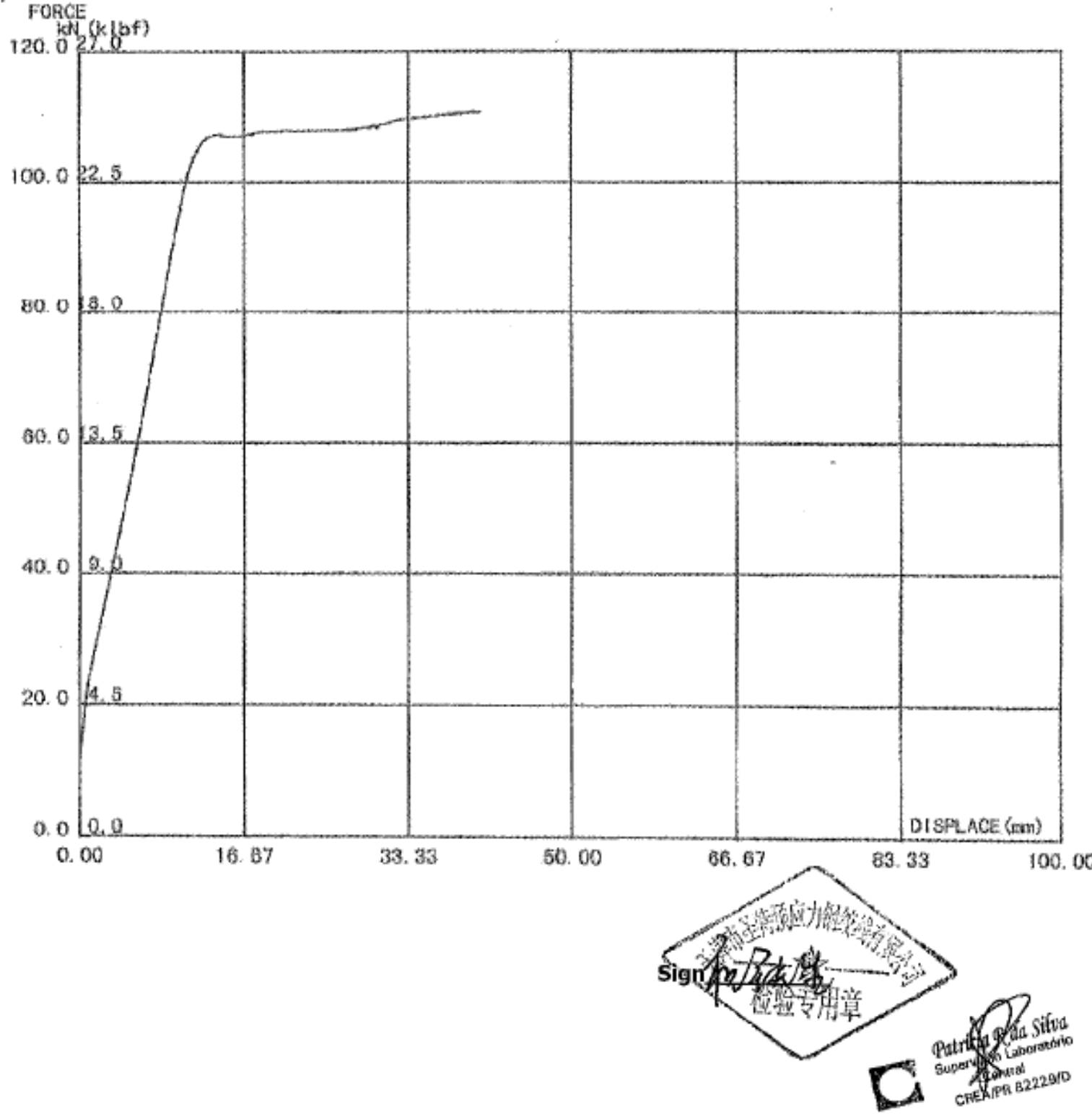

Figura APB7.5 - Relatório da armadura ativa fornecido pelo fabricante do modelo EM2. FOLHA 5/10. 


\section{TIANJIN SHENGTE PRESTRESSED CONCRETE STEEL STRAND CO., LTD TEST REPORT OF MECHANICAL PROPERTIES}

\begin{tabular}{|c|c|c|c|c|c|c|c|c|}
\hline \multicolumn{3}{|c|}{ ROLL NO. 1A0216-132-2 } & \multicolumn{3}{|c|}{$\begin{array}{l}\text { SAMPLE NAME: PC STRAND } \\
\text { STANDARD: NBR 7483:2008 }\end{array}$} & \multicolumn{3}{|r|}{ NO. 71} \\
\hline Dia & Area & $\begin{array}{c}\text { Tensile } \\
\text { Strength } \\
\text { Mpa }\end{array}$ & $\begin{array}{c}\text { Breaking } \\
\text { Load } \\
\text { KN }\end{array}$ & Elongation & $\begin{array}{c}\text { Yeild } \\
\text { Strength } \\
\text { KN }\end{array}$ & $\begin{array}{c}\begin{array}{c}\text { Net } \\
\text { Weight }\end{array} \\
\text { KG }\end{array}$ & $\begin{array}{c}\text { Approximate } \\
\text { Length } \\
\text { M }\end{array}$ & $\begin{array}{l}\text { Modulus } \\
\text { of } \\
\text { Elasticity } \\
\text { Gpa }\end{array}$ \\
\hline 12.96 & 101.88 & 1950 & 196 & 4.5 & 182 & 2225 & 2782 & 199 \\
\hline
\end{tabular}

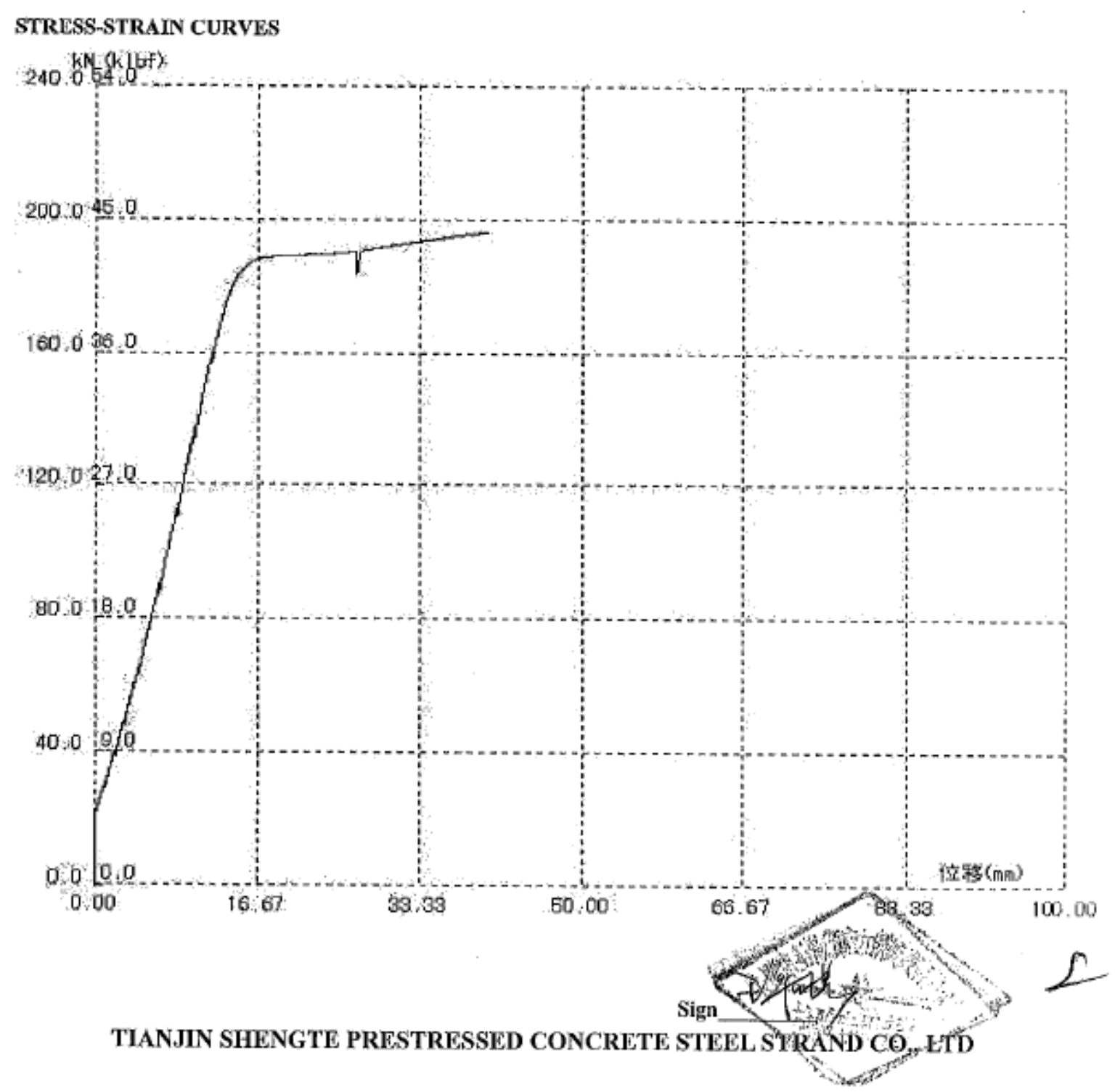

Figura APB7.6 - Relatório da armadura ativa fornecido pelo fabricante do modelo EM2. FOLHA 6/10. 


\section{TEST REPORT OF MECHANICAL PROPERTIES}

NO. 72

ROLL NO.1A0211-121-8
\begin{tabular}{|c|c|c|c|c|c|c|c|c|} 
TEST DATE: 2012.02 .11 & \multicolumn{2}{c}{ SAMPLE NAME: PC STRAND } & \multicolumn{2}{c}{ SPEC:12.7MM } \\
Sia & Area & $\begin{array}{c}\text { Tensile } \\
\text { Strength }\end{array}$ & $\begin{array}{c}\text { Breaking } \\
\text { Load }\end{array}$ & Elongation & $\begin{array}{c}\text { Yeild } \\
\text { Strength }\end{array}$ & $\begin{array}{c}\text { Net } \\
\text { Weight }\end{array}$ & $\begin{array}{c}\text { Approximate } \\
\text { Length }\end{array}$ & $\begin{array}{c}\text { Modulus } \\
\text { of } \\
\text { Elasticity } \\
\text { Gpa }\end{array}$ \\
\hline 12.92 & 101.37 & 1940 & 194 & 4.5 & 184 & 2143 & 2693 & 196 \\
\hline
\end{tabular}

\section{STRESS-STRAIN CURVES}

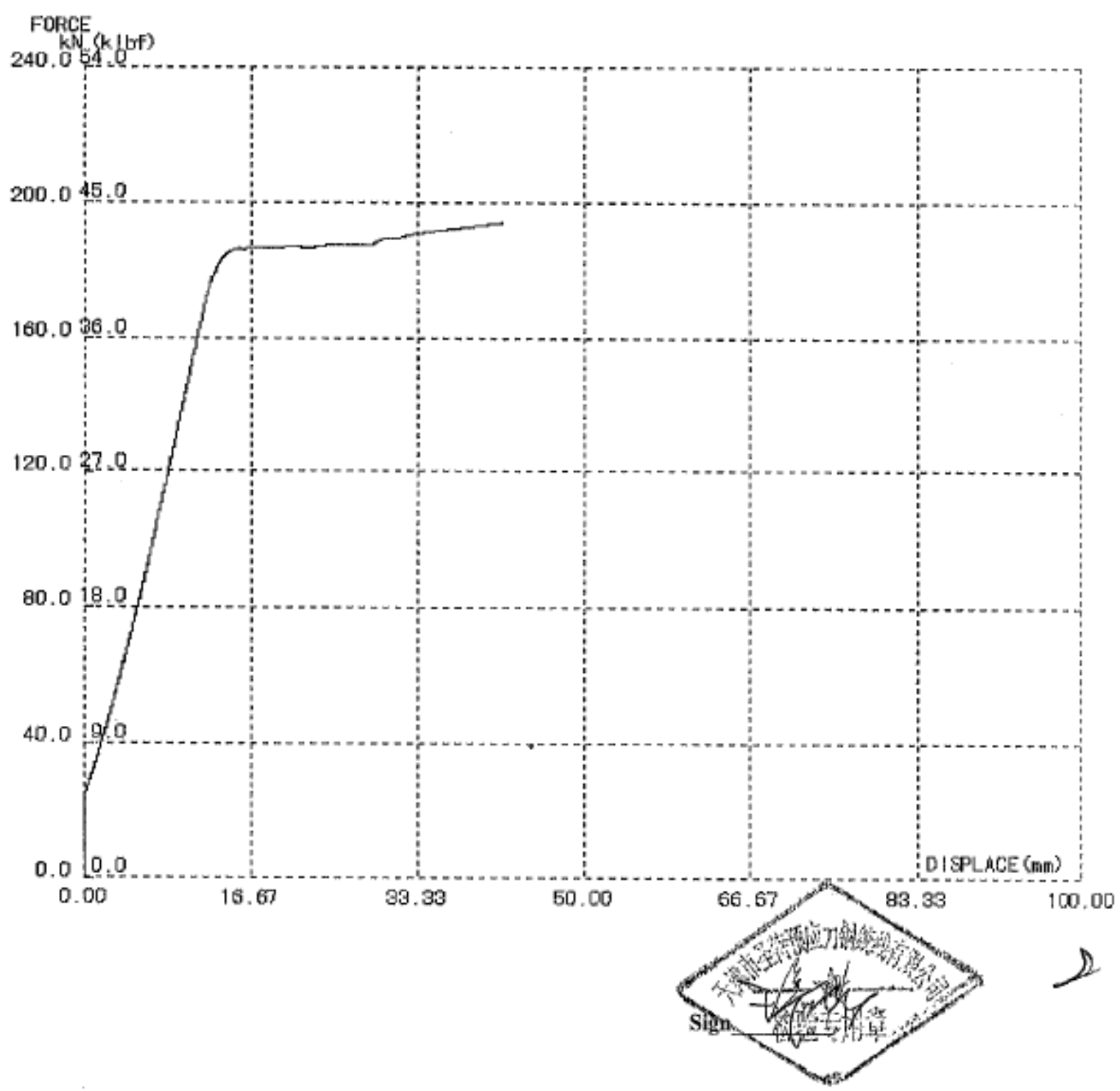

Figura APB7.7 - Relatório da armadura ativa fornecido pelo fabricante do modelo EM2. FOLHA 7/10. 


\section{TIANJIN SHENGTE PRESTRESSED CONCRETE STEEL STRAND CO., LTD}

\section{TEST REPORT OF MECHANICAL PROPERTIES}

NO. 73

ROLL NO. 1A0211-120-3

SAMPLE NAME: PC STRAND

SPEC: $12.7 \mathrm{MM}$

TEST DATE: 2012.02 .11

STANDARD: NBR 7483: 2008

\begin{tabular}{|c|c|c|c|c|c|c|c|c|}
\hline Dia & Area & $\begin{array}{c}\text { Tensile } \\
\text { Strength }\end{array}$ & $\begin{array}{c}\text { Breaking } \\
\text { Load }\end{array}$ & Elongation & $\begin{array}{c}\text { Yeild } \\
\text { Strength }\end{array}$ & $\begin{array}{c}\text { Net } \\
\text { Weight }\end{array}$ & $\begin{array}{c}\text { Approximate } \\
\text { Length }\end{array}$ & $\begin{array}{c}\text { Modulus } \\
\text { of } \\
\text { Elasticity } \\
\text { Gm }\end{array}$ \\
\hline $\mathbf{m m}$ & $\mathbf{M p a}$ & $\mathbf{K N}$ & $\%$ & $\mathbf{K N}$ & $\mathbf{K G}$ & $\mathbf{M}$ & \\
\hline 12.92 & 101.89 & 1940 & 195 & 4.5 & 184 & 2369 & 2962 & 194 \\
\hline
\end{tabular}

\section{STRESS-STRAIN CURVES}

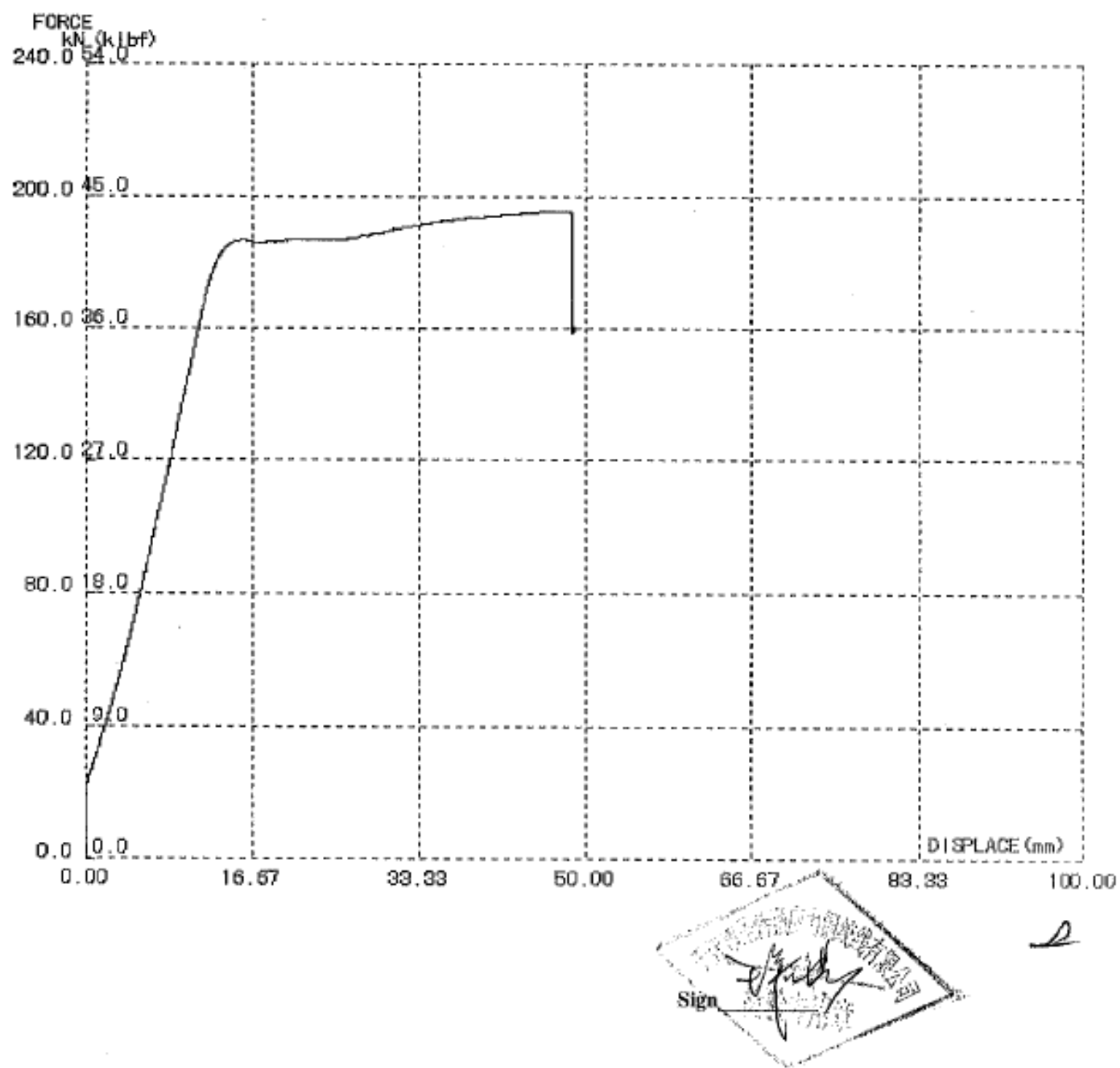

Figura APB7.8 - Relatório da armadura ativa fornecido pelo fabricante do modelo EM2. FOLHA 8/10. 
TIANJIN SHENGTE PRESTRESSED CONCRETE STEEL STRAND CO., LTD

TEST REPORT OF MECHANICAL PROPERTIES

NO. 74

ROLL NO. 1A0213-126-5

SAMPLE NAME: PC STRAND

SPEC:12.7MM

TEST DATE: 2012.02.13

STANDARD: NBR 7483: 2008

\begin{tabular}{|c|c|c|c|c|c|c|c|c|}
\hline Dia & Area & $\begin{array}{c}\text { Tensile } \\
\text { Strength }\end{array}$ & $\begin{array}{c}\text { Breaking } \\
\text { Load }\end{array}$ & Elongation & $\begin{array}{c}\text { Yeild } \\
\text { Strength }\end{array}$ & $\begin{array}{c}\text { Net } \\
\text { Weight }\end{array}$ & $\begin{array}{c}\text { Approximate } \\
\text { Length }\end{array}$ & $\begin{array}{c}\text { Modulus } \\
\text { of } \\
\text { Elasticity } \\
\text { Gpa }\end{array}$ \\
\hline 12.97 & 101.62 & 1940 & 195 & 4.5 & 182 & 2863 & 3589 & 203 \\
\hline
\end{tabular}

STRESS-STRAIN CURVES

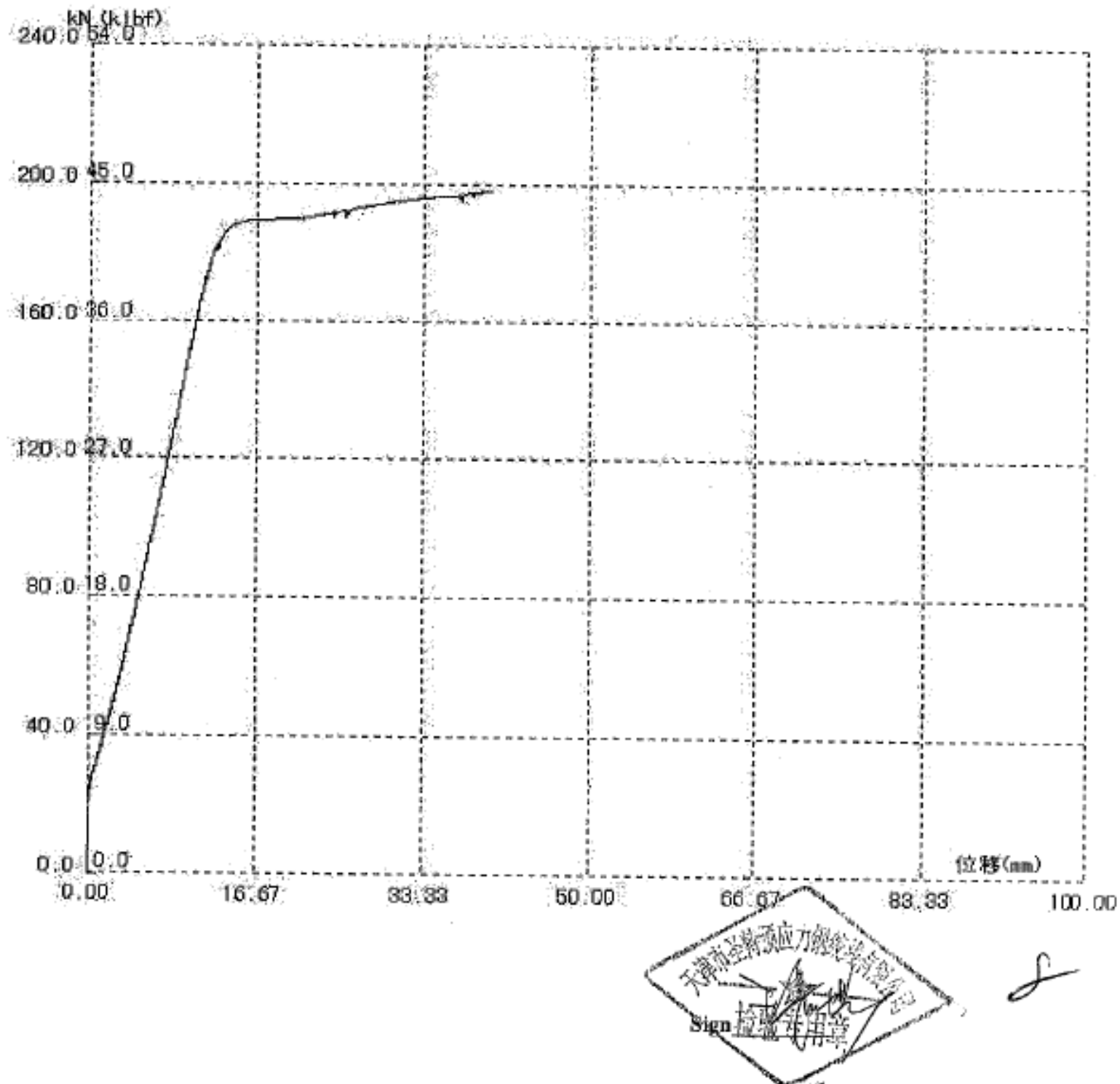

Figura APB7.9 - Relatório da armadura ativa fornecido pelo fabricante do modelo EM2. FOLHA 9/10. 
TIANJIN SHENGTE PRESTRESSED CONCRETE STEEL STRAND CO., LTD TEST REPORT OF MECHANICAL PROPERTIES

\begin{tabular}{|c|c|c|c|c|c|c|c|c|}
\hline \multicolumn{3}{|c|}{$\begin{array}{l}\text { ROLL NO. 1A0213-125-5 } \\
\text { TEST DATE: } \quad 2012.02 .13\end{array}$} & \multicolumn{3}{|c|}{$\begin{array}{l}\text { SAMPLE NAME: PC STRAND } \\
\text { STANDARD: NBR } 7483: 2008\end{array}$} & \multicolumn{3}{|c|}{$\begin{array}{l}\text { SPEC:12.7MM } \\
\text { GRADE:1900Mpa }\end{array}$} \\
\hline Dia & Area & $\begin{array}{c}\text { Tensile } \\
\text { Strength } \\
\\
\text { Mpa }\end{array}$ & $\begin{array}{c}\text { Breaking } \\
\text { Load } \\
\text { KN }\end{array}$ & Elongation & $\begin{array}{c}\text { Yelld } \\
\text { Strength } \\
\text { KN }\end{array}$ & $\begin{array}{c}\text { Net } \\
\text { Weight }\end{array}$ & $\begin{array}{c}\text { Approximate } \\
\text { Length } \\
\text { M }\end{array}$ & $\begin{array}{c}\text { Modulus } \\
\text { of } \\
\text { Elasticity } \\
\text { Gpa }\end{array}$ \\
\hline 12.95 & 101.92 & 1950 & 195 & 4.5 & 181 & 2609 & 3261 & 195 \\
\hline
\end{tabular}

STRESS-STRAIN CURVES

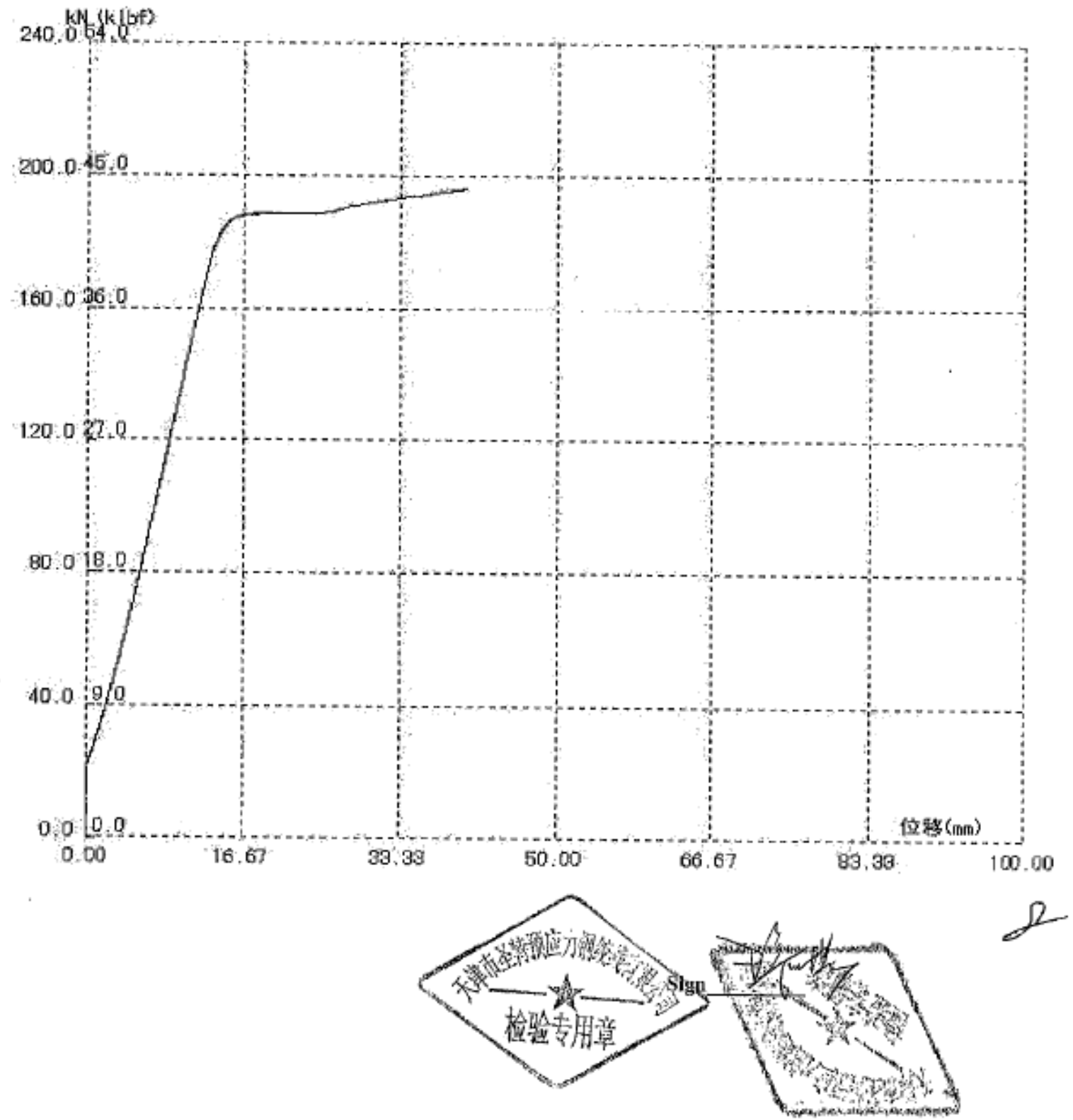

Figura APB7.10 - Relatório da armadura ativa fornecido pelo fabricante do modelo EM2. FOLHA 10/10. 
APB8 - Relatórios de ensaios da armadura ativa - EM3

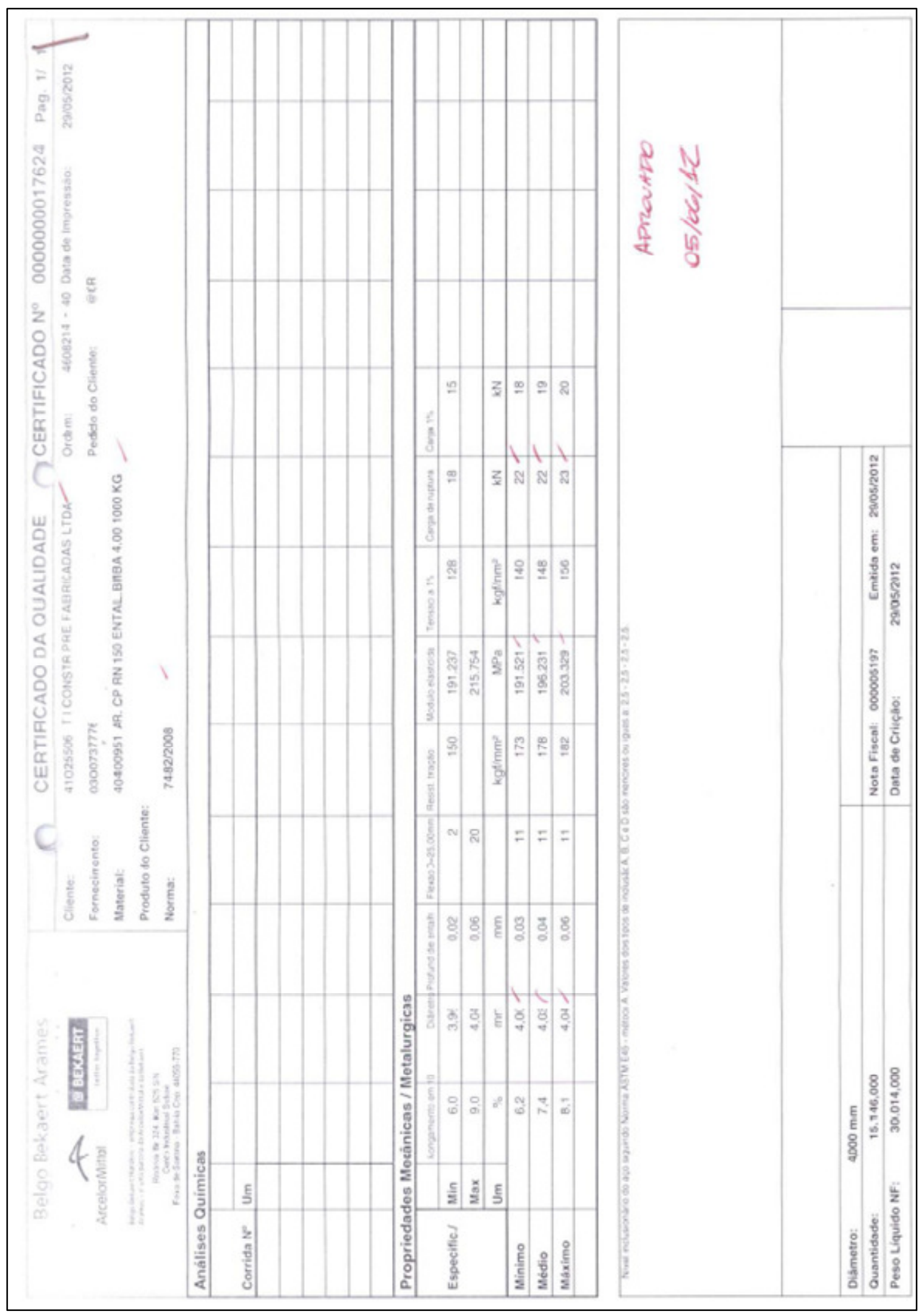

Figura APB8.1 - Relatório da armadura ativa fornecido pelo fabricante do modelo EM3. FOLHA 1/6. 

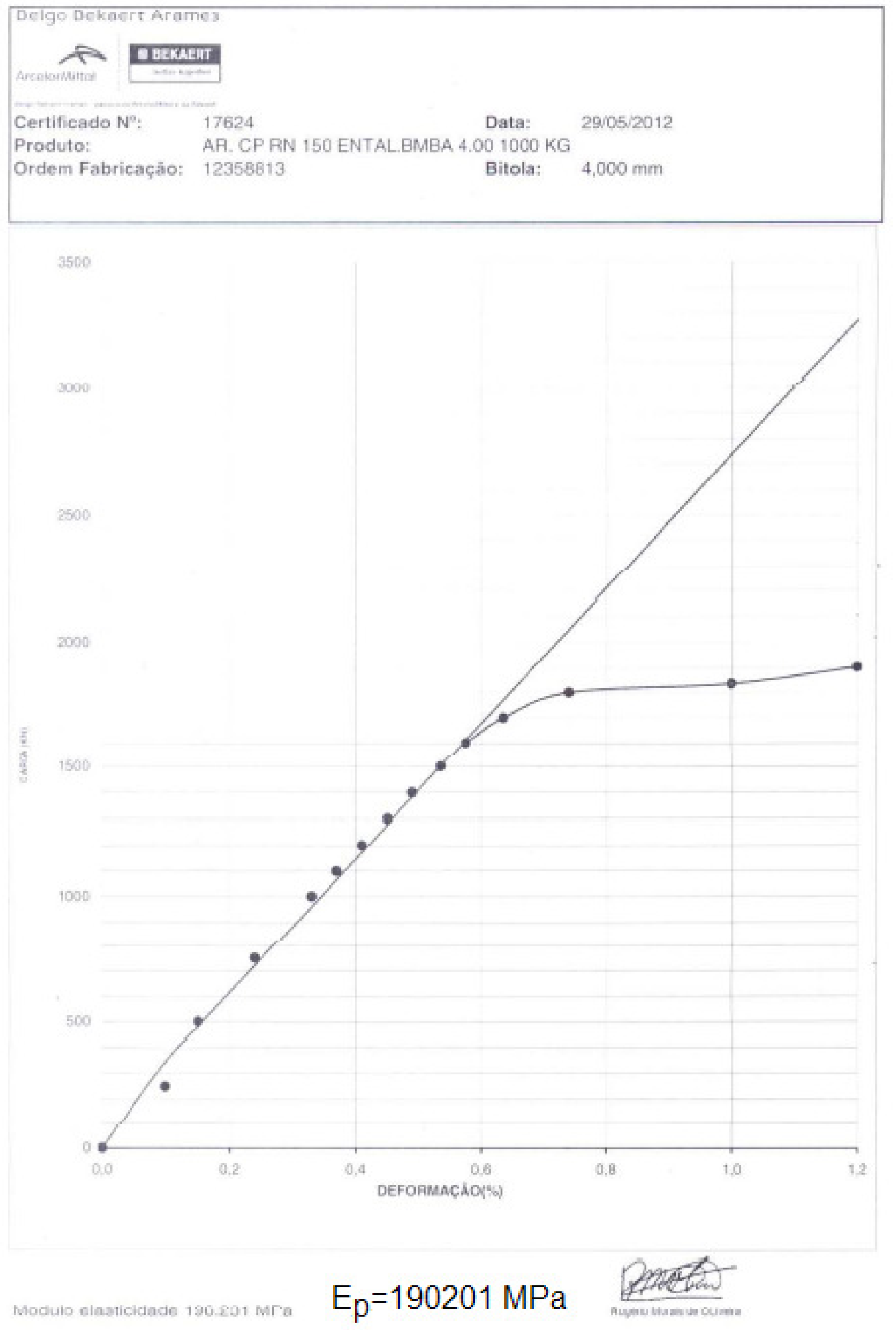

Figura APB8.2 - Relatório da armadura ativa fornecido pelo fabricante do modelo EM3. FOLHA 2/6. 


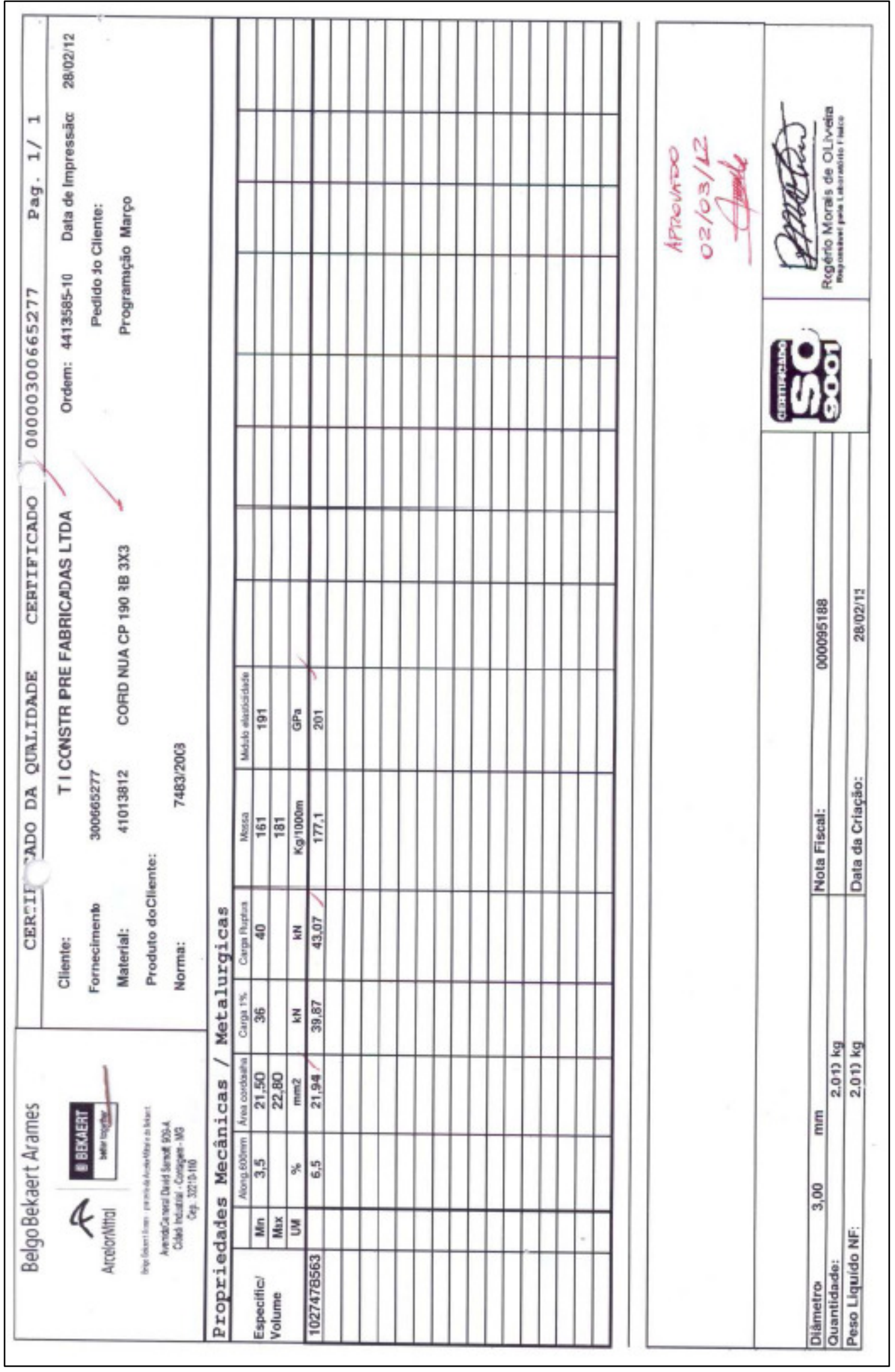

Figura APB8.3 - Relatório da armadura ativa fornecido pelo fabricante do modelo EM3. FOLHA 3/6. 


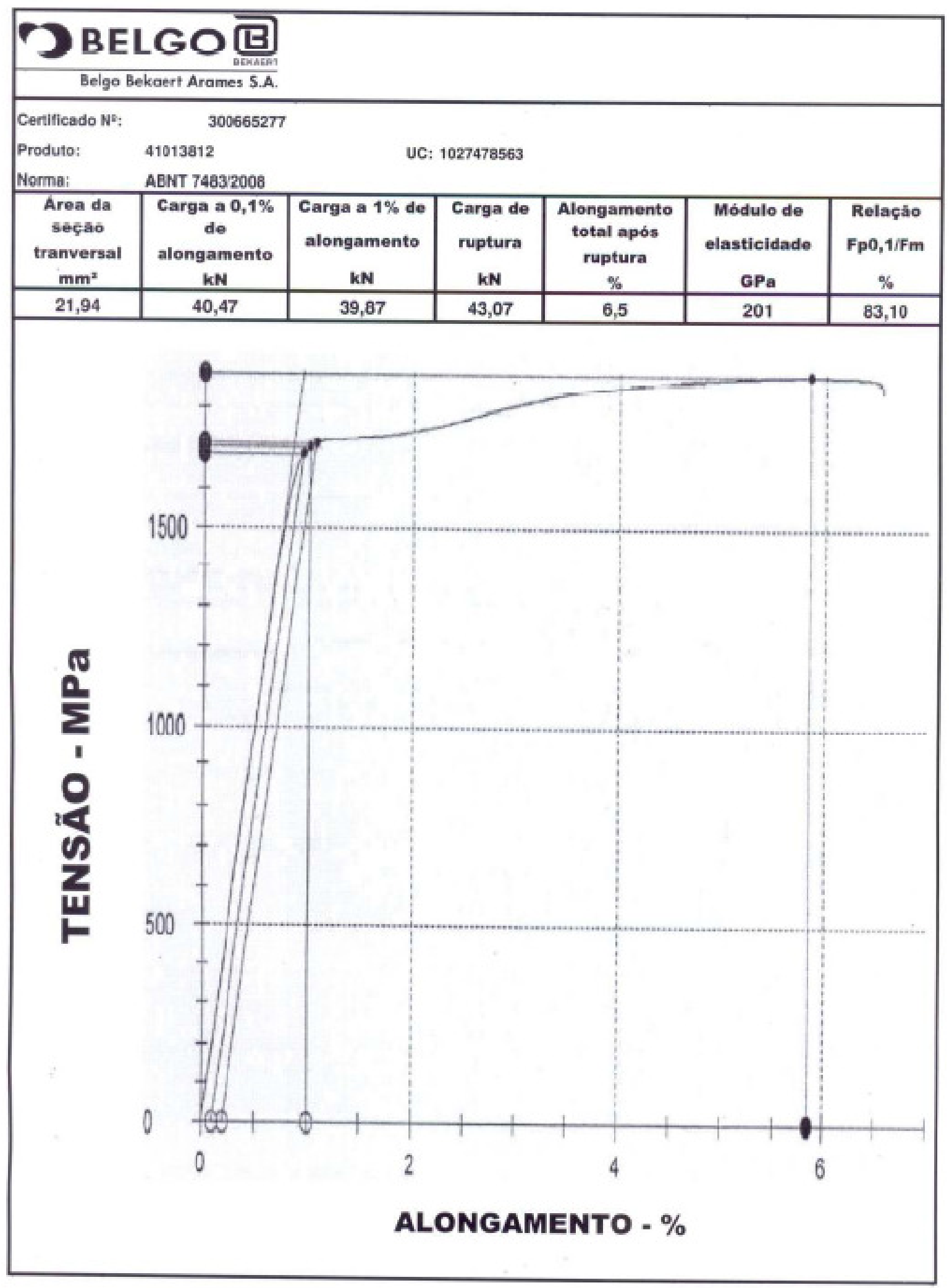

Figura APB8.4 - Relatório da armadura ativa fornecido pelo fabricante do modelo EM3. FOLHA 4/6. 


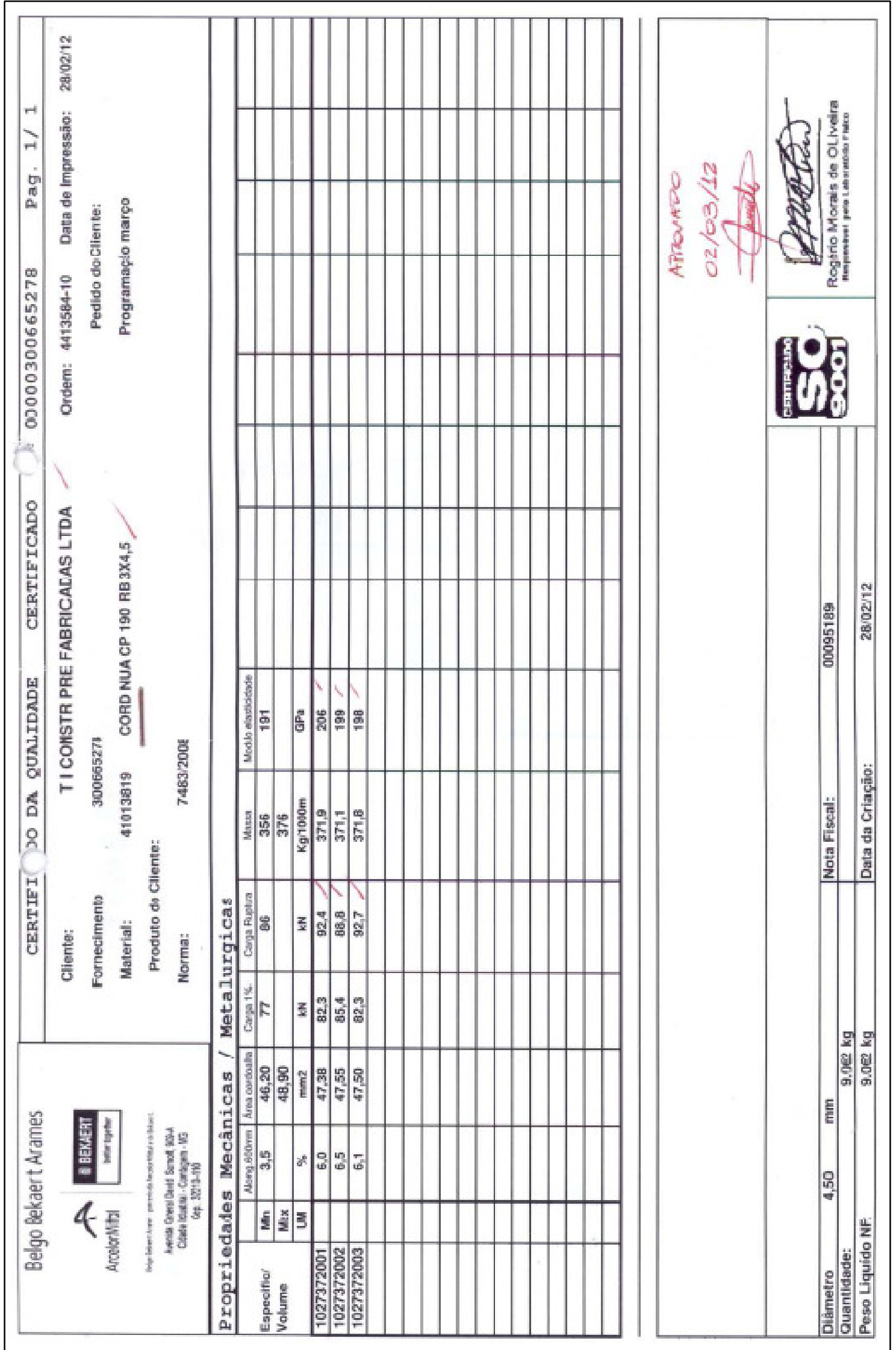

Figura APB8.5 - Relatório da armadura ativa fornecido pelo fabricante do modelo EM3. FOLHA 5/6. 


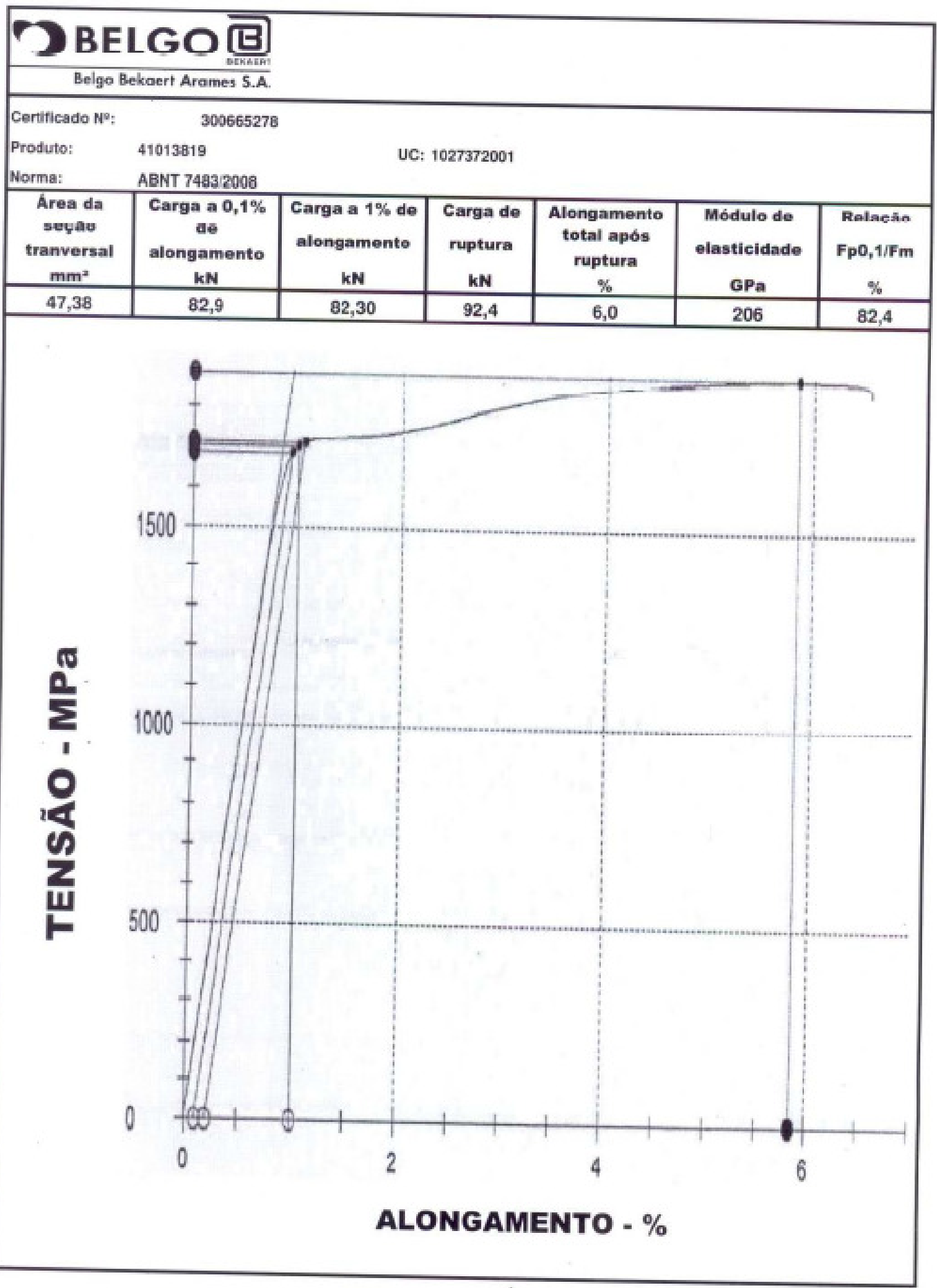

Figura APB8.6 - Relatório da armadura ativa fornecido pelo fabricante do modelo EM3. FOLHA 6/6. 


\section{APÊNDICE C}

\section{APC1 - Instrumentação das armaduras passivas}

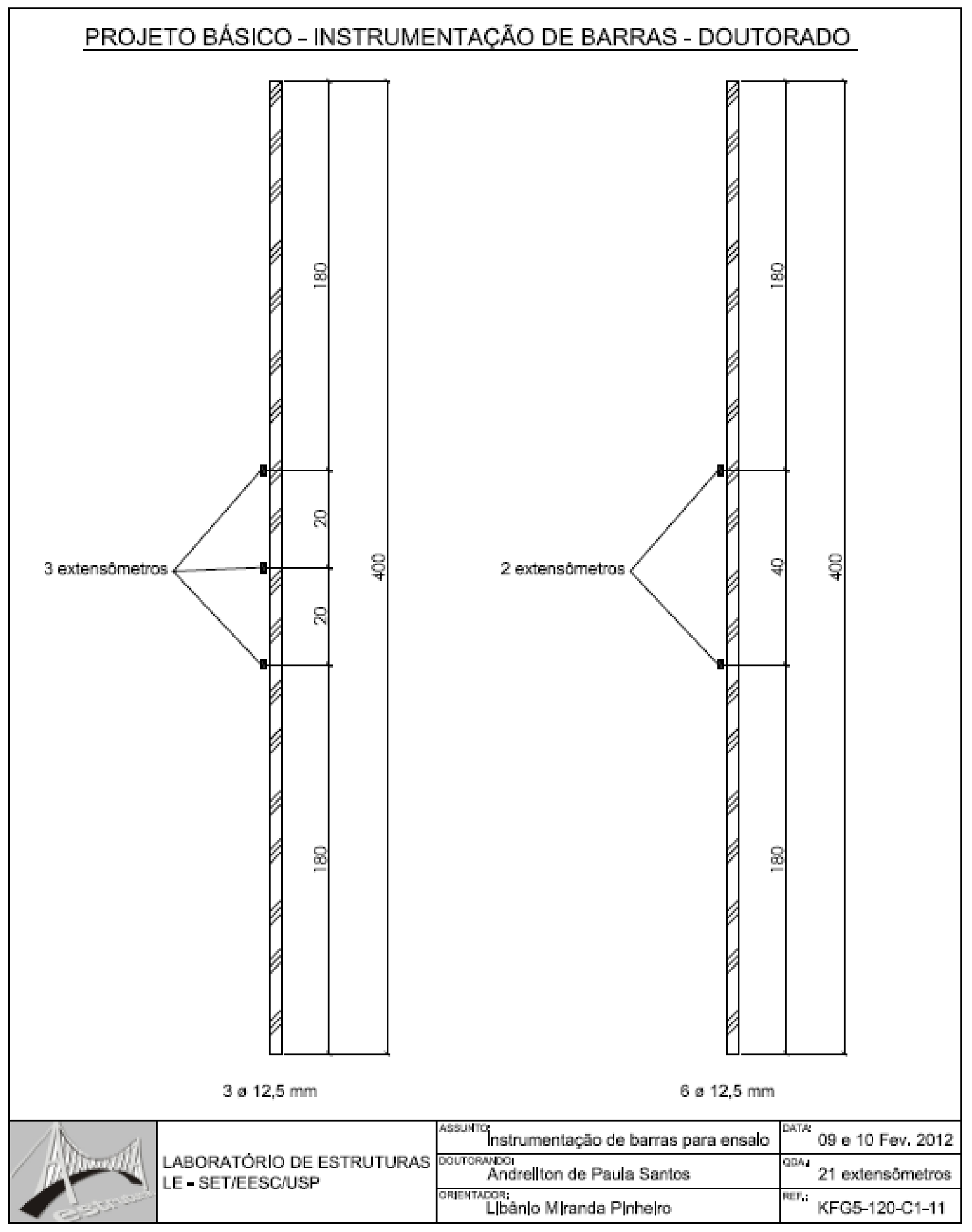

Figura APC1.1 - Projeto para colocação dos extensômetros elétricos de resistência nas armaduras passivas. 
TITYWA

TYPE KFG-5-120-C1-11

\begin{tabular}{|c|c|c|c|c|}
\hline \multicolumn{2}{|l|}{$\begin{array}{l}\text { GAGE FACTOR } \\
\left(24^{\circ} \mathrm{C}, 50 \% \mathrm{RH}\right)\end{array}$} & \multirow{2}{*}{$\begin{array}{l}\text { LOT No. Y3522S } \\
\text { TEMPERATURE COEFFIIENT } \\
\text { OF GAGE FACTOR }\end{array}$} & BATCH & \multirow[t]{2}{*}{ R04 } \\
\hline GAGE LENGTH & & & $+0.008 \% /{ }^{\circ} \mathrm{C}$ & \\
\hline GAGE RESISTANCE $\left(24^{\circ} \mathrm{C}, 50 \%\right.$ RH & $119.8 \pm 0.2 \Omega$ & APPLICABLE GAGE CEMENT & $C C-33 \mathrm{~A}, \quad \mathrm{PC}-6$ & \\
\hline ADOPTABLE THERMAL EXPANSI & $11.7 \mathrm{PPM} /{ }^{\circ} \mathrm{C}$ & QUANTITY & 10 & \\
\hline
\end{tabular}

\section{KYOWA UAMHA GAGES}

共和ひずみゲージのお取扱いは面をご覧ください。

See the back of package for installation of Kyowa strain gages.

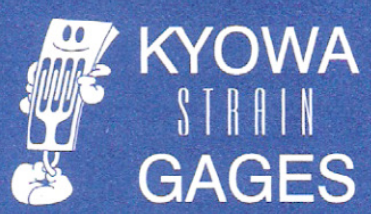

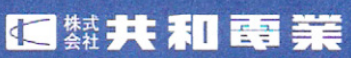

テ182-8520 東京都甿布市調布ヶ丘3-5-1

TEL : 042-488-1111(大代) FAX : 042-481-3258

URL: http://www.kyowa-ei.co.jp
LIRTOWA

KYOWA ELECTRONIC INSTRUMENTS CO., LTD.

3-5-1, Chofugaoka, Chofu, Tokyo. 182-8520, Japan

Phone : $+81-42-488-1111$ Fax : $+81-42-481-3258$

URL: http://www.kyowa-ei.com

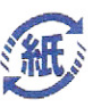

表紙,台紙

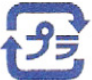

外袋: PP ゲージ保護シート：PET 接着用フィルム : PE

Figura APC1.2 - Especificações técnicas dos extensômetros usados neste trabalho. 


\section{ANEXO A}

\section{A1 - Cálculo de armadura longitudinal (flexão simples)}

Tabela A1.1 - Valores para cálculo de armadura longitudinal de seções retangulares. CARVALHO (2012).

\begin{tabular}{||c|c|c|c|c||}
\hline KMD & KX & KZ & $\boldsymbol{\varepsilon}_{\mathbf{c}}$ & $\boldsymbol{\varepsilon}_{\mathbf{s}}$ \\
\hline 0,0100 & 0,0148 & 0,9941 & 0,1502 & 10,000 \\
0,0200 & 0,0298 & 0,9881 & 0,3068 & 10,000 \\
0,0300 & 0,0449 & 0,9820 & 0,4704 & 10,000 \\
0,0400 & 0,0603 & 0,9759 & 0,6414 & 10,000 \\
0,0500 & 0,0758 & 0,9697 & 0,8205 & 10,000 \\
\hline 0,0550 & 0,0836 & 0,9665 & 0,9133 & 10,000 \\
0,0600 & 0,0916 & 0,9634 & 1,0083 & 10,000 \\
0,0650 & 0,0995 & 0,9602 & 1,1056 & 10,000 \\
0,0700 & 0,1076 & 0,9570 & 1,2054 & 10,000 \\
0,0750 & 0,1156 & 0,9537 & 1,3077 & 10,000 \\
\hline 0,0800 & 0,1238 & 0,9505 & 1,4126 & 10,000 \\
0,0850 & 0,1320 & 0,9472 & 1,5203 & 10,000 \\
0,0900 & 0,1403 & 0,9439 & 1,6308 & 10,000 \\
0,0950 & 0,1485 & 0,9406 & 1,7444 & 10,000 \\
0,1000 & 0,1569 & 0,9372 & 1,8611 & 10,000 \\
\hline 0,1050 & 0,1654 & 0,9339 & 1,9810 & 10,000 \\
0,1100 & 0,1739 & 0,9305 & 2,1044 & 10,000 \\
0,1150 & 0,1824 & 0,9270 & 2,2314 & 10,000 \\
0,1200 & 0,1911 & 0,9236 & 2,3621 & 10,000 \\
0,1250 & 0,1998 & 0,9201 & 2,4967 & 10,000 \\
\hline 0,1300 & 0,2086 & 0,9166 & 2,6355 & 10,000 \\
0,1350 & 0,2175 & 0,9130 & 2,7786 & 10,000 \\
0,1400 & 0,2264 & 0,9094 & 2,9263 & 10,000 \\
0,1450 & 0,2354 & 0,9058 & 3,0787 & 10,000 \\
0,1500 & 0,2445 & 0,9022 & 3,2363 & 10,000 \\
\hline 0,1550 & 0,2536 & 0,8985 & 3,3391 & 10,000 \\
0,1600 & 0,2630 & 0,8948 & 3,5000 & 9,8104 \\
0,1650 & 0,2723 & 0,8911 & 3,5000 & 9,3531 \\
0,1700 & 0,2818 & 0,8873 & 3,5000 & 8,9222 \\
0,1750 & 0,2913 & 0,8835 & 3,5000 & 8,5154 \\
\hline 0.1800 & 0.3009 & 0,8796 & 3.5000 & 8.3106 \\
0,1850 & 0,3106 & 0,8757 & 3,5000 & 7,7662 \\
0,1900 & 0,3205 & 0,8718 & 3,5000 & 7,4204 \\
0,1950 & 0,3305 & 0,8678 & 3,5000 & 7,0919 \\
0,2000 & 0,3405 & 0,8638 & 3,5000 & 6,7793 \\
\hline \hline
\end{tabular}

\begin{tabular}{||c|c|c|c|c||}
\hline KMD & $\mathbf{K X}$ & $\mathbf{K Z}$ & $\boldsymbol{\varepsilon}_{\mathbf{c}}$ & $\boldsymbol{\varepsilon}_{\mathbf{s}}$ \\
\hline 0,2050 & 0,3506 & 0,8597 & 3,5000 & 6,4814 \\
0,2100 & 0,3609 & 0,8556 & 3,5000 & 6,1971 \\
0,2150 & 0,3714 & 0,8515 & 3,5000 & 5,9255 \\
0,2200 & 0,3819 & 0,8473 & 3,5000 & 5,6658 \\
0,2250 & 0,3925 & 0,8430 & 3,5000 & 5,4170 \\
\hline 0,2300 & 0,4033 & 0,8387 & 3,5000 & 5,1785 \\
0,2350 & 0,4143 & 0,8343 & 3,5000 & 4,9496 \\
0,2400 & 0,4253 & 0,8299 & 3,5000 & 4,7297 \\
0,2450 & 0,4365 & 0,8254 & 3,5000 & 4,5181 \\
0,2500 & 0,4479 & 0,8208 & 3,5000 & 4,3144 \\
\hline 0,2550 & 0,4594 & 0,8162 & 3,5000 & 4,1181 \\
0,2600 & 0,4711 & 0,8115 & 3,5000 & 3,9287 \\
0,2650 & 0,4830 & 0,8068 & 3,5000 & 3,7459 \\
0,2700 & 0,4951 & 0,8020 & 3,5000 & 3,5691 \\
0,2750 & 0,5074 & 0,7970 & 3,5000 & 3,3981 \\
\hline 0,2800 & 0,5199 & 0,7921 & 3,5000 & 3,2324 \\
0,2850 & 0,5326 & 0,7870 & 3,5000 & 3,0719 \\
0,2900 & 0,5455 & 0,7818 & 3,5000 & 2,9162 \\
0,2950 & 0,5586 & 0,7765 & 3,5000 & 2,7649 \\
0,3000 & 0,5721 & 0,7712 & 3,5000 & 2,6179 \\
\hline 0,3050 & 0,5858 & 0,7657 & 3,5000 & 2,4748 \\
0,3100 & 0,5998 & 0,7601 & 3,5000 & 2,3355 \\
0,3150 & 0,6141 & 0,7544 & 3,5000 & 2,1997 \\
0,3200 & 0,6287 & 0,7485 & 3,5000 & 2,0672 \\
0,3300 & 0,6590 & 0,7364 & 3,5000 & 1,8100 \\
\hline 0,3400 & 0,6910 & 0,7236 & 3,5000 & 1,5652 \\
0,3500 & 0,7249 & 0,7100 & 3,5000 & 1,3283 \\
0,3600 & 0,7612 & 0,6955 & 3,5000 & 1,0983 \\
0,3700 & 0,8003 & 0,6799 & 3,5000 & 0,8732 \\
0,3800 & 0,8433 & 0,6627 & 3,5000 & 0,6506 \\
\hline \hline
\end{tabular}


Tabela A1.2 - Equacionamento para cálculo de armadura longitudinal de seções retangulares. CARVALHO (2012).

\begin{tabular}{|c|c|c|}
\hline Variável & Equação & Comentários \\
\hline KMD & $K M D=\frac{M_{d}}{b \cdot d^{2} \cdot f_{c d}}$ & Equação de KMD \\
\hline KX & $K X=\frac{x}{d}$ & Equação de KX \\
\hline $\begin{array}{l}\text { KMD e } \\
\text { KX }\end{array}$ & $K M D=0,68 \cdot K X-0,272 K X^{2}$ & $\begin{array}{c}\text { Equação que relaciona } \\
\text { KMD e KX }\end{array}$ \\
\hline $\mathrm{KZ}$ & $K Z=\frac{z}{d}$ & Equação de KZ \\
\hline $\mathrm{KZ}$ e $\mathrm{KX}$ & $\mathrm{KZ}=1-0,4 . \mathrm{KX}$ & $\begin{array}{c}\text { Equação que relaciona } \\
\text { KX e KZ }\end{array}$ \\
\hline$A_{p}$ & $A_{p}=\frac{M_{d}}{K Z \cdot d \cdot \sigma_{p d}}$ & $\begin{array}{l}\text { Equação para o cálculo da } \\
\text { armadura ativa }\end{array}$ \\
\hline $\begin{array}{c}\mathrm{KX}, \varepsilon_{\mathrm{c}} \mathrm{e} \\
\varepsilon_{\mathrm{s}}\end{array}$ & $K X=\frac{\varepsilon_{c}}{\varepsilon_{c}+\varepsilon_{s}}$ & $\begin{array}{l}\text { Equação que relaciona } \\
K X, \varepsilon_{\mathrm{c}} \text { e } \varepsilon_{\mathrm{s}}\end{array}$ \\
\hline
\end{tabular}

Legenda:

- $\mathrm{M}_{\mathrm{d}}=$ momento de cálculo atuante na seção;

- b = largura da seção transversal;

- d = altura útil da seção;

- $\mathrm{f}_{\mathrm{cd}}=$ valor de cálculo da resistência do concreto à compressão;

- $\mathrm{x}=$ posição da linha neutra;

- $\mathrm{z}=$ braço de alavanca entre as forças que atuam na seção;

- $\mathrm{A}_{\mathrm{p}}=$ área da armadura de protensão;

- $\sigma_{\mathrm{pd}}=$ valor da tensão de protensão;

- $\varepsilon_{\mathrm{c}}=$ deformação no concreto;

- $\varepsilon_{\mathrm{s}}=$ deformação no aço. 


\section{A2 - Cálculo do momento resistente e da armadura}

O dimensionamento da armadura longitudinal de uma seção qualquer consiste em um processo iterativo, no qual, variando a posição da linha neutra ao longo da seção, determina-se o momento resistente $\left(M_{R}\right)$, e caso este seja maior ou igual ao momento de cálculo $\left(M_{d}\right)$, tem-se a solução da posição da linha neutra. Conhecida a posição da linha neutra e a força resultante de compressão, determina-se a área de aço da armadura de protensão $\left(A_{p}\right)$.

O cálculo de armadura $A_{p}$ de uma seção qualquer pode ser feito por iterações. $O$ procedimento é feito fazendo a divisão da seção transversal em elementos com pequenos valores de altura, que serão chamadas de tiras. Um exemplo de seção desse tipo é dado na Figura A2.1, e sua discretização é indicada na Figura A2.2.

No passo posterior os trechos são transformados em retângulos.

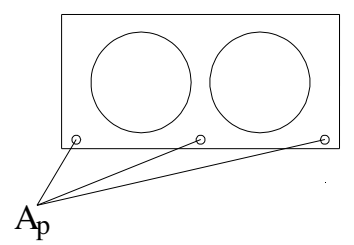

FiguraA2.1 - Seção com geometria qualquer e armadura $A_{p}$.
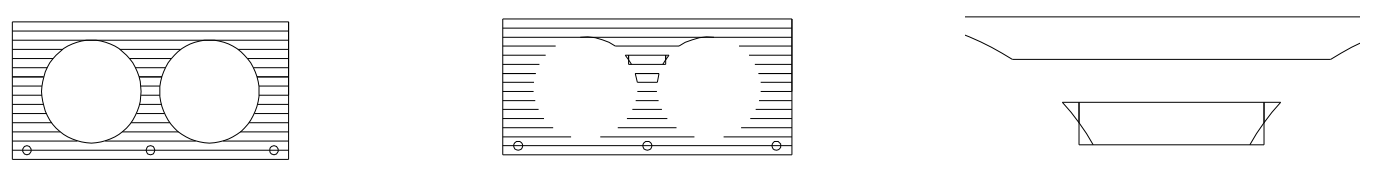

Figura A2.2 - Seção divida em tiras e pedaço da tira transformado em retângulo.

(Fonte: CARVALHO, 2010).

Depois disso é possível considerar diversas posições de linha neutra, como as indicadas na Figura A2.3.

Para cada posição da linha neutra x, calculada para cada tira comprimida (retângulo), determina-se o valor de deformação do concreto $\varepsilon_{c i}$ na altura média, e através deste calculam-se a correspondente tensão $\sigma_{c i}$ e a força $F_{c i}$ relativa a essa tira (expressão A2.1).

$$
F_{c i}=b_{w, i} \cdot h_{i} \cdot \sigma_{c i}
$$



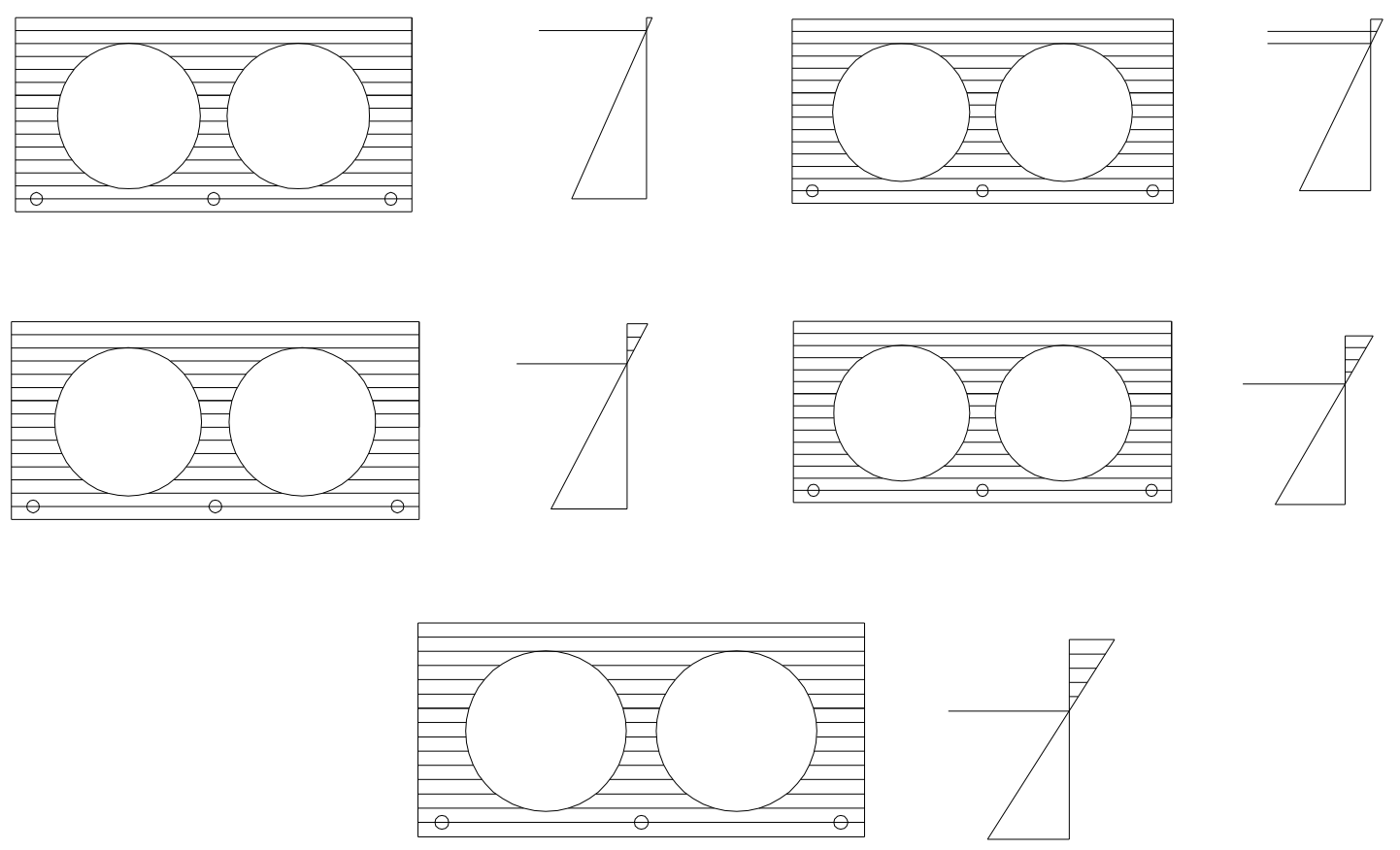

FiguraA2.3 - Posições da linha neutra para a seção adotada.

(Fonte: CARVALHO, 2010).

O valor de $\sigma_{c i}$ é obtido de forma condicional. Para isso, inicialmente fixa-se o valor de $\varepsilon_{s i}=0,01$ e calcula-se $\varepsilon_{c i}$ (expressão A2.2). Se $\varepsilon_{c i} \leq 0,002$, calcula-se $\sigma_{c i}$ (expressão A2.4); se $\varepsilon_{c i}>0,002$, a tensão $\sigma_{c i}$ é calculada conforme a expressão A2.7. Até essa situação a seção trabalha em um dos domínios 2 a ou 2 b. Se $\varepsilon_{c i}>0,0035$ tem se a seção no domínio 3 e, neste caso, fixa-se $\varepsilon_{c i}=0,0035$ e calcula-se $\sigma_{c i}$ (expressão A2.10), ou seja, a tensão no concreto se mantém constante. Por último pode-se ter $\varepsilon_{s i}<\varepsilon_{s, \text { lim }}$, sendo $\varepsilon_{s, \text { lim }}$ calculado com a expressão A2.14. Essa situação corresponde ao domínio 4. Em seguida são indicadas as deformações e as tensões no concreto para cada domínio (Expressões A2.2 a A2.14).

- Domínio 2a:

$$
\begin{aligned}
& \mathcal{E}_{c i}=-\frac{\mathcal{E}_{s} \times x}{(x-d)} \rightarrow 0 \leq \varepsilon_{c} \leq 0,002 \\
& \mathcal{E}_{s}=0,01 \\
& \sigma_{c i}=0,85 \cdot f_{c d} \cdot\left[1-\left(1-\frac{\varepsilon_{c i}}{0,002}\right)^{2}\right]
\end{aligned}
$$


- Domino 2b:

$$
\begin{aligned}
& \mathcal{E}_{c i}=-\frac{\varepsilon_{s} \times x}{(x-d)} \rightarrow 0,002<\varepsilon_{c}<0,0035 \\
& \mathcal{E}_{s}=0,01 \\
& \sigma_{c i}=0,85 \cdot f_{c d}
\end{aligned}
$$

- Domino 3:

$\varepsilon_{c}=0,0035$

$$
\begin{aligned}
& \mathcal{E}_{s i}=\frac{\mathcal{E}_{c} \times(d-x)}{x} \rightarrow 0,01>\varepsilon_{s} \geq \varepsilon_{s, \mathrm{lim}} \\
& \sigma_{c i}=0,85 \cdot f_{c d}
\end{aligned}
$$

- Domínio 4:

$\varepsilon_{c}=0,0035$

$\varepsilon_{s i}=\frac{\varepsilon_{c} \times(d-x)}{x} \rightarrow \varepsilon_{s}<\varepsilon_{s, \lim }$

$\sigma_{c i}=0,85 \cdot f_{c d}$

A deformação $\varepsilon_{s, \text { lim }}$ é dada por:

$$
\varepsilon_{s, \lim }=\frac{\mathcal{E}_{c} \times\left(1-\frac{x}{d} \lim \right)}{\frac{x}{d} \lim }
$$

A distância do centro da tira até o cg da armadura é conhecida e chamada de $z_{i}$. Assim, já é possível calcular a parcela de momento resistente devida a essa tira.

$$
M_{R}=F_{c i} \cdot z_{i}
$$


Depois disso, basta repetir a operação para todos os retângulos comprimidos que se obterá as resultantes da força de compressão e do momento resistente, dados pelas expressões A2.16 e A2.17, respectivamente.

$$
\begin{aligned}
& F_{c}=\sum_{i=1 . . n} F_{c i} \\
& M_{R}=\sum_{i=1 . . n} M_{R i}
\end{aligned}
$$

Esses valores correspondem a uma posição de linha x. Para cada posição de linha neutra existirá um valor de $\mathrm{F}_{\mathrm{c}}$ e um do momento resistente $\mathrm{M}_{\mathrm{R}}$. Se $M_{R}=M_{d}$, a linha neutra em questão é a solução do problema e o valor da armadura é dado pela equação:

$$
A_{P}=\frac{F_{c}}{\sigma_{p d}}
$$

